\title{
Die Werke Georg Friedrich Händels in Göttingen
}

\author{
Eine Darstellung der Sammlung G. F. Händels \\ in der Niedersächsischen Staats- und Universitätsbibliothek Göttingen \\ unter Berücksichtigung des identischen Bestandes \\ in weiteren ausgewählten Göttinger Institutionen
}

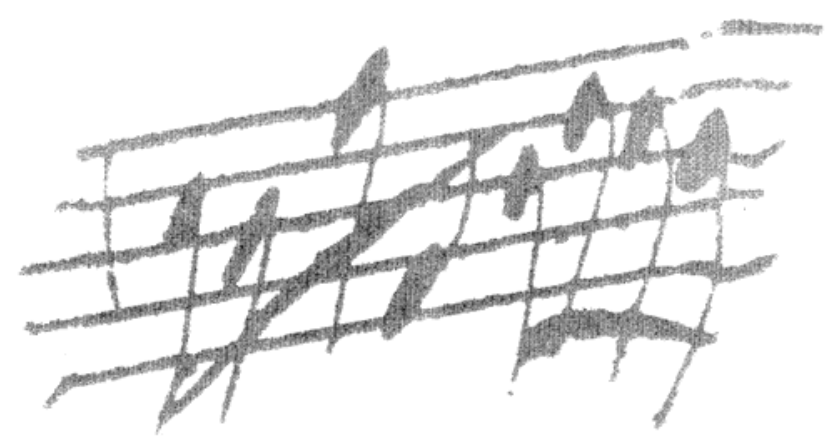

T e x t

von

Poupak Amirazodi

Göttingen, November 2005 

Vorwort

Einleitung

$1 \quad$ Allgemeines

$1.1 \quad$ Die Niedersächsische Staats- und Universitätsbibliothek Göttingen 4

1.1.1 Anfänge 5

1.1.2 Das 20. Jahrhundert 9

1.2 Die Musiksammlung 11

$\begin{array}{lll}\text { 1.2.1 Umfang } & 12\end{array}$

1.2.2 Aufstellung - Signierung 15

$2 \quad$ Übersicht über die Kataloge der Universitätsbibliothek 17

2.1 Der Akzessionskatalog 18

$\begin{array}{lll}2.2 & \text { Alphabetische Kataloge } & 21\end{array}$

2.3 Systematische und Sachkataloge 24

2.4 Sonderkataloge 26

2.5 Der Ars-Musica-Katalog 28

2.5.1 Der Ars Musica Catalogus realis 29

2.5.2 Der Ars Musica Catalogus alphabeticus 33

2.5.3 Besonderheiten der Katalogisierung im
Göttinger Musikalienkatalog

$3 \quad$ Musikalien und Musikliteratur 38

3.1 Die Ära Notendrucke und musikalische Literatur 38

3.2 Musiksammlungen und Musikbibliotheken 40

3.3 Musik in der bibliothekarischen Praxis 43

$4 \quad$ Georg Friedrich Händel 45

4.1 Lebensgeschichte 46

$\begin{array}{lll}4.2 & \text { Werke } & 49\end{array}$ 
5.1 Bericht über die Arbeit 51

5.2 Händel in der SUB Göttingen 55

5.2.1 Umfang des Händel-Bestandes 55

5.2.2 Aufbau und Erschließung 58

6 Musik und Händel in Göttingen 60

6.1 Musikwissenschaft und Musikpflege in Göttingen 61

6.2 Musikwissenschaftliche Institutionen 63

6.3 Das Musikwissenschaftliche Seminar der Universität Göttingen $\quad 64$

6.3.1 Die Bibliothek 65

6.3.2 Der Händel-Bestand 67

6.4 Die Göttinger Händel-Gesellschaft 68

6.4.1 Entwicklung der Gesellschaft 69

6.4.2 Die Händel-Festspiele Göttingen 69

$\begin{array}{ll}\text { 6.4.3 Bestandsaufbau und Erschließung } & 71\end{array}$

6.5 Das Stadtarchiv Göttingen $\quad 72$

6.5.1 Geschichte des Stadtarchivs 72

6.5.2 Händel im Stadtarchiv $\quad 75$

6.6 Die Werke Händels im Programm des

Göttinger Symphonie Orchesters 75

$\begin{array}{lll}7 & \text { Zusammenfassung } & 76\end{array}$

8 Literaturverzeichnis

$\begin{array}{lll}8.1 & \text { Literatur } & 79\end{array}$

8.2 Internet-Veröffentlichungen 85

8.3 Unveröffentlichtes Material 87

9. Abkürzungsverzeichnis 88

10. Anhänge

10.1 Beilagen zur Arbeit I - XXXII

10.2 Katalog (separat) 


\section{Vorwort}

In der Vielfalt des über den Komponisten Georg Friedrich Händel Publizierten fehlte bis jetzt ein Katalog des Händel-Bestandes der Niedersächsischen Staats- und Universitätsbibliothek Göttingen (SUB), ein Verzeichnis, in dem die Werke Händels und die Sekundärliteratur über sein Leben und Werk systematisch nachgewiesen werden. Diese Arbeit will eine Übersicht über Inhalt, Herkunft und Verzeichnung dieses Teilbestandes der SUB geben. Anhand von Katalogen wird die Geschichte speziell des vorhandenen Materials von und über Georg Friedrich Händel dargelegt. Ferner werden die Bibliothek des Musikwissenschaftlichen Seminars der Universität, die der HändelGesellschaft und das Stadtarchiv Göttingen im Abriß vorgestellt. Der zweite Teil der Arbeit beschäftigt sich mit der Erfassung des Händel-Bestandes der Universitätsbibliothek - sofern der eine oder andere Titel sich auch im Bestand der drei oben genannten Institutionen befindet, ist dies entsprechend vermerkt worden.

Bei der Fassung dieser Arbeit habe ich mich nach den alten Regeln der deutschen Rechtschreibung gerichtet.

Die Arbeit wurde bereits Ende 2002 provisorisch abgeschlossen; aus technischen Gründen konnten damals nur einige Titelaufnahmen der im Katalog aufgeführten Werke eingefügt werden. In der vorliegenden Fassung sind im Textteil einige textliche Überarbeitungen vorgenommen worden und der Katalogteil wurde vervollständigt, ferner sind weitere Titel aufgenommen worden, die seit dem letzten Abschluß in die SUB gekommen sind.

Großen Dank gebührt dem ehemaligen stellvertretenden Direktor der SUB Göttingen, Dr. Axel Halle, der mir die Möglichkeit gegeben hat, den Händel-Bestand der Bibliothek zu erfassen. Mein besonderer Dank gilt Herrn Dr. Helmut Rohlfing, Frau Kristine Hillenkötter und Herrn Dr. Armin Müller-Dreier für die Anregungen und den intensiven und helfenden Gesprächen. Für die bedingungslose Unterstützung gilt mein tiefster Dank den Dienststellen-Mitarbeitern der Forschungsbibliothek, der Zentralredaktion, des Lesesaals, der Integrierten Monographien- und Serienbearbeitung, der Mikroformen und Neue Medien, der Fotostelle, der Buchbinderei, der Beschriftungsstelle sowie des Magazins der SUB.

Für die Fassung der Kapitel über die weiteren Institutionen stellten die Mitarbeiter der Bibliothek und des Archivs des Musikwissenschaftlichen Seminars, der Göttinger Händel-Gesellschaft, des Stadtarchivs und des Göttinger Symphonie Orchesters nütz- 
liche Materialien zur Verfügung und gaben Antwort auf wichtige Fragen. Auch ihnen bin ich zu großem Dank verpflichtet. Desweiteren bedanke ich mich sehr bei den Personen, die die Last auf sich genommen und diese Arbeit zu vorliegender Form korrigiert haben.

Mit dieser Arbeit (Text und Katalog) verbinde ich die Hoffnung, daß ihre Leser Göttingen als eine Stätte der Händel-Forschung entdecken, und daß dieses zweiteilige Werk von möglichst vielen Lesern als Informationsquelle für solches Vorhaben genutzt wird.

Natürlich kann ein Katalog wie dieser, der den Händel-Bestand einiger ausgewählter Bibliotheken verzeichnet, kein umfassender Querschnitt durch die gesamte HändelForschung sein. Und doch meine ich, daß als Ergebnis meiner musikbibliothekarischen Arbeit ein Mosaik entstanden ist, das sich als die erste göttingische geschriebene Gesamtschau an Händelinteressierte Bürger, auswärtige Gäste und Gesellschaftsmitglieder gleichermaßen empfiehlt. 


\section{Einleitung}

Als ich einige Mitarbeiter der SUB Göttingen auf die Musikaliensammlung der Bibliothek ansprach, bekam ich Verschiedenes, teils Enttäuschendes zur Antwort. Dies bewog mich umso mehr, mich mit dem Sammelgebiet Musik zu befassen. Ausgangspunkt für das Projekt Händel war die These, daß der Musikalienkatalog der SUB über 7.300 Titel aufweist, die aber nur z. T. maschinenlesbar erfaßt sind. Mein ursprünglicher Plan, der die Online-Katalogisierung aller jener Titel vorsah, wurde aufgrund der großen Menge und Vielfalt und der beschränkten Zeit umstrukturiert. Im weiteren Verlauf meiner Nachforschungen kristallisierte sich ein besonderes Interesse immer mehr heraus: In Göttingen finden alljährlich die von der hiesigen Händel-Gesellschaft organisierten Internationalen Händel-Festspiele statt, und da liegt es nahe, von allen in der SUB verwahrten Musikalien gerade Georg Friedrich Händels auszuwählen.

Die Bestandsbeschreibung einer Bibliothek wirft mehr die Frage ihres Sammelgebiets als ihrer Bestandsgröße auf. Ist der Händel-Bestand der SUB Göttingen wirklich so klein wie zunächst angenommen wurde? Um dies herauszubekommen, galt es zum einen, in den Katalogen der Bibliothek - Band-, Zettel- und Online-Katalog - nach Händel-Einträgen direkt zu suchen, zum anderen den Signaturenbereich MUS I - MUS VIII nach Händel zu durchkämmen; unter dieser ursprünglichen Signaturform lassen sich nämlich Musica practica und theoretica an einem Ort finden. Das Resultat war alles Andere als nichts: Dutzende Regalmeter voll von Drucken und Handschriften zum besagten Komponisten. Damit war meine Vermutung bestätigt, daß die SUB eine enorme Sammlung an Händel-Material beherbergt.

Der Händel-Bestand in der Niedersächsischen Staats- und Universitätsbibliothek Göttingen basiert nicht nur auf den im ersten Drittel des 20. Jahrhunderts begonnenen Händel-Festspielen, sondern auch auf die gezielte Erwerbungspolitik, die seit Mitte des 18. Jahrhunderts zahlreiche Musikalien von Georg Friedrich Händel sowie Literatur über ihn in die damals Königliche Universitätsbibliothek brachten. Hier ist von 158 Zugängen mit den Erscheinungsjahren 1700-1899, 455 mit den Jahren 1900-1999 und 37 Zugängen mit den Jahren 2000-2004 die Rede; für 28 Zugänge wird das Jahr, in dem das Werk gedruckt oder niedergeschrieben ist, ein Geheimnis bleiben ${ }^{1}$. Es

\footnotetext{
${ }^{1}$ Die Zahl der Zugänge rechnet sich aus der Summe jeder einzelnen Medieneinheit, d. h. bei Zeitschriften ist jedes Heft und bei der Nachlaßakte ist jedes Dokument mitgezählt - Einladungskarten und dgl. ausgenommen. Bei den Werken ohne zeitliche Angabe handelt es sich zumeist um Notenhandschriften, aber auch um Notendrucke und musiktheoretische Drucke.
} 
spricht einiges dafür, daß infolge enger Beziehungen Göttingens zu London ${ }^{2}$ auch Göttingen vom Ruhm des in Großbritannien tätigen Komponisten angezogen wurde. Wie hat aus den Anfängen eine solche Sammlung entstehen können? Diese Frage läßt sich beantworten, wenn es gelingt, die Herkunft der einzelnen Werke zu ermitteln. Verschiedene Zugangsverzeichnisse ermöglichen eine genaue Rekonstruktion der Bestandsgeschichte seit Gründung der Bibliothek, insbesondere das Manual und der parallel dazu geführte Akzessionskatalog. Die Zugänge wurden, je nach Dokumenttyp (Hochschulschriften, Musikalien), in gesonderten Katalogen eingetragen. In dieser Arbeit sind lediglich die Kataloge der Bibliothek beschrieben, die musikalische Titel über Händel nachweisen. Der beiliegende Katalog gibt Aufschluß über den HändelBestand in der Göttinger Universitätsbibliothek und parallel dazu, in der Bibliothek des Musikwissenschaftlichen Seminars der Universität, in der Händel-Gesellschaft sowie im Stadtarchiv Göttingen.

Auf welche Dokumenttypen ist der Händel-Bestand der einbezogenen Institutionen spezialisiert? Während die Händel-Gesellschaft mehr Libretti in ihrem Bestand aufweist, finden sich im Stadtarchiv hauptsächlich Programmhefte und in der Universitätsbibliothek Biographien und Musikalien; dagegen hat man im Archiv des Musikwissenschaftlichen Seminars Zugriff auf Schallplatten.

Unter der Musikliteratur wurden Werke berücksichtigt, die sich ganz oder überwiegend mit Händel befassen, nicht aber solche, die sich nur am Rande mit Händel beschäftigen sowie Aufsätze. Im Katalog sind ebenso Musikalien einbezogen, in denen auch Händelsche Werke enthalten sind.

Die Katalogisierung des darin erfaßten Bestandes erfolgte auf der Grundlage der »Regeln für die alphabetische Katalogisierung in wissenschaftlichen Bibliotheken« (RAKWB), der »Regeln für die alphabetische Katalogisierung von Musikdrucken, Musiktonträgern und Musik-Bildtonträgern« (RAK-Musik) und des Entwurfs zu »Musikdrucke, Musiktonträger und Musik-Bildtonträger« (Stand: März 2001), ferner der »Katalogisierungsrichtlinie für den Gemeinsamen Bibliotheksverbund«.

Libretti bilden, neben Musikalien und Tonträgern, das musikalische Spektrum des in Bibliotheken und Museen versammelten kulturellen Erbes. Für die Musik- und Bibliothekswissenschaften haben mehrfach vertonte, aber bibliographisch anonyme Libretti eine besonders signifikante Bedeutung. Ihnen geht es nicht nur um die Komposition

${ }^{2}$ Die dynastische Personalunion von Großbritannien und Hannover (s. dazu Kapitel 1.1) 
und den Erscheinungsvermerk, sondern auch darum, wann dieses Libretto von wem, wo und zu welchem Anlaß vertont worden ist. Im Bestand der SUB kamen einige wenige solcher Libretti zum Vorschein, die vom Titel her in Händels Kompositionsprogramm gehören - weshalb sie im Katalog verzeichnet wurden - von der Vorlage her jedoch von anderen Komponisten vertont worden sind ${ }^{3}$.

Im Laufe des Projektes hatte ich auch mit Problemen zu rechnen: Bände waren nicht sofort auffindbar, weil verliehen oder verstellt; die zuständige Person, der die eine oder andere Frage galt, war nicht gleich erreichbar; die Katalogregeln wurden um einiges abgeändert, z. B. die Umstrukturierung der Aufnahmen bei mehrbändigen Werken $^{4}$ oder die Änderung der Bestimmung, Kongreßschriften nun monographisch zu behandeln; wie nicht anders zu erwarten, haben sich manchmal technische Probleme eingeschlichen und die Arbeit lahmgelegt.

Ziel des Händel-Projektes ist es, den Händel-Bestand nach den genannten Richtlinien vereint in einem Katalog zu verzeichnen. Eng damit verknüpft ist die Aufgabe des Kataloges, Interessierten und Forschern verstärkt Möglichkeiten zur gezielten Recherche und Benutzung dieser Spezialsammlung zu sichern.

Ein Katalog wie dieser kann weder vollständig noch fehlerfrei sein. Er umfaßt aber den weitaus größten Teil der Werke Händels und die Veröffentlichungen über ihn. Folgendes Goethe-Zitat trifft auch auf diesen Katalog zu: „So eine Arbeit wird eigentlich nie fertig, man muß sie für fertig erklären, wenn man nach Zeit und Umständen das Möglichste gethan hat.“5

Die dem Berichtsteil anschließenden Beilagen sollen Bandbeschriftungen, Katalogaufbau u. a. bildlich veranschaulichen; ferner werden die in dieser Arbeit beschriebenen Bestände und Kataloge der Bibliotheken und Archive fotografisch dargestellt.

Für die Fassung dieser Arbeit habe ich neben der verfügbaren Literatur auch verschiedene Zeitungsartikel sowie eine Reihe Webseiten benutzt, die sich mit dem Thema Bibliothek, Händel und Musik befassen.

\footnotetext{
${ }^{3}$ Die Antwort, ob diese Libretti Händel zuzuschreiben sind, ergab sich bei einem telefonischen Gespräch mit Herr Traxdorf vom Händel-Haus Halle.

${ }^{4}$ Erläuterung dazu unter Kapitel 5.1

${ }^{5}$ Zitiert nach Johann Wolfgang von Goethe: „Italienische Reise“ (1890), S. 272
} 


\section{$1 \quad$ Allgemeines}

\subsection{Niedersächsische Staats- und Universitätsbibliothek Göttingen}

Eine Universitätsbibliothek ist Wissensspeicher und akademisches Zentrum für Studenten, Professoren und wissenschaftlich Interessierte. Der Prototyp der ersten neuzeitlich orientierten wissenschaftlichen Gebrauchsbibliothek war die jetzige Staatsund Universitätsbibliothek in Göttingen. Die Gründung dieser Bibliothek in der jungen Universitätsstadt stand in engem Zusammenhang mit den Bemühungen des ersten Kurators und Förderers der Universität, Gerlach Adolph Freiherr von Münchhausen (1688-1770). Diesem hannoverschen Minister verdanken diese beiden zusammenhängenden Einrichtungen ihre Entstehung wie ihren schnellen Aufstieg. Münchhausen, der über drei Jahrzehnte - von 1734 bis 1770 - Kurator der Universität war, versuchte dieser von Anfang an Ansehen zu verschaffen durch die Berufung hervorragender Gelehrter, die die Wissenschaft ihrer Zeit repräsentierten. Dem Aufbau d. h. Finanzierung und Organisation der Bibliothek, widmete er sich seine gesamte Amtszeit hindurch mit großer Hingabe.

Als geistiger Vater der Universitätsbibliothek gilt der Universalwissenschaftler Gottfried Wilhelm Leibniz (1646-1716). Er vertrat die Ansicht, daß zur Erzielung von „wahre[m] wissenschaftlichen Fortschritt [...] der einzelne Gelehrte sich bequem und leicht über die Summe der Forschungsergebnisse seiner Vorgänger unterrichten“6 können sollte. Zu diesem Zweck sollte die Bibliothek nicht der bloßen Ansicht, sondern dem Gebrauch dienen. So wurde nach seiner Vorstellung in Göttingen der Grundstein zu einer Bibliothek für die Allgemeinheit gelegt. Bereits wenige Jahrzehnte nach ihrer Errichtung erlangte die damalige Königliche Universitätsbibliothek einen Ruhm, der zu einem erheblichen Teil in ihren historischen Beständen lag, welche vermehrt wurden: Eine konsequente staatliche Förderung wie auch gezielte Erwerbungspolitik nutzte alle internationalen Beziehungen der Landesherren, der Universität und der Akademie. Mit der vielseitigen Erwerbung des wissenschaftlich relevanten in- und ausländischen Schrifttums in allen an der Universität vertretenen Fachgebieten und ihrer Erschließung durch systematische und alphabetische Kataloge stieg sie zur führenden modernen deutschen Forschungsbibliothek auf und wurde weltweit zum Vorbild.

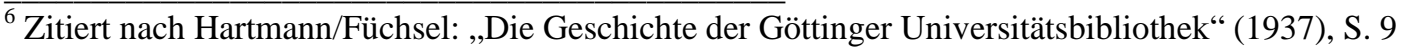


Über diese Bibliothek mit ihrer langjährigen bibliothekarischen Tradition sind viele Bücher und Aufsätze erschienen, so daß es hier bei einer komprimierten Darstellung belassen wird. Im folgenden stellt ein kurzer historischer Abriß dar, wie in den letzten drei Jahrhunderten die Aufgaben und Probleme, die das Göttinger Bibliothekswesen betrafen, bewältigt wurden. Zudem wird der Bestandsaufbau der SUB in Geschichte und Gegenwart dargelegt.

\subsubsection{Die Anfänge}

Das Kurfürstentum Hannover, zu dem auch die Stadt Göttingen gehörte, wurde von 1714 bis 1837 in Personalunion mit Großbritannien von London aus regiert. Es war König Georg August II., der für die Idee eintrat, eine eigene Universität zu schaffen. Für das Kurfürstentum bedeutete die Errichtung eines solchen akademischen Zentrums einen notwendigen Schritt: Der Monarch verband damit nicht nur die Ausbildung der Landeskinder im eigenen Fürstentum, eine Alma mater wurde seiner Ansicht nach auch gebraucht, um durch die Verbindung mit Studenten aus anderen Teilen des Reiches und dem Ausland Mittel wie auch Kräfte für Forschung und Unterricht nach Hannover fließen zu lassen und so im Land Wohlstand zu fördern. ${ }^{7}$

„Ohne eine große Bibliothec ist die Universität einer Guarnison gleich ohne Zeug-

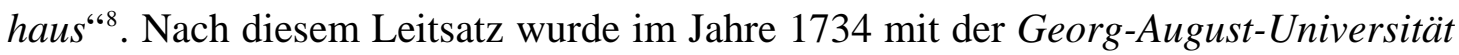
die Bibliothek gegründet und am 17. September 1737 vom englischen König Georg August II., gleichzeitig Kurfürst von Hannover, mit einem Festakt in der Paulinerkirche eingeweiht. Noch vor der Universität wurde die Bibliothek eingerichtet und auf einem etwa 12.000 Bände umfassenden Bestand bei der Eröffnung aufgebaut, so daß sie „eine größere Bibliothek besaß [...] ehe ein Professor Göttinger Boden betreten hatte, als irgend eine der alten Universitäten.“9

Zum ursprünglichen Bestand der Königlichen Universitätsbibliothek gehörte die Bibliothek des Gymnasium Academicum, das vor der Universität im Pauliner Kloster un-

\footnotetext{
${ }^{7}$ Vgl. Kind-Doerne: „Die Niedersächsische Staats- und Universitätsbibliothek Göttingen“ (1986), S. 1f. ${ }^{8}$ Zitiert nach Hans-Werner Wolf: „Joachim Heinrich Freiherr von Bülow oder Die Anfänge der Göttinger Universitätsbibliothek“, in Göttingen 18 (1971), 8, S. 10

${ }^{9}$ Ebenda, S. 13
} 
tergebracht war und 708 Bände umfaßte. Überdies gab die Hofbibliothek in Hannover 2.154 Bände aus ihren Dubletten dazu.

Die Universitätsbibliothek ist in einer Ära, der Wende vom 17. zum 18. Jh., entstanden, die dadurch begünstigt war, daß ihr durch den literarischen Enthusiasmus der Bürger kostbare Privatsammlungen zukamen. Dies war eine Zeit gewaltiger kultureller Entwicklung. Fürsten und Bürger sammelten Bücher, Instrumente, Kunstgegenstände, Raritäten und Naturalien. Dieser Sammeleifer hatte zur Folge, daß bedeutende Privatbibliotheken zustande kamen, die an Bücherzahl und Bedeutung die öffentlichen übertrafen. Eine Vielzahl dieser privaten Sammlungen verhalf mancher Universitätsbibliothek zu ihrer Grundausstattung an Büchern, so geschehen auch in Göttingen.

Neben dem erwähnten Anfangsbestand bildete die Privatbibliothek des Lüneburger Geheimrats und Großvogts Joachim Hinrich von Bülow (1650-1724), die 8.912 Bände zählt, den größten Teil des ursprünglichen Bestandes. Diese Sammlung fiel nach dem Tode Bülows testamentarisch der Universität zu und wurde 1736 mit den beiden besagten Sammlungen nach Göttingen überführt. Sie wurde vom ersten Leiter der Bibliothek, Johann Matthias Gesner (1691-1761), zu Ehren des Stifters unter der Bezeichnung Bibliotheca Buloviana ${ }^{10}$ in die Universitätsbibliothek eingegliedert.

Für die stetige Vermehrung des Göttinger Bibliotheksbestandes war ein fester Etat angesetzt. Diese aus verschiedenen Kassen ${ }^{11}$ anfallende Summe betrug etwa 400 Taler jährlich. Trotz allem hielt Münchhausen für alle Bücherwünsche überdurchschnittliche Mittel bereit, die es ermöglichten, Summen bis zum Zehnfachen der Planmittel für wissenschaftliche Literatur auszugeben. Im Gegensatz zur Universitätsbibliothek Göttingen führten die meisten Bibliotheken damals ein finanzielles Schattendasein. Das bedeutet, daß Buchkaufmittel knapp waren und unregelmäßig flossen. Über die finanziellen Mittel hinaus hatte Münchhausen der Bibliothek einen weiteren materiellen Zuschuß verschafft: Die Göttinger Buchdrucker wurden dazu verpflichtet, „von allen ihren Erzeugnissen ein Pflichtexemplar an die Bibliothek abzuliefern. “12 Die Mitwirkung der Professoren trug entscheidend zur Bereicherung der Bibliothek bei. Die ersten Bibliothekare der Göttinger Universitätsbibliothek waren, wie es im 17. und 18.

\footnotetext{
${ }^{10}$ Vgl. Wolf (1971), S. 13

${ }^{11}$ Neben den Mitteln aus der Regierungskasse wurde ein Teil der studentischen Immatrikulationsgebühren (Inskriptionsgelder), Promotionsgebühren, Mahngebühren sowie der Umsätze der in Göttingen stattfindenden Auktionen überwiesen.

12 Zitiert aus Richard Fick: „Die Universitätsbibliothek Göttingen als niedersächsische Landesbibliothek“, in Mitteilungen des Universitätsbundes Göttingen 10 (1929), 2, S. 31
} 
Jh. üblich war, zugleich Professoren an der Universität. Ihr Auftrag war vorrangig die Beschaffung solcher Bücher, die Privatleute nicht erwerben konnten. Die Oberaufsicht erfolgte in dieser Zeit von Hannover aus unter Münchhausen und seinem bibliothekarischen Gehilfen Philipp August Schlüter.

Weitere Literatur wurde auf Auktionen erworben, die in Hannover und in anderen deutschen Städten stattfanden. Die Anschaffung ausländischer Literatur erfolgte auf dem internationalen Büchermarkt in Holland und über Residenten im Ausland. Seit Ende der vierziger Jahre des 18. Jahrhunderts wurden aus London englische Publikationen bezogen. Der Legationsrat Wilhelm Philipp Best (1712-1785), der dort für die Göttinger Bibliothek tätig war, pflegte die Beziehungen zu den Buchhändlern Thomas Osborne und John Ridley, die von 1749 bis 1782 Göttingens Hauptlieferanten waren. In der Zeit zwischen der Gründung der Universität und 1800 wurden unzählige Werke, darunter auch aus dem musikwissenschaftlichen Bereich, aus London angeschafft, die in dem von Bernhard Fabian herausgegebenen "A catalogue of English books printed before 1801 held by the University Library at Göttingen« (Hildesheim, 1987) aufgeführt sind. Darüber hinaus haben der spanische Infant Karl III., das Königliche Universitätskuratorium, allem voran die Göttingische Gesellschaft der Wissenschaften der Bibliothek wertvolle Geschenke zukommen lassen.

Die Göttinger Universitätsbibliothek zeichnete sich außerdem durch ihre Benutzerfreundlichkeit aus, d. h. freie Benutzung und ab 1738 Ausleihe für Studenten. Die heute übliche Fernleihe stellte damals ein Problem dar. Laut eines Erlasses der hannoverschen Regierung aus dem Jahre 1747 war es untersagt, Bücher außerhalb der Stadt zu entleihen. Das Verbot wurde später durch Heyne (Bibliotheksdirektor 1763-1812) mit der Auslegung eines Gesetzes aufgehoben, in dem die Ausleihe nach auswärts gestattet wurde, wovon sogar Städte wie Bremen, München und Länder wie die Schweiz, profitierten. Dieses Konzept fand in der von Wilmanns (Bibliotheksleiter 1875-1885) erlassenen Benutzungsordnung im Jahre 1879 ihr offizielles Statut.

Während des Siebenjährigen Krieges (1756-1763) gerieten sowohl die Universität als auch die Bibliothek durch die französische Besetzung in den Jahren 1757 bis 1762 in Notstand. Es waren so gut wie keine Hilfsquellen mehr für die Bibliothek vorhanden, und die Ankäufe entfielen. Die Erhaltung der Bibliothek bereitete große Sorgen. Dennoch hinterließ Gesner im Jahre 1761 ca. 60.000 Bände.

1763 wurde der klassische Philologe Christian Gottlob Heyne (1729-1812) zum neuen Leiter der Bibliothek ernannt, der diese fast ein halbes Jahrhundert verwaltete und ihr 
zu europaweitem Ansehen verhalf. Heynes Einsatz im bibliothekarischen Umfeld ist es zu verdanken, daß die Verwaltung der Bibliothek von Hannover an Göttingen übergeben wurde. Zudem liegen seine Verdienste in der Beschaffung von Frühdrucken; nicht umsonst wird die Zeit zwischen 1764 und 1812 das „Goldene Zeitalter“13 der Göttinger Inkunabelerwerbung genannt.

In der Folgezeit wurde der Aufschwung der Universitätsbibliothek durch politische Ereignisse gehemmt. Im Jahre 1807 trat König Jerôme I. die Herrschaft über das Königreich Westfalen an, zu dem auch Göttingen gehörte. Es kam zu massiven Einbrüchen beim Bestandsaufbau, und die finanziellen Mittel für die Erwerbung wurden vermindert. Der König erstrebte, wie in Frankreich mit der „Weltbibliothek Paris“14, Buchbestände durch die Säkularisierung der Klöster und Auflösung der Universitäten „in großen zentralen Bibliotheken zu vereinigen und so dem zielgerichteten Sammeln in Göttingen widerstrebende Strukturen zu schaffen.“15 Dies führte dazu, daß Göttingen im Jahre 1809 in den Besitz von Bibliotheken kam. Es handelte sich dabei hauptsächlich um Handschriftensammlungen aus Klöstern und Universitäten. Bereits 1815 wurden durch den zweiten Pariser Frieden die alten Besitzrechte wiederhergestellt, und so mußten die fremden Bestände bis 1828 an ihren Herkunftsort zurückgegeben werden. Trotz allem hatte die Universitätsbibliothek im Jahre 1812, als Heyne starb, einen Bestand von 200.000 Bänden erreicht.

Schließlich bekam die Bibliothek 1828 das Pflichtexemplarrecht für die gesamte Buchproduktion des Königreichs, später die der preußischen Provinz Hannover und nach 1945 die des Bundeslandes Niedersachsen; es erlosch 1970. Neben dem Eingang der regionalen Buchproduktion brachten seit 1817 Tauschbeziehungen mit deutschen Universitäten und dem British Museum London zahlreiche Publikationen in den stagnierenden Bestand.

Als 1829 die Brüder Jacob (1785-1863) und Wilhelm (1786-1859) Grimm ${ }^{16}$ aus Kassel als Bibliothekare und gleichzeitig als ordentliche Professoren an die Universität berufen wurden, bemerkten sie die Bestandslücken. Jacob Grimm wies 1833 in einer Denkschrift darauf hin und sicherte eine einstweilige Erhöhung des Etats. Nach dieser

\footnotetext{
${ }^{13}$ Zitiert nach Kind/Rohlfing: „Gutenberg und der europäische Frühdruck“ (1995), S. 31

${ }^{14}$ Vgl. Hartmann/Füchsel (1937), S. 92

${ }^{15}$ Zitiert aus Kind-Doerne (1986), S. 27

161837 protestierten sieben Göttinger Professoren, darunter die Brüder Grimm, gegen die Abschaffung der Verfassung von 1833 durch König Ernst August; sie wurden vom König ihrer Ämter enthoben und teilweise des Landes verwiesen. Vgl. Hans Kück: „Die "Göttinger Sieben"“ (1934)
} 
Zeit hatte die Universität einen Niedergang, der erst ab den 1850er Jahren durch den Aufstieg der Naturwissenschaften aufgefangen wurde. Zu Beginn des 20. Jahrhunderts bis in die fünfziger Jahre war Göttingen eine Hochburg der Naturwissenschaften. Umso weniger konnte die Bibliothek den Bereich Musikwissenschaft betreuen.

Bis in die Mitte des 19. Jahrhunderts stand Göttingen mit seinem nun auf 300.000 Bände gewachsenen Bestand an der Spitze der europäischen Universitätsbibliotheken. Dies änderte sich nach der Niederlage Hannovers im Deutschen Krieg 1866. Göttingen wurde preußisch, und die Universitätsbibliothek galt nun, obgleich zweite große norddeutsche Bibliothek, nur als eine unter den zehn Universitätsbibliotheken des Landes ${ }^{17}$ und verlor damit ihre privilegierte Stellung.

Als erster Leiter preußischer Prägung übernahm ab 1875 der Philologe August Wilmanns (1833-1917) die Direktion der Bibliothek. In seiner Amtsperiode bis 1885 modernisierte er die Verwaltung und das Katalogwesen. Trotz der noch angespannten Finanzlage kam ein Gesamtbestand von etwa 500.000 Bänden zustande.

\subsubsection{Das 20. Jahrhundert}

Das 20. Jh. war für die Universitätsbibliothek Göttingen eine sogenannte Reform-Ära. Die Räumlichkeiten, der Bestandsaufbau, und vor allem die Funktionen, die ihr zugeschrieben wurden, gaben ihr einen anderen Namen und weitere wichtige Funktionen im Bibliothekswesen.

Der Erste Weltkrieg und die Inflationszeit verhinderten, wie in den übrigen deutschen Bibliotheken, den Bestandsaufbau, vor allem den der ausländischen Literatur. Mit Unterstützung der Notgemeinschaft der deutschen Wissenschaft ${ }^{18}$ konnte die Bibliothek ab 1922 wegen ihrer guten Basis die Sondersammelgebiete Angloamerikanistik sowie die Naturwissenschaften weiter und intensiver pflegen. Heute pflegt sie darüber

\footnotetext{
$\overline{17}$ Die anderen neun Universitätsbibliotheken waren Berlin, Breslau, Halle, Marburg, Bonn, Münster, Kiel, Greifswald, Königsberg. Vgl. Kind-Doerne (1986), S. 31

${ }^{18}$ Um die wissenschaftliche Forschung zu bewahren, wurde dieser Verein Oktober 1920 von Fritz Haber und Friedrich Schmidt-Ott gegründet. Ihre Aufgabe war es, mittels sachbezogener Gutachten durch eigens eingerichtete Fauchausschüsse staatliche Mittel und private Zuwendungen zu verteilen und so die Wissenschaft und Forschung mit ihren Einrichtungen (z. B. Bibliotheken Laboratorien) zu fördern. Im August 1951 wurden die Notgemeinschaft und das Forschungsrat vereinigt, seitdem besteht diese Körperschaft, mit Sitz in Bonn-Bad Godesberg, als Deutsche Forschungsgemeinschaft (DFG) fort. Vgl. LeMO: „Notgemeinschaft der Deutschen Wissenschaft“ und „DFG-Chronologie“
} 
hinaus 19 weitere Sondersammelgebiete, wie universale wissenschaftliche Zeitschriften. Ferner wurden der Bibliothek Mittel lokaler Institutionen, der Klosterkammer und des Provinziallandtages in Hannover sowie des Universitätsbundes Göttingen zuteil. Wegen zunehmender Luftangriffe im Zweiten Weltkrieg wurde 1944 ein Teil der Bestände, darunter Zeitungen und Karten, in das Bergwerk Volpriehausen ausgelagert, während der Hauptbestand im Keller der Bibliothek aufbewahrt wurde. Mitte 1945 vernichtete eine Detonation das im Bergwerk befindliche Auslagerungsgut.

Gleich nach dem Krieg stand der auf rund eine Million Bände angewachsene Bestand wieder der Öffentlichkeit zur Verfügung. Der restaurierte Kirchensaal wurde 1973 von der Bibliothek wieder bezogen. Als dann, durch die rasche wie stetige Bestandsentwicklung, die letzten Raumreserven aufgezehrt waren, mußten aus Raumnot rund eine Million Bände in angemieteten Fabrikhallen und Kellern untergebracht werden. 1949 umbenannt in Niedersächsische Staats- und Universitätsbibliothek, verwaltet die Bibliothek seitdem die zentralen bibliothekarischen Aufgaben des Landes Niedersachsen, so den 1956 erstellten konventionellen Niedersächsischen Zentralkatalog (NZK). In dem 1982 eingerichteten Bibliotheksrechenzentrum Niedersachsen (BRZN) wurden der Niedersächsische Monographien-Nachweis (NMN) sowie der Niedersächsische Zeitschriften-Nachweis (NZN) aufgebaut. Daraus entwickelte sich mit dem niederländischen PICA-System 1993 der Gemeinsame Bibliotheksverbund (GBV) ${ }^{19}$.

Mit dem Einsatz der EDV im bibliotheksinternen Bereich gelang der SUB als erster deutscher Bibliothek der Durchbruch der elektronischen Bestandsaufnahme. 1966 kam der Zeitschriftenkatalog heraus und 1973 wurde die Zeitschriftenakzession auf EDV umgestellt.

Überdies sind in der SUB Sondersammlungen, deren Material gesondert aufbewahrt und in eigenen Abteilungen bearbeitet und benutzt wird. Das betrifft unter anderem die Handschriftenabteilung (Handschriften, Papyri und Nachlässe), die zugleich die Inkunabeln und Rara mitverwaltet. Im Jahre 1990, als der jetzige Bibliotheksdirektor Prof. Elmar Mittler (*1940) seinen Dienst antrat, wurde die SUB in das Programm Arbeitsgemeinschaft Sammlung Deutscher Drucke 1450-1912 einbezogen, in dessen Rahmen sie als deutsche Nationalbibliothek für das 18. Jh. das Schrifttum des Zeitabschnitts 1701 bis 1800 betreut.

\footnotetext{
${ }^{19}$ Bremen, Hamburg, Mecklenburg-Vorpommern, Niedersachsen, Sachsen-Anhalt, Schleswig-Holstein, Thüringen und die Stiftung Preußischer Kulturbesitz gehören dem Verbund an.
} 
Mit 5 Mio. Einheiten an Druck- und Handschriften sowie neuen Medien aus nahezu allen Wissenschaftsgebieten, die über die ganze Stadt dezentral aufgestellt sind, zählt die Göttinger SUB zu den fünf größten Bibliotheken in Deutschland.

\subsection{Die Musiksammlung}

Auf meine Frage, wie groß der Bestand der Musikliteratur und vor allem der Noten der SUB Göttingen ist, wurde dieser von Mitarbeiter der SUB (Zentrale Information, Fachreferat) als zahlenmäßig gering eingestuft. Aber nach einem Blick in die ArsMusica-Kataloge der Bibliothek und dem Rundgang durch die Magazine mit Regalen voller Musikwerke erschien die Aussage zweifellos untertrieben, in der SUB gebe es kaum bzw. sehr wenige Musikalien. Die Abteilung der Musikhandschriften, Musikdrucke sowie der Musikliteratur nimmt unter den von der Bibliothek zusammengetragenen Sammlungen von Inkunabeln, Karten und Drucken eine besondere Stellung ein, was auch der beiliegende Katalog dokumentiert. Zahlreiche Autographe, Handschriften, Nachlässe von Sammlern und Gelehrten, Musikdrucke und musiktheoretische Schriften sowie Originalausgaben sind hier vorhanden. Sieht man von den Musiksammlungen und -archiven der anderen Bibliotheken im niedersächsischen Raum - z. B. der Stadtbibliothek Hannover mit ihrer umfangreichen Musikbibliothek - ab, darf hier von einer fachlichen Vollständigkeit der Literatursammlung im Musikbereich sowie der Notensammlung gesprochen werden - als Beispiel dafür seien der Händelund der Bach-Bestand genannt.

Es existiert zur Zeit kein Verzeichnis, das den Musikbestand der SUB einheitlich, d. h. in einem Katalog erfaßt. Obwohl alle von der Bibliothek ab Januar 1993 erworbenen Musikwerke nun im OPAC recherchierbar sind, sind in manchen Fällen, die Musikalien in dem alphabetischen wie systematischen Ars-Musica-Katalog, und das Musikschrifttum im Zettelkatalog (bis 1992) oder im Alphabetischen (bis 1930) bzw. Systematischen (bis 1945) Bandkatalog auffindbar.

Im folgenden wird die Musiksammlung der Göttinger Universitätsbibliothek in verschiedenen Zusammenhängen vorgestellt. Das erste Kapitel bietet einen Überblick über den Bestand und dessen Größe an Musikalien und Musikliteratur. Das zweite Kapitel setzt sich mit der Aufstellung des Musikbestandes auseinander. 


\subsubsection{Umfang}

Der Gesamtumfang der in den Magazinen stehenden Musiksammlung beträgt rund 260 Regalmeter. Daneben sind auf 196 Regalmetern unter der Notation GU bis GY Bestände in den Freihandbereichen im Neubau aufgestellt (Bibliographischer Apparat und Lehrbuchsammlung, Monographien- (LS1) und Zeitschriftenlesesaal (LS2) ${ }^{20}$ ). Die Musiksammlung der SUB verwahrt zahlreiche Musikhandschriften und Musikdrucke, eine große Anzahl an Bänden Musikschrifttum, Schallplatten und CD, sowie Akten aus Nachlässen. Dementsprechend groß ist daher die Anzahl der Kostbarkeiten aus annähernd allen musikgeschichtlichen Epochen. Die dezentrale Aufstellung der musikbezogenen Bestände der SUB Göttingen resultiert aus der geschichtlichen Entwicklung der Bibliothek.

Die ältesten musiktheoretischen Werke in der SUB sind die zwei Ausgaben der »Practica musicae« (Mailand, 1496 und Brescia, 1497) von Franchino Gaffori, die »Flores musicae cantus gregoriani« (Straßburg, 1488) von Hugo Spechtshart von Reutlingen, ferner Veröffentlichungen von Balthasar Prasperg und Nicolaus Wollick (1501) wie auch von Udalricus Burchardi (1518) und Andreas Ornitoparchus (1519). Sind von den allerfrühesten Zeugnissen des Musikdruckes, den Wiegendrucken, wenige vorhanden, so gehen die Drucke des 16. Jahrhunderts in die Hunderte, welche in dem von Albert Quantz erstellten Verzeichnis »Die Musikdrucke der kgl. UniversitätsBibliothek in Göttingen« (Göttingen, 1879), aufgeführt sind. Wie eine handschriftliche Notiz bei manchen dieser Werke besagt, wurden einige „1919 an [die] Staatsbibliothek München abgegeben“ ${ }^{\text {‘21 }}$, die später wieder zurück gelangten. Es ist nicht auszuschließen, daß die Göttinger Bibliothek einige jener Werke nicht mehr wieder bekam. Einige bemerkenswerte Musikwerke, die ihren Weg in die SUB gefunden haben, z. T. durch Schenkung von Persönlichkeiten oder Institutionen, sollen hier aufgezählt werden. Vorerst wären einige Werke barocker Tonkünstler zu nennen, etwa das von Carl Philipp Emanuel Bach komponierte und verlegte »Heilig, mit zwey Chören und einer Ariette zur Einleitung« (Leipzig, 1779) und das Manuskript von Alessandro Scarlattis »Tue es Petrus: Antifona a due chori«; von ähnlicher Bedeutung ist die erstmals gedruckte Oper »King Arthur« (London, 1843), komponiert von Henry Purcell.

\footnotetext{
${ }^{20}$ s. Fotografien im Anhang S. I

${ }^{21}$ Es handelt sich um 16 von 145 in Quantz’ Verzeichnis enthaltene Titel.
} 
Aus der Abteilung Musica I sind erwähnenswert, aus Spanien »La música Espãnola desde la edad media hasta nuestros dias« (Barcelona, 1941), geschenkt von der „Gesellschaft der Wissenschaften zu Göttingen“"22 und Johann Friedrich Reichardts »Briefe eines aufmerksamen Reisenden die Musik betreffend; Theil 1 und Theil 2« (Frankfurt, 1774, 1776). Das Werk von Alexander Flammant »Das Reich der Töne: Bildnisse und Schilderungen berühmter Künstler und Künstlerinnen« (Dresden, 1881) gelangte „Aus dem Nachlasse des Herrn Professor Dr. Joseph Joachim. 1908“23 in die Biographiensammlung - es enthält eine handschriftliche Widmung von Maud Powell an Prof. Dr. Joachim, datiert auf Dezember 1884. Die Abteilung Musica IV enthält unter anderem Leopold Mozarts »Gründliche Violinschule« (Augsburg, 1770). Aus der Rubrik Musikalien ist das »Choralbuch zum Gesangbuch für die Herzogtümer Sachsen-Coburg und Gotha« (Gotha, 1897) hervorzuheben. Dieses Werk wurde samt einer Anzahl anderer Choralbücher der Bibliothek von der Albani-Gemeinde Göttingen $^{24}$ geschenkt. Aus dem englischsprachigen Raum ist das sechsbändige »The Scotish minstrel: a selection from the vocal melodies of Scotland ancient \& modern« (Edinburgh, 1825) von Robert Archibald Smith zu nennen. Ebenso Werke von Fürsten, wie z. B. vom preußischen König Friedrich II. »Musikalische Werke Friedrich’s des Grossen« (Leipzig, 1889), finden sich in der Musikaliensammlung. Nicht zuletzt sollten die zusammengebundenen Werke des Musikers Ludwig Meinardus erwähnt werden, die jeweils einer Persönlichkeit gewidmet sind: Dr. Franz Listz, Fräulein Ottilie Heinke, Ihrer Königlichen Hoheit Elisabeth Grossherzogin von Oldenburg, usw. Desweiteren sind die zahlreichen umfangreichen Notenschriftenreihen, so »Nagels MusikArchiv« (Kassel, 1927-) zu nennen.

Ferner sind hier musikalische Jahrbücher aufbewahrt, beispielsweise das von der $\mathrm{Neu}$ en Bachgesellschaft herausgegebene »Bach-Jahrbuch« (Leipzig, 1904-), »Neues Beethoven-Jahrbuch« (Augsburg, 1924-) von Adolf Sandberger, »Gluck-Jahrbuch« (Wiesbaden, 1913-) von Hermann Abert, »Händel-Jahrbuch« (Leipzig, 1928-) von Rudolf Steglich sowie »Mozart-Jahrbuch« (Augsburg, 1923-). Aus dem Katalog von Bernhard Fabian ${ }^{25}$ geht hervor, daß die SUB 29 englische Titel aus dem 18. Jh. in ih-

\footnotetext{
${ }^{22}$ s. Exlibris im Buch mit der Signatur: 8 MUS I, 2828

${ }^{23}$ s. Exlibris im Buch mit der Signatur: 4 MUS III, 113

${ }^{24}$ s. Exlibris im Buch mit der Signatur: 8 MUS V, 2472

25 »A catalogue of English books printed before 1801 held by the University Library at Göttingen« (Hildesheim, 1987-) - Part 2: Books printed between 1701 and 1800 ; Vol. 1-4
} 
rer Musiksammlung besitzt, darunter fünf Werke von bzw. über den Komponisten Georg Friedrich Händel.

Einen Schwerpunkt in den Beständen der Musiksammlung bilden die in großer Anzahl vorhandenen Notendrucke und -handschriften aus nahezu allen Epochen, wie z. B. von Jean-Baptiste Lully, Claudio Monteverdi, Giovanni Pierluigi da Palestrina, Henry Purcell, Samuel Scheidt und Robert Schumann.

Der Bestand im 19. Jh. ist lückenhaft. Das hängt damit zusammen, daß in der zweiten Hälfte des 19. Jahrhunderts die Göttinger Universitätsbibliothek, nun unter preußischer Verwaltung, an Bedeutung verlor und trotz ihres weltweit gerühmten Bestandes in finanzieller Hinsicht keine Sonderstellung unter den anderen preußischen Universitätsbibliotheken einnahm.

Die SUB verfügt neben der Sammlung von Abschriften zur Kirchenmusik (Vokalwerke) aus dem 18. Jh. über eine sehr begrenzte Zahl an Musikhandschriften, die im Signaturbereich „Cod. Ms. Philos. 84“ zu finden sind, etwa Robert Grölls »Mathemat.musikalische Arbeiten« (elf Hefte umfassend), ferner Partitur, Klavierauszug sowie Chor-, Orchester- und Solostimmen zu »Bianca, Romantische Oper in 3 Aufz.« von Eduard Hille. Dazu kommen noch die 1855 aus dem Nachlaß des Akademischen Musikdirektors Arnold Wehner (1820-1880) erworbene Musikaliensammlung, weiter die Dokumente im Nachlaß des Musikwissenschaftlers Friedrich Ludwig (1872-1930) in Form von Abschriften und Fotokopien mittelalterlicher Musikhandschriften vom 11. bis zum frühen 15. Jh. der verschiedensten Bibliotheken Europas, sowie der 1984 erworbene Nachlaß des Musikwissenschaftlers Heinrich Husmann (*1908). Ebenso gebührt der Stiftung von Karl von Schlözer, die unter anderem zahlreiche Kompositionen mit 31 Titeln enthält, besonderer Erwähnung. Dem folgen die Nachlässe der Komponisten Sethus Calvisius (1556-1615) und Ludwig Meinardus (1827-1896). Zahlenmäßig hat die SUB dem Répertoire international des sources musicales (RISM) zufolge 1.904 Musikhandschriften in ihrem Besitz. Daneben ist auf die Bestände der Sammlung Deutscher Drucke 1701-1800 (DD18) hinzuweisen, worunter auch diverse musiktheoretische Werke und Liederbücher, aber nicht Musikalien, zu finden sind. Die Sammlung der deutschen Drucke dieses Zeitraumes umfaßt die Epoche des Barock und somit die der Händelschen Musik.

Darüber hinaus verwahrt die Bibliothek 120 Schallplatten, 60 Tonkassetten und 171 Audiodisketten (CD) musikalischen Inhalts. Unter den CD befinden sich Aufnahmen zu Johann Sebastian Bachs »Matthäus-Passion«, Ludwig van Beethovens »Fidelio«, 
Vincenzo Bellinis »Norma«, Gaëtano Donizettis »Anna Bolena«, Charles Gounods »Faust«, Georg Friedrich Händels »Rodelinda«, Engelbert Humperdincks »Königskinder«, Joseph Haydns »Armida«, Tom Johnsons »Bonhoeffer-Oratorium«, Ruggero Leoncavallos »La Bohème«, Claudio Monteverdis »L’ incoronazione di Poppea«, Giacomo Puccinis »Le Villi«, Gioacchino Rossinis »La Cenerentola«, Franz Schuberts »Die schöne Müllerin« sowie Giuseppe Verdis »Othello«. In der Schallplattensammlung ist unter anderem Carl Maria von Weber vertreten.

Für das weitere Anwachsen der historischen Bestände der heutigen Musiksammlung war das in der Stadt bestehende Musikinteresse, das sich beispielsweise in der Gründung bzw. Einrichtung der Göttinger Händel-Gesellschaft (1920) und des JohannSebastian-Bach-Instituts (1951) niederschlug, von ausschlaggebender Bedeutung. Die Einrichtung des musikwissenschaftlichen Seminars an der Georg-August-Universität, wie auch des Universitätsorchesters und -chors, waren weitere Schritte für die Entwicklung einer musikalischen Atmosphäre in der Universitätsstadt.

\subsubsection{Aufstellung - Signierung}

Die Musikbestände der SUB wurden mehrfach neu gegliedert und umsigniert. Zu Anfang bildete die ausführliche wie differenzierte Signaturform mit den Abteilungen, MUS I - MUS IV für Musikliteratur und MUS V - MUS VIII ${ }^{26}$ für Musikalien, den Grundstandort. Diese Signatur wurde bis einschließlich 1945 angewandt. Ab dem Jahr 1946 bis Ende 1955 wurde für alle Fachbereiche die Signatur mit Gruppen-Numeruscurrens, d. h. ohne Gliederung in römische Ziffern, eingesetzt. Demnach setzt sich die Signatur aus den Komponenten Format $\left(2^{\circ}, 4^{\circ}, 8^{\circ}\right)$, Fachgebiet (wie HIST) und der laufenden Zugangsnummer zusammen ${ }^{27}$. 1956 wurde die Fachgliederung aufgelöst und die Signaturvergabe nach Numerus currens eingeführt. Die Buchnummer wurde nach dem Zugangsjahr des Werkes in die Bibliothek, nach dem ABCD-Format und nach der laufenden Inventarisierungsnummer vergeben, beispielsweise „56 A 5941“; diese Signaturvergabe wird bis heute beibehalten.

\footnotetext{
${ }^{26}$ Im Kapitel 2.5.1 ist die Signaturgruppe MUS erläutert.

${ }^{27}$ Beispiel für die Sign. mit Abteilung: „8 MUS II, 3156“ und für die Sign. ohne römische Ziffer: „8 MUS 153“.
} 
Eine Erläuterung in bezug auf das Etikettieren der Zugänge: Die SUB erstellte für ihre Bestände mit den Altbestands- bzw. Abteilungssignaturen bis 1945 eine Farbsystematik zur Signierung und Aufstellung. Jede Abteilung erhielt eine andere Farbe, die indes für alle Formate galt. Die Musiksammlung wurde durch folgende Farben kenntlich gemacht: MUS I = gelb, MUS II = rot, MUS III = blau, MUS IV = orange, MUS V = grün, MUS VI = beige, MUS VII = hellorange bzw. rosa (heute), und schließlich MUS VIII = wei $\aleph^{28}$. Dabei ist zu bemerken, daß die Farben für die Abteilungen nicht für alle Signaturgruppen identisch sind. Dies hat den Vorteil, daß die Werke gattungsweise im Magazin stehen und daher das Verstellen eines Buches leichter auffällt. Bei den Bestandssignaturen ab 1945 ist für jede Fachsammlung eine andere Farbe genommen worden. Die MUS-Bestände (Gruppen-Numerus-currens) sind mit der Schildfarbe orange gekennzeichnet. Auch für die Zeitschriften und Reihen sind einfarbige, nämlich rote, Etiketten gewählt; hierbei ist kein Unterschied zwischen den Fachgebieten gemacht worden. Ab 1956, mit der Einsetzung der Numerus-currens-Signatur, wurde für jedes Rechnungs- bzw. Erwerbungsjahr eine spezielle Farbe für die Signaturschilder bestimmt, die bei allen Formaten einheitlich ist: Z. B. ein Buch aus dem Jahr 1957 hat die Farbe lila, eins aus 1961 rot, das von 1970 dunkelgrün, und zu guter letzt das Buch von 1990 gold. Was die Bestände in den Freihandbereichen der Bibliothek Lesesäle, Lehrbuchsammlung und Freihandmagazin - betrifft, so sind diese lediglich mit weißem Etikett versehen. Dieses Signierungsschema stellt den Gegensatz zu der obengenannten mit den farbigen Schildern für jede Abteilung dar; das bedeutet den Wegfall der farblichen Orientierungshilfen bei verstellten Büchern.

Die Musiksammlung der Bibliothek wird geteilt in den beiden Bibliotheksgebäuden aufbewahrt: Im Neubau und im Historischen Gebäude (HG). Sowohl die musiktheoretischen Werke als auch die Noten mit der Altbestandssignatur, d. h. MUS I - MUS VIII (alle Formate) sind im HG aufgestellt; hier sind auch die Bestände aus der DD18 archiviert. Alle weiteren Bestände, also die mit der Signatur $2^{\circ}, 4^{\circ}$ bzw. $8^{\circ}$ MUS, $2^{\circ}$, $4^{\circ}$ bzw. $8^{\circ}$ Z MUS, ZA/ZB (Zeitschriften) und FA/FB (Fortsetzungswerke) sowie die Bestände mit der Numerus-currens-Signatur (,56 A“ und folgende) und die Neuen Medien sind im Neubau zu finden.

Die im HG befindlichen Musikalien und die Musikliteratur können auch im Neubau bestellt und ausgeliehen werden. Ausgenommen von der Außer-Haus-Ausleihe sind

${ }^{28}$ Im Anhang S. II 
Notenhandschriften. Diese Dokumente dürfen nur im Handschriften-Lesesaal im HG eingesehen werden. Dasselbe trifft auf Stimmhefte und Notendrucke zu (historische und neuere) mit Beilagen wie Partitur-Ausgaben mit einzelnen Stimmen und nicht auch die Bestände aus der DD18 und solche, die älter als hundert Jahre alt sind.

Der Bibliothek ist es gelungen, durch die Jahrhunderte mit Sorgfalt eine beachtliche Musiksammlung aufzubauen. Heute ist eine Vervollständigung bzw. Erweiterung nur eingeschränkt möglich, da nur wenige musikalische Kostbarkeiten im Handel erhältlich sind und diese meist zu Preisen, die die verfügbaren staatlichen Mittel übersteigen. Nicht nur in der SUB, sondern auch in den einzelnen universitären (Seminarbibliotheken), öffentlichen (Stadtbibliothek) sowie musikalischen (Orchester, Gesellschaften) Institutionen finden sich Musikschätze. Im Gegensatz zu den Sammlungen der Orchester und der Gesellschaften - die nur für deren Mitglieder zugänglich sind stehen die Musikbestände der anderen erwähnten Bibliotheken der Öffentlichkeit zur Verfügung; die Stadt Göttingen ist eine bescheidene Musikbibliothek.

\section{2 Übersicht über die Kataloge der Universitätsbibliothek}

„Gute catalogi sind die Seele einer bibliothecae publicae“ ${ }^{\text {29 }}$ meinte Johann Matthias Gesner. Das Katalogwesen hat sich im Laufe der Jahrhunderte, und insbesondere im Zeitalter des Computers, modernisiert. Heute erfassen die meisten Bibliotheken und auch Archive ihre Sammlungen elektronisch. Dennoch bleiben die klassischen Kataloge - in Band- oder Zettelform - für immer ein wichtiges Hilfsmittel für die Benutzung des Altbestandes und für die Forschung.

Während früher das Buch in die Bibliothek eingestellt wurde, sobald es in dem Inventar oder Manual verzeichnet war, mußte in Göttingen jedes eingegangene Buch nach seiner Inventarisierung erst den Katalog passieren bevor es in den Regalen aufgestellt werden konnte. Die Anlage von systematischen und alphabetischen Katalogen blieb in einigen Bibliotheken späterer Bearbeitung vorbehalten, die sogar in manchen Fällen aus Zeit- und Personalmangel ganz wegfiel.

${ }^{29}$ Zitiert nach Hartmann/Füchsel (1937), S. 112 
Die Bestandsbearbeitung wie auch das Katalogsystem, also die Koppelung von Akzessionskatalog, Manual, BdAK und $\mathrm{BdRK}^{30}$, der Göttinger Universitätsbibliothek, das eine moderne Erschließung des Bestandes bewirkte, wurden Vorbild für viele wissenschaftliche Bibliotheken im In- und Ausland. Mit der Einführung von PICA (Project for Integrated Catalog Automation) wurde 1992/93 die Bestandsaufnahme auf EDV umgestellt und somit die Fortführung der Band- und Zettelkataloge eingestellt. Neben ihrem Online-Katalog, dem Online Public Access Catalog (OPAC), besitzt die SUB andere elektronische wie auch konventionelle Kataloge, die den Bestand festhalten. Eine Reihe von thematisch eingegrenzten Beständen und geschlossen erworbenen oder geschenkten Sammlungen hat die Bibliothek in Sonderkatalogen verzeichnet. Im folgenden wird versucht, die Kataloge der SUB, angefangen mit dem Akzessionskatalog, weiter die alphabetischen wie systematischen Kataloge bis hin zu den Sonderkatalogen, einzeln darzustellen. Der Schwerpunkt liegt dabei im musikalischen Bereich.

\subsection{Der Akzessionskatalog}

Schon in frühesten Zeiten wurde der Buchbestand der Bibliotheken in Verzeichnissen, die eigentlich Inventare und ursprünglich der Hauptkatalog der Bibliothek waren, niedergelegt. Dieses Zugangsbuch gibt die Identität jedes einzelnen Mediums in der Bibliothek, seine Herkunft und Erwerbungsart - Kauf, Tausch, Geschenk oder Pflichtexemplar - preis.

Als der Großvogt von Bülow mit seiner Sammlung das dazugehörige Bestandsverzeichnis der Universitätsbibliothek Göttingen vermachte, legte er damit den Grundstock für den Göttinger Akzessionskatalog, den Grundkatalog der Bibliothek.

Die Entstehung dieses Kataloges geht auf das Jahr 1702 zurück, als von Bülow damit begann, einen, zugleich den ersten Katalog seiner bibliophilen Erwerbungen eigenhändig zu erstellen. Diesen Gruppenstandortkatalog gliederte er nach den vier Wissenschaftsgruppen Theologie, Recht, Geschichte sowie Philosophie oder Miscellanea, und diese Gruppen wiederum nach den drei Formaten $2^{\circ}, 4^{\circ}$ und $8^{\circ}$. Innerhalb dieser Abteilungen sind die Bücher in der Reihenfolge des Beschaffungsdatums mit ihrer Standortsignatur eingetragen. Zusätzlich stellte er für die zwölf Abteilungen jeweils

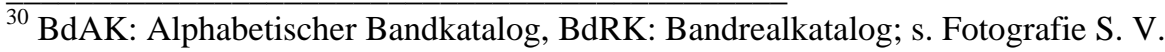


ein Autorenregister zusammen. 1705 legte er einen Realkatalog an, der, mit Ausnahme der dreizehn ergänzten Untergruppen, die gleichen Ordnungsprinzipien aufweist wie der Erwerbungskatalog. 1712 waren beide Kataloge voll beschrieben. Der erste wurde von einem Sekretär erneuert; indes verfertigte ein anderer Sekretär einen neuen Realkatalog in zwei Bänden. Von Bülow führte bis 1722 die Eintragungen selbst fort. Im Jahre 1723 legte Bülows letzter Gehilfe, Philipp August Schlüter, einen neuen Katalog an, den er erst 1735 zu Ende führte. Schlüter hatte nach dem Tod Bülows 1724 dessen Bibliothek bis zu ihrer Beförderung nach Göttingen 1736 verwaltet. Der Schlütersche Katalog umfaßt vier Bände. Jeder Band ist in drei Formatklassen gegliedert, jede von diesen nochmals in vier Fachgruppen: Libri theologici, juridici, historici und miscellanei. Im Gegensatz zu Bülows Fassung erhielt jeder Titel anstatt der Standortsignatur eine Zählung nach volumina (Bänden) und an zweiter Stelle nach tractatus (Werken). Schlüters Katalog gelangte mit der Schenkung der Bülowschen Sammlung in die Universitätsbibliothek Göttingen ${ }^{31}$ und bildete den Anfang des Akzessionskataloges, »Catalogus librorum qui Bibliothecae Bulovianae accesserunt « ${ }^{32}$, der nach jenen Richtlinien, die im Anschluß an die Bülowsche Sammlung neuerworbenen Bücher der hiesigen Bibliothek verzeichnete.

An die ursprünglichen Bände 1 bis 4 schlossen sich hier die Bände 5, 6 und 7 an, die die Jahre 1735-1747 umfassen; danach setzte sich der Katalog in Jahresbänden fort. Bei der Weiterführung bestimmten weiterhin die drei Formate die Hauptklassen und die vier Wissenschaftsgruppen die Unterabteilungen, von denen jede einzelne ihre gesonderte laufende Numerierung hat; später wurde bei der Gliederung den Fakultäten vor den Formaten der Vorrang gewährt. Wann genau dieses Verfahren eingesetzt wurde, ist ungewiß. Eine Prüfung hat ergeben, daß die Zugänge in den AccessioBänden 1-6 ebenfalls nach dem letzteren System eingetragen wurden. „Bis zum Sommer 1743 erfolgte die Umstellung der Bibliothek nach systematischer Ordnung.“33 Aufgrund dieser Hinweise ist es möglich, daß die zweite Gliederungsweise - erstens nach Wissenschaftsgruppe, zweitens nach Format - bereits mit dem ersten Band des Akzessionskataloges begann.

\footnotetext{
${ }^{31}$ Die Bände des Akzessionskataloges werden heute im Bibliotheksarchiv aufbewahrt und sind im HG einsehbar.

${ }^{32}$ Kind-Doerne (1986), S. 50

33 Zitiert aus Hartmann/Füchsel (1937), S. 112
} 
Ab 1747 diente zusätzlich das sogenannte Manual für den Handgebrauch. Im Akzessionskatalog wurden die Titel mit absoluter Vollständigkeit, genauer Wortlaut des Titelblattes, Erscheinungsort und -jahr, teilweise auch der Name des Verlegers bzw. Druckers und die Bezeichnung der angebundenen Stücke, angegeben. Dagegen wurden im Manual bzw. Accessions-Journal die Titel in möglichster Kürze, aber mit Datum und Art der Erwerbung, teils mit Nennung des Preises, nebst der Angabe der Provenienz, unter Beifügung einer laufenden Nummer, eingetragen. Verlorengegangene oder zurückgegebene Werke wurden in dem Manual durchgestrichen, und die Zugangsnummer des beschafften Ersatz-, vereinzelt auch Zusatzexemplars, hinzugefügt. Ab 1790 wurden die beiden Kataloge miteinander verzahnt; im Manual wurden für eine Neuerwerbung Klasse und Nummer des Akzessionskataloges sowie das Fach des BdRK, im Akzessionskatalog wiederum die Seite des Manuals sowie Fach und Blatt des BdRK eingefügt. Im darauf begonnenen Realkatalog und Alphabetischen Katalog wurden die Titel vor allem wegen mangelnder Arbeitskräfte weit kürzer gefaßt als im Akzessionskatalog. Aufgrund seiner ausführlichen bibliographischen Angaben blieb der Akzessionskatalog 140 Jahre lang der Hauptkatalog der Bibliothek, bis er 1876 stillgelegt wurde; ab diesem Datum wurden das Manual und der Akzessionskatalog zu einem Katalog, nämlich zum sogenannten Zugangsbuch, vereinigt. Bülow hatte die Fächereinteilung nach den Schwerpunkten seiner Bibliothek im 17. und beginnenden 18. Jh. entworfen. Je weiter die Wissenschaft sich entwickelte und differenzierte, desto weniger entsprach die Anlage dieses Kataloges den praktischen Bedürfnissen, was die enorm gewachsene Klasse der Miscellanea erklärte.

Die Provenienzangaben dienen dazu, die Herkunft der einzelnen bibliothekarischen Einheiten - Bücher, Musikalien, Zeitschriften - zu ermitteln. Sie finden sich in und auf den Bänden selbst, nämlich als Exlibris und andere schriftliche oder durch Stempel gesetzte Besitzvermerke in der Vorlage oder als Supralibros auf dem Einbanddeckel. In den meisten Fällen jedoch läßt sich der ursprüngliche Vorbesitzer nicht anhand des Werkes, sondern anhand der Angabe (Akzessionsnummer) in der Spalte Access. im Alphabetischen Bandkatalog und bei Notendrucken im Musikalienkatalog ermitteln.

Dieses sah in der Praxis wie folgt aus: Auf dem Titelblatt wie auch im Musikalienkatalog ist zu dem Titel »Teseo: opera« von Georg Friedrich Händel folgendes angegeben: „74.6.4.M.40491“. Die ersten beiden Zahlen beziehen sich auf das Manual, den 
Vorläufer des Zugangsbuchs (Akzessionsjournals) der Bibliothek. „74“ ist der Jahresband des Manuals und „6“ die Seitenangabe, mit folgender Eintragung:

„Dec. 30. Von dem Ober-Präsidenten Grafen von Eulenburg in Hannover übersandt“‘34

Das betreffende Werk ist also 1874 aus dem Vorbesitz des Grafen Eulenburg in die Universitätsbibliothek Göttingen gelangt. Die „4“ in der Mitte gibt das Format Quart an. Darüber hinaus findet sich die Notation „M.40491“, die auf die Stelle im Akzessionskatalog hinweist; „M“ steht für die Wissenschaftsgruppe Musik, „40491“ für die Zählung. Ab einschließlich 1876 gab es die einfache Akzessionsnummer, nämlich die Ziffernfolge Erwerbungsjahr und laufende Nummer, z. B. „1909.8574“ oder „1953.4113“. Zu diesen beiden Akzessionsnummern ist in dem Manual folgendes eingetragen:

1909: „Febr. 26., D, Bibl. Dr. Joachim“

1953: „29.1.54, Verl. d. Gött. Händelges. e.V., P“35

Das Notenwerk »Judas Maccabäus« (Karlsruhe, 1847) von Georg Friedrich Händel, wurde hiernach 1909 von dem Bibliothekar Dr. Joachim der Universitätsbibliothek übergeben. Die Festschrift »Die Göttinger Händel-Festspiele« (Göttingen, 1953) war eine Pflichtlieferung der hiesigen Händel-Gesellschaft.

Ab 1876 bis 1992 dienten die anfangs noch Manual genannten Zugangsbücher ${ }^{36}$ als Erwerbungskatalog. Seit 1993 werden die Bestandszugänge online akzessioniert.

\subsection{Alphabetische Kataloge}

Die erste Katalogform, nach Manual und Standortkatalog, war der systematische Katalog. Erst später, als die Büchermasse zunahm, bedurfte es alphabetischer Register und während des 19. Jahrhunderts wurde der Alphabetische Katalog (AK) zum Hauptkatalog der Bibliotheken. In Göttingen bestand schon neun Jahre nach ihrer Gründung ein vollständiger AK.

\footnotetext{
${ }^{34}$ Im Anhang S. III

${ }^{35}$ s. beide Einträge im Anhang S. IV

${ }^{36}$ Die Zugangsbücher des Zeitraumes 1956-1993 sind im Neubau der SUB, in der Abteilung Monographienbearbeitung (IMB), zu finden.
} 
Die SUB hat zwei alphabetische Hauptkataloge: Der Alphabetische Bandkatalog (BdAK) bzw. Catalogus Alphabeticus, der die Bestände bis zum Erscheinungsjahr 1930 nachweist, und der Zettelkatalog, der an den ersten anschließend die Titel von diesem Zeitpunkt bis zum ersten Drittel des Jahres 1992 verzeichnet; das Jahr 1930 ist in beiden Katalogen vertreten. Seit 1976 werden alle Monographien, und später auch die anderen Dokumenttypen, elektronisch aufgenommen. Sie sind seit 1993 über den OPAC suchbar. Dieser Katalog ist ein elektronisches Verzeichnis, in dem einerseits der aus dem NMN in die PICA Datenbank konvertierte SUB-Bestand enthalten ist, andererseits die seit Einführung von PICA (1992) in die Bibliothek eingegangenen Werke erfaßt werden.

In dem Zeitraum von 1740 bis 1743 erstellte Gesner gemeinsam mit dem Mediziner und ersten Kustos der Universitätsbibliothek, Georg Matthiae (1708-1773), einen vollständigen alphabetischen Katalog. Zuvor wurden die hinzugekommenen und neuerworbenen Bestände in dem Akzessionskatalog eingetragen. Die Vorform des Göttinger Alphabetischen Bandkataloges bildete der alphabetische Index, den Matthiae 1738 zum damaligen Gesamtbestand der Universitätsbibliothek anlegte. Dieser Index enthielt die Bülow-Sammlung, die hannoverschen Dubletten sowie die Gymnasialbibliothek; an bibliographischen Daten wurde nur der Name des Autors bzw. bei Anonyma der Kurztitel angegeben.

Mit zehn Bänden beginnend umfaßte der BdAK neben den Druckschriften auch die Handschriften der Bibliothek. Die Abfassung eines solchen Kataloges wurde dringlich, zumal der Büchererwerb von Hannover aus betrieben wurde, um Dublettenkäufe zu vermeiden. Der BdAK war nur als Ergänzung zum oben genannten Akzessionskatalog gedacht, weshalb er lediglich die zur Identifizierung erforderlichen Angaben eines Werkes enthielt: Verfassername, Kurzform des Titels, Auflage, Erscheinungsort und -jahr, sowie Format und Nummer des Akzessionskataloges. Auf jeder Katalogseite befinden sich, in drei Kolumnen geordnet, links die Verweisung auf das Manual, in der Mitte das Werk und rechts die Signatur, d. h. die Angabe des Realkataloges und die Seite desselben, auf der das Buch eingetragen ist und diese Seitenzahl bezeichnete zugleich den Standort des Buches in der Bibliothek.

Der BdAK besteht aus Titelaufnahmen dreier Kategorien. Erste Regeln für die Eintragungen wurden 1876 von Karl Boysen aufgestellt ${ }^{37}$. Danach wurde der Bestand nach

$\overline{37}$ »Der alphabetische Katalog der Göttinger Universitäts-Bibliothek« 
der zweiten Fassung der Boysenschen Katalogisierungsmethode erfaßt. Zuletzt wurden die Titel nach den Preußischen Instruktionen (PI) aufgenommen, die der einstige Göttinger Bibliotheksdirektor Karl Dziatzko (1842-1903) im Jahre 1899 für alle preußischen wissenschaftlichen Bibliotheken konzipiert hatte. ${ }^{38}$

Als durch das rapide Bestandswachstum der Katalog überfüllt war, wurde er in den Jahren 1776 bis 1790 in 147 Bänden erneuert; um die Übertragung nicht zu beeinträchtigen, wurde zwischen 1780 und 1785 ein zehnbändiger Interimskatalog geführt. Bis tief ins 19. Jh. hieß es über den BdAK, „daß er von immerwährender Dauer sei““39, weil von 1783 an jedem Autor und jedem sachlichen Ordnungswort eines anonymen Titels ein eigenes Blatt zugewiesen und damit die Funktion des Bandkataloges als Zettelkatalog ermöglicht wurde. So konnte sich der neue BdAK durch das Einfügen hinzukommender Blätter und das Zerlegen von Bänden erweitern und die bis 1930 erschienene Literatur aufnehmen. Nunmehr auf 1.056 gezählte Foliobände angewachsen, die oftmals aus mehreren Teilbänden bestehen, befindet er sich heute im HG; bei vier von den insgesamt 1.312 Bänden steht ersatzweise eine Katalogattrappe, mit der Aufschrift „Vermisst | Siehe Ersatzkartei | am Ende | des | alphabetischen Katalogs“ auf dem Rücken. Der BdAK umfaßt mit Ausnahme der Handschriften, Musikalien, Dissertationen und Schulprogramme den gesamten Bestand der Bibliothek, darunter auch die bis 1930 erschienenen Antiquaria. Die hier aufgezählten fehlenden Teilbestände wurden, entgegen des ersten BdAK, in Sonderkatalogen verzeichnet.

Nachdem der Akzessionskatalog eingestellt war und der BdAK nun als Hauptkatalog fungieren sollte, begann man 1885 einen bibliographisch übergenauen Zettelkatalog ${ }^{40}$, der 1892 wegen fehlender Geldmittel abgebrochen wurde. 1931 entstand schließlich durch Anwendung der Berliner Titeldrucke (in Zettelform), der Alphabetische Zettelkatalog $^{41}$ als Fortsetzung des BdAK. Seit 2002 steht ein Teil des Zettelkataloges, nämlich die Bücher mit Erscheinungsjahr 1946-1976, Dissertationen 1930-1976 und Zeitschriften 1930-1945, im Digitalen alphabetischen Zettelkatalog online zur Verfügung.

\footnotetext{
${ }^{38}$ Zur ausführlichen Darstellung der Struktur des BdAK siehe: »Geschichte und Anlage des Alphabetischen Bandkataloges der Niedersächsischen Staats- und Universitätsbibliothek Göttingen« (1951) von Ingeborg Gildemeister und »Einführung in die Besonderheiten der Katalogisierung am Göttinger Alphabetischen Bandkatalog und am Göttinger Musikalienkatalog « (1972) von Ragnhild Rabius.

${ }^{39}$ Zitiert nach Georg Schwedt: „Zur Geschichte der Göttinger Universitätsbibliothek“ (1983), S. 43

${ }^{40}$ Die Kästen mit den großen beschriebenen Karten wurden im Zweiten Weltkrieg (1944) beim Bombenangriff vernichtet. Vgl. Kind-Doerne (1986), S. 54

${ }^{41}$ s. Fotografie S. V
} 
In dieser Datenbank liegen die als Bild vorliegenden eingescannten Zettel des Alphabetischen Zettelkataloges vor.

Von 1930 an wurden zwei alphabetische Zettelkataloge, ein Dienst- und ein Benutzerkatalog, geführt. Der zweite, der auch das unvollständige Material aus den Jahren 1920-1929 enthält, setzte den ersten alphabetischen Zettelkatalog fort. In den fünfziger Jahren ging aus dem Dienstkatalog der NZK für die Göttinger Bestände hervor.

\subsection{Systematische und Sachkataloge}

Neben der alphabetischen Erfassung sind die Bestände der SUB sachlich in zwei zeitlich aneinander anschließenden systematischen Katalogen und einem Schlagwortkatalog verzeichnet. Diese beiden Sachkataloge ergänzen sich dadurch, daß sie die Literatur in ihrem systematischen Kontext aufführen und über einen Begriff schnell und gezielt zur gesuchten Literatur führen.

Der Systematische Bandkatalog bzw. Realkatalog (BdRK) ${ }^{42}$ entstand zwischen 1743 und 1945 in zwei Fassungen. Bereits 1738 war ein Realkatalog gefordert worden. Nach der Fertigstellung des BdAK erarbeitete Matthiae während eines Zeitraumes von zwölf Jahren zwischen 1743 und 1755 die erste dieser Fassungen in 83 Bänden ${ }^{43}$. Er hatte den BdRK nach einem eigenen System angelegt, das sich an der Abfolge der im Universitätsbereich gebräuchlichen Ordnung der Fakultäten orientiert. Dieser zerfiel in sechs Klassen: Theologie zu 16 Bänden, Recht zu elf, Medizin zu acht, Philosophie mit Naturwissenschaft, Politik und Kunst zu zwölf, Geschichte mit ihren Hilfswissenschaften zu 23, Philologie zu zehn, sowie Literär- und Buchgeschichte zu drei Bänden. Sein Prinzip, der „Ordo Catalogi librorum Materialis secundum quem Bibliotheca Universitatis Georgiae Augustae Publica alias Buloviana, collocata est ${ }^{\star 44}$ bezeichnet die Gebiete in fortlaufender Folge in lateinischer Form, jedoch ohne übergreifende zusammenfassende Bezeichnungen wie Jurisprudentia, Historia, Philosophia, usw. Die Überschriften, z. B. »Scriptores de Libris Theologicis universales«

\footnotetext{
42 s. Fotografie S. V

${ }^{43} \mathrm{Im}$ Bericht von Georg Leyh ist von einem anfangs 80bändigen Realkatalog die Rede, dem in den folgenden Jahren sechs weitere Bände folgten. Vgl. „Die Göttinger Bibliothek in den Grundzügen ihrer Entwicklung“, in Nordisk tidskrift för bok - och biblioteksväsen 36 (1949), S. 85

${ }^{44}$ Zitiert nach Kind-Doerne (1986), S. 62
} 
(erster Band), waren am Kopf eines jeden Blattes angebracht bis 1783 am Anfang eines jeden Bandes ein Conspectus mit Blattzahlen eingelegt und so die Benutzung übersichtlicher gemacht wurde.

Was die Anordnung der Eintragungen im Katalog betrifft, so wurden die Titel einer Fachgruppe im Katalog chronologisch, die Bücher am Standort hingegen - um schneller gefunden zu werden - in alphabetischer Reihe aufgeführt, weil die Bücher Jahrzehnte lang nicht mit einer Standortsbezeichnung versehen wurden. ${ }^{45}$

In den Jahren 1790 bis 1796 wurde die Universitätsbibliothek an Hand des BdRK revidiert: In jedes Buch wurde mit Blei Fachbezeichnung und Seite des Kataloges, Paginal- bzw. danach Individualsignatur eingetragen, auf der das Buch verzeichnet war; somit war der BdRK zugleich Standortkatalog geworden. Auch der BdAK wurde in die Verzahnung mit einbezogen, in dem darin die Seite des Manuals, die Klasse und Nummer des Akzessionskataloges sowie das Fach, später auch die Blattnummer des BdRK, eingeschrieben wurden.

Als der BdRK vollgeschrieben war, begann man 1796 mit der Neubearbeitung, der zweiten Fassung des Realkataloges, die bis zu seinem Abbruch nie abgeschlossen wurde - zumindest für die Theologie, die Jurisprudenz und die Medizin. Diese Version, die in zehn Klassen, wie z. B. Encyclopaedia, Historia literaria und Artes, eingeteilt ist, erfaßt die Literatur bis zum Erscheinungsjahr 1945; trotzdem sind noch einige nicht ersetzte Bände der ersten Fassung in Gebrauch. Heute umfaßt der BdRK mit der Abteilung Musik 802 Foliobände, die im HG verbleiben. Diese Bände beinhalten gut gegliederte Inhaltsübersichten, die je nach dem Zeitpunkt ihrer Überarbeitung bis gegen Ende des 19. Jahrhunderts in lateinischer oder in deutscher Sprache verfaßt sind. Eine Besonderheit des Göttinger systematischen Katalogsystems war, daß das Schrifttum zu einem bestimmten Gebiet oft auf mehrere Signaturgruppen verteilt wurde, wie dies in der Klasse Wissenschaftsgeschichte anschaulich ist: Historia literaria librorum (H L L) - Buchkunde, Buchdruck, Buchhandel, Bibliothekswesen, Historia literaria biographica (H L BI) - Wissenschaftsgeschichte nach Personen (Sammel- und Einzelbiographien) sowie Historia literaria particularis (H L P) - Wissenschaftsgeschichte nach Institutionen. Diese Praxis wurde bis 1945 beibehalten.

${ }^{45}$ Vgl. Schwedt (1983), S. 43 
Der BdRK wurde vom Systematischen Zettelkatalog ${ }^{46}$ abgelöst, der die Bestände ab Erscheinungsjahr 1946, mit Einschränkung schon ab 1930, verzeichnet; er wurde, wie der alphabetische Zettelkatalog, bis 1992 geführt. Die Gliederung der Fächer fängt mit A für Allgemeines an, geht über $G$ für Kunst- und Musikwissenschaften, und endet bei Z für Technik, Handwerk ${ }^{47}$.

Neben dem Systematischen Band- und Zettelkatalog verfügt die SUB über einen Schlagwortkatalog ${ }^{48}$ als zweiten Sachkatalog, der in einem Alphabet von Schlagwörtern die Literatur seit 1920 nachweist; er wurde 1990 abgebrochen. Die Entstehung dieses in Zettelform geführten Kataloges basiert auf dem 1928 erstellten Schlagwortkatalog nach dem 1927 von Hans Füchsel entworfenen Regelwerk ${ }^{49}$. Schriften vermischten Inhalts und gesammelte Werke, sofern sie nicht ein bestimmtes Thema behandeln, sind aber nicht im Schlagwortkatalog aufgeführt.

\section{$2.4 \quad$ Sonderkataloge}

Die SUB hat eine Reihe von thematisch eingegrenzten Beständen und geschlossen erworbenen oder geschenkten Sammlungen in Sonderkatalogen verzeichnet.

Zunächst ist der in Bandform geführte Dissertationskatalog, der in zwei Fassungen vorhanden ist, zu beschreiben. Die erste umfaßt elf Bände mit theologischen (4 Bd.), juristischen (5 Bd.) und medizinischen (2 Bd.) Dissertationen. Die Hochschulschriften sind nach dem Alphabet der Präsiden mit Verweisungen vom Respondenten geordnet. Zwischen 1814 und 1850 wurden diese Katalogbände durch die zweite Fassung ersetzt, die bis in die achtziger Jahre des 20. Jahrhunderts für Hochschulschriften - Dissertationen, Habilitationsschriften - Academica sowie Schulprogramme bis zum Erscheinungsjahr 1908 fortgesetzt wurde. Die anfängliche Trennung nach Fakultäten wurde beibehalten. Die 86 foliogroßen Katalogbände ${ }^{50}$ - Theologie (2 Bd.), Jurisprudenz (11 Bd.), die medizinischen Disziplinen (48 Bd.) und die Fächer der Philosophi-

\footnotetext{
${ }^{46}$ s. Fotografie S. V

${ }^{47}$ Zum Aufbau des Göttinger Katalogsystems vgl. Kind-Doerne (1986), S. 68f.

${ }^{48}$ s. Fotografie S. V

${ }^{49}$ H. Füchsels Regelwerk »Richtlinien für die Anlage von Schlagwortkatalogen«; W. M. Luthers Fassung »Richtlinien für die Bearbeitung des Schlagwortkataloges: eine Erweiterung der Füchselschen Instruktionen«. Vgl. Kind-Doerne (1986), S. 70

${ }^{50}$ s. Fotografie S. VI
} 
schen Fakultät (25 Bd.) - befinden sich heute im Neubau. Mit der Aufnahme der 1909-1929 erschienenen Hochschul- und Schulschriften im Katalog Dissertationen wurde der erste Zettelkatalog der Universitätsbibliothek Göttingen geschaffen. Seit 1997 wird der Dissertationsbestand mit den Erscheinungsjahren 1909-1929 (1. Segment) und 1930-1936 (2. Segment) maschinenlesbar erfaßt ${ }^{51}$.

Der ab 1946 in Zettelform geführte Serienkatalog in 120 Katalogkästen ist heute nicht mehr öffentlich zugänglich. In den noch erhaltenen Kästen finden sich Eintragungen Serien auf gelben Leitkarten, gefolgt von Stücktiteln auf weißen Zetteln - zu den in der SUB vorhandenen Schriftenreihen. In den achtziger Jahren wurde der Serienkatalog mittels elektronischer Datenverarbeitung umgesetzt. Folglich wurden die einzelnen Serienstücke ab dem Erscheinungsjahr 1977 nicht mehr im Zettelkatalog nachgetragen, sie wurden unter ihrem Stücktitel im Alphabetischen Zettelkatalog verzeichnet; neue Serien wurden unter ihrem Titel auf einer gelben Karte im Serienkatalog aufgenommen. Seit der Umstellung auf PICA werden Serien elektronisch aufgeführt. Einen wesentlichen Teil des SUB-Bestandes macht wegen ihrer zunehmenden Bedeutung für die wissenschaftliche Forschung die Zeitschriftenliteratur aus, die in Göttingen eine gesonderte Behandlung erfahren hat. Auf der Grundlage eines 1924 entworfenen Verzeichnisses ${ }^{52}$ entstand 1932 die erste Ausgabe des Göttinger Zeitschriftennachweis[es](GÖZN), der neben den Beständen der SUB auch die der Universitätsinstitute enthielt. Dieser Katalog führte nach dem Prinzip der PI, Titel, Erscheinungsort, Zugangsnummer und Signatur der SUB sowie Sigel der besitzenden Institute auf. Die Einführung der EDV in die Zeitschriftenwelt brachte den anfangs in Bandform geführten Göttinger Zeitschriften- und Seriennachweis (ebenfalls GÖZN genannt) hervor, der neben Zeitschriften auch Serien enthält. Mitte 1994 wurde der GÖZN mit Unterstützung der Zeitschriftendatenbank (ZDB) in die PICA-Datenbank konvertiert. Im folgenden handelt es sich um die Kataloge, welche einzig die Schenkungen an die SUB festhalten sowie die über 70 alphabetisch nach dem Namen des Nachlassers (Person oder Institution) geordneten Findbücher, worin die vorhandenen 350 Nachlässe verzeichnet sind. Nachträglich eingegangene Nachlässe sind auf losen Blättern ver-

\footnotetext{
${ }^{51}$ Die Bearbeitung der Dissertationen aus diesem Erscheinungszeitraum hängt mit deren Signierung zusammen ( nach Format, dann nach Fakultät, und innerhalb der Disziplinen alphabetisch nach Orten) nach 1937 wurden die Abhandlungen mit der Hochschulschriften-Nummer versehen (z. B. „, $8^{\circ} \mathrm{U}$ 61.8458“); dazu kommt, daß viele Dissertationen zu Konvoluten zusammengebunden worden waren.

52 »Verzeichnis der an der UB und den Universitätsinstituten zu Göttingen laufend gehaltenen Zeitschriften«. Aus Kind-Doerne (1986), S. 57
} 
zeichnet, die in drei gekennzeichneten Kartonkästen ${ }^{53}$ einsortiert sind. 1997 wurde der Nachlaß-Katalog Hansopac in der SUB integriert, der übers Internet ${ }^{54}$ öffentlich zugänglich ist. In dieser Datenbank werden die Nachlässe - Handschriften und Alte Drucke - der Bibliotheken Deutschlands, Österreichs und der Schweiz maschinenlesbar erfaßt. In der SUB Göttingen werden die Eintragungen aus den hier vorliegenden Findbüchern, aus dem gebundenen Verzeichnis der Göttinger Handschriften, aus dem Autographen- und Nachlässe-Zettelkatalog sowie die Nachlaß-Zugänge seit der Entstehung jener Datenbank aufgenommen. Die im vorangegangenen Absatz dargestellten konventionellen Kataloge stehen im Lesesaal Handschriften und Seltene Drucke (HSD) im HG für den öffentlichen Gebrauch zur Verfügung. Nicht zuletzt ist der zweibändige »Inkunabeln-Standortkatalog« samt dem »Alphabetischen Inkunabelstandortkatalog der UB Göttingen« (1 Bd.), zu nennen.

Ebenfalls zu erwähnen und von ähnlicher Bedeutung sind die von 1757 bis 1888 chronologisch geführten Ausleihregister ${ }^{55}$. Mit diesen semesterweise angelegten Journalen, die die ausgeliehenen Bände alphabetisch nach Verfassern oder Sachtiteln verzeichnen, läßt sich ermitteln, welche Bestände die einzelnen Benutzer im besagten Zeitraum ausgeliehen haben.

\subsection{Der Ars-Musica-Katalog}

Beim Thema alphabetischer Katalog stellt sich die Frage, ob eine Bibliothek wie die SUB die Musikalien, Dissertationen und Autographen in den allgemeinen Katalog namentlich im BdAK - aufnehmen oder sie in einem gesonderten Katalog führen soll. Im alphabetischen Zettelkatalog können alle Titel problemlos vereint werden. Doch in einem Bandkatalog werden die genannten „Specialia“56 separat verzeichnet, weil dessen Umfang sonst gesprengt würde.

\footnotetext{
53 „Katalognachträge, Nachlässe“ - in den ersten zwei Kästen wurde die Ordnung nach Namensalphabet, in dem dritten, nach Fachgebiet durchgeführt.

54 http://www.sub.uni-goettingen.de/hans/

${ }^{55}$ Die Register wurden getrennt angelegt: Ab 1793 war die Aufteilung in A (Professoren) und B (Studierende), und ab 1878/79 war die Aufteilung in A-L, $M-Z$ und Auswärtige Benutzer bestimmend.

${ }^{56}$ Aus Karl Diesch-Königsberg: „Katalogfragen“, in Zentralblatt für Bibliothekswesen 54 (1937),

S. 433
} 
Nach weit über hundert Jahren seit Gründung der Universitätsbibliothek Göttingen begann diese in den sechziger Jahren des 19. Jahrhunderts, den Bestand ihrer Musiksammlung zu erfassen. Dieses Vorhaben hat den in Bandform geführten Ars-MusicaKatalog (im folgenden: AMK) hervorgebracht. Der AMK besteht aus zwei Teilen, dem Ars Musica (AM) Catalogus realis und dem Ars Musica Catalogus alphabeticus $^{57}$, die zusammen 28 Bände umfassen. Der letztere, auch Musikalienkatalog genannt, wurde aus zweierlei Gründen erstellt: Zum einen waren die Komponisten mit ihren Werken nicht im allgemeinen BdAK eingetragen und zum anderen erlaubte der AM-Realkatalog mit seinen Systemstellen MUS V - MUS VIII keinen raschen Zugriff auf Notenwerke.

Der Ars-Musica-Katalog spiegelt nicht nur eine über zwei Jahrhunderte gewachsene Musikkultur und Musikpflege wider, sondern er liefert auch einen gewichtigen Beitrag sowohl zur südniedersächsischen wie zur überregionalen Musikgeschichte.

\subsubsection{Der Ars Musica Catalogus realis}

Im Jahre 1860 legte der Musikwissenschaftler und „Hülfsarbeiter bei der königlichen Universitäts-Bibliothek“ Dr. Eduard Krüger (1807-1885) ${ }^{58}$ den systematischen bzw. Realkatalog - Catalogus realis - zum Bestand der Musikliteratur und Noten an; daß dieses Werk von Krüger selbst begonnen und bearbeitet wurde, bestätigt seine Unterschrift auf dem ersten Blatt des ersten Katalogbandes ${ }^{59}$.

Der AM-Realkatalog besteht aus fünf Folio-Bänden, die gegenwärtig im Historischen Gebäude der Bibliothek aufgestellt sind. Im ersten Band finden sich ein Conspectus der alten Systematik in lateinischer und ein neuer achtseitiger Fundstellenhinweis in deutscher Sprache ${ }^{60}$. Der Katalog umfaßt auf über tausend Seiten 2.409 Titel und 743 Musikdrucke $^{61}$, die in acht Systemstellen, MUS I - MUS VIII, erfaßt sind. Diese Systematik entspricht nur teilweise einer modernen Klassifikation.

\footnotetext{
${ }^{57}$ s. Fotografie S. VI

58 Eduard Krüger, „bisheriger Hülfsarbeiter bei der königlichen Universitäts-Bibliothek, Oberschulinspector a.D.“ wurde zum 1. April des Jahres 1862 „zum außerordentlichen Professor in der philosophischen Facultät ernannt.“ Zitiert aus der Personalakte Krüger, (Bibl. Arch. B, Personalia 2)

${ }^{59}$ s. im Anhang S. VII

${ }^{60}$ s. »Fundstellenhinweis«, S. VIII-XI

${ }^{61}$ Vgl. Raabe (1998), S. 198
} 
In welchem Katalogband welche Signaturgruppe verzeichnet ist und wie die jeweiligen Bände betitelt und numeriert sind, verdeutlicht folgende Zusammenstellung ${ }^{62}$ :

\begin{tabular}{|c|c|c|c|c|c|}
\hline Ifd. $N r$. & Buch-Nr. & Titel & Band & Seite & Signaturgruppe MUS \\
\hline 465 & $534^{\circ}$ & Ars Musica & $\overline{\mathrm{I}, 1}$ & $1-72$ & $\begin{array}{l}\text { I (Musica in universum), } \\
\text { II (Historia artis musicae) }\end{array}$ \\
\hline 466 & 534b & " & $\mathrm{I}, 2$ & $73-299$ & $\begin{array}{l}\text { III (Historia artificum musicorum), } \\
\text { IV (Doctrina artis musicae) }\end{array}$ \\
\hline 467 & 535 & " & II & $300-656$ & $\begin{array}{l}\text { V (Opera artificum, diversorum } \\
\text { collecta), } \\
\text { VI-VII (Opera artificum, opera } \\
\text { singulorum) }\end{array}$ \\
\hline 468 & 536a & $"$ & III,1 & $\begin{array}{l}657-866 \\
{[1-860]}\end{array}$ & VII \\
\hline 469 & 536b & " & III,2 & $\begin{array}{l}\text { 866g-(1019) } \\
{[861-\text { Schluß] }}\end{array}$ & $\begin{array}{l}\text { VIII (Opera artificum, opera } \\
\text { singulorum) }\end{array}$ \\
\hline
\end{tabular}

Den Katalogbänden wurden mit den Jahren Blätter für neue Titelaufnahmen eingefügt. Die ergänzten Seiten haben neben der numerischen eine Zählung mit Kleinbuchstabenexponenten erhalten, beispielsweise $24^{\mathrm{b}}, 30^{\mathrm{d}}, 310^{\mathrm{bb}}$ oder $311^{\mathrm{gc}}$.

Am Kopf jeder Katalogseite sind zentriert der Titel „Ars Musica“ und darunter die Bezeichnung der jeweiligen Systematik, z. B. „Opera artificum. II. Opera singulorum. | saec. XVIII.“ eingetragen. Zur Linken steht das Format, zugleich der erste Teil der Signatur, $2^{\circ}$ bzw. fol., $4^{\circ}$ oder $8^{\circ}$. Auf der ersten Seite zu jedem Komponisten sind oben der Name sowie das Sterbedatum angegeben, z. B.:

„Georg Friedr. Haendel.

$$
\dagger \text { 1759, Apr. 14.“63 }
$$

Dann folgen die Titeleintragungen. In der linken Rubrik steht unter der Systemstelle „MUS VII“ der vierte Teil der Signatur, z. B. „341“. Zusammengefaßt sieht sie so aus: „2 MUS VII, $341^{\circ}$.

Die verzeichneten Musikbestände reichen bis in die zweite Hälfte des 15. Jahrhunderts zurück, d. h. in die Epoche der Wiegendrucke. Es sind zehn musikalische Inkunabeln,

\footnotetext{
${ }^{62}$ Aus »Bandübersicht des systematischen Katalogs« (Handapparat)

${ }^{63}$ s. im Anhang S. XII
} 
206 Titel des 16. Jahrhunderts, 235 des 17., 427 des 18. und 1.538 des 19. Jahrhunderts wie auch 47 Zeitschriften ${ }^{64}$ eingetragen.

Dem Bestand an Musikliteratur und Noten wurde in der Universitätsbibliothek Göttingen, zumindest in den ersten hundert Jahren ihres Bestehens, nur geringe Bedeutung beigemessen. Dies läßt sich damit erklären, daß die Bibliothek aufgrund ihrer traditionellen Sammelschwerpunkte - voran Angloamerikanistik und Slavistik sowie die Naturwissenschaften - die Fachbereiche Kunst und Musik weniger betreute; um so beachtlicher ist daher deren Umfang. Zum anderen kommt wohl die Tatsache in Betracht, daß erst in den 1860er Jahren mit der Anlage eines Musikalienkataloges begonnen wurde. Zum Bestand zählen französische, englische, lateinische, italienische und nicht zuletzt ein Großteil deutschsprachiger Titel, ferner beispielsweise auch Titel in polnischer und spanischer Sprache.

Die Abteilung MUS I Musica in universum umfaßt Sammelbände und Periodika [MUS I, 1700-2499] ${ }^{65}$ zur Musikphilosophie und -ästhetik [MUS I, 1-599, 600-855 und 1200-1234], Nachschlagewerke [MUS I, 2500-2699] wie Johann Gottfried Walthers »Musicalisches Lexicon Oder Musicalische Bibliothec« (Leipzig, 1732) oder die »Encyclopädie der gesammten musicalischen Wissenschaften« (Stuttgart, 1835-1838), herausgegeben von Gustav Schilling, überdies Bibliographien, Bibliothekskataloge [MUS I, 2700-2842] und auch Zeitschriften, so »Cäcilia« (Mainz, 1824ff.), mit zahlreichen Aufsätzen über Händel und seine Werke.

Unter MUS II Historia artis musicae findet sich Literatur zur Musikwissenschaft [MUS II, 1140-1419], unter anderem zur Notation und zur Musikgeschichte. Bei letzterer handelt es sich um Gesamtdarstellungen und Darstellungen einzelner Epochen von der Antike bis zum 20. Jahrhundert [MUS II, 500-1139 und 1520-1799] von Ländern wie Frankreich, Großbritannien, der Schweiz, Deutschland, Polen, Australien, des Orients [MUS II, 1450-1519 und 1800-3549] und um Gattungen wie Bühnen- und Kirchenmusik [MUS II, 1819, 1829, 3550-4000 und 4030-4510].

Bei MUS III Historia artificum musicorum sind Sammel- und Einzelbiographien von Komponisten und Interpreten [MUS III, 1-499 und 500-8999] eingetragen und Werke über das Musikleben [MUS III, 9000-9286]. Das biographische Schrifttum ist prä-

\footnotetext{
${ }^{64}$ Vgl. Raabe (1998), S. 198

${ }^{65}$ Für diese und die unmittelbar folgenden Sign. vgl. den »Fundstellenhinweis« im ersten Band des AM-Catalogus realis bzw. im Anhang S. VIII-XI.
} 
zise nach dem Sterbedatum, nicht nach dem Namensalphabet der Musiker geordnet, also nach Jahr, Monat, Tag. So folgt z. B. nach Henry Purcell, gestorben 21. November 1695, Giovanni Paolo Colonna, gestorben 28. November 1695. Unter den Lebensbeschreibungen stehen einige besonders erwähnenswerte zu Johann Sebastian Bach, Ludwig van Beethoven, Georg Friedrich Händel, Joseph Haydn, Franz Liszt, Wolfgang Amadeus Mozart, Franz Schubert und Louis Spohr; zu diesen Personen sind mehr bzw. überhaupt Biographien in der SUB vorhanden.

Die Gruppe Doctrina artis musicae, MUS IV, enthält außer dem Bestand zur allgemeinen Musiktheorie [MUS IV, 1-1089] auch einiges zur Akustik [MUS IV, 1090-1599] und Musiklehre im allgemeinen [MUS IV, 1600-2999, 3700-3999], Kompositions-, Harmonie- und Formenlehre sowie Instrumentation und Aufführungspraxis. Darauf folgt die Musikpädagogik mit den Teilen Allgemeines [MUS IV, 3000-3699], Gesang, Tasten- und andere Instrumente [MUS IV, 4000-5489].

Im Bibliothekskatalog Nummer 534b lohnt sich ein Blick auf die Seite 130 zu MUS IV, wo fünf der ältesten Musikwerke ${ }^{66}$ in der SUB eingetragen sind; die ersten beiden Titeln im Catalogus realis sind ebenfalls im »Inkunabeln - Standortkatalog I« der Bibliothek registriert.

Mit MUS V Opera artificum diversorum collecta beginnt die Rubrik Musikalien. Hierunter sind Notensammlungen verschiedenen Inhalts verzeichnet [MUS V, 1-999], etwa die umfangreiche »Eulenburg’s kleine Partitur-Ausgabe« (Leipzig, 1874ff.), Textbücher sowie Schul- und Volksliederbücher [MUS V, 1000-1999, 4000-5999]. Außerdem sind Noten zur geistlichen und weltlichen Musik [MUS V, 2000-2999 und 3000-3999], und Literatur zur Kirchenmusik aufgenommen.

Die Abteilung Opera artificum, opera singulorum, mit den Systemstellen MUS VI, VII und VIII stellt den größten Teil der Ars Musica dar. Auf diesen Seiten sind die in der Bibliothek vorhandenen Notenausgaben einzelner Komponisten, darunter auch Gesamt- und Erstausgaben eingetragen. Die wertvollen, zum Teil handschriftlichen Musikalien sind in gleicher Weise wie die Biographien nach Sterbedaten der Komponisten geordnet. Die letzten drei Signaturgruppen gleichen einer bibliographischen Chronik, in der Werke namhafter Musiker aus tausend Jahren Erwähnung finden. Unter MUS VI sind Tonkünstler aus dem 10. bis zum 17. Jh. [MUS VI, 1-1999], unter

\footnotetext{
$\overline{66} »$ Practica musicae« (Mailand, 1496 und Brescia, 1497), »Flores musicae omnis cantus gregoriani« (Straßburg, 1488), »Opus aureum musice castigatissimum de gregoriana et figurativa« (Köln, 1501).
} 
MUS VII die aus dem 18. und 19. Jh. [MUS VII, 1-859] und schließlich unter MUS VIII die aus dem 20. Jh. [MUS VIII, 1-2560] erfaßt. Eine Anzahl von Notenausgaben findet sich jedoch in anderen Teilen des Ars-Musica-Kataloges, wie z. B. die »Sonata [...] für Alt-Blockflöte in -f'- und Basso continuo« (Celle, 1934-1935) von G. F. Händel (Signatur: 8 MUS I, 1035:11-14).

Im Internet gelangte man über die Homepage der SUB in Rubrik Literatursuche zu einer ausführlichen Liste, in der die Signaturgruppe Ars Musica ${ }^{67}$ systematisch fein nach Klassenbezeichnung, (z. B. Carmina popularia), Schlagwörtern (z. B. Volkslied / Quelle) und Signaturintervall (z. B. MUS V, 4000-5618) aufgeführt ist.

Den Musikbestand der SUB Göttingen ergänzte die 1773 aus dem Nachlaß des Historikers, Juristen und Professors Georg Christian Gebauer (1690-1733) erworbene Bibliotheca Cantionum mit ihren rund tausend Bänden. Diese Sammlung an Gesangbüchern $^{68}$, Kantionalien, Liturgica und Kirchenordnungen ist in einem Sonderkatalog, dem Katalogband 90a, erfaßt, von denen ungefähr 300 Titel die Signatur Cantica Gebaueriana (CANT GEB) tragen. Die restlichen Titel samt der Werke, die nicht aus der Gebauerschen Sammlung stammen, finden sich an anderen Systemstellen: Schlagwörter wie Gesangbuch, Kirchenlied und Kirchenmusik unter Historia Ecclesiastica Rituum (H E RIT), Oper unter Poetae Dramatici (P DRAM) und Tanz unter Artes Illiberales (ART ILL). ${ }^{69}$

\subsubsection{Der Ars Musica Catalogus alphabeticus}

Im 19. Jahrhundert wurde die Einrichtung eines alphabetischen Kataloges notwendig, der ausschließlich die Musikalien der Universitätsbibliothek verzeichnen sollte. Der Lösung dieses bis dahin ungelösten Problems widmete sich der Philologe, Musikwissenschaftler und Bibliothekar Dr. Hermann Oesterley (1833-1891), als er in den 1860er Jahren den AM-Catalogus alphabeticus anlegte. Dieses von ihm geschaffene Verzeichnis war lange Zeit der wichtigste und einzige Musikalienkatalog der Biblio-

\footnotetext{
67 s. im Anhang S. XIII-XXIV. Zum Zeitpunkt des Händel-Projektes erhielt man auf dem besagten Suchweg die im Anhang abgebildete Liste; auf der SUB-Homepage ist nun eine deutsche Kurzfassung.

${ }^{68}$ Zur Gebauerschen Gesangbuch-Sammlung siehe: »Georg Christian Gebauers Gesangbuchsammlung in der Niedersächsischen Staats- und Universitätsbibliothek Göttingen« (1985) von Kristine Knüppel

${ }^{69}$ Aus Bötte/Sickmüller (1993), S. 36, 48, 76, 109
} 
thek, der erst 1987 abgebrochen wurde. Danach wurden Musikalien im Alphabetischen Zettelkatalog und ab 1992 im OPAC eingetragen.

Hermann Oesterley wurde laut Dokument vom 27. September 1862 durch das „Königlich Hannoversche Universitäts Curatorium“ an der „Königlichen Bibliothekscommission in Göttingen“ als außerordentlicher Hilfsarbeiter bei der „Königlichen Universitätsbibliothek“ eingestellt ${ }^{70}$. Neben der Arbeit am alphabetischen Musikalienkatalog hatte Oesterley die Aufgabe, sich unter anderem auch um den von Krüger begonnenen AM-Realkatalog zu kümmern, wie es aus seinem Schreiben vom 25. Juli 1865 hervorgeht. Er schreibt darin: „An laufenden Arbeiten wurde mir bei meiner Anstellung zunächst die Fortführung der Realkataloge über die Philosophie, die Romane und die Musik übertragen [...]“71.

Der AM-Alphabetische Katalog enthält die Musica practica der Bibliothek, also Noten und Textbücher. Die Notenwerke sind nach dem Alphabet der Komponisten, der Sachtitel bei Sammelwerken sowie der Titel des größten Teils der Notenreihen eingetragen. Aus anfangs zwei, drei Bänden mit einigen hundert Seiten Inhalt wurden im Laufe von über 120 Jahren 23 Bände. Wie bei den anderen Bandkatalogen kamen immer wieder Blätter für neu aufgenommene Eintragungen hinzu. Die in Leder gebundenen Folio-Bände ${ }^{72}$, die sich im Neubau der Bibliothek befinden, sind nach folgender Buchstabenfolge geordnet und beziffert:

\begin{tabular}{|l|l||l|l||l|l|}
\hline Band-Nr. & enthaltenes Alphabet & Band-Nr. & enthaltenes Alphabet & Band-Nr. & enthaltenes Alphabet \\
\hline \hline 1 & A - Bac & 10 & If - Kon & 19 & Schum - Stef \\
\hline 2 & Bad - Biz & 11 & Koo - Liec & 20 & Steg - Tel \\
\hline 3 & Bk - Carh & 12 & Lied - Mane & 21 & Tem - Vit \\
\hline 4 & Cari - Das & 13 & Manf - Mor & 22 & Viu - Wera \\
\hline 5 & Dat - Enk & 14 & Mos - Nek & 23 & Werb - Zz \\
\hline 6 & Enl - Fz & 15 & Nel - Pfk & \\
\hline 7 & G - Gul & 16 & Pfl - Reg & & \\
\hline 8 & Gum - Hel & 17 & Reh - Sog & & \\
\hline 9 & Hem - Ie & 18 & Sch - Schul & \\
\hline
\end{tabular}

\footnotetext{
${ }^{70}$ Vgl. Personalakte Oesterley (Bibl. Arch. B, Personalia 2)

${ }^{71}$ Ebenda

${ }^{72}$ s. Fotografie S. VI
} 
In den 1960er Jahren erhielt jeder Band eine durchgehende Blattzählung - keine Seitenzählung[!] - in Bleistift. Die später zusätzlich eingebundenen Blätter wurden mit Kleinbuchstabenexponenten versehen, z. B. $74^{\mathrm{a}}$.

Jede Seite ist in drei Spalten aufgeteilt. Unter „Access[io].“ steht die Akzessionsnummer ${ }^{73}$ der eingetragenen Titel. In der mittleren Spalte der Katalogseite ist der Name des Musikers genannt, zuerst abgekürzt in der Kopfzeile, z. B. „HAE“, danach ungekürzt „Haendel, Georg Friedrich“ mit dem Geburts- und Sterbedatum und mitunter auch dem Geburts- und Sterbeort. Hierunter sind die Titel eingetragen. Die Kolumne „Catal. Realis. (Signatur)“ teilt, wie schon die Überschrift sagt, die Signatur des Werkes mit. ${ }^{74}$

Viele Titel sind sowohl unter den Komponisten als auch unter der Serie eingetragen; Doppeleintragungen sind aber nicht durchgängig angelegt worden. Die Werke vieler Komponisten, insbesondere im 20. Jh., sind in Reihen erschienen. Deshalb sind die Reihen das wichtigste Fundament für die Erfassung der Musica-practica-Titel; danach kommen die Titel, die sich auf einzelne Komponisten beziehen und bei denen es sich nicht um Reihenstücke handelt. Der AM-Catalogus alphabeticus weist 210 Notenreihen mit insgesamt 4.750 Stücken nach. Die Anzahl der Werke, die keine Serienstücke sind bzw. der Sammelbände beläuft sich auf ungefähr 2.600 Titel. Der alphabetische AMK registriert insgesamt 7.350 Notenbände.

Was die Ansetzungsfragen und vor allem den Umfang an Informationen über ein Notenwerk, also die Vollständigkeit der Titelaufnahmen betrifft, so sind diese unterschiedlich ausführlich angelegt. Im allgemeinen werden nur notwendigste Daten mitgeteilt; bei den Aufnahmen aus der Zeit vor 1945 sind detailliertere Angaben, z. B. zu den Stimmen, im Realkatalog enthalten.

Neben dem AMK weisen der Serienkatalog, der GÖZN sowie der Systematische Zettel-Katalog Musikalien wie Musikliteratur nach. Ein Großteil der Notenbestände aus der Zeit vor 1987, insbesondere die vor 1945, ist mittlerweile maschinenlesbar erfaßt worden. Dennoch ist meines Erachtens der konventionelle AMK für die bibliothekarisch-musikwissenschaftliche Forschung unersetzlich und von großer Bedeutung.

\footnotetext{
$\overline{73}$ Diese Angabe führt zu Akzessionskatalog und Manual; darüber im Kapitel „Der Akzessionskatalog“ ${ }^{74}$ Vgl. im Anhang S. XXV
} 


\subsubsection{Besonderheiten der Katalogisierung im Göttinger Musikalienkatalog}

Im alphabetischen Katalog der Ars Musica sind die Titel nach den Regeln der PI geordnet, wobei bei Vornamen eine normierte Schreibweise berücksichtigt wurde. Der Name „Bach, Carl Philipp Emanuel“ z. B. ist daher bei „Bach, Karl Philipp Emanuel“ nachzuschlagen; über das alte $C$ ist (mit Bleistift) ein $K$ geschrieben. Desweiteren werden $I$ und $J$ als ein Buchstabe, $U$ und $V$ jedoch getrennt behandelt.

Dem Regelwerk von Ragnhild Rabius aus dem Jahre 1972 zufolge sollten vor 1945 erschienene Bände sowohl in den AM-Catalogus realis als auch in den AM-Catalogus alphabeticus eingetragen werden. Alle Bände, die nach 1945 publiziert worden sind, wurden nur im Alphabetischen Katalog aufgenommen. Demnach war dieser Bandkatalog der einzige Bestandsnachweis der Musikalien für die Zeit nach $1945^{75}$.

In Serien herausgegebene Noten und Textbücher werden seit 1945 im Serienkatalog geführt. Serien, die nur Musica practica aufweisen, sind nur im Musikalienkatalog verzeichnet. Hierzu wird im Serienkatalog auf den Musikalienkatalog verwiesen. „Bei einigen Serien fallen sämtliche Stückaufnahmen weg.“76

Bei manchen im Musikalienkatalog eingetragenen Reihen bricht die Auflistung der Einzeltitel mit folgender Bemerkung ab: „Näheres s. Serienkatalog“; „Bestand s. Serienkatalog“ (bei Serien, die theoretische Musikliteratur enthalten); „Vollst. Bestand s. Serienkatalog | Einzeltitel in Auswahl im Musikalienkatalog“ (bei gemischten Serien, die allgemeine Literatur, theoretische Musikliteratur und Notenwerke umfassen); „Stücktitel s. Zettelkatalog bzw. alph. Bandkatalog, da Text“ (bei Textstücken innerhalb einer Musica practica Serie); „Weiterer Bestand s. Zeitschriftenkatalog. Einzeltitel s. Systemat. Katalog“ (Reihen und ihre Einzelstücke) ${ }^{77}$.

Bei den Signaturen der Musikbestände, wie auch bei denen anderer Fächer, der Universitätsbibliothek Göttingen sind Sonderstandorte zusätzlich vermerkt, wie z. B.:

$$
\begin{aligned}
& 8^{\circ} \text { MUS VII, } 387 \text { Schrank } \\
& 4^{\circ} \text { MUS VII, } 359 \text { Rara }^{78}
\end{aligned}
$$

Ein wichtiger Punkt, den Zusatz zur Titelaufnahme betreffend, ist die sogenannte Ausgabebezeichnung. In RAK-Musik - das Regelwerk für Bibliotheken mit Musikbe-

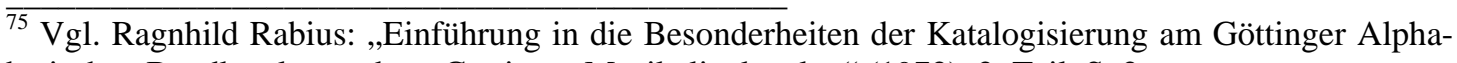
betischen Bandkatalog und am Göttinger Musikalienkatalog“(1972), 2. Teil, S. 2

${ }^{76}$ Zitiert aus: Rabius (1972), 2. Teil, S. 4

77 Aus: Rabius (1972), 2. Teil, S. 3ff.

${ }^{78}$ s. im Anhang S. XXVI
} 
stand - heißt es unter Paragraph § M 141, es müsse durch einen musikalischen Terminus, z. B. „Partitur“, „Klavierauszug“, „Stimmen“, kenntlich gemacht werden, daß es sich bei der Vorlage um eine Notenausgabe handelt. Dieser kann entweder aus der Vorlage übernommen werden oder, wenn keine Bezeichnung angegeben ist, von dem Bearbeiter definiert und in eckigen Klammern angesetzt werden. Diese heutige Richtlinie wurde schon vor über hundert Jahren in der Universitätsbibliothek Göttingen bei der Katalogisierung im AMK angewandt. Das Regelwerk von Rabius besagt, daß wenn auf dem Titelblatt nicht angegeben ist, um welche musikalische Ausgabe - Partitur, Klavierauszug usw. - es sich bei der Vorlage handelt, diese in eckigen Klammern ergänzt wird: [Partitur], [Klavierausz.] ${ }^{79}$.

Bei der Titelaufnahme werden die Tonarten entgegen andersartiger Typographie auf dem Titelblatt, laut Rabius folgendermaßen angesetzt: Dur-Tonarten werden großgeschrieben, z. B. „C-Dur“, Moll-Tonarten erhalten Kleinschreibung, z. B. „C-moll“. „Bei einer Partita in A handelt es sich um A Dur, bei einer Partita in a handelt es sich um a moll. ${ }^{\text {“80 }}$ RAK-Musik behandelt dieses Thema etwas anders. Das Tongeschlecht (Moll, Dur) wird bei der Titelangabe und der Ansetzung des Einheits- bzw. Formalsachtitels großgeschrieben. Die Tonart $\mathrm{c}-\mathrm{d}-\mathrm{e}-\mathrm{f}-\mathrm{g}-\mathrm{h}$ wird jedoch von der Vorlage übernommen, die Groß- bzw. Kleinschreibung richtet sich danach, ob die Terz der betreffenden Tonleiter eine große oder kleine ist.

Ein weiteres Merkmal stellt der Punkt Textdichter dar. In RAK-Musik heißt es unter $\S$ M 614, daß bei einem Werk, das aus einer musikalischen Komposition mit entsprechendem Text besteht, der Komponist als Verfasser gilt. „Unter dem Namen des besonders hervorgehobenen bzw. zuerst genannten Textdichters wird eine Nebeneintragung gemacht. “81 Im Göttinger Musikalienkatalog wurde nach Rabius vom Textdichter auf den Komponisten verwiesen, beispielsweise:

Colman, Francis

Ariadne. [Text]

s. Haendel, Georg Friedrich [Komp.] ${ }^{82}$

\footnotetext{
${ }^{79}$ Vgl. Rabius (1972), 2. Teil, S. 3

${ }^{80}$ Zitiert aus: Rabius (1972), 2. Teil, S. 3

${ }^{81}$ Aus RAK-Musik (1997), S. 81 (§ M 614)

${ }^{82}$ Aus Rabius (1972), 2. Teil, S. 4
} 
Während der letzten zweihundert Jahre sind Musikalien oft als ein Nebenprodukt des Buchwesens behandelt worden. Dies betrifft die allgemeinen Gepflogenheiten, besonders im bibliothekarischen Umfeld, wo Katalogisierungspraxis und Terminologie der Bücher auch für Musikalien gelten sollte.

$\mathrm{Zu}$ allen Zeiten war Musik durch das gesellschaftliche Leben bedingt. Insofern ist es möglich, Zeitstile - Mittelalter, Renaissance, Barock, Klassik, Romantik und Moderne - auseinanderzuhalten. Die Verbindung zwischen dem Komponisten und seiner Umgebung, die geschichtliche Entwicklung von Gattungen - Oper, Sinfonie, Konzert u. a. - sowie der Vertrieb von Musikalien, dies alles hat gesellschaftliche Hintergründe. Bis ins Mittelalter hinein waren mündliche Überlieferung und Gedächtnis die Hauptspeichersysteme für Musik. Erst die Sorge um die weitere Bewahrung und das Streben nach Vereinheitlichung führten in Europa zur Entwicklung von Notationssystemen.

Obschon heute Tonträger in Form von Schallplatten, Kassetten und insbesondere CD immer mehr Einzug in Bibliotheken und Archive halten und ihrerseits eigene Archivformen entwickeln, ist die Wichtigkeit der konventionellen Musiknotation nach wie vor ungebrochen. Sei es als Vorlage zum Musizieren oder in Belangen der Musikausbildung sowie der Musiktheorie und -wissenschaft - Notenwerke bleiben unersetzlich. Bei Recherchen zum Kapitel 3.1 habe ich mich auf die Publikation »Gedruckte Musik« (Mainz, 1995) herausgegeben vom Gutenberg-Museum gestützt; die Texte der Kapitel 3.2 und 3.3 beruhen auf das Buch »Musik in Bibliotheken« (Wiesbaden, 1997) von Kurt Dorfmüller und Markus Müller-Benedict.

\subsection{Die Ära Notendrucke und musikalische Literatur}

Nachdem es gelungen war, Texte im Buchdruck zu vervielfältigen, brachte der Notendruck eine zusätzliche Herausforderung für Setzer und Drucker der Frühdruckbzw. Inkunabelzeit. Vorher wurden Noten von Musikern und musizierenden Laien kopiert; an allen Zentren der Musikpflege waren Notenkopisten tätig. Durch die Plazierung der einzelnen Noten und Notenzeichen auf den fünf Notenlinien und die genaue Kombination mit dem zu singenden Text war das System der Notenschrift komplizierter und aufwendiger als das einfache Zusammenfügen von Lettern zu Worten 
und Zeilen. Dieses Verfahren wurde erst in der Druckerei von Johann Fust und Peter Schöffer bewältigt. Um die Produktion zu vereinfachen, fügten die Drucker Leerraum ein, in den dann Linien und Noten per Hand eingetragen werden konnten. Später wurden die Linien gedruckt, auf denen anschließend die Käufer selbst die Noten einfügen konnten. Diese Methode ermöglichte die Eintragung unterschiedlicher Melodien.

Angesichts der Schwierigkeiten, die mit dem Musiktypendruck verbunden waren Genauigkeit und Planung sowie die Kenntnis der Regeln musikalischer Wiedergaben - kommt es gelegentlich vor, daß auch gedruckte Noten ohne Notenlinien zu finden sind. Im 15. Jh. wurde großenteils die doppelte, generell zweifarbige Methode des Typendruckes verwendet: Linien in roter, Noten in schwarzer Farbe, fast ausschließlich bei Choralmusik in römischer (quadratische Notenköpfe) wie in gotischer (rhomboide Notenköpfe) Notation. Die ersten Notendrucke mit und ohne Notenlinien stammen aus den siebziger Jahren des 15. Jahrhunderts, wobei sich die Hauptmenge auf die letzten beiden Jahrzehnte konzentriert. Auch Holzschnitte wurden zum Notendruck eingesetzt. Eine Ausgabe mehrstimmiger Kompositionen erschien erst im 16. Jh. Manche Musiker brachten ihre Werke in Notenstich-Technik heraus.

In der Zeit der Wiegendrucke befaßten sich nur wenige Drucker mit dem Notendruck - einer der ersten war Konrad Fyner in Esslingen. In der zweiten Hälfte des 18. Jahrhunderts und im 19. Jh. nahm die Notenproduktion einen bisher ungeahnten Umfang an, die durch Verlage wie Breitkopf (Leipzig), Schott (Mainz) und Simrock (Bonn), um nur einige zu nennen, betrieben wurde. Der Musikalienhandel bildete einen bedeutenden Faktor im musikalischen Leben der Menschen und galt als Treffpunkt der Komponisten mit der musizierenden Käuferschaft; erst durch den Musikhandel wurden die Kompositionen klingende Musik. Das florierende Verlagswesen drängte dadurch den Stellenwert der Musikhandschrift im praktischen Musikbetrieb deutlich hinter den Musikdruck zurück. Der Notendruck hat sich im Laufe der Jahrhunderte vom Stichverfahren zum unkomplizierten Computersatz entwickelt.

An dieser Stelle sollen einige Unterscheidungsmerkmale zwischen den beiden Dokumenttypen Buch und Musikdruck erläutert werden. Bücher sind national, d. h. sie erscheinen in nationaler Sprache und in nationalen Verlagen, Notenwerke hingegen werden in der einzigen internationalen Sprache, nämlich der musikalischen Notation, herausgebracht. Diese Internationalität wird in Nachdrucken an vielen Druckorten deutlich. Während Bücher in einer Druckerei in festgelegter Auflage produziert wurden, stellte sich der Notendruck als ein umständliches Verfahren dar: Die Hauptmenge 
der Musikalien wurde in Plattendruck auf von Notenstechern bzw. Lithographen gefertigten Platten hergestellt - eine immerwährende Druckvorlage. Nach dieser geschah der Druck durch andere Drucker und oftmals in anderen Werkstätten, die sich nicht selten in einer anderen Stadt befanden. Schließlich wurde die Titelseite, wiederum manchmal in einer dritten Werkstatt, gestaltet und gedruckt, so daß der Erscheinungsvermerk oft nur auf die Herstellung der Titelseite Bezug nimmt.

Auch Formate wurden bei Büchern und Noten unterschiedlich gehandhabt. Bücher waren meist in Folio, Quart oder Oktav, Notendrucke erschienen in großen dünnen Heften, die weniger handlich waren. Bis um 1845 war bei letzteren das Querformat üblich und wurde dann auf Hochformat umgestellt. Auch in der Funktion sind Bücher und Noten verschieden. Ein Buch wird Zeile für Zeile gelesen. Die Musikalien sind ihrer Beschaffenheit nach kein Lesestoff, sondern dienen praktischen Zwecken. Bei Noten muß aufgrund der Partitur-Systeme waagerecht und senkrecht gelesen werden.

\subsection{Musiksammlungen und Musikbibliotheken}

Jahrhunderte hindurch bildeten fast ausschließlich handschriftliche Aufzeichnungen und gedrucktes Schrifttum das Sammelgut der Bibliotheken. Musikhandschriften und Musikdrucke kamen allmählich hinzu; sie wurden erst durch die öffentlichen Bibliotheken des 20. Jahrhunderts zum legitimen Bibliotheksgut.

Die historische Wurzel des Musiksammelns ist der Sammelcodex. Dieser im gesamten Mittelalter vorherrschende Buchtyp birgt sozusagen eine ganze Bibliothek in sich. Musikalische Codices mit einem Repertoire von mehr als 300 Stücken sind keine Seltenheit; so beherbergt die Sammlung mittelalterlicher Neumenhandschriften des Klosters St. Gallen nur 20 Codices und die der Stimmbuch-Handschriften des Jobst Schalreuter in der Ratsschulbibliothek Zwickau 140. Was die Vielschichtigkeit ihres Inhalts betrifft, gleichen diese Codices ganzen Musikaliensammlungen und vereinen häufig unterschiedliches Material, vom Choral bis zur höfischen Gebrauchsmusik. Im Gegensatz zu ihren handlicheren Nachfahren waren die mittelalterlichen Sammelcodices weniger Medien des täglichen Gebrauchs. Sie dienten größtenteils rein archivarischem Zweck und wurden dementsprechend meist in Bibliotheken verwahrt und von Kantoren und Kapellmeistern betreut. 
Von Bibliotheken wurden Musikalien anfangs kaum gekauft und selten gesammelt. Musikalien wurden grundsätzlich stets dort aufbewahrt, wo sie auch tatsächlich gebraucht wurden, d. h. wo musiziert wurde, nämlich in den Kirchen im Chor und auf der Orgelempore, im Theater, in den Schulen und in Proberäumen, die Militärmusik in den Kasernen, die handschriftlichen Noten in der Privatsammlung des Komponisten selbst. Dieser Sonderbestand wurde wie bei den Codices nicht von gelernten Bibliothekaren, sondern von Musikern verwaltet, die auch Kopien anfertigten und für die Beschaffung sorgten. Diese Praxis kam den Sammlungen nicht zugute, denn bedauerlicherweise wurde das nicht mehr gebrauchte Notenmaterial vernachlässigt oder gar vernichtet; bestenfalls wurden eigene Musikarchive angelegt, die nur in vagem oder gar keinem Zusammenhang zu einer Bibliothek standen.

Gleichwohl sind die historischen Fragen zum Sammeln von Musikalien die gleichen wie die von nichtmusikalischem Schrifttum, was daran liegen mag, daß Schrifttum wie auch Musikkultur Begriff einer oft identischen Trägerschaft waren und sind. $\mathrm{Zu}$ nennen sind hier kirchliche Institutionen mit Klöstern und Kathedralen, Herrscherund Adelshöfe, Privatsammler, Universitäten und Musikschulen sowie staatliche Institutionen, schließlich kommerzielle Leihbibliotheken und Verlagsarchive. Hinzu kommen als besondere musikbezogene Spezies die Archive von Orchestern, Bühnen und Rundfunkanstalten sowie die Militärmusikformationen.

Die im Mittelalter tragende Rolle der Kirche im Musik- und Bildungswesen ließ deren einstigen, überwiegend klösterlichen Archiven zu jener Zeit eine herausragende Stellung zukommen. Sie bewahrten im späteren Verlauf nicht nur rein religiöses Musikmaterial, sondern im Nachhinein auch umfangreiche Bestände an weltlicher Kammerund Orchestermusik wie an musikdramatischen Werken des 18. und 19. Jahrhunderts. Dies ist durch eine enge Verbindung zu den Meistern der Zeit und der höfischen $\mathrm{Mu}$ sikkultur belegt. Aus der Vielzahl der alten kirchlichen Musikarchive sind nur wenige bis in unsere Zeit erhalten geblieben. Durch Brand, Enteignung, Klosteraufhebung durch Reformation, Revolution und Säkularisation wurde vieles zerstreut, in manchen Fällen wurden die Bestände in staatliche und kommunale Bibliotheken übernommen. Heute befassen sich kirchliche Archive, außer mit der Bewahrung des historischen Bestandes, mit Sicherung und Erschließung von verstreutem und in kirchenmusikalischem Alltag nicht mehr in Gebrauch stehendem Musikgut.

Musik als Teil der höfischen Kultur und als Mittel der Repräsentation führte ab dem 15. Jh., mitgetragen vom Mäzenatentum im Geiste der Renaissance, zu wachsenden 
Notenbeständen an den Adelshöfen. Die Sammelgunst der Renaissancefürsten ließ neben Schatzkammern, Kunstgalerien und Bibliotheken auch Musikalienarchive entstehen, für die teilweise komplette Privatsammlungen erworben wurden.

Das dynamische Musikleben an den Höfen des 17. und 18. Jahrhunderts, an denen öfters bedeutende Meister wirkten - etwa Georg Friedrich Händel am Hofe Carnarvons in Chandos und Joseph Haydn am Hofe Esterházys in Eisenstadt - und deren Fürsten selbst musizierten, führte zu einem Musikbedarf, wodurch, entsprechend der individuellen Geschmacksrichtungen der Hofhaltenden, umfangreiche, bedeutende und geschlossene Musiksammlungen entstanden. Mit schwindender Bedeutung der aristokratischen Hofkultur im 19. Jh. wird auch das Zentrum des Musikwesens in den öffentlich-bürgerlichen Bereich verlegt. Früher oder später gelangten die Hofmusikbestände in die Landes- oder Nationalbibliotheken - selten blieben sie beim Adel selbst. Unzählige Bestände wurden wegen sinkender Finanzkraft verkauft oder auch wegen fehlenden Interesses der Besitzer verstreut.

Die ab dem 16. Jh. aufstrebende bürgerliche Kultur und Finanzkraft, insbesondere der großen Handels- und Bankhäuser und Industrieunternehmen, ließ beachtliche private Musiksammlungen entstehen wie die bekannte Sammlung der Familie Fugger oder die des Aloys Fuchs. Seitdem zeichnet sich, bedingt durch innere wie äußere Motive, ein ausgeweitetes musiktheoretisches und historisches Interesse in der privaten Sammelkultur ab. Durch Pfändung, Desinteresse oder Finanzeinbußen bisheriger Eigentümer wurden ab dem 17. Jh. reiche Bestände frei und gelangten über diverse Stationen, darunter den Antiquariatshandel in die Hände von Privatsammlern. Ebenso wie die höfischen Musiksammlungen gerieten auch die privaten in Landes- oder Nationalbibliotheken. Viele davon sind Spezialsammlungen einzelner Komponisten, Stile oder Epochen oder spezifische Materialien wie Autographen. Dank der Privatsammler ist durch deren geplantes Vorgehen die globale Kultur des Musiksammelns entstanden.

An den frühen Universitäten, im deutschen Sprachraum seit dem 14. Jh., fand Musik als Lehrfach als ein Teil der artes liberales statt. Musiksammlungen wurden kaum oder gar nicht unterhalten, zumal es bis ins späte 18. Jh. üblich war, daß die Professoren ihren Bedarf an Unterrichtsmaterialien mittels ihrer beachtlichen Privatbibliotheken deckten und die Studenten ihre Texte selbst schrieben. Nach und nach kamen durch private Nachlässe und musikalische Institutionen Musiksammlungen an Universitäten zustande. Erst im 20. Jh. veranlaßte die Disziplin Musikwissenschaft die Bildung von universitären, musikalisch ausgerichteten Sammlungen. 
Die aus den ersten öffentlichen Musikschulen im 17. Jh. entstandenen Konservatorien, von denen einige heute die Stellung von nationalen Musikhochschulen mit größeren Musikbeständen haben, richten sich bei der Organisation ihrer Archive nach den jeweiligen Universitätsstatuten. Manche dieser Bibliotheken nehmen zusammen mit den staatlichen Institutionen die Funktion zentraler Sammelstellen für Musikgut ein.

In Deutschland ist es bislang nicht zur Einrichtung einer Nationalbibliothek gekommen. Die zentralen Bibliotheken mit musikalischem Schwerpunkt sind die beiden großen Staatsbibliotheken in München und Berlin; in München liegen Musica practica und theoretica im umfassenden Bestand aus dem 16. Jh. wie in den reichen ehemaligen Klosterbeständen und in Berlin in den Quellensammlungen aus der Zeit von Bach bis Beethoven. An nächster Stelle stehen die Landesbibliotheken, worunter die Sächsische Landesbibliothek in Dresden mit den Musiksammelschwerpunkten Kirchenmusik vom 16. bis 18. Jh. sowie Oper und Instrumentalmusik des 18. und 19. Jahrhunderts als die bedeutendste gilt.

Mit zunehmenden Aktivitäten der freien wie städtischen Bühnen und Orchesterunternehmen, die ab dem 18. Jh. in Konkurrenz zu den höfischen und später staatlichen Einrichtungen traten, entstanden auch hier nach und nach Notenarchive. Ihr Aufgabengebiet schließt, neben der Bereitstellung von Notenmaterialien zum Gebrauch, auch die von für ein Ensemble angefertigten Vorlagen oder individuellen Transkriptionen mit ein. Diesbezüglich sind die Musikarchive von Rundfunkanstalten zu nennen. Für Musikübertragungen werden heute noch eigene Orchester und Ensembles eingesetzt, die einen großen Bestand an Notenmaterial verschiedenster Stilrichtungen vorweisen. Überall, wo keine eigenen Archive in größerem Umfang geführt werden, wird nicht mehr gebrauchtes Material staatlichen Bibliotheken übergeben.

\subsection{Musik in der bibliothekarischen Praxis}

Heute sind Musikbibliothekare mit drei großen Gruppen neuerer Publikationen konfrontiert: Druckschriften über Musik, Musikdrucken ${ }^{83}$ sowie Tonträgern. Innerhalb dieser Gruppen taucht auch Material auf, das aufgrund seiner besonderen Pflege und

\footnotetext{
${ }^{83}$ Darunter zählen Denkmälerreihen (Sammlungen von Musikwerken eines Landes, einer Epoche oder einer Gattung), Gesamtausgaben, Faksimiles und Taschen- bzw. Studienpartituren
} 
Sicherung, separate Verwaltung erfordert, wie seltene Drucke, ältere Tonträger, Musikerbriefe und Musikhandschriften, Mikrofilme und -fiches, Dokumente, Daten-, Bildund Bildtonträger sowie Musikinstrumente. In diese Kategorien fallen partiell Nachlässe und Graue Literatur ${ }^{84}$.

Der Aufbau und die Erschließung von musikalischem Bestand - Noten und neue Medien - setzen neben den bibliothekarischen auch musikwissenschaftliche Kenntnisse voraus. Die Kriterien zur Auswahl des Musikschrifttums sind die gleichen wie bei anderem Schrifttum. Für Musikwerke jedoch kommen noch einige musikspezifische Merkmale hinzu, nämlich Material- bzw. Ausgabeart, Besetzung, Niveau und Anspruch, Zweck, Anlaß und Inhalt sowie musikalische Gattung.

Früher dienten die seit 1564 in Frankfurt und seit 1594 in Leipzig bis ins 19. Jh. halbjährlich erscheinenden Meßkataloge als Ankündigungsblätter von musikalischen Neuerscheinungen. Zu Beginn des 17. Jahrhunderts wurden erstmals Kataloge von Musikverlegern und Musikalienhändlern herausgegeben, die ausschließlich auf diesen Dokumenttyp ausgerichtet waren. Heute werden Bibliographien, Diskographien, Bibliothekskataloge wie auch Werkverzeichnisse zum Ausbau des auf Gattung oder Komponist bezogenen Bestandes herangezogen. Für Erwerb von Novitäten sind sie geeignet, sofern sie über die neuesten Titel regelmäßig in kurzen Zeitabständen berichten. Nebenbei informieren Anzeigen in Zeitungen und Zeitschriften über Neuerscheinungen. Im Computerzeitalter werden musikalische Neuerscheinungen auch im Internet bekanntgegeben; seltene Musikdrucke lassen sich in elektronischen Antiquariatskatalogen ausfindig machen.

Während Musikbücher und -zeitschriften über den normalen Buchhandel - örtliche Buchhandlungen, Buchversandfirmen und Zeitschriftenagenturen - vertrieben werden, sind Musikdrucke gemeinhin bei Musikalienhandlungen zu erhalten, die außerdem Bücher und Zeitschriften, Tonträger und Musikinstrumente anbieten. Musikautographen werden auf Auktionen und Antiquariatsmessen erworben oder gelangen durch Nachlässe in die Bibliothek bzw. ins Archiv.

Beim Stichwort Katalogisierung kommen zwei Regelwerke in Betracht: RAK-Musik für Musikdrucke, Musiktonträger und Musik-Bildtonträger sowie RAK-WB für Musikschrifttum. Unterscheidende Besonderheiten bei der Erschließung von Musikalien

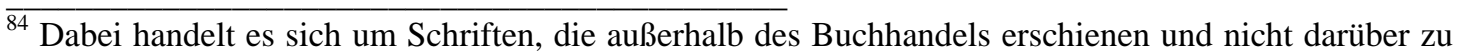
beziehen sind, z. B. Broschüre, Flugblatt, Katalog (Antiquariat, Verlag) und Typoskript.
} 
sind die musikalische Ausgabebezeichnung - z. B. Chorpartitur, Stimmen, Orgelauszug, Songbook - die Bestimmung des Einheits- bzw. Originalsachtitels oder des Formalsachtitels - wie Konzerte, Sonaten, Variationen - sowie die Umfangsangabe bei Musiktonträgern, Bildtonträgern und Mikromaterialien.

Die in Bibliotheken prinzipielle Funktion der Handschriftenkataloge als Standortkataloge auch für Musikhandschriften wird bis 1600 übernommen, für neuere Musikhandschriften hingegen wird der alphabetische Katalog als Hauptkatalog herangezogen. Diese Normen finden sich in den »Richtlinien Handschriftenkatalogisierung « (Bonn, 1992) der Deutschen Forschungsgemeinschaft. Darin werden die Vorlagen mit einstimmiger geistlicher Musik im Rahmen der mittelalterlichen Handschriften bearbeitet und die Handschriften mit mehrstimmiger Musik in den vier Gruppen, Chor- und Stimmbücher sowie Tabulatoren, Partituren und Stimmen, Handschriften ab 1830 und Einzelautographen, kompositorische Nachlässe aus dem 19. und 20. Jh. gegliedert.

Das System der Aufstellung (Freihand oder Magazin), Präsentation und Nutzung des Bestandes in Musikbibliotheken ist mit einigen Ausnahmen, etwa im Auskunftsdienst - die Ermittlung und der Nachweis von musikalischen Werken, z. B. Lieder, Songs und Arien, wie auch die ausdrückliche Verwendung von Repertoire- und Werkverzeichnissen - dasselbe wie in Nichtmusikbibliotheken. Die Arbeit einer Musikbibliothekskraft läßt sich wie folgt beschreiben: Pflege des musikalischen Schaffens und Musikschrifttums und ihre Erschließung für die wissenschaftliche Forschung; Förderung aller auf die Verbreitung der Musikkultur in Wissenschaft und Ausübung gerichteten Bestrebungen; Kooperation mit allen Stellen, die sich in Deutschland und anderen Staaten der Entwicklung einer progressiven Musikkultur gewidmet haben; und nicht zuletzt die Entwicklung neuer, eventuell spezieller Hilfsmittel zur Erschließung und Aufbewahrung der Musikbestände.

\section{$4 \quad$ Georg Friedrich Händel}

Wer in der Zeit um 1700 bis Mitte des 18. Jahrhunderts in Halle an der Saale oder in London lebte, der wußte, wer der Organist Georg Friedrich Händel war, wo er wirkte, was man über ihn sagte und schrieb. Händels Leben ist eine lange Kette seiner Erleb- 
nisse in bedeutenden Musikzentren; das gilt für seine kompositorischen Leistungen wie für seine Erfolge im Konzertsaal. Es ist nicht möglich, das Kolossalwerk Händels auf wenigen Seiten zusammenzufassen.

Die folgenden beiden Kapitel sollen die Wirkung von Händels Persönlichkeit und Werk bis in die Gegenwart hinein verfolgen. Im ersten Teil wird der Lebenslauf des Komponisten geschildert; der zweite Teil stellt sein musikalisches Schaffen dar.

\subsection{Lebensgeschichte}

Am 14. April 1759 starb der gebürtige Hallenser und englische Nationalkomponist Georg Friedrich Händel in London, wo er 47 Jahre lang gelebt hatte. Er kam am 23. Februar 1685 in Halle an der Saale als Sohn des Fürstlichen Leibchirurgen Georg Händel und der Pfarrerstochter Dorothea Taust zur Welt, und wurde tags darauf in der hallenser Liebfrauenkirche getauft.

Entgegen seines Vaters ${ }^{85}$ Willen folgte Georg Friedrich bereits in jungen Jahren seiner Vorliebe für Musik und lernte heimlich und ohne Lehrer das Clavichord so gut zu spielen, daß Herzog Johann Adolf I. von Sachsen-Weißenfels auf ihn aufmerksam wurde. Das Angebot des Fürsten, ihn die Musikerlaufbahn ergreifen zu lassen, lehnte der Vater ab, willigte aber ein, ihn musikalisch auszubilden. So wurde der neunjährige Georg Friedrich in die Hände des Organisten der hallenser Liebfrauenkirche, Friedrich Wilhelm Zachow (1663-1712) gegeben, der ihn in die Geheimnisse der Komposition sowie des Cembalo-, Orgel-, Geige- und Oboespiels einweihte. Der Schüler schrieb zeitgenössische rare Kompositionen ab und komponierte selbst Kirchenkantaten und Orgelstücke; den mit »G. F. H.« betitelten Band mit den Abschriften nahm Händel immer auf Reisen mit.

In den Jahren 1698 bis 1700 besuchte Händel das lutherische Stadtgymnasium, wo er sich nebenbei unter dem Rektor Johann Praetorius in der Kirchenmusik weiterbilden konnte. Nach seiner Schulausbildung begann er im Februar 1702 nach dem Wunsch seines Vaters mit dem Studium der Rechte an der Universität seiner Heimatstadt. Im

\footnotetext{
${ }^{85}$ Als der Vater im Februar 1697 starb, verfaßte Georg Friedrich ein Abschiedsgedicht zu dessen Tod, das er mit „George Friedrich Händel | der freien Künste ergebener“ unterzeichnete. Zitiert nach Barna (1972), S. 9
} 
März wurde er als Organist der reformierten Dom- und Schloßkirche, als Nachfolger von Johann Christoph Leporin, ein Jahr auf Probe angestellt.

1703 ging der junge Händel nach Hamburg, wo er als zweiter Geiger und Cembalist unter der Leitung von Reinhard Keiser (1674-1739) am Opernorchester am Gänsemarkt - dem ersten öffentlichen Opernhaus in Deutschland - wirkte. In der Hansestadt komponierte der Kapellmeister, so erinnerte er sich später, „wie der Teufel!““86 Bühnenwerke und machte die Bekanntschaft seines späteren Biographen, Johann Mattheson (1681-1764), der ihm sodann auch Schüler verschaffte.

Im Jahre 1706 zog es den 21jährigen Händel auf Veranlassung des Prinzen Gian Gastone de Medici, zu Studienzwecken nach Italien - Florenz, Neapel, Rom und Venedig - wo er bald als der „berühmte Sassone“ ${ }^{\text {877 }}$ (Sachse) gefeiert wurde. In dem Land, in dem ein Musiker künstlerische Fähigkeiten entwickeln konnte wie sonst nirgendwo, in den vier Hauptpflegestätten der italienischen Oper, setzte er sich als Opernkomponist durch. Am Ende seiner italienischen Jahre war Händel in der Musikwelt ein weithin bekannter Komponist und Meister auf den Tasteninstrumenten Orgel und Cembalo. Vier Jahre später, 1710, kehrte er nach Deutschland zurück und wurde bis 1716 zum Kapellmeister am Hofe des Hannoverschen Kurfürsten Georg Ludwig (1660-1727) ernannt. Am Ende desselben Jahres zog es ihn nach London, das seine Wahlheimat werden sollte. Auf seinen Reisen von bzw. nach Deutschland stattete Händel, neben Ansbach, Dresden, Düsseldorf und Hamburg, stets seiner Heimatstadt Halle - etwa fünf Mal - einen Besuch ab; seine letzte Fahrt nach Deutschland und somit nach Halle unternahm Händel in seinem 65. Lebensjahr, im August 1750.

Seit Herbst 1712 war Händel in England, wo er zahlreiche Opern und Oratorien schrieb und zur Aufführung brachte. Neun Jahre, von 1720 bis 1728, umfaßt die Zeit von Händels Dienst als Direktor der 1719 gegründeten ersten Opernakademie Englands Royal Academy of Music in King's Theatre, die sich der Pflege und Aufführung der italienischen Oper verschrieben hatte. Im Jahre 1729, nach der Auflösung der ersten Akademie, wurde die New Royal Academy of Music ins Leben gerufen, mit Johann Jakob Heidegger als geschäftlichem und Händel als musikalischem Leiter.

Händels Studien der englischen Oper haben ihr nachhaltiges Echo gefunden in einer Reihe von Publikationen, in Berichten der englischen Tageszeitungen und nicht zu-

\footnotetext{
${ }^{86}$ Zitiert nach Richard Friedenthal: „Georg Friedrich Händel in Selbstzeugnissen und Bilddokumenten“ (1959), S. 18

${ }^{87}$ Zitiert nach „Das ABC der Klassischen Musik“ (München, 1994)
} 
letzt in Auszeichnungen des Königlichen Hofes, des englischen Adels, etwa des Herzogs von Chandos, für den Händel unter anderem sein erstes englisches Oratorium Esther und die Chandos-Anthems ${ }^{88}$ schuf. In England feierte er so große Erfolge, daß ihm 1727 das englische Bürgerrecht verliehen wurde.

Während seines musikalischen Lebensweges hatte er mit zahlreichen Musikern und Sängern seiner Zeit in beruflichem und persönlichem Kontakt gestanden. Sein Lebenswerk umfaßt auch die Unterstützung wohltätiger Zwecke durch Aufführungen seiner Werke, so die um 1733 gegründete Society of musicians - ein Hilfswerk für verarmte Musiker, ihre Witwen und Waisen - und das 1739 gestiftete Foundling Hospital - ein Asyl zur Erziehung verlassener Kinder.

Im Jahre 1751 traf Händel bei der Komposition des Oratoriums Jephta ein schweres Schicksal: Sein Sehvermögen schwächte sich, wie er das auch in der Partitur des besagten Werkes, das er im August desselben Jahres vollendete, notiert hatte: „biss hierher kommen, den 13. Febr. 1751, Mittwoch, verhindert worden wegen relaxation des Gesichts meines linken auges“89. Trotz mehrfacher Augenoperationen verlor er 1753 endgültig sein Augenlicht. Der mit Blindheit geschlagene Komponist führte weiterhin seine Oratorien sowie Orgelimprovisationen und -konzerte selbst auf; die Niederschrift überließ er John Christopher Smith jun. (1712-1795). Neukompositionen sind vereinzelt entstanden; Händel revidierte und ergänzte mit Hilfe seines ehemaligen Schülers ältere Arbeiten. Wenige Wochen vor seinem Tode erlitt Händel bei der Aufführung des Messiah am 6. April in Covent Garden einen Schwächeanfall, der ihn bettlägerig machte; sein Ende kam acht Tage später. Er wurde am 20. April in Anwesenheit von etwa dreitausend Trauergästen in der Westminster Abbey beigesetzt.

Wenn Händel auch nicht mehr nach Deutschland zurückkehrte, wurden seine Werke hier doch weiterhin wiederholt aufgeführt. Zum Repertoire beispielsweise der Göttinger Händel-Festspiele gehörte namentlich die Oper Rodelinda, deren erste Aufführung seit Lebzeiten des Komponisten in Göttingen geschah.

\footnotetext{
${ }^{88}$ Der Schreibweise von in diesem und folgendem Abschnitt erwähnten Werkstiteln liegt, soweit möglich, das vierbändige »Händel-Handbuch« zugrunde.

${ }^{89}$ Zitiert nach Friedenthal (1959), S. 148
} 


\subsection{Werke}

Dieser Abschnitt befaßt sich nicht mit Händels Musiziertechnik. Es soll lediglich eine Aufstellung von seinen zahlreichen Werken gegeben werden. Mit seinem musikalischen Lebenswerk hat Händel Geschichte geschrieben; sein kompositorisches Schaffen umfaßt über 40 italienische Opern, ferner zahlreiche Oratorien und Instrumentalwerke. Mit ihm hat die barocke Operntradition ihren Höhepunkt und zugleich ihren Abschluß erreicht. Dank Friedrich Chrysander (1826-1901) und Georg Gottfried Gervinus (1805-1871), die 1856 die Deutsche Händel-Gesellschaft in Leipzig gründeten, hat hierzulande die künstlerische Beschäftigung mit Händels Werken begonnen.

Eine Reihe seiner Werke schuf der Komponist während seiner Italien- und besonders während seiner Englandjahre. Seine in Italien erlangten Kenntnisse werden sich ein Leben lang in seiner Musik wiederfinden, nämlich lateinische und italienische Kirchenmusik, Volkslieder und auch die Opera Buffa aus dem Königreich Neapel. Seine erste Oper Almira schrieb Händel 1705 für das Hamburgische Opernhaus; sie wurde am 8. Januar mit großem Erfolg uraufgeführt. In Hamburg entstand Anfang 1704 das früheste Werk seiner Jugendzeit, sein erstes Oratorium Passions-Oratorium, das vermutlich in der Passionswoche des gleichen Jahres zur Aufführung kam. Die zweite und letzte Passion, letzte Komposition in deutscher Sprache, komponierte Händel um 1716. Die Jahre 1711 - als er mit Rinaldo seinen ersten Opernerfolg feierte - bis 1737 datieren die Zeit seines Opernschaffens in England. Von 1738 an, nach vielen Höhen und Tiefen des Opernunternehmens, komponierte Händel nur noch Oratorien.

An Gelegenheitswerken schuf er, neben der Ode zum Geburtstag von Königin Anne, die Krönungshymnen zur Krönung von König Georg II. am 11. September 1727 in der Westminster Abbey und die Ode Alexanders Fest zur Feier des Cäcilienfestes, ferner die Trauerhymne, die fünf Tage nach deren Vollendung bei der Bestattung der Königin Caroline am 17. Dezember 1737 erklang. Politisch ausgelegt sind die Vertonungen des Te Deum zum Frieden von Utrecht und zum Sieg der Engländer über die Franzosen bei Dettingen. Ebenso gehört das Oratorium Athalia zu den wenigen Werken, die nicht für die Öffentlichkeit komponiert wurden, sondern es entstand anläßlich einer Universitätsfeierlichkeit in Oxford, zu welcher Händel eingeladen worden war; am 10. Juli 1733 brachte er dieses Werk zum ersten Mal zur Aufführung.

Darüber hinaus hat Händel zwischen 1707 und 1709, weiter nach 1740, ungefähr 100 italienische Kantaten komponiert; zur gleichen Zeit entstanden zusätzlich über 20 
Kammerduette und -terzette. Nicht zu übergehen sind die Concerti grossi, deren sechs er 1734 unter der Opusnummer 3, fünf Jahre später zwölf weitere als Opus 6 veröffentlichte; die zwei Suitensammlungen, die 1720 (erste Sammlung mit acht Suiten) und 1733 (zweite Sammlung mit neun Suiten) erschienen, unterstreichen Händels Virtuosität als Cembalospieler.

Das oratorische Werk L'allegro, il penseroso, ed il moderato wurde in 17 Tagen (19. Januar - 4. Februar 1740) geschrieben und am 27. Februar desselben Jahres im Theater zu Lincoln's-Inn-Fields in London uraufgeführt. Messiah, im Sommer 1741 entstanden und 1742 in Dublin uraufgeführt, ist nicht nur das populärste Werk Händels, sondern auch eines der bekanntesten Oratorien überhaupt. Unmittelbar nach der Vollendung dieses Werkes machte Händel sich an die Komposition des Samson, den er im Oktober desselben Jahres abschloß und im darauffolgenden Jahr aufführen ließ. Israel in Egypt, Judas Maccabaeus und Solomon sind weitere Höhepunkte des Händelschen Oratorienschaffens.

Auch die Wassermusik aus dem Jahre 1717, die zur Unterhaltung König Georgs I. bei einer Wasserfahrt auf der Themse diente, und die Feuerwerksmusik, die Händel anläßlich des Aachener Friedens am 27. April 1749 schrieb, waren nicht weniger bekannt.

Dem Oratorium The triumph of time and truth liegt ein Werk zugrunde, das Händel um $1708 \mathrm{zu}$ italienischen Worten in Rom komponierte und das er im Jahre 1737 in London mit italienischem Text zur Aufführung brachte; die englische, zugleich dritte Fassung war das letzte und einzige umfangreiche Werk, das er während seiner Blindheit schuf und 1757 zur Aufführung brachte.

\section{$5 \quad$ Das Projekt G. F. Händel}

Anregung zu diesem Arbeitsthema waren Vorrecherchen zu in der SUB Göttingen vorhandenen Werken Händels und zu Veröffentlichungen über den Komponisten und sein Schaffen. Es zeigte sich, daß diese Sammlung der Forschung bislang nahezu völlig entgangen ist und dazu ein umfassender Katalog fehlte. Diese Tatsache bewog mich umso mehr, den Händel-Bestand im Gesamtbestand der Bibliothek verzeichnen und kommentieren zu wollen. Im Laufe der Zeit ist daraus eine aktuelle Bestandsauf- 
nahme der Werke Händels und der über ihn vorhandenen Sekundärliteratur geworden. Es stellte sich im nachhinein heraus, daß die in der SUB vorhandenen Bestände zu Händel größer sind als ursprünglich angenommen. Zum gesamten verzeichneten Bestand kommen noch Titelverweise aus Sammelwerken und Schriftenreihen. Aufgabe des beiliegenden Händel-Kataloges ist es, die Sammlung Georg Friedrich Händels in der SUB Göttingen mittels der neuen Katalogisierungsrichtlinien zu verzeichnen und diese dann in der Bibliothek des Musikwissenschaftlichen Seminars der Universität Göttingen, der Bibliothek der Händel-Gesellschaft und im Stadtarchiv nachzuweisen. Es muß betont werden, daß sich außer in der SUB, in den anderen genannten Bibliotheken sowie im Stadtarchiv bei weitem mehr Werke von und über Händel finden lassen als in diesem Verzeichnis angegeben sind. Hauptsächlich die beschränkte, zur Verfügung stehende Zeit setzte einer kompletten Erfassung des Händel-Bestandes der Bibliothek des Musikwissenschaftlichen Seminars, der Händel-Gesellschaft, des Stadtarchivs und der Stadtbibliothek Göttingen gewisse Grenzen.

Dieser Teil der Arbeit gibt einen Überblick über Umfang und Bedeutung, Herkunft und Inhalt des Händel-Bestandes der SUB Göttingen. Zuvor wird über die bei der Katalogisierung entstandenen Probleme und Besonderheiten berichtet. Aufbau und Inhalt des beiliegenden Kataloges werden in der Einführung im Katalog selbst erläutert.

\subsection{Bericht über die Arbeit}

Im Einverständnis mit Dr. Axel Halle (ehemals stellvertretender Direktor der SUB Göttingen) begann ich die Bearbeitung der dort gesammelten, zum Teil bisher noch nicht online verzeichneten Notenwerke von Georg Friedrich Händel und der Literatur über ihn. Anfangs hatte ich die Absicht, neben den Musikalien und der selbständig erschienenen Literatur auch Aufsätze aufzunehmen, sah aber bald ein, daß bei der überaus großen Menge des Bestandes die begrenzte Zeit nicht hinreichen würde, diese Aufgabe zu bewältigen. Ich entschied mich also für die Bearbeitung der Musica practica und der Musica theoretica. Zusätzlich wurden die Musikalien aus den Systemstellen MUS V - MUS VIII miterfaßt, die unter anderem Werke von Händel enthalten. Die Auswahl nur dieser Signaturgruppen beruht darauf, daß diese Bestandsgruppen im 
Magazin nebeneinander stehen, wogegen bei der Numerus-currens-Signatur die $\mathrm{Mu}-$ sikliteratur und die Musikalien mit allen anderen Fachgebieten zusammenstehen.

Mit der Suche in den einschlägigen Katalogen und Bibliographien wurde der praktische Teil der Arbeit begonnen. Aus Band 8 des Musikalienkataloges wurden alle Signaturen unter „Händel, Georg Friedrich“ in einer Liste notiert; ebenso wurde bei dem Alphabetischen Zettelkatalog verfahren. Anschließend wurden die in Konrad Sasses »Händel-Bibliographie« (Leipzig, 1963, 1967) verzeichneten Musikdrucke sowie das selbständige Schrifttum einer elektronischen Überprüfung im OPAC unterzogen.

Nachdem die bibliographischen Recherchen erledigt waren, wurden die Titelaufnahmen der vorhandenen Werke per Autopsie im PICA-Katalogisierungssystem bearbeitet. Dieser Arbeitsschritt erwies sich bald als zu aufwendig: Einige Inventare mußten erst elektronisch verzeichnet werden, andere wiederum waren im lokalen System als sog. „O.T.-Aufnahme“ ${ }^{\text {90 }}$ vorhanden; ein Teil der Werke - 223 Stücke allein im HG hatte noch keinen Barcode, der nun im nachhinein vergeben wurde. Zudem kam, nach Absprache mit der Zentralredaktion in der SUB Göttingen, die Umstrukturierung der Datensätze bei mehrbändigen Werken in c- und f/F-Stufen - vor allem der beiden Händel-Gesamtausgaben; diese Titelaufnahmen waren nach der alten PICA-Richtlinie dreistufig (c- e- f) angelegt.

Zur Bearbeitung der Titelaufnahmen kam auch die der Signaturen, die in manchen Fällen zwei oder gar drei Mal vergeben waren, so bei „4 MUS VII, 353“, „4 MUS VII, 362“, „4 MUS VII, 371“ und „4 MUS VII, 381“. Denen wurde nun, je nach Vorlage, die entsprechende Bezeichnung hinzugefügt und damit das Werk kenntlicher gemacht, etwa „4 MUS VII, 371:BASs“ und „4 MUS VII, 371:KLAVIERAUSZUG“.

Obendrein konnten einige Werke nicht unverzüglich bearbeitet werden, weil sie entweder zu dem Zeitpunkt ausgeliehen oder nicht auffindbar waren oder weil sie Probleme aufwiesen, die einzig von der zuständigen Abteilung erledigt werden konnten. Manche Anfragen ließen sich im Haus klären, andere erforderten Dienste von außerhalb, so vom Musikverlag Bärenreiter in Kassel oder von der Göttinger HändelGesellschaft.

\footnotetext{
${ }^{90}$ O.T. Dabei handelt es sich um eine Aufnahme Ohne Titel, die nur erstellt wird, wenn kein anderer Datensatz in den Systemen - lokalen wie zentralen - vorhanden ist. In dieser sog. Blankoaufnahme wird lediglich der Bandbarcode mit dem Erscheinungsjahr und der Signatur verknüpft. Dieses Verfahren dient dazu, bestellte Bände schnellstmöglich für die EDV-Entleihung verbuchbar zu machen.
} 
Bei der Arbeit ist ein Punkt noch berücksichtigt worden, und zwar der in den einzelnen Quellen gesetzte Besitzstempel sowie das eingeklebte Etikett, das unter anderem die widmende Person oder auch Körperschaft angibt. Es kamen insgesamt 18 Stempeltexte vor, von denen allein neun mit dem Namen der SUB Göttingen in diversen Formulierungen auftauchen: „EX BIBLIOTHECA REGIA ACADEM. GEORGIAE AUG.“, „BIBL. R. ACAD. G. A.“ und „Universitätsbibliothek Göttingen“, heute „NIEDERSÄCHS. STAATS. U. UNIV.-BIBLIOTHEK GÖTTINGEN“.

Es wurden über 650 Titel, hauptsächlich Musikalien (392, inklusive Tonträger) und Musikliteratur (265, inklusive Libretti und Nachlaßdokumente), verzeichnet; auch dokumentarisches Material, nämlich eine Nachlaßakte („Cod. Ms. K. Brandi 21“) sowie Musik-CD gehören dazu. Nicht bearbeitet wurden jedoch die über 200 Mikrofilme. Dennoch sind die Mikrofilme mit der PPN, der Signatur und dem Erscheinungsjahr des verfilmten Werkes unter dem jeweils übergeordneten Titel chronologisch aufgeführt. Zur Ermittlung der Mikrofilme wurde jedes Opus aus dem HändelWerkverzeichnis im lokalen Bibliothekssystem recherchiert.

An dieser Stelle ist bezüglich der Titelaufnahmen anzumerken, daß ich bei dieser Arbeit über die Vorschriften der RAK-Musik hinausgegangen bin, z. B. bei der Nennung der Bestell- bzw. Platten-Nummer und der ISMN ${ }^{91}$ : Laut RAK-Musik soll, sofern beide vorliegen, nur die ISMN angegeben werden, für die GBV-Aufnahme dagegen müssen sowohl Bestell-Nummer als auch ISMN eingetragen werden. Was nicht im GBV bearbeitet werden konnte, waren die Zeitschriften; bei denen, wo Korrekturen nötig waren - z. B. fehlende Jahrgänge ergänzen - wurden diese in der Titelaufnahme im Händel-Katalog durchgeführt.

Laut RAK-WB (§ 36) gelten vor 1800 erschienene Werke als Alte Drucke, die spezifischer Katalogisierungsrichtlinien bedürfen, z. B. die wörtliche (ungekürzte) wie typographische (Groß- und Kleinschreibung) Übernahme des Titels und des Erscheinungsvermerks. Dagegen werden der PICA-Katalogisierungsrichtlinie zufolge bis einschließlich 1850 erschienene Werke als Alte Drucke behandelt. In der SUB Göttingen werden alle Werke - Literatur wie auch Musikalien - bis Erscheinungsjahr 1850 als solche behandelt. In dieser Arbeit wurde die lokale Katalogisierungstradition beibehalten. Ein Problem bei der Katalogisierung stellte die Nachlaßakte Brandi dar. Der Aktenbestand ist grob verzeichnet, d. h. es fehlen ausführliche bibliographische An-

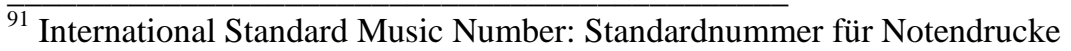


gaben über die einzelnen enthaltenen Dokumente. So wurden nachträglich und nur für den Händel-Katalog die enthaltenen, in diese Arbeit miteinbezogenen Dokumente separat detailliert verzeichnet.

Allen Problemen voran stehen die Konvolute - das sind zwei oder mehr selbständig erschienene Werke, in der Bibliothek jedoch zusammengebunden und nur zusammen ausleihbar. Sind jedoch die in einem Konvolut zusammengebundenen Bände nicht im OPAC miteinander verknüpft, so kann die Bestellung und Ausleihverbuchung nicht online erfolgen. Im Rahmen meines Projektes bin ich auf einige Konvolute gestoßen. In einem dieser Konvolute (Signatur: 4 MUS III, 9220) fand sich etwas Besonderes: Sein Inhalt war noch nicht im GBV nachgewiesen und wäre womöglich unentdeckt geblieben; im wesentlichen sind es ein- und zweiblättrige Dokumente sowie ein 16seitiges Libretto »Texte zum ersten und dritten Concerte beim neunten Elbmusikfeste« (Braunschweig, 1836), das auch Händels Messias beinhaltet.

Ein erfreuliches Ergebnis waren die Funde zweier bisher unkatalogisierter Textbü-

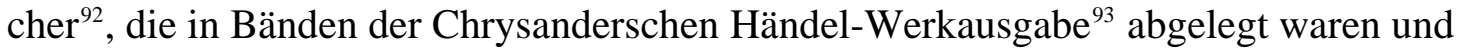
nachträglich akzessioniert wurden. Auf der Suche nach dem zweiten Teil von Joachim Eisenschmidts »Die szenische Darstellung der Opern Georg Friedrich Händels auf der Londoner Bühne seiner Zeit« (Wolfenbüttel, 1940-) stieß ich zu meiner Freude auf der Homepage des Händel-Hauses Halle über die Liste ihrer Veröffentlichungen ${ }^{94}$ darauf - die SUB war bereits im Besitz des ersten Bandes. Durch ein Telefongespräch meinerseits mit dem Händel-Haus gelangten der gesuchte Band, »Der Darstellungsstil der Händeloper« (Wolfenbüttel, 1941) ${ }^{95}$ sowie drei weitere Schriften als großzügige Schenkung aus Halle in die SUB Göttingen. Durch dieses Projekt konnte ich anregen, daß auch die Göttinger Händel-Gesellschaft elektronische und gedruckte Publikationen, hervorgegangen aus den Internationalen Händel-Festspielen, der SUB gespendet hat: Die inzwischen fünf Werk-CD (vier Opern, ein Oratorium) der Jahre 1999 bis 2004, die zu Anfang dieses Jahrhunderts angefangene CD-Publikation »FestspielEdition« von 2000 bis einschließlich 2004 sowie die Programmbücher der Jahre 2002 bis 2004.

\footnotetext{
92 Signatur: „ALT 2001 A 1554“ und „K 2001 A 735“

93 »Georg Friedrich Händel’s Werke« (Leipzig, 1858-1903), Ausgabe der Deutschen Händelgesellschaft, herausgegeben von Friedrich Chrysander.

94 http://www.haendelhaus.de/haendelhaus/veroeffentl.html

95 s. Signatur: „8 MUS I, 2105:6““
} 
Nachdem die Katalogarbeit beendet war, sind die Titeleintragungen im AM-Catalogus alphabeticus und im Catalogus realis mit „+DV“ versehen - ein Hinweis darauf, daß jene Titel nun elektronisch erfaßt sind. Anschließend wurde der Bestand der Bibliothek des Musikwissenschaftlichen Seminars und anschließend der des Stadtarchivs anhand der SUB-Bestandsliste überprüft; vorhandene Titel wurden entsprechend unter der SUB-Signatur gekennzeichnet.

\subsection{Händel in der SUB Göttingen}

Trotz der Zerstörungen, die Göttingen in den Kriegen erlitten hat, befinden sich heute noch oder wieder an unterschiedlichen Stellen des Göttinger Stadtgebietes Sammlungsstätten, in denen Musikliteratur und Musikalien, insbesondere von bzw. über Händel aufbewahrt werden.

Nach vorsichtigen Schätzungen umfaßt der Händel-Bestand in Göttingen einschließlich überlieferter Dokumente und neuer Medien zwischen vier- und fünftausend Einheiten. Der größte Bestand befindet sich in der SUB; weitere größere Bestände gibt es in der Bibliothek des Musikwissenschaftlichen Seminars der Georg-AugustUniversität, der Händel-Gesellschaft, im Stadtarchiv sowie in der Stadtbibliothek.

Im Folgenden wird allein der Händel-Bestand der SUB ausgewertet. Die Sammlung von Werken und Dokumenten von und über Georg Friedrich Händel darf neben der von Johann Sebastian Bach und der Bach-Familie als einer der bedeutendsten $\mathrm{Mu}$ sikerbestände und ausgesprochener Schwerpunkt in Göttingen bezeichnet werden.

\subsubsection{Umfang des Händel-Bestandes}

Im Musikalienkatalog konnten auf 65 Blättern (Blattnummern 24b-74a) Titel von Händel nachgewiesen werden. Im systematischen AMK (Band 534a) findet sich in fast jeder Abteilung mindestens ein Eintrag. Es sind unter MUS I 13 Titel, unter MUS II sieben, MUS III 39, MUS IV ein, MUS V 37, MUS VII 203 und schließlich unter MUS VIII ein Titel verzeichnet. Was die Standorte des Händel-Bestandes betrifft, so 
befinden sich die Werke mit der Signatur MUS I - MUS VIII im $\mathrm{HG}^{96}$; alles andere ist im Neubau aufgestellt. Auch im Freihandbereich sind Bestände mit der Abteilungssignatur und der Gruppen-Numerus-currens-Signatur aufgestellt.

Im Bestand der SUB tauchen vorwiegend Notendrucke (381 Titel) von Händel auf, daneben neun Notenhandschriften und 19 Textbücher; den Rest machen Musikliteratur (228 Titel) sowie Musiktonträger (11 CD-Titel) aus. Zudem finden sich in der Nachlaßakte des Historikers Karl Brandi auch noch Briefe und Belege sowie KonzertBestellkarten und Zeitungsausschnitte. Eine Sonderstellung ist zum einen der »Ansprache in dem Konzert zur Feier der 20. Wiederkehr der Erstaufführung von G. F. Händels Rodelinde in Göttingen, 26. Juni 1920« von 1941 einzuräumen, die bis Ende des Händel-Projektes (Herbst 2002) in keiner GBV-Bibliothek nachweisbar ${ }^{97}$ war, und zum anderen den Briefen, die Einblicke in die Entwicklung der Göttinger HändelGesellschaft und -Festspiele erlauben. Nicht nur die Druckwerke sind von Interesse, sondern auch die zahlreichen Händel betreffenden Mikrofilme. Die wenigen anonymen Libretti in DD18, die neben Händel von anderen Musikern gleichfalls vertont worden sind, dürften für die Forschung nicht uninteressant sein, zumal diese Vorlagen, nach einem Gespräch mit dem Händel-Haus Halle, nicht von Händel sind.

Unter den Musikdrucken ragen die Partituren der Opern und Oratorien sowie mehrere Kantaten und Sonaten hervor. Die wenigen in der SUB erhaltenen Musikhandschriften von Händels Werken stellen, auch wenn es sich dabei um Abschriften handelt, angesichts ihrer Titel einzigartige und musikhistorische Kostbarkeiten dar, etwa die in den Rara-Bestand aufgenommenen Stimmen des »Messias $«^{98}$.

Partituren und vor allem Stimmen vieler, häufig aufgeführter Werke befinden sich oft in einem erbarmungswürdigen Zustand. Es finden sich Anmerkungen aller Art: Bleistift- oder Farbstiftstriche geben Tempi an, bezeichnen Stimmen, ändern Notenwerte, Ein- und Überklebungen decken Notenzeilen - ein Vorgehen, das sich aus der Aufführungspraxis ergibt und jeder Musiker nachvollziehen kann, aber angesichts der Seltenheit bzw. Einmaligkeit der entsprechenden Musikalien schmerzt.

Zwar war der Großteil der Publikationen von bzw. über Händel am Standort, sechs den Bibliothekskatalogen entnommene Titel - überwiegend Notendrucke - waren

\footnotetext{
${ }^{96}$ s. Fotografien S. II

${ }^{97}$ Die Ersterfassung dieser Broschüre erfolgte laut PICA-Zentralsystem (CBS) am 03.09.04 durch die Bibliothek des Musikwissenschaftlichen Seminars der Universität Göttingen.

98 s. Signatur: „2 MUS VII, 364 RARA“
} 
jedoch nicht auffindbar, und Nachforschungen blieben ohne Ergebnis. Über die Existenz eines vermißten Werkes, nämlich Elisabeth Bredenfoerders »Die Texte der Händel-Oratorien « (Leipzig, 1934) ${ }^{99}$, ist bekannt, daß die Bibliothek des Musikwissenschaftlichen Seminars der Universität Göttingen ein Exemplar davon besitzt.

Unter den Musikalien finden sich seltene und bedeutende Werke, z. B. »The favourite songs in the opera call’d Flavius« (London, 1723), die Chorstimmen zu »Israel in Aegypten« (Leipzig) und zu »Jephta« (Wien), der Klavierauszug von »Mein Lied sing auf ewig« (Berlin, 1947), »Das Autograph des Oratoriums Messias« (Hamburg, 18891892) und die beiden großen Werkausgaben, die 94bändige Ausgabe der Deutschen Händel-Gesellschaft, »Georg Friedrich Händel’s Werke« (HGA) (Leipzig, 18581903), herausgegeben von Friedrich Chrysander, sowie die hundert Jahre später erschienene neue kritische Gesamtausgabe der Werke Händels, die »Hallische HändelAusgabe« (HHA) (Kassel, 1955ff.), herausgegeben von Max Schneider. Überdies sind vereinzelt umfangreiche Sammlungen von gedruckten wie handschriftlichen Chorstimmen erhalten.

Zum musiktheoretischen Bestand zählen über 37 biographische Werke, desweiteren 14 Kataloge und Bibliographien. Im übrigen gehören auch 24 Tagungsberichte, 28 Programmhefte und zehn Dissertationen zum aufgenommenen Bestand.

Im Gesamtbestand der SUB befinden sich außerdem spezielle Sammlungskataloge, in denen ebenfalls Händelsche Werke registriert sind, z. B. im ersten Band des »Catalogo generale delle opere musicali, teoriche o pratiche, manoscritte o stampate, die autori vissuti sino ai primi decenni del XIX secolo, esistenti nelle biblioteche e negli archivi d’ Italia « (Parma, 1911) und im dritten Teil des Kataloges der King's Music Library »Printed music and musical literature« (London, 1929). Es gibt sicher weitere solcher Verzeichnisse, die in dieser Arbeit jedoch nicht berücksichtigt wurden, es sei denn sie registrieren ganz oder überwiegend Händel-Ausgaben, so der fünfte Band des Katalogs der Sammlung Anthony van Hobokens in der Musiksammlung der Österreichischen Nationalbibliothek »Christoph Willibald Gluck, Georg Friedrich Händel« (Tutzing, 1985) von Karin Breitner.

Erwähnenswerte Neuzugänge sind Partitur und Klavierauszug von Händels bisher unbekannter Komposition »Gloria in excelsis deo « ${ }^{100}$, deren Manuskript im Herbst

\footnotetext{
$\overline{99}$ In der SUB ist es mit „8 LING VIII, 627:19“ signiert - s. im Anhang S. XII.

${ }^{100}$ s. Signatur: „K 2002 B 1825“ (Partitur) und „K 2002 B 1826“ (Klavierausz.)
} 
2000 von dem Musikwissenschaftler Hans Joachim Marx in der Bibliothek der Londoner Royal Academy of Music entdeckt wurde. Diese Komposition kommt bisher in keinem Werkverzeichnis vor. Dazu sind vier weitere Bände der Hallischen HändelAusgabe - »Rodelinda« (2002, Bd. 2,16), »Lotario« (2003, Bd. 2,23), »Imeneo« (2002, Bd. 2,40), »Anthem for the Funeral of Queen Caroline« (2004, Bd. 3,12) sowie CD der folgenden Göttinger Händel-Festspiele gekommen und nachgetragen.

Der große und vielfältige Händel-Bestand der SUB Göttingen reicht vom 21. bis ins 18. Jh. zurück, wie die unten dargestellte Tabelle im Detail zeigt. Jede einzelne Medieneinheit ist in dieser Zählung berücksichtigt: Bei Zeitschriften ist jedes Heft und bei der Nachlaßakte, bis auf Einladungskarten u. ä., jedes Dokument gezählt. Allein die in der SUB vertretenen Namen Beethoven, Händel, Mozart, Palestrina, Schubert um hier einige zu nennen - geben Grund genug, dem Bereich Musik einen eigenen Saal zu widmen, entsprechend dem Asien-Afrika-Lesesaal.

\begin{tabular}{|l|l|l|l|l|l|}
\hline & $\begin{array}{l}\text { [s.a.] } \\
\text { ohne Jahr }\end{array}$ & $\mathbf{1 7 0 0 - 1 7 9 9}$ & $\mathbf{1 8 0 0 - 1 8 9 9}$ & $\mathbf{1 9 0 0 - 1 9 9 9}$ & $\mathbf{2 0 0 0}-$ \\
\hline \hline Literatur \& Dokumente & 3 & 4 & 21 & 260 & 16 \\
\hline Libretti & 0 & 2 & 0 & 17 & 0 \\
\hline Musikalien & 25 & 4 & 127 & 176 & 11 \\
\hline CD & 0 & 0 & 0 & 2 & 9 \\
\hline
\end{tabular}

Der Umfang der Dubletten aus dem Händel-Bestand in den anderen ausgewählten Sammlungsinstitutionen ist unterschiedlich: Im Stadtarchiv wurden 13 und in der Seminarbibliothek 216 Titel registriert. Die Händel-Gesellschaft kann sich jedenfalls durch die beiden Händel-Gesamtausgaben mit der SUB vergleichen. Der Grund, das Sigel des Göttinger Symphonie Orchesters (GSO) im Katalog nicht einzubeziehen, ist der, daß dessen Bestand vom öffentlichen Zugang ausgeschlossen ist.

\subsubsection{Aufbau und Erschließung}

Von Beginn des 19. Jahrhunderts bis zur Gegenwart wurden sämtliche Händel-Werke, deren die SUB habhaft werden konnte, erworben. Andere Materialien kamen durch 
Schenkung, Pflichtlieferung oder Tausch hinzu. Der gesamte bearbeitete HändelBestand weist über 371 Akzessionsnummern auf. Es muß noch hinzugefügt werden, daß für einen unbeträchtlichen Rest von über zehn Nummern Zeitpunkt der Erwerbung und unmittelbarer Vorbesitz offen bleiben. Die Bestände selbst wie auch die vorliegenden Kataloge geben darüber keine Auskunft.

Zur Orientierung an dieser Stelle eine Zusammenfassung: Mehr als 195 Käufe, über 105 Geschenke, 15 Pflicht- und 11 Tauschexemplare. Im Hinblick auf die Stellung der Göttinger Universitätsbibliothek in der preußischen Ära sowie der finanziellen Lage wurde, den Erwerbungsjahren zufolge, bis einschließlich 1899 die Musiksammlung, trotz des Prestigeverlustes und der eingeschränkten Geldmittel, um über 70 HändelZeugnisse ergänzt. Dieser hauptsächlich Notenwerke umfassende Zugang gelangte großenteils durch Kauf (über 50), teils durch Schenkungen (über 12) in die Bibliothek. Die 94 Bände der Chrysanderschen Händel-Gesamtausgabe kamen vorwiegend durch Kauf vom Leipziger Verlag Wilhelm Engelmann und teils „,von der Direction der Händelgesellschaft in Leipzig“, teils durch Schenkung „von dem Ober-Präsidenten Grafen Eulenburg in Hannover“ in die Musiksammlung ${ }^{101}$. Aus dem Manual geht außerdem hervor, daß einige Bände der Universitätsbibliothek zweifach erworben wurden, und zwar ein Exemplar als Geschenk vom besagten Präsidenten und das andere durch Kauf vom Verlag. Es ist zu vermuten, daß das zweite Stück abgegeben wurde, zumal derzeit nur ein Exemplar im Magazin steht.

An dieser Stelle sei auf einige erwähnenswerte Geschenke hingewiesen: »Händel’s Oratorium der Messias« (Hamburg, 1809), geschenkt von der „Kgl. Bibl. Berlin (a. d. Schenkung d. Consuls a. s. Glücksberg)“, 20. Mai 1896; die von Arnold Schering gehaltene Rede »Die Welt Händels« (Essen, 1922), gespendet von der „Redaktion d. gel. Anz. Gött.“, 16. Juni 1924; der Klavierauszug von »Debora« (Leipzig, 1909), gestiftet vom „Bibl. Insp. G. Dittrich, Gött.“, 29. April 1937. Als Provenienz dreier Bände (8, 9, 12) von Händels »Orgelkonzerte« (Mainz, 1940-) wird im Manual der Bibliothek ein „K[auf], Hack Gött.“ vom 1. Juli 1943 angeführt. Desweiteren haben „Kuhnhardt“, die „Notgemeinschaft“, „Stud. R. F. Schmidt“ aus Celle, „Antonie Dittrich“ aus Göttingen, der „Deutsch-engl. Kulturaustausch“, die in Halle/Saale ansässige „Georg-Friedrich-Händel-Gesellschaft“ und die „Händel-Gesellschaft Göttingen“, die „Musikbibliothek der Stadt Leipzig“, zahlreiche Verlage, z. B. Moeck, Möseler und

${ }^{101}$ Vgl. die Manuale der Jahre 1873-1903 
Olms, sowie die damalige Göttinger Musikalienhandlung Hack der SUB viele beachtliche Musikwerke zukommen lassen.

Darüber hinaus wurden der SUB von ihrem 2001 verstorbenen Mitarbeiter, Dr. Michael Berndt 12 Programmbücher der Händel-Festspiele Göttingen der Jahre 1994 bis 2001 und der Händel-Festspiele Halle (Saale) der Jahre 1990 bis 2001 geschenkt.

\section{Musik und Händel in Göttingen}

Als Metropole der Universitas literarum war Göttingen seit jeher eine besondere Pflegestätte vielfältiger und weitreichender kultureller Beziehungen. Die Musikpflege war Sache der Kirche und der Universität, deren geistliche und weltliche Autorität Jahrhunderte hindurch die Tradition sakraler Musik und festlicher Musikaufführungen bestimmte. Die Gesangsvereine, Verbreitung der Hausmusik, die öffentliche Pflege der Kammermusik, die Orchester wie auch die akademische Musikpflege weisen auf die klingende Kultur in Göttingen hin. Eine Steigerung erfuhr das musikalische Leben durch die Händel-Renaissance. Damit war die Voraussetzung geschaffen, Musiker von Rang einzuladen und so die Pflege und Inszenierung barocker Musik in dieser Stadt zu fördern. Demzufolge haben sich in den Bibliotheken und Archiven Göttingens massenhaft Materialien von und über den Komponisten angesammelt, die, je nach Hausregeln, entsprechend verzeichnet und aufgestellt sind.

Bestimmt läßt sich das Musikinteresse in der kurhannöverischen Universitätsstadt mittels Quellenmaterials erklären. Damit sind die in Musikdrucken, musiktheoretischen Schriften und Gedichtsammlungen mit Notenbeilagen enthaltenen Subskribentenlisten gemeint, welche zwischen 1770 und 1800 weitaus verbreitet waren. Die in Göttingen tätigen Komponisten haben beachtlich viele, zwischen 40 und $170^{102}$ Exemplare absetzen können. Im Gegensatz zu Halle mit einem Komponisten, zählte Göttingen mindestens sieben mit eigenen zur Subskription ausgeschriebenen Musikdrucken. Unter ihnen hervorzuheben ist Johann Nikolaus Fleischmann, der 1785 eine für Klavier bearbeitete Auswahl der Arien aus Händels Alexanderfeste herausgab; die

\footnotetext{
${ }^{102}$ Aus Klaus Hortschansky: „Die Academia Georgia Augusta zu Göttingen als Stätte der Musikvermittlung in der 2. Hälfte des 18. Jahrhunderts“, in Akademie und Musik (1993), S. 239
} 
Anzahl der in Göttingen verkauften Exemplare beläuft sich auf 64 von 126 subskribierten Exemplare. Die Subskriptionsverzeichnisse führen neben Hochschullehrern sowie deren Gattinnen und Töchter, auch Bürgerstöchter, Handwerker, Offiziere, allen voran Studenten $\mathrm{an}^{103}$.

Überhaupt versteht sich der hier erzielte Verkaufserfolg darin, daß es am Ort ein lebhaftes Interesse für Lied- und Klaviermusik gegeben hat, welches durch den persönlichen Umgang der Komponisten und Herausgeber mit den Käufern zusätzlich gefördert wurde ${ }^{104}$, daß das damalige Erziehungsideal ein frühzeitiges Erlernen von Klavier und Gesang voraussetzte ${ }^{105}$ und, daß laut Verordnung begleitend zum Universitätsstudium Musik unterrichtet wurde ${ }^{106}$.

\subsection{Musikwissenschaft und Musikpflege in Göttingen}

Die frühesten Hinweise auf eine Musikpflege in Göttingen finden sich im Kontext mit der Lateinschule samt ihrem Schulchor, der allen Stadtkirchen verpflichtet war und liturgische Gesänge aufführte. Eine Militärkapelle gab es seit der Stationierung der Garnison im Jahre 1632, eine städtischen Kapelle kam 1862 hinzu. Seit 1767 unterhielt der Stadtmusikus Lehrlinge und Gesellen, um kirchliche Feiertage und Anlässe musikalisch zu gestalten.

Die Gründung der Universität im 18. Jh. beeinflußte auch das Musikwesen. 1735 wurde ein Collegium musicum, zu der auch ein Chor gehörte, eingerichtet, mit dessen Leitung Johann Friedrich Schweinitz beauftragt wurde. Mit der Aufführung wöchentlicher Konzerte sowie der akademischen Kirchenmusik und feierlichen Musik begründete er im Jahr darauf die akademische Musikpflege in Göttingen. Die im Jahre 1777 eingerichteten Akademischen Winter-Konzerte wurden erst durch Johann Nikolaus Forkels (1749-1818) Leitung zu einem gesellschaftlichen Ereignis. Zu jener Zeit war der Ruf Göttingens als Musikstadt so gefestigt, daß hervorragende Virtuosen, namentlich Wilhelm Friedrich Bach (1759-1845), in der hiesigen Universitätskirche (Nikolaikirche) Orgelkonzerte gaben.

\footnotetext{
${ }^{103}$ Vgl. Hortschansky (1993), S. 244ff.

${ }^{104}$ Ebenda S. 241

${ }^{105}$ Ebenda S. 244f.

${ }^{106}$ Ebenda S. 247
} 
Immer wieder lösten aktuelle Ereignisse wie die Göttinger Revolution im Jahre 1831 und die Protestaktion der Göttinger Sieben 1837 einen Interessenschwund am Musikleben aus. Nach der Gründung des hiesigen Cäcilienvereins (1838) gedieh die Musik wieder durch Auftritte bekannter Musiker wie Johannes Brahms (1833-1897) und Joseph Joachim (1831-1907). Unter Eduard Hille (1823-1891) wurde 1855 der Academische Orchesterverein ins Leben gerufen, der akademische Konzerte gab.

Das 18. Jh. war die Geburt des Musiktheaters in Göttingen. Doch erst 1834 konnte die Stadt einen Ball- und Konzertsaal für Theatervorstellungen in Anspruch nehmen, in dem vorzugsweise Operetten aufgeführt wurden; diese Glanzzeit verging Ende der 1880er Jahre. Mit dem 20. Jh. konnte die Musikpflege in Göttingen allmählich festen Fuß fassen. Um 1910 herum war das Musiktheater, das seit den 1920er Jahren über ein eigenes Operensemble verfügte, das ansprechende Ereignis überhaupt. Das Opernrepertoire umfaßte die aktuellen Belange, wie Richard Strauß’ „Der Rosenkavalier«, der im November 1932 unter seiner Leitung in Göttingen aufgeführt wurde. Die finanzielle Misere im Jahre 1936 verursachte die Schließung der Oper. Die Oper im Theater endete jedoch erst mit der Spielzeit 1949/50. Ebenso verlor die Kirchenmusik durch die zunehmende Säkularisation an Zuspruch, so daß Göttinger Einwohner und Kirchenvertreter zur Zusammenstellung eines Kirchenchores aufgerufen wurden.

Zwei weitere musikkulturelle Einrichtungen, deren Spuren bis heute reichen, sind ausschlaggebend für das Göttinger barocke Musikwesen: Die Gründung der HändelGesellschaft (1920) mit den Festspielen und des Johann-Sebastian-Bach-Instituts, das seit 1951 existiert. Die Bach-Renaissance in Göttingen setzte allerdings schon früher mit dem 1894 errichteten Bach-Chor und der Stadtkantorei (1930) ein. „Göttingen war nichts als eine Universität [...]“107, und diese war das Publikum bei kulturellen Begegnungen. Als 1920 mit der Aufführung von der Oper Rodelinda die Händelrenaissance ${ }^{108}$ begann, war dies ein kulturelles Ereignis, das über die Stadtgrenzen hinaus auf Resonanz stieß.

Nach dem Zweiten Weltkrieg mußte die untergegangene Kultur wiedererweckt werden. So wurde der Arbeitskreis Göttinger Kunstfreunde gegründet, dem das akademische Konzertkomitee, der Universitätsbund, die Akademische Orchestervereinigung,

\footnotetext{
107 Zitiert aus Jürgen Gidion: „Kulturelles Leben in Göttingen“, in Göttingen 3 (1999), S. 539

${ }^{108}$ Ebenda, S. 548
} 
der Kunstverein, das Stadttheater, die Händel-Gesellschaft und die Stadtkantorei angehörten.

Im Göttinger Musikleben der Gegenwart haben das Orchester Göttinger Musikfreunde (OGM) und das Göttinger Symphonie Orchester (GSO) unter anderem Werke von Händel auf ihrem Spielplan. Die Göttinger Musikpflege umfaßt auch seit jeher (1434) den Bau von Instrumenten, und zwar von Orgel, Klarinette, Clavichord und Klavier. In Göttingen hat die Musikwissenschaft als Studienfach ihre Wurzeln im Dienste Forkels, der von 1772 bis ins frühe 19. Jahrhundert neben der praktischen, auch theoretische Musik lehrte. Anfängliche Versuche, einen Lehrstuhl der Musik einzurichten, blieben bis 1920 ergebnislos.

\subsection{Musikwissenschaftliche Institutionen}

Die musikalische Sammlung der SUB Göttingen sowie der Bibliothek des Musikwissenschaftlichen Seminars der Universität, der Händel-Gesellschaft, des Stadtarchivs und, wenn auch nicht in diese Arbeit einbezogen, der Stadtbibliothek ist herausgewachsen aus einer ungeheuer breiten und reichen Tradition, die in Göttingen vom zweiten Drittel des 19. Jahrhunderts bis in die Gegenwart reicht. Das alles, insbesondere der Händel-Bestand, spiegelt sich aufgrund der gleichnamigen, alljährlich stattfindenden Festspiele in den Beständen der Musiksammlungen wieder.

Das Musikwissenschaftliche Seminar der Universität Göttingen mit seiner Bibliothek und seinen Archiven nimmt eine besondere Stelle im musikbibliothekarischen Wesen der Stadt ein. Neben dem Seminar stellt sich die Händel-Gesellschaft als musikwissenschaftliches Organ in das Göttinger Musikbild. Das Stadtarchiv ist vor allem als Aufbewahrungs- und Informationsstelle zu charakterisieren. Mit seinem HändelBestand pflegt es die Musikwissenschaft mit Betonung auf den Barock. Nachfolgend wird ein kurzer Abriß der oben genannten Institutionen gegeben, um ihr Sammelmotiv und vornehmlich den daraus gewachsenen Händel-Bestand zu verdeutlichen. 


\subsection{Das Musikwissenschaftliche Seminar der Universität Göttingen}

Die Verbindung des Faches Musikwissenschaft mit der Universität Göttingen liegt weiter zurück als dessen Etablierung als akademisches Fach. Schon seit 1772 wurden hier von Johann Nikolaus Forkel auf eigene Initiative Vorlesungen gehalten und unter seiner Leitung das universitäre Konzertwesen gepflegt. Zudem übernahm er 1779 das Amt des Organisten, das für alle späteren Musikdirektoren der Universität verpflichtend wurde. Das Fach Musik war zumeist durch einen Professor der Musikwissenschaft und einen Akademischen Musikdirektor vertreten, wie es 1862-1885 für Eduard Krüger und Eduard Hille (1822-1891) zutraf.

Im Juli 1920 wurde das Musikwissenschaftliche Seminar gegründet, das vorläufig im Musiksaal des Aulagebäudes untergebracht war und mit dessen Leitung Friedrich Ludwig (1872-1930), der Begründer der mittelalterlichen Musikgeschichtsforschung, beauftragt wurde; eine außerordentliche Professur gab es bereits seit 1862 .

Das Musikwissenschaftliche Seminar, das seit 1987 seinen Sitz im Accouchierhaus ${ }^{109}$ hat, umfaßt neben seiner Bibliothek ein Schall- und ein Mikrofilmarchiv ${ }^{110}$ sowie eine Sammlung historischer Musikinstrumente mit 1.785 Exponaten, die aus allen Ländern und aus verschiedensten Epochen zusammengetragen wurden.

Das Seminar unterstützt nebenbei Symposien im Rahmen der Händel-Festspiele. Außerdem veranstaltet es seit 1986 im Rahmen der Reihe musica viva in jedem Semester ein Konzert mit neuer Musik, bei dem jeweils ein wichtiger zeitgenössischer Komponist zugegen ist. Nicht zu vergessen sind die laufend stattfindenden Aufführungen des Universitätsorchesters und des Universitätschors.

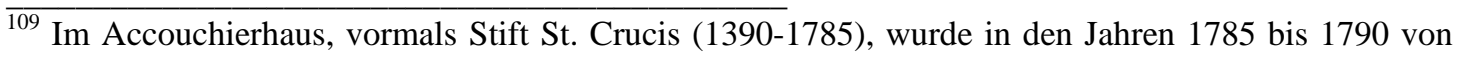
Universitätsbaumeister Georg Heinrich Borheck (1751-1834) die erste deutsche Frauenklinik gegründet und bis 1896 als solche genutzt. 1987 wurde dieses Haus renoviert und danach vom Musikwissenschaftlichen Seminar bezogen. Vgl. „Geschichte des Accouchierhaus“

${ }^{110}$ s. Fotografie S. XXVIII
} 


\subsubsection{Die Bibliothek}

Das Musikwissenschaftliche Seminar der Universität Göttingen hat eine lange Tradition, über die bereits geschrieben worden ist ${ }^{111}$. Die Seminarbibliothek (Sigel 7/056) ist jedoch bis heute kaum erforscht und dargestellt ${ }^{112}$. Nichtsdestoweniger läßt sich Seminargeschichte entdecken, etwa daß in der ersten Hälfte der 1920er Jahre der Bibliotheksbestand sich wenig vermehrte. Ergänzend haben Seminarmitglieder, Persönlichkeiten (z. B. Frau Geheimrat Voigt), Verlage (Breitkopf \& Härtel Leipzig, Drei Masken-Verlag München) sowie die Notgemeinschaft der deutschen Wissenschaft der Bibliothek Materialien als Schenkung überlassen.

Heute hat die Präsenzbibliothek einen Bestand von etwa 15.000 Büchern, Musikalien und Zeitschriften ${ }^{113}$; der Sammelschwerpunkt liegt auf historische Musikwissenschaft in verschiedenen Sprachen: Deutsch, englisch, französisch, italienisch und teilweise auch holländisch. Rund 40 Zeitschriften werden laufend gehalten. Vom Umfang her bildet das Musikschrifttum den größeren Teil des Bestandes, gefolgt von Notenwerken, darunter viele Gesamtausgaben von Komponisten. Die Erwerbung geschieht vorwiegend durch Kauf, manchmal auch durch Schenkung.

Der Bibliotheksbestand ist verzeichnet in dem in Zettelform geführten alphabetischen Publikums- und Schlagwortkatalog, zusätzlich in dem Standortkatalog, der eigentlich als Dienstkatalog dient. Die ersten beiden weisen auch Aufsätze aus Zeitschriften und Festschriften auf. Die Kasten-Beschriftung des Zettelkataloges ist in verschiedene Farben gruppiert: Unter blau befinden sich Bücher, unter grün Aufsätze, unter gelb Schrifttum über Komponisten und unter orange Musikalien; der mit rosa beschriftete ist der Schlagwortkatalog. ${ }^{114}$

\footnotetext{
$\overline{111}$ Hier seien einige Titel genannt: »Musikwissenschaft und Musikpflege an der Georg-AugustUniversität Göttingen: Beiträge zu ihrer Geschichte« (Göttingen, 1987) herausgegeben von Martin Staehelin; Klaus-Peter Brenners »Erlesene Musikinstrumente aus der Sammlung des Musikwissenschaftlichen Seminars der Georg-August-Universität Göttingen« (Göttingen, 1989)

${ }^{112}$ Auf meine Frage an Akad. Rat Dr. Klaus-Peter Brenner, ob und was über die besagte Bibliothek veröffentlicht worden ist, antwortete er wie folgt: „Bislang ist meines Wissens niemand auf die Idee gekommen, eine Geschichte unserer Seminarbibliothek zu schreiben [...] Um diesbezüglich zu fundierten Aussagen zu gelangen als eine kursorische Rekapitulation der Seminargeschichte dies erlaubt, müßte man wohl erst umfangreiche Bibliotheks- und Archivrecherchen (Universitätsarchiv) anstellen, um die thematischen Forschungs-, Publikations- und Lehrschwerpunkte sämtlicher Professor(inn)en und Assistent(inn)en seit der Seminargründung bis auf den heutigen Tag - und damit indirekt die Entwicklung der Erwerbungsschwerpunkte - zu eruieren und das Ergebnis dieser Recherchen anschließend mit unseren Bibliotheksbeständen vergleichen. Eine solche Arbeit ist aber, wie gesagt, bislang von niemandem geleistet worden.“ (2002).

113 s. Fotografie S. XXVII

${ }^{114}$ Die Kataloge sind im Anhang S. XXVII abgebildet.
} 
Mit Beginn des Jahres 2002 ist hier in den Bereichen Katalogisierung und Recherche die EDV eingeführt worden. Die Eintragungen aus dem Zettelkatalog werden seit Mitte 2001 für den OPAC retrokatalogisiert. Daneben existieren noch Sonderkataloge, etwa der Nachlaßkatalog Friedrich Ludwigs und das Inventarverzeichnis von Walter Mertes. Die Zugänge sind nach hausinternen Regeln verzeichnet. Vermutlich aus Personalmangel wurden in den letzten acht Jahren vor 2002 nur Titel, Autor und Erscheinungsjahr angegeben, der Erscheinungsort entfiel.

Der Bibliotheksbestand ist jedem zugänglich, ausgeliehen darf der Bestand aber nur von Mitgliedern des Musikwissenschaftlichen Seminars (Wochenendausleihe). Fernleihverkehr findet nicht statt. Gelegentlich werden aus der SUB Göttingen Semesterleihgaben an die Seminarbibliothek gegeben; umgekehrt ist das jedoch nicht der Fall. Das Schallarchiv, das Aufnahmen aus dem Bereich europäischer Kunstmusik sowie musikethnologische Feldforschungsaufnahmen aus allen Erdteilen umfaßt, dient als Lehr- und Forschungssammlung. 1982 begann der damalige Leiter des Schallarchivs, Rudolf Maria Brandl (*1943), mit dessen Aufbau.

Die Sammlung europäischer Kunstmusik ist in einem Komponistenkatalog, die musikethnologische Sammlung in einem eigenen Katalog ${ }^{115}$ erfaßt. Die Sammlung Kunstmusik enthält 2.800 Schallplatten (Schellack und Vinyl), 500 Tonbänder, 1.000 Musikkassetten und 500 CD. Die musikethnologische Sammlung schließt neben den 320 Schallplatten (Schellack und Vinyl) 90 Musikkassetten, 90 CD sowie 1.300 Tonbänder ein. Eine ganze Reihe von Schallplatten sind dem Schallarchiv vermacht worden, darunter die Plattensammlungen von F. Schmidt ${ }^{116}$ und von Walter Mertes sowie von Heinrich Husmann. Desgleichen hat der Umzug des Musikwissenschaftlichen Seminars in das Accouchierhaus akustische Kostbarkeiten ${ }^{117}$ zutage gefördert. Der Schallarchivbestand kann generell nicht ausgeliehen werden. Allerdings können gewünschte Aufnahmen auf vom Benutzer mitgebrachte Tonbänder überspielt werden.

Nicht zuletzt ist das Mikrofilmarchiv des Seminars zu nennen. Der um 550 Mikrofilme betragende Bestand hat Musikhistorie und Musikethnologie aller Jahrhunderte zum Inhalt. Er ist in dem maschinenschriftlichen Katalog »Mikrofilme des Musikwis-

\footnotetext{
${ }_{115}$ s. Fotografie S. XXVIII

${ }^{116}$ Der Vorname konnte leider nicht ermittelt werden - auch das Schallarchiv konnte keine Auskunft darüber geben. Diese Sammlung ist im Anhang S. XXVIII fotografisch dargestellt.

${ }^{117}$ Vgl. Bockemühl/Gizler: „Einblick: die Georgia Augusta in ihrem 250. Jahr“ (Göttingen, 1987),

S. 96
} 
senschaftlichen Seminars« (Göttingen, 2001) von Joachim Lüdtke beschrieben. Der Mikrofilmbestand ist nach Vereinbarung zugänglich.

\subsubsection{Der Händel-Bestand}

In diesem Abschnitt wird einer der umfangreichen Bestandsblöcke der Seminarbibliothek dargestellt: Der ebenfalls in der SUB Göttingen vorhandene Händel-Bestand. Es ist die Rede von 161 Musikalien und 55 Bänden Händel-Literatur, darunter - bis auf zwei - alle Jahrgänge des »Händel-Jahrbuches«.

Neben dem konventionellen Bestand in seiner Bibliothek hat das Musikwissenschaftliche Seminar zahlreiche Schallplatten in Besitz, wovon viele aus den Nachlässen Schmidt und Mertes stammen. Im Komponistenkatalog wurden unter Händel über 250 Schallplattentitel nachgewiesen, die nach 13 Gruppen klassifiziert sind:

\begin{tabular}{l|l}
\hline Gruppennr. & Bezeichnung \\
\hline 1 & Rundfunksendungen / Zweifelsfälle (14) \\
2 & Anthems (14) \\
3 & Arien (2) \\
4 & Concerti grossi (7) \\
5 & Kantaten (6) \\
6 & Konzerte (41) \\
7 & Oden (6) \\
8 & Opern (38) \\
9 & Oratorien (96) \\
10 & Schauspielmusiken (1) \\
11 & Sonaten (20) \\
12 & Suiten (20) \\
13 & Triosonaten (2) \\
\hline
\end{tabular}

Die Ziffern in Klammern geben die Anzahl der in der jeweiligen Gruppe vorhandenen Titel an. Es ist aufgefallen, daß manche Signaturen mitunter mehrere Stücke, nicht Alben, umfassen und unter etlichen Klassifikationen auftauchen; es ist daher nicht auszuschließen, daß dieser Teilbestand tatsächlich kleiner ist. Die Gruppen sind auf 
grünen Karten und die Stücktitel auf weißen Karten verzeichnet. Einige Titel seien hier aufgeführt: »Athalia«, »Let the bright seraphim«, »Suite für Cembalo Nr. 5« und »Tercentenary concert«.

In der Schallplattensammlung von Mertes wurden 4 Titel ermittelt: „Sämtliche Concerti grossi op. $3+6$ «, »Der Messias«, »Violinsonaten Opus 1« und »Wassermusik«. Die Sammlung Schmidts dagegen weist 38 Titel nach, unter anderem »Das Alexander Fest«, »Vier Sonaten für Oboe und Basso continuo«, »Royal Firework’s Music« und die »Geburtstagsode für Queen Anne«.

Der Begründer der Göttinger Händel-Festspiele, Oskar Hagen (1888-1957), hat zu Lebzeiten ein Familienarchiv zusammengestellt. Laut Mitteilung der HändelGesellschaft wird dieses Privatarchiv demnächst der Bibliothek des Musikwissenschaftlichen Seminars übergeben. Dadurch werden eventuell weitere Zeugnisse zu Händel diesen Teilbestand der Bibliothek ergänzen.

\subsection{Die Göttinger Händel-Gesellschaft}

Nachdem Göttingen als Pflegestätte barocker Tonkunst - Johann-Sebastian-BachInstitut und Händel-Gesellschaft - ins Blickfeld der musikalischen Welt gerückt ist, scheint es als eine lohnenswerte Aufgabe, die Entwicklung der Göttinger HändelOpernfestspiele, wie das Ereignis anfangs hieß, seit dem Jahre 1920 bis heute festzuhalten. Diese nach dem Vorbild der seit 1784 in England durchgeführten Veranstaltungen wurden und werden in Presse und Funk, in Publikationen sowie im Internet gewürdigt. Konnte man damals noch nicht ahnen, welche Bedeutung diese Festspiele und damit alle dazugehörigen Unterlagen einmal erlangen sollten, kann heute durch die in den Göttinger Archiven und Bibliotheken enthaltenen Händel-Sammlungen jeder dieses Musikereignis verfolgen.

Der Beitrag unter Kapitel 6.4.3 beruht auf meinem Interview mit dem Geschäftsführer der Gesellschaft, Herrn Benedikt Poensgen und auf meine Recherchen und Funde vor Ort. 


\subsubsection{Entwicklung der Gesellschaft}

Die Universitätsstadt Göttingen und voran ihre Händel-Gesellschaft haben Weltgeltung. Zumindest siebzigmal wurde hier Händelsche Aufführungsgeschichte geschrieben. Wenn von dem Weltruf Göttingens als Händel-Stadt die Rede ist, so darf der Name Oskar Hagen nicht fehlen. Im Jahre 1920, nahm der Kunsthistoriker als Gründungsvater der Göttinger Händel-Festspiele, hier seine musikalische Tätigkeit auf. Ihm folgten nach dem Zweiten Weltkrieg Fritz Lehmann (bis 1956), Günther Weißenborn (bis 1980), John Eliot Gardiner (bis 1990) und seit 1991 Nicholas McGegan.

Es waren akademische Kräfte, die die Entstehung der Göttinger Händelfestspiele ermöglichten. Anfangs wurden sie vom hiesigen Universitätsbund unter Führung des damaligen Rektors der Universität, Karl Brandi (1868-1946), veranstaltet, und seit 1931 von der Göttinger Händel-Gesellschaft. Ihren Vorsitz hatte Walter Meyerhoff von 1920 bis 1976, Friedrich Riethmüller bis 1992 und seit 1993 Hans-Ludwig Schreiber. Ihm steht der Geschäftsführer der Gesellschaft, Benedikt Poensgen, zur Seite. Im Jahre 1955 trat die Göttinger der Hallenser Gesellschaft bei.

Weltweit gibt es außer der Göttinger elf weitere Händel-Gesellschaften und -Institute, etwa die Georg-Friedrich-Händel-Gesellschaft in Halle an der Saale, die HändelGesellschaft in Karlsruhe, die Cambridge Handel Opera Group, die Handel Society (London), die Nederlandse Händelvereinigung (Bussum), die Händel-Gesellschaft in der Tschechischen Republik sowie die American Handel Society (Maryland) und die Handel Society of Dartmouth College (New Hampshire) in den USA. ${ }^{118}$

\subsubsection{Die Händel-Festspiele Göttingen}

In Göttingen begann mit der Uraufführung der vergessenen Oper Rodelinda am 26. Juni 1920 im Stadttheater die Händel-Pflege über die Grenzen der Stadt hinaus und zugleich die Wiederentdeckung von Händels Opern schlechthin. Mit diesem Stück bekamen die ersten Musiktage ihre Sensation, obwohl es damals nicht vorauszusehen war, daß daraus eine internationale, inzwischen alljährlich stattfindende Veranstaltungsreihe werden sollte.

${ }^{118}$ Aus „Societies/Institutes“ 
Es gab allerdings auch Zeiten, in denen keine Festspiele stattfanden, so in den Jahren 1925, 1929, 1931 bis 1933 (Einzelveranstaltungen) und nicht selten in den fünfziger Jahren; danach gab es keinen Ausfall mehr. Während des Deutschen Reiches gab es eine Auseinandersetzung um die Händel-Festspiele, die letzten Endes soweit ging, daß „eine Art Unbedenklichkeitserklärung durch die Reichsmusikkammer für den Kompo-

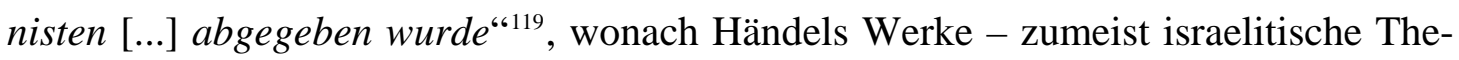
men behandelnd - ohne propagandistische Textänderungen gespielt werden durften. ${ }^{120}$ Auf dem Spielplan standen unter anderem Ezio, Giulio Cesare, Partenope, Il Pastor fido, Radamisto, Serse, Teseo und Tolomeo. Die Opern wurden damals in Übersetzung, gelegentlich auch mit Kürzungen, gesungen. In den Jahren, die seit der Gründung vergangen sind, ist in Göttingen eine Musik- und Theaterkultur aufgeblüht. All das bedürfte einer etwas breiteren Schilderung, um verständlich zu machen, wie es dazu kam, daß man in den Göttinger Opern- und Oratorienaufführungen zur Förderung barocker Tonkunst auch den Anschluß an das musikalische Schaffen der Gegenwart fand und damit eine Institution schuf, die bahnbrechend war und den Namen Göttingens in der Musikgeschichte verankert hat. Der Dirigent Gardiner (*1943) stellte hier mit den von ihm gegründeten Ensembles, dem Monteverdi Choir und den English Baroque Soloists, neben den Werken Händels die Tonstücke seiner Zeitgenossen vor und gab dem Festival einen neuen Blickwinkel. Nahezu alle diese Aufführungen liegen in Schallplatten- und CD-Aufnahmen vor, als Live-Mitschnitte oder als Koproduktion mit den Händel-Festspielen.

Wie bereits erwähnt, dreht sich in Göttingen einmal im Jahr alles um Georg Friedrich Händel; die Stadt ist im musikalischen Ausnahmezustand oder wie es so schön heißt: In Göttingen „händelt“ es. Neben den musikalischen Veranstaltungen, den Konzerten und Opern stehen wissenschaftliche Symposien auf dem Programm des HändelFestivals. Die Festspiele werden grundsätzlich Jahre im voraus geplant: Drei Jahre vorher wird z. B. abgesprochen, welches Orchester mitspielt, im zweiten Jahr wird festgelegt, was aufgeführt wird und im Jahr davor ist das Programmheft fertiggestellt. Seit Jahrzehnten besteht eine Kooperation zwischen den Göttinger und den Hallenser, den Karlsruher und den amerikanischen (Maryland) Händel-Festspielen. Weitere Händel-Festspiele finden in Denver und natürlich in London statt.

\footnotetext{
119 Zitiert aus Gidion, S. 561

${ }^{120}$ Vgl. Gidion (1999), S. 561
} 


\subsubsection{Bestandsaufbau und Erschließung}

Die Göttinger Händel-Gesellschaft verfügt über ein zweiteiliges Archiv. Das Notenarchiv mit einem Bestand von rund 5.000 Musikalien befindet sich in den Räumlichkeiten der Gesellschaft ${ }^{121}$. Das Archiv zur Geschichte der Göttinger Festspiele, mit Berichtszeitraum 1920 bis heute wird indes im Stadtarchiv ${ }^{122}$ verwahrt. Die Musikaliensammlung bezieht sich auf die Jahre von 1940 bis 1970. Darin befinden sich neben handschriftlichen Noten auch Klavierauszüge, Chorstimmen und die beiden Werkausgaben (nicht vollständig). Ferner sind Libretti und Tonträger archiviert, darunter historische Aufnahmen der Göttinger Händel-Festspiele aus den Jahren 1953 bis 2000 mit ungefähr 100 Titeln. Zudem stößt man auf Briefe von Interpreten und Musikern, die in der Gesellschaft tätig waren, auf Zeitungsausschnitte und Prospekte. Dabei handelt es sich zumeist um Postkarten mit Bühnenbildern der Festspiele. Jedes Jahr gelangen diverse Dokumente ins Haus. Neben dem bibliothekarischen Bestand beherbergt die Händel-Gesellschaft Bühnenkostüme. Es ist darauf hinzuweisen, daß die HändelGesellschaft über keine zielgerichtete Bibliothek verfügt, die auf Vermehrung ihres Bestandes bedacht ist; sie hat eher einen musealen Sammelcharakter. Der Musikalienbestand ist Präsenzbestand und nur an Orchester und Kantoreien, die für das Spielen von Händels Werken bestimmtes Notenmaterial nicht entbehren können. Der Gesamtbestand der Gesellschaft ist in einem internen Zettelkatalog verzeichnet.

Die Aufstellung des Musikalienbestandes erfolgt nach den HWV-Nummern aus dem Händel-Werkverzeichnis und an zweiter Stelle nach Numerus currens, z. B.:

H $78: 1$

$\mathrm{H} 78: 2$

Der Buchstabe „H“ steht für „Händel-Werkverzeichnis“ und „78“ für die ihr entnommene Nummer. Die Ziffer nach dem Doppelpunkt ist die Zugangsnummer, die bei jeder HWV-Nummer mit 1 beginnt. Die beiden Händel-Gesamtausgaben jedoch sind anders signiert:

H $750: 85$

$\mathrm{H} 700: \mathrm{II}^{1}$

\footnotetext{
${ }^{121}$ s. Fotografien S. XXIX

${ }^{122}$ Genaueres über diese Sammlung in Kapitel 6.5.2
} 
Bei dem ersten Beispiel handelt es sich um den 85sten Band der Chrysanderschen Ausgabe; der zweitgenannte kennzeichnet Band 1 der zweiten Serie (Opern) der Hallischen Händel-Ausgabe.

\subsection{Das Stadtarchiv Göttingen}

In Stadtarchiven wird die langjährige Geschichte einer oder mehrerer Ortschaften sowie von Privatpersonen, Familien, Vereinen und Firmen dokumentarisch erhalten. Von der Existenz eines Archivs in Göttingen wurde in einem Schreiben des Herzogs Julius von Braunschweig-Lüneburg (1528-1589) vom 8. November 1588 berichtet. Angesichts der ältesten im Stadtarchiv erhaltenen Pergamenturkunde, datiert 1229, wird der Beginn des Göttinger städtischen Archivwesens bis zum Beginn des 13. Jahrhunderts zurückgeführt ${ }^{123}$.

Dieses Archiv hat in der zweiten Hälfte des 20. Jahrhunderts eine umfangreiche Sammlung von Quellen zur Geschichte der Händel-Festspiele von der Göttinger Händel-Gesellschaft erhalten. Auf welche Weise bestimmte Materialien ins städtische Archiv eingegangen sind, erläutert Unterkapitel 6.5.2. Zuvor aber ein Einblick in das Gestern und Heute des Archivs der Stadt Göttingen.

\subsubsection{Geschichte des Stadtarchivs}

Wie bereits erwähnt, gehen die Wurzeln des Göttinger Stadtarchivs ins 13. Jh. zurück. Dennoch hat die Ordnung nach archivarischen Prinzipien erst im 15. Jh. begonnen; bis dahin war es ein ungeordnetes Sammelbecken. Die zahlenmäßig wachsenden Archivalien - Urkunden, Briefe und Amtsbücher - wurden im hiesigen Rathaus, der zwischen 1369 und 1372 erbauten Alten Ratsstube, gelagert. ${ }^{124}$ Das Stadtarchiv Göttingen war von jeher für wissenschaftliche Arbeiten öffentlich zugänglich. Dieser Regel gilt bis auf den heutigen Tag weiter.

\footnotetext{
$\overline{123}$ Vgl. Walter Nissen: „Das Göttinger Stadtarchiv“ (1969), S. 11

${ }^{124}$ Ebenda, S. 12
} 
Das Göttinger Stadtarchiv erlebte eine positive Phase, bis in den Zeiten des 30jährigen Krieges (1618-1648) Personal entlassen wurde und dem Archivbestand gewaltige Schäden zugefügt wurden. Aufgrund einiger Hindernisse wie des langfristigen Verbleibens der Archivdokumente in den Häusern der Benutzer und des Personalmangels, wurde die Organisation von Archiv und Registratur immer weiter hinausgeschoben. Während des Siebenjährigen Krieges (1756-1763) und danach stockte die Archivarbeit. Mit der Anstellung von Johann Anton Ludwig Seidensticker (17601817) als Stadtsyndikus im Jahre 1797 tritt eine Person in die Geschichte des Göttinger Stadtarchivs ein, die seinen Ordnungszustand bis heute beeinflussen sollte.

Beinahe wäre das Göttinger Archiv, der Rundverfügung vom 24. Juli $1876^{125}$ zufolge, ins Staatsarchiv Hannover überführt worden. Dank eines Gutachtens blieb das Archiv an seinem ursprünglichen Sitz. In den Jahren 1898, 1902/03 und 1936 fanden Übersiedlungen des Archivs statt, sei es wegen der die Archivbestände gefährdenden Feuchtigkeit oder wegen Raumnot.

Als der Zweite Weltkrieg ausbrach, kam es in Göttingen zur Unterbrechung der Archivarbeiten, im August 1939 zur Schließung des Archivs, das im Oktober 1940 wieder eröffnet wurde. Außerdem wurden, gemäß der ministeriellen Verfügungen für die deutschen Archive und Bibliotheken die wertvollsten Archivbestände, unter anderem Chroniken, Urkunden, und Tagebücher, an vier verschiedene, in Stadt und Umgebung gelegene Plätze ausgelagert. Nach Kriegsende, im Juni 1946, waren die ausgelagerten unbeschädigten Archivalien für die Öffentlichkeit wieder zugänglich.

Seit April 1981 hat das Stadtarchiv seinen Platz im Neuen Rathaus. Neben dem Archivmagazin sind dort außerdem eine Bibliothek sowie ein Arbeits- und Lesesaal eingerichtet, in dem auch die Kataloge ${ }^{126}$ stehen. Im Internet ist das Archiv unter der Adresse http://www.stadtarchiv.goettingen.de mit einer Homepage vertreten.

Die Archivbibliothek ${ }^{127}$ bildet mit ihren etwa 25.000 Bänden eine umfangreiche Sammlung zur Göttinger Kultur-, Sozial-, Stadt- und Wirtschaftsgeschichte. Das Archivgut im Magazin beläuft sich auf knapp 4.000 Regalmeter und umfaßt Akten, Autographen, Flugblätter und -schriften, Pläne, Plakate, Programmhefte, Stammbücher

\footnotetext{
$\overline{125}$ Nach diesem Erlaß sollten diejenigen Städte, ,welchen die zur Aufbewahrung der vorhandenen Urkunden pp. Erforderlichen Räume oder die zur Ordnung der Archivalien nötigen Kräfte nicht zu Gebote stehen“, ihre Urkunden „gegen Revers und unter Vorbehalt des Eigentumsrechts“ an das besagte Staatsarchiv „zur Aufbewahrung“ überweisen. Vgl. Nissen (1969), S. 29

${ }^{126}$ s. Fotografien S. XXX

127 s. Fotografie S. XXX
} 
des 18. und 19. Jahrhunderts, Göttinger Tageszeitungen sowie Filme und Tonkassetten. Die Stadt Göttingen ist verpflichtet, dem Stadtarchiv jegliches Aktenmaterial zu übergeben. Die Bibliothek dagegen erweitert sich durch Belegexemplare: Jeder Nutzer von Archiv und Bücherei, der eine Arbeit schreibt, hat ein Exemplar abzuliefern.

Der Bestand der Archivbibliothek wird nach RAK-WB und zusätzlich noch nach Hausregeln erschlossen; für die Katalogisierung des Archivbestandes liegt kein spezielles Regelwerk vor; die Richtlinie hierfür gibt die eingesetzte Datenbank vor. Die elektronische Bestandsaufnahme erfolgt seit 1998 in zwei Datenbanken: Die Archivalien in AIDA und die Literatur (Bibliotheksbestand) in Allegro. Die Aktensammlungen, die seit 2000 ins Archiv gelangen, sind zweifach recherchierbar, d. h. die Titelaufnahme per EDV liegt auch gedruckt als Findbuch vor. Ein Teil des Archivbestandes kann unter der Rubrik Findbücher ${ }^{128}$ über die Homepage des Stadtarchivs recherchiert werden.

Vor Einführung der EDV in die Katalogisierung wurden die Bibliotheksbestände in Zettelkatalogen und die Archivalien in Findbüchern verzeichnet. Zu ersteren zählen der alphabetisch geordnete Personenkatalog ${ }^{129}$ sowie die systematischen Kataloge, der Göttingen-Katalog (GöK) mit dem dazugehörigen Schlagwortindex, der Ortskatalog (OK), der Regionenkatalog (ReK) und der Universitätskatalog (UK).

Das Stadtarchiv Göttingen gehört hinsichtlich der Zusammensetzung und Geschlossenheit seiner Bestände zu den wichtigsten Stadtarchiven in Südniedersachsen. Die Gründe dafür liegen nicht nur in der überaus reichen Geschichte der Stadt, sondern in dem Umstand, daß das Archiv kaum Substanzverluste durch Feuer, Wasser, Diebstahl oder Kriegsschäden hinnehmen mußte. Es hat durch seinen Händel-Bestand eine wichtige Funktion als sogenanntes vermittelndes Organ für Händel-Freunde und als bewahrendes für das musikalische Vermächtnis des Barockkomponisten.

\footnotetext{
${ }_{128}$ http://www.stadtarchiv.goettingen.de/frames/fr_online_findbuecher.htm

${ }^{129}$ Er verzeichnet die gesamte eine Person betreffende Literatur zentral unter dem analogen Personennamen Die vorhandenen, unter einer Person nachgewiesenen Titel werden so geordnet: Auf gelben Karten stehen Schriften, zu deren Publikation die betreffende Person den Anlaß gab (z. B. die an sie adressierte Briefsammlung, Festschrift, Personalbibliographie); weiße Karten enthalten die von der Person selbst verfaßten herausgegebenen oder bearbeiteten Titel; auf grünen Karten stehen Sekundärliteratur und Zeitschriftenaufsätze über die Person; die roten Karten enthalten Zeitungsartikel, die zur Person erschienen sind.
} 


\subsubsection{Händel im Stadtarchiv}

Die Bedeutung der Musiksammlung des Stadtarchivs steht in erster Linie mit dem Namen Händel in Verbindung; damit ist nicht die Musikaliensammlung gemeint, sondern der Bestand der musiktheoretischen Werke, die aufgrund ihres für die Stadt historischen Interesses als Archivmaterialien angesehen werden.

Der Händel-Bestand des Archivs besteht aus zwei Teilen. Der ältere und erste Teilbestand - sieben laufende Meter - wurde von dem ehemaligen Vorsitzenden der Göttinger Händel-Gesellschaft, Landgerichtspräsident i. R. Walter Meyerhoff (*1890) als Nachlaß dem Stadtarchiv geschenkt ${ }^{130}$. Diese Sammlung, die Aktenpakete mit Schriftwechseln und Abrechnungen, Kritiken (1927-1968) sowie Zeitungsausschnitte (Juli 1971) beinhaltet, gelangte 1971 ins Archiv und wurde fortan als „Kleine Erwerbungen Nr. 47“ signiert. Der zweite Teil - über fünf laufende Meter - ist dem Stadtarchiv durch einen Depositalvertrag ausgeliehen ${ }^{131}$. Er umfaßt vor allem Programmhefte der Händel-Festspiele aus den Jahren 1920 bis 1999; diese Sammlung wird in Zukunft fortgeführt. Während der erste Teilbestand noch in konventioneller Form, nämlich im Findbuch »Stadtarchiv Göttingen: kleine Erwerbungen / Nachlässe 1-79« verzeichnet ist, ist der zweite in der Datenbank AIDA maschinenlesbar erfaßt.

Darüber hinaus sind zahlreiche Publikationen zu Händel in der Archivbibliothek aufgestellt. Davon ist der überwiegende Teil in dem dieser Arbeit anschließenden Katalog nachgewiesen. Es handelt sich dabei um zehn Textbücher, zwei Musikalien sowie eine Zeitschrift. Die Sammlung von Programmheften wie auch von Zeitungsausschnitten des Stadtarchivs ist in ihrer Vielfalt ein Schwerpunkt der Händel-Sammlung. Die Ausschnitte behandeln vornehmlich die Händel-Festspiele ab.

\subsection{Die Werke Händels auf dem Programm des Göttinger Symphonie Orchesters}

Das Repertoire des GSO umfaßt vorwiegend die Klassik und Romantik sowie die Musik der Gegenwart; barocke Musik steht selten auf dem Programm, was verdeutlicht, daß Händel-Musik selten aufgeführt wird. Und wenn, dann stehen ab und zu Händels Wassermusik und Feuerwerksmusik auf dem Spielplan. Seit nicht allzu langer Zeit tritt

\footnotetext{
$\overline{130}$ s. im Anhang S. XXXI. Aus: „Stadtarchiv Göttingen: Deposita 100 -“

${ }^{131}$ s. im Anhang S. XXXI. Aus: „Stadtarchiv Göttingen: kleine Erwerbungen / Nachlässe 1-79“
} 
das Orchester auch bei den Göttinger Händel-Festspielen auf. In der Zeit zwischen 1995 und 2002 wurden insgesamt siebenmal Händel-Werke vom GSO gespielt ${ }^{132}$, darunter das Concerto grosso C-Dur, das Largo aus Xerxes, Halleluja, die Arie der Cleopatra aus Julius Cäsar und das Orgelkonzert Nr. 4.

Im Besitz des GSO befinden sich ein Notenarchiv und eine Instrumentensammlung (Harfe, Klavier, Kontrabässe und Schlagzeug). Der Archivbestand wird nach hausinternen Regeln elektronisch erfaßt. Gefragte Notenwerke werden von Verlagen gegen Gebühr an das Orchester ausgeliehen, sofern sie nicht im Archiv vorhanden und wegen der Urheberrechte der Komponisten nicht käuflich sind.

Von Händel sind nicht mehr als 17 Notensätze im Archiv vorhanden. Bei der Führung durch das Archiv fiel mir ein Titel ins Auge, den die SUB ebenfalls in ihrem Besitz hat; das betrifft die Dirigierpartitur zu »The water music« (London, 1973).

Es ist zu beachten, daß sich im Archiv des GSO eine, wenn auch kleine, Sammlung zu Händel befindet, welche im beiliegenden Händel-Katalog aufzunehmen gewesen wäre; doch der GSO-Bestand ist überhaupt nicht öffentlich zugänglich und ausleihbar. Aus diesem Grunde bat der Orchesterdirektor darum, den Händel-Bestand nicht im besagten Katalog aufzuführen. Daher soll an dieser Stelle lediglich ein kurzer deskriptiver Überblick über Händel im Archiv des GSO gegeben werden.

\section{$7 \quad$ Zusammenfassung}

Der sich über zweieinhalb Jahrhunderte erstreckende Händel-Bestand der SUB Göttingen zählt mit seinen über 640 Titeln zu einem der historisch bedeutsamsten musikalischen Teilbestände der Bibliothek. Göttingen als Händel-Zentrum wäre undenkbar ohne die Internationalen Händel-Festspiele, die Jahr für Jahr von der hiesigen HändelGesellschaft arrangiert werden. Dieses Ereignis zeichnet sich durch historische Aufführungspraxis sowie die Pflege unbekannter und vernachlässigter Werke Händels aus. Die Musiksammlung sollte folglich versuchen, in der Gegenwart in intensivem Maße Schaffenszeugnisse für diesen Teilbestand zu erwerben und somit für die Händel-Forschung zu sammeln. Überdies sollte sie das musikalische Kulturgut, im beson-

${ }^{132}$ s. das Schreiben im Anhang S. XXXII 
deren das historische, detaillierter erfassen und damit das Erkennen jedes einzelnen Stückes in bibliographischer wie auch inhaltlicher Hinsicht ermöglichen.

Um Werke und Wirken Händels gerade in einem der Händel-Zentren, Göttingen, besser präsentieren zu können, ist die Idee geboren worden, alle seine Kompositionen sowie das Schrifttum über ihn in der größten Bibliothek Göttingens zu erfassen, auszuwerten und den Inhalt dieses Teilbestandes im musikbibliothekarischen Rahmen näher zu beschreiben.

Die obigen Darstellungen können nur einen ersten Eindruck des Händel-Bestandes in den ausgewählten Göttinger Bibliotheken und Archiven vermitteln. Indessen dürfte deutlich geworden sein, daß es sich hier alles in allem um eine einzigartig angelegte Musiksammlung handelt. Die hier beschriebenen Sammlungen ergänzen sich dadurch, daß sie jeweils aus einem bestimmten Bereich mehr enthalten, z. B. die Libretti in der Händel-Gesellschaft, die Programmhefte im Stadtarchiv, die Musikalien und Schallplatten in der Bibliothek und im Archiv des Musikwissenschaftlichen Seminars, schließlich die biographischen sowie die Notenwerke in der SUB Göttingen.

Meinem Anspruch, alle Händel-Standorte zu erfassen, konnte ich in Bezug auf das Archiv des GSO nicht gerecht werden, weil deren Bestand nicht dem breiten Publikum zugänglich ist, und der Orchesterdirektor um Ausschluß des Händel-Bestandes der GSO im anliegenden Katalog bat.

Die Bearbeitung des Händel-Bestandes der SUB ist ein unerwarteter Gewinn für die Bibliothek wie für die Benutzer. Nunmehr sind auch die vor 1992 eingetroffenen und in diversen konventionellen Katalogen verzeichneten Bestände sowie die aufgefundenen Textbücher, die bis zu ihrer Entdeckung während dieses Projektes im Verborgenen lagen, online recherchierbar und vor allem online bestellbar. Zu diesem Zweck habe ich darauf geachtet, daß, außer den Dokumenten der Nachlaßakte Brandi ${ }^{133}$, alle in diesem Katalog verzeichneten Medieneinheiten einen Barcode haben. Die elektronische Erfassung und das Etikettieren des Bestandes mit Barcode hat sich im Leihverkehr bewährt und für die Bibliotheksstatistik als positiv erwiesen.

Ich bin überaus froh, daß es mir gelungen ist, vier Schriften aus der Vorweltkriegszeit vom Händel-Haus Halle zu erlangen. Auch der Zugang von drei Programmbüchern und zehn CD der Internationalen Händel-Festspiele von der Göttinger HändelGesellschaft sind meiner Initiative zuzuschreiben. Unter den CD sind die fünf der

$\overline{133}$ In der SUB Göttingen werden Nachlaßdokumente grundsätzlich nicht mit Barcode etikettiert. 
»Festspiel-Edition« als Besonderheit hervorzuheben; wenn man bedenkt, daß diese CD nicht in den Handel gelangen, sondern nur für Mitglieder und Sponsoren der Gesellschaft gedacht sind. Mit meinem Vorgehen sowie dem großzügigen Beitrag der Händel-Gesellschaft und der Bereitstellung der SUB wünsche ich mir, daß sich ebenfalls die breite Öffentlichkeit die Konzertausschnitte der Händel-Festspiele auf diesen CD anhören kann, indem sie sie in der SUB ausleiht.

Wer die Gelegenheit hat, Händel im musikalischen wie im archivarischen Rahmen in Göttingen durch die Festspiele oder die Sammlung zu erleben und die Gesamtheit dieser Persönlichkeit zu erfassen, wird sicher den Sinn und Grund erkennen, daß hier der Versuch unternommen wurde, ein Stück Göttinger Musik- und Bibliotheksgeschichte aufzuzeichnen. Es kann nicht oft und nicht genug darauf hingewiesen werden, daß ohne eine langfristige, umfassende, tiefgehende Erschließung über Generationen hinweg die Musik, geschweige denn eine solche Spezialsammlung gar keinen Wert hat. 


\section{$8 \quad$ Literaturverzeichnis}

\subsection{Literatur}

Das ABC der Klassischen Musik : die großen Komponisten und ihre Werke. [München] : Naxos. - 325 S. : zahlr. Ill.

[CD-Booklet]

Akademie und Musik : Erscheinungsweisen und Wirkungen des Akademiegedankens in Kultur- und Musikgeschichte: Institutionen, Veranstaltungen, Schriften ; Festschrift für Werner Braun zum 65. Geburtstag / hrsg. von Wolf Frobenius. - Saarbrücken :

Saarbrücker Dr. und Verl., 1993. - 378 S.

(Saarbrücker Studien zur Musikwissenschaft ; N.F., 7)

ISBN 3-925036-82-2

Barna, István:

Wenn Händel ein Tagebuch geführt hätte / István Barna. [Dt. von Irene Rübberdt]. Budapest : Corvina K., 1985. - 283 S. : Notenbeisp.

ISBN 963-13-2003-0

Baselt, Bernd:

Georg Friedrich Händel / Bernd Baselt. Mit 55 Abb. zsgest. von Edwin Werner. 1. Aufl. - Leipzig : Bibliogr. Inst., 1988. - 109 S. : zahlr. Ill., Notenbeisp.

(Bildbiographie)

ISBN 3-323-00198-2 - ISBN 3-323-00196-6

Cherbuliez, Antoine-Elisée:

Georg Friedrich Händel : Leben und Werk / Antoine-E. Cherbuliez. - Olten : Walter, 1949. - 389 S. : Ill., Faks.

(Musikerreihe in auserlesenen Einzeldarstellungen ; 5)

Chronik der Georg-August-Universität zu Göttingen. - Göttingen 1921, 1924, 1927, 1931 
Diesch-Königsberg, Karl: Katalogfragen

In: Zentralblatt für Bibliothekswesen. - Leipzig : Bibliogr. Inst. - 54 (1937), S. 428 - 447

Dorfmüller, Kurt:

Musik in Bibliotheken : Materialien, Sammlungstypen, musikbibliothekarische Praxis / von Kurt Dorfmüller und Markus Müller-Benedict. - Wiesbaden : Reichert, 1997. XII, 302 S. : Ill., graph. Darst., Notenbeisp.

(Elemente des Buch- und Bibliothekswesens ; 15)

ISBN 3-88226-887-5

Einblick : die Georgia Augusta in ihrem 250. Jahr ; ein Blick auf das Forschungsspektrum der Georg-August-Universität Göttingen / [Red.:] Michael Bockemühl ...

- Göttingen : Verl. Göttinger Tagebl., 1987. - 271 S. : zahlr. Ill.

ISBN 3-924781-12-5

Einführung in die Besonderheiten der Katalogisierung am Göttinger Alphabetischen Bandkatalog und am Göttinger Musikalienkatalog / [Ragnhild Rabius ; Brigitte Kallmann]. - [Göttingen], 1972. - IV, 60, 5 Bl.

Fick, Richard: Die Universitätsbibliothek Göttingen als niedersächsische Landesbibliothek

In: Mitteilungen des Universitätsbundes Göttingen. - 10 (1929), 2, S. 29 - 45

Friedenthal, Richard:

Georg Friedrich Händel in Selbstzeugnissen und Bilddokumenten / dargest. von Richard Friedenthal. [Den dokumentarischen und bibliogr. Anh. bearb. Paul Raabe]. - [1. - 15. Tsd.]. - Hamburg : Rowohlt, 1959. - 172 S., [4] Bl. : Ill., Notenbeisp. (rowohlts monographien ; 36) 
Fuchs, Wilhelm:

Zur Theorie und Praxis des Realkatalogs : Untersuchungen über wissenschaftliche Bibliotheksordnung ; zugleich ein Beitrag zur Theorie der Sach- und Fachbibliographie ; Hauptband / von Wilhelm Fuchs. - Göttingen : Häntzschel, 1941-1945. - 404, 52, LXXX S.

(Hainbergschriften ; 9)

Geschichte der Göttinger Universitäts-Bibliothek / verf. von Göttinger Bibliothekaren. Hrsg. von Karl Julius Hartmann ... - Göttingen : Vandenhoeck \& Ruprecht, 1937. 331 S. : Ill. [17 ungez. Bl.]

Goethe, Johann Wolfgang von:

Italienische Reise : Teil 1 / hrsg. Von Heinrich Düntzer. - Berlin [u.a.] : Spemann, 1890. - 395 S.

(Goethes Werke ; 21,1). - (Deutsche National-Litteratur ; 102)

Göttingen : Geschichte einer Universitätsstadt / hrsg. von Erich Böhme ... Göttingen : Vandenhoeck \& Ruprecht, 1999. - VII, 952 S. : Ill., graph. Darst. (Von der preußischen Mittelstadt zur südniedersächsischen Großstadt ; 3) ISBN 3-525-36198-X

Handbuch der historischen Buchbestände in Deutschland / in Zsarb. mit Severin Corsten ... hrsg. von Bernhard Fabian ; Bd. 2,2: Niedersachsen ; H - Z / hrsg. von Paul Raabe. - Hildesheim [u.a.] : Olms-Weidmann, 1998. - 358 S. ISBN 3-487-09576-9

Jefcoate, Graham:

A catalogue of English books printed before 1801 : held by the University Library at Göttingen / comp. by Graham Jefcoate and Karen Kloth. Ed. for the library by Bernhard Fabian ; Pt. 2: Books printed between 1701 and 1800 ; Vol. 1: A-C. Hildesheim [u.a.] : Olms-Weidmann, 1988. - XX, 413 S.

ISBN 3-487-07889-9 
A catalogue of English books printed before 1801 : held by the University Library at Göttingen / comp. by Graham Jefcoate and Karen Kloth. Ed. for the library by Bernhard Fabian ; Pt. 2: Books printed between 1701 and 1800 ; Vol. 2: D-J. Hildesheim [u.a.] : Olms-Weidmann, 1988. - S. 417-882

ISBN 3-487-07890-2

A catalogue of English books printed before 1801 : held by the University Library at Göttingen / comp. by Graham Jefcoate and Karen Kloth. Ed. for the library by Bernhard Fabian ; Pt. 2: Books printed between 1701 and 1800 ; Vol. 3: K-Q. Hildesheim [u.a.] : Olms-Weidmann, 1988. - S. 885-1317

ISBN 3-487-07891-0

A catalogue of English books printed before 1801 : held by the University Library at Göttingen / comp. by Graham Jefcoate and Karen Kloth. Ed. for the library by Bernhard Fabian ; Pt. 2: Books printed between 1701 and 1800 ; Vol. 4: R-Z. Hildesheim [u.a.] : Olms-Weidmann, 1988. - S. 1321-1769

ISBN 3-487-07892-9

Jefcoate, Graham: Wilhelm Philipp Best und der Londoner Buchhandel In: Leipziger Jahrbuch zur Buchgeschichte. - Wiesbaden : Harrassowitz. ISSN 0940-1954, 6 (1996) 1, S. 199 - 210

Kiefert, Hans-Joachim: Niedersächsische Staats- und Universitätsbibliothek Göttingen In: Methodisches Handbuch für Heimatforschung in Niedersachsen / hrsg. Von Helmut Jäger. - Hildesheim : Lax, 1965. - S. 19 - 26. - (Veröffentlichungen des Instituts für Historische Landesforschung der Universität Göttingen ; 1)

Kind, Helmut:

Gutenberg und der europäische Frühdruck : zur Erwerbungsgeschichte der Göttinger Inkunabelsammlung / Helmut Kind ; Helmut Rohlfing. - Göttingen : Wallstein, 1995. - 112 S. : Ill.

ISBN 3-89244-204-5 
Die Luthersammlung der Niedersächsischen Staats- und Universitätsbibliothek Göttingen : Umfang und Aufstellung, Katalogisierung und Geschicht / von Helmut Kind. - Göttingen : Vandenhoeck \& Ruprecht, 1970. - 68 S., [5] Bl. : Ill. (Arbeiten aus der Niedersächsischen Staats- und Universitätsbibliothek Göttingen ; 8)

Kind-Doerne, Christiane:

Die Niedersächsische Staats- und Universitätsbibliothek Göttingen : ihre Bestände und Einrichtungen in Geschichte und Gegenwart / Christiane Kind-Doerne. Mit einem Beitr. von Klaus Haenel über die Handschriftenabt. - Wiesbaden : Harrassowitz, 1986. - X, 168 S., [8] Bl. : Ill., graph. Darst.

(Beiträge zum Buch- und Bibliothekswesen ; 22)

ISBN 3-447-02590-5

Kück, Hans:

Die „Göttinger Sieben“ : ihre Protestation und ihre Entlassung im Jahre 1837 / Hans Kück. - 222 S.

Göttingen, Univ., Diss., 1934

Leyh, Georg: Die Göttinger Bibliothek in den Grundzügen ihrer Entwicklung In: Nordisk Tidskrift for bok-och biblioteksväsen. - Oslo : Scandinavian Univ. Press. - 36 (1949), S. 69 - 89

Mainwaring, John:

Memoirs of the life of the late George Frederic Handel : to which is added, a catalogue of his works, and observations upon them / [John Mainwaring]. London : Dodsley, 1760. - [3] Bl., 208 S. : Ill.

Mattheson, Johann:

Georg Friedrich Händels Lebensbeschreibung, nebst einem Verzeichnisse seiner Ausübungswerke und deren Beurtheilung / übersetzet, auch mit einigen Anmerkungen, absonderlich über den hamburgischen Artikel versehen vom Legations-Rath Mattheson. - Hamburg : Übers., 1761. - [6] Bl., 156 S., [4] Bl. : Frontisp. 
Müller-Blattau, Joseph:

Georg Friedrich Händel : der Wille zur Vollendung / Müller-Blattau. - Mainz : Schott, 1959. - 204, 36 S. : zahlr. Ill., Notenbeisp.

Die Musik in Geschichte und Gegenwart : allgemeine Enzyklopädie der Musik ; [MGG] / ... hrsg. von Friedrich Blume ; Bd. 5: Gesellschaften - Hayne. - Kassel [u.a.] : Bärenreiter, 1956. - XVIII, 1952 Sp. : Ill., Notenbeisp.

Gedruckte Musik : 225 Jahre Musikverlag Schott in Mainz / Gutenberg-Museum. Mainz, 1995. - 47 S. : zahlr. Ill.

Musikwissenschaft und Musikpflege an der Georg-August-Universität Göttingen :

Beiträge zu ihrer Geschichte / hrsg. von Martin Staehelin. - Göttingen : Vandenhoeck \& Ruprecht, 1987. - 200 S. : Ill.

(Göttinger Universitätsschriften : Serie A, Schriften ; 3)

ISBN 3-525-35832-6

Nissen, Walter:

Das Göttinger Stadtarchiv : seine Geschichte und seine Bestände / von Walter Nisssen. - Göttingen : Vandenhoeck \& Ruprecht, 1969. - 108 S. : Ill., graph. Darst.

Quantz, Albert:

Die Musikwerke der kgl. Universitäts-Bibliothek in Göttingen / verz. von Albert Quantz. - [Göttingen], [ca. 1879]. - 45 S.

Scharschuch, Horst:

Georg Friedrich Händel : sein Leben in Bildern / von Horst Scharschuch. Mannheim : Bibliogr. Inst., 1959. - 32 S., [16] Bl. : zahlr. Ill.

(Meyers Bildbändchen : N.F. ; 13)

Schmelzer, Hans-Jürgen:

Siehe, dein König kommt : Leben und Musik des Georg Friedrich Händel ; eine

Biographie / Hans-Jürgen Schmelzer. - Düsseldorf : Drost, 1995. - 363 S. : Ill.

ISBN 3-7700-1044-2 
Schwedt, Georg:

Zur Geschichte der Göttinger Universitätsbibliothek : zeitgenössische Berichte aus 3 Jahrhunderten. - Göttingen : Verl. Göttinger Tagebl., 1983. - 184 S. : Ill.

700 Jahre Pauliner Kirche : vom Kloster zur Bibliothek / hrsg. von Elmar Mittler. Göttingen : Wallstein, 1994. - 171 S. : Ill., graph. Darst. + 1 Faltbl.

ISBN 3-89244-188-X

Siegmund-Schultze, Walther:

Georg Friedrich Händel / Walther Siegmund-Schultze. - Leipzig : Dt. Verl. für Musik, 1962. - 232 S. : Ill., Notenbeisp.

Übersicht über die Systematik des Band-Realkatalogs der Niedersächsischen Staatsund Universitätsbibliothek Göttingen / bearb. von Gerd-J. Bötte und Dieter Sickmüller. - Göttingen : Niedersächs. Staats- und Univ.-Bibliothek, 1993. - XIII, 75, 126 Bl. (Göttinger Bibliotheksschriften ; 3)

Vogt, Helmut: Zweihundertfünfzig Jahre Niedersächsische Staats- und Universitätsbibliothek Göttingen

In: Mitteilungsblatt der Bibliotheken in Niedersachsen. - Hannover : Landesbibl. 58 (1984), S. 6 - 10

Wolf, Hans-Werner: Joachim Heinrich Freiherr von Bülow oder Die Anfänge der Göttinger Universitätsbibliothek In: Informationszeitschrift für die Universitäts- und Kongressstadt / Kulturdezernat der Stadt Göttingen - Göttingen. - 18 (August 1971), S. 10 - 14

\subsection{Internet-Veröffentlichungen}

[Georg-August-Universität Göttingen, Musikwissenschaftliches Seminar, Bibliothek Homepage] - Stand: 18.11.2002

URL: http://www.gwdg.de/ musik/biblio.html 
[Georg-August-Universität Göttingen, Musikwissenschaftliches Seminar, Geschichte des Accouchierhaus] - Stand: 01.03.1999

URL: http://www.gwdg.de/ musik/biblio.html

[Hallische Händel-Ausgabe, kritische Gesamtausgabe - Homepage]

URL: http://www.haendelhaus.de/gfhaendel/haendel_ausgabe_main.html

Handel on the Web : Societies, Institutes

URL: http://www.omm.de/feuilleton/haendel-gloria.html

[Hauptklasse/Signaturgruppe: Ars Musica - Startseite]

URL: http://www.sub.uni-goettingen.de

Lebendiges virtuelles Museum Online (LeMO)

URL: http://www.dhm.de/lemo/html/weimar/wissenschaft/notgemeinschaft/

Poensgen, Benedikt (2001): Musikalische Sensation : unbekannte frühe Komposition Händels entdeckt.

In: Online Musik Magazin

URL: http://www.omm.de/feuilleton/haendel-gloria.html

[Stadtarchiv Göttingen - Startseite]

URL: http://www.stadtarchiv.goettingen.de

DFG-Chronologie: Von der Notgemeinschaft der Deutschen Wissenschaft zur Deutschen Forschungsgemeinschaft

URL: http://www.dfg.de/dfg_im_profil/geschichte/geschichte_der_dfg/dfg_chronologie.html 


\subsection{Unveröffentlichtes Material}

Bandübersicht des Systematischen Katalogs. - 63 Bl.

[Handapparat]

Berndt, Michael:

Der Ars-Musica-Katalog der SUB : seine Geschichte und seine Inhalte ... / Schreiben vom 20.08.1999, SUB Göttingen. - 3 Bl.

Krüger, Eduard, Personalakte

Sign.: Bibl. Arch. B, Personalia 2, H-P : Krüger

Manual der Jahre 1873-1955; Zugangsbücher der Jahre 1956-1992

Oesterley, Hermann, Personalakte

Sign.: Bibl. Arch. B, Personalia 2, H-P : Oesterley 


\section{Abkürzungsverzeichnis}

\begin{tabular}{ll}
\hline Abt. & Abteilung \\
\hline Akad. & Akademie \\
\hline Bsp. & Beispiel \\
\hline bzw. & beziehungsweise \\
\hline ca. & circa \\
\hline d. h. & das heißt \\
\hline dgl. & dergleichen \\
\hline f. & folgende \\
\hline Jh. & Jahrhundert \\
\hline Mio. & Million \\
\hline s. & siehe \\
\hline S. & Seite \\
\hline Sign. & Signatur \\
\hline u. a. & und andere \\
\hline u. ä. & und ähnliches \\
\hline Univ. & Universität \\
\hline usw. & und so weiter \\
\hline vgl. & vergleiche \\
\hline Vol. & Volume \\
\hline$\ldots$ wiss. & $\ldots$ zumsenschaftlich \\
\hline z. B. & zum Beispiel \\
\hline z. T. & \\
\hline & \\
\hline
\end{tabular}


A N H A N G 



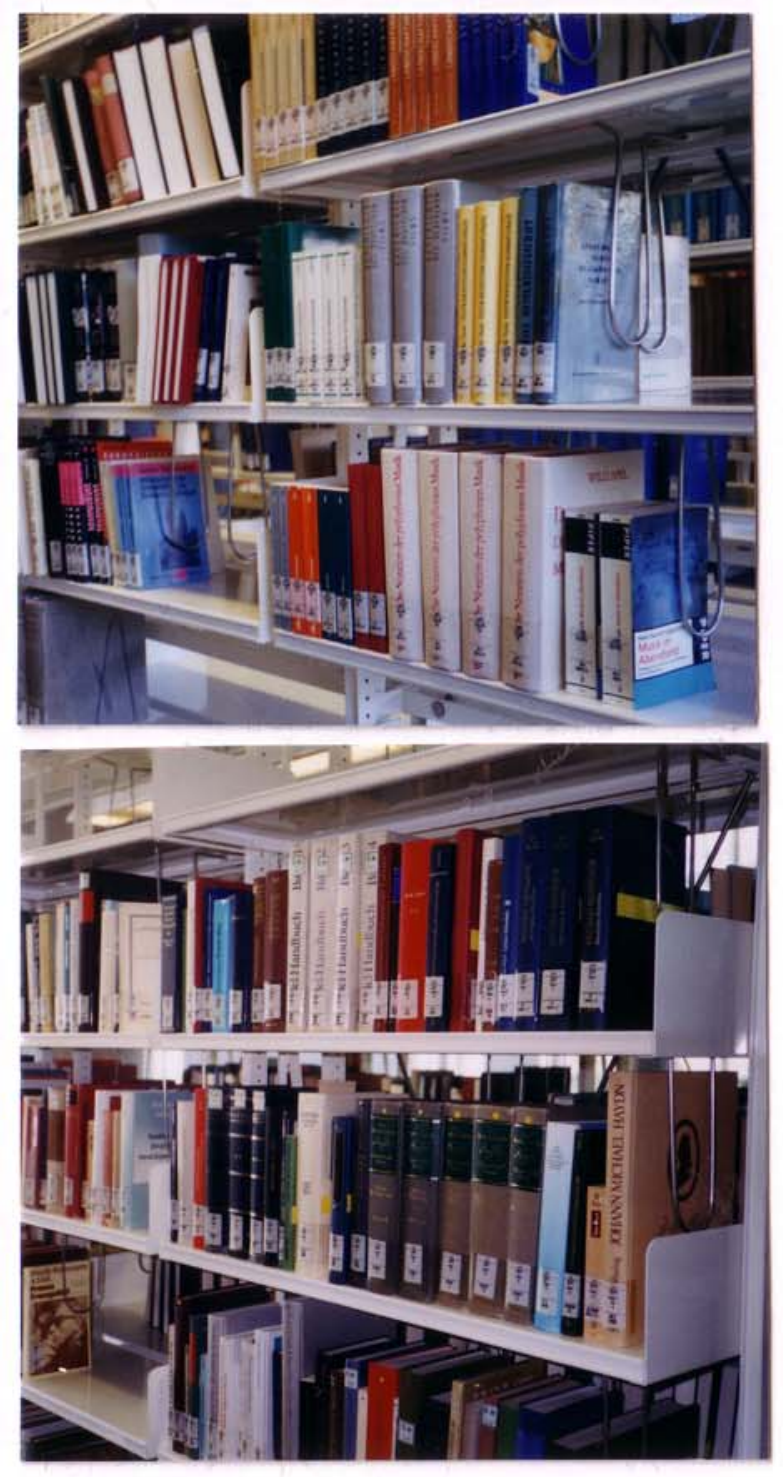

im Freihandbereich aufgestellte Musikbestände der SUB Göttingen

im EG:

(li. oben) die Lehrbuchsammlung (LBS),

(re. oben) Bibliographischer Apparat (BIB)

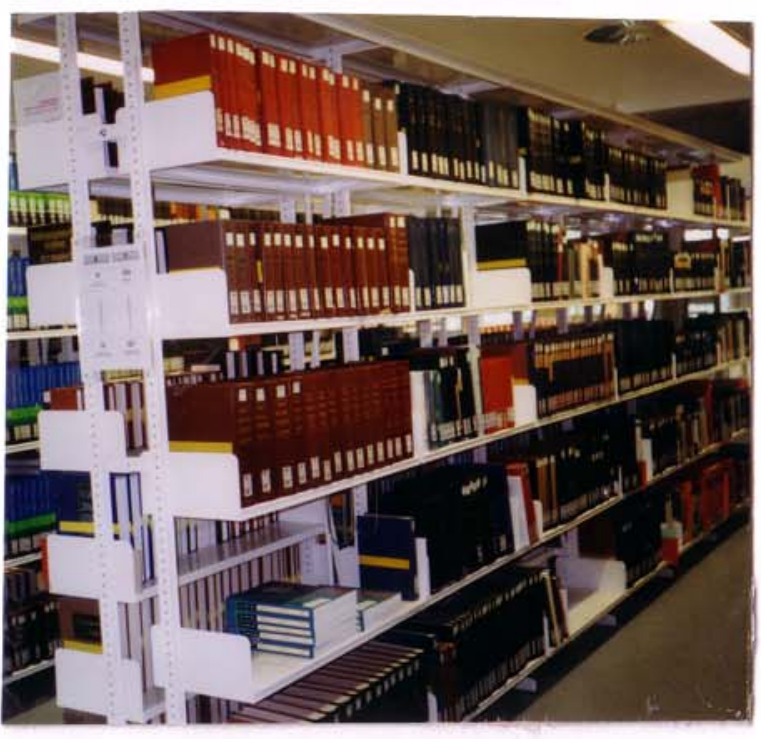

(li. unten) Musikliteratur im Lesesaal 1,

(re. unten) Musikzeitschriften im Lesesaal 2

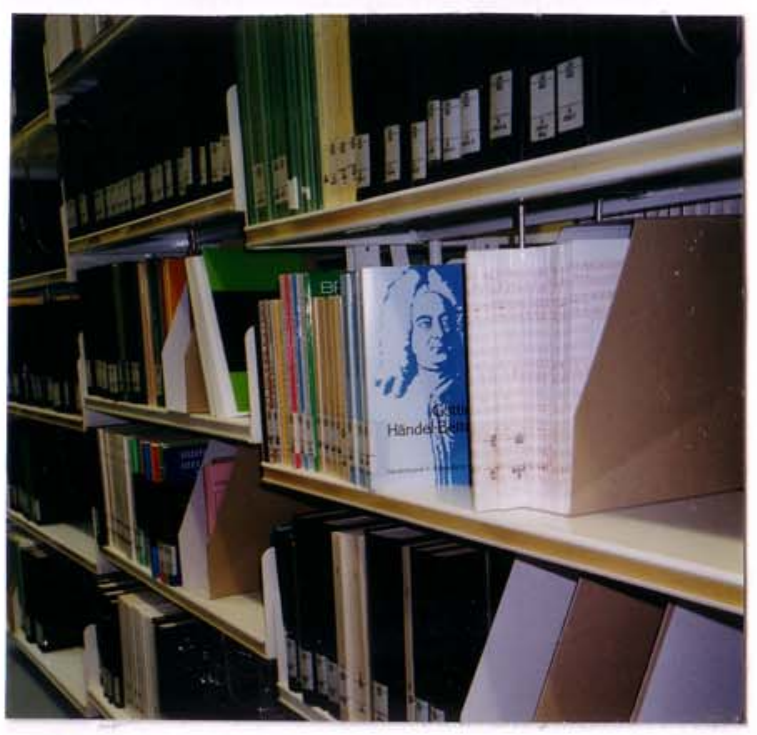




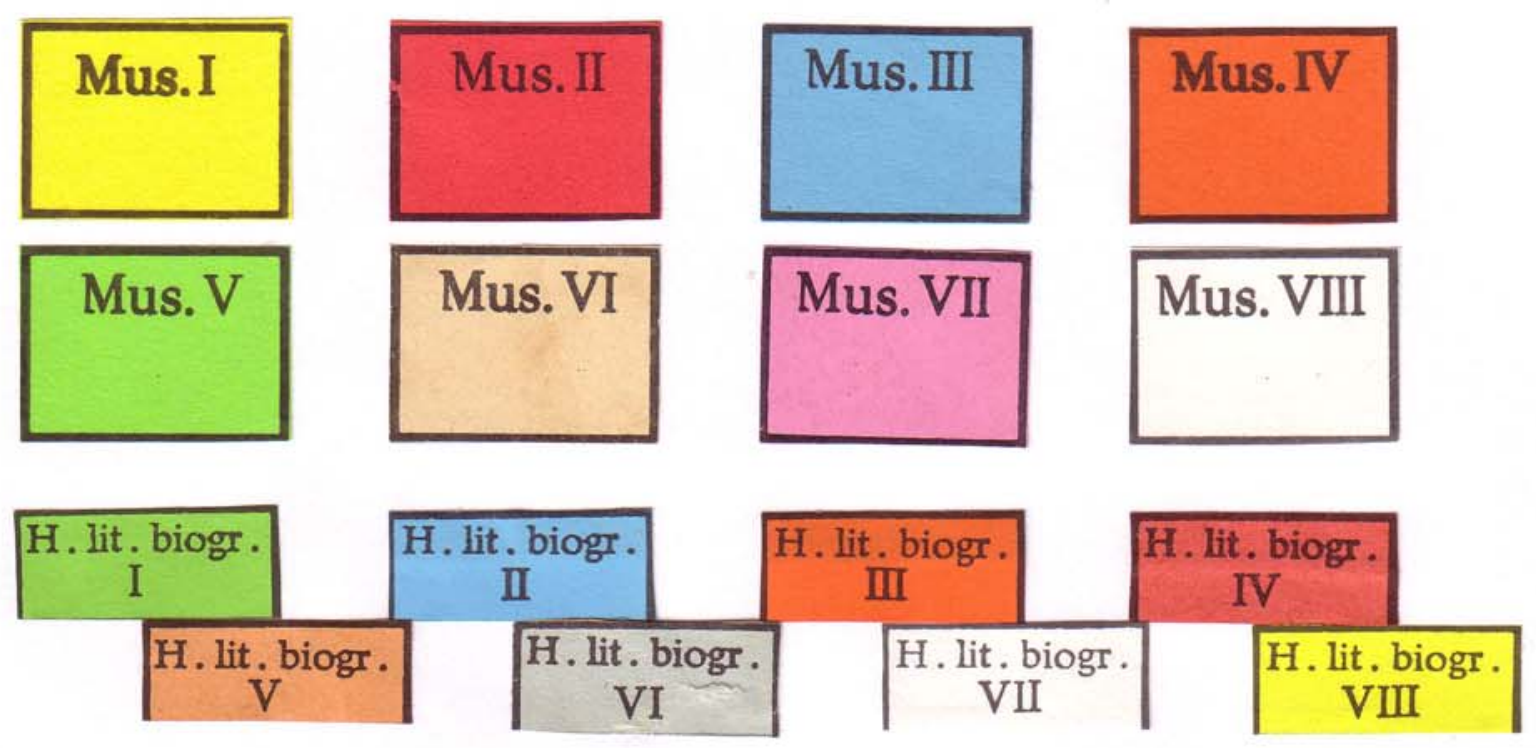

Signaturschilder der Gruppen MUS I-MUS VIII und H L BI I-H L BI VIII
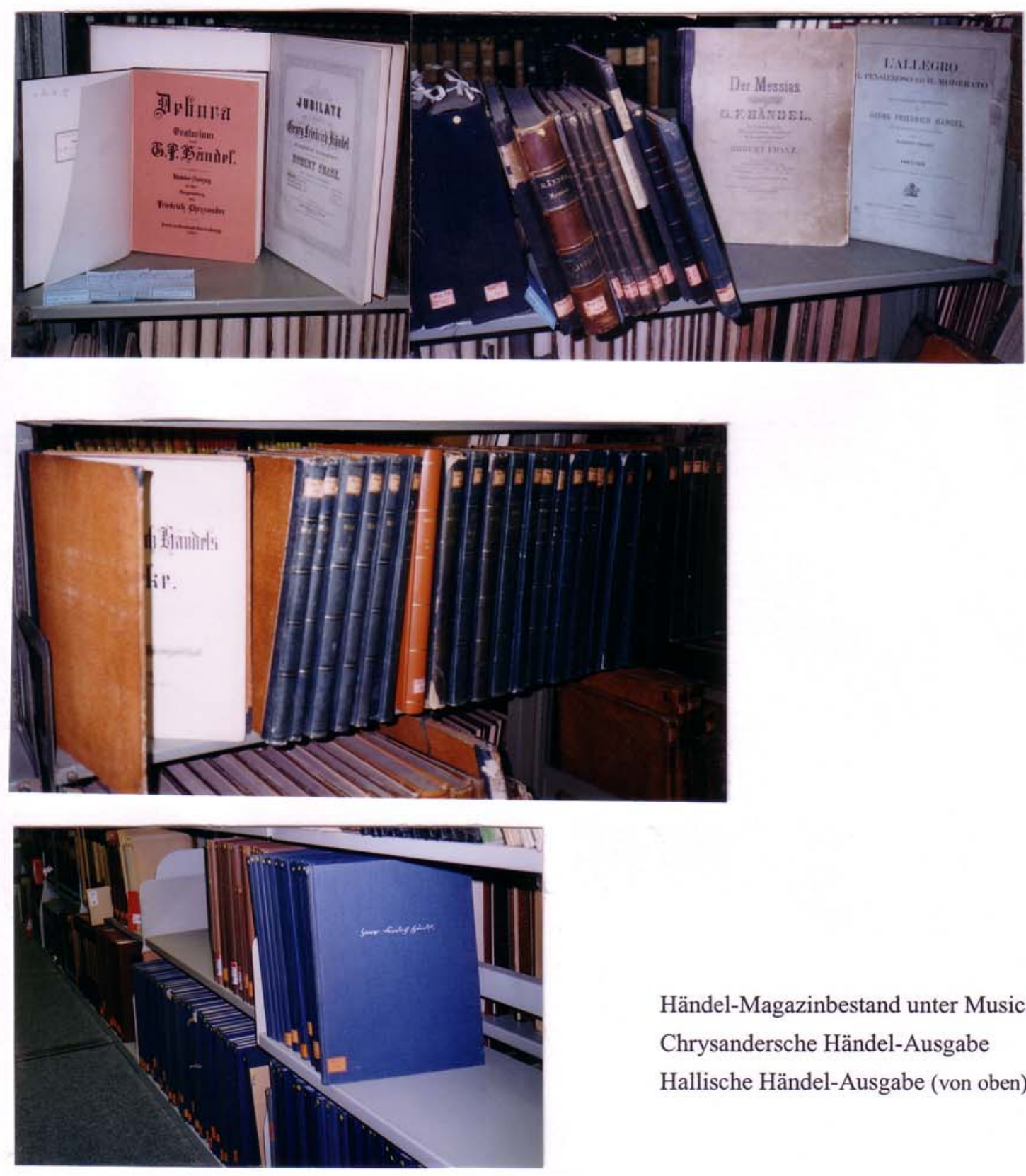

Händel-Magazinbestand unter Musica Chrysandersche Händel-Ausgabe Hallische Händel-Ausgabe (von oben) 
Aus dem Manual 1874:

April 20.

Von dem Ober-Präsidenten Grafen Eulenburg in Hannover eingesandt (s. Markierung)

Dec. 30.

Von dem Ober-Präsidenten

Grafen Eulenburg in Hannover übersandt

(s. Markierung)

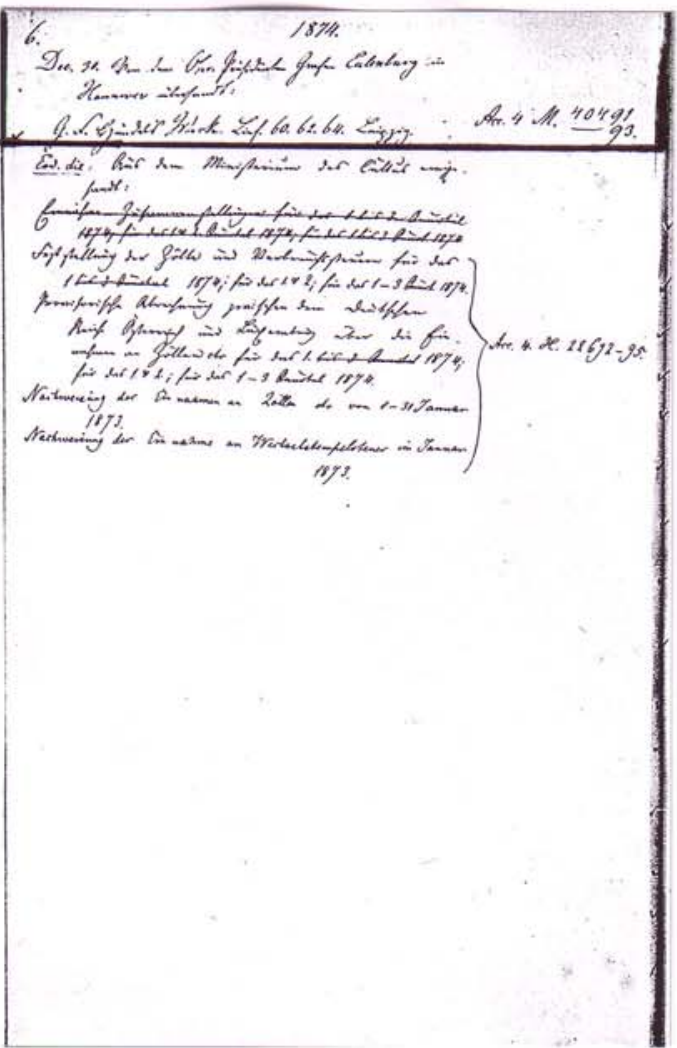


Aus dem Manual:

1909:

Febr-26-D - br. - " (s. Nr. 8574)

1953:

29.1.54-Verl. d. Gött. Händelges. e.V. $-P-M u$

(s. Nr. 4113)

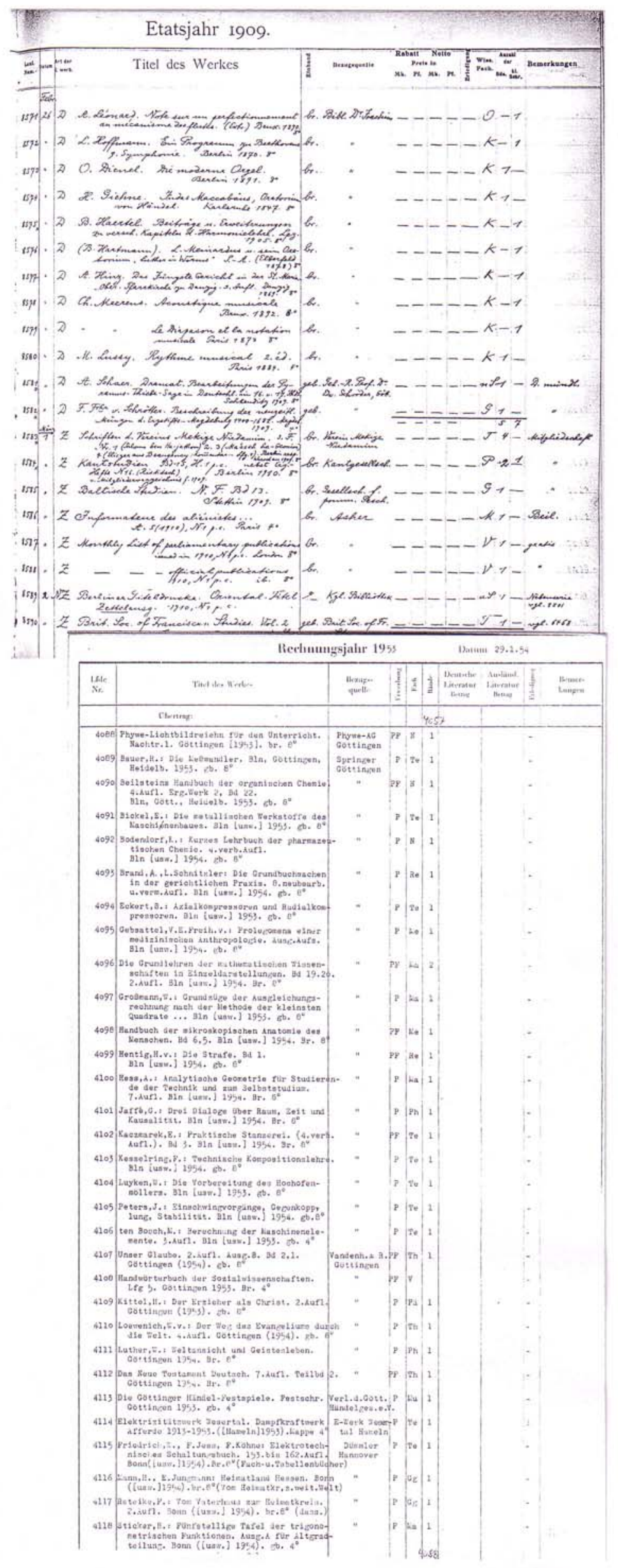



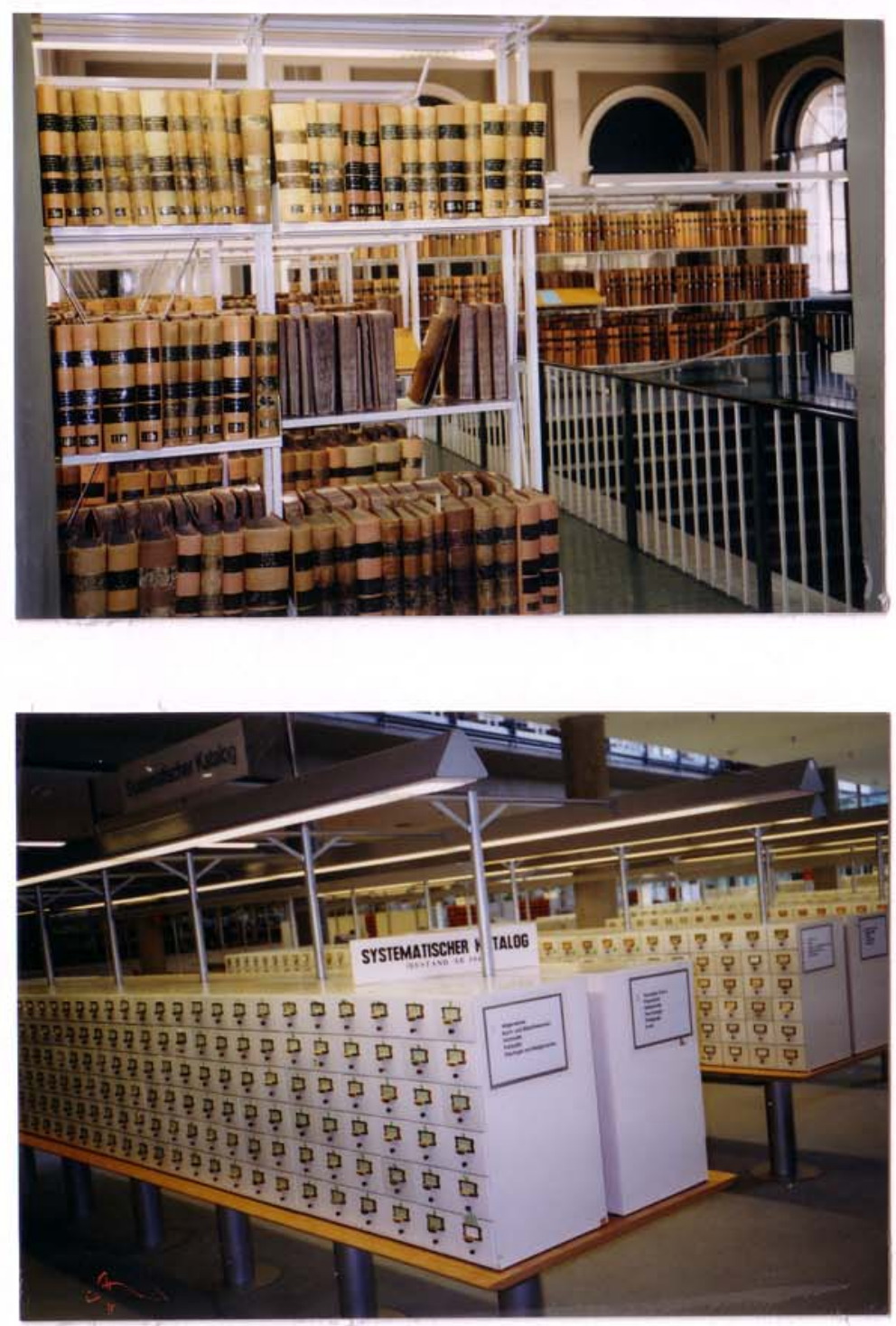

konventionelle Kataloge der SUB Göttingen im HG:

(li. oben) BdRK (vorne), BdAK (hinten)

im Neubau:

(re. oben) Alphabet. ZK, (li. unten) System. ZK, (re. unten) SW-Katalog
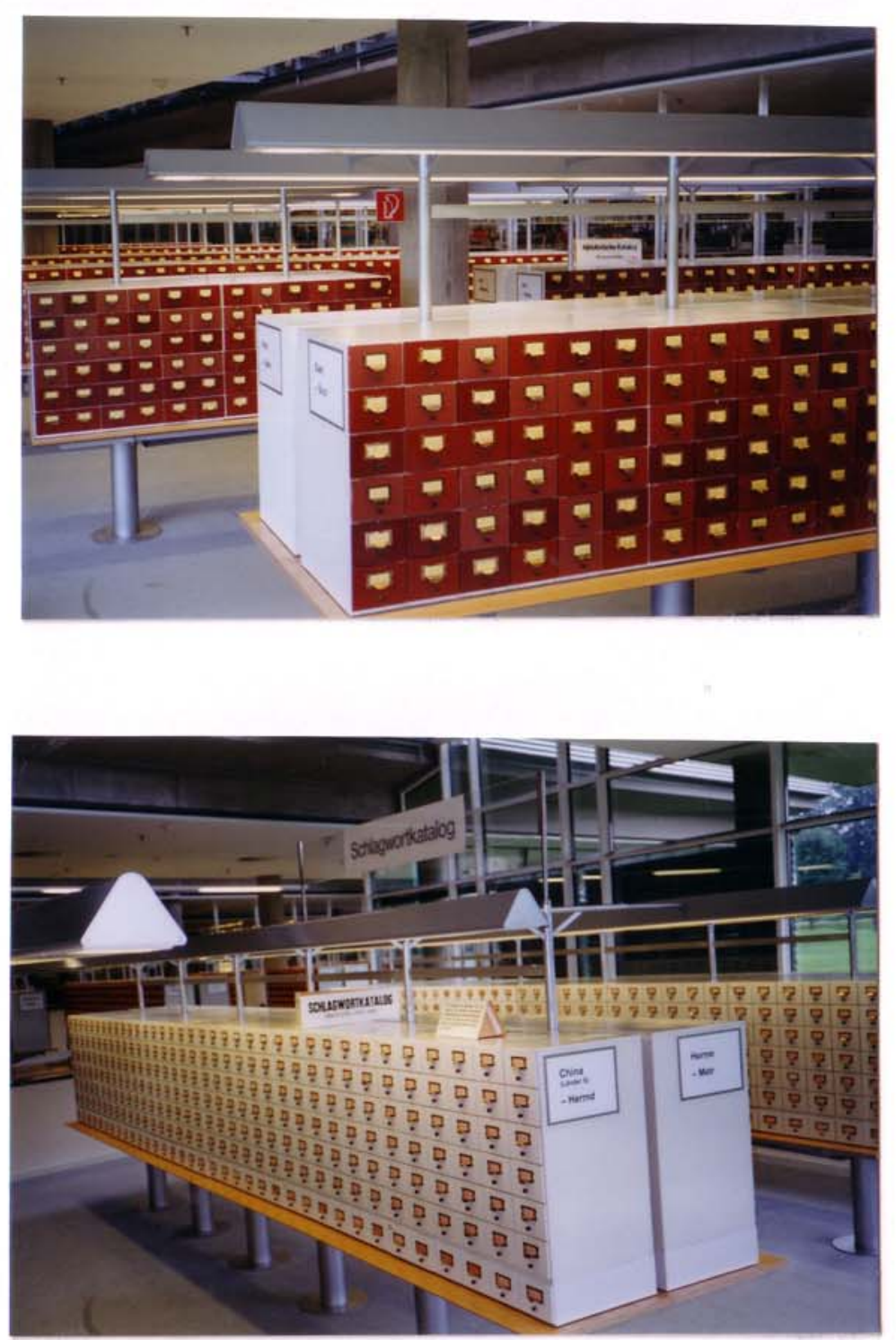
im Neubau:

der nach vier Fakultäten geordnete Dissertationskatalog der SUB Göttingen (li.)

Ars-Musica-Katalog:

Catalogus realis im HG (Mitte)

Catalogus alphabeticus (unten)

$=$ Musikalienkatalog im Neubau
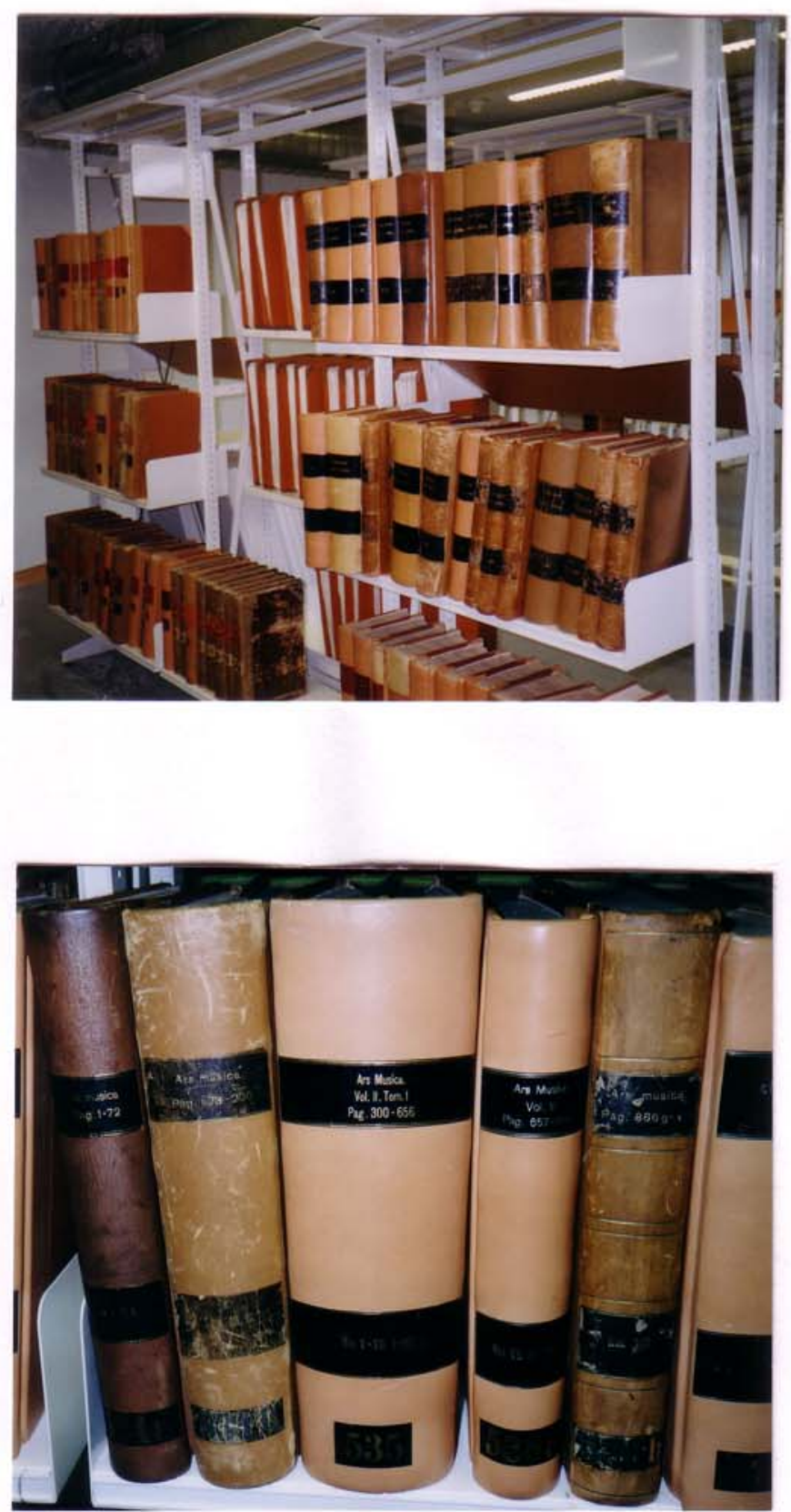

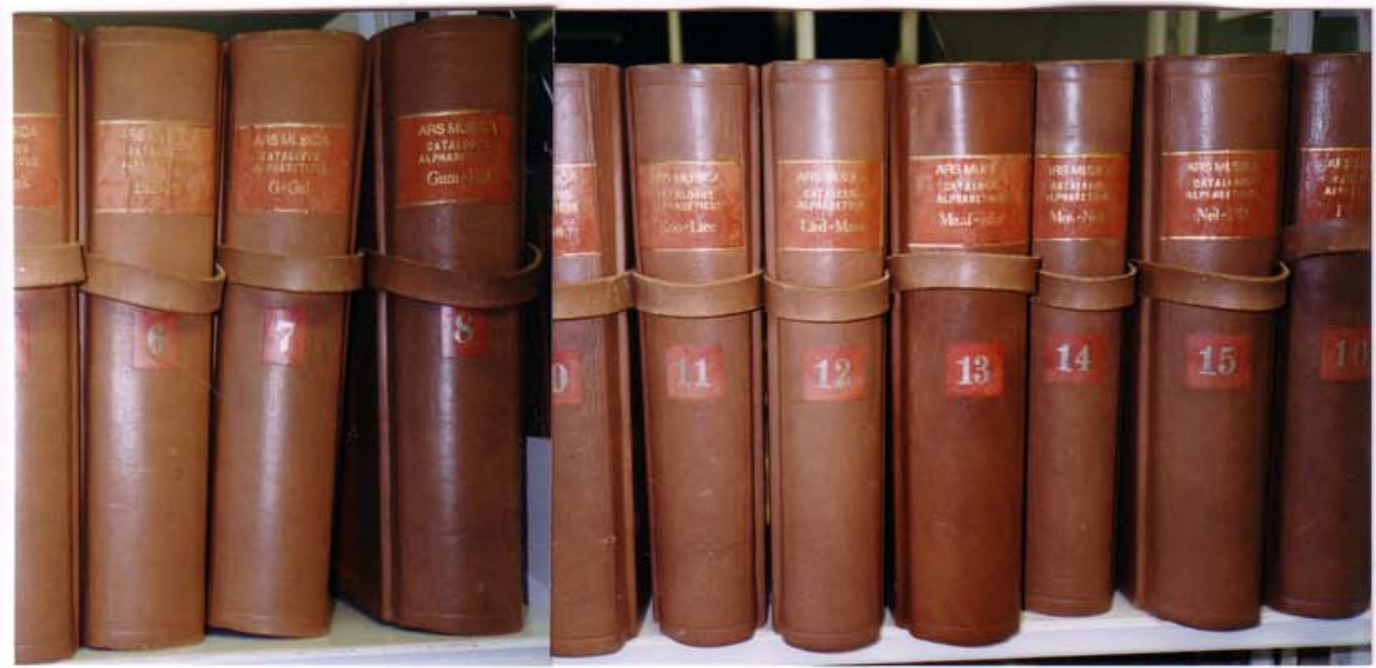




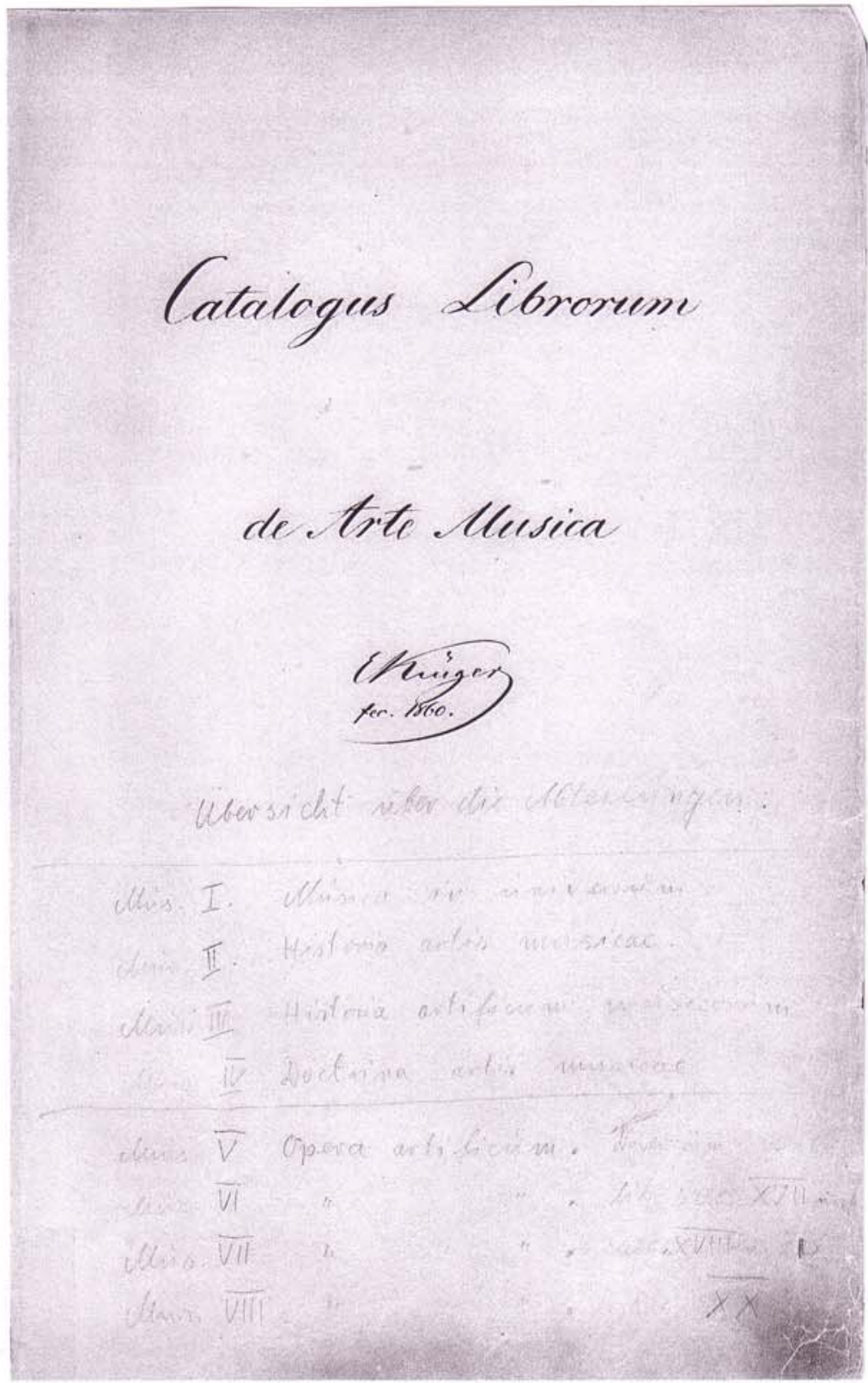

erstes B1. aus dem Ars Musica Catalogus realis, mit Unterschrift des Bearbeiters $E$ [duard] Krüger 
Fundstellenhinweis aus Ars Musica Catalogus realis (Umfang: $8 \mathrm{~S}$.)

Fundstellenhinweise

$$
\text { Musikw1ssenschoft }
$$$$
\text { MUS I-VIII (Kat.-Bde 534-536b) }
$$

Allgemeiner Hinweis fur fede Gruppe:

$$
\begin{aligned}
& \text { s. o. A/I Bibllogrophien } \\
& \text { A/5 KongreBberichte, Festschriften, } \\
& \text { Sommelbonde, Periodiko } \\
& \text { A/8 Gesammelte Werke }
\end{aligned}
$$

\section{A Nochschlagewerke und Sommelbände / \\ Bibliotheks- und Verlogswesen}

Bibliogrophien, Bibliothekskataloge, Li teroturberichte
s. $0 . \mathrm{HLL}$ S. $657 \mathrm{ff}$.

2 Katologe und Verzetchnisse

3 Lexiko und Enzyklopödien
5. $0 . \mathrm{K} / 3$

4 Einfohrungen $5 \begin{aligned} & \text { KongreBberichte, Festschriften, } \\ & \text { Sommelbönde, Periodika }\end{aligned}$
$\begin{array}{ll}\text { MUS I, } 861-1199 \\ \text { MUS } 1700-2499\end{array}$

6 Bibliothekswesen

7 Verlogswesen und Urheberrecht.

8 Gesommelte Werke

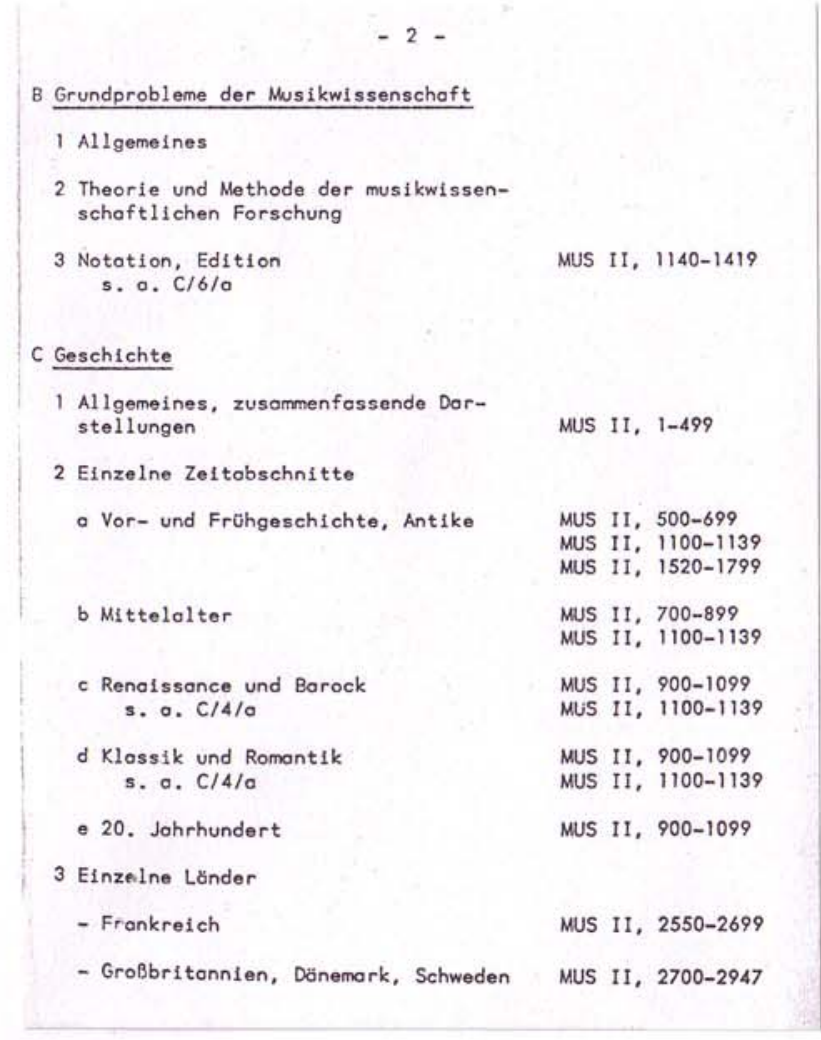




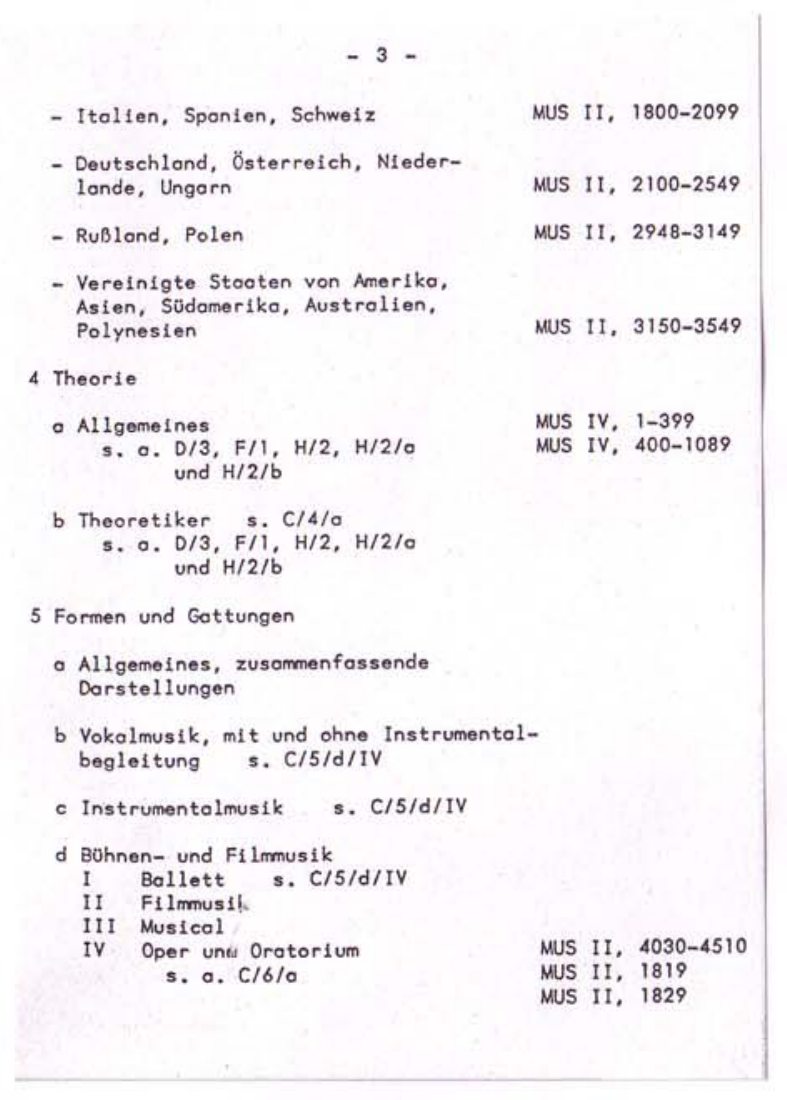




\section{- 5 -}

\begin{tabular}{|c|c|}
\hline 1 Allgemeines s. $C / 5 / d / I V$ & \\
\hline \multicolumn{2}{|l|}{2 Einzelne Lönder } \\
\hline - Orient & MUS $11,1450-1519$ \\
\hline - Spanien & MUS II, $2013^{2}$ \\
\hline \multicolumn{2}{|l|}{ F Musikpädagogik und Didaktik } \\
\hline 1 Allgemeines & MUS IV, $3000-3699$ \\
\hline 2 Einzelne Länder $\quad$ s. $F / 1$ & \\
\hline \multicolumn{2}{|l|}{$\begin{array}{l}3 \text { Spezielles } \\
\text { s. a. F/1 }\end{array}$} \\
\hline - Gesang und Stimmbildung & MUS IV, $4000-4599$ \\
\hline - Tosteninstrumente & NUS IV, $4600-4949$ \\
\hline - Verschiedene Instrumente & MUS IV, $4950-5489$ \\
\hline - Dirigieren u. Begleiten S. $H / 3 / b$ & \\
\hline 4 Schulmusik $\quad$ S. $F / 1$ & \\
\hline \multicolumn{2}{|l|}{$G$ Musikleben } \\
\hline $\begin{array}{l}1 \text { Allgemeines } \\
\text { s. o. C C/4/a }\end{array}$ & $\begin{array}{l}\text { MUS III, } 9000-9199 \\
\text { MUS III, } 9200-9286\end{array}$ \\
\hline 2 Einzelne Lönder s. $G / 1$ und $C / 4 / 0$ & \\
\hline 3 Musikkritik s. $\mathrm{C} / 4 / \mathrm{a}$ & \\
\hline
\end{tabular}

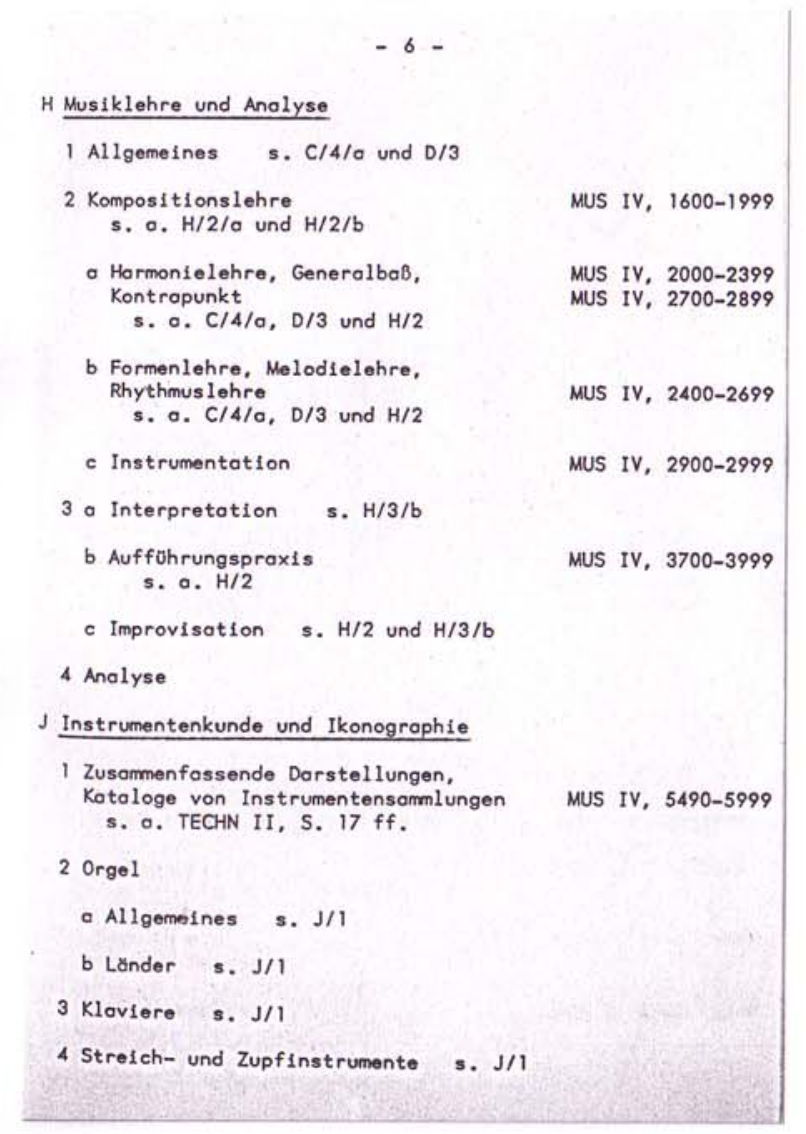




\begin{tabular}{|c|c|}
\hline \multicolumn{2}{|l|}{$-7-$} \\
\hline \multicolumn{2}{|l|}{5 Blos- und Bolginstrumente $\quad$ s. J/1 } \\
\hline \multicolumn{2}{|l|}{6 Schloginstrumente, Glocken s. J/1 } \\
\hline \multicolumn{2}{|l|}{$\begin{array}{l}7 \text { Mechonische, elektrische und elektronische } \\
\text { Musikinstrumente }\end{array}$} \\
\hline \multicolumn{2}{|l|}{8 Sonstiges s. J/1 } \\
\hline \multicolumn{2}{|l|}{ 9 Ikonogrophie } \\
\hline \multicolumn{2}{|l|}{ K Personen } \\
\hline $\begin{array}{l}1 \text { Komponisten, Interpreten, Musikwissen- } \\
\text { schoftler } \\
\text { 5. o. K/3 }\end{array}$ & MUS III, 500-8999 \\
\hline \multicolumn{2}{|l|}{$\begin{array}{l}2 \text { Oichter, Bildende Künster, } \\
\text { Philosophen u. a. } 5 . \mathrm{K} / 3\end{array}$} \\
\hline 3 Sormelbiogrophien & MUS III, $1-499$ \\
\hline \multicolumn{2}{|l|}{ Musiknoten } \\
\hline \multicolumn{2}{|l|}{ Sommelwerke und Reihen } \\
\hline Allgemeine & MUS V, $1-999$ \\
\hline Schulgesönge & MUS V, 1000-1999 \\
\hline $\begin{array}{l}\text { Geistliche } \\
\text { s. a. HE RIT I, } 9195 \text { ff. }\end{array}$ & MUS V, 2000-2999 \\
\hline $\begin{array}{l}\text { Welt1iche } \\
\text { s. a. Poetoe }\end{array}$ & MUS V, $3000-3999$ \\
\hline Volkslieder & MUS V, $4000-5999$ \\
\hline
\end{tabular}

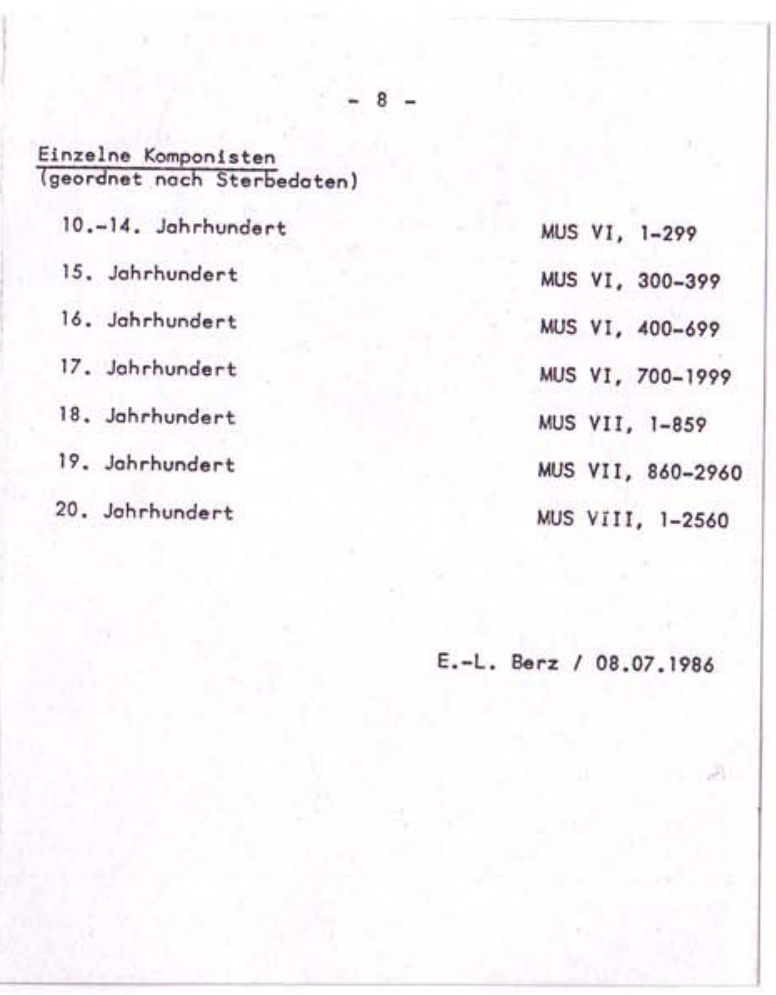




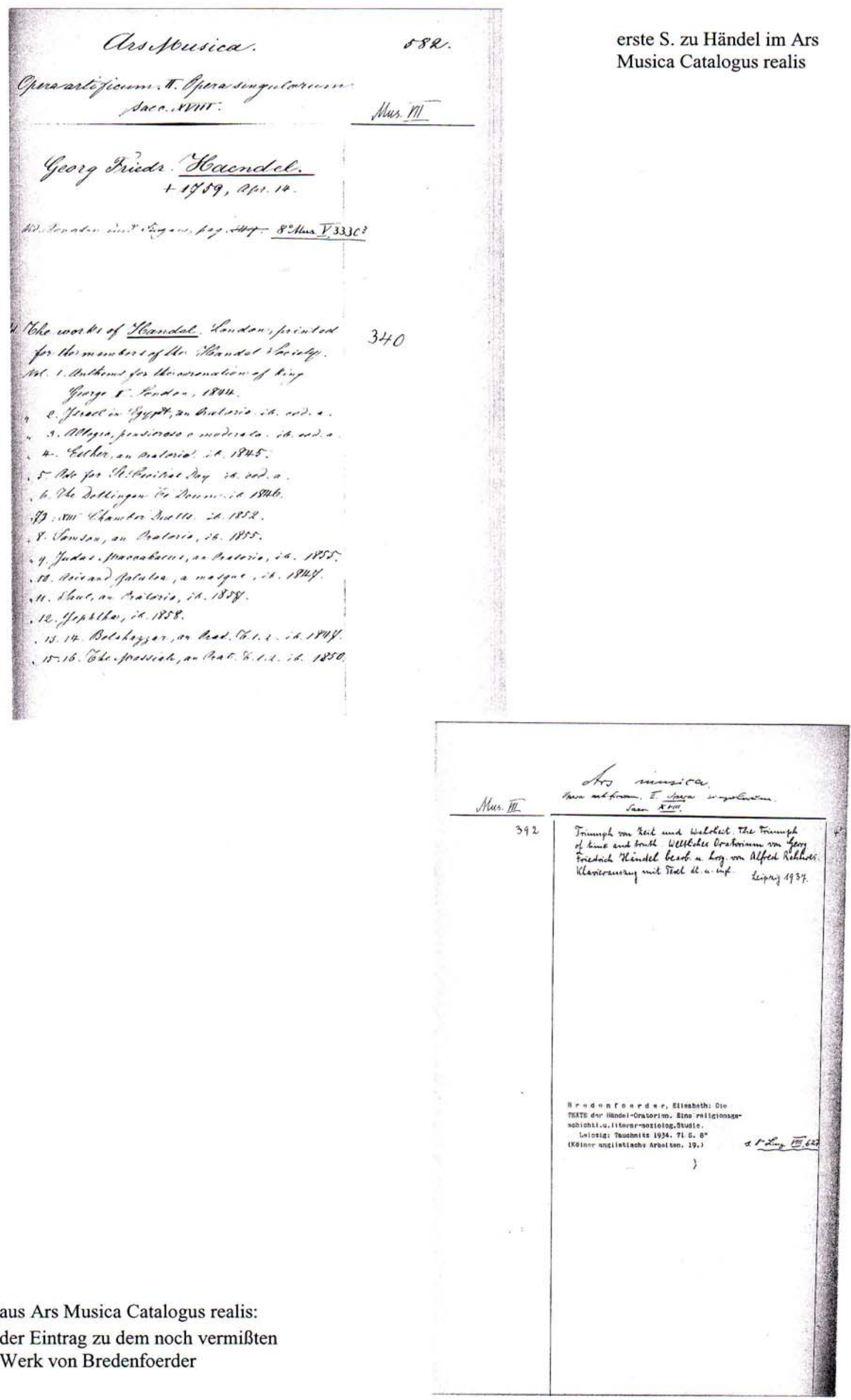




\section{Hauptklasse/Signaturgruppe: Ars Musica}

$\begin{array}{ll} & 0 \\ \text { Klassenbezeichnung: } & \text { Ars Musica } \\ \text { Signaturintervall: } & \text { MUS }\end{array}$

0

Klassenbezeichnung: Musica

Signaturintervall: $\quad$ MUS

Klassenbezeichnung: In universum

Signaturintervall: $\quad$ MUS

1.1

Klassenbezeichnung: Prolegomena

Signaturintervall: $\quad$ MUS

1.1.1

Klassenbezeichnung: De natura atque genio artis musicae

Schlagwörter: $\quad$ Musik, Musikästhetik, Musikphilosophie, Musikpsychologie

Signaturintervall: $\quad$ MUS I, 0-a-344-a

1.1 .2

Klassenbezeichnung: De ratione quae musicam intercedit et alias disciplinas

Schlagwörter: $\quad$ Musik / Künste, Künste / Musik

Signaturintervall: $\quad$ MUS I, 600-645

1.2

Klassenbezeichnung: Libri quibus argumenta varia tractantur

Signaturintervall: $\quad$ MUS

1.2.1

Klassenbezeichnung: Ordine chronologico

Signaturintervall: $\quad$ MUS

1.2.1.1

Klassenbezeichnung: Opuscula et dissertationes plurium scriptorum

Signaturintervall: $\quad$ MUS 
1.2.1.1.1

Klassenbezeichnung: Collectiones publice editae

Schlagwörter: Musik, Musik / Quelle, Musikwissenschaft

Signaturintervall: $\quad$ MUS I, 855-1069

1.2.1.1.2

Klassenbezeichnung: Collectiones privato studio factae

Schlagwörter: Musik, Musikwissenschaft

Signaturintervall: $\quad$ MUS I, 1200-1200-c

1.2.1.2

Klassenbezeichnung: Opuscula singulorum

Schlagwörter: Musik, Musikwissenschaft

Signaturintervall: $\quad$ MUS I, 1225-1510

1.2.1.3

Klassenbezeichnung: Ephemerides

Schlagwörter: $\quad$ Musik / Zeitschrift, Musik / Schriftenreihe

Musikwissenschaft / Zeitschrift, Musikwissenschaft / Schriftenreihe

Signaturintervall: $\quad$ MUS I, 1700-2118

1.2.2

Klassenbezeichnung: Ordine alphabetico

Signaturintervall: $\quad$ MUS

1.2.2.1

Klassenbezeichnung: Lexica

Schlagwörter: $\quad$ Musik / Lexikon, Musikwissenschaft / Lexikon

Signaturintervall: $\quad$ MUS I, 2500-2575-a

Klassenbezeichnung: Ordine systematico

Signaturintervall: $\quad$ MUS

1.2.3.1

Klassenbezeichnung: Encyclopaediae systematicae

Schlagwörter: $\quad$ Musik / Lexikon, Musikwissenschaft / Lexikon

Signaturintervall: $\quad$ MUS I, 2589-2607

1.2.4

Klassenbezeichnung: Catalogi

Schlagwörter: Musik / Bibliographie, Musik / Werkverzeichnis

Signaturintervall: $\quad$ MUS I, 2607-a-2842 
Klassenbezeichnung: In specie

Signaturintervall: MUS

2.1

Klassenbezeichnung: Historia

Signaturintervall: $\quad$ MUS

2.1.1

Klassenbezeichnung: Artis musicae

Signaturintervall: $\quad$ MUS

2.1.1.1

Klassenbezeichnung: Generatim

Schlagwörter: Musik / Geschichte

Signaturintervall: $\quad$ MUS II, 3-318

2.1.1.2

Klassenbezeichnung: Speciatim ratione habita

Signaturintervall: $\quad$ MUS

2.1.1.2.1

Klassenbezeichnung: Temporum

Signaturintervall: $\quad$ MUS

2.1.1.2.1.1

Klassenbezeichnung: Veterum

Schlagwörter: $\quad$ Musik / Geschichte 800 v. Chr.-500

Signaturintervall: $\quad$ MUS II, 500-535

Klassenbezeichnung:

Schlagwörter: $\quad$ Musik / Geschichte 500-1500

Signaturintervall: $\quad$ MUS II, 700-768

2.1.1.2.1.3

Klassenbezeichnung: Recentiorum

Schlagwörter: Musik / Geschichte 1500-1945

Signaturintervall: $\quad$ MUS II, 900-980

2.1.1.2.2

Klassenbezeichnung: Populorum

Signaturintervall: $\quad$ MUS 
2.1.1.2.2.1

Klassenbezeichnung: Complurium

Schlagwörter: $\quad$ Musik / Geschichte, Notenschrift / Geschichte

Signaturintervall: $\quad$ MUS II, 1100-1420

2.1.1.2.2.2

Klassenbezeichnung: Singulorum

Signaturintervall: $\quad$ MUS

2.1.1.2.2.2.1

Klassenbezeichnung: Orientalium

Schlagwörter: Orient / Musik / Geschicht

Signaturintervall: $\quad$ MUS II, 1450-1486

2.1.1.2.2.2.2

Klassenbezeichnung: Europaeorum

Signaturintervall: $\quad$ MUS

Klassenbezeichnung:

2.1.1.2.2.2.2.1

Schlagwörter:

Graecorum

Signaturintervall: $\quad$ MUS II, 1520-1600

2.1.1.2.2.2.2.2

Klassenbezeichnung: Italorum

Schlagwörter: Italien / Musik / Geschichte

Signaturintervall: $\quad$ MUS II, 1800-1849

Klassenbezeichnung:

2.1.1.2.2.2.2.3

Schlagwörter:

Hispanorum

Signaturintervall: $\quad$ MUS II, 2000-2013<2>-a

2.1.1.2.2.2.2.4

Klassenbezeichnung: Helvetorum

Schlagwörter: $\quad$ Schweiz / Musik / Geschichte

Signaturintervall: $\quad$ MUS II, 2060-2060-b

2.1.1.2.2.2.2.5

Klassenbezeichnung: Germanorum cum Austria

Schlagwörter: Deutschland / Musik / Geschichte

Signaturintervall: $\quad$ MUS II, 2100-2113 
2.1.1.2.2.2.2.6

Klassenbezeichnung: Austriae

Schlagwörter: Ö̈sterreich / Musik / Geschichte

Signaturintervall: $\quad$ MUS II, 2150-2167

2.1.1.2.2.2.2.7

Klassenbezeichnung: Hungaricorum

Schlagwörter: $\quad$ Ungarn / Musik / Geschichte

Signaturintervall: $\quad$ MUS II, 2176<2>-2180

2.1.1.2.2.2.2.8

Klassenbezeichnung: Germanorum

Schlagwörter: Deutschland / Musik / Geschichte

Signaturintervall: $\quad$ MUS II, 2200-2416

2.1.1.2.2.2.2.9

Klassenbezeichnung: Batavorum, Belgarum

Schlagwörter: $\quad$ Niederlande / Musik / Geschichte, Belgien / Musik / Geschichte

Signaturintervall: $\quad$ MUS II, 2416-a-2504-b

Klassenbezeichnung: Gallorum

Schlagwörter: $\quad$ Frankreich / Musik / Geschichte

Signaturintervall: $\quad$ MUS II, 2550-2630

2.1.1.2.2.2.2.11

Klassenbezeichnung: Rumänien

Schlagwörter: Rumänien / Musik / Geschichte

Signaturintervall: $\quad$ MUS II, 2630-a

Klassenbezeichnung:

2.1.1.2.2.2.2.12

Schlagwörter:

Britannorum

Signaturintervall: $\quad$ MUS II, 2700-2753-c

2.1.1.2.2.2.2.13

Klassenbezeichnung: Danorum

Schlagwörter: Dändemark / Musik / Geschichte

Signaturintervall: $\quad$ MUS II, 2850-2874

Klassenbezeichnung:

Schlagwörter:

2.1.1.2.2.2.2.14

Signaturintervall: $\quad$ MUS II, 2874-a 
2.1.1.2.2.2.2.15

Klassenbezeichnung: Russorum

Schlagwörter: Rußland / Musik / Geschichte

Signaturintervall: $\quad$ MUS II, 2948-2960

2.1.1.2.2.2.2.16

Klassenbezeichnung: Polonorum

Schlagwörter: $\quad$ Polen / Musik / Geschichte

Signaturintervall: $\quad$ MUS II, 3050

2.1.1.2.2.2.2.17

Klassenbezeichnung: Americanorum

Schlagwörter: Amerika / Musik / Geschichte

Signaturintervall: $\quad$ MUS II, 3131-3166

2.1.1.2.2.2.2.18

Klassenbezeichnung: Asiaticorum

Schlagwörter: Asien / Musik / Geschichte

Signaturintervall: $\quad$ MUS II, 3199-3285-a

2.1.1.2.2.2.2.19

Klassenbezeichnung: Australien und Neu-Guinea

Schlagwörter: $\quad$ Papua / Musik

Signaturintervall: $\quad$ MUS II, 3330

2.1.1.2.3

Klassenbezeichnung: Generum artis

Signaturintervall: $\quad$ MUS

2.1.1.2.3.1

Klassenbezeichnung: Sacrae s. ecclesiasticae

Schlagwörter: Kirchenmusik

Signaturintervall: $\quad$ MUS II, 3550-4000

2.1.1.2.3.2

Klassenbezeichnung: Profanae

Schlagwörter: $\quad$ Weltliche / Musik

Signaturintervall: $\quad$ MUS II, 4000-a-4510

2.1.2

Klassenbezeichnung: Artificum musicorum (Praecognita)

Schlagwörter: Musiker

Signaturintervall: $\quad$ MUS III, 5 
2.1.2.1

Klassenbezeichnung: Vitae collectae

Signaturintervall: $\quad$ MUS

2.1.2.1.1

Klassenbezeichnung: Generatim

Schlagwörter: $\quad$ Musiker / Biographie, Komponist / Biographie

Signaturintervall: $\quad$ MUS III, 50-150

2.1.2.1.2

Klassenbezeichnung: Speciatim

Signaturintervall: $\quad$ MUS

\subsection{1}

Klassenbezeichnung: Nationum

Schlagwörter: $\quad$ Musiker / Biographie, Komponist / Biographie

Signaturintervall: $\quad$ MUS III, 225-355-a

2.1.2.1.2.1

Klassenbezeichnung: Temporum

Signaturintervall: $\quad$ MUS

\subsection{2}

Klassenbezeichnung: Generum artis

Schlagwörter: $\quad$ Musiker / Biographie, Komponist / Biographie

Signaturintervall: $\quad$ MUS III, 365-390-a

2.1.2.2

Klassenbezeichnung: Vitae singulorum

Signaturintervall: $\quad$ MUS

2.1.2.2.1

Klassenbezeichnung: Auctorum

Schlagwörter: $\quad$ Komponist, Komponist / Biographie

Signaturintervall: $\quad$ MUS III, 390-b-6152

2.1.2.2.2

Klassenbezeichnung: Cantorum, ludionum

Schlagwörter: $\quad$ Musiker / Biographie · Virtuose / Biographie

Signaturintervall: $\quad$ MUS III, 8000-8473

2.1.3

Klassenbezeichnung: Akademien und Hochschulen der Musik

Schlagwörter: $\quad$ Musikakademie, Musikhochschule, Singakademie

Signaturintervall: $\quad$ MUS III, 9000-9030 
Klassenbezeichnung: Acroamatum

Schlagwörter:

Konzert <Veranstaltung>, Musikveranstaltung,

Signaturintervall: $\quad$ MUS III, 9200-9286-a

2.2

Klassenbezeichnung: Doctrina artis musicae

Signaturintervall: $\quad$ MUS

2.2.1

Klassenbezeichnung: Theoretica

Signaturintervall: $\quad$ MUS

2.2.1.1

Klassenbezeichnung: In universum

Signaturintervall: $\quad$ MUS

2.2.1.1.1

Klassenbezeichnung: Theoria generalis

Schlagwörter: Musiktheorie, Musiklehre

Signaturintervall: $\quad$ MUS IV, 0-a-268

2.2.1.1.2

Klassenbezeichnung: Varia critica, polemica caet

Schlagwörter: Musiktheorie, Musiklehre, Musikkritik

Signaturintervall: $\quad$ MUS IV, 268-a-1020

2.2.1.2

Klassenbezeichnung: In specie

Signaturintervall: $\quad$ MUS

2.2.1.2.1

Klassenbezeichnung: Doctrina naturalis s. physico-mathematica

Signaturintervall: $\quad$ MUS

2.2.1.2.1.1

Klassenbezeichnung: Harmonia naturalis s. canonica

Schlagwörter: $\quad$ Musikalische Akustik, Ton / Musik, Temperatur $<$ Musik $>$;

Harmonie $<$ Musik $>$

Signaturintervall: $\quad$ MUS IV, 1020-a-1557

2.2.1.2.1.2

Klassenbezeichnung: Temperamentum s. temperatura v. MUS IV, 1020-a-1557

Signaturintervall: $\quad$ MUS

Verweisungen: $\quad$ MUS IV, 1020-a-1557 
2.2.1.2.2

Klassenbezeichnung: Doctrina artificialis s. poetica

Signaturintervall: $\quad$ MUS

2.2.1.2.2.1

Klassenbezeichnung: Ars componendi in genere

Schlagwörter: $\quad$ Kompositionslehre, Komposition $<$ Musik $>$, Tonsatzlehre

Signaturintervall: $\quad$ MUS IV, 1557-a-1900

2.2.1.2.2.2

Klassenbezeichnung: In specie

Signaturintervall: $\quad$ MUS

\subsection{1}

Klassenbezeichnung: Ars harmonica s. bassus generalis

Schlagwörter: Harmonik - Generalbaß

Signaturintervall: $\quad$ MUS IV, 2000-2357

2.2.1.2.2.2.2

Klassenbezeichnung: Ars rhythmica et melopoeia

Schlagwörter: Melodie, Rhythmus / Musik

Signaturintervall: $\quad$ MUS IV, 2400-2600-a

\subsection{3}

Klassenbezeichnung: Contrapunctus et fuga

Schlagwörter: Kontrapunkt, Fuge

Signaturintervall: $\quad$ MUS IV, 2700-2862

2.2.1.2.2.2.4

Klassenbezeichnung: Ars instrumendandi et transponendi

Schlagwörter: Instrumentation, Orchestration

Signaturintervall: $\quad$ MUS IV, 2900-2920<4>-a

2.2.2

Klassenbezeichnung: Practica

Signaturintervall: $\quad$ MUS

2.2.2.1

Klassenbezeichnung: Doctrina practica generalis

Schlagwörter: Musikerziehung

Signaturintervall: $\quad$ MUS IV, 3000-3544

2.2.2.2

Klassenbezeichnung: Doctrina practica specialis

Signaturintervall: $\quad$ MUS 
2.2.2.2.1

Klassenbezeichnung: De repraesentandi ratione

Schlagwörter: Musikalische Aufführungspraxis

Signaturintervall: $\quad$ MUS IV, 3700-3920

2.2.2.2.2

Klassenbezeichnung: De exercitiis instituendis s. practica methodica

Signaturintervall: $\quad$ MUS

2.2.2.2.2.1

Klassenbezeichnung: Vocis humanae s. de arte canendi

Schlagwörter: $\quad$ Gesang, Gesangstechnik, Gesangunterricht, Stimmbildung

Signaturintervall: $\quad$ MUS IV, 4000-4363

2.2.2.2.2.2

Klassenbezeichnung: Instrumentorum s. de arte organizandi

Signaturintervall: $\quad$ MUS

Klassenbezeichnung: Clavicymbali et organi ecclesiastici

Schlagwörter: Klavierunterricht, Klaviertechnik, Orgelunterricht

Signaturintervall: $\quad$ MUS IV, 4600-4930

2.2.2.2.2.2.2

Klassenbezeichnung: Aliorum instrumentorum

Schlagwörter: Instrumentalunterricht

Signaturintervall: $\quad$ MUS IV, 4950-5300-a

Klassenbezeichnung: Organologia s. de instrumentis fabricandis et restituendis

Schlagwörter: Musikinstrumentenkunde

Signaturintervall: $\quad$ MUS IV, 5490-5975

3

Klassenbezeichnung: Opera artificium

Signaturintervall: MUS

3.1

Klassenbezeichnung: Diversorum collecta

Signaturintervall: MUS

3.1.1

Klassenbezeichnung: Generatim

Schlagwörter: Musik / Quelle

Signaturintervall: $\quad$ MUS V, 5-791 
3.1.1.1

Klassenbezeichnung: In usum scholarum

Schlagwörter: $\quad$ Schullied / Quelle

Signaturintervall: $\quad$ MUS V, 1000-1275

3.1.2

Klassenbezeichnung: Speciatim

Signaturintervall: $\quad$ MUS

3.1.2.1

Klassenbezeichnung: Ecclesiastica s. sacra

Schlagwörter: $\quad$ Kirchengesang / Quelle, Kirchenlied / Quelle

Signaturintervall: $\quad$ MUS V, 2000-2780

\subsubsection{2}

Klassenbezeichnung: Profana

Schlagwörter: $\quad$ Lied / Quelle, Weltliches Lied / Quelle

Signaturintervall: $\quad$ MUS V, 3000-3969/9

Klassenbezeichnung: Carmina popularia

Schlagwörter: $\quad$ Volkslied / Quelle

Signaturintervall: $\quad$ MUS V, 4000-5618

3.2

Klassenbezeichnung: Opera singulorum

Signaturintervall: $\quad$ MUS

3.2.1

Klassenbezeichnung: Saec. X usq. XIII

Schlagwörter: Musik / Geschichte 900-1300 / Quelle

Signaturintervall: $\quad$ MUS VI, 0-a-101

3.2.2

Klassenbezeichnung: Saec. XV

Schlagwörter: $\quad$ Musik / Geschichte 1400-1500 / Quelle

Signaturintervall: $\quad$ MUS VI, 301

3.2 .2

Klassenbezeichnung: frei

Signaturintervall: $\quad$ MUS

3.2.3

Klassenbezeichnung: Saec. XVI

Schlagwörter: $\quad$ Musik / Geschichte 1500-1600 / Quelle

Signaturintervall: $\quad$ MUS VI, 301-a-680-r 
3.2.3

Klassenbezeichnung: frei

Signaturintervall: $\quad$ MUS

3.2.4

Klassenbezeichnung: Saec. XVII

Schlagwörter: $\quad$ Musik / Geschichte 1600-1700 / Quelle

Signaturintervall: $\quad$ MUS VI, 680-s-1070

3.2 .5

Klassenbezeichnung: Saec. XVIII

Schlagwörter: $\quad$ Musik / Geschichte 1700-1800 / Quelle

Signaturintervall: $\quad$ MUS VII, 2-850

3.2.6

Klassenbezeichnung: Saec. XIX

Schlagwörter: $\quad$ Musik / Geschichte 1800-1900 / Quelle

Signaturintervall: $\quad$ MUS VII, 860-2960

3.2.7

Klassenbezeichnung: Saec. XX

Schlagwörter: $\quad$ Musik / Geschichte 1900-1945 / Quelle

Signaturintervall: $\quad$ MUS VIII, 1-2560 
Aus dem Ars Musica

Catalogus alphabeticus

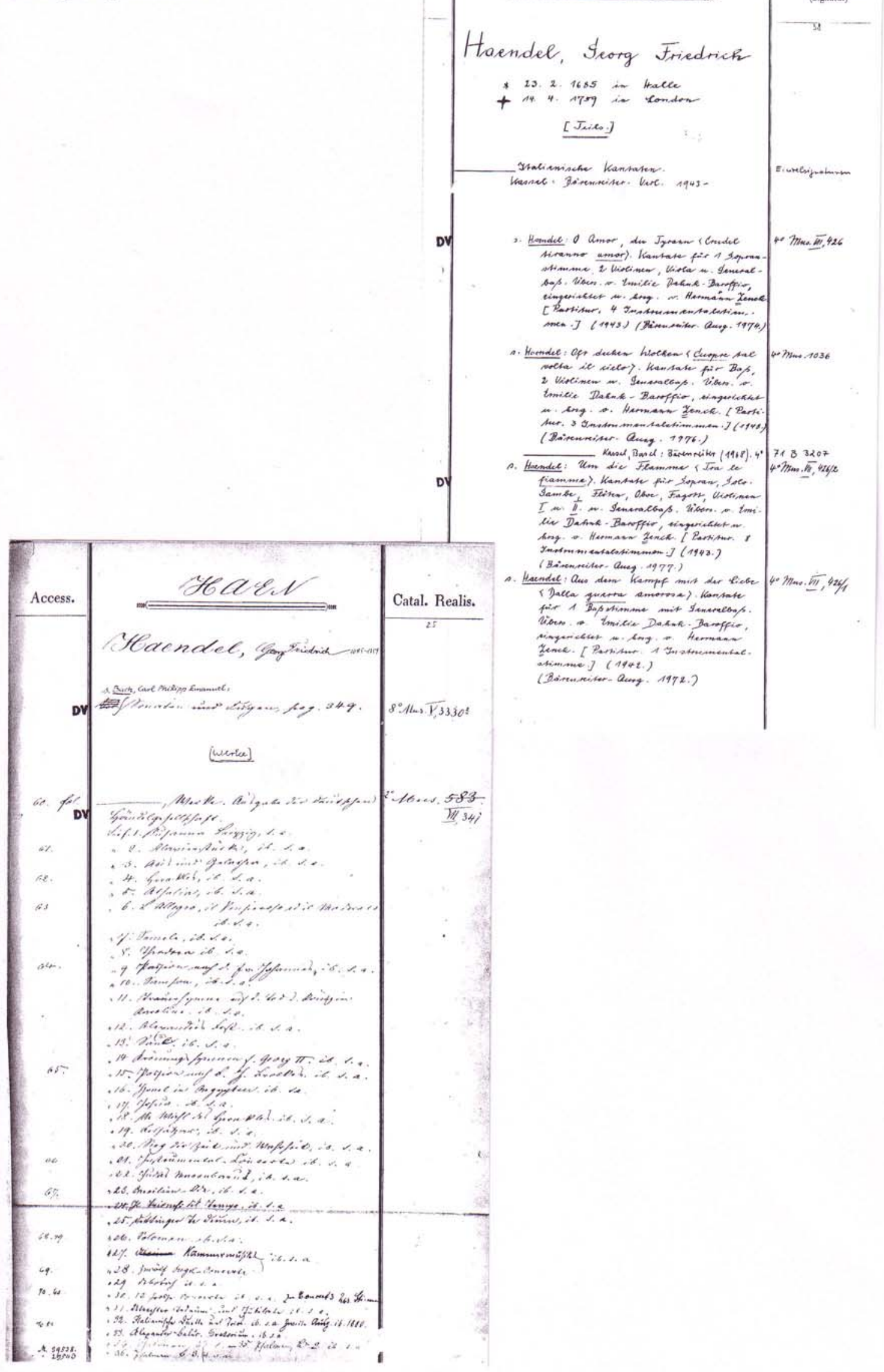


Aus Ars Musica Katalog:

Eintragungen mit Sonderstandort: aus Catalogus alphabeticus (oben) aus Catalogus realis (unten)

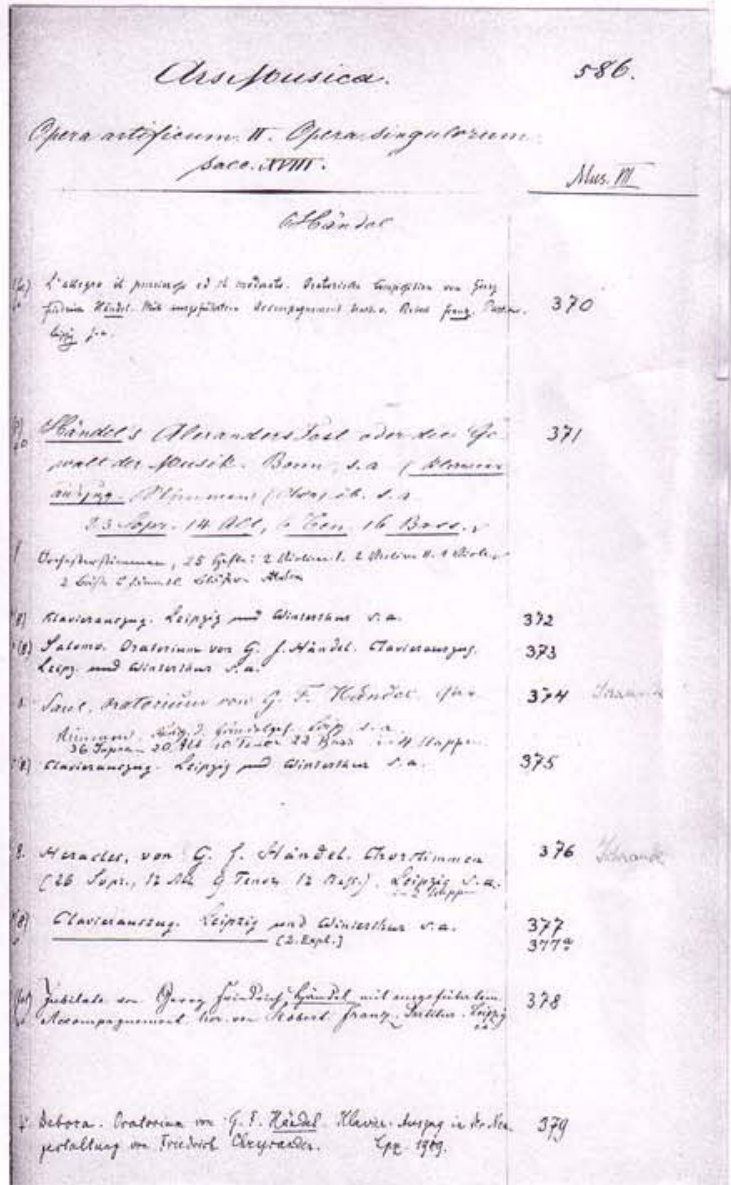

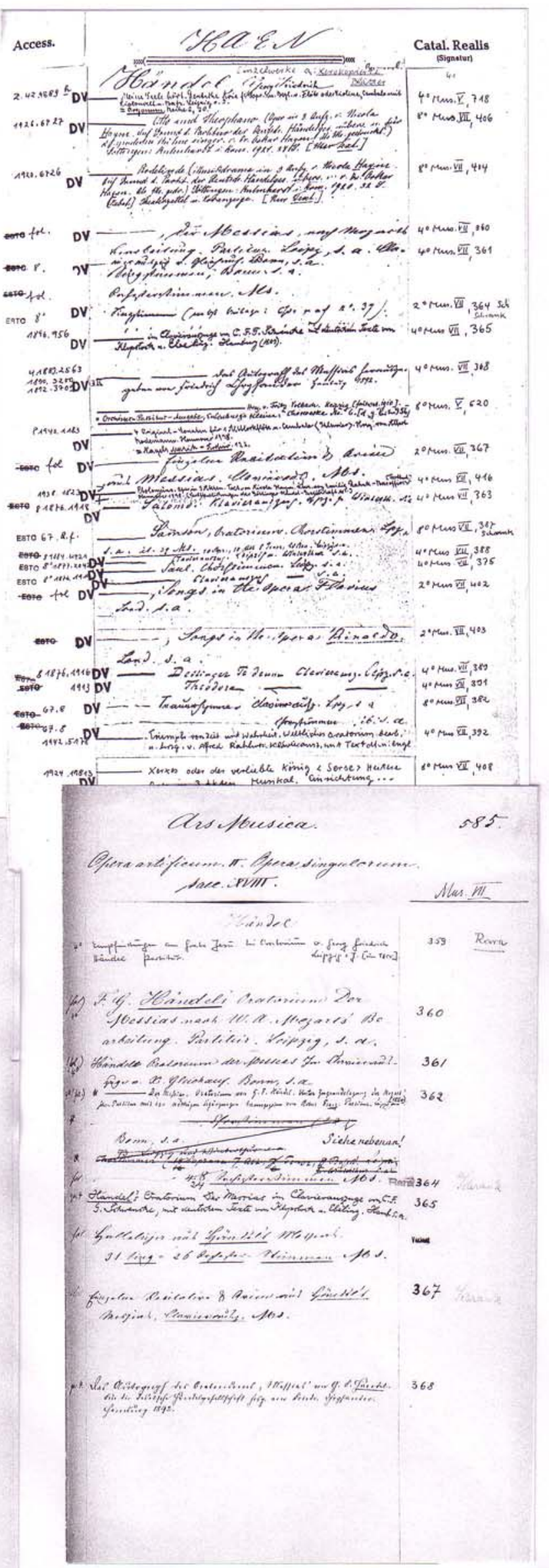




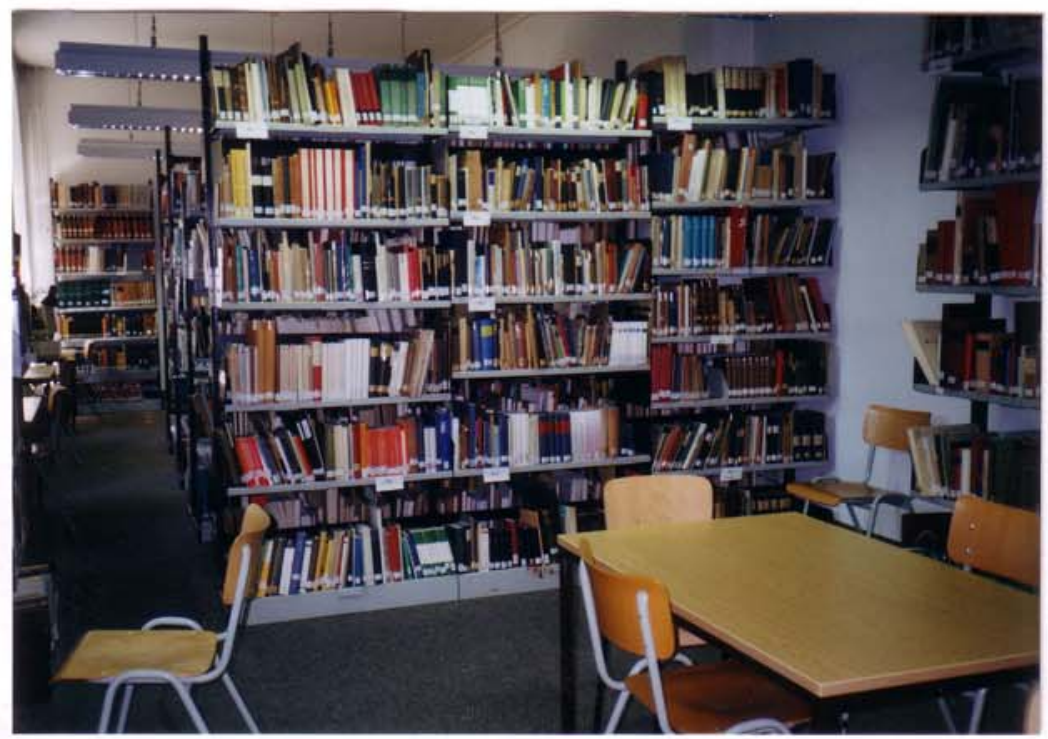

1. Saal:

Musikschrifttum
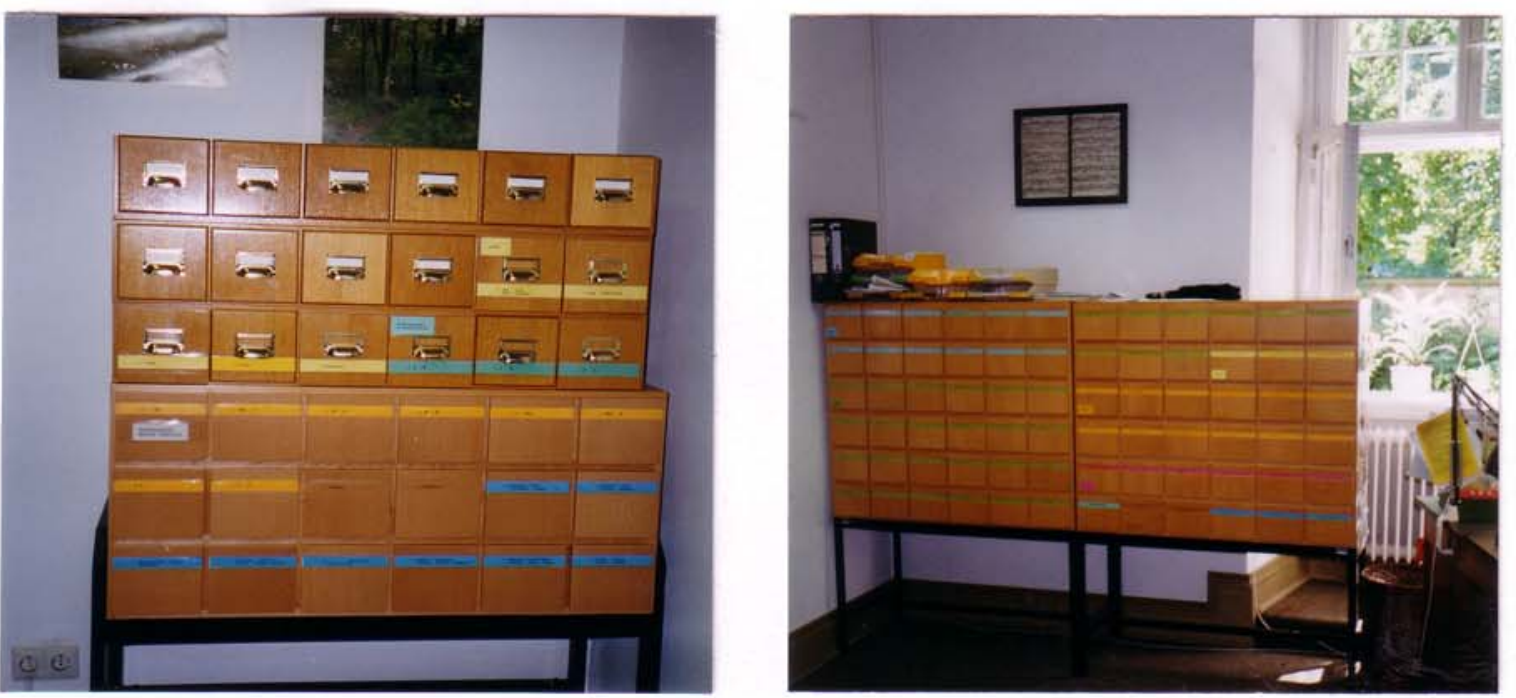

ZK der Bibliothek des Musikwiss. Seminars der Univ. Göttingen

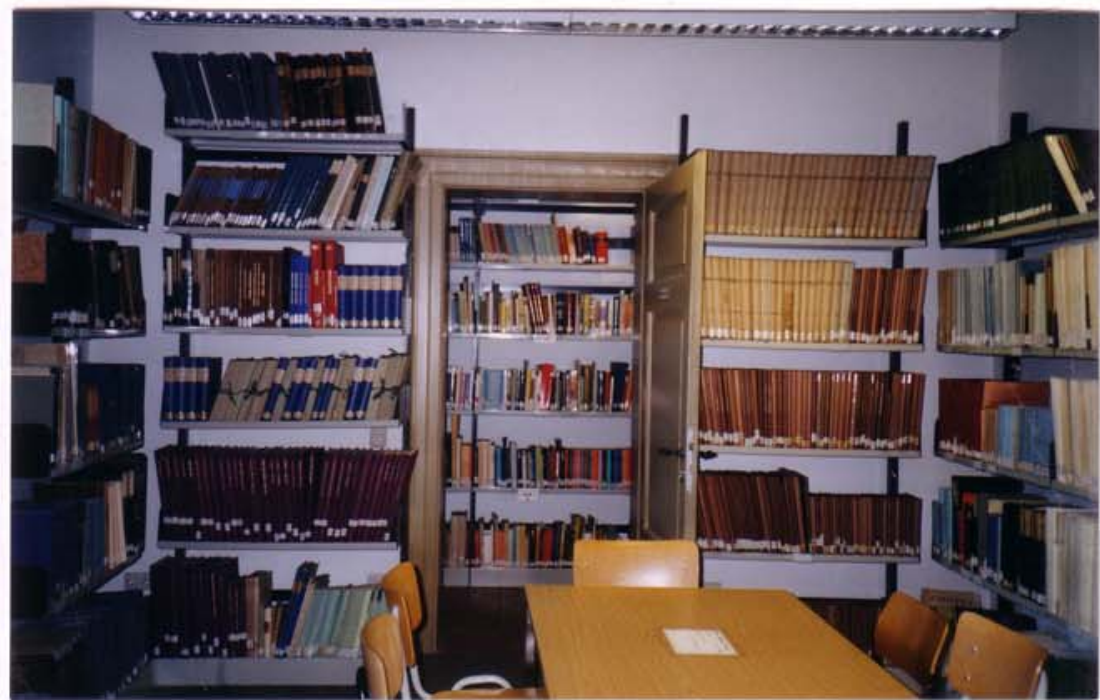

Musikaliensäle

I u. II 


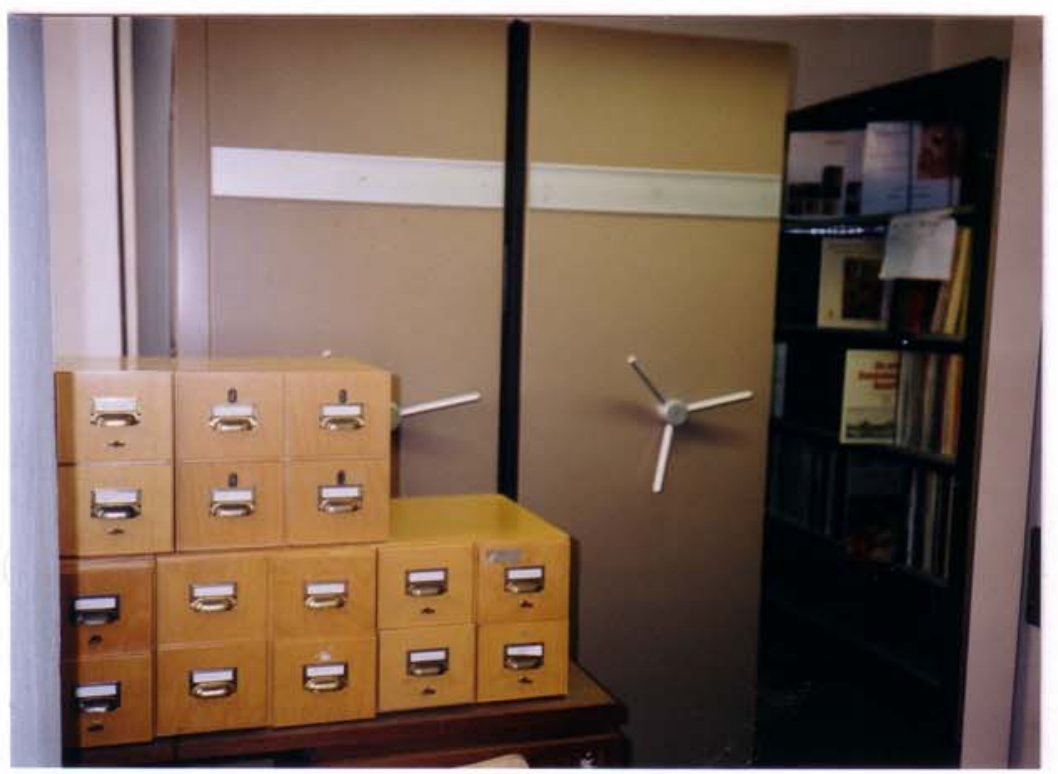

Katalog des Schallarchivs des Musikwiss. Seminars

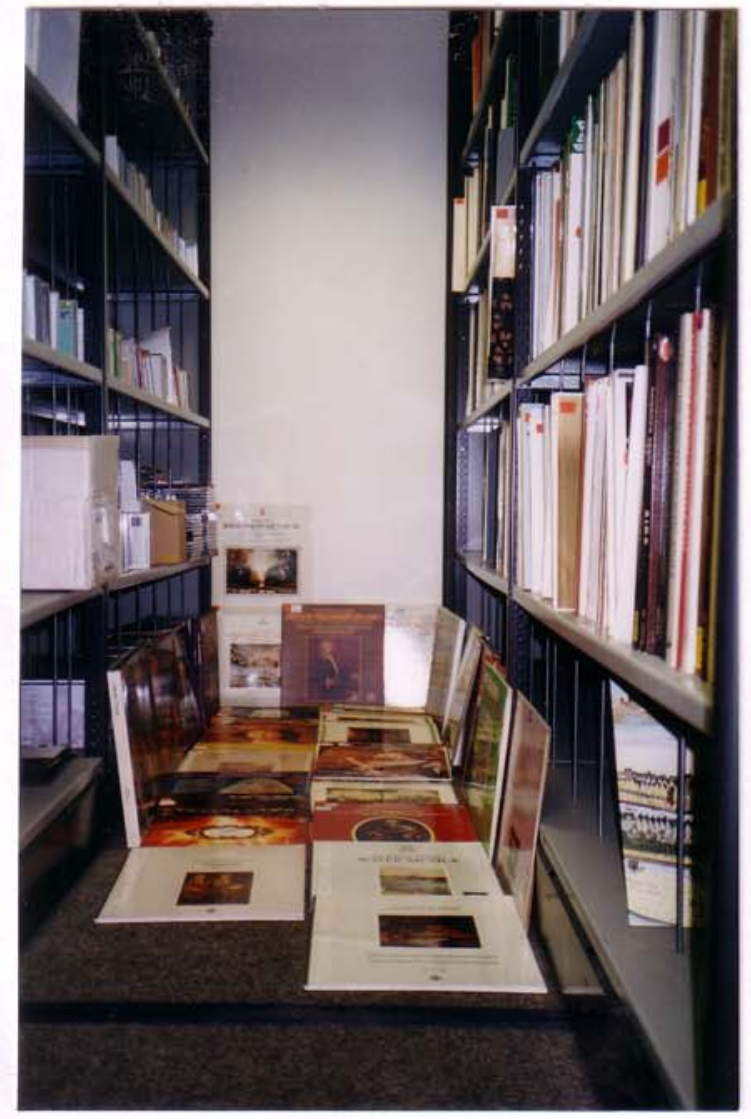

aus der Plattensammlung von F. Schmidt: Händel-Titel zwischen den Regalen

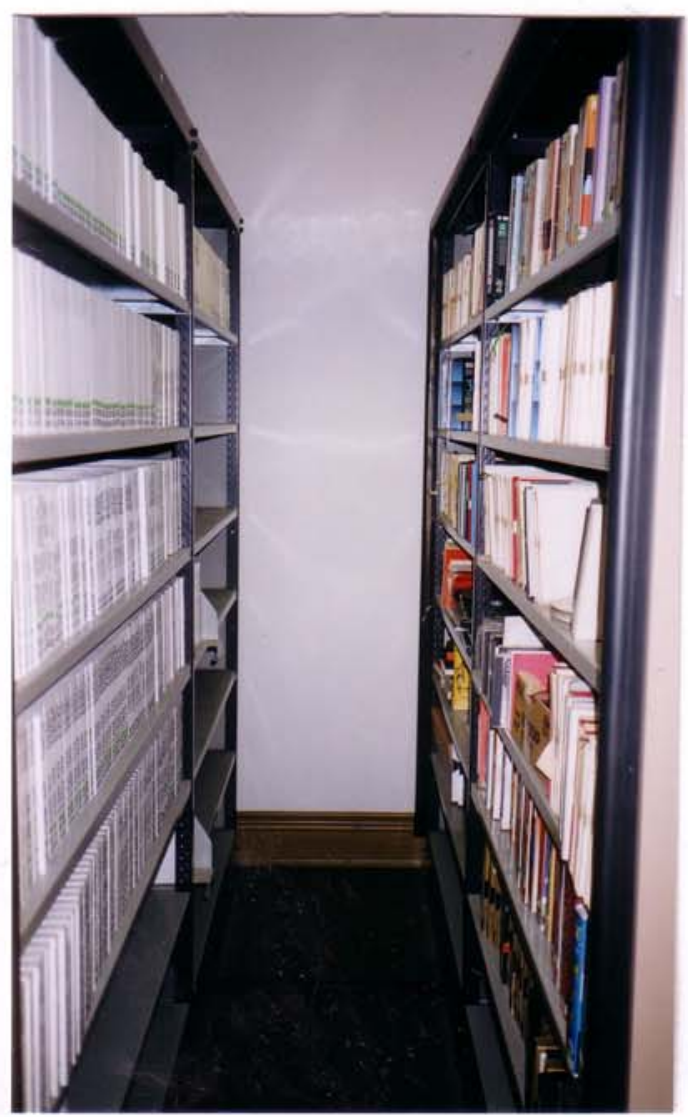

Mikrofilmarchiv des Musikwiss. Seminars 


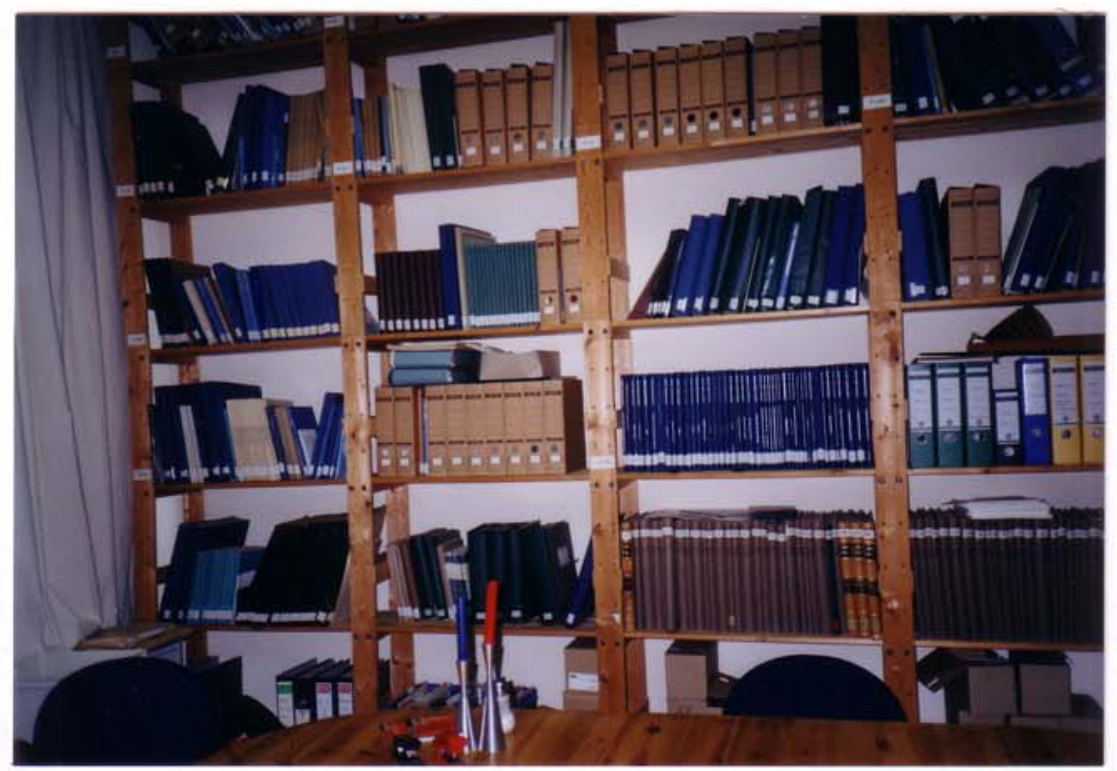

Musikalienbestand der Göttinger Händel-Gesellschaft (von oben)

(Mitte) Bild an der Wand: Oskar Hagen Pappstatue: Nicholas McGegan
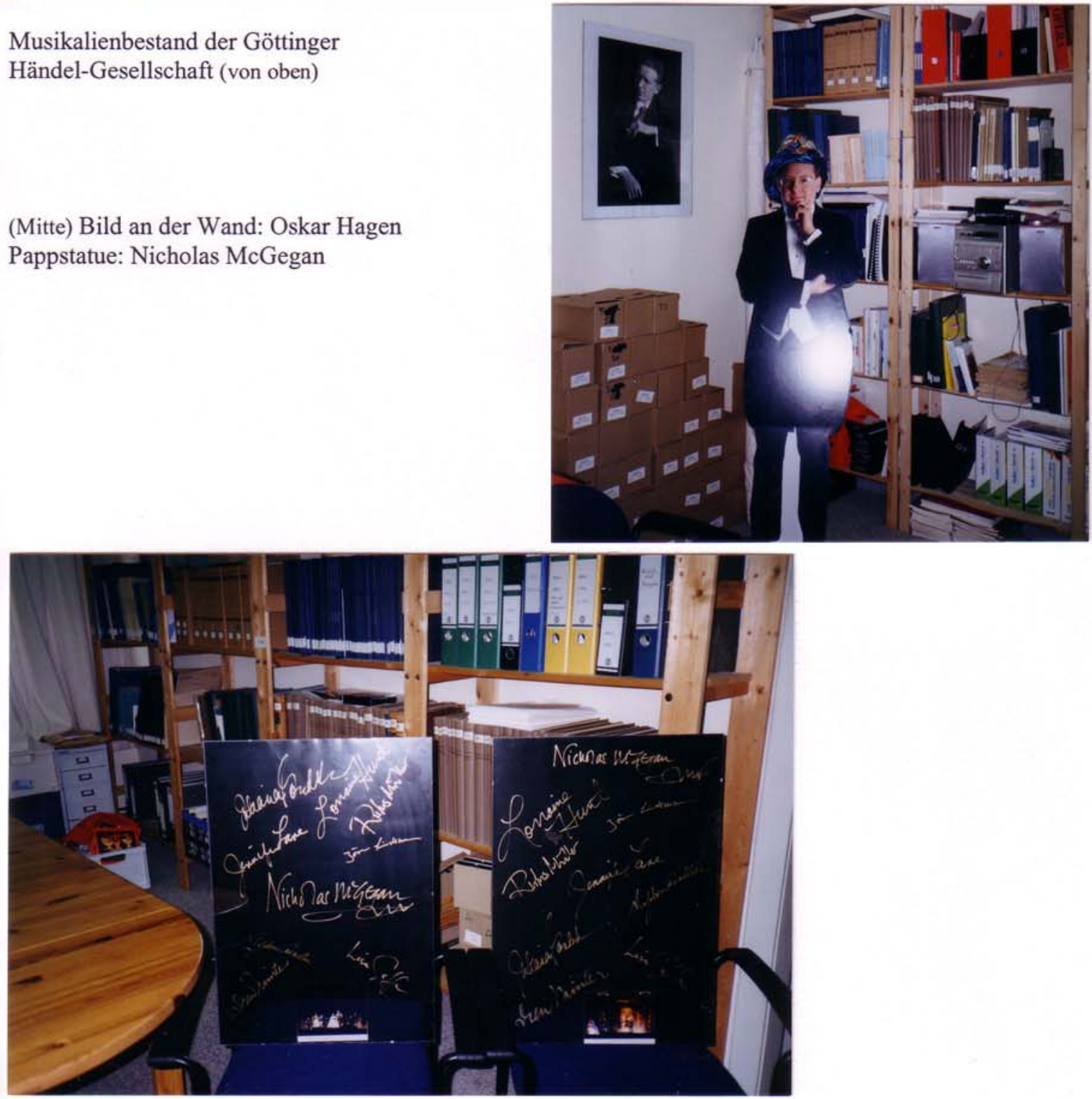

(im Vordergrund) die Rahmen mit Autogramme der musikalischen Mitwirkenden an den Festspielen (unten) 


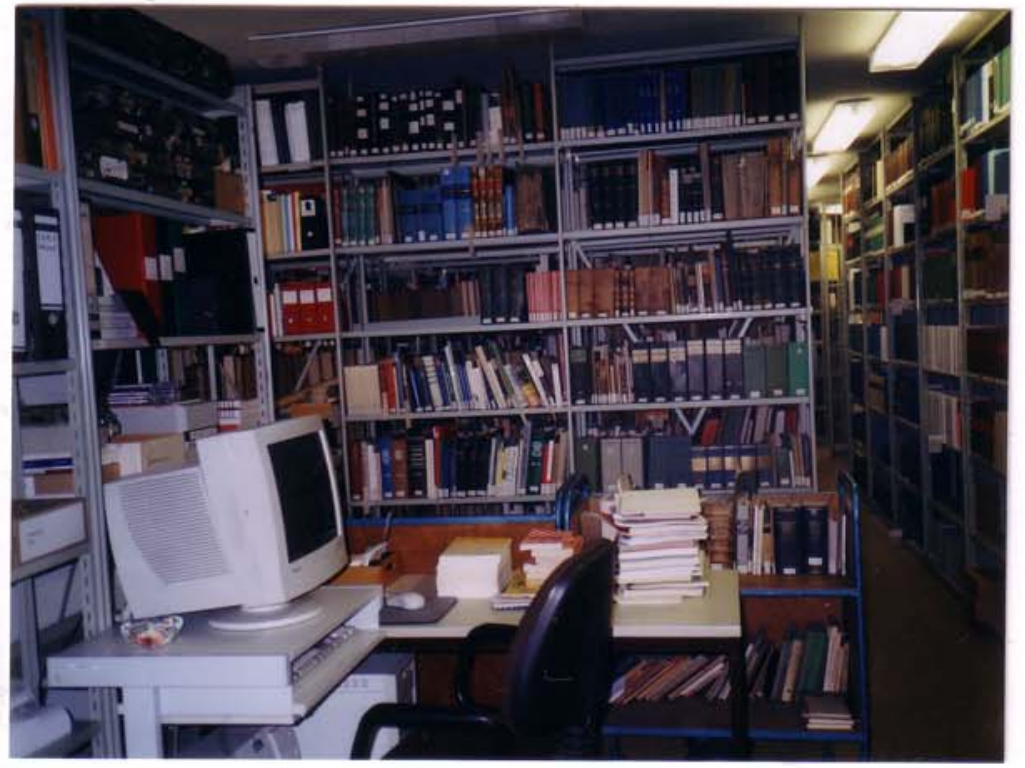

Bibliothek des

Göttinger Stadtarchivs

Personenkatalog des Stadtarchivs
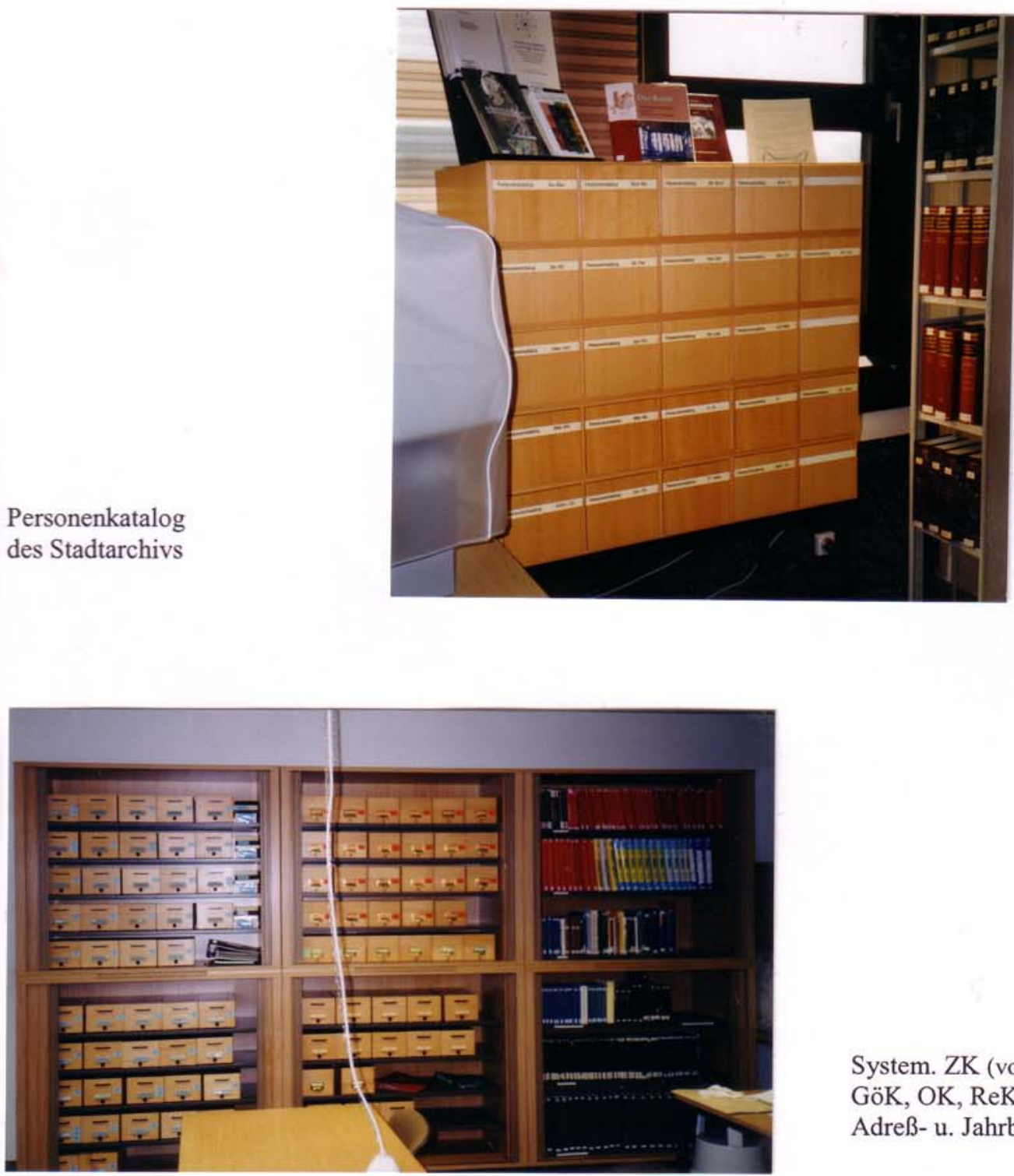

System. ZK (von li.):

GöK, OK, ReK

Adreß- u. Jahrbücher (re.) 


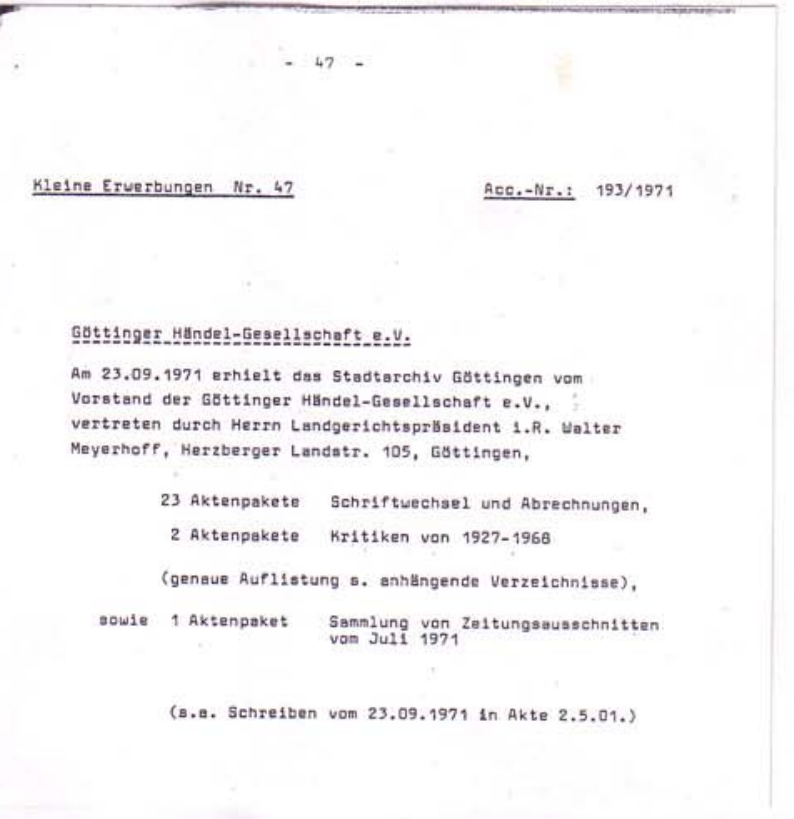

Eintragung der ersten Schenkung von Händel-Material an das Stadtarchiv (S. aus: »Stadtarchiv Göttingen: Deposita $100-\ll$ )

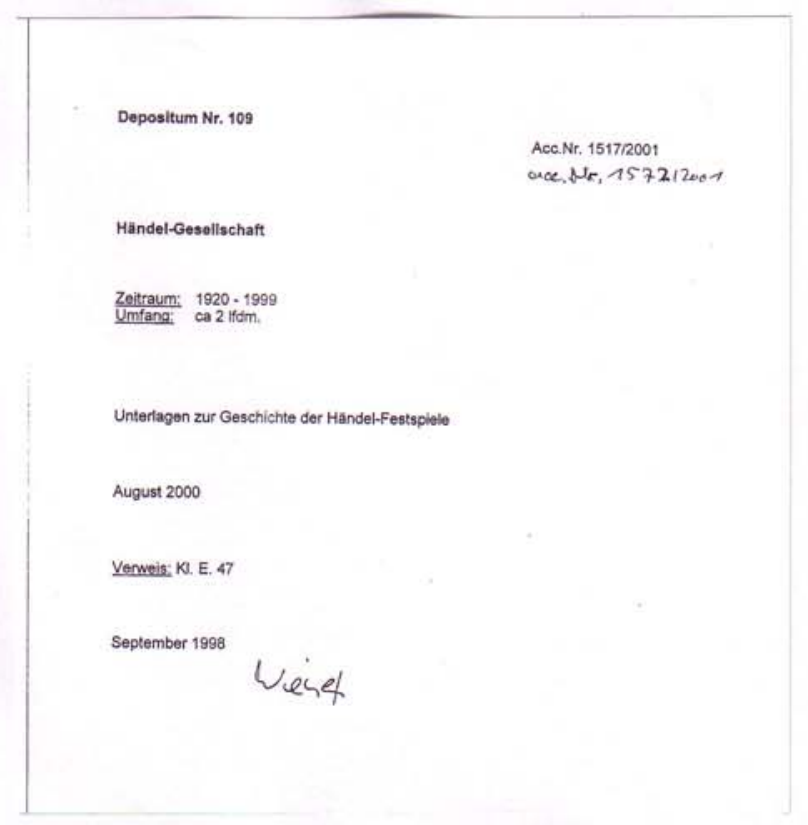

Eintragung des Zuganges vom Händel-Bestand von der Göttinger Händel-Gesellschaft ins Stadtarchiv (S. aus: »Stadtarchiv Göttingen: kleine Erwerbungen / Nachlässe 1 - 79«) 


\section{GSe}

Götinger symphonie orchester

Handel

Werke vorhanden gespielt

op. $6 \mathrm{Nr}-12$

op. 3 Nr. 49

C-Dur tlesounterfest 30.5.01

Fewerverksminth $\quad 5.6 .95 \quad 10.6 .00$

Vranermusith $\quad 5.6 .95 \quad 10.6 .00$

Duppelchivipes drchesterkompert N. 27

Mallehina

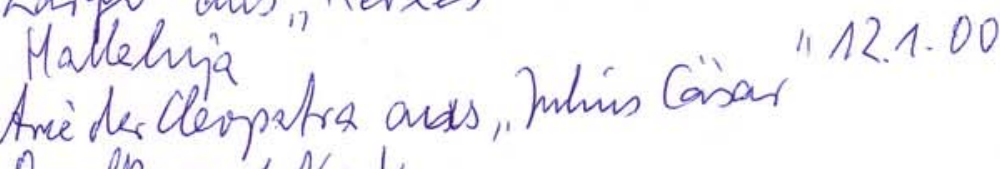

Oreelkowert Nr. 4

Vidarkowert (Bearbity. Ca sadeus)

Konsed a due coni B-Dur 1312.01

7.2 .02

15.5 .02

Antwortschreiben des GSO auf die Frage, wie viel und welches Werk von Händel

im Notenarchiv vorhanden ist und vom Orchester gespielt wurde 


\title{
Die Werke Georg Friedrich Händels in Göttingen
}

\author{
Eine Darstellung der Sammlung G. F. Händels \\ in der Niedersächsischen Staats- und Universitätsbibliothek Göttingen \\ unter Berücksichtigung des identischen Bestandes \\ in weiteren ausgewählten Göttinger Institutionen
}

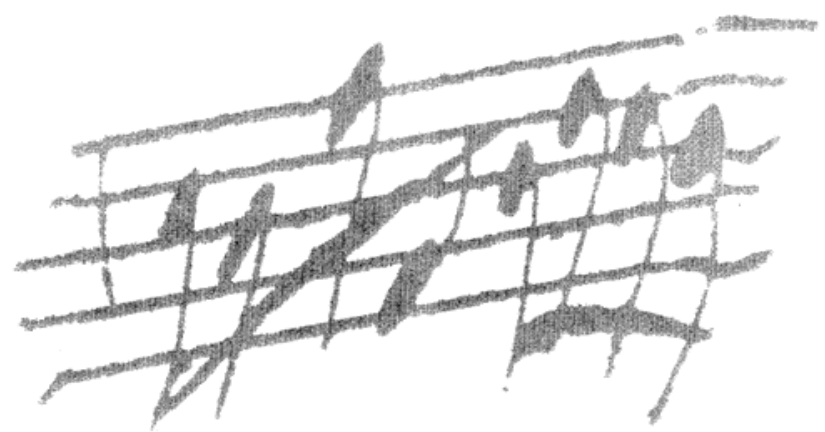

Kat a log

von

Poupak Amirazodi

Göttingen, November 2005 

0. Einführung I

1. Händels Leben

1.1. Biographien 1

1.2. Händel und Musik 13

1.3. Händel und andere Persönlichkeiten 18

2. Quellen

$2.1 \quad$ Bibliographien, Kataloge 25

2.2 Werkverzeichnisse, Werkführer 28

2.3 Beiträge, Chroniken, Jahrbücher 34

2.4 Sammlungen 36

2.5 Dokumente 38

3. Händel-Pflege

3.1 Feierlichkeiten

3.1.1 Händel-Festspiel Göttingen 42

3.1.2 Händel-Festspiel Halle/Saale 48

3.1.3 Händel-Feste international 52

3.2 Ausstellungen 55

3.3 Vorträge, Symposien 57

$\begin{array}{lll}3.4 & \text { Festschriften } & 67\end{array}$

4. Gesamtausgaben

4.1 Händel-Werkausgabe von Chrysander 71

4.2 Hallische Händel-Ausgabe

4.2.1 Musikdrucke 105

4.2.2 Kritische Berichte 127

5. Händels Werke

5.1 Opern

5.2 Oratorische Werke

5.2.1 Oratorien

5.2.2 Serenaden, Oden 
5.3 Vokale und instrumentale Kammermusik

$\begin{array}{lll}\text { 5.3.1 Kantaten } & 144\end{array}$

5.3.2 Kammerduette und -trios 148

5.3.3 Arien und Lieder 150

5.3.4 Sonaten und Triosonaten, Fugen 154

$5.4 \quad$ Kirchenmusik

5.4.1 Anthems, Te Deum, Jubilate 165

5.4.2 Liturgische Kompositionen 167

5.5 Orchesterwerke

$\begin{array}{lll}\text { 5.5.1 Konzerte } & 168\end{array}$

5.5.2 Concerti grossi 173

5.5.3 Ouvertüren, Sinfonien, Suiten, Märsche 179

$\begin{array}{ll}\text { 6. Klavierauszüge } & 184\end{array}$

$\begin{array}{ll}\text { 7. Chorstimmen } & 195\end{array}$

8. Quellen zu Händels Werken 200

9. Händel „zwischen den Zeilen“ 203

10. Textbücher 208

11. Abhandlungen über Händels Werke 214

12. Musik-CD zu Händel 221

$\begin{array}{ll}\text { 13. Anonyma } & 227\end{array}$

14. Gesamttitelaufnahmen

14.1 Mehrbändige Werke 229

14.2 Serien 239

15. Händel auf Mikroformen 249

16. Register

16.1 Abkürzungsverzeichnis 262

$\begin{array}{lll}\text { 17. Signatur-Verzeichnis } & 269\end{array}$ 


\section{Einführung}

Mit dem Katalog »Die Werke Georg Friedrich Händels in Göttingen« soll versucht werden, die Beziehungen Händels zum Musik- und Geistesleben der Universitätsstadt und den Einfluß seiner Werke auf das Musikleben Göttingens in späterer Zeit anhand von Zeugnissen sichtbar zu machen. Denn wer weiß schon, daß die Opern aus Händels Londoner Zeit zu den meistgespielten Werken während der gleichnamigen Festspiele seit 1920 gehören? Und daß es der Kunsthistoriker Oskar Hagen (1888-1957) war, der mit seinem Schaffen - Göttinger Händel-Festspiele - die Händel-Forschung begründete und damit der historischen Aufführungspraxis neue Aspekte gab?

Der vorliegende Katalog, der insgesamt 727 Titelaufnahmen (654 Stücktitel, 73 Gesamttitel ${ }^{1}$ ) enthält, bietet eine bibliographische Zusammenfassung dessen, was über Händel und seine Werke in der SUB Göttingen und parallel dazu, in einigen weiteren Göttinger bibliothekarischen und musikwissenschaftlichen Einrichtungen aufbewahrt liegt - die Bibliothek des Musikwissenschaftlichen Seminars der Georg-AugustUniversität, die Händel-Gesellschaft und das Stadtarchiv Göttingen. Erstmals werden hier Nachweise verschiedenster Provenienz (Musikalien, Monographien, Hochschulschriften, Neue Medien) in kumulierter Form veröffentlicht, die bisher nur durch zeitaufwendiges Recherchieren in diversen Katalogen (Bandkatalog, Zettelkatalog, OPAC) ermittelt werden konnten. An dieser Stelle wird daran erinnert, daß dieses Verzeichnis Aufsätze betreffs Händel ausschließt.

Die Titelaufnahme wurde nach den »Regeln für die alphabetische Katalogisierung in wissenschaftlichen Bibliotheken« (RAK-WB), den »Regeln für die alphabetische Katalogisierung von Musikdrucken, Musiktonträgern und Musik-Bildtonträgern« (RAKMusik), dem Entwurf zu »Musikdrucke, Musiktonträger und Musik-Bildtonträger« (Stand: März 2001) und nach der »Katalogisierungsrichtlinie für den Gemeinsamen Bibliotheksverbund « vorgenommen.

Der Auftakt des Händel-Kataloges führt in die biographischen Drucke über Händel ein. Unter dem verzeichneten Musikalienbestand dominieren die Partituren und Musikdrucke. Die Klavierauszüge und die Chorstimmen, die gesondert aufgeführt sind, stellen zusammen ungefähr ein Zehntel dieses Bestandes dar. Ebenso sind die Textbücher für sich separat aufgenommen. Unter Musikschrifttum nehmen die Festschriften

\footnotetext{
${ }^{1}$ Darunter sind sowohl die Gesamttitel bei mehrbändigen Werken als auch die der Serien gezählt. Gesamttitel ist Titel des Gesamtwerkes, unter der Teile (gezählt oder ungezählt) erschienen sind.
} 
und Bildsammlungen einen verschwindend geringen Anteil ein. Dagegen machen die biographischen Werke sowie die Literatur über Händels Musik einen großen Teil aus. Bei der Gliederung dieses Kataloges wurden für Musikalien das HändelWerkverzeichnis und für Musikliteratur Sasses Händel-Bibliographie hinzugezogen. Innerhalb der Gliederungspunkte ist die Literatur alphabetisch nach Verfasser und Titel, voran die Anonyma, sortiert. Verschiedene Ausgaben ein und desselben Werkes sind chronologisch geordnet - die ältere Ausgabe ist zuerst genannt. Bei der Ordnung der Titel sind Artikel, Adjektive sowie Ziffern (in Zahl oder ausgeschrieben) am Anfang übergangen worden. Folgen mehrere Werke eines Autors bzw. eines Komponisten untereinander, wurde deren Name nicht jedesmal wiederholt.

Nachfolgende Tabelle soll stichwortartig anklingen lassen, was sich hinter den Kapiteln 1 bis 10 verbirgt:

\begin{tabular}{|c|c|c|}
\hline \multicolumn{2}{|c|}{ Kapitelnummer und -überschrift } & \multirow{2}{*}{$\begin{array}{l}\text { Erklärung } \\
\text { Ausschnitte aus Händels Leben }\end{array}$} \\
\hline 1.1 & Biographien & \\
\hline 1.2 & Händel und Musik & Händel und seine Musik \\
\hline 1.3 & Händel und andere Persönlichkeiten & Abhandlungen über Händel und andere Personen \\
\hline 2.1 & Bibliographien, Kataloge & $\begin{array}{l}\text { bibliographische Verzeichnisse zu Publikationen } \\
\text { über und von Händel }\end{array}$ \\
\hline 2.2 & Werkverzeichnisse, Werkführer & $\begin{array}{l}\text { Verzeichnisse zu Händels Werken, erläuternde } \\
\text { lexikalische Zusammenstellungen }\end{array}$ \\
\hline 2.3 & Beiträge, Jahrbücher & Händel-Beiträge, -Jahrbuch, Chronikartiges \\
\hline 2.4 & Sammlungen & Bild- und Handschriftensammlungen \\
\hline 2.5 & Dokumente & Belege aus Nachlaßakten, Kundgaben \\
\hline 3.1 & Händel-Festspiele & $\begin{array}{l}\text { Gedrucktes über die Festspiele in Göttingen, } \\
\text { Halle an der Saale und andernorts }\end{array}$ \\
\hline 3.2 & Ausstellungen & Ausstellungskataloge bezüglich Händel \\
\hline 3.3 & Vorträge, Symposien & Tagungsschriften \\
\hline 3.4 & Festschriften & $\begin{array}{l}\text { Schriftwerke mit verschiedenen Beiträgen zu } \\
\text { Ehren Händels bzw. anläßlich Jubiläen }\end{array}$ \\
\hline 4.1 & Händel-Werkausgabe von Chrysander & $\begin{array}{l}\text { Gesamtausgabe von Händels Werken, } \\
\text { herausgegeben von Friedrich Chrysander }\end{array}$ \\
\hline 4.2 & Hallische Händel-Ausgabe & $\begin{array}{l}\text { Werkausgabe Händels, herausgegeben } \\
\text { von Max Schneider }\end{array}$ \\
\hline 5.1 & Opern & Händels Bühnenstücke \\
\hline 5.2 & Oratorische Werke & $\begin{array}{l}\text { geistliche Musikwerke für Chor, Soli, } \\
\text { Orchester }\end{array}$ \\
\hline 5.3. & Vokale und instrumentale Kammermusik & $\begin{array}{l}\text { mehrteilige Musikstücke für Gesang mit } \\
\text { Instrumentalbegleitung }\end{array}$ \\
\hline
\end{tabular}




\begin{tabular}{|l|l|l|}
\hline \multicolumn{2}{|l|}{ Kapitelnummer und -überschrift } & Erklärung \\
\hline \hline 5.4 & Kirchenmusik & geistliche Gesang- und Chorstücke \\
\hline 5.5 & Orchesterwerke & Konzertstücke für kleines und großes Orchester \\
\hline 6 & Klavierauszüge & Partitur eines Orchesterwerkes umgesetzt für Klavier \\
\hline 7 & Chorstimmen & Stimmausgaben für Gesang \\
\hline 8 & Quellen zu Händels Werken & $\begin{array}{l}\text { Kompositionen anderer Meister, die als } \\
\text { Quelle zu Händels Werken dienen }\end{array}$ \\
\hline 9 & Händel zwischen den Zeilen & $\begin{array}{l}\text { Händels Stücke in Sammelausgaben } \\
\text { (nur aus MUS V - MUS VIII) }\end{array}$ \\
\hline 10 & Textbücher & Libretti zu Händels Kompositionen \\
\hline 11 & Abhandlungen über Händels Werke & kritische Literatur über Händels Musik und Werk \\
\hline 12 & Musik-CD zu Händel & Tonträger zu Händel \\
\hline 13 & Anonyma & $\begin{array}{l}\text { von anderen Musikern vertonte Texte, } \\
\text { die sich in Händels Programmen befinden }\end{array}$ \\
\hline
\end{tabular}

Die Titel unter 3.1-3.3 sind nicht alphabetisch, sondern chronologisch nach Zeitpunkt, zu dem die Festspiele, das Symposium oder die Rede stattgefunden hat, geordnet. Die Aufnahmen unter 3.4 dagegen sind alphabetisch nach Titel und Verfasser geordnet. Die Musikalien haben je nach Gattung unterschiedliche Behandlung erfahren. Opern, Oratorien und alle Werke mit einer namentlichen Bezeichnung sind alphabetisch nach Titel - nicht nach Bearbeiter, Herausgeber und anderen sonstigen beteiligten Personen - sortiert. Bei Werken mit Sachtiteln aus musikalischen Gattungsbegriffen (z. B. Fuge, Konzert, Sinfonie) erfolgt die Ordnung nach den sechs Erweiterungspunkten zum Formalsachtitel aus RAK-Musik (§ M 507, Abs. 2); jeweils der nächste Punkt bildet das zweite, dritte, ... Sortierkriterium:

1. Besetzung (z. B. Flöte, Oboe)

2. Zählung des Werkverzeichnisses (HWV 289)

3. Opus (op. 3)

4. Zählung einer Werkgruppe (Nr. 4)

5. Tonart (D-Dur)

6. Entstehungszeit ${ }^{2}$

Der Abschnitt Musikalien beginnt mit den beiden Händel-Gesamtausgaben: »Georg Friedrich Händel’s Werke« (Leipzig, 1858-1903) herausgegeben von Friedrich Chrysander, und »Hallische Händel-Ausgabe: kritische Gesamtausgabe« (Kassel, 1955-)

\footnotetext{
${ }^{2}$ z. B. folgt dem Titel »Sonate für drei Violinen« die »Zwei Sonaten für Altblockflöte, HWV 377«
} 
herausgebracht von der Georg-Friedrich-Händel-Gesellschaft. Die Ordnung der Aufnahmen der Werkausgaben erfolgt jeweils nach Bandangabe, nicht nach Titel.

Unter Kapitel 9 finden sich die Titel von Händels Werken, die in den Bänden unter MUS V - MUS VIII enthalten sind. Sie sind ähnlich wie Zeitschriftenaufsätze aufgenommen worden: Stücktitel, Titel des Bandes, Erscheinungsort, Verlag, allenfalls Bandangabe, Erscheinungsjahr, eventuell Heftnummer und Seiten, auf denen sich das Stück befindet. Die Textbücher (Kapitel 10) findet man unter alphabetischer Titelordnung. Unter Anonyma (Kapitel 13) sind Librettotitel wie Tamerlano oder Ezio verzeichnet, die in Händels Programm gehören, aber vermutlich als Grundlage anderer Vertonungen dienten. Kapitel 12 beginnt mit den Werk-CD (Opern/Oratorien) alphabetisch nach Titel geordnet, und wird fortgesetzt von CD der Festspiel-Edition, chronologisch mit dem ältesten Jahrgang beginnend.

Im Anschluss an die Stücktitelaufnahmen sind unter 14.1 und 14.2 die Gesamttitelaufnahmen der mehrbändigen Werke (MBW) und der Schriftenreihen (SER) aufgeführt - Namen und Titel vereint unter einem Alphabet. Danach folgt die chronologische Auflistung der über 200 Mikrofilme unter dem Opustitel (aus HWV) - unter Angabe der PPN, der Signatur und des Erscheinungsjahrs des verfilmten Werkes.

Es wird darauf hingewiesen, daß gemäß der PICA-Katalogisierungsrichtlinie (Alte Drucke) bei Werken mit Erscheinungsjahr bis einschließlich 1850 die Titel- und Verfasserangabe sowie der Erscheinungsvermerk in Groß- und Kleinschreibung und im Wortlaut der Angaben des Titelblattes entsprechen.

Erläuternde Zusätze zu den Titelaufnahmen sind in der Rubrik „Notizen“ in folgender Reihenfolge, getrennt durch Bindestrich, wiedergegeben: Akzessionsnummer, Text des Stempels, Text der Etikette, Umfang der physikalischen Einheit (Mappen oder Kapseln bei Chorstimmen), und Verweisung auf die Gesamttitelaufnahme bei Stücktitel eines mehrbändigen Werkes (MBW) oder einer Serie. Durch die Akzessionsnummer und die Etikette kann nachvollzogen werden, in welchen Jahren und teilweise von wem Bücher und Musikalien in die SUB gelangt sind. Der Text der Stempel ist typographisch so wiedergegeben wie sie auf der Vorlage steht. Die gelegentlich auftauchende Ziffernfolge in der Rubrik „Anmerkung“ (z. B. 2.2.2.2, 2.3.2.0.0.1; 2.2.1.1.1; 1 $=$ Flöten.Oboen.Klarinetten.Fagotten, Hörner.Trompeten.Posaunen.Tuba.Pauken; Violine1.Violine2.Viola/Bratschen.Violoncelli.Kontrabässe) gibt den in der Bibliothek vorhandenen Umfang der Stimmen in dieser Rangfolge an: Holzblasinstrumente, Blechblasinstrumente mit Pauke; Streichinstrumente, Tasteninstrumente. 
Die unter manchen Signaturen angegebenen Abkürzungen hinter „Vorh. in“ weisen auf die Institution hin, in der das betreffende Werk ebenfalls vorhanden ist: „GHG“ steht für Göttinger Händel-Gesellschaft, „MuSe“ für die Bibliothek des Musikwissenschaftlichen Seminars der Universität und „StAr“ für Stadtarchiv. Die vereinzelt auftauchende eingeklammerte Zahl hinter dem Standort bezieht sich auf die in der genannten Bibliothek bzw. im Archiv vorhandenen Exemplare; wenn keine Zahl angegeben ist, dann handelt es sich um ein Exemplar.

Bibliographisch ermittelte Daten zu den Titeln stehen in eckigen Klammern. In einigen Fällen war keine Bestimmung des Erscheinungsortes, des Verlages oder des Erscheinungsjahres möglich. So wird er durch die RAK-Formel (§ 144,3) in eckigen Klammern ersetzt: [S.l.] sine loco steht für „ohne Ort“, [s.n.] sine nomine für „ohne Verlag“ bzw. „ohne Drucker“ und [s.a.] sine anno für „ohne Jahr“.

Bei Titeln mit einem Sternchen hinter der Signatur handelt es sich um solche, wo das Format der Vorlage (2, 4, 8 und A, B bzw. FA/ZA, FB/ZB) nicht dem aufgeführten entspricht. Die Formatangabe in der Signatur wurde nicht geändert - da das Werk in den entsprechenden Katalogen unter der vorliegenden Signatur zu finden ist - in der Titelaufnahme jedoch korrigiert.

Neben den üblichen und allgemein bekannten Abkürzungen wurden Kürzungen aus den verwendeten Richtlinien »Regeln für die alphabetische Katalogisierung in wissenschaftlichen Bibliotheken« (RAK-WB), »Regeln für die alphabetische Katalogisierung von Musikdrucken, Musiktonträgern und Musik-Bildtonträgern« (RAK-Musik) und »Katalogisierungsrichtlinie für den Gemeinsamen Bibliotheksverbund « im Katalog vorgenommen; ein Verzeichnis am Ende soll helfen, sich im Abkürzungsdschungel zurechtzufinden. Wie die im Abkürzungsverzeichnis enthaltenen Wörter werden ebenso behandelt:

- grammatisch unterschiedliche Formen dieser Wörter (Band/Bände = Bd.)

- stammverwandte Wörter der gleichen Sprache (imprimerie/imprimé = impr.)

- sinn- und stammverwandte Wörter anderer Sprachen, deren Schreibung sich im vierten oder folgenden Buchstaben unterscheidet (Universität/Universidade = Univ.)

Nicht enthalten sind die Abkürzungen von Personen-, Orts- und Körperschaftsnamen sowie Währungsbezeichnungen, ferner solche im Text des Stempels oder des Etiketts. Ein Index aller Signaturen zum Schluß, beginnend mit der ersten in der SUB eingeführten Signaturform, erleichtert das numerische Suchen und Finden der erfaßten Exemplare; nicht aufgelistet sind allerdings die Signaturen der Mikrofilme. Die Ordnung 
der Numerus-currens-Signaturen erfolgt nach Zugangsjahr der Medieneinheit in die SUB. Das Format (A bzw. B) bildet das zweite Sortierkriterium, gefolgt von Inventarisierungsnummer.

Möge dieser Katalog dem Rechercheur einen besseren Einblick in den überaus umfangreichen Händel-Bestand der Festspielstadt Göttingen vermitteln. 
1. Händels L e b e n

\subsection{B i o g r a p h i e n}

PPN: 197653545

Georg Friedrich Händel : eine Biographie. - Cassel : Balde, 1855. - 100 S. : Ill. ; kl.-8 In Fraktur

Signatur: $\quad 8$ MUS III, 84:3

Anmerkung: Biogr. 1 - 5 zsgeb.*

Notizen: $\quad$ EX BIBLIOTHECA REgIA ACADEM. GEORGIAE AUG.

PPN: 015715566

Barna, István:

Wenn Händel ein Tagebuch geführt hätte... / István Barna. [Dt. von Irene Rübberdt]. Budapest : Corvina K., 1985. - 283 S. : Notenbeisp. ; $8^{\circ}$

Einheitssacht.: Georg Friedrich Händel életének krónikája <dt.>. - Aus dem Ungar. übers. ISBN 963-13-2003-0

Signatur: $\quad 88$ A 26118

Notizen: $\quad$ NIEDERSÄCHS. STAATS. U. UNIV.-BIBLIOTHEK GÖTTINGEN Gesch. v. Verband ungar. Verleger, Stuttgart

PPN: 02531646X

Baselt, Bernd:

Georg Friedrich Händel / Bernd Baselt. Mit 55 Abb., zsgest. von Edwin Werner. 1. Aufl. - Leipzig : Bibliogr. Inst., 1988. - 109 S. : zahlr. Ill., Notenbeisp. ; $8^{\circ}$ (Bildbiographie) Literaturverz. S. 108 - [110]

ISBN 3-323-00198-2 - ISBN 3-323-00196-6

Signatur: $\quad 89$ A 11198

Notizen: $\quad$ NIEDERSÄCHS. STAATS. U. UNIV.-BIBLIOTHEK GÖTTINGEN 


\section{PPN: 147553954}

Burney, Charles:

Dr. Karl Burney’s Nachricht von Georg Friedrich Händel's Lebensumständen und der ihm zu London im Mai und Jun. 1784 angestellten Gedächtnißfeyer / Aus dem Englischen übersetzt von Johann Joachim Eschenburg. - Faks.-Dr. d. Ausg. Berlin und Stettin, bei Friedrich Nicolai, 1785. - Leipzig : Dt. Verl. f. Musik, 1965 = 1785. - [14] Bl., LII, 102 S., [2] Bl. : Frontisp., Ill. (Kupferst.). ; $4^{\circ}+1$ Beil.

Einheitssacht.: Sketch of the life of Handel <dt.>. - In Fraktur

Signatur: $\quad 66$ A 2938

Notizen: $\quad 1966.2938$ - NIEDERSÄCHS. STAATS. U. UNIV.-BIBLIOTHEK GÖTTINGEN ; Stadtbibliothek zu Leipzig, G. F. Beckers Stiftung G. F. Becker, 1933 [hs. Vermerk auf HTS]

Vorh. in: $\quad$ MuSe

\section{PPN: 163962995}

Burrows, Donald:

Handel / Donald Burrows. - Oxford [u.a.] : Oxford Univ. Press, 1994. - XII, 491 S., [4] Bl. : Ill., Kt., Notenbeisp. ; $8^{\circ}$

(The Master musicians)

Cal. and list of works of Handel, S. 379 - 441. - Bibliogr. und Index S. 463 - 491

ISBN 0-19-816470-X*hardback : $£ 25.00$

Signatur: $\quad 96$ A 9234

Notizen: $\quad$ NIEDERSÄCHS. STAATS. U. UNIV.-BIBLIOTHEK GÖTTINGEN

\section{PPN: 175740976}

Cherbuliez, Antoine-Elisée:

Georg Friedrich Händel : Leben und Werk / Antoine-E. Cherbuliez. - Olten : Walter, 1949. - 389 S., [1] Bl. : Ill., Faks. ; $8^{\circ}$

(Musikerreihe in auserlesenen Einzeldarstellungen ; 5)

*Lw. : 13.60

Signatur: $\quad 8$ MUS 153

Notizen: $\quad$ 1949.3696 - EX BIBLIOTHECA ACAD. GEORGIAE AUG. verknüpft zur Serie PPN 182197425 


\section{PPN: 135314461}

Chrysander, Friedrich:

G. F. Händel / von Friedrich Chrysander ; Bd. 1. - Leipzig : Breitkopf und Härtel, 1858. - VIII, [1] Bl., 495 S. : Notenbeisp. ; $8^{\circ}$

In Fraktur

Signatur: $\quad 8$ MUS III, 1053:1

Notizen: $\quad$ EX BIBLIOTHECA REGIA ACADEM. GEORGIAE AUG. verknüpft zum MBW PPN 135314445

Vorh. in: $\quad$ MuSe

PPN: 135314488

G. F. Händel / Friedrich Chrysander ; Bd. 2. - Leipzig : Breitkopf und Härtel, 1860. - IV, [1] Bl., 481 S. : Notenbeisp. ; $8^{\circ}$

Beil.: S. [463] - 481. - In Fraktur

Signatur: $\quad 8$ MUS III, 1053:2

Notizen: $\quad$ EX BIBLIOTHECA REGIA ACADEM. GEORGIAE AUG. verknüpft zum MBW PPN 135314445

Vorh. in: $\quad$ MuSe

PPN: 13531450X

G. F. Händel / Friedrich Chrysander ; Bd. 3, Hälfte 1. - Leipzig : Breitkopf und Härtel, 1867. - [2] Bl., 224 S. : Notenbeisp. ; $8^{\circ}$

In Fraktur

Signatur: $\quad 8$ MUS III, 1053:3,1

Notizen: $\quad$ EX BIBLIOTHECA REGIA ACADEM. GEORGIAE AUG. verknüpft zum MBW PPN 135314445 -

Fortsetzung ist nicht erschienen

Vorh. in: $\quad$ MuSe 


\section{PPN: 176195149}

Fellerer, Karl Gustav:

Georg Friedrich Händel : Leben und Werk / von Karl Gustav Fellerer. - Hamburg : Sikorski, 1953. - 72 S. : Ill. ; kl.-8

(Kleine Musikbücherei ; 2)

*kart., geb. : 2.20

Signatur: $\quad 8$ Z MUS 128:2

Notizen: $\quad$ 1954.10447 - NIEDERSÄCHS. STAATS. U. UNIV.-BIBLIOTHEK GÖTTINGEN verknüpft zur Serie PPN 131030965

PPN: 135356032

Flower, Newman:

George Frideric Handel : his personality \& his times / by Newman Flower. - London [u.a.] : Cassell, 1923. - XV, 378 S. : zahlr. Ill. ; $8^{\circ}$

Signatur: $\quad 8$ MUS III, 1070

Notizen: $\quad 1924.7084$ - EX BIBLIOTHECA REGIA ACADEM. GEORGIAE AUG. Überwiesen von der Notgemeinschaft der deutschen Wissenschaft, Berlin 1924

\section{PPN: 135356059}

Georg Friedrich Händel : der Mann und seine Zeit ; mit 5 farbigen Tafeln und 47 zumeist unveröffentlichten Abbildungen, darunter zahlreichen Wiedergaben von Handschriften Händels / Neumann Flower. Aus dem Engl. übers. von Alice Klengel. - Leipzig : Koehler, 1925. - X, [16] Bl., 324 S. : zahlr. Ill. ; $8^{\circ}$

Einheitssacht.: George Frideric Handel <dt.>. - In Fraktur

\section{Signatur: $\quad 8$ MUS III, 1072}

Notizen: $\quad 1924.9244$ - EX BibliotheCA REgIA ACADEM. GEORGIAE AUG. -

Vorh. in: MuSe 


\section{PPN: 135314402}

Förstemann, Karl Eduard:

Georg Friedrich Händel's Stammbaum, nach Original-Quellen und authentischen Nachrichten / aufgestellt und erläutert von Karl Eduard Förstemann. - Leipzig : Breitkopf \& Härtel, 1844. 14 S. : 3 Taf. ; $2^{\circ}$

Enth. Widmung d. Verf. an Johann Gottfried Gruber: ,... zur Jubelfeier eines 50jährigen treuen und edlen Wirkens am 14. December 1843 im Namen des Thüringisch-Sächsischen Vereins für Erforschung des vaterländischen Alterthums ...“

Signatur: $\quad 2$ MUS III, 1047

Notizen: $\quad$ EX BIBLIOTHECA REGIA ACADEM. GEORGIAE AUG.

\section{PPN: 176317562}

Friedenthal, Richard:

Georg Friedrich Händel in Selbstzeugnissen und Bilddokumenten / dargest. von Richard Friedenthal. [Den dokumentarischen und bibliogr. Anh. bearb. Paul Raabe]. - [1. - 15. Tsd.]. - Hamburg : Rowohlt, 1959. - 172 S., [4] Bl. : Ill., Notenbeisp. ; $8^{\circ}$

(rowohlts monographien ; 36)

*kart. mit Lw.-Rücken : 2.20

Signatur: $\quad$ ZA 16436:36

Notizen: $\quad$ 1959.16436 - NIEDERSÄCHS. STAATS. U. UNIV.-BIBLIOTHEK GÖTTINGEN verknüpft zur Serie PPN 035855584

Vorh. in: $\quad$ MuSe

PPN: 029175941

Hogwood, Christopher:

Handel / Christopher Hogwood. Chronological tab. by Anthony Hicks. - London : Thames and Hudson, 1984. - 312 S. : 100 Ill., Kt., Notenbeisp. ; $8^{\circ}$

Literaturverz. - „Chronological table“ S. 277 - 294

ISBN 0-500-01355-1

Signatur: $\quad 87$ A 13662

Notizen: $\quad$ NIEDERSÄCHS. STAATS. U. UNIV.-BIBLIOTHEK GÖTTINGEN 
PPN: 025429086

Jonke, Gert:

Der Kopf des Georg Friedrich Händel / Gert Jonke. - 2. Aufl. - Salzburg ;

Wien : Residenz-Verl., 1988. - 31 S. ; $8^{\circ}$

(Liber : Libertas)

ISBN 3-7017-0534-8

Signatur: $\quad 89$ A 18104

Notizen: $\quad$ NIEDERSÄCHS. STAATS. U. UNIV.-BIBLIOTHEK GÖTTINGEN

PPN: 02730907X

Keates, Jonathan:

Handel : the man and his music / by Jonathan Keates. - London : Gollancz, 1985. - 346 S., [4] Bl. : Ill., Notenbeisp. ; $8^{\circ}$

Bibliogr. und Indizes S. 328 - 346

ISBN 0-575-03573-0

Signatur: $\quad 85$ A 14268

Notizen: $\quad$ NIEDERSÄCHS. STAATS. U. UNIV.-BIBLIOTHEK GÖTTINGEN

PPN: 021029024

Labie, Jean-François:

George Frédéric Haendel / Jean-François Labie. - Paris : Laffont, 1980. - 862 S.,

[4] Bl. : Ill., Notenbeisp. ; $8^{\circ}$

(Diapason)

Literaturverz. und Diskogr. S. [825] - 845. - 8 ungez. ill. S. in d. Vorlage, u.d.T.: L’ image et la réalité; Enfance et souvenir; Exécutions musicales; Caricatures

ISBN 2-221-00566-X

Signatur: $\quad 81$ A 11612

Notizen: $\quad$ NIEDERSÄCHS. STAATS. U. UNIV.-BIBLIOTHEK GÖTTINGEN Beschafft aus Mitteln der Stiftung Volkswagenwerk 


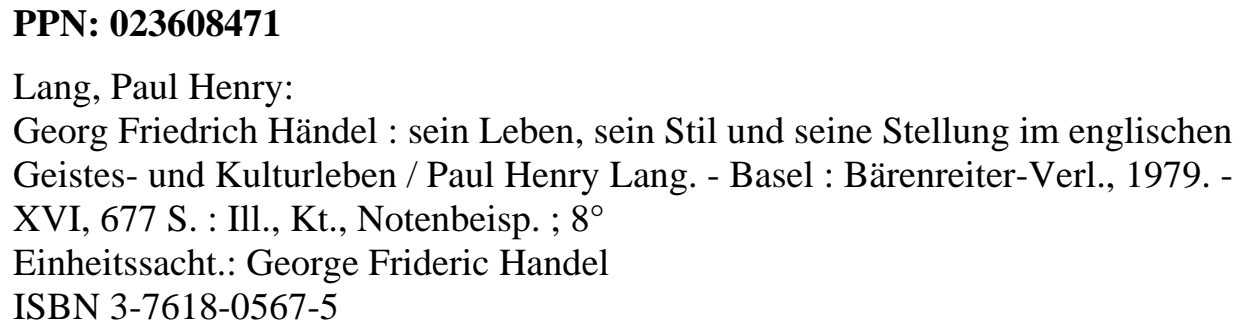

Signatur: $\quad 80$ A 10785

Notizen: $\quad$ NIEDERSÄCHS. STAATS. U. UNIV.-BIBLIOTHEK GÖTTINGEN Beschafft aus Mitteln der Stiftung Volkswagen

Vorh. in: $\quad$ MuSe

PPN: 135356075

Leichtentritt, Hugo:

Händel / von Hugo Leichtentritt. - Stuttgart ; Berlin : Dt. Verl.-Anst., 1924. - 871

S. : Notenbeisp. ; $8^{\circ}$

(Klassiker der Musik)

Signatur: $\quad 8$ MUS III, 1075

Notizen: $\quad$ EX BIBLIOTHECA REGIA ACAD. GEORGIAE AUG.

PPN: 026681552

Mainwaring, John:

G. F. Händel / John Mainwaring. Nach Johann Matthesons dt. Ausg. von 1761 mit andern Dokumenten hrsg. von Bernhard Paumgartner. - 2. Aufl. - Zürich : Atlantis Musikbuch-Verl., 1987. - 260 S. : Ill. ; $8^{\circ}$

Einheitssacht.: Memoirs of the life of the late George Frederic Handel <dt.>. -

Literaturverz. S. 258 - 260

ISBN 3-254-00139-7*Pp. : sfr 25.00

Signatur: $\quad 99$ A 5243

Notizen: NIEDERSÄCHS. STAATS. U. UNIV.-BIBLIOTHEK GÖTTINGEN 


\section{PPN: 135314364}

Memoirs of the life of the late George Frederic Handel : To which is added, a Catalogue of his works, and Observations upon them / [John Mainwaring]. - London : Printed for R. and J. Dodsley, 1760. - [3] Bl., 208 S. : Ill. ; $8^{\circ}$

Enth. außerdem: „Catalogue of the works of George Frederic Handel“ (S. [145] - 155);

„Observations on the works of George Frederic Handel“ (S. [157] - 208). - Verf. ermittelt. S. 83 - 94 kopfüber und von rechts geb.

Signatur: $\quad 8$ MUS III, 1040

Notizen: $\quad$ EX BIBliotheCA REgIA ACAD. GEORgIAE AUG. auch Mikrofilmausg., Sign.: MA 96-340:8421, no. 01

Vorh. in: $\quad$ MuSe

PPN: 351901752

Georg Friedrich Händel : Biographie von John Mainwaring ; Briefe und Schriften / hrsg. im Auftr. des Internat. Musiker-Brief-Archivs von Hedwig Mueller von Asow ... - Lindau im Bodensee : Werk-Verl. Frisch \& Perneder, 1949. - 219 S., [6] Bl. : Faks., Ill. ; $8^{\circ}$

Einheitssacht.: Memoirs of the life of G. F. Handel <dt.>. - „Briefe und Schriften“ S. [91] - 219. - Briefe teilw. dt., teilw. engl., teilw. franz.

*Lw. : 10.50

Signatur: $\quad 8$ MUS 129

Notizen: $\quad 1949.2887$ - EX BIBLIOTHECA ACAD. GEORGIAE AUG.

\section{PPN: 135314380}

Mattheson, Johann:

Georg Friedrich Händels Lebensbeschreibung, nebst einem Verzeichnisse seiner Ausübungswerke und deren Beurtheilung / übersetzet, auch mit einigen Anmerkungen, absonderlich über den hamburgischen Artikel versehen vom Legations-Rath Mattheson.

- Hamburg : Übers., 1761. - [6] Bl., 156 S., [4] Bl. : Ill. ; $8^{\circ}$

[Aus dem Engl. übers.]. - In Fraktur

Signatur: $\quad 8$ MUS III, 1043

Notizen: $\quad$ EX BIBLIOTHECA REGIA ACADEM. GEORGIA AUG.

Vorh. in: $\quad$ MuSe 
PPN: 135314429

Meyer, G. M. ${ }^{3}$ :

G. F. Händel : eine biographische Charakteristik / von G. M. Meyer. - Berlin : Trautwein, 1857. - IV, 62 S. ; $8^{\circ}$

Signatur: $\quad 8$ MUS III, 1050

Notizen: $\quad$ EX BIBLIOTHECA REgIA ACADEM. GEORGIA AUG.

Vorh. in: $\quad$ MuSe

PPN: 135356210

Moser, Hans Joachim:

Georg Friedrich Händel / von Hans Joachim Moser. - Kassel : Bärenreiter, [1942]. -

96 S. : Ill. ; $8^{\circ}$

(Kleines Bärenreiter-Buch ; 20)

Signatur: $\quad 8$ MUS III, 1098

Notizen: $\quad$ EX BIBLIOTHECA ACAD. GEORGIA AUG. verknüpft zur Serie PPN 169455076

PPN: 135356091

Müller-Blattau, Joseph Maria:

Georg Friedrich Händel / von Joseph Müller-Blattau. - Potsdam : Akad. Verl.-Ges. Athenaion, 1933. - 160 S. : zahlr. Ill. und Notenbeisp. ; $4^{\circ}$

(Die großen Meister der Musik)

Literaturverz. und Werkverz. S. 159

Signatur: $\quad 4$ MUS III, 1085

Notizen: $\quad 1933.3206$ - EX BIBLIOTHECA ACAD. GEORGIA AUG.

Vorh. in: $\quad$ MuSe

\footnotetext{
${ }^{3}$ Die Vornamen waren weder in der Vorlage, noch in Bibliographien ausgeschrieben.
} 


\section{PPN: 148832504}

Georg Friedrich Händel : der Wille zur Vollendung / Müller-Blattau. - Mainz : Schott, 1959. - 204, 36 S. : 36 Taf., Notenbeisp. ; $8^{\circ}$

Signatur: $\quad 58$ A 7094

Notizen: $\quad 1958.7094$ - NIEDERSÄCHS. STAATS. U. UNIV.-BIBLIOTHEK GÖTTINGEN Beschafft aus Bundesmitteln

\section{PPN: 178115991}

Nettl, Paul:

Georg Friedrich Händel / Paul Nettl. - Berlin : Merseburger, 1958. - 155 S. : Notenbeisp. ; $8^{\circ}$ (Edition Merseburger ; 1123)

*brosch. : 9.80

\section{Signatur: $\quad 59$ A 6568}

Notizen: $\quad 1959.6568$ - NIEDERSÄCHS. STAATS. U. UNIV.-BIBLIOTHEK GÖTTINGEN verknüpft zur Serie PPN 035942029

\section{PPN: 331510154}

Pieck, Werner:

Leben Händels : Biographie / Werner Pieck. - Hamburg : Europ. Verl.-Anst., 2001. 288 S. : Ill. ; $8^{\circ}$

Literaturverz. und Reg. S. 265 - 288

ISBN 3-434-50455-9*Geb. : ca. DM 50.00, ca. sfr 45.70, ca. S 365.00

Signatur: $\quad 2002$ A 1723

Notizen: $\quad$ NIEDERSÄCHS. STAATS. U. UNIV.-BIBLIOTHEK GÖTTINGEN

\section{PPN: 224911368}

Rauschenberger, Walther:

Georg Friedrich Händel / von Walther Rauschenberger. - [1949]. - [3] Bl. ; $4^{\circ}$

Hs. Widmung d. Verf. an Univ.-Bibliothek Göttingen. - In Fraktur. -

Aus: Genealogie und Heraldik; (1949), H. 6

Signatur: $\quad 4$ MUS 69

Notizen: $\quad 1949.273$ - EX BIBLIOTHECA ACAD. GEORGIAE AUG. -

Der Universitätsbibliothek Göttingen, Rauschenberger 


\section{PPN: 135314704}

Rolland, Romain:

Das Leben G. F. Händels / Romain Rolland. [Übers. aus dem Franz. von L. Langnese-Hug]. 1. - 10. Tsd. - Zürich : Rascher \& Cie, 1922. - 278 S., [2] Bl. : Notenbeisp. ; kl.-8

(Europäische Bücher)

\section{Signatur: $\quad 8$ MUS III, 1065/i \\ Notizen: $\quad$ 1946.1527 - EX BIBLIOTHECA ACAD. GEORGIAE AUG. - Schweizer Spende-Bücherhilfe}

Vorh. in: $\quad$ MuSe

\section{PPN: 178731552}

Scharschuch, Horst:

Georg Friedrich Händel : sein Leben in Bildern / von Horst Scharschuch. -

Mannheim : Bibliogr. Inst., 1959. - 32 S., [16] Bl. : zahlr. Ill. ; $8^{\circ}$

(Meyers Bildbändchen : N.F. ; 13)

Signatur: $\quad$ ZA 17555:13

Notizen: $\quad 1959.17555$ - NIEDERSÄCHS. STAATS. U. UNIV.-BIBLIOTHEK GÖTTINGEN verknüpft zur Serie PPN 130888591

PPN: 18724457X

Schmelzer, Hans-Jürgen:

Siehe, dein König kommt : Leben und Musik des Georg Friedrich Händel ; eine Biographie / Hans-Jürgen Schmelzer. - Düsseldorf : Droste, 1995. - 363 S. : Ill. ; $8^{\circ}$ ISBN 3-7700-1044-2*Pp. : DM 44.00, ca. sfr 39.80, ca. S 311.00

Signatur: $\quad 96$ A 9210

Notizen: $\quad$ NIEDERSÄCHS. STAATS. U. UNIV.-BIBLIOTHEK GÖTTINGEN 


\section{PPN: 179010255}

Siegmund-Schultze, Walther:

Georg Friedrich Händel : (1685 - 1759) / Walther Siegmund-Schultze. - 2., stark veränd. und erw. Aufl. - Leipzig : Dt. Verl. f. Musik, 1959. - 223 S., [2] Bl. : Ill. ; $8^{\circ}$

Händel-Werkverz. S. 214 - 222

*Lw. : DM-Ost 9,-

Signatur: $\quad 59$ A 4057

Notizen: $\quad$ 1959.405777 - NIEDERSÄCHS. STAATS. U. UNIV.-BIBLIOTHEK GÖTTINGEN

\section{PPN: 192552635}

Georg Friedrich Händel / Walther Siegmund-Schultze. - 3., stark veränd. und erw. Aufl. - Leipzig : Dt. Verl. f. Musik, 1962. - 232 S., [2] Bl. : Ill. , Notenbeisp. ; $8^{\circ}$ 1. Aufl. erschien u.d.T.: Georg Friedrich Händel, Leben und Werk

Signatur: $\quad 63$ A 7211

Notizen: $\quad 1963.7211$ - NIEDERSÄCHS. STAATS. U. UNIV.-BIBLIOTHEK GÖTTINGEN

\section{PPN: 021457824}

Weinstock, Herbert:

Händel / Herbert Weinstock. - München : Winkler, 1950. - 363 S. : Ill., Notenbeisp. ; $8^{\circ}$ Einheitssacht.: Handel <dt.>. - Literaturverz. und Werkverz. S. 353 - 362. - Aus dem Amerikan. übertr. von Gert Mahold

Signatur: $\quad 8$ MUS 448

Notizen: $\quad 1957.4472$ - NIEDERSÄCHS. STAATS. U. UNIV.-BIBLIOTHEK GÖTTINGEN 


\section{$1.2 \quad H$ ä nde l und M u si k}

\section{PPN: 19617497X}

Dean, Winton:

Handel and the opera seria / Winton Dean. - London [u.a.] : Oxford Univ. Press, 1970. XI, 220 S. : Ill., Notenbeisp. ; $4^{\circ}$

(The Ernest Bloch lectures ; 1)

Signatur: $\quad$ ZB 31856:1,1965/66

Notizen: $\quad$ NIEDERSÄCHS. STAATS- U. UNIV.-BIBLIOTHEK GÖTTINGEN verknüpft zur Serie PPN 131074113

PPN: 330496344

Handel's dramatic oratorios and masques / Winton Dean. - London [u.a.] : Oxford Univ. Press, 1959. - XII, 694 S., [6] Bl. : Ill., Notenbeisp. ; $4^{\circ}+1$ Beil.

Beil. u.d.T.: Variants in the text of Esther

Signatur: $\quad 59$ A 2238*

Notizen: $\quad 1959.2238$ - NIEDERSÄCHS. STAATS- U. UNIV.-BIBLIOTHEK GÖTTINGEN Beschafft aus Bundesmitteln

\section{PPN: 032325207}

Eisenschmidt, Joachim:

Die Stellung Händels im Londoner Theaterleben und seine Theater / Joachim Eisenschmidt.

- Wolfenbüttel ; Berlin : Kallmeyer, 1940. - 77 S. : 10 Taf. (14 Ill.). ; $8^{\circ}$

(Die szenische Darstellung der Opern Georg Friedrich Händels auf der Londoner Bühne seiner Zeit ; Teil 1)

(Schriftenreihe des Händelhauses in Halle ; 5)

Zugl.: Halle, Univ., Diss., 1940. - In Fraktur

Signatur: $\quad 8$ MUS I, 2105:5

Notizen: $\quad 1940.3535$ - Universitätsbibliothek Göttingen verknüpft zum MBW PPN 135306248 und zur Serie PPN 036112534

Vorh. in: $\quad$ MuSe 
PPN: 265182832

Der Darstellungsstil der Händeloper / Joachim Eisenschmidt. - Wolfenbüttel ;

Berlin : Kallmeyer, 1941. - 136 S. : 12 Taf. (18 Ill.). ; $8^{\circ}$

(Die szenische Darstellung der Opern Georg Friedrich Händels auf der Londoner

Bühne seiner Zeit ; Teil 2)

(Schriftenreihe des Händelhauses in Halle ; 6)

Zugl.: Halle, Univ., Diss., 1940. - In Fraktur

Signatur: $\quad 8$ MUS I, 2105:6

Notizen: $\quad$ NIEDERSÄCHS. STAATS. U. UNIV.-BIBLIOTHEK GÖTTINGEN Geschenk des Händel-Hauses Halle (Saale), Musikmuseum der Stadt, Juli 2001 - verknüpft zum MBW PPN 135306248 und zur Serie PPN 036112534

Vorh. in: $\quad$ MuSe

\section{PPN: 013241230}

Die szenische Darstellung der Opern Georg Friedrich Händels auf der Londoner Bühne seiner Zeit / Joachim Eisenschmidt. - Unveränd. Neuaufl. / hrsg. von Hans Joachim Marx. - Laaber : Laaber-Verl, 1987. - XIII, 239 S. : Ill. (XXIV Taf.). ; $8^{\circ}$

(Veröffentlichungen der Internationalen Händel-Akademie Karlsruhe ; 1)

Literaturverz. S. 196 - 201. - Zugl.: Halle-Wittenberg, Univ., Diss. 1939

ISBN 3-89007-123-6

Signatur: $\quad$ ZA 67246:1

Notizen: $\quad$ NIEDERSÄCHS. STAATS. U. UNIV.-BIBLIOTHEK GÖTTINGEN verknüpft zur Serie PPN 036066869

PPN: 135217253

Händel, Georg Friedrich:

Judas Maccabäus : Oratorium / von Georg Friedrich Händel. Mit folgenden Beigaben ... von Heinrich Giehne. - Karlsruhe : Dr. d. Chr. Fr. Müller’schen Hofbuchdruckerei, 1847. - 83, [1 ungez.] S. ; $8^{\circ}$

In Fraktur

Signatur: $\quad 8$ MUS VII, 356

Notizen: $\quad 1909.8574$ - EX BIBLIOTHECA REGIA ACADEM. GEORGIAE AUG. Geschenk des Herrn Bibliothekar Dr. Joachim Göttingen 1910 


\section{PPN: 165291710}

LaRue, C. Steven ${ }^{4}$ :

Handel and his singers : the creation of the Royal Academy Operas, 1720 - 1728 / C. Steven LaRue. - Oxford : Clarendon Press, 1995. - XIV, 213 S. : Ill., Notenbeisp. ; $8^{\circ}$ (Oxford monographs on music)

Literaturverz. (S. 205 - 210) und Index

ISBN 0-19-816315-0*cloth.

Signatur: $\quad 95$ A 11286

Notizen: $\quad$ NIEDERSÄCHS. STAATS. U. UNIV.-BIBLIOTHEK GÖTTINGEN

\section{PPN: 128348267}

Leitich, Ann Tizia:

Premiere in London : Georg Friedrich Händel und seine Zeit / Ann Tizia Leitich. München : Ehrenwirth, 1962. - 240 S., [2] Bl. : Ill. (auf Taf.). ; $8^{\circ}$

Signatur: $\quad 63$ A 2828

Notizen: $\quad 1963.2828$ - NIEDERSÄCHS. STAATS. U. UNIV.-BIBLIOTHEK GÖTTINGEN

\section{PPN: 02562217X}

Möller, Dirk:

Besetzung und Instrumentation in den Opern Georg Friedrich Händels / Dirk Möller. Frankfurt am Main [u.a.] : Lang, 1989. - IX, 231 S. : Notenbeisp. ; $8^{\circ}$

(Europäische Hochschulschriften : Reihe 36, Musikwissenschaft ; 38)

Zugl.: Hamburg, Univ., Diss., 1988

ISBN 3-631-40784-X

Signatur: $\quad$ ZA 46593:38

Notizen: $\quad$ NIEDERSÄCHS. STAATS. U. UNIV.-BIBLIOTHEK GÖTTINGEN verknüpft zur Serie PPN 035934859

\footnotetext{
${ }^{4}$ Der erste Vorname war weder in der Vorlage noch in Bibliographien ermittelbar.
} 


\section{PPN: 031764495}

Rackwitz, Werner:

Geschichte und Gegenwart der hallischen Händel-Renaissance / Werner Rackwitz ; Teil 1: 1803-1929. - Halle an der Saale : Händel-Haus, 1977. - 122 S., [1] Bl. : Ill. ; $8^{\circ}$ (Schriften des Händelhauses in Halle ; 1)

Teilw. zugl.: Halle, Univ., Diss., 1963 u.d.T.: Die hallische Händel-Renaissance von 1859-1952

\section{Signatur: $\quad$ ZA 74426:1}

Notizen: $\quad$ NIEDERSÄCHS. STAATS. U. UNIV.-BIBLIOTHEK GÖTTINGEN verknüpft zum MBW PPN 031764487 und zur Serie PPN 036115452

Vorh. in: $\quad$ MuSe

\section{PPN: 031764509}

Geschichte und Gegenwart der hallischen Händel-Renaissance / Werner Rackwitz ; Teil 2: 1929-1976. - Halle an der Saale : Händel-Haus, 1979. - S. 129 - 253, [1] Bl. : Ill. ; $8^{\circ}$ (Schriften des Händelhauses in Halle ; 2)

Teilw. zugl.: Halle, Univ., Diss., 1963 u.d.T.: Die hallische Händel-Renaissance von 1859-1952

\section{Signatur: $\quad$ ZA 74426:2 \\ Notizen: $\quad$ NIEDERSÄCHS. STAATS. U. UNIV.-BIBLIOTHEK GÖTTINGEN - verknüpft zum MBW PPN 031764487 und zur Serie PPN 036115452}

Vorh. in: $\quad$ MuSe

PPN: 221834338

Rudolph, Johanna:

Händelrenaissance : eine Studie / Johanna Rudolph ; Bd. 1. - Berlin : Aufbau-Verl., 1960. - 244 S. : Ill. ; $8^{\circ}$

Zugl.: Berlin, Humboldt-Univ., Diss., 1966

Signatur: $\quad$ FA 1874:1

Notizen: $\quad 1960.1874$ - NIEDERSÄCHS. STAATS. U. UNIV.-BIBLIOTHEK GÖTTINGEN verknüpft zum MBW PPN 22183432X 
PPN: 266136001

Händels Rolle als Aufklärer. - 1. Aufl. - Berlin ; Weimar : Aufbau-Verl., 1969. 464 S. : Ill., Notenbeisp. ; $8^{\circ}$

(Händelrenaissance ; Bd. 2)

Zugl.: Berlin, Humboldt-Univ., Diss., 1966

Signatur: $\quad$ FA $1874: 2$

Notizen: $\quad$ NIEDERSÄCHS. STAATS. U. UNIV.-BIBLIOTHEK GÖTTINGEN verknüpft zum MBW PPN 22183432X

PPN: 135356237

Wolff, Hellmuth Christian:

Agrippina : eine italienische Jugendoper / von Georg Friedrich Händel. Einf. von Hellmuth

Christian Wolff. - Wolfenbüttel ; Berlin : Kallmeyer, 1943. - 36 S. : Notenbeisp. ; $8^{\circ}$

Signatur: $\quad 8$ MUS III, 1099

Notizen: $\quad 1943.867$ - Universitätsbibliothek Göttingen 


\subsection{Händel und andere Persönlichkeiten}

\section{PPN: 152341803}

Anderson, Nicholas:

Baroque music : from Monteverdi to Handel / Nicholas Anderson. Pref. by Nikolaus Harnoncourt. - London : Thames and Hudson, 1994. - 224 S. : Ill., Notenbeisp. ; $8^{\circ}$ Literaturverz. (S. 217 - 218) und Index

ISBN 0-500-01606-2

Signatur: $\quad 96$ A 31494

Notizen: $\quad$ NIEDERSÄCHS. STAATS. U. UNIV.-BIBLIOTHEK GÖTTINGEN

PPN: 30968059X

Musikalisch-historisches-lustiges Anekdoten-Büchlein aus der Zeit von Bach und Händel bis Dr. Richard Strauß und Caruso / mit Beitr. von Ernst von Possart ... und Orig.-Beitr. von Felix Mottl, mitget. von W. Krienitz .... Ges. und hrsg. von Josef Seiling sen. ; Bd. 2. - Diessen vor München : Huber, 1913. - 150, XX S. : Ill. ; $8^{\circ}$

Enth. Index und Verz. d. Ill. d. 3 Bd. (S. I - XX). - In Fraktur

(à Mk. 1.20)

Signatur: $\quad$ ALT 2001 A 921:2

Notizen: $\quad$ NIEDERSÄCHS. STAATS. U. UNIV.-BIBLIOTHEK GÖTTINGEN Überreicht von der Deutschen Forschungsgemeinschaft verknüpft zum MBW PPN 30968045X

\section{PPN: 245426493}

Bartelmus, Rüdiger:

Theologische Klangrede : Studien zur musikalischen Gestaltung und Vertiefung theologischer Gedanken durch J. S. Bach, G. F. Händel, F. Mendelssohn, J. Brahms und E. Pepping /

Rüdiger Bartelmus. - Zürich : Pano-Verl., 1998. -

VI, 242 S. : graph. Darst., Notenbeisp. ; $8^{\circ}$

Literaturangaben

ISBN 3-907576-07-1

Signatur: $\quad 99$ A 11678

Notizen: $\quad$ NIEDERSÄCHS. STAATS. U. UNIV.-BIBLIOTHEK GÖTTINGEN 
PPN: 135264758

Bitter, Carl Hermann:

Ueber Gervinus’ Händel und Shakespeare / von C. H. Bitter. - Berlin : Müller, 1869. 45 S. ; $8^{\circ}$

Signatur: $\quad 8$ MUS I, 86

Notizen: $\quad$ EX BIBLIOTHECA REgIA ACADEM. GEORGIAE AUG.

PPN: 02391274X

Boetticher, Wolfgang:

Von Palestrina zu Bach / Wolfgang Boetticher. - Erw. Neuausg. - Wilhelmshaven :

Heinrichshofen, 1981. - 224 S. : 48 Taf. (Ill., Notenbeisp.). ; $8^{\circ}$

(Taschenbücher zur Musikwissenschaft ; 66)

1. Aufl. im Verlag Kohlhammer, Stuttgart erschienen

ISBN 3-7959-0306-8

Signatur: $\quad$ ZA 39691:66

Notizen: $\quad$ NIEDERSÄCHS. STAATS. U. UNIV.-BIBLIOTHEK GÖTTINGEN verknüpft zur Serie PPN 167350005

PPN: 21525404X

Carlsson, Anders:

"Handel och Bacchus eller Händel och Bach?" : Det borgerliga musiklivet och dess orkesterbildningar i köpmannastaden Göteborg under andra hälften av 1800-talet / Anders Carlsson. - Göteborg : Tre Böcker, 1996. - 612 S. : Ill., Notenbeisp. ; $8^{\circ}$ (Skrifter från Musikvetenskap, Göteborgs Universitet ; 43)

Zugl.: Göteborg, Univ., Diss., 1996. - Zsfassung (S. 555 - 576) und Abstract engl. ISBN 91-7029-195-0

Signatur: $\quad$ DISS 96 A 4184

Notizen: $\quad$ NIEDERSÄCHS. STAATS. U. UNIV.-BIBLIOTHEK GÖTTINGEN verknüpft zur Serie PPN 035920246 
PPN: 135295904

Franz, Robert:

Offener Brief an Eduard Hanslick : über Bearbeitungen älterer Tonwerke namentlich Bach'scher und Händel'scher Vocalmusik / von Robert Franz. - Leipzig : Leuckart, 1871. - 40 S. : Notenbeisp. ; $8^{\circ}$

Signatur: $\quad 8$ MUS IV, 880

Notizen: $\quad 1925.6730$ - EX BIBLIOTHECA REGIA ACADEM. GEORGIAE AUG.

\section{PPN: 135308097}

Fuller-Maitland, John Alexander:

The age of Bach \& Handel / by J. A. Fuller Maitland. - Oxford : Clarendon Press, 1902. - XIV, 362 S. : Notenbeisp. ; $8^{\circ}$

(The Oxford history of music ; 4)

Signatur: $\quad 8$ MUS II, 225:4

Notizen: $\quad 1925.1837$ - EX BIBLIOTHECA REGIA ACADEM. GEORGIAE AUG. verknüpft zum MBW PPN 135307961

PPN: 135308259

The age of Bach \& Handel / by J. A. Fuller Maitland. - 2. ed. - London : Oxford Univ. Press, 1931. - XVI, 362 S. : Notenbeisp. ; $8^{\circ}$

(The Oxford history of music ; 4)

Signatur: $\quad 8$ MUS II, 225:4 <2>

Notizen: $\quad 1931.4001$ - EX BIBLIOTHECA ACAD. GEORGIAE AUG. verknüpft zum MBW PPN 135308178

PPN: 135264731

Gervinus, Georg Gottfried:

Händel und Shakespeare : zur Ästhetik der Tonkunst / von G. G. Gervinus. -

Leipzig : Engelmann, 1868. - XIV, [1] Bl., 496 S. ; $8^{\circ}$

In Fraktur

Signatur: $\quad 8$ MUS I, 83

Notizen: $\quad$ EX BIBLIOTHECA REgIA ACADEM. GEORGIAE AUG. 
PPN: 135264863

Haweis, Hugh Reginald:

Music and morals / by H. R. Haweis. - 7. ed. - London : Daldy, Isbister, 1876. - XIII, 556 S., [3] Bl. : Ill. ; $8^{\circ}$

Nebent.: Handel, Gluck, Haydn, Mozart, Beethoven, Schubert, Chopin, Mendelssohn

Signatur: $\quad 8$ MUS I, $100<7>$

Notizen: $\quad 1932.11697$ - Englisches Seminar Göttingen Ausleihebibliothek ; EX BIBLIOTHECA ACAD. GEORGIAE AUG. ;

Geschenk des Englischen Seminars der Universität Göttingen

PPN: 135356172

Langley, Hubert:

Doctor Arne / by Hubert Langley. - Cambridge : Univ. Press, 1938. - [5] Bl., 119 S. : Ill., 1 Taf., Notenbeisp. ; $8^{\circ}$

Signatur: $\quad 8$ MUS III, 1140

Notizen: $\quad 1939.1053$ - Universitätsbibliothek Göttingen

PPN: 135269229

Mohr, Ernst:

Die Allemande : eine Untersuchung ihrer Entwicklung von den Anfängen bis zu

Bach und Händel / Ernst Mohr ; Teil 1: Text. - Zürich ; Leipzig : Hug, 1932. -

159 S., [1] Bl. : Notenbeisp. ; $8^{\circ}$

Signatur: $\quad 8$ MUS II, 746:1,TEXT

Notizen: $\quad 1932.2725$ - EX BIBLIOTHECA ACAD. GEORGIAE AUG. verknüpft zum MBW PPN 135269202 


\title{
PPN: 135269245
}

Die Allemande : eine Untersuchung ihrer Entwicklung von den Anfängen bis zu Bach und Händel / Ernst Mohr ; Teil 2: Noten-Beispiele. - [Musikdr.]. - Zürich ; Leipzig : Hug, 1932. - 66 S. ; $8^{\circ}$

\author{
Signatur: $\quad 8$ MUS II, 746:1,NOTEN \\ Notizen: $\quad$ 1932.2726 - EX BIBLIOTHECA ACAD. GEORGIAE AUG. - \\ verknüpft zum MBW PPN 135269202
}

PPN: 135312701

Naumann, Emil:

Deutsche Tondichter : von Sebastian Bach bis auf die Gegenwart ; Vorträge, gehalten im Wintersemester von 1870 auf 1871, an dem, unter dem Protectorat Ihrer k. k. Hoheit der Frau Kronprinzessin von Deutschland stehenden Victoria-Lyceum zu Berlin / von Emil Naumann. - Berlin : Oppenheim, 1871. - X S., [1] Bl., 313, [1 ungez.] S. : Ill. ; $8^{\circ}$ Enth. am Ende Druckfehler-Verz.

In Fraktur

Signatur: $\quad 8$ MUS III, 374

Notizen: $\quad$ EX BIBLIOTHECA REGIA ACADEM. GEORGIAE AUG.

\section{PPN: 018594050}

Schering, Arnold:

Geschichte des Oratoriums / Arnold Schering. - Reprogr. Nachdr. d. Ausg. Leipzig, 1911. - Hildesheim : Olms ; Wiesbaden : Breitkopf \& Härtel, 1966 = 1911. - 647, XXXIX S. : Notenbeisp. ; $8{ }^{\circ}$

(Kleine Handbücher der Musikgeschichte nach Gattungen ; 3)

Anh.: Textbeil. ital., Musikbeil. ital. und dt.

\section{Signatur: $\quad 67$ A 6510}

Notizen: $\quad 1967.6512$ - NIEDERSÄCHS. STAATS. U. UNIV.-BIBLIOTHEK GÖTTINGEN verknüpft zur Serie PPN 036162779 
PPN: 135312485

Schering, Arnold:

Von großen Meistern der Musik / Arnold Schering. - Leipzig : Koehler \& Amelang, 1940. - 188 S., [2] Bl. : Notenbeisp. ; $8^{\circ}$

In Fraktur

Signatur: $\quad 8$ MUS III, 251

Notizen: $\quad 1940.3467$ - Universitätsbibliothek Göttingen

PPN: 135312426

Scherwatzky, Robert:

Die großen Meister deutscher Musik in ihren Briefen und Schriften / von Robert Scherwatzky.

- Göttingen : Deuerlich, 1939. - 326, [2 ungez.] S. : Ill. ; $8^{\circ}$

In Fraktur

Signatur: $\quad 8$ MUS III, 248

Notizen: $\quad 1939.3153$ - Universitätsbibliothek Göttingen

PPN: 135312442

Die großen Meister deutscher Musik in ihren Briefen und Schriften / von Robert Scherwatzky. - 3., wesentlich veränd. und verm. Aufl. - Göttingen : Deuerlich, 1942. - 372 S. ; $8^{\circ}$

In Fraktur

Signatur: $\quad 8$ MUS III, $248<3>$

Notizen: $\quad 1944.1399$ - EX BIBLIOTHECA ACAD. GEORGIAE AUG. 


\section{PPN: 128736623}

Schwab, Heinrich Wilhelm:

Konzert : öffentliche Musikdarbietung vom 17. bis 19. Jahrhundert / Heinrich W.

Schwab. - Leipzig : Dt. Verl. f. Musik, 1971. - 228, [2 ungez.] S. : zahlr. Ill. ; $4^{\circ}$

(Musikgeschichte in Bildern : Bd. 4, Musik der Neuzeit ; Lfg. 2)

Literaturverz. S. 211 - 216

Signatur: $\quad$ FB 2624:4,2

Notizen: $\quad$ NIEDERSÄCHS. STAATS- U. UNIV.-BIBLIOTHEK GÖTTINGEN verknüpft zum MBW PPN 125306091

PPN: 135372283

Serauky, Walter:

Von Samuel Scheidt bis in die Zeit Georg Friedrich Händels und Johann Sebastian

Bachs / von Walter Serauky. - Halle/Saale ; Berlin : Buchh. d. Waisenhauses,

1939. - XVI, 585 S. : Notenbeisp. ; $8^{\circ}$

(Musikgeschichte der Stadt Halle ; Bd. 2,1)

(Beiträge zur Musikforschung ; 6)

In Fraktur

Signatur: $\quad 8$ MUS II, 2379:2,1

Notizen: $\quad 43.9634$ - Universitätsbibliothek Göttingen -

verknüpft zum MBW PPN 135372240 und zur Serie PPN 167050397

\section{PPN: 029175194}

Smither, Howard E.

The oratorio in the baroque era : Protestant Germany and England / by Howard E. Smither. Chapel Hill : Univ. of North Carolina Press, 1977. - XXII, 393 S. : Ill., Notenbeisp. ; $8^{\circ}$

(A history of the oratorio ; Vol. 2)

Literaturverz. S. 361 - 381

ISBN 0-8078-1294-3

\section{Signatur: $\quad$ FA 9250:2}

Notizen: $\quad$ NIEDERSÄCHS. STAATS. U. UNIV.-BIBLIOTHEK GÖTTINGEN verknüpft zum MBW PPN 029175178 


\section{Q u e l l e n}

\subsection{B i b liographien, Kat a loge}

\section{PPN: 125277687}

Breitner, Karin:

Christoph Willibald Gluck, Georg Friedrich Händel / bearb. von Karin Breitner. -

Tutzing : Schneider, 1985. - XII, 169 S. : zahlr. Ill ., Notenbeisp. ; $4^{\circ}$

(Katalog der Sammlung Anthony van Hoboken in der Musiksammlung der

Österreichischen Nationalbibliothek ; Bd. 5)

ISBN 3-7952-0454-2

\section{Signatur: $\quad$ FB 12165:5}

Notizen: $\quad$ NIEDERSÄCHS. STAATS. U. UNIV.-BIBLIOTHEK GÖTTINGEN verknüpft zum MBW PPN 125277504

PPN: 127514406

Burrows, Donald:

A catalogue of Handel's musical autographs / Donald Burrows and Martha J. Ronish. Oxford : Clarendon Press, 1994. - XXXVIII, 332 S., [100] Bl. : zahlr. Ill., Notenbeisp. ; quer- $4^{\circ}$

Literaturverz. (S. [317] - 318) und Indizes (S. [319] - 332)

ISBN 0-19-315250-9

Signatur: $\quad 95$ A 3022

Notizen: $\quad$ NIEDERSÄCHS. STAATS. U. UNIV.-BIBLIOTHEK GÖTTINGEN

\section{PPN: 136714536}

The Handel manuscripts. - London : Clowes, 1927. - 143 S. : Frontisp. ; $4^{\circ}+3$ Beil. (Faks.) (Catalogue of the King's Music Library ; Pt. 1)

Signatur: $\quad 4$ HLL IX, 2546:1

Notizen: $\quad 1928.2171$ - EX BIBLIOTHECA REGIA ACADEM. GEORGIAE AUG. Überwiesen von der Notgemeinschaft der deutschen Wissenschaft Berlin verknüpft zum MBW PPN 136714528 


\section{PPN: 014151472}

Krause, Peter:

Handschriften und ältere Drucke der Werke Georg Friedrich Händels in der Musikbibliothek der Stadt Leipzig / [bearb. von Peter Krause]. - Leipzig : Musikbibliothek, 1966. - 44 S., [1] Bl. ; $8^{\circ}$

(Bibliographische Veröffentlichungen der Musikbibliothek der Stadt Leipzig ; 4)

Nebent.: Georg Friedrich Händel

Signatur: $\quad$ ZA 42204:4

Notizen: $\quad$ NIEDERSÄCHS. STAATS. U. UNIV.-BIBLIOTHEK GÖTTINGEN verknüpft zur Serie PPN 040724379

PPN: 031830722

Sasse, Konrad:

Händel-Bibliographie : unter Verwendung des im Händel-Jahrbuch 1933 von Kurt Taut veröffentlichten Verzeichnisses des Schrifttums über Georg Friedrich Händel / zsgest. von Konrad Sasse ; [Hauptbd.]: Abgeschlossen im Jahre 1961. - Leipzig : Dt. Verl. f. Musik, 1963. - 352 S., [2] Bl. ; $4^{\circ}$

Signatur: $\quad 64$ B 4378:HAUPTW

Notizen: $\quad 1964.4378$ - NIEDERSÄCHS. STAATS. U. UNIV.-BIBLIOTHEK GÖTTINGEN verknüpft zum MBW PPN 031830714

PPN: 031830730

Händel-Bibliographie : unter Verwendung des im Händel-Jahrbuch 1933 von Kurt Taut veröffentlichten Verzeichnisses des Schrifttums über Georg Friedrich Händel; abgeschlossen im Jahre 1961 / zsgest. von Konrad Sasse ; Nachtr. 1: 1962 - 1965. Leipzig : Dt. Verl. f. Musik, 1967. - [2] Bl., S. 357 - [433]. ; $4^{\circ}$

\section{Signatur: $\quad 64$ B 4378:NACHTR}

Notizen: $\quad$ 1967.64/4378 - NIEDERSÄCHS. STAATS. U. UNIV.-BIBLIOTHEK GÖTTINGEN verknüpft zum MBW PPN 031830714 
PPN: 018567150

Smith, William Charles:

Handel : a descriptive catalogue of the early editions / by William C. Smith, assisted by Charles Humphries. - London [u.a.] : Cassell, 1960. - XXIII, 366 S. : Ill. ; $4^{\circ}$ Index of musical works and titles (S. 333 - 358)

Signatur: $\quad 60$ B 4130

Notizen: $\quad 1960.4130$ - NIEDERSÄCHS. STAATS. U. UNIV.-BIBLIOTHEK GÖTTINGEN 


\section{$2.2 \quad$ W e r k verze i c h n is se, W e r kf üh re r}

PPN: 135348501

Bagge, Selmar:

Verzeichnis sämmtlicher Werke von Joh. Seb. Bach, L. v. Beethoven, Fr. Chopin, Friedrich dem Grossen, Chr. W. Gluck, A. E. M. Grétry, G. F. Händel, Jos. Lanner, F. Mendelssohn Bartholdy, W. A. Mozart, G. P. da Palestrina, H. Purcell, Fr. Schubert, R. Schumann, H. Schütz, Joh. Strauss u. R. Wagner / unter Red. von Selmar Bagge ... - 1. kritisch durchges. Gesammtausg. - Leipzig [u.a.] : Breitkopf \& Härtel, [1893]. - 149 S. ; $8^{\circ}$

Signatur: $\quad 8$ MUS I, 2744

Notizen: $\quad 1893.1390$ - EX BIBLIOTHECA REGIA ACADEM. GEORGIAE AUG. Geschenk des Verlags

PPN: 031203396

Dokumente zu Leben und Schaffen : auf der Grundlage von Otto Erich Deutsch ; Handel, a documentary biography / hrsg. von der Ed.-Ltg. der Hallischen Händel-Ausgabe. - Kassel [u.a.] : Bärenreiter, 1985. - 621 S., [1] Bl. : Notenbeisp. ; $4^{\circ}$

(Händel-Handbuch ; Bd. 4)

Beitr. teilw. dt., teilw. engl., teilw. franz.

ISBN 3-7618-0717-1

Signatur: $\quad 4$ MUS 936:HANDBUCH,4

Notizen: $\quad$ 1986.56/2749 - NIEDERSÄCHS. STAATS. U. UNIV.-BIBLIOTHEK GÖTTINGEN verknüpft zum MBW PPN 031203345

Vorh. in: $\quad$ GHG, MuSe

PPN: 031203353

Lebens- und Schaffensdaten / zsgest. von Siegfried Flesch. - Kassel [u.a.] : Bärenreiter, 1978. - 539, [1 ungez.] S. : zahlr. Notenbeisp. ; $4^{\circ}$

(Händel-Handbuch ; Bd. 1)

Literaturangaben. - Die Vorlage enth. insges. 2 Werke

ISBN 3-7618-0610-8 


\section{[Enthaltenes Werk, PPN 031203361]}

Baselt, Bernd:

Thematisch-systematisches Verzeichnis: Bühnenwerke / von Bernd Baselt. - 1978. -

S. [37] - 539

\section{Signatur: $\quad 4$ MUS 936:HANDBUCH,1}

Notizen: $\quad$ 1979.56/2749 - NIEDERSÄCHS. STAATS. U. UNIV.-BIBLIOTHEK GÖTTINGEN verknüpft zum MBW PPN 031203345

Vorh. in: $\quad$ GHG, MuSe

PPN: 031203388

Thematisch-systematisches Verzeichnis: Instrumentalmusik, Pasticci und Fragmente / von Bernd Baselt. - Kassel [u.a.] : Bärenreiter, 1986. - 442 S. : zahlr. Notenbeisp. ; $4^{\circ}$ (Händel-Handbuch ; Bd. 3)

Literaturangaben

ISBN 3-7618-0716-3

Signatur: $\quad 4$ MUS 936:HANDBUCH,3

Notizen: $\quad$ 1986.56/2749 - NIEDERSÄCHS. STAATS. U. UNIV.-BIBLIOTHEK GÖTTINGEN verknüpft zum MBW PPN 031203345

Vorh. in: $\quad$ GHG, MuSe

\section{PPN: 03120337X}

Thematisch-systematisches Verzeichnis: oratorische Werke, vokale Kammermusik, Kirchenmusik / von Bernd Baselt. - Kassel [u.a.] : Bärenreiter, 1984. - 800 S. : überw. Notenbeisp. ; $4^{\circ}$

(Händel-Handbuch ; Bd. 2)

Literaturangaben. - S. 497 - 512 d. Vorlage fehlen

ISBN 3-7618-0715-5

\section{Signatur: $\quad 4$ MUS 936:HANDBUCH,2 \\ Notizen: $\quad$ 1985.56/2749 - NIEDERSÄCHS. STAATS. U. UNIV.-BIBLIOTHEK GÖTTINGEN - verknüpft zum MBW PPN 031203345}

Vorh. in: $\quad$ GHG, MuSe 


\section{PPN: 016552199}

Baselt, Bernd:

Verzeichnis der Werke Georg Friedrich Händels : (HWV) ; kleine Ausgabe / zsgest. von Bernd Baselt. - 1. Aufl. - Leipzig : Dt. Verl. f. Musik, 1986. - 300 S. ; kl.-8

Literaturverz. S. 7 - 11

ISBN 3-370-00235-3*brosch. : DM 22.00, sFr 20.00, öS 161.00

\section{Signatur: $\quad 87$ A 12846}

Notizen: $\quad$ NIEDERSÄCHS. STAATS. U. UNIV.-BIBLIOTHEK GÖTTINGEN

Vorh. in: MuSe

\section{PPN: 220629560}

Burrows, Donald:

The Cambridge companion to Handel / ed. by Donald Burrows. - Cambridge [u.a.] : Cambridge Univ. Press, 1997. - XVI, 349 S. : Ill., Notenbeisp. ; $4^{\circ}$ (Cambridge companions to music) Literaturverz. (S. 286 - 330), Werkverz. (S. [331] - 337) und Index ISBN 0-521-45425-5*hbk. - ISBN 0-521-45613-4*pbk.

Signatur: $\quad 98$ B 1405

Notizen: $\quad$ NIEDERSÄCHS. STAATS. U. UNIV.-BIBLIOTHEK GÖTTINGEN

\section{PPN: 02419025X}

Dean, Winton:

Handel's operas, 1704-1726 / Winton Dean and John Merrill Knapp. - Oxford [u.a.] : Clarendon Press, 1987. - XX, 751 S. : Ill., Notenbeisp. ; $8^{\circ}$

Literaturverz. (S. 727 - 729) und Indizes (S. [731] - 751)

ISBN 0-19-315219-3

\section{Signatur: $\quad 87$ A 12682}

Notizen: $\quad$ NIEDERSÄCHS. STAATS. U. UNIV.-BIBLIOTHEK GÖTTINGEN

Vorh. in: $\quad$ MuSe 
PPN: 181717441

Handel's operas : 1704-1726 / Winton Dean and John Merrill Knapp. - Rev. ed. - Oxford [u.a.] : Clarendon Press, 1995. - XX, 771 S., [8] Bl. : Ill., Faks., Notenbeisp. ; $8^{\circ}$ Previous ed.: 1987. - Bibliogr. [S. 747 - 750] und Indizes [S. 751 - 771] ISBN 0-19-816441-6*Pbk. : $£ 22.50$

Signatur: $\quad 96$ A 2838

Notizen: $\quad$ NIEDERSÄCHS. STAATS. U. UNIV.-BIBLIOTHEK GÖTTINGEN

PPN: 330496344

Handel's dramatic oratorios and masques / Winton Dean. - London [u.a.] : Oxford Univ. Press, 1959. - XII, 694 S., [6] Bl. : Ill., Notenbeisp. ; $4^{\circ}+1$ Beil.

Beil. u.d.T.: Variants in the text of Esther

Signatur: $\quad 59$ A 2238*

Notizen: $\quad 1959.2238$ - NIEDERSÄCHS. STAATS- U. UNIV.-BIBLIOTHEK GÖTTINGEN Beschafft aus Bundesmitteln

PPN: 331841193

Eulenburgs kleine Partitur-Ausgabe : thematisches Verzeichnis. - Leipzig : Eulenburg, [s.a.]. - 32 S. ; kl.-8 ${ }^{\circ}$

Umschlags. ist die Haupttitels.

(M. 2.-, Schw. Frcs. -.80)

Signatur: $\quad 8$ MUS V, 520:IND

Notizen: $\quad 1924.9936$ - EX BIBLIOTHECA REGIA ACADEM. GEORGIAE AUG. 


\section{PPN: 016432827}

Konzertführer Georg Friedrich Händel : 1685-1759 / [Walther Siegmund-Schultze ...]. Mainz [u.a.] : Schott ; Leipzig : Dt. Verl. f. Musik, 1984. - 155 S. : Notenbeisp. ; $8^{\circ}$ (Konzertführer) Lizenzausg. mit Genehmigung d. VEB Dt. Verl. f. Musik Leipzig Nebent.: Georg Friedrich Händel

ISBN 3-7957-2467-8

Signatur: $\quad 2002$ A 1892

Notizen: $\quad$ NIEDERSÄCHS. STAATS. U. UNIV.-BIBLIOTHEK GÖTTINGEN

\section{PPN: 24293806X}

Marx, Hans Joachim:

Händels Oratorien, Oden und Serenaten : ein Kompendium / Hans Joachim Marx. -

Göttingen : Vandenhoeck \& Ruprecht, 1998. - XXXV, 302 S. ; $8{ }^{\circ}$

Literaturverz. S. 280 - 293. - Anh. [S. [257] - 302] enth. unter anderem chronologisches Verz., Kal. d. Aufführ. Händels, Verz. d. “dramatis personae”, Zsstellung d. Bibelstellen ISBN 3-525-27815-2*kart. : DM 44.00, sfr 41.00, S 321.00

Signatur: $\quad 98$ A 27343

Notizen: $\quad$ NIEDERSÄCHS. STAATS. U. UNIV.-BIBLIOTHEK GÖTTINGEN

\section{PPN: 026829630}

Parker-Hale, Mary Ann:

G.F. Handel : a guide to research / Mary Ann Parker-Hale. - New York ; London : Garland, 1988. - XVII, 294 S. : Ill. ; $8^{\circ}$

(Garland composer resource manuals ; 19). -

(Garland reference library of the humanities ; 717)

Indizes S. 275 - 294

ISBN 0-8240-8452-7

Signatur: $\quad$ ZA 40336:717

Notizen: $\quad$ NIEDERSÄCHS. STAATS. U. UNIV.-BIBLIOTHEK GÖTTINGEN -

verknüpft zu den Serien PPN 03607571X und PPN 035825324 


\section{PPN: 323799000}

Rätzer, Manfred:

Szenische Aufführungen von Werken Georg Friedrich Händels vom 18. bis 20. Jahrhundert : eine Dokumentation / Manfred Rätzer. - Halle an der Saale : Händel-Haus, 2000. - 512 S. ; $8^{\circ}$ (Schriften des Händel-Hauses in Halle ; 17)

Literatuverz. S. 506 - 508. - Enth. umfangreiche Reg. S. 291 - 505

ISBN 3-910019-16-1*Pp. : DM 22.00

Signatur: $\quad 2001$ A 25815

Notizen: $\quad$ NIEDERSÄCHS. STAATS. U. UNIV.-BIBLIOTHEK GÖTTINGEN verknüpft zur Serie PPN 036115452

\section{PPN: 185960219}

Scheibler, Albert:

Sämtliche 53 Bühnenwerke des Georg Friedrich Händel : Opern-Führer / Albert

Scheibler. Hrsg.: Europ. Barock-Akad. e.V. ... - Lohmar/Rheinl. : Ed. Köln GbR, 1995. - 823 S. : zahlr. Ill. und Notenbeisp. ; $8^{\circ}$

Diskogr. und Literaturverz. S. 796 - 808. - Nebent.: Opernführer. -

Nebent.: Georg Friedrich Händel

ISBN 3-928010-05-0*kart. : DM 74.00

$\begin{array}{ll}\text { Signatur: } & 95 \text { A } 15023 \text { (1. Ex.) } \\ & 96 \text { A } 25825 \text { (2. Ex.) }\end{array}$

Notizen: $\quad$ NIEDERSÄCHS. STAATS. U. UNIV.-BIBLIOTHEK GÖTTINGEN

\section{PPN: 126325391}

Georg Friedrich Händel : Oratorien-Führer / Albert Scheibler ; Julia Evdokimova. Lohmar : Ed. Köln, 1993. - 591 S. : Ill., Notenbeisp. ; $8^{\circ}$

Literaturverz. und Diskogr. S. 574 - 582

ISBN 3-928010-04-2

Signatur: $\quad 93$ A 26017

Notizen: $\quad$ NIEDERSÄCHS. STAATS. U. UNIV.-BIBLIOTHEK GÖTTINGEN Geschenk des Herausgebers 


\subsection{B e i t r äge, C h ro n i ke n, J a h r b ü ch e r}

\section{PPN: 129579890}

Göttinger Händel-Beiträge / im Auftr. der Göttinger Händel-Ges. hrsg. Göttingen : Vandenhoeck \& Ruprecht ; Kassel : Bärenreiter [1984-1993], 1.1984 -

ISSN 0177-7319

Signatur: $\quad$ ZA 60330

Notizen: NIEDERSÄCHS. STAATS. U. UNIV.-BIBLIOTHEK GÖTTINGEN (bei allen Jg.) Geschenk der Verlage (Jg. 7-8) - In d. SUB Jg. 1-8 vorh.

Vorh. in: $\quad$ MuSe (Jg. 1-6), StAr (Jg. 1-2, 4, 6-7)

PPN: 330060341

Zauft, Karin:

Händel und die Händel-Festspiele in Halle / Karin Zauft. [Übers.: Gesina Falana]. 1. Aufl. - Halle (Saale) : mdv Mitteldt. Verl., 2001. - 129 S. : zahlr. Ill. ; $8^{\circ}$

Text dt. und engl.

ISBN 3-89812-085-6

Signatur: $\quad 2002$ A 1893

Notizen: NIEDERSÄCHSISCHE STAATS- U. UNIV.-BIBLIOTHEK GÖTTINGEN 


\section{PPN: 129527483}

Händel-Jahrbuch / hrsg. von der Georg-Friedrich-Händel-Ges. - Kassel [u.a.] : Bärenreiter ; Leipzig : Breitkopf \& Härtel [1928-1933] ; Leipzig : Dt. Verl. f. Musik [1955-1991] ; Köln : Studio [1992-1995], 1.1928 - 6.1933; [N.F.] 1=7.1955 - 4=10.1958; 5.1959 Beteil. Körp. bis 6.1933: Händel-Gesellschaft. - Repr.: New York, NY : Johnson ; Wiesbaden : Breitkopf \& Härtel. - 1934 - 1954 nicht erschienen - 1=2; 2=3; 3=5; 4=6; 5=8; 6=9 von: Händel-Ges.: Veröffentlichungen der Händel-Gesellschaft ISSN 0440-0615

Signatur: $\quad 8$ MUS III, 1089:1

8 MUS III, 1089:2

8 MUS III, 1089:3

8 MUS III, 1089:4

8 MUS III, 1089:5

8 MUS III, 1089:6

8 Z MUS 119:1-46

Notizen: $\quad 8$ MUS III, 1089: 1929.956 (Jg. 1), 1931.1530 (2-3), 1932.1530 (4), 1933.1530 (5), 1934.1530 (6) - 1956.8268 (Jg. 1-2), 1958.8268 (3-4), 1959.8268 (5), 1961.8268 (6), 1962.8268 (7/8), 1964.8268 (9), 1965.8268 (10/11), 1967.8268 (12), 1969.8268 (13/14), 1971.8268 (15/16), 1972.8268 (17), 1974.8268 (18/19), 1976.8268 (20), 1977.8268 (21/22), 1978.8268 (23-24), 1979.8268 (25), 1980.8268 (26), 1981.8268 (27), 1982.8268 (28), 1983.8268 (29), 1984.8268 (30), 1985.8268 (31), 1986.8268 (32), 1987.8268 (33), 1988.8268 (34), 1989.8268 (35), 1990.8268 (36), 1993.8268 (37-38), 1995.8268 (39), 2000.8268 (44-46) -

EX BIBLIOTHECA REGIA ACADEM. GEORGIAE AUG. (Jg. 1-5) ; EX BIBLIOTHECA ACAD. GEORGIA AUG. (Jg. 6) ; NIEDERSÄCHS. STAATS. U. UNIV.-BIBLIOTHEK GÖTTINGEN (Jg. 7-46) - Überwiesen von der Notgemeinschaft der deutschen Wissenschaft Berlin (Jg. 6)

Vorh. in: $\quad$ MuSe (Jg. 1-38) 


\section{$2.4 \quad$ S a m m l un g e n}

\section{PPN: 032912714}

Bildsammlung : Hogarth-Graphik ; Darstellungen zur Geschichte, Händel-Pflege und Musikkunde. - Halle an der Saale : [Kreuz-Verl.], 1966. - 164 S., [2] Bl. : überw. Ill. ; $8^{\circ}$ (Katalog zu den Sammlungen des Händel-Hauses in Halle ; Teil 4)

\section{Signatur: $\quad$ FA 3135:4}

Notizen: $\quad 1967$ F 3135 - NIEDERSÄCHS. STAATS. U. UNIV.-BIBLIOTHEK GÖTTINGEN verknüpft zum MBW PPN 032912676

PPN: 032912692

Bildsammlung : Porträts. - Halle an der Saale : Kreuz-Verl., 1962. - 288 S. : überw. Ill. ; $8^{\circ}$ (Katalog zu den Sammlungen des Händel-Hauses in Halle ; Teil 2)

Literaturhinweise zur Händel-Ikonogr. S. [281] - 288

\section{Signatur: $\quad$ FA 3135:2}

Notizen: $\quad 1966$ F 3135 - NIEDERSÄCHS. STAATS. U. UNIV.-BIBLIOTHEK GÖTTINGEN verknüpft zum MBW PPN 032912676

\section{PPN: 032912706}

Bildsammlung : Städte- und Gebäudedarstellungen. - Halle an der Saale : [Kreuz-Verl.], 1964. - 380 S., [1] Bl. : überw. Ill., Kt. ; $8^{\circ}$

(Katalog zu den Sammlungen des Händel-Hauses in Halle ; Teil 3)

\section{Signatur: $\quad$ FA 3135:3}

Notizen: $\quad 1966$ F 3135 - NIEDERSÄCHS. STAATS. U. UNIV.-BIBLIOTHEK GÖTTINGEN verknüpft zum MBW PPN 032912676 
PPN: 032912684

Handschriftensammlung. - Halle an der Saale : Kreuz-Verl., 1961. - 330 S., [1] Bl. : Ill., Notenbeisp. ; $8^{\circ}$

(Katalog zu den Sammlungen des Händel-Hauses in Halle ; Teil 1)

Signatur: $\quad$ FA 3135:1

Notizen: $\quad 1963$ F 3135 - NIEDERSÄCHS. STAATS. U. UNIV.-BIBLIOTHEK GÖTTINGEN verknüpft zum MBW PPN 032912676

PPN: 135312469

Schmieder, Wolfgang:

Musikerhandschriften in drei Jahrhunderten : ein Bilderquerschnitt durch die deutsche Musikgeschichte von Bach bis Reger / Wolfgang Schmieder. - Leipzig : Breitkopf \& Härtel, [1939]. - 81 S. : Ill. (45 Faks.). ; $8^{\circ}+1$ Beil.

In Fraktur

Signatur: $\quad 8$ MUS III, 249

Notizen: $\quad 1940.99$ - Universitätsbibliothek Göttingen

\section{PPN: 136145213}

Souvenir : Acis and Galatea ; Masque of love ; as produced at the Great Queen Street Theatre, March 10th, 1902 / by Martin Shaw and [ill. by] Gordon Craig. - [London] : [s.n.], [1902]. [33] Bl. : 18 Taf., Notenbeisp. ; $4^{\circ}$

Signatur: $\quad 4$ MUS III, 1060

Notizen: $\quad 1927.9312$ - EX BIBLIOTHECA REGIA ACADEM. GEORGIAE AUG. -

Geschenk aus dem Nachlass von Prof. W. Voigt. 1927 


\section{$2.5 \quad$ D o k u m e n t e}

\section{Nachlaß K. Brandi}

Händel-Opern-Festspiele in Göttingen.

(Universitätsbund Göttingen)

Papiere, Unterlagen, Zeitungen (Berichte) u. dergl., Korrespondenzen.

1920 - 1934 (vor allem 1923/24)

1 Mappe. Nr. 1 - $118^{5}$

Signatur: $\quad$ Cod. Ms. K. Brandi 21

Anmerkung: Die Nr. über die Titelaufn. ist die auf das Dok. not. Nr.

Nr. 1

Ansprache in dem Konzert zur Feier der 20. Wiederkehr der Erstaufführung von G.

F. Händels Rodelinde in Göttingen, 26. Juni 1920 / von Karl Brandi. - 6 S. ; $8^{\circ}$

Sonderdr. aus: Mitteilungen des Universitätsbundes Göttingen ; 21 (1941) 1

Vorh. in: $\quad$ MuSe

Nr. 2

Eine Wiederbelebung von Opern Händels / von F. Bernoulli. - 2 S.

In Fraktur. - Artikel aus: Neue Zürcher Zeitung ; Jg. 142 (1921), 26. Juli

Nr. 3

Einladung zur Hauptversammlung auf Mittwoch, 5. Juli 1922, 41/2 Uhr in die Aula der Universität ... : Uraufführung von G. Fr. Händels Julius Cäsar ... ; Die Oper Otto und Theophano ... / Univ.-Bund Göttingen e.V. - 1 Bl.

[Konzert-Bestellkarte]

Nr. 5

Händel-Opernfestspiele Göttingen : Veranstaltung des Universitätsbundes / Ltg. des Univ.-Bundes Göttingen . - $1 \mathrm{Bl}$.

[Einladungsschreiben]

\footnotetext{
${ }^{5}$ Aus dem Findbuch »Nachlass Karl Brandi (1868-1946) Verzeichnis«
} 
Nr. 6

[Erklärung über Beitragszahlung] für den Händelopern-Fonds des Universitätsbundes

Göttingen. - $1 \mathrm{Bl}$.

Maschinenschriftl.

Nr. 25

Händel-Opern-Festspiele Göttingen. - 2 Ex.

[Erklärung über Beitragszahlung] für den Händel-Opern-Fonds des Universitätsbundes Göttingen. - $1 \mathrm{Bl}$.

Nr. 53

Schreiben von Feuilleton-Red. Dr. Eberhard Sarter an Geheimen Reg. Rat Prof. Dr.

Karl Brandi : Hannover, den 24. Sept. 1923

Maschinenschriftl., auf Vordr.: Hannoverscher Kurier, Zeitung für Norddeutschland

Nr. 55

Händelfeier in Hannover. - $2 \mathrm{~S}$.

Enth. 5 Beitr.: Unsere Händeloper / von Hanns Niedecken-Gebhard. Stimmen der

Vergangenheit. Zeitechte Aufführungen / von Th. W. Werner. Was ist uns Händel.

Händels Persönlichkeit / von Hugo Leichtentritt.

Artikeln aus: Die Unterhaltung, literarische Beilage zum hannoverschen Kurier ;

Nr. 469/70 (1923), 7. Oktober

Nr. 56

Händel-Fest in Hannover / Bernard Wieman. - $1 \mathrm{~S}$.

Artikel aus: Drittes Blatt der Osnabrücker Zeitung ; Jg. 158 (1923), 13. Oktober, Musik

Nr. 64

Satzung der Händelstiftung des Universitätsbundes. - 1924. - 1 Bl.

Maschinenschriftl.

Nr. 77-78

Händel-Opern-Festspiele : fünftes Jahr, 5.-13. Juli 1924 ; G. Fr. Händels Opern ; ...

Xerxes ... ; Rodelinde ... - 2 Ex.

[Konzert-Bestellkarte] 
Nr. 100

Händels „Herakles“ : szenische Uraufführung in Münster / G. A. Walters [Zeitungs-Artikel]

Nr. 101

Händels „Herakles“ in Münster : szenische Aufführung des Oratoriums. - 1 S. : Ill. [Zeitungs-Artikel]

Nr. 102

Ausfallen der Göttinger Händelfestspiele

Artikel aus: Hannoverscher Curier ; (1925), Mai

Nr. 108

Göttingens Händel-Festspiele / von Th. W. Werner

Artikel aus: Beilage zum Hannoverschen Kurier ; Nr. 248/49 (1925), 30. Mai

Nr. 109

Händel-Konzert des Universitätsbundes

Artikel aus: Göttinger Tageblatt ; Nr. 167 (1925), 19. Juli

Nr. 110

Aus der Haendelstadt : Konzert des Göttinger Universitätsbundes / Th. W. Werner Artikel aus: Hannoverscher Kurier ; Jg. 77 (1925), 20. Juli

Nr. 118

Göttinger Händel-Fest 1934 / veranst. von der Göttinger Händelges. e. V. Göttingen : Wurm, [1934]. - [4] Bl.

Enth.: Händel-Musik in Göttingen / Brandi. Zur szenischen Aufführung von „Acis und Galatea“ / Fritz Lehmann. Bemerkungen zur Abendmusik / Gustav Adolf Trumpff. - In Fraktur 
PPN: 22535330X

Ordnung des neunten Elbmusikfestes / Musikfest-Comité. - Braunschweig, 1836. - [1] Bl. ; 8 ○ In Fraktur

Signatur: $\quad 4$ MUS III, $9220(1)$

Anmerkung: $\quad$ Stück $1-6$ zsgeb.

Notizen: $\quad$ EX BIBLIOTHECA REgIA ACADEM. GEORGIAE AUG.

PPN: 251758796

Texte zum ersten und dritten Concerte beim neunten Elbmusikfeste. -

Braunschweig : gedruckt bei Friedrich Krampe, 1836. - 16 S. ; $8^{\circ}$

In Fraktur. - Die Vorlage enth. insges. 2 Werke

\section{[Enthaltenes Werk, PPN 35761562X]}

Der Messias / von Händel. - 1836. - S. [3] - 12

In d. Vorlage als I bezeichnet

Signatur: $\quad 4$ MUS III, 9220 (5)

Anmerkung: Stück 1 - 6 zsgeb. 


\title{
3. $\quad H$ ä n d e l - P f l e g e
}

\subsection{F e i e r l i c h k e i t e n}

\subsubsection{Händ e l-Fest spie le Göt tingen}

\section{PPN: 129931977}

Göttinger Händel-Festspiele / Göttinger Händelgesellschaft e.V. - Göttingen : Händelges., Nachgewiesen [2.]1921 - 5.1924; 7.1927; 1947 - 1955; 1958 - 1959; 1961; 1963; 1965; 1967; 1969 - 1970; 1973; 1980 - 1989

Nebent. teils: Händel-Festspiele. - 1970: 50 Jahre Göttinger Händel-Festspiele. - 1980: 60 Jahre Göttinger Händel-Festspiele 1920 - 1980. - Beteil. Körp. anfangs: Universitätsbund Göttingen. - Forts. als Monographie behandelt. - 4.1923 - 7.1927: Händelopernfestspiele $<$ Göttingen>: Händelopernfestspiele, 1946: Händelopernfestspiele <Göttingen>: Göttinger Händel-Opern-Festspiele, 1956 - 1957; 1971 - 1972: Göttinger Händel-Fest: Göttinger Händelfest, 1960; 1962; 1964; 1966 und 1968: Göttinger Händelfestspiele: Göttinger Händel-Tage

\author{
Signatur: $\quad 8$ MUS III, 1066 (1921) \\ 8 MUS III, 1067 (1922 - 1927) \\ ZA 87468 \\ Notizen: $\quad 1921.4132$ (Jg. 2), 1922.3114 (Jg. 3), 1937.3463 (Jg. 4), 1924.2872 (Jg. 5), \\ 1927.7460 (Jg. 7) - EX BIBLIOTHECA REGIA ACADEM. GEORGIAE AUG. \\ (Jg. 2, 4-7) ; EX BIBLIOTHECA ACAD. GEORGIAE AUG. (Jg. 3) - In d. ZDB \\ fehlt die Angabe einiger Jg. d. Bestandes in d. SUB: 1960, 1964, 1966, \\ 1968, 1971-1972, 1974-1979
}

\section{PPN: 253569702}

Göttinger Händel-Festspiele 1990, 1. bis 6. Juni : Programme, Texte und Einführungen in die Werke ; [70 Jahre Göttinger Händel-Festspiele] / künstlerischer Leiter: John Eliot Gardiner. Hrsg. vom Vorstand der Göttinger Händel-Ges. e. V. - Göttingen, 1990. 111 S. : zahlr. Ill. ; $8^{\circ}$

Kongr.: Göttinger Händel-Festspiele ; 70 (Göttingen) : 1990.06.01-06

(Göttinger Händel-Festspiele ; 1990)

Signatur: $\quad$ K 99 A 316

Notizen: $\quad$ NIEDERSÄCHS. STAATS. U. UNIV.-BIBLIOTHEK GÖTTINGEN verknüpft zur Serie PPN 315683457

Vorh. in: $\quad$ GHG, StAr 
PPN: 253570506

Göttinger Händel-Festpiele 1991, 14. bis 17. Juni : Programme, Texte und Einführungen in die Werke ; [Händel in Italien] / künstlerischer Leiter: Nicholas McGegan. Hrsg. vom Vorstand der Göttinger Händel-Ges. e. V. - Göttingen, 1991. - 103 S. : zahlr. Ill. ; $8^{\circ}$ Kongr.: Göttinger Händel-Festspiele ; 71 (Göttingen) : 1991.06.14-17 (Göttinger Händel-Festspiele ; 1991)

Signatur: $\quad$ K 99 A 317

Notizen: $\quad$ NIEDERSÄCHS. STAATS. U. UNIV.-BIBLIOTHEK GÖTTINGEN verknüpft zur Serie PPN 315683457

Vorh. in: $\quad$ GHG, StAr

PPN: 254022316

Göttinger Händel-Festspiele 1992, 4. bis 8. Juni : Programme, Texte und Werkeinführungen ; [Händel in Deutschland] / künstlerischer Leiter: Nicholas McGegan. Hrsg. vom Vorstand der Göttinger Händel-Ges. e. V. - Göttingen, 1992. - 142 S. : zahlr. Ill., Kt., Notenbeisp. ; 8

Kongr.: Göttinger Händel-Festspiele ; 72 (Göttingen) : 1992.06.04-08

(Göttinger Händel-Festspiele ; 1992)

Händel-Diskogr.: Opern und Oratorien, S. 131 - 139

Signatur: $\quad 99$ A 18217

Notizen: $\quad$ NIEDERSÄCHS. STAATS. U. UNIV.-BIBLIOTHEK GÖTTINGEN verknüpft zur Serie PPN 315683457

Vorh. in: $\quad$ GHG, StAr

PPN: 254022197

Göttinger Händel-Festspiele 1993, 9. bis 13. Juni : Programme, Texte und Werkeinführungen ; [Händel und das Haus Hannover] / künstlerischer Leiter: Nicholas McGegan. Hrsg. vom Vorstand der Göttinger Händel-Ges. e. V. - Göttingen, 1993. - 155 S. : zahlr. Ill., Kt. ; 8 Kongr.: Göttinger Händel-Festspiele ; 73 (Göttingen) : 1993.06.09-13

(Göttinger Händel-Festspiele ; 1993)

Signatur: $\quad 99$ A 18218

Notizen: $\quad$ NIEDERSÄCHS. STAATS. U. UNIV.-BIBLIOTHEK GÖTTINGEN verknüpft zur Serie PPN 315683457

Vorh. in: $\quad$ GHG, StAr 


\section{PPN: 254661742}

Programme, Texte und Werkeinführungen : Göttinger Händel-Festspiele 10. bis 13. Juni 1994 ; [Händel und der Herzog von Chandos] / künstlerischer Leiter: Nicholas McGegan. Hrsg. vom Vorstand der Göttinger Händel-Ges. e.V. - Göttingen, 1994. - 96 S. : zahlr. Ill. ; 8 Kongr.: Göttinger Händel-Festspiele ; 74 (Göttingen) : 1994.06.10-13

(Göttinger Händel-Festspiele ; 1994)

Gesangstext engl. und dt.

Signatur: $\quad$ K 2000 A 1855

Notizen: $\quad$ NIEDERSÄCHS. STAATS. U. UNIV.-BIBLIOTHEK GÖTTINGEN verknüpft zur Serie PPN 315683457 - Geschenk des Herausgebers

Vorh. in: $\quad$ GHG, MuSe, StAr

\section{PPN: 250628627}

Händel und die englische Tradition : Programme, Texte und Werkeinführungen ; Göttinger Händel-Festspiele 1. bis 6. Juni 1995 / künstlerischer Leiter: Nicholas McGegan. Hrsg. von der Göttinger Händel-Ges. e.V. - Göttingen, 1995. - 124 S. : zahlr. Ill., Kt., Notenbeisp. ; 8 Kongr.: Göttinger Händel-Festspiele ; 75 (Göttingen) : 1995.06.01-06

(Göttinger Händel-Festspiele ; 1995)

Gesangstexte engl. und dt.

$\begin{array}{ll}\text { Signatur: } & \text { K } 99 \text { A } 2766 \\ \text { Notizen: } & \text { NIEDERSÄCHS. STAATS. U. UNIV.-BIBLIOTHEK GÖTTINGEN - } \\ & \text { verknüpft zur Serie PPN } 315683457\end{array}$

Vorh. in: $\quad$ GHG, MuSe, StAr

\section{PPN: 250628783}

Händel und seine deutschen Zeitgenossen : Programme, Texte und Werkeinführungen ; Göttinger Händel-Festspiele 31. Mai bis 3. Juni 1996 / künstlerischer Leiter: Nicholas McGegan. Hrsg. von der Göttinger Händel-Ges. e.V. - Göttingen, 1996. - 139 S. : Ill., Kt., Notenbeisp. ; quer-8 ${ }^{\circ}$

Kongr.: Göttinger Händel-Festspiele ; 76 (Göttingen) : 1996.05.31-06.03

(Göttinger Händel-Festspiele ; 1996)

Signatur: $\quad$ K 99 A 2768

Notizen: $\quad$ NIEDERSÄCHS. STAATS. U. UNIV.-BIBLIOTHEK GÖTTINGEN verknüpft zur Serie PPN 315683457

Vorh. in: $\quad$ GHG, StAr 
PPN: 305258273

Händel und die Welt des Orient : Programme, Texte und Werkeinführungen ; Göttinger Händel-Festspiele 28. Mai - 2. Juni 1998 / künstlerischer Leiter: Nicholas McGegan.

Hrsg. von der Göttinger Händel-Ges. e.V. - Göttingen, 1998. - 167 S. : zahlr. Ill., Kt. ; $8^{\circ}$ Kongr.: Göttinger Händel-Festspiele ; 78 (Göttingen) : 1998.05.28-06.02

(Göttinger Händel-Festspiele ; 1998)

Gesangstexte teilw. ital., teilw. engl., mit dt. Übers.

Signatur: $\quad$ K 99 A 2774 (1. Ex.)

$$
\text { Za } 1 / 2 \text { (2. Ex.) }
$$

Notizen: $\quad$ NIEDERSÄCHS. STAATS. U. UNIV.-BIBLIOTHEK GÖTTINGEN verknüpft zur Serie PPN 315683457

Vorh. in: $\quad$ GHG, StAr

PPN: 271034777

Frauengestalten bei Händel : Programme, Texte und Werkeinführungen ; Göttinger HändelFestspiele 27. Mai - 1. Juni 1999 / künstlerischer Leiter: Nicholas McGegan. Hrsg. von der Göttinger Händel-Ges. e. V. - Göttingen, 1999. - 168 S. : zahlr. Ill., Kt. ; $8^{\circ}$

Kongr.: Göttinger Händel-Festspiele ; 79 (Göttingen) : 1999.05.27-06.01

(Göttinger Händel-Festspiele ; 1999)

Gesangstexte teilw. engl., teilw. ital., mit dt. Übers.

Signatur: $\quad$ K 99 A 2770

Notizen: $\quad$ NIEDERSÄCHS. STAATS. U. UNIV.-BIBLIOTHEK GÖTTINGEN verknüpft zur Serie PPN 315683457

Vorh. in: $\quad$ GHG, MuSe, StAr

\section{PPN: 317489518}

Händel - ein Weltbürger : Programme, Texte und Werkeinführungen ; Internationale Händel-Festspiele Göttingen 7. Juni - 13. Juni 2000 / künstlerischer Leiter: Nicholas McGegan. Hrsg. von der Göttinger Händel-Ges. e.V. [Red.: Dorothea Schröder]. Göttingen, 2000. - 203 S. : zahlr. Ill., Kt. ; $8^{\circ}$

Kongr.: Internationale Händel-Festspiele ; 80 (Göttingen) : 2000.06.07-13

(Göttinger Händel-Festspiele ; 2000)

Gesangstext teilw. ital., teilw. engl., mit dt. Übers.

Signatur: $\quad 2000$ A 21489

Notizen: $\quad$ NIEDERSÄCHS. STAATS. U. UNIV.-BIBLIOTHEK GÖTTINGEN verknüpft zur Serie PPN 315683457

Vorh. in: $\quad$ GHG, MuSe, StAr 


\section{PPN: 332967638}

Händel - Pastorale und Drama : Programme, Texte und Werkeinführungen ; Internationale Händel-Festspiele Göttingen 30. Mai - 5. Juni 2001 / künstlerischer Leiter: Nicholas McGegan. Hrsg. von der Göttinger Händel-Ges. e.V. [Red.: Dorothea Schröder]. - Göttingen, 2001. - 203 S. : zahlr. Ill., Kt. ; $8^{\circ}+1$ eingeb. Beil.

Kongr.: Internationale Händel-Festspiele ; 81 (Göttingen) : 2001.05.30-06.05

(Göttinger Händel-Festspiele ; 2001)

Gesangstext teilw. engl., teilw. ital., teilw. lat., mit dt. Übers.

Signatur: 2001 A 27220

Notizen: $\quad$ NIEDERSÄCHS. STAATS. U. UNIV.-BIBLIOTHEK GÖTTINGEN verknüpft zur Serie PPN 315683457

Vorh. in: $\quad$ GHG, MuSe, StAr

\section{PPN: 34926810X}

Händel und „Le goût français“ : Programme, Texte und Werkeinführungen ; Internationale Händel-Festspiele Göttingen 15. Mai - 21. Mai 2002 / künstlerischer Leiter: Nicholas McGegan. Hrsg. von der Göttinger Händel-Ges. e. V. - Göttingen, 2002. - 185 S. : zahlr. Ill. ; quer-8 ${ }^{\circ}$

Kongr.: Internationale Händel-Festspiele ; 82 (Göttingen) : 2002.05.15-21

(Göttinger Händel-Festspiele ; 2002)

Gesangstext teilw. franz., teilw. ital., teilw. engl., mit dt. Übers.

Signatur: $\quad 2002$ A 28035

Notizen: $\quad$ NIEDERSÄCHS. STAATS. U. UNIV.-BIBLIOTHEK GÖTTINGEN verknüpft zur Serie PPN 315683457

Vorh. in: $\quad$ GHG, StAr

\section{PPN: 36358398X}

Der späte Händel und die Neue Musik des 18. Jahrhunderts : Programme, Texte und Werkeinführungen ; Internationale Händel-Festspiele Göttingen 27. Mai - 03. Juni 2003 / künstlerischer Leiter: Nicholas McGegan. Hrsg. von der Göttinger Händel-Ges. e. V. - Göttingen, 2003. - 150 S. : zahlr. Ill., Notenbeisp. ; quer-8

Kongr.: Internationale Händel-Festspiele ; 83 (Göttingen) : 2003.05.27-06.03

(Göttinger Händel-Festspiele ; 2003)

Gesangstexte teilw. engl., teilw. lat., teilw. ital., mit dt. Übers.

Signatur: $\quad 2003$ A 26806

Notizen: $\quad$ NIEDERSÄCHS. STAATS. U. UNIV.-BIBLIOTHEK GÖTTINGEN verknüpft zur Serie PPN 315683457

Vorh. in: $\quad$ GHG, StAr 


\section{PPN: 387329897}

„The power of musick” - Das Erhabene bei Händel : Programme, Texte und Werkeinführungen ; Internationale Händel-Festspiele Göttingen 23. Mai 02. Juni 2004 / künstlerischer Leiter: Nicholas MacGegan. Hrsg. von der Göttinger Händel-Ges. e. V. - Göttingen, 2004. - 220 S. : zahlr. Ill. ; quer-8º Kongr.: Internationale Händel-Festspiele ; 84 (Göttingen) : 2004.05.23-06.02 (Göttinger Händel-Festspiele ; 2004)

Gesangstexte teilw. engl., teilw. ital., mit dt. Übers.

Signatur: $\quad 2004$ A 8815

Notizen: $\quad$ NIEDERSÄCHS. STAATS. U. UNIV.-BIBLIOTHEK GÖTTINGEN verknüpft zur Serie PPN 315683457

Vorh. in: $\quad$ GHG, StAr

\section{PPN: 484902121}

„The king shall rejoice“ : Händel und das Welfenhaus Hannover : Programme, Texte, Werkeinführungen ; Internationale Händel-Festspiele Göttingen 10. - 21. Mai 2005 / künsterische Leiter: Nicholas MacGegan. Hrsg. von der Göttinger Händel-Ges. e. V. - Göttingen, 2005. - 260 S. : zahlr. Ill. ; quer-8 ${ }^{\circ}$

Kongr.: Internationale Händel-Festspiele ; 85 (Göttingen) : 2005.05.10-21

(Göttinger Händel-Festspiele ; 2005)

Gesangstexte teilw. engl., teilw. ital., teilw. lat., mit dt. Übers.

Signatur: $\quad 2005$ A 26147

Notizen: $\quad$ NIEDERSÄCHS. STAATS. U. UNIV.-BIBLIOTHEK GÖTTINGEN verknüpft zur Serie PPN 315683457

Vorh. in: $\quad$ GHG, StAr 


\subsubsection{Händel-Festspiele Halle/Sale}

\section{PPN: 196584930}

Reichs-Händelgedenktage in Halle : Händel ; 1685/1935. - Halle : Brandt, 1935. 32 S. : zahlr. Ill., Notenbeisp. ; $4^{\circ}$

Kongr.: Reichs-Händelgedenktage ; (Halle) : 1935.02.-06.

(Deutsche Mitte : Sonderh.)

Signatur: $\quad 4$ MUS III, 1094

Notizen: $\quad 1938.1573$ - Universitätsbibliothek Göttingen -

Geschenk des Herrn Oberbürgermeisters der Stadt Halle a. S.

PPN: 130474886

Festschrift der Händelfestspiele ... Halle / Händelfestspielausschuß. - Leipzig : Dt. Verl. f. Musik, 3.1954 - 5.1956

Vorg.: Händelfestspiele: Festschrift

Forts.: Händelfestspiele: Händelfestspiele Halle

$\begin{array}{ll}\text { Signatur: } & 4 \text { Z MUS 104:1954 } \\ & 4 \text { Z MUS 104:1955 } \\ & 4 \text { Z MUS 104:1956 }\end{array}$

Notizen: $\quad 1955.11313$ (Jg. 3), 1980.11313 (Jg. 4), 1956.11313 (Jg. 5) NIEDERSÄCHS. STAATS. U. UNIV.-BIBLIOTHEK GÖTTINGEN (bei alle Jg.) ; Theaterwissenschaftliche Abteilung des Seminars für deutsche Philologie (bei Jg. 4) - Geschenk des Herausgebers (bei Jg. 5)

Vorh. in: $\quad$ MuSe (nur 1956)

PPN: 176349057

Fünf Jahre Händel-Festspiele in Halle. - [Halle] : [Rat der Stadt Halle (Saale)], 1957. [8] Bl. : zahlr. Ill. ; $8^{\circ}$

Text dt., engl., franz. und tschech.

Signatur: $\quad 58$ A 2774

Notizen: $\quad 1958.2774$ - NIEDERSÄCHS. STAATS. U. UNIV.-BIBLIOTHEK GÖTTINGEN Geschenk des Herausgebers 


\section{PPN: 130293237}

Händelfestspiele Halle. - Halle, S. : Festspielausschuß, 6.1957 - 7.1958; 9.1960 - 22.1973

Vorg.: Händelfestspiele: Festschrift der Händelfestspiele ... Halle

1959: Händel-Ehrung der DDR: Festschrift zur Händel-Ehrung der Deutschen

Demokratischen Republik

Forts.: Händelfestspiele der DDR: Händelfestspiele der Deutschen Demokratischen Republik

$\begin{array}{ll}\text { Signatur: } & \text { 4 Z MUS 104:6 } \\ & 4 \text { Z MUS 104:7 } \\ & 4 \text { Z MUS 104:10 } \\ & 4 \text { Z MUS 104:11 } \\ & 4 \text { Z MUS 104:13 } \\ & 4 \text { Z MUS 104:22 }\end{array}$

Notizen: $\quad$ NIEDERSÄCHS. STAATS. U. UNIV.-BIBLIOTHEK GÖTTINGEN (in alle H.) Geschenk des Herausgebers (alle H.)

\section{PPN: 215859197}

39. Händel-Festspiele : vom 8. bis 12. Juni 1990 in Georg Friedrich Händels Geburtsstadt Halle/Saale / [Red.: Hanna John ...]. - Reichertshausen : Gemi, 1990. - 168 S. : zahlr. Ill. ; $8^{\circ}+1$ Beil

Kongr.: Händel-Festspiele ; 39 (Halle <Saale>) : 1990.06.08.-12

Nebent.: Milde Sorte. - Beitr. teilw. dt., teilw. engl., teilw. ital.

*kart.

Signatur: $\quad 2000$ A 29299

Notizen: $\quad$ NIEDERSÄCHS. STAATS. U. UNIV.-BIBLIOTHEK GÖTTINGEN

\section{PPN: 117982172}

40. Händel-Festspiele : vom 7. bis 11. Juni 1991 in Georg Friedrich Händels Geburtsstadt Halle (S.) / [Red.: Hanna John ...]. - Reichertshausen : Gemi, 1991. - 192 S. : zahlr. Ill. ; $8^{\circ}$ Kongr.: Händel-Festspiele ; 40 (Halle <Saale>) : 1991.06.07-11

Beitr. teilw. dt., teilw. engl., teilw. ital.

*kart.

Signatur: $\quad 2000$ A 29300

Notizen: $\quad$ NIEDERSÄCHS. STAATS. U. UNIV.-BIBLIOTHEK GÖTTINGEN

\footnotetext{
${ }^{6}$ Die Signatur mit Jahrgangsangabe steht jeweils nur auf der Vorlage. Zu recherchieren sind die einzelnen Jahrgänge mit „4 Z MUS 104“. Dieser Suchweg betrifft auch den Vorgänger, die Jahrgänge 1954 - 1956.
} 
PPN: 121055701

41. Händel-Festspiele : vom 12. bis 16. Juni 1992 in Halle an der Saale / [Red.: Hanna John .... . - [Reichertshausen] : [Gemi], 1992. - 151 S. : zahlr. Ill. ; $8^{\circ}$

Kongr.: Händel-Festspiele ; 41 (Halle $<$ Saale $>$ ) : 1992.06.12-16

„Das Textbuch“ S. 101 - 151. - Beitr. im Textbuch teilw. engl., teilw. lat., teilw. ital., jeweils mit dt. Übers.

*kart.

Signatur: $\quad 2000$ A 29301

Notizen: $\quad$ NIEDERSÄCHS. STAATS. U. UNIV.-BIBLIOTHEK GÖTTINGEN

PPN: 18374439X

43. Händel-Festspiele in Händels Geburtsstadt Halle (Saale) vom 3. bis 7. Juni 1994 / [Veranst. ist die Stadt Halle. Red.: Patricia Reese ...]. - Halle (Saale), 1994. - 152 S. : zahlr. Ill. ; $8^{\circ}$

Kongr.: Händel-Festspiele ; 43 (Halle <Saale>) : 1994.06.03-07

„Das Textbuch“ S. 117 - 152. - Textbuch teilw. engl., teilw. ital., jeweils mit dt. Übers. *kart.

Signatur: $\quad$ K 99 A 2776

Notizen: NIEDERSÄCHS. STAATS. U. UNIV.-BIBLIOTHEK GÖTTINGEN

Vorh. in: $\quad$ MuSe

PPN: 213317052

45. Händel-Festspiele in Georg Friedrich Händels Geburtsstadt Halle an der Saale : internationales Musikfest an authentischem Ort vom 6. bis 11. Juni 1996 / [Hrsg.: Direktion der Händel-Festspiele. Red.: Patricia Reese]. - [Reichertshausen] : [Gemi], 1996. - 247 S., [6] Bl. : zahlr. Ill., Notenbeisp. ; $8^{\circ}$

Kongr.: Händel-Festspiele ; 45 (Halle $<$ Saale $>$ ) : 1996.06.06-11

Beitr. teilw. dt., teilw. engl., teilw. ital.

*kart.

Signatur: $\quad 99$ A 24206

Notizen: NIEDERSÄCHS. STAATS. U. UNIV.-BIBLIOTHEK GÖTTINGEN

Vorh. in: $\quad$ MuSe 


\section{PPN: 230217672}

46. Händel-Festspiele in Georg Friedrich Händels Geburtsstadt Halle an der Saale : internationales Musikfest an authentischem Ort vom 5. bis 10. Juni 1997 / [Hrsg.: Direktion der Händel-Festspiele. Red.: Patricia Reese]. - [Reichertshausen] : [Gemi], 1997. - 269 S., [3] Bl. : zahlr. Ill., Notenbeisp. ; $8^{\circ}$

Kongr.: Händel-Festspiele ; 46 (Halle $<$ Saale $>$ ) : 1997.06.05-10

Beitr. teilw. dt., teilw. engl., teilw. ital.

*kart.

Signatur: $\quad 2000$ A 19162

Notizen: $\quad$ NIEDERSÄCHS. STAATS. U. UNIV.-BIBLIOTHEK GÖTTINGEN

PPN: 331695782

50. Händel-Festspiele in Georg Friedrich Händels Geburtsstadt Halle an der Saale : vom 8. bis 17. Juni 2001 / Schirmherrschaft Gerhard Schröder ... Veranst. ist die Stadt Halle. [Hrsg.: Direktion der Händelfestspiele. Red.: Patricia Reese ...]. - Halle (Saale), 2001. 190 S., [7] Bl. : zahlr. Ill. ; $8^{\circ}$

Kongr.: Händel-Festspiele ; 50 (Halle <Saale>) : 2001.06.08-17

*kart.

Signatur: $\quad 2001$ A 27221

Notizen: $\quad$ NIEDERSÄCHS. STAATS. U. UNIV.-BIBLIOTHEK GÖTTINGEN

\section{PPN: 34926919X}

Händel-Festspiele : seit 1922 in Georg Friedrich Händels Geburtsstadt Halle an der Saale : vom 7. bis 16. Juni 2002 / Halle [Veranst.]. [Hrsg.: Direktion der HändelFestspiele. Red.: Patricia Reese...]. - Halle (Saale), 2002. - 206 S. : zahlr. Ill. ; $8^{\circ}$ Kongr.: Händel-Festspiele ; (Halle <Saale>) : 2002.06.07-16

Nebent.: "The King shall rejoice"

*kart.

Signatur: $\quad 2003$ A 26658

Notizen: $\quad$ NIEDERSÄCHS. STAATS. U. UNIV.-BIBLIOTHEK GÖTTINGEN 


\subsubsection{Händel-Feste international}

\section{PPN: 135277388}

Burney, Charles:

An account of the musical performances in Westminster-Abbey, and the Pantheon : May 26th, 27th, 29th; and June the 3d, and 5th, 1784 ; in commemoration of Handel / by Charles Burney. - London : Printed for the Benefit of the Musical Fund; and sold by T. Payne and G. Robinson, 1785. - VII, [1 ungez.] S., XVI, 56, 139, [2 ungez.] S. : Ill., Notenbeisp. ; $4^{\circ}$ Enth. anfangs: Widmung an den König, Vorw., Lebensskizze und chronologische Werksliste Händels, Anh., Einl.

Signaturformel: A2-I, B-T

[Auch Sekundärausg.]

Signatur: $\quad 4$ MUS III, 9200

Notizen: $\quad$ EX BIBLIOTHECA REGIA ACAD. GEORGIAE AUG. Sign. d. Sekundärausg. (Mikrofilm): MA 83-57:1501, no. 46

\section{PPN: 13527740X}

Hiller, Johann Adam:

[Der Messias] Nachricht von der Aufführung des Händelschen Messias, in der Domkirche zu Berlin, den 19. May 1786 / von Johann Adam Hiller. - Berlin : gedruckt bey Christian Sigismund Spener, 1786. - 32 S. : Ill. ; $4^{\circ}$

Enth. Widmung an „Sr. Königlichen Hoheit, dem Durchlauchtigsten Prinzen Friedrich Wilhelm, Prinzen von Preußen, ...“. - Erscheinungsjahr nach d. dat. Widmungsr. Signaturformel: A3-D3. - In Fraktur

Signatur: $\quad 4$ MUS III, 9205

Notizen: $\quad$ EX BIBLIOTHECA REGIA ACAD. GEORGIAE AUG. 
PPN: 135277426

Bowley, Robert Kanzow:

Grand Handel musical festival at the Crystal Palace in 1857 : a letter addressed to the members, subscribers, and assistants of the Sacred Harmonic Society / by Robert Bowley. - London : Bradbury and Evans, 1856. - 27 S. ; $8^{\circ}$

Signatur: $\quad 8$ MUS III, 9210

Notizen: $\quad$ EX BIBLIOTHECA REgIA ACADEM. GEORGIAE AUG.

PPN: 135277442

The Handel commemoration festival at the Crystal Palace in 1859 : programme of arrangements / [by Robert K. Bowley]. - London : Burt, 1859. - 15 S. : Notenbeisp. ; $8^{\circ}+1$ Beil.

Beil. u.d.T.: „Block plan of seats“ ; „Comparative dimensions of the principal orchestras of the country“

Signatur: $\quad 8$ MUS III, 9213

Notizen: $\quad$ EX BIBLIOTHECA REgIA ACADEM. GEORGIAE AUG.

PPN: 135277469

The third great triennial Handel Festival at the Crystal Palace, June, 1868 : programme of arrangements / [by Robert K. Bowley]. - London : Exeter Hall, 1868. - [2] Bl., 24 S., [2] Bl. ; $8^{\circ}+1$ Beil.

Beil. u.d.T.: „Approximate plan of stalls“

Signatur: $\quad 8$ MUS III, 9216

Notizen: $\quad$ EX BIBLIOTHECA REGIA ACADEM. GEORGIAE AUG. 


\section{PPN: 135313902}

Bach-Händel-Feier in Celle ; verbunden mit der Wiedereröffnung des Schloßtheaters, des ältesten Theaters Deutschlands, aus dem Jahre 1685 / durchgeführt von der Reichsmusikkammer. - Celle, 1935. - 32 S. : Ill. ; $4^{\circ}$

Kongr.: Deutsche Bach-Händel-Schütz-Feier ; (Celle) : 1935.05.13-14

Umschlags. ist die Hauptitels. - In Fraktur

Signatur: $\quad 4$ MUS III, 1092

Notizen: $\quad 1941.3358$ - Universitätsbibliothek Göttingen -

Geschenk von Herrn Studienrat Fr. Schmidt. Celle

\section{PPN: 013113135}

Bach-Händel-Schütz-Ehrung der DDR 1985 : V. Internationales Bachfest in Verbindung mit dem 60. Bachfest der Neuen Bachgesellschaft ; Leipzig, 19. bis 27. März 1985 / Veranst.: Rat der Stadt Leipzig, Nat. Forschungs- und Gedenkstätten Johann Sebastian Bach der DDR .... Leipzig, 1985. - 303 S. : Ill., Notenbeisp. ; $8^{\circ}$

Kongr.: Internationales Bachfest ; 5 (Leipzig) : 1985.03.19-27

Kongr.: Bachfest der Neuen Bachgesellschaft ; 60 (Leipzig) : 1985.03.19-27

Literaturverz. S. 296f. - Nebent.: Bach

Signatur: $\quad$ ZA 56715:60

Notizen: $\quad$ NIEDERSÄCHS. STAATS. U. UNIV.-BIBLIOTHEK GÖTTINGEN 


\subsection{A u s s t e ll ungen}

\section{PPN: 135347556}

Aus zwei Jahrhunderten deutscher Musik : Ausstellung zur Deutschen Bach-HändelSchütz-Feier 1935. - Berlin : Preuß. Staatsbibliothek, 1935. - 50 S. : Ill. (Portr.). ; $8^{\circ}$ [Katalog]. - In Fraktur

Signatur: $\quad 8$ MUS I, 2826

Notizen: $\quad 1935.872$ - EX BIBLIOTHECA ACAD. GEORGIAE AUG. Geschenk der Preuß. Staatsbibliothek Berlin

\section{PPN: 362518238}

George Frideric Handel, 1685-1759 : catalogue of an exhibition held during the Edinburgh Musical Festival 23 August - 11 September 1948 / National Library of Scotland. - Edinburgh : Clark, 1948. - 20 S.. ; kl.-8

Kongr.: Exhibition ; (Edinburgh) : 1948.08.23-09.11

Introd. by Wm. C. Smith

Signatur: $\quad 58$ A 2883

Anmerkung: Mehrere Ausst.-Kat. zsgeb.

Notizen: $\quad 1958.2883$ - NIEDERSÄCHS. STAATS. U. UNIV.-BIBLIOTHEK GÖTTINGEN Geschenk des Herausgebers

PPN: 014154854

Musikbibliothek der Stadt Leipzig : Joh. Sebas. Bach, George Frideric Handel, Heinrich Schütz. - Leipzig : Musikbibliothek d. Stadt, 1985. - [6 ungez.] S. : Ill. ; $8^{\circ}$

Signatur: $\quad 87$ A 25649

Notizen: $\quad$ NIEDERSÄCHS. STAATS. U. UNIV.-BIBLIOTHEK GÖTTINGEN

\section{PPN: 025112309}

Händel und Hamburg : Ausstellung anlässlich des 300. Geburtstages von Georg Friedrich Händel ; Staats- und Universitätsbibliothek Hamburg Carl von Ossietzky ; 15. Mai bis 29. Juni 1985 / [hrsg. von Hans Joachim Marx ...]. - Hamburg : Verl. d. Musikalienh. Wagner, 1985. - 179, [3 ungez.] S. : zahlr. Ill., Notenbeisp. ; $8^{\circ}$

Kongr.: Ausstellung ; (Hamburg) : 1985.05.15-06.29

ISBN 3-88979-009-7

\section{Signatur: $\quad 87$ A 11044}

Notizen: $\quad$ NIEDERSÄCHS. STAATS. U. UNIV.-BIBLIOTHEK GÖTTINGEN 


\section{PPN: 013520121}

Johann Sebastian Bach, Georg Friedrich Händel : 1685 - 1985 ; Ausstellung vom 22. Juli bis 5. Oktober 1985 / Univ.- und Stadtbibliothek Köln. [Katalogbearb. : Gunter Quarg]. Köln : Univ.- u. Stadtbibliothek, 1985. - 62 S., [2] Bl. : Ill., Notenbeisp. ; $8^{\circ}$

\section{Signatur: $\quad 85$ A 26920}

Notizen: $\quad$ NIEDERSÄCHS. STAATS. U. UNIV.-BIBLIOTHEK GÖTTINGEN

\section{PPN: 023566205}

Handel : a celebration of his life and times, 1685 - 1759 ; [publ. for the exhibition held from 8 November 1985 to 23 February 1986 at the National Portrait Gallery, London] / ed. by Jacob Simon. - London : Nat. Portr. Gallery, 1985. - 296 S. : zahlr. Ill., Notenbeisp. ; $4^{\circ}$ Kongr.: Handel ; (National Portr. Gallery, London) : 1985.11.08.-1986.02.23

Nebent.: Georg Frideric Handel

ISBN 0-904017-68-0 - *ISBN 0-904017-67-0*Pbk.

Signatur: $\quad 88$ B 14142

Notizen: $\quad$ NIEDERSÄCHS. STAATS. U. UNIV.-BIBLIOTHEK GÖTTINGEN

\section{PPN: 252142047}

Musketa, Konstanze:

Musikgeschichte der Stadt Halle : Führer durch die Ausstellung des Händel-Hauses /

Konstanze Musketa. - Halle an der Saale : Händel-Haus, 1998. - 113 S. : zahlr. Ill., Notenbeisp. ; $8^{\circ}$

Literaturverz.

ISBN 3-910019-13-7*kart. : DM 10.00

\section{Signatur: $\quad 99$ A 28504}

Notizen: NIEDERSÄCHS. STAATS. U. UNIV.-BIBLIOTHEK GÖTTINGEN 


\subsection{V o r t r äge $-\mathrm{S}$ y m p o s i e n}

\section{PPN: 135314585}

Voigt, Woldemar:

Händels Samson und Bachs Matthäus-Passion : ein Vortrag / gehalten von W. Voigt. Göttingen : Vandenhoeck \& Ruprecht, 1885. - 31 S. ; $8^{\circ}$

In Fraktur

Signatur: $\quad 8$ MUS III, 1056

Notizen: $\quad 1885.969$ - EX BIBLIOTHECA REGIA ACADEM. GEORGIAE AUG.

\section{PPN: 135314607}

Vier Vorträge gehalten anlässlich der I. Aufführungen der Kaiserin Friedrichstiftung (Werke von G. F. Händel) in Mainz am 17. und 18. Mai 1906 / Mainzer Liedertaf. und Damengesangverein. - Mainz : Verl. d. Kaiserin Friedrich-Stiftung, 1906. 81 S. : Notenbeisp. ; ${ }^{\circ}$

Die Vorlage enth. insges. 4 Werke

\section{[Enthaltenes Werk, PPN 135314623]}

Weber, Wilhelm:

1. Die Grundsätze und Ziele Friedrich Chrysanders bei der Neugestaltung der Händelwerke / Wilhelm Weber. - [1906]. - S. 3 - 19.

\section{[Enthaltenes Werk, PPN 13531464X]}

Bernoulli, Eduard:

2. Quellen zum Studium Händel’scher Chorwerke / E. Bernoulli. - [1906]. -

S. 21 - 45. : Notenbeisp.

\section{[Enthaltenes Werk, PPN 135314666]}

Goldschmidt, Hugo:

3. Nach welchen Grundsätzen haben wir die Ausgestaltung und Vervollkommnung des Händel'schen Einzelgesangs vorzunehmen? / Hugo Goldschmidt. - [1906]. - S. 47 - 74. : Notenbeisp. 


\section{[Enthaltenes Werk, PPN 135314682]}

Volbach, Fritz:

4. Bericht über die Vorführung von Instrumenten, welche für die Aufführung Händel'scher und Bach'scher Werke von praktischer Bedeutung sind / Fritz Volbach. - [1906]. - S. 75 - 81.

Signatur: $\quad 8$ MUS III, 1064

Notizen: $\quad 1935.2581$ - EX BIBLIOTHECA ACAD. GEORGIAE AUG. Geschenk von Herrn Bibliotheksrat i. R. Dr. Joachim, Göttingen

Vorh. in: $\quad$ MuSe

PPN: 135356016

Schering, Arnold:

Die Welt Händels : Rede, gehalten beim Hallischen Händelfest 1922 in der Aula der Universität Halle-Wittenberg, am 27. Mai 1922 / von Arnold Schering. - Essen (Ruhr) : Baedeker, 1922. - 16 S. ; kl.-8º

In Fraktur

Signatur: $\quad 8$ MUS III, 1068

Notizen: $\quad 1924.2090$ - EX BIBLIOTHECA REGIA ACADEM. GEORGIAE AUG. Geschenk der Redaktion der gelehrten Anzeigen Göttingen 1924

Vorh. in: $\quad$ MuSe

PPN: 304413666

Handel : a symposium / ed. by Gerald Abraham. - London [u.a.] : Oxford Univ. Press, 1954. - VI, 328 S. : Notenbeisp. ; $8^{\circ}$

Signatur: $\quad 8$ MUS 759

Notizen: $\quad 1953.4322$ - NIEDERSÄCHS. STAATS. U. UNIV.-BIBLIOTHEK GÖTTINGEN

Vorh. in: MuSe 


\section{PPN: 176679189}

Händel-Ehrung der Deutschen Demokratischen Republik : Halle 11.-19. April 1959 ; Konferenzbericht / [im Auftr. des Händel-Komitees der Dt. Demokrat. Republik hrsg. von Walther Siegmund-Schultze]. - Leipzig : Dt. Verl. f. Musik, 1961. - 271 S., [1] Bl. : Ill., Notenbeisp. ; $8^{\circ}$

Kongr.: Händel-Ehrung der Deutschen Demokratischen Republik ; (Halle <Saale>) : 1959.04.11-19

Literaturangaben

*kart. : DM-Ost 22.-

Signatur: $\quad 62$ A 3622

Notizen: $\quad 1962.3622$ - NIEDERSÄCHS. STAATS. U. UNIV.-BIBLIOTHEK GÖTTINGEN

\section{PPN: 05603041X}

Johann Sebastian Bach und Georg Friedrich Händel : zwei führende musikalische Repräsentanten der Aufklärungsepoche ; Bericht über das wissenschaftliche Kolloquium der 24. Händelfestspiele der DDR, Halle (Saale), 9./10. Juni 1976 / [hrsg. im Auftr. der Georg-Friedrich-Händel-Ges. von Walther Siegmund-Schultze]. - [Halle (Saale)], 1976. - 102 S. : Ill. ; $8^{\circ}$

Kongr.: Wissenschaftliches Kolloquium der Händelfestspiele der DDR ; 24 (Halle $<$ Saale $>$ ) : 1975.06.09-10

Literaturangaben. - Falsche Jahresangabe auf Haupttitels.

Signatur: $\quad$ ZA 49162:24

Notizen: $\quad$ NIEDERSÄCHS. STAATS. U. UNIV.-BIBLIOTHEK GÖTTINGEN

Vorh. in: $\quad$ MuSe

\section{PPN: 023191945}

Georg Friedrich Händel als Wegbereiter der Wiener Klassik : [Bericht über die wissenschaftliche Konferenz zu den 26. Händelfestspielen der DDR in Halle (Saale) am 24. und 25. Juni 1977] / im Auftr. der Georg-Friedrich-Händel-Ges. hrsg. von Walther Siegmund-Schultze. - Halle (Saale), 1977. - 143 S. : Notenbeisp. ; $8^{\circ}$ Kongr.: Händelfestspiele der DDR ; 26 (Halle <Saale>) : 1977.06.24-25

Kongr.: Wissenschaftliche Konferenz zu den Händelfestspielen der DDR ; 26 (Halle <Saale>) : 1977.06.24-25

(Kongress- und Tagungsberichte der Martin-Luther-Universität Halle-Wittenberg). (Wissenschaftliche Beiträge / Martin-Luther-Universität Halle-Wittenberg ; 1977,39 = G 4) Literaturangaben

Signatur: $\quad$ ZA 27855:1977,39

Notizen: $\quad$ NIEDERSÄCHS. STAATS. U. UNIV.-BIBLIOTHEK GÖTTINGEN verknüpft zur Serie PPN 167351621 


\section{PPN: 012347612}

G. F. Händel und seine italienischen Zeitgenossen : [Bericht über die wissenschaftliche Konferenz zu den 27. Händelfestspielen der DDR in Halle (Saale) am 5. und 6. Juni 1978] / im Auftr. der Georg-Friedrich-Händel-Ges. hrsg. von Walther Siegmund-Schultze. - Halle (Saale), 1979. - 118 S. : Notenbeisp. ; $8^{\circ}$

Kongr.: Händelfestspiele der DDR ; 27 (Halle <Saale>) : 1978.06.05-06

Kongr.: Wissenschaftliche Konferenz zu den Händelfestspielen der DDR ; 27

(Halle $<$ Saale $>$ ) : 1978.06.05-06

(Kongress- und Tagungsberichte der Martin-Luther-Universität Halle-Wittenberg). (Wissenschaftliche Beiträge / Martin-Luther-Universität Halle-Wittenberg ; 1979,8 = G 5)

Literaturangaben. - Beitr. teilw. dt., teilw. franz.

Signatur: $\quad$ ZA 27855:1979,8

Notizen: $\quad$ NIEDERSÄCHS. STAATS. U. UNIV.-BIBLIOTHEK GÖTTINGEN verknüpft zur Serie PPN 167351621

Vorh. in: $\quad$ MuSe

PPN: 023758236

Fragen der Aufführungspraxis und Interpretation Händelscher Werke in Vergangenheit und Gegenwart : [Bericht über die wissenschaftliche Konferenz zu den 28. Händelfestspielen der DDR in Halle (Saale) am 11. und 12. Juni 1979] / im Auftr. der Georg-Friedrich-Händel-Ges. hrsg. von Walther Siegmund-Schultze. - Halle (Saale), 1980. - 136 S. : Notenbeisp. ; $8^{\circ}$ Kongr.: Händelfestspiele der DDR ; 28 (Halle <Saale>) : 1979.06.11-12

Kongr.: Wissenschaftliche Konferenz zu den Händelfestspielen der DDR ; 28 (Halle $<$ Saale $>$ ) : 1979.06.11-12

(Kongress- und Tagungsberichte der Martin-Luther-Universität Halle-Wittenberg). (Wissenschaftliche Beiträge / Martin-Luther-Universität Halle-Wittenberg ; 1980,7 = G 6) Literaturangaben

Signatur: $\quad$ ZA 27855:1980,7

Notizen: $\quad$ NIEDERSÄCHS. STAATS. U. UNIV.-BIBLIOTHEK GÖTTINGEN verknüpft zur Serie PPN 167351621

Vorh. in: $\quad$ MuSe 


\section{PPN: 012648817}

Anthem, Ode, Oratorium : ihre Ausprägung bei G. F. Händel ; [Bericht über die wissenschaftliche Konferenz zu den 29. Händelfestspielen der DDR am 16. und 17. Jui 1980 in Halle (Saale)] / hrsg. von Walther Siegmund-Schultze. - Halle (Saale), 1981. - 107 S. : Notenbeisp. ; $8^{\circ}$

Kongr.: Händelfestspiele der DDR ; 29 (Halle <Saale>) : 1980.06.16-17

Kongr.: Wissenschaftliche Konferenz zu den Händelfestspielen der DDR ; 29

(Halle $<$ Saale $>$ ) : 1980.06.16-17

(Kongress- und Tagungsberichte der Martin-Luther-Universität Halle-Wittenberg). -

(Wissenschaftliche Beiträge / Martin-Luther-Universität Halle-Wittenberg ; 1981,14 = G 7)

Literaturangaben

Signatur: $\quad$ ZA 27855:1981,14

Notizen: $\quad$ NIEDERSÄCHS. STAATS. U. UNIV.-BIBLIOTHEK GÖTTINGEN verknüpft zur Serie PPN 167351621

Vorh. in: $\quad$ MuSe (2 Ex.)

\section{PPN: 024289396}

Probleme der Händelschen Oper (insbesondere am Beispiel „Poro”) : [Bericht über die wissenschaftliche Konferenz zu den 30. Händelfestspielen der DDR am 15. und 16. Juni 1981 in Halle (Saale)] / hrsg. von Walther Siegmund-Schultze. - Halle (Saale), 1982. 123 S. : Notenbeisp. ; $8^{\circ}$

Kongr.: Händelfestspiele der DDR ; 30 (Halle <Saale>) : 1981.06.15-16

Kongr.: Wissenschaftliche Konferenz zu den Händelfestspielen der DDR ; 30

(Halle $<$ Saale $>$ ) : 1981.06.15-16

(Kongress- und Tagungsberichte der Martin-Luther-Universität Halle-Wittenberg). (Wissenschaftliche Beiträge / Martin-Luther-Universität Halle-Wittenberg ; 1982,21 = G 8) Literaturangaben

Signatur: $\quad$ ZA 27855:1982,21

Notizen: $\quad$ NIEDERSÄCHS. STAATS. U. UNIV.-BIBLIOTHEK GÖTTINGEN verknüpft zur Serie PPN 167351621 


\section{PPN: 013219413}

Thematik und Ideenwelt der Antike bei Georg Friedrich Händel : [Bericht über die wissenschaftliche Konferenz zu den 31. Händelfestspielen der DDR am 14. und 15. Juni 1982 in Halle (Saale)] / hrsg. von Walther Siegmund-Schultze. - Halle (Saale), 1983. - 110 S. ; $8^{\circ}$

Kongr.: Händelfestspiele der DDR ; 31 (Halle <Saale>) : 1982.06.14-15

Kongr.: Wissenschaftliche Konferenz zu den Händelfestspielen der DDR ; 31

(Halle $<$ Saale $>$ ) : 1982.06.14-15

(Kongress- und Tagungsberichte der Martin-Luther-Universität Halle-Wittenberg). (Wissenschaftliche Beiträge / Martin-Luther-Universität Halle-Wittenberg ; 1983,24 = G 10) Literaturangaben

Signatur: $\quad$ ZA 27855:1983,24

Notizen: $\quad$ NIEDERSÄCHS. STAATS. U. UNIV.-BIBLIOTHEK GÖTTINGEN verknüpft zur Serie PPN 167351621

\section{PPN: 014016397}

Georg Friedrich Händel im Verständnis des 19. Jahrhunderts : [Bericht über die wissenschaftliche Konferenz zu den 32. Händelfestspielen der DDR am 13. und 14. Juni 1983 in Halle (Saale)] / hrsg. von Walther Siegmund-Schultze. - Halle (Saale), 1984. - 159 S. : Ill. ; $8^{\circ}$

Kongr.: Händelfestspiele der DDR ; 32 (Halle <Saale>) : 1983.06.13-14

Kongr.: Wissenschaftliche Konferenz zu den Händelfestspielen der DDR ; 32

(Halle < Saale >) : 1983.06.13-14

(Kongress- und Tagungsberichte der Martin-Luther-Universität Halle-Wittenberg). -

(Wissenschaftliche Beiträge / Martin-Luther-Universität Halle-Wittenberg ; 1984,38 = G 11)

Literaturangaben

Signatur: $\quad$ ZA 27855:1984,38

Notizen: $\quad$ NIEDERSÄCHS. STAATS. U. UNIV.-BIBLIOTHEK GÖTTINGEN verknüpft zur Serie PPN 167351621

Vorh. in: $\quad$ MuSe 


\section{PPN: 026662280}

Bach-Händel-Schütz-Ehrung der Deutschen Demokratischen Republik 1985 : Bericht über die internationale wissenschaftliche Konferenz »Georg Friedrich Händel - Persönlichkeit, Werk, Nachleben «; anläßlich der 34. Händelfestspiele der Deutschen Demokratischen Republik in Halle (Saale) vom 25. bis 27. Februar 1985 / [im Auftr. der Georg-Friedrich-Händel-Ges. und der Martin-Luther-Univ. Halle-Wittenberg hrsg. von Walther Siegmund-Schultze ...]. - Als Ms. gedr., 1. Aufl. - Leipzig : Dt. Verl. f. Musik, 1987. - 231 S. : Notenbeisp. ; $8^{\circ}$

Kongr.: Internationale wissenschaftliche Konferenz ; (Halle $<$ Saale $>$ ) : 1985.02.25-27

Kongr.: Händelfestspiele der Deutschen Demokratischen Republik ; 34

(Halle $<$ Saale $>$ ) : 1985.02.25-27

Beitr. teilw dt., teilw. engl.

ISBN 3-370-00059-8

Signatur: $\quad$ ZA 49162:34

Notizen: $\quad$ NIEDERSÄCHS. STAATS. U. UNIV.-BIBLIOTHEK GÖTTINGEN

\section{PPN: 125453558}

Alte Musik als ästhetische Gegenwart : Bach, Händel, Schütz ; Bericht über den internationalen musikwissenschaftlichen Kongreß, Stuttgart 1985 / Ges. f. Musikforschung. Hrsg. von Dietrich Berke ... ; Bd. 1. - Kassel [u.a.] : Bärenreiter, 1987. - XIII, 543 S. : Notenbeisp. ; $8^{\circ}$

Kongr.: Internationaler musikwissenschaftlicher Kongreß ; (Stuttgart) : 1985.09.15-20

Beitr. teilw. dt., teilw. engl.

ISBN 3-7618-0767-8

Signatur: $\quad 96$ A 22541:1

Notizen: $\quad$ NIEDERSÄCHS. STAATS. U. UNIV.-BIBLIOTHEK GÖTTINGEN verknüpft zum MBW PPN 125453515

\section{PPN: 125453582}

Alte Musik als ästhetische Gegenwart : Bach, Händel, Schütz ; Bericht über den internationalen musikwissenschaftlichen Kongreß, Stuttgart 1985 / Ges. f. Musikforschung. Hrsg. von Dietrich Berke ... ; Bd. 2. - Kassel [u.a.] : Bärenreiter, 1987. - 475 S. : Ill., graph. Darst., Notenbeisp. ; $8^{\circ}$

Kongr.: Internationaler musikwissenschaftlicher Kongreß ; (Stuttgart) : 1985.09.15-20

Beitr. teilw. dt., teilw. engl.

ISBN 3-7618-0767-8

Signatur: $\quad 96$ A 22541:2

Notizen: $\quad$ NIEDERSÄCHS. STAATS. U. UNIV.-BIBLIOTHEK GÖTTINGEN verknüpft zum MBW PPN 125453515 


\section{PPN: 013357190}

Das mitteldeutsche Musikleben vor Händel, Christoph Willibald Gluck (1714-1787) : [Bericht über die wissenschaftliche Konferenz zu den 36. Händelfestspielen der DDR in Halle (Saale) am 15. und 16. Juni 1987] / im Auftr. der Georg-Friedrich-Händel-Ges. hrsg. von Bernd Baselt ... - Halle (Saale), 1988. - 115 S. : Notenbeisp. ; $8^{\circ}$ Kongr.: Händelfestspiele der DDR ; 36 (Halle <Saale>) : 1987.06.15-16

Kongr.: Wissenschaftliche Konferenz zu den Händelfestspielen ; 36

(Halle $<$ Saale $>$ ) : 1987.06.15-16

(Kongress- und Tagungsberichte der Martin-Luther-Universität Halle-Wittenberg). (Wissenschaftliche Beiträge / Martin-Luther-Universität Halle-Wittenberg ; 1988,26 = G 16) Literaturangaben

ISBN 3-86010-151-X

Signatur: $\quad$ ZA 27855:1988,26

Notizen: $\quad$ NIEDERSÄCHS. STAATS. U. UNIV.-BIBLIOTHEK GÖTTINGEN verknüpft zur Serie PPN 167351621

\section{PPN: 024842966}

Händel auf dem Theater : Bericht über die Symposien der Internationalen Händel-Akademie Karlsruhe 1986 und 1987 / hrsg. von Hans Joachim Marx. - Laaber : Laaber-Verl., 1988. 225 S. : Ill., Notenbeisp. ; $8^{\circ}$

Kongr.: Symposium der Internationalen Händel-Akademie ; (Karlsruhe) : 1986.06.30-07.01

Kongr.: Symposium der Internationalen Händel-Akademie ; (Karlsruhe) : 1987.06.18-19 (Veröffentlichungen der Internationalen Händel-Akademie Karlsruhe ; 2). - (Bericht über die Symposien der Internationalen Händel-Akademie ; 1986/1987)

Literaturangaben

ISBN 3-89007-146-5

\section{Signatur: $\quad$ ZA 67246:2}

Notizen: $\quad$ NIEDERSÄCHS. STAATS. U. UNIV.-BIBLIOTHEK GÖTTINGEN verknüpft zu den Serien PPN 170516253 und PPN 182181545

Vorh. in: $\quad$ MuSe 


\section{PPN: 171746082}

Zwischen Bach und Mozart : Vorträge des Europäischen Musikfestes Stuttgart 1988 / Internat. Bachakad. Stuttgart. [Red. Ulrich Prinz]. - Kassel [u.a.] : Bärenreiter, 1994. 367 S. : Ill., Notenbeisp. ; $8^{\circ}$

Kongr.: Europäisches Musikfest ; (Stuttgart) : 1988

(Schriftenreihe der Internationalen Bachakademie Stuttgart ; 4)

Literaturverz. S. 359 - 367

ISBN 3-7618-1029-6

Signatur: $\quad$ ZA 74577:4

Notizen: $\quad$ NIEDERSÄCHS. STAATS. U. UNIV.-BIBLIOTHEK GÖTTINGEN verknüpft zur Serie PPN 036121495

Vorh. in: $\quad$ MuSe

\section{PPN: 026916584}

Aufführungspraxis der Händel-Oper : Bericht über die Symposien der Internationalen Händel-Akademie Karlsruhe 1988 und 1989 / hrsg. von Hans Joachim Marx. -

Laaber : Laaber-Verl., 1990. - 218 S., [2] Bl. : Ill., Notenbeisp. ; $8^{\circ}$

Kongr.: Symposium der Internationalen Händel-Akademie ; (Karlsruhe) : 1988.06.03-04

Kongr.: Symposium der Internationalen Händel-Akademie ; (Karlsruhe) : 1989.03.03-05

(Veröffentlichungen der Internationalen Händel-Akademie Karlsruhe ; 3). - (Bericht über die Symposien der Internationalen Händel-Akademie ; 1988/1989)

Literaturangaben

ISBN 3-89007-210-0

Signatur: $\quad$ ZA 67246:3

Notizen: $\quad$ NIEDERSÄCHS. STAATS. U. UNIV.-BIBLIOTHEK GÖTTINGEN verknüpft zu den Serien PPN 170516253 und PPN 182181545

\section{PPN: 110426568}

Gattungskonventionen der Händel-Oper : Bericht über die Symposien der Internationalen Händel-Akademie Karlsruhe 1990 und 1991 / hrsg. von Hans Joachim Marx. - Laaber : Laaber-Verl., 1992. - 225 S. : Ill., Notenbeisp.. ; $8^{\circ}$

Kongr.: Symposium der Internationalen Händel-Akademie ; (Karlsruhe) : 1990.02.23-24

Kongr.: Symposium der Internationalen Händel-Akademie ; (Karlsruhe) : 1991.03.02.04

(Veröffentlichungen der Internationalen Händel-Akademie Karlsruhe ; 4). - (Bericht über die Symposien der Internationalen Händel-Akademie ; 1990/1991)

Literaturangaben

ISBN 3-89007-267-4

\section{Signatur: $\quad$ ZA 67246:4}

Notizen: $\quad$ NIEDERSÄCHS. STAATS. U. UNIV.-BIBLIOTHEK GÖTTINGEN verknüpft zu den Serien PPN 170516253 und PPN 182181545 


\title{
PPN: 185503012
}

Zur Dramaturgie der Barockoper : Bericht über die Symposien der Internationalen Händel-Akademie Karlsruhe 1992 und 1993 / hrsg. von Hans Joachim Marx. Laaber : Laaber-Verl., 1994. - 230 S. : Ill., Notenbeisp. ; $8^{\circ}$

Kongr.: Symposium der Internationalen Händel-Akademie ; (Karlsruhe) : 1992.02.21-22 Kongr.: Symposium der Internationalen Händel-Akademie ; (Karlsruhe) : 1993.02.20.24 (Veröffentlichungen der Internationalen Händel-Akademie Karlsruhe ; 5). - (Bericht über die Symposien der Internationalen Händel-Akademie ; 1992/1993)

Literaturangaben

ISBN 3-89007-299-2

Signatur: $\quad 96$ A 13978

Notizen: $\quad$ NIEDERSÄCHS. STAATS. U. UNIV.-BIBLIOTHEK GÖTTINGEN verknüpft zur Serie PPN 182181545 und PPN 170516253

\section{PPN: 345955390}

Ausdrucksformen der Musik des Barock : Passionsoratorium, Serenata, Rezitativ ; Bericht über die Symposien der Internationalen Händel-Akademie Karlsruhe 1998 bis 2000 / hrsg. von Siegfried Schmalzriedt. - Laaber : Laaber-Verl., 2002. 297 S. : Ill., zahlr. Notenbeisp. ; $8^{\circ}$

Kongr.: Symposium der Internationalen Händel-Akademie ; (Karlsruhe) : 1998.02.28 Kongr.: Symposium der Internationalen Händel-Akademie ; (Karlsruhe) : 1999.02.27 Kongr.: Symposium der Internationalen Händel-Akademie ; (Karlsruhe) : 2000.02.26 (Veröffentlichungen der Internationalen Händel-Akademie Karlsruhe ; 7). - (Bericht über die Symposien der Internationalen Händel-Akademie ; 1998/2000)

ISBN 3-89007-529-0

\author{
Signatur: $\quad 2002$ A 22676 \\ Notizen: $\quad$ NIEDERSÄCHS. STAATS. U. UNIV.-BIBLIOTHEK GÖTTINGEN - \\ verknüpft zur Serie PPN 182181545 und PPN 170516253
}




\title{
3.4 F e s t s c h r if t e n
}

\section{PPN: 145736520}

Dent, Edward Joseph:

Händel in England : Gedächtnis-Rede anläßlich der 250. Geburtstagsfeier in Halle am 24. Februar 1935 / gehalten von Edward Dent. - Halle (Saale) : Niemeyer, 1936. - 17 S. ; $8^{\circ}$ (Hallische Universitätsreden ; 68)

$\begin{array}{ll}\text { Signatur: } & 8 \text { SVA I, 7449/5:68 } \\ \text { Notizen: } & \text { 1936.2357 - EX BIBLIOTHECA ACAD. GEORGIAE AUG. - } \\ & \text { verknüpft zur Serie PPN 130148296 } \\ \text { Vorh. } \text { in: } & \text { MuSe }\end{array}$

PPN: 02730924X

Bach, Handel, Scarlatti : tercentenary essays / ed. by Peter Williams. - Cambridge [u.a.] : Cambridge Univ. Press, 1985. - XIV, 363 S. : Ill., Notenbeisp. ; $4^{\circ}$ Literaturangaben ISBN 0-521-25217-2

Signatur: $\quad 85$ B 14160

Notizen: $\quad$ NIEDERSÄCHS. STAATS. U. UNIV.-BIBLIOTHEK GÖTTINGEN

\section{PPN: 026594994}

Beiträge zur Geschichte des Oratoriums seit Händel : Festschrift ; Günther Massenkeil zum 60. Geburtstag / hrsg. von Rainer Cadenbach ... - Bonn : Voggenreiter, 1986. - [IX], 595 S. : graph. Darst., Tab., Notenbeisp. ; $8^{\circ}$

Literaturangaben. - Beitr. teilw. dt., teilw. franz. ISBN 3-8024-0146-8

\author{
Signatur: $\quad 87$ A 12000 \\ Notizen: $\quad$ NIEDERSÄCHS. STAATS. U. UNIV.-BIBLIOTHEK GÖTTINGEN \\ Vorh. in: $\quad$ MuSe
}


PPN: 127439196

Festschrift zur Händel-Ehrung der Deutschen Demokratischen Republik 1959. Leipzig : Dt. Verl. für Musik, 1959. - 124 S., [2] Bl. : Notenbeisp. ; $4^{\circ}$

Nebent.: Händel-Ehrung 1959

Signatur: $\quad 59$ B 6829

Notizen: $\quad 1959.6829$ - NIEDERSÄCHS. STAATS. U. UNIV.-BIBLIOTHEK GÖTTINGEN

PPN: 135356199

Georg Friedrich Händel : Abstammung und Jugendwelt ; Festschrift zur 250. Wiederkehr des Geburtstages Georg Friedrich Händels / mit einem Geleitw. von Johannes Weidemann. Beitr.: Richard Bräutigam ... Hrsg. vom Stadtarchiv Halle. - Halle : Gebauer-Schwetschke, 1935. - XVI, 135 S. : 2 Taf. ; $8^{\circ}$

In Fraktur

Signatur: $\quad 8$ MUS III, 1096

Notizen: $\quad 1938.1572$ - Universitätsbibliothek Göttingen

Vorh. in: $\quad$ MuSe

PPN: 18687524X

Georg Friedrich Händel - ein Lebensinhalt : Gedenkschrift für Bernd Baselt (1934 - 1993) / [im Auftr. der Georg-Friedrich-Händel-Ges. und des HändelHauses hrsg. von Klaus Hortschansky ...]. - Halle an der Saale [u.a.] : HändelHaus [u.a.], 1995. - 551 S. : Ill., Notenbeisp. ; $8^{\circ}$ (Schriften des Händel-Hauses in Halle ; 11)

Literaturverz. S. 537 - 551. - Beitr. teilw. dt., teilw. engl.

ISBN 3-910019-09-9 (Händel-Haus) - ISBN 3-7618-1261-2 (Bärenreiter) : DM 58.00

ISMN M-006-31590-1*kart. : DM 58.00

Signatur: $\quad 96$ A 26283

Notizen: $\quad$ NIEDERSÄCHS. STAATS. U. UNIV.-BIBLIOTHEK GÖTTINGEN verknüpft zur Serie PPN 036115452 
PPN: 195757297

Die Göttinger Händel-Festspiele : Festschrift. - Göttingen : Göttinger Händelges., 1953. - 53, [2 ungez.] S. : Ill. (auf 12 Taf.). ; $4^{\circ}$

Signatur: $\quad 4$ MUS 708

Notizen: $\quad 1953.4113$ - NIEDERSÄCHS. STAATS. U. UNIV.-BIBLIOTHEK GÖTTINGEN

Vorh. in: MuSe

\section{PPN: 13535613X}

G. F. Handel and Halle : in memory of the 250th anniversary of the composer's birth / ed. by Lore Liebenam. - Halle (Saale) : Dt.-Engl. Kulturaustausch, 1935. - [12] Bl. : Frontisp., Ill. ; $8^{\circ}$

Vorw. dt.

Signatur: $\quad 8$ MUS III, 1093

Notizen: $\quad 1935.1505$ - EX BIBLIOTHECA ACAD. GEORGIAE AUG. Geschenk vom Deutsch-Englischen Kulturaustausch, Halle

PPN: 024348856

Handel : tercentenary collection / ed. by Stanley Sadie ... Publ. for the Royal Musical Assoc. - Houndmills [u.a.] : Macmillan, 1987. - XI, 308 S. : Ill., Notenbeisp. ; $8^{\circ}$ Indizes (S. 291 - 308). - Based on papers presented at a conference held at the Royal Society of Arts, London in July 1985

ISBN 0-333-42882-X

Signatur: $\quad 88$ A 13588

Notizen: $\quad$ NIEDERSÄCHS. STAATS. U. UNIV.-BIBLIOTHEK GÖTTINGEN

PPN: 157277852

50 Jahre Göttinger Händel-Festspiele : Festschrift ; Göttingen 1970 / hrsg. von Walter Meyerhoff. - Kassel [u.a.] : Bärenreiter-Verl., 1970. - 208 S. ; 8 ○

Chronik der Göttinger Händel-Festspiele 1920-1970, S. 186 - 207

Signatur: $\quad 71$ A 3781

Notizen: $\quad$ NIEDERSÄCHS. STAATS. U. UNIV.-BIBLIOTHEK GÖTTINGEN Beschafft aus Mitteln der Stiftung Volkswagenwerk 
PPN: 135310512

Parke, William Thomas:

Musical memoirs : comprising an account of the general state of music in England, from the first commemoration of Handel, in 1784, to the year 1830 / by W. T. Parke ; Vol. 1. - London : Henry Colburn and Richard Bentley, 1830. - VII, 350 S. ; $8^{\circ}$

Signatur: $\quad 8$ MUS II, 2700:1

Anmerkung: $\quad$ Bd. 1 und 2 zsgeb.

Notizen: $\quad 1916.5747$ - EX BIBLIOTHECA REGIA ACADEM. GEORGIAE AUG. verknüpft zum MBW PPN 135310490

PPN: 188645047

Musical memoirs : comprising an account of the general state of music in England, from the first commemoration of Handel, in 1784, to the year 1830 / by W. T. Parke ; Vol. 2. - London : Henry Colburn and Richard Bentley, 1830. - 333 S. ; $8^{\circ}$

Signatur: $\quad 8$ MUS II, 2700:2

Anmerkung: Bd. 1 und 2 zsgeb.

Notizen: $\quad 1916.5747$ - verknüpft zum MBW PPN 135310490

PPN: 021270406

Strohm, Reinhard:

Essays on Handel and Italian opera / Reinhard Strohm. - Cambridge [u.a.] : Cambridge Univ. Press, 1985. - X, 303 S. : Notenbeisp. ; $8^{\circ}$

Literaturverz. [S. 271 - 290] und Index [S. 291 - 303]

ISBN 0-521-26428-6

Signatur: $\quad 86$ A 13535

Notizen: $\quad$ NIEDERSÄCHS. STAATS. U. UNIV.-BIBLIOTHEK GÖTTINGEN

Vorh. in: $\quad$ MuSe 
4. Ges a m t a u g a b e n

\subsection{Händel-Werkaus gabe von Chrysander}

\section{PPN: 135215226}

Händel, Georg Friedrich:

[Werke] Georg Friedrich Händel’s Werke / hrsg. von Friedrich Chrysander. [Musikdr.], Ausg. der Dt. Händelges. - Leipzig : Breitkopf \& Härtel ; Stich und Dr. d. Ges., 1858-1903

Einheitssacht.: Werke. - Sacht. teilw.: The works of George Frederic Handel. Pr. for the German Handel Soc.

\section{PPN: 135215234}

Susanna : Oratorium / von Georg Friedrich Händel. - [Partitur], Ausg. der Dt. Händelges. - Leipzig : Breitkopf \& Härtel, 1858. - IV, 10, 216 S. ; $2^{\circ}$ (Georg Friedrich Händel’s Werke ; Lfg. 1) Vorw. dt. - Gesangstext engl. und dt. Best.-Nr.: H.W.1

Signatur: $\quad 2$ MUS VII, 341:1

Notizen: $\quad$ EX BIBLIOTHECA REGIA ACADEM. GEORGIAE AUG.

Vorh. in: $\quad$ GHG, MuSe

PPN: 135215242

Klavierstücke / von Georg Friedrich Händel. - [Musikdr.], Ausg. der Dt. Händelges. Leipzig : Breitkopf \& Härtel, 1859. - IV, 174 S. ; $2^{\circ}$

(Georg Friedrich Händel’s Werke ; Lfg. 2)

Best.-Nr.: H.W.2

Signatur: $\quad 2$ MUS VII, 341:2

Notizen: $\quad$ EX BIBLIOTHECA REgIA ACADEM. GEORGIAE AUG.

Vorh. in: MuSe 
PPN: 135215250

Acis und Galatea : Pastoral / von Georg Friedrich Händel. - [Partitur], Ausg. der Dt. Händelges. - Leipzig : Breitkopf \& Härtel, 1859. - V, 4, 132 S. ; $2^{\circ}$

(Georg Friedrich Händel's Werke ; Lfg. 3)

Vorw. dt. - Gesangstext engl. und dt.

Best.-Nr.: H.W.3

Signatur: $\quad 2$ MUS VII, 341:3

Notizen: $\quad 1894.3961$ - EX BIBLIOTHECA REGIA ACADEM. GEORGIAE AUG.

Vorh. in: $\quad$ GHG, MuSe

PPN: 135215269

Herakles : Oratorium / von Georg Friedrich Händel. - [Partitur], Ausg. der Dt.

Händelges. - Leipzig : Breitkopf \& Härtel, 1859. - 12, 262 S. ; $2^{\circ}$

(Georg Friedrich Händel's Werke ; Lfg. 4)

Einheitssacht.: Hercules, HWV 60. - Vorw. dt. - Gesangstext engl. und dt.

Best.-Nr.: H.W.4

Signatur: $\quad 2$ MUS VII, 341:4

Notizen: $\quad$ EX BIBLIOTHECA REGIA ACADEM. GEORGIAE AUG.

Vorh. in: $\quad$ GHG, MuSe

PPN: 135215277

Athalia : Oratorium / von Georg Friedrich Händel. - [Partitur], Ausg. der Dt.

Händelges. - Leipzig : Breitkopf \& Härtel, 1859. - 11, 215 S. ; $2^{\circ}$

(Georg Friedrich Händel's Werke ; Lfg. 5)

Vorw. dt. - Gesangstext engl. und dt.

Best.-Nr.: H.W.5

Signatur: $\quad 2$ MUS VII, 341:5

Notizen: $\quad$ EX BIBLIOTHECA REGIA ACADEM. GEORGIAE AUG.

Vorh. in: $\quad$ GHG, MuSe 
PPN: 135215285

L' allegro, il pensieroso ed il moderato : Oratorium / von Georg Friedrich Händel. - [Partitur], Ausg. der Dt. Händelges. - Leipzig : Breitkopf \& Härtel, 1859. - [2] Bl., 12, 180 S. ; $2^{\circ}$ (Georg Friedrich Händel's Werke ; Lfg. 6)

Parallelsacht.: Frohsinn, Schwermut und Mäßigung. - Vorw. dt. - Gesangstext engl. und dt. Best.-Nr.: H.W.6

Signatur: $\quad 2$ MUS VII, 341:6

Notizen: $\quad$ EX BIBLIOTHECA REGIA ACADEM. GEORGIAE AUG.

Vorh. in: $\quad$ GHG, MuSe

PPN: 135215293

Semele : Oratorium / von Georg Friedrich Händel. - [Partitur], Ausg. der Dt. Händelges. - Leipzig : Breitkopf \& Härtel, 1860. - [1] Bl., 12, 234 S. ; $2^{\circ}$

(Georg Friedrich Händel’s Werke ; Lfg. 7)

Vorw. dt. - Gesangstext engl. und dt.

Best.-Nr.: H.W.7

Signatur: $\quad 2$ MUS VII, 341:7

Notizen: $\quad$ EX BIBLIOTHECA REGIA ACADEM. GEORGIAE AUG.

Vorh. In: GHG, MuSe

PPN: 135215307

Theodora : Oratorium / von Georg Friedrich Händel. - [Partitur], Ausg. der Dt. Händelges. - Leipzig : Breitkopf \& Härtel, 1860. - [1] Bl., 10, 223 S. ; $2^{\circ}$

(Georg Friedrich Händel's Werke ; Lfg. 8)

Vorw. dt. - Gesangstext engl. und dt.

Best.-Nr.: H.W.8

Signatur: $\quad 2$ MUS VII, 341:8

Anmerkung: Lfg. 8 und 9 zsgeb.

Notizen: $\quad$ EX BIBLIOTHECA REGIA ACADEM. GEORGIAE AUG.

Vorh. in: GHG, MuSe 
PPN: 135215315

Passion nach dem Evang. Johannes / von Georg Friedrich Händel. - [Partitur], Ausg. der Dt. Händelges. - Leipzig : Breitkopf \& Härtel, 1860. - V, 4, 78 S. ; $2^{\circ}$

(Georg Friedrich Händel’s Werke ; Lfg. 9)

Vorw. dt. - Gesangstext dt. und engl.

Best.-Nr.: H.W.9

Signatur: $\quad 2$ MUS VII, 341:9

Anmerkung: Lfg. 8 und 9 zsgeb.

Vorh. in: GHG, MuSe

PPN: 135215323

Samson : Oratorium / von Georg Friedrich Händel. - [Partitur], Ausg. der Dt. Händelges. -

Leipzig : Breitkopf \& Härtel, 1861. - XI, 12, 296 S. ; $2^{\circ}$

(Georg Friedrich Händel’s Werke ; Lfg. 10)

Vorw. dt. - Gesangstext dt. und engl.

Best.-Nr.: H.W.10

Signatur: $\quad 2$ MUS VII, 341:10

Anmerkung: $\quad$ Lfg. 8 und 9 zsgeb.

Notizen: $\quad$ EX BIBLIOTHECA REGIA ACADEM. GEORGIAE AUG.

Vorh. in: $\quad$ GHG, MuSe

PPN: 135215331

Trauerhymne auf den Tod der Königin Karoline / von Georg Friedrich Händel. - [Partitur], Ausg. der Dt. Händelges. - Leipzig : Breitkopf \& Härtel, 1861. - [5] Bl., 81 S. ; $2^{\circ}$

(Georg Friedrich Händel's Werke ; Lfg. 11)

Einheitssacht.: The ways of Zion do mourn, HWV 264. - Vorw. dt. - Gesangstext engl. und dt. Best.-Nr.: H.W.11

Signatur: $\quad 2$ MUS VII, 341:11

Anmerkung: Lfg. 11 und 12 zsgeb.

Notizen: $\quad$ EX BIBLIOTHECA REGIA ACADEM. GEORGIAE AUG.

Vorh. in: $\quad$ GHG, MuSe 
PPN: 13521534X

Alexander's Fest oder die Macht der Tonkunst : eine Ode zu Ehren der heil. Cäcilia von John Dryden / in Musik gesetzt von Georg Friedrich Händel. - [Partitur], Ausg. der Dt. Händelges. - Leipzig : Breitkopf \& Härtel, 1862. - IV, [1] Bl., 4, 162 S. ; $2^{\circ}$

(Georg Friedrich Händel's Werke ; Lfg. 12)

Einheitssacht.: Alexander's feast or The power of musick, HWV 75. - Vorw. dt. -

Gesangstext engl. und dt.

Best.-Nr.: H.W.12

Signatur: $\quad 2$ MUS VII, 341:12

Anmerkung: Lfg. 11 und 12 zsgeb.

Vorh. in: GHG, MuSe

PPN: 135215358

Saul : an oratorio / by George Frederic Handel. - [Partitur], pr. for the German Handel Soc. - Leipzig : Breitkopf \& Härtel, 1862. - [3] Bl., 11, 286 S. ; $2^{\circ}$

(The works of George Frederic Handel ; Lfg. 13)

Vorw. engl. - Gesangstext engl. und dt.

Best.-Nr.: H.W.13

Signatur: $\quad 2$ MUS VII, 341:13

Notizen: $\quad$ EX BIBLIOTHECA REGIA ACADEM. GEORGIAE AUG.

Vorh. in: GHG, MuSe

PPN: 135215366

Krönungshymnen für König Georg II. / von Georg Friedrich Händel. - [Partitur],

Ausg. der Dt. Händelges. - Leipzig : Breitkopf \& Härtel, 1863. - 129 S. ; $2^{\circ}$

(Georg Friedrich Händel's Werke ; Lfg. 14)

Einheitssacht.: On the resurrection, HWV 286. - Vorw. dt. - Inh.-Verz. und

Gesangstext engl. und dt.

Best.-Nr.: H.W.14

Signatur: $\quad 2$ MUS VII, 341:14

Anmerkung: Lfg. 14 und 15 zsgeb.

Notizen: $\quad$ EX BIBLIOTHECA REGIA ACADEM. GEORGIAE AUG.

Vorh. in: $\quad$ GHG, MuSe 
PPN: 135215374

Passion nach B. H. Brockes / von Georg Friedrich Händel. - [Partitur], Ausg. der Dt. Händelges. - Leipzig : Breitkopf \& Härtel, 1863. - [5] Bl., 155 S. ; $2^{\circ}+1$ eingeb. Beil. (Georg Friedrich Händel’s Werke ; Lfg. 15)

Einheitssacht.: Der für die Sünde der Welt gemarterte und sterbende Jesus, HWV 48. Vorw. dt. - Gesangstext engl. und dt.

Best.-Nr.: H.W.15

Signatur: $\quad 2$ MUS VII, 341:15

Anmerkung: Lfg. 14 und 15 zsgeb.

Vorh. in: $\quad$ GHG, MuSe

PPN: 135215382

Israel in Aegypten : Oratorium / von Georg Friedrich Händel. - [Partitur], Ausg. der Dt. Händelges. - Leipzig : Breitkopf \& Härtel, 1863. - IV, 279 S. ; $2^{\circ}$

(Georg Friedrich Händel’s Werke ; Lfg. 16)

Einheitssacht.: Israel in Egypt (Exodus), HWV 54. - Vorw. dt. - Inh.-Verz. und

Gesangstext engl. und dt.

Best.-Nr.: H.W.16

Signatur: $\quad 2$ MUS VII, 341:16

Notizen: $\quad$ EX BIBLIOTHECA REgIA ACADEM. GEORGIAE AUG.

Vorh. in: $\quad$ GHG, MuSe

PPN: 135215390

Josua : Oratorium / von Georg Friedrich Händel. - [Partitur], Ausg. der Dt. Händelges. Leipzig : Breitkopf \& Härtel, 1864. - 8, 199 S. ; $2^{\circ}$

(Georg Friedrich Händel's Werke ; Lfg. 17)

Einheitssacht.: Joshua, HWV 64. - Vorw. dt. - Gesangstext engl. und dt.

Best.-Nr.: H.W.17

Signatur: $\quad 2$ MUS VII, 341:17

Notizen: $\quad$ EX BIBLIOTHECA REGIA ACADEM. GEORGIAE AUG.

Vorh. in: $\quad$ GHG, MuSe 


\section{PPN: 135215404}

Die Wahl des Herakles / von Georg Friedrich Händel. - [Partitur], Ausg. der Dt.

Händelges. - Leipzig : Breitkopf \& Härtel, 1864. - 3, [1], 90 S., [2] Bl. ; $2^{\circ}$

(Georg Friedrich Händel's Werke ; Lfg.18)

Einheitssacht.: The choice of Hercules, HWV 69. - Vorw. dt. - Inh.-Verz. und

Gesangstext engl. und dt.

Best.-Nr.: H.W.18

Signatur: $\quad 2$ MUS VII, 341:18

Notizen: $\quad$ EX BIBLIOTHECA REgIA ACADEM. GEORGIAE AUG.

Vorh. in: $\quad$ GHG, MuSe

PPN: 135215412

Belsazar : Oratorium / von Georg Friedrich Händel. - [Partitur], Ausg. der Dt. Händelges.

- Leipzig : Stich und Dr. der Ges., 1864. - V, 14, 267 S. ; $2^{\circ}$

(Georg Friedrich Händel’s Werke ; Lfg. 19)

Einheitssacht.: Belshazzar, HWV 61. - Vorw. dt. - Gesangstext engl. und dt.

Best.-Nr.: H.W.19

Signatur: $\quad 2$ MUS VII, 341:19

Notizen: $\quad$ EX BIBLIOTHECA REGIA ACADEM. GEORGIAE AUG.

Vorh. in: $\quad$ GHG, MuSe

PPN: 135215420

Sieg der Zeit und Wahrheit : Oratorium / von Georg Friedrich Händel. - [Partitur], Ausg. der Dt. Händelges. - Leipzig : Stich und Dr. der Ges., 1865. - [3] Bl., 7 , 168 S. ; $2^{\circ}+1$ Beil.

(Georg Friedrich Händel's Werke ; Lfg. 20)

Einheitssacht.: The triumph of time and truth, HWV 71. - Nachtr. zu S. 145 (145 - 145/l).

- Vorw. dt. - Gesangstext engl. und dt.

Best.-Nr.: H.W.20

Signatur: $\quad 2$ MUS VII, 341:20

Notizen: $\quad$ EX BIBLIOTHECA REgIA ACADEM. GEORGIAE AUG.

Vorh. in: GHG, MuSe 
PPN: 135215439

Instrumental-Concerte / von Georg Friedrich Händel. - [Partitur], Ausg. der Dt. Händelges. - Leipzig : Stich und Dr. der Ges., 1865. - IV, 116 S. ; $2^{\circ}+1$ Beil.

(Georg Friedrich Händel's Werke ; Lfg. 21)

Einheitssacht.: Konzerte, Instr. / Ausw. - Vorw. dt.

Best.-Nr.: H.W.21

Signatur: $\quad 2$ MUS VII, 341:21

Notizen: $\quad$ EX BIBLIOTHECA REGIA ACADEM. GEORGIAE AUG.

Vorh. in: $\quad$ MuSe

PPN: 135215447

Judas Maccabäus : Oratorium / von Georg Friedrich Händel. - [Partitur], Ausg. der Dt.

Händelges. - Leipzig : Stich und Dr. der Ges., 1866. - IV, 7, 231 S. ; $2^{\circ}$

(Georg Fridrich Händel's Werke ; Lfg. 22)

Einheitssacht.: Judas Maccabaeus, HWV 63. - Vorw. dt. - Gesangstext engl. und dt.

Best.-Nr.: H. W.22

Signatur: $\quad 2$ MUS VII, 341:22

Notizen: $\quad$ EX BIBLIOTHECA REgIA ACADEM. GEORGIAE AUG.

Vorh. in: GHG, MuSe

PPN: 135215455

Cäcilien-Ode / von Georg Friedrich Händel. - [Partitur], Ausg. der Dt. Händelges. -

Leipzig : Stich und Dr. der Ges., 1866. - 3, 87 S. ; $2^{\circ}$

(Georg Friedrich Händel’s Werke ; Lfg. 23)

Einheitssacht.: Ode for St. Cecilia’s Day, HWV 76. - Vorw. dt. - Gesangstext engl. und dt.

Best.-Nr.: H.W.23

Signatur: $\quad 2$ MUS VII, 341:23

Anmerkung: Lfg. 23 - 25 zsgeb.

Notizen: $\quad$ EX BIBLIOTHECA REgIA ACADEM. GEORGIAE AUG.

Vorh. in: $\quad$ MuSe 
PPN: 135215463

Il trionfo del tempo e della verità / comp. dal G. F. Händel. - [Partitur], Ausg. der Dt. Händelges. - Leipzig : Stich und Dr. der Ges., 1866. - III, 120 S. ; $2^{\circ}$

(Georg Friedrich Händel’s Werke ; Lfg. 24)

Vorw. dt. - Gesangstext ital.

Best.-Nr.: H.W.24

Signatur: $\quad 2$ MUS VII, 341:24

Anmerkung: Lfg. $23-25$ zsgeb.

Vorh. in: $\quad$ MuSe

PPN: 135215471

Dettinger Te Deum / von Georg Friedrich Händel. - [Partitur], Ausg. der Dt. Händelges. - Leipzig : Stich und Dr. der Ges., 1866. - 4, 108 S., [2] Bl. ; $2^{\circ}$

(Georg Friedrich Händel’s Werke ; Lfg. 25)

Einheitssacht.: Te Deum for the victory of Dettingen, HWV 283. - Vorw. dt.

- Gesangstext engl. und dt.

Best.-Nr.: H.W.25

Signatur: $\quad 2$ MUS VII, 341:25

Anmerkung: Lfg. $23-25$ zsgeb.

Vorh. in: MuSe

PPN: 13521548X

Solomon : an oratorio / by George Frederic Handel. - [Partitur], Ausg. der Dt.

Händelges. - Leipzig : Stich und Dr. der Ges., 1867. - 8, 327 S. ; $2^{\circ}$

(Georg Friedrich Händel’s Werke ; Lfg. 26)

Vorw. dt. - Gesangstext engl. und dt.

Best.-Nr.: H.W.26

Signatur: $\quad 2$ MUS VII, 341:26

Notizen: $\quad$ EX BIBLIOTHECA REgIA ACADEM. GEORGIAE AUG.

Vorh. in: $\quad$ GHG, MuSe 


\section{PPN: 135215498}

Sonate da Camera / di G. F. Händel. - [Partitur], Ausg. der Dt. Händelges. Leipzig : Stich und Dr. der Ges., [ca. 1867]. - [3] Bl., 200 S. ; $2^{\circ}$

(Georg Friedrich Händel's Werke ; Lfg. 27)

Einheitssacht.: Sonaten, Fl Ob Vl Cemb / Ausw. - Nebent.: Kammermusik.

Best.-Nr.: H.W.27

Signatur: $\quad 2$ MUS VII, 341:27

Anmerkung: Lfg. 27 und 28 zsgeb.

Notizen: $\quad$ EX BIBLIOTHECA REGIA ACADEM. GEORGIAE AUG.

Vorh. in: MuSe

PPN: 135215501

12 Orgel-Concerte / von Georg Friedrich Händel. - [Partitur], Ausg. der Dt. Händelges.

- Leipzig : Stich und Dr. der Ges., 1868. - S. 1-69, 73-140. ; $2^{\circ}$

(Georg Friedrich Händel’s Werke ; Lfg. 28)

Einheitssacht.: Konzerte, Org. - Vorw. dt.

Best.-Nr.: H.W.28

Signatur: $\quad 2$ MUS VII, 341:28

Anmerkung: Lfg. 27 und 28 zsgeb.

Vorh. in: $\quad$ MuSe

PPN: 13521551X

Debora : Oratorium / von Georg Friedrich Händel. - [Partitur], Ausg. der Dt. Händelges.

- Leipzig : Stich und Dr. der Ges., 1869. - 7, 243 S. ; $2^{\circ}$

(Georg Friedrich Händel's Werke ; Lfg. 29)

Einheitssacht.: Deborah, HWV 51. - Nachtr. zu S. 172 (172/a - 172/m). - Vorw. dt. -

Gesangstext engl. und dt.

Best.-Nr.: H.W.29

Signatur: $\quad 2$ MUS VII, 341:29

Notizen: $\quad$ EX BIBLIOTHECA REGIA ACADEM. GEORGIAE AUG.

Vorh. in: $\quad$ MuSe 
PPN: 303740035

12 große Concerte / von Georg Friedrich Händel. - [Partitur], Ausg. der Dt. Händelges.

- Leipzig : Stich und Dr. der Ges., 1869. - [2] Bl., 180 S. ; $2^{\circ}$

(Georg Friedrich Händel's Werke ; Lfg. 30)

Einheitssacht.: Konzerte, Vl Va Vc Kb. - Vorw. dt.

Best.-Nr.: H.W.30

Signatur: $\quad 2$ MUS VII, 341:30

Notizen: $\quad 1894.3961$ - EX BIBLIOTHECA REGIA ACADEM. GEORGIAE AUG.

Vorh. in: $\quad$ MuSe

PPN: 345558561

Concert für Streichinstrumente : Emole / Händel. - Stimmen. - [s.a.]. - 18 St. ; $2^{\circ}$ (Georg Friedrich Händel’s Werke ; Lfg. 30,3)

Hs., in eine Mappe. - Stimmen zu „Concerto III“ in der Lfg. 30 der Ausg. der Dt. Händelges. - Stimmen: Vl 1 2, Va, Vc, Kb.

Signatur: $\quad 2$ MUS VII, 341:30,3

Notizen: GÖTTINGER CONCERT-VEREIN

\section{PPN: 135215544}

Utrechter Te Deum und Jubilate / von Georg Friedrich Händel. - [Partitur, mit unterlegtem Klavierausz.], Ausg. der Dt. Händelges. - Leipzig : Stich und Dr. der Ges., 1869. - [4] Bl., 87 S., [2] Bl. ; $2^{\circ}+3$ Beil.

(Georg Friedrich Händel's Werke ; Lfg. 31)

Einheitssacht.: Te Deum (We praise thee) und Jubilate (O be joyful), HWV 278 - 279. - Inh.-Verz. und Gesangstext engl. und dt.

Best.-Nr.: H.W.31

Signatur: $\quad 2$ MUS VII, 341:31

Notizen: $\quad 1877.3955$ - EX BIBLIOTHECA REGIA ACADEM. GEORGIAE AUG.

Vorh. in: $\quad$ MuSe 
PPN: 135215552

Italienische Duette und Trios / von Georg Friedrich Händel. - [Musikdr.], Ausg. der Dt. Händelges. - Leipzig : Stich und Dr. der Ges., 1870. - III, 109 S. ; $2^{\circ}$

(Georg Friedrich Händel’s Werke ; Lfg. 32)

Einheitssacht.: Duette / Ausw. - Vorw. dt. - Gesangstext ital.

Best.-Nr.: H.W.32

Signatur: $\quad 2$ MUS VII, 341:32

Notizen: $\quad$ EX BIBLIOTHECA REGIA ACADEM. GEORGIAE AUG.

Vorh. in: $\quad$ MuSe

PPN: 135215560

Duetti e Terzetti / di G. F. Händel. - [Musikdr.], 2., vervollst. Ausg., Ausg. der Dt. Händelges. - Leipzig : Stich und Dr. der Ges., 1880. - VI, II, 175 S. ; $2^{\circ}$

(Georg Friedrich Händel’s Werke ; Lfg. $32<2>$ )

Einheitssacht.: Duette / Ausw. - Nebent.: Italienische Duette und Trios. - Inh.-Verz. ital. und dt. - Vorw. dt. - Gesangstext ital.

Best.-Nr.: H.W.32

Signatur: $\quad 2$ MUS VII, 341:32 <2>

Notizen: $\quad 1880.3470$ - EX BIBLIOTHECA REGIA ACADEM. GEORGIAE AUG.

Vorh. in: $\quad$ MuSe

PPN: 135215579

Alexander Balus : Oratorium / von Georg Friedrich Händel. - [Partitur], Ausg. der Dt. Händelges. - Leipzig : Stich und Dr. der Ges., 1870. - IV, 8, 213 S. ; $2^{\circ}$

(Georg Friedrich Händel’s Werke ; Lfg. 33)

Vorw. dt. - Inh.-Verz. und Gesangstext engl. und dt.

Best.-Nr.: H.W.33

Signatur: $\quad 2$ MUS VII, 341:33

Notizen: $\quad$ EX BIBLIOTHECA REGIA ACADEM. GEORGIAE AUG.

Vorh. in: $\quad$ MuSe 
PPN: 135215595

Psalmen : Bd. 1. - [Partitur], Ausg. der Dt. Händelges. - Leipzig : Stich und Dr. der Ges., 1871. - VIII, 288 S. ; $2^{\circ}$

(Georg Friedrich Händel’s Werke ; Lfg. 34)

Einheitssacht.: Psalmen / Ausw. - Vorw. dt. - Inh.-Verz. und Gesangstext engl. und dt. Best.-Nr.: H.W.34

Signatur: $\quad 2$ MUS VII, 341:34

Notizen: $\quad$ EX BIBLIOTHECA REGIA ACADEM. GEORGIAE AUG.

Vorh. in: $\quad$ MuSe

PPN: 135215617

Psalmen : Bd. 2. - [Partitur], Ausg. der Dt. Händelges. - Leipzig : Stich und Dr. der Ges., 1871. - VI, 300 S. ; $2^{\circ}$

(Georg Friedrich Händel’s Werke ; Lfg. 35)

Einheitssacht.: Psalmen / Ausw. - Vorw. dt. - Inh.-Verz. und Gesangstext engl. und dt. Best.-Nr.: H.W.35

Signatur: $\quad 2$ MUS VII, 341:35

Notizen: $\quad$ 11.97.4.M.39240 - EX BIBLIOTHECA REGIA ACADEM. GEORGIAE AUG.

Vorh. in: MuSe

PPN: 135215633

Psalmen : Bd. 3. - [Partitur], Ausg. der Dt. Händelges. - Leipzig : Stich und Dr. der Ges., 1872. - [2] Bl., VII, 247 S. ; $2^{\circ}+2$ Beil.

(Georg Friedrich Händel's Werke ; Lfg. 36)

Einheitssacht.: Psalmen / Ausw. - Vorw. dt. - Inh.-Verz. und Gesangstext engl. und dt. Best.-Nr.: H.W.36

Signatur: $\quad 2$ MUS VII, 341:36

Notizen: $\quad$ 12.126.4.M.39330 - EX BIBLIOTHECA REGIA ACADEM. GEORGIAE AUG.

Vorh. in: MuSe 


\section{PPN: 135215641}

Drei Te Deum / von Georg Friedrich Händel. - [Partitur], Ausg. der Dt. Händelges. Leipzig : Stich und Dr. der Ges., 1872. - [4] Bl., 138 S. ; $2^{\circ}$

(Georg Friedrich Händel's Werke ; Lfg.37)

Einheitssacht.: Te Deum / Ausw. - Inh.-Verz. und Gesangstext engl. und dt.

Best.-Nr.: H.W.37

\section{Signatur: $\quad 2$ MUS VII, 341:37}

Anmerkung: Lfg. 37 und 38 zsgeb.

Notizen: $\quad$ 73.4.M.39780 - EX BIBLIOTHECA REGIA ACADEM. GEORGIAE AUG.

Vorh. in: GHG, MuSe

\section{PPN: 13521565X}

Lateinische Kirchenmusik / von Georg Friedrich Händel. - [Partitur], Ausg. der Dt.

Händelges. - Leipzig : Stich und Dr. der Ges., 1872. - IV, 172 S. ; $2^{\circ}$

(Georg Friedrich Händel’s Werke ; Lfg. 38)

Einheitssacht.: Kirchensonaten / Ausw. - Inh.-Verz. und Gesangstext lat.

Best.-Nr.: H.W.38

Signatur: $\quad 2$ MUS VII, 341:38

Anmerkung: $\quad$ Lfg. 37 und 38 zsgeb.

Notizen: $\quad$ 73.4.M.39781

Vorh. in: $\quad$ GHG, MuSe

\section{PPN: 135215668}

La Resurrezione : oratorio / di G. F. Händel. - [Musikdr.], Ausg. der Dt. Händelges.

- Leipzig : Stich und Dr. der Ges., 1878. - 10, 78 S. ; $2^{\circ}$

(Georg Friedrich Händel’s Werke ; Lfg. 39)

Einheitssacht.: Oratorio per la Risurrezione di Nostro Signor Giesù Cristo, HWV 47.

- Vorw. dt. und engl. - Gesangstext ital.

Best.-Nr.: H.W.39

Signatur: $\quad 2$ MUS VII, 341:39

Notizen: $\quad 1878.3458$ - EX BIBLIOTHECA REGIA ACADEM. GEORGIAE AUG.

Vorh. in: GHG, MuSe 


\section{PPN: 135215676}

Esther : Oratorium ; erste Bearbeitung: 1720 / von Georg Friedrich Händel. - [Partitur], Ausg. der Dt. Händelges. - Leipzig : Stich und Dr. der Ges., 1882. - VI, [1] Bl., 139 S. ; $2^{\circ}$ (Georg Friedrich Händel’s Werke ; Lfg. 40)

Einheitssacht.: Esther (Haman and Mordecai), HWV 50a. - Gesangstext engl. und dt. Best.-Nr.: H.W.40

Signatur: $\quad 2$ MUS VII, 341:40

Anmerkung: Lfg. 40 und 41 zsgeb.

Notizen: $\quad$ 73.4.M.39780 - EX BIBLIOTHECA REGIA ACADEM. GEORGIAE AUG.

Vorh. in: $\quad$ MuSe

\section{PPN: 135215684}

Esther : Oratorium ; zweite Bearbeitung: 1732 / von Georg Friedrich Händel. - [Partitur], Ausg. der Dt. Händelges. - Leipzig : Stich und Dr. der Ges., 1882. - XVIII, 172 S. ; $2^{\circ}$

(Georg Friedrich Händel’s Werke ; Lfg. 41)

Vorw. und Gesangstext engl. und dt.

Best.-Nr.: H.W.41

Signatur: $\quad 2$ MUS VII, 341:41

Anmerkung: Lfg. 40 und 41 zsgeb.

Vorh. in: $\quad$ GHG, MuSe

PPN: 135215692

Joseph : Oratorium / von Georg Friedrich Händel. - [Musikdr.], Ausg. der Dt. Händelges. - Leipzig : Stich und Dr. der Ges., 1883. - XVII, 260 S. ; $2^{\circ}$

(Georg Friedrich Händel's Werke ; Lfg. 42)

Einheitssacht.: Joseph and his brethren, HWV 59. - Vorw. und Gesangstext engl. und dt. Best.-Nr.: H.W.42

Signatur: 2 MUS VII, 341:42

Notizen: $\quad$ EX BIBLIOTHECA REgIA ACADEM. GEORGIAE AUG.

Vorh. in: GHG, MuSe 
PPN: 135215706

Gelegenheits-Oratorium / von 3000 Georg Friedrich Händel. - [Musikdr.], Ausg. der Dt. Händelges. - Leipzig : Stich und Dr. der Ges., 1884. - II, X, 267 S. ; $2^{\circ}$

(Georg Friedrich Händel's Werke ; Lfg. 43)

Einheitssacht.: Occasional oratorio, HWV 62. - Vorw. und Gesangstext engl. und dt. Best.-Nr.: H.W.43

Signatur: $\quad 2$ MUS VII, 341:43

Notizen: $\quad 1884.2834$ - EX BIBLIOTHECA REGIA ACADEM. GEORGIAE AUG.

Vorh. in: $\quad$ GHG, MuSe

PPN: 135215714

Jephtha : Oratorium / von Georg Friedrich Händel. - [Musikdr.], Ausg. der Dt. Händelges. - Leipzig : Stich und Dr. der Ges., 1886. - XVII, 260 S., [1] Bl. ; ${ }^{\circ}$

(Georg Friedrich Händel’s Werke ; Lfg. 44)

Inh.Verz., Vorw. und Gesangstext engl. und dt.

Best.-Nr.: H.W.44

Signatur: $\quad 2$ MUS VII, 341:44

Notizen: $\quad 1886.1076$ - EX BIBLIOTHECA REGIA ACADEM. GEORGIAE AUG.

Vorh. in: $\quad$ GHG, MuSe

PPN: 135215722

Der Messias : Oratorium / von Georg Friedrich Händel. - [Musikdr.], Ausg. der Dt. Händelges. - Leipzig : Stich und Dr. der Ges., 1901 [erschienen] 1902. - XVII, 317 S. ; $2^{\circ}$ (Georg Friedrich Händel's Werke ; Lfg. 45)

Einheitssacht.: Messiah, HWV 56. - Vorw. und Gesangstext engl. und dt.

Best.-Nr.: H.W.45

Signatur: $\quad 2$ MUS VII, 341:45

Notizen: $\quad 1903.1863$ - EX BIBLIOTHECA REGIA ACADEM. GEORGIAE AUG.

Vorh. in: $\quad$ MuSe 


\section{PPN: 135215730}

Ode für den Geburtstag der Königin Anna / von Georg Friedrich Händel. - [Musikdr.], Ausg. der Dt. Händelges. - Leipzig : Stich und Dr. der Ges., 1887. - IV, 54 S. ; $2^{\circ}$ (Georg Friedrich Händel's Werke ; Lfg. 46A)

Einheitssacht.: Eternal source of light divine, HWV 74. - Vorw., Inh.-Verz. und Gesangstext engl. und dt.

Best.-Nr.: H.W.46A

Signatur: $\quad 2$ MUS VII, 341:46A

Anmerkung: Lfg. 46A und 46B zsgeb.

Notizen: $\quad 1887.2438$ - EX BIBLIOTHECA REGIA ACADEM. GEORGIAE AUG.

Vorh. in: GHG, MuSe

PPN: 135215749

Musikalische Scenen zu dem englischen Drama Alceste / von Georg Friedrich Händel. [Musikdr.], Ausg. der Dt. Händelges. - Leipzig : Stich und Dr. der Ges., 1887. - IV, 87 S. ; $2^{\circ}$ (Georg Friedrich Händel's Werke ; Lfg. 46B)

Einheitssacht.: Alceste (Alcides), HWV 45. - Vorw., Inh.-Verz. und Gesangstext engl. und dt. Best.-Nr.: H.W.46B

Signatur: $\quad 2$ MUS VII, 341:46B

Anmerkung: Lfg. 46A und 46B zsgeb.

Notizen: $\quad 1887.3955$

Vorh. in: $\quad$ GHG, MuSe

\section{PPN: 135215757}

Wassermusik, Feuerwerksmusik, Concerte und Doppelconcerte für grosses Orchester / von Georg Friedrich Händel. - [Partitur, Ausg. der Dt. Händelges.]. - Leipzig : Stich und Dr. der Ges., 1886. - III [IV], 231 S. ; $2^{\circ}$

(Georg Friedrich Händel's Werke ; Lfg. 47)

Einheitssacht.: Konzerte, Orch. - Nebent.: Instrumentalmusik für großes Orchester. Vorw. dt.

Best.-Nr.: H.W.47

Signatur: $\quad 2$ MUS VII, 341:47

Notizen: $\quad 1886.2469$ - EX BIBLIOTHECA REGIA ACADEM. GEORGIAE AUG.

Vorh. in: $\quad$ GHG, MuSe 


\section{PPN: 135215765}

Concert III : berichtigender Nachtrag zu dem 47sten Bande von Händel's Werken. - [Partitur, Ausg. der Dt. Händelges.]. - Leipzig : Stich und Dr. der Ges., 1894. - [1] Bl., S. 203-241. ; $2^{\circ}$ (Georg Friedrich Händel's Werke ; Lfg. 47,Suppl.)

Einheitssacht.: Konzerte, Orch. - Nachw. dt. und engl.

Best.-Nr.: H.W.47

Signatur: $\quad 2$ MUS VII, 341:47,SUP

Notizen: $\quad 1894.3961$ - EX BIBLIOTHECA REGIA ACADEM. GEORGIAE AUG.

Vorh. in: $\quad$ GHG, MuSe

PPN: 13521579X

Sammlung verschiedener Instrumental-Werke für Orgel und Klavier, Orchester- und Kammer-Musik / von G. F. Händel. - [Musikdr., Ausg. der Dt. Händelges.]. -

Leipzig : Stich und Dr. der Ges., 1894. - VIII, 243 S. ; $2^{\circ}$

(Georg Friedrich Händel's Werke ; Lfg. 48)

Einheitssacht.: Werke, Kl Org Orch / Ausw. - [Nachtr. zu S. 222, 222/a-222/d]. -

Nebent.: Instrumentalmusik. - Vorw. dt.

Best.-Nr.: H.W.48

Signatur: $\quad 2$ MUS VII, 341:48

Notizen: $\quad 1894.3961$ - EX BIBLIOTHECA REGIA ACADEM. GEORGIAE AUG.

Vorh. in: MuSe

\section{PPN: 135215811}

Cantate a voce sola e basso : libro primo / di G. F. Händel. - [Musikdr., Ausg. der Dt. Händelges.]. - Leipzig : Stich und Dr. der Ges., 1887. - II, [2] Bl., 187 S. ; $2^{\circ}$

(Georg Friedrich Händel’s Werke ; Lfg. 50)

Einheitssacht.: Kantaten / Ausw. - Vorw. dt. und engl. - Gesangstext ital.

Best.-Nr.: H.W.50

Signatur: $\quad 2$ MUS VII, 341:50

Anmerkung: Lfg. 50 und 51 zsgeb.

Notizen: $\quad 1887.2438$ - EX BIBLIOTHECA REGIA ACADEM. GEORGIAE AUG.

Vorh. in: GHG, MuSe 


\section{PPN: 135215838}

Cantate a voce sola e basso : libro secondo / di G. F. Händel. - [Musikdr., Ausg. der Dt. Händelges.]. - Leipzig : Stich und Dr. der Ges., 1887. - II, 172 S. ; $2^{\circ}$

(Georg Friedrich Händel's Werke ; Lfg. 51)

Einheitssacht.: Kantaten / Ausw. - Vorw. dt. und engl. - Inh.-Verz. ital.

Best.-Nr.: H.W.51

Signatur: $\quad 2$ MUS VII, 341:51

Anmerkung: Lfg. 50 und 51 zsgeb.

Notizen: $\quad 1887.3955$

Vorh. in: GHG, MuSe

PPN: 303729643

Cantate con stromenti : libro primo / di G. F. Händel. - [Musikdr., Ausg. der Dt. Händelges.]. - Leipzig : Stich und Dr. der Ges., 1888. - II, 178 S., [1] Bl. ; $2^{\circ}$

(Georg Friedrich Händel's Werke ; Lfg. 52A)

Einheitssacht.: Kantaten / Ausw. - Vorw. dt. - Gesangstext ital.

Best.-Nr.: H.W.52A

Signatur: $\quad 2$ MUS VII, 341:52A

Anmerkung: Lfg. 52A und 52B zsgeb.

Notizen: $\quad 1888.2886$ - EX BIBLIOTHECA REGIA ACADEM. GEORGIAE AUG.

Vorh. in: $\quad$ GHG, MuSe

PPN: 135215854

Cantate con stromenti : libro secondo / di G. F. Händel. - [Musikdr., Ausg. der Dt. Händelges.]. - Leipzig : Stich und Dr. der Ges., 1889. - II, [2] Bl., 159 S. ; $2^{\circ}$

(Georg Friedrich Händel's Werke ; Lfg. 52B)

Einheitssacht.: Kantaten / Ausw. - Vorw. dt. und engl. - Gesangstext ital.

Best.-Nr.: H.W.52B

Signatur: 2 MUS VII, 341:52B

Anmerkung: Lfg. 52A und 52B zsgeb.

Notizen: $\quad 1889.2562$

Vorh. in: GHG, MuSe 
PPN: 135215862

Aci, Galatea, e Polifemo : serenata / di G. F. Händel. - [Musikdr., Ausg. der Dt. Händelges.]. - Leipzig : Stich und Dr. der Ges., 1892. - [2] Bl., 98 S. ; $2^{\circ}$

(Georg Friedrich Händel's Werke ; Lfg. 53)

Einheitssacht.: Serenaten, HWV 49a - 49b

Best.-Nr.: H. W. 53

Signatur: $\quad 2$ MUS VII, 341:53

Anmerkung: Lfg. 53 und 54 zsgeb.

Notizen: $\quad 1892.129$ - EX BIBLIOTHECA REGIA ACADEM. GEORGIAE AUG.

Vorh. in: $\quad$ GHG, MuSe

PPN: 135215870

Il Parnasso in festa : serenata / di G. F. Händel. - [Musikdr.], Ausg. der Dt. Händelges. Leipzig : Stich und Dr. der Ges., 1878. - [1] Bl., 136 S. ; $2^{\circ}$

(Georg Friedrich Händel's Werke ; Lfg. 54)

Einheitssacht.: Il Parnasso in festa per gli sponsali di Teti e Peleo $<$ Serenate $>$, HWV 73. -

Vorw. dt. und engl. - Inh.-Verz. und Gesangstext ital.

Best.-Nr.: H. W. 54

Signatur: $\quad 2$ MUS VII, 341:54

Anmerkung: Lfg. 53 und 54 zsgeb.

Vorh. in: GHG, MuSe

PPN: 135215897

Almira : opera / di G. F. Händel. - [Musikdr.], Ausg. der Dt. Händelges. - Leipzig : Stich und Dr. der Ges., 1873. - [1] Bl., 119 S. ; $2^{\circ}$

(Georg Friedrich Händel’s Werke ; Lfg. 55: Opern ; Bd. 1)

Einheitssacht.: Der in Kronen erlangte Glückswechsel, oder: Almira, Königin von

Kastilien, HWV 1. - Vorw. dt. und engl. - Gesangstext teilw. dt., teilw. ital.

Best.-Nr.: H. W. 55

Signatur: $\quad 2$ MUS VII, 341:55

Anmerkung: Lfg. 55 und 56 zsgeb.

Notizen: $\quad$ 73.8.4.M.40070 - EX BIBLIOTHECA REGIA ACADEM. GEORGIAE AUG.

Vorh. in: $\quad$ GHG, MuSe 
PPN: 135215919

Rodrigo : opera / di G. F. Händel. - [Musikdr.], Ausg. der Dt. Händelges. - Leipzig : Stich und Dr. der Ges., 1873. - [5] Bl., 96 S. ; $2^{\circ}$

(Georg Friedrich Händel's Werke ; Lfg. 56: Opern ; Bd. 2)

Einheitssacht.: Vincer se stesso è la maggior vittoria (Rodrigo), HWV 5. - Vorw. dt. und engl. - Gesangstext ital.

Best.-Nr.: H. W. 56

Signatur: $\quad 2$ MUS VII, 341:56

Anmerkung: Lfg. 55 und 56 zsgeb.

Notizen: $\quad$ 73.8.4.M.40071

Vorh. in: GHG, MuSe

PPN: 135215935

Agrippina : opera / di G. F. Händel. - [Musikdr.], Ausg. der Dt. Händelges. - Leipzig : Stich und Dr. der Ges., 1874. - [3] Bl., 139 S. ; $2^{\circ}$

(Georg Friedrich Händel’s Werke ; Lfg. 57: Opern ; Bd. 3)

Vorw. dt. und engl.

Best.-Nr.: H. W. 57

Signatur: $\quad 2$ MUS VII, 341:57

Anmerkung: Lfg. 57 und 58 zsgeb.

Notizen: $\quad$ 74.8.4.M.40177 - EX BIBLIOTHECA REGIA ACADEM. GEORGIAE AUG.

Vorh. in: $\quad$ MuSe

\section{PPN: 135215951}

Rinaldo : opera / di G. F. Händel. - [Musikdr.], Ausg. der Dt. Händelges. - Leipzig : Stich und Dr. der Ges., 1874. - [3] Bl., 115 S. ; $2^{\circ}$

(Georg Friedrich Händel's Werke ; Lfg. 58: Opern ; Bd. 4)

Einheitssacht.: Rinaldo, HWV 7b. - Vorw. dt. und engl.

Best.-Nr.: H. W. 58

Signatur: $\quad 2$ MUS VII, 341:58

Anmerkung: Lfg. 57 und 58 zsgeb.

Notizen: $\quad$ 74.8.4.M.40178

Vorh. in: $\quad$ GHG, MuSe 


\section{PPN: 135215978}

Rinaldo : opera / di G. F. Händel. - [Musikdr., Ausg. der Dt. Händelges.], 2. Ausg. in zwei Bearb. - Leipzig : Stich und Dr. der Ges., 1896. - VI, 215 S. ; $2^{\circ}$

(Georg Friedrich Händel’s Werke ; Lfg. 58, Ausg. 2: Opern ; Bd. 4)

Einheitssacht.: Rinaldo, HWV 7b. - Vorw. dt. und engl.

Best.-Nr.: H. W. 58

Signatur: 2 MUS VII, 341:58<2>

Notizen: $\quad 1896.1207$ - EX BIBLIOTHECA REgIA ACADEM. GEORGIAE AUG.

Vorh. in: $\quad$ GHG, MuSe

PPN: 135215994

Il Pastor Fido : opera / di G. F. Händel. - [Partitur], Ausg. der Dt. Händelges. -

Leipzig : Stich und Dr. der Ges., 1876. - [4] Bl., 72 S. ; $2^{\circ}$

(Georg Friedrich Händel's Werke ; Lfg. 59: Opern ; Bd. 5)

Einheitssacht.: Il Pastor Fido, HWV 8a. - Vorw. dt. und engl.

Best.-Nr.: H. W. 59

Signatur: $\quad 2$ MUS VII, 341:59

Notizen: $\quad 1876.2409$ - EX BIBLIOTHECA REGIA ACADEM. GEORGIAE AUG.

Vorh. in: GHG, MuSe

PPN: 303653906

Teseo : opera / di G. F. Händel. - [Musikdr.], Ausg. der Dt. Händelges. - Leipzig : Stich und Dr. der Ges., 1874. - [3] Bl., 113 S., [2] Bl. ; $2^{\circ}$

(Georg Friedrich Händel’s Werke ; Lfg. 60: Opern ; Bd. 6)

Vorw. dt. und engl.

Best.-Nr.: H. W. 60

Signatur: $\quad 2$ MUS VII, 341:60

Anmerkung: Lfg. 60 - 62 zsgeb.

Notizen: $\quad$ 74.6.4.M.40491

Vorh. in: GHG, MuSe 
PPN: 135216036

Silla : opera / di G. F. Händel. - [Musikdr.], Ausg. der Dt. Händelges. - Leipzig : Stich und Dr. der Ges., 1875. - [3] Bl., 59 S. ; $2^{\circ}$

(Georg Friedrich Händel's Werke ; Lfg. 61: Opern ; Bd. 7)

Einheitssacht.: Lucio Cornelio Silla, HWV 10. - Vorw. dt. und engl.

Best.-Nr.: H. W. 61

Signatur: $\quad 2$ MUS VII, 341:61

Anmerkung: Lfg. $60-62$ zsgeb.

Notizen: $\quad$ 75.50.4.M.40591

Vorh. in: $\quad$ GHG, MuSe

PPN: 135216052

Amadigi : opera / di G. F. Händel. - [Musikdr.], Ausg. der Dt. Händelges. - Leipzig : Stich und Dr. der Ges., 1874. - [3] Bl., 100 S. ; $2^{\circ}$

(Georg Friedrich Händel’s Werke ; Lfg. 62: Opern ; Bd. 8)

Einheitssacht.: Amadigi di Gaula, HWV 11. - Vorw. dt. und engl.

Best.-Nr.: H. W. 62

Signatur: $\quad 2$ MUS VII, 341:62

Anmerkung: Lfg. 60 - 62 zsgeb.

Notizen: $\quad$ 74.6.4.M.40492

Vorh. in: $\quad$ GHG, MuSe

PPN: 135216079

Radamisto : opera / di G. F. Händel. - [Musikdr.], Ausg. der Dt. Händelges. - Leipzig : Stich und Dr. der Ges., 1875. - [3] Bl., 207 S. ; $2^{\circ}$

(Georg Friedrich Händel’s Werke ; Lfg. 63: Opern ; Bd. 9)

Einheitssacht.: Radamisto, HWV 12a. - Vorw. dt. und engl.

Best.-Nr.: H. W. 63

Signatur: $\quad 2$ MUS VII, 341:63

Anmerkung: Lfg. 63 und 64 zsgeb.

Notizen: $\quad$ 75.50.4.M.40592 - EX BIBLIOTHECA REGIA ACADEM. GEORGIAE AUG.

Vorh. in: $\quad$ GHG, MuSe 


\section{PPN: 135216095}

Muzio Scevola : opera, atto terzo / di G. F. Händel. - [Musikdr.], Ausg. der Dt. Händelges. Leipzig : Stich und Dr. der Ges., 1874. - [3] Bl., 72 S. : 1 Beil. ; $2^{\circ}$

(Georg Friedrich Händel’s Werke ; Lfg. 64: Opern ; Bd. 10)

Hs. Beil. u.d.erm.T.: Nr. 18 Arie Irene und 5 letzten Takte des vorigen Rezitativs (gem. S. 36-39 im Bd.). - Vorw. dt. und engl. - Gesangstext ital. und dt.

Best.-Nr.: H. W. 64

Signatur: $\quad 2$ MUS VII, 341:64

Anmerkung: Lfg. 63 und 64 zsgeb.

Notizen: $\quad$ 74.6.4.M.40493 - EX BIBLIOTHECA REGIA ACADEM. GEORGIAE AUG.

Vorh. in: $\quad$ GHG, MuSe

\section{PPN: 135216117}

Floridante : opera / di G. F. Händel. - [Musikdr.], Ausg. der Dt. Händelges. - Leipzig : Stich und Dr. der Ges., 1876. - [3] Bl., 131 S. ; $2^{\circ}$

(Georg Friedrich Händel’s Werke ; Lfg. 65: Opern ; Bd. 11)

Einheitssacht.: Il Floridante, HWV 14. - Vorw. dt. und engl.

Best.-Nr.: H.W.65

Signatur: $\quad 2$ MUS VII, 341:65

Notizen: $\quad 1876.1330$ - EX BIBLIOTHECA REGIA ACADEM. GEORGIAE AUG.

Vorh. in: $\quad$ GHG, MuSe

PPN: 135216133

Ottone : opera / di G. F. Händel. - [Musikdr.], Ausg. der Dt. Händelges. - Leipzig : Stich und Dr. der Ges., 1881. - [3] Bl., 144 S. ; $2^{\circ}$

(Georg Friedrich Händel’s Werke ; Lfg. 66: Opern ; Bd. 12)

Einheitssacht.: Ottone, re di Germania, HWV 15. - Vorw. dt.

Best.-Nr.: H.W.66

Signatur: $\quad 2$ MUS VII, 341:66

Notizen: $\quad 1881.2181$ - EX BIBLIOTHECA REGIA ACADEM. GEORGIAE AUG.

Vorh. in: GHG, MuSe 


\section{PPN: 13521615X}

Flavio : opera / di G. F. Händel. - [Musikdr.], Ausg. der Dt. Händelges. - Leipzig : Stich und Dr. der Ges., 1875. - [4] Bl., 88 S. ; $2^{\circ}$

(Georg Friedrich Händel's Werke ; Lfg. 67: Opern ; Bd. 13)

Einheitssacht.: Flavio, re de' Langobardi, HWV 16. - Vorw. dt. und engl.

Best.-Nr.: H.W.67

Signatur: $\quad 2$ MUS VII, 341:67

Anmerkung: Lfg. 67 und 68 zsgeb.

Notizen: $\quad$ 75.110.f.M.9178 ${ }^{7}$ - EX BIBLIOTHECA REGIA ACADEM. GEORGIAE AUG.

Vorh. in: GHG, MuSe

PPN: 135216176

Giulio Cesare : opera / di G. F. Händel. - [Musikdr.], Ausg. der Dt. Händelges. -

Leipzig : Stich und Dr. der Ges., 1875. - [4] Bl., 156 S. ; $2^{\circ}$

(Georg Friedrich Händel’s Werke ; Lfg. 68: Opern ; Bd. 14)

Einheitssacht.: Giulio Cesare in Egitto, HWV 17. - Vorw. dt. und engl.

Best.-Nr.: H.W.68

Signatur: $\quad 2$ MUS VII, 341:68

Anmerkung: Lfg. 67 und 68 zsgeb.

Notizen: $\quad$ 75.110.f.M.9179 - EX BIBLIOTHECA REGIA ACADEM. GEORGIAE AUG.

Vorh. in: $\quad$ GHG, MuSe

\section{PPN: 135216192}

Tamerlane : opera / di G. F. Händel. - [Musikdr.], Ausg. der Dt. Händelges. - Leipzig : Stich und Dr. der Ges., 1876. - [3] Bl., 156 S. ; $2^{\circ}$

(Georg Friedrich Händel’s Werke ; Lfg. 69: Opern ; Bd. 15)

Vorw. dt. und engl.

Best.-Nr.: H.W.69

Signatur: $\quad 2$ MUS VII, 341:69

Notizen: $\quad 1876.2409$ - EX BIBLIOTHECA REGIA ACADEM. GEORGIAE AUG.

Vorh. in: $\quad$ GHG, MuSe

${ }^{7}$ „f“ steht hier für das Format Folio 
PPN: 135216214

Rodelinda : opera / di G. F. Händel. - [Musikdr.], Ausg. der Dt. Händelges. - Leipzig : Stich und Dr. der Ges., 1876. - [5] Bl., 123 S. ; $2^{\circ}$

(Georg Friedrich Händel's Werke ; Lfg. 70: Opern ; Bd. 16)

Einheitssacht.: Rodelinda, Regina de’ Langobardi, HWV 19. - Vorw. dt. und engl.

Best.-Nr.: H.W.70

Signatur: $\quad 2$ MUS VII, 341:70

Notizen: $\quad 1876.1330$ - EX BIBLIOTHECA REGIA ACADEM. GEORGIAE AUG.

Vorh. in: $\quad$ GHG, MuSe

PPN: 135216230

Scipione : opera / di G. F. Händel. - [Musikdr.], Ausg. der Dt. Händelges. - Leipzig : Stich und Dr. der Ges., 1877. - [5] Bl., 135 S. ; $2^{\circ}$

(Georg Friedrich Händel’s Werke ; Lfg. 71: Opern ; Bd. 17)

Einheitssacht.: Publio Cornelio Scipione, HWV 20. - Vorw. dt. und engl.

Best.-Nr.: H.W.71

Signatur: $\quad 2$ MUS VII, 341:71

Notizen: $\quad 1877.2988$ - EX BIBLIOTHECA REGIA ACADEM. GEORGIAE AUG.

Vorh. in: $\quad$ GHG, MuSe

PPN: 135216257

Alessandro : opera / di G. F. Händel. - [Musikdr.], Ausg. der Dt. Händelges. - Leipzig : Stich und Dr. der Ges., 1877. - [3] Bl., 136 S. ; $2^{\circ}$

(Georg Friedrich Händel’s Werke ; Lfg. 72: Opern ; Bd. 18)

Vorw. dt. und engl.

Best.-Nr.: H.W.72

Signatur: $\quad 2$ MUS VII, 341:72

Notizen: $\quad 1877.2988$ - EX BIBLIOTHECA REGIA ACADEM. GEORGIAE AUG.

Vorh. in: MuSe 
PPN: 135216273

Admeto : opera / di G. F. Händel. - [Musikdr.], Ausg. der Dt. Händelges. - Leipzig : Stich und Dr. der Ges., 1877. - [3] Bl., 128 S. ; $2^{\circ}$

(Georg Friedrich Händel's Werke ; Lfg. 73: Opern ; Bd. 19)

Einheitssacht.: Admeto, re di Tessaglia, HWV 22. - Vorw. dt. und engl.

Best.-Nr.: H.W.73

Signatur: $\quad 2$ MUS VII, 341:73

Notizen: $\quad 1877.2988$ - EX BIBLIOTHECA REGIA ACADEM. GEORGIAE AUG.

Vorh. in: $\quad$ GHG, MuSe

PPN: 13521629X

Riccardo : opera / di G. F. Händel. - [Musikdr.], Ausg. der Dt. Händelges. - Leipzig : Stich und Dr. der Ges., 1877. - [3] Bl., 127 S. ; $2^{\circ}$

(Georg Friedrich Händel’s Werke ; Lfg. 74: Opern ; Bd. 20)

Einheitssacht.: Riccardo I., re d’ Inghilterra, HWV 23. - Vorw. dt. und engl.

Best.-Nr.: H.W.74

Signatur: $\quad 2$ MUS VII, 341:74

Notizen: $\quad 1877.2988$ - EX BIBLIOTHECA REGIA ACADEM. GEORGIAE AUG.

Vorh. in: $\quad$ GHG, MuSe

PPN: 135216311

Siroe : opera / di G. F. Händel. - [Musikdr.], Ausg. der Dt. Händelges. - Leipzig : Stich und Dr. der Ges., 1878. - [3] Bl., 104 S. ; $2^{\circ}$

(Georg Friedrich Händel’s Werke ; Lfg. 75: Opern ; Bd. 21)

Einheitssacht.: Siroe, re di Persia, HWV 24. - Vorw. dt. und engl.

Best.-Nr.: H.W.75

Signatur: $\quad 2$ MUS VII, 341:75

Notizen: $\quad 1878.3458$ - EX BIBLIOTHECA REGIA ACADEM. GEORGIAE AUG.

Vorh. in: $\quad$ GHG, MuSe 
PPN: 135216338

Tolomeo : opera / di G. F. Händel. - [Musikdr.], Ausg. der Dt. Händelges. - Leipzig : Stich und Dr. der Ges., 1878. - [3] Bl., 95 S., [2] Bl. ; $2^{\circ}$

(Georg Friedrich Händel's Werke ; Lfg. 76: Opern ; Bd. 22)

Einheitssacht.: Tolomeo, re d' Egitto, HWV 25. - Vorw. dt. und engl.

Best.-Nr.: H.W.76

Signatur: $\quad 2$ MUS VII, 341:76

Notizen: $\quad 1878.3458$ - EX BIBLIOTHECA REGIA ACADEM. GEORGIAE AUG.

Vorh. in: $\quad$ GHG, MuSe

PPN: 135216354

Lotario : opera / di G. F. Händel. - [Musikdr.], Ausg. der Dt. Händelges. - Leipzig : Stich und Dr. der Ges., 1879. - [3] Bl., 124 S., [2] Bl. ; $2^{\circ}$

(Georg Friedrich Händel’s Werke ; Lfg. 77: Opern ; Bd. 23)

Vorw. dt. und engl.

Best.-Nr.: H.W.77

Signatur: $\quad 2$ MUS VII, 341:77

Notizen: $\quad 1894.3961$ - EX BIBLIOTHECA REGIA ACADEM. GEORGIAE AUG.

Vorh. in: $\quad$ GHG, MuSe

PPN: 135216370

Partenope : opera / di G. F. Händel. - [Musikdr.], Ausg. der Dt. Händelges. - Leipzig : Stich und Dr. der Ges., 1879. - [3] Bl., 126 S. ; $2^{\circ}$

(Georg Friedrich Händel’s Werke ; Lfg. 78: Opern ; Bd. 24)

Vorw. dt. und engl.

Best.-Nr.: H.W.78

Signatur: $\quad 2$ MUS VII, 341:78

Notizen: $\quad 1895.2002$ - EX BIBLIOTHECA REGIA ACADEM. GEORGIAE AUG.

Vorh. in: $\quad$ MuSe 


\section{PPN: 135216397}

Poro : opera / di G. F. Händel. - [Musikdr.], Ausg. der Dt. Händelges. - Leipzig : Stich und Dr. der Ges., 1880. - [3] Bl., 119 S. ; $2^{\circ}$

(Georg Friedrich Händel’s Werke ; Lfg. 79: Opern ; Bd. 25)

Einheitssacht.: Poro, re dell' Indie, HWV 28. - Vorw. dt. und engl.

Best.-Nr.: H.W.79

Signatur: $\quad 2$ MUS VII, 341:79

Anmerkung: Lfg. 79 und 80 zsgeb.

Notizen: $\quad 1903.1863$ - EX BIBLIOTHECA REGIA ACADEM. GEORGIAE AUG.

Vorh. in: GHG, MuSe

PPN: 135216419

Ezio : opera / di G. F. Händel. - [Musikdr.], Ausg. der Dt. Händelges. - Leipzig : Stich und Dr. der Ges., 1880. - [3] Bl., 116 S. ; $2^{\circ}$

(Georg Friedrich Händel’s Werke ; Lfg. 80: Opern ; Bd. 26)

Vorw. dt. und engl.

Best.-Nr.: H.W.80

Signatur: $\quad 2$ MUS VII, 341:80

Anmerkung: Lfg. 79 und 80 zsgeb.

Vorh. in: $\quad$ MuSe

PPN: 135216435

Sosarme : opera / di G. F. Händel. - [Musikdr.], Ausg. der Dt. Händelges. - Leipzig : Stich und Dr. der Ges., 1880. - [3] Bl., 112 S. ; $2^{\circ}$

(Georg Friedrich Händel’s Werke ; Lfg. 81: Opern ; Bd. 27)

Einheitssacht.: Sosarme, re di Media, HWV 30. - Vorw. dt. und engl.

Best.-Nr.: H.W.81

Signatur: $\quad 2$ MUS VII, 341:81

Notizen: $\quad$ EX BIBLIOTHECA REgIA ACADEM. GEORGIAE AUG.

Vorh. in: $\quad$ MuSe 


\section{PPN: 135216451}

Orlando : opera / di G. F. Hände. - [Musikdr.], Ausg. der Dt. Händelges. - Leipzig : Stich und Dr. der Ges., 1881. - [3] Bl., 112 S. ; $2^{\circ}$

(Georg Friedrich Händel’s Werke ; Lfg. 82: Opern ; Bd. 28)

Vorw. dt.

Best.-Nr.: H.W.82

Signatur: $\quad 2$ MUS VII, 341:82

Anmerkung: Lfg. 82 und 83 zsgeb.

Notizen: $\quad$ EX BIBLIOTHECA REgIA ACADEM. GEORGIAE AUG.

Vorh. in: $\quad$ MuSe

PPN: 135216478

Arianna : opera / di G. F. Händel. - [Musikdr.], Ausg. der Dt. Händelges. - Leipzig : Stich und Dr. der Ges., 1881. - [3] Bl., 119 S. ; $2^{\circ}$

(Georg Friedrich Händel’s Werke ; Lfg. 83: Opern ; Bd. 29)

Einheitssacht.: Arianna in Creta, HWV 32. - Vorw. dt.

Best.-Nr.: H.W.83

Signatur: $\quad 2$ MUS VII, 341:83

Anmerkung: Lfg. 82 und 83 zsgeb.

Vorh. in: $\quad$ GHG, MuSe

\section{PPN: 135216494}

Terpsichore, Prologo, e la seconda versione dell opera Il Pastor Fido / di G. F. Händel. - [Musikdr., Ausg. der Dt. Händelges.]. - Leipzig : Stich und Dr. der

Ges., 1890. - VIII, 115, [2 ungez.] S. ; $2^{\circ}$

(Georg Friedrich Händel's Werke ; Lfg. 84: Opern ; Bd. 30)

Einheitssacht.: Opern, HWV 8a - 8c. - Vorw. dt. und engl.

Best.-Nr.: H.W.84

Signatur: $\quad 2$ MUS VII, 341:84

Anmerkung: Lfg. 84 und 85 zsgeb.

Notizen: $\quad 1890.3200$ - EX BIBLIOTHECA REGIA ACADEM. GEORGIAE AUG.

Vorh. in: MuSe 
PPN: 135216516

Ariodante : opera / di G. F. Händel. - [Musikdr.], Ausg. der Dt. Händelges. Leipzig : Stich und Dr. der Ges., 1881. - [3] Bl., 143 S. ; $2^{\circ}$

(Georg Friedrich Händel’s Werke ; Lfg. 85: Opern ; Bd. 31)

Vorw. dt.

Best.-Nr.: H.W.85

Signatur: $\quad 2$ MUS VII, 341:85

Anmerkung: Lfg. 84 und 85 zsgeb.

Notizen: $\quad 1881.2181$

Vorh. in: $\quad$ GHG, MuSe

PPN: 135216532

Alcina : Oper [in drei Akten] / von Georg Friedrich Händel. - [Musikdr.], Ausg. der Dt. Händelges. - Leipzig : Stich und Dr. der Ges., 1868. - [3] Bl., 150 S., [2] Bl. ; $2^{\circ}$ (Georg Friedrich Händel's Werke ; Lfg. 86: [Opern ; Bd. 32])

Vorw. dt. und engl. - Gesangstext ital. und dt.

Best.-Nr.: H.W.86

Signatur: $\quad 2$ MUS VII, 341:86

Notizen: $\quad$ EX BIBLIOTHECA REgIA ACADEM. GEORGIAE AUG.

Vorh. in: $\quad$ GHG, MuSe

PPN: 135216559

Atalanta : opera / di G. F. Händel. - [Musikdr.], Ausg. der Dt. Händelges. - Leipzig : Stich und Dr. der Ges., 1882. - [3] Bl., 92 S. ; $2^{\circ}$

(Georg Friedrich Händel’s Werke ; Lfg. 87: Opern ; Bd. 33)

Vorw. dt. und engl.

Best.-Nr.: H.W.87

Signatur: $\quad 2$ MUS VII, 341:87

Anmerkung: Lfg. 87 und 88 zsgeb.

Notizen: $\quad$ EX BIBLIOTHECA REGIA ACADEM. GEORGIAE AUG.

Vorh. in: $\quad$ MuSe 


\section{PPN: 135216575}

Giustino : opera / di G. F. Händel. - [Musikdr.], Ausg. der Dt. Händelges. - Leipzig : Stich und Dr. der Ges., 1883. - [3] Bl., 119 S. ; $2^{\circ}$

(Georg Friedrich Händel’s Werke ; Lfg. 88: Opern ; Bd. 34)

Vorw. dt. und engl.

Best.-Nr.: H.W.88

Signatur: $\quad 2$ MUS VII, 341:88

Anmerkung: Lfg. 87 und 88 zsgeb.

Vorh. in: MuSe

\section{PPN: 135216591}

Arminio : opera / di G. F. Händel. - [Musikdr.], Ausg. der Dt. Händelges. - Leipzig : Stich und Dr. der Ges., 1882. - [3] Bl., 104 S. ; $2^{\circ}$

(Georg Friedrich Händel’s Werke ; Lfg. 89: Opern ; Bd. 35)

Vorw. dt. und engl.

Best.-Nr.: H.W.89

Signatur: $\quad 2$ MUS VII, 341:89

Anmerkung: Lfg. 89 und 90 zsgeb.

Notizen: $\quad$ EX BIBLIOTHECA REGIA ACADEM. GEORGIAE AUG.

Vorh. in: $\quad$ MuSe

PPN: 135216613

Berenice : opera / di G. F. Händel. - [Musikdr.], Ausg. der Dt. Händelges. - Leipzig : Stich und Dr. der Ges., 1883. - [3] Bl., 104 S. ; $2^{\circ}$

(Georg Friedrich Händel’s Werke ; Lfg. 90: Opern ; Bd. 36)

Einheitssacht.: Berenice, Regina d’ Egitto, HWV 38. - Vorw. dt. und engl.

Best.-Nr.: H.W.90

Signatur: $\quad 2$ MUS VII, 341:90

Anmerkung: Lfg. 89 und 90 zsgeb.

Vorh. in: GHG, MuSe 


\section{PPN: 13521663X}

Faramondo : opera / di G. F. Händel. - [Musikdr.], Ausg. der Dt. Händelges. - Leipzig : Stich und Dr. der Ges., 1884. - [3] Bl., 128 S. ; $2^{\circ}$

(Georg Friedrich Händel’s Werke ; Lfg. 91: Opern ; Bd. 37)

Vorw. dt. und engl.

Best.-Nr.: H.W.91

Signatur: $\quad 2$ MUS VII, 341:91

Anmerkung: Lfg. 91 und 92 zsgeb.

Notizen: $\quad$ EX BIBLIOTHECA REGIA ACADEM. GEORGIAE AUG.

Vorh. in: GHG, MuSe

\section{PPN: 135216656}

Serse : opera / di G. F. Händel. - [Musikdr.], Ausg. der Dt. Händelges. - Leipzig : Stich und Dr. der Ges., 1884. - [3] Bl., 123 S. ; $2^{\circ}$

(Georg Friedrich Händel' Werke ; Lfg. 92: Opern ; Bd. 38)

Oper in drei Akten, nach "Xerxes" von Niccolò Minato, Venedig 1654. - Vorw. dt. und engl. Best.-Nr.: H.W.92

Signatur: $\quad 2$ MUS VII, 341:92

Anmerkung: Lfg. 91 und 92 zsgeb.

Notizen: $\quad$ EX BIBLIOTHECA REgIA ACADEM. GEORGIAE AUG.

Vorh. in: GHG, MuSe 
PPN: 135216672

Imeneo : opera / di G. F. Händel. - [Musikdr.], Ausg. der Dt. Händelges. - Leipzig : Stich und Dr. der Ges., 1885. - [3] Bl., 112 S., [1] Bl. ; $2^{\circ}$

(Georg Friedrich Händel’s Werke ; Lfg. 93: Opern ; Bd. 39)

Einheitssacht.: Imeneo (Hymen), HWV 41. - Vorw. dt.

Best.-Nr.: H.W.93

Signatur: $\quad 2$ MUS VII, 341:93

Anmerkung: Lfg. 93 und 94 zsgeb.

Notizen: $\quad 1885.2414$ - EX BIBLIOTHECA REGIA ACADEM. GEORGIAE AUG.

Vorh. in: $\quad$ GHG, MuSe

PPN: 135216699

Deidamia : opera / di G. F. Händel. - [Musikdr.], Ausg. der Dt. Händelges. 1885. - [3] Bl., 144 S. ; $2^{\circ}$

(Georg Friedrich Händel’s Werke ; Lfg. 94: Opern ; Bd. 40)

Vorw. dt.

Best.-Nr.: H.W.94

Signatur: $\quad 2$ MUS VII, 341:94

Anmerkung: Lfg. 93 und 94 zsgeb.

Notizen: $\quad 1889.2414$

Vorh. in: GHG, MuSe 


\subsection{Hallis che Händel-A u g a b e}

\subsubsection{M u s i k d r u c ke}

\section{PPN: 030192803}

Händel, Georg Friedrich:

Hallische Händel-Ausgabe : kritische Gesamtausgabe / im Auftr. der Georg-FriedrichHändel-Ges. hrsg. von Max Schneider ... - Kassel [u.a.] : Bärenreiter ; Leipzig : Dt. Verl. f. Musik, 1955-2023

Einheitssacht.: Werke. - Ab Ser. 4, Bd. 4 (2001) Ed.-Leiter: Terence Best ; Wolfgang Ruf ${ }^{8}$

\section{PPN: 148819109}

Das Alexander-Fest oder Die Macht der Musik : Ode zu Ehren der heiligen Cäcilia von John Dryden / Georg Friedrich Händel. Hrsg. von Konrad Ameln. - [Partitur] . Kassel [u.a.] : Bärenreiter [u.a.] ${ }^{9}$, 1957. - VIII, [2] Bl., 155 S. : Ill., Faks. ; $4^{\circ}$ (Hallische Händel-Ausgabe : Ser. 1, Oratorien und große Kantaten ; Bd. 1) Einheitssacht.: Alexander's feast or The power of musick, HWV 75. - Inh.-Verz. und Gesangstext dt. und engl.

Best.-Nr.: BA 4001

\section{Signatur: $\quad 4$ MUS 936:1,1,HAUPTBD}

Notizen: $\quad$ 1957.56/2749 - NIEDERSÄCHS. STAATS. U. UNIV.-BIBLIOTHEK GÖTTINGEN

\section{PPN: 030192838}

Passion nach dem Evangelisten Johannes / Georg Friedrich Händel. Hrsg. von Karl Gustav Fellerer. - [Partitur]. - Kassel [u.a.] : Bärenreiter [u.a.], 1964. - XII, 71 S. : Faks. ; $4^{\circ}$ (Hallische Händel-Ausgabe : Ser. 1, Oratorien und große Kantaten ; Bd. 2) Gesangstext dt.

Best.-Nr.: BA 4022

\section{Signatur: $\quad 4$ MUS 936:1,2 \\ Notizen: $\quad$ 1965.56/2749 - NIEDERSÄCHS. STAATS. U. UNIV.-BIBLIOTHEK GÖTTINGEN \\ Vorh. in: $\quad$ GHG}

\footnotetext{
${ }^{8}$ Die Hallische Händel-Ausgabe (HHA) erscheint seit 1955 und soll 2023 abgeschlossen sein. Geplant sind 116 Notenbände mit eingebundenen Kritischen Berichten und Faksimiles der Libretti bei Opern und Oratorien sowie ca. 10 Bände Supplemente. Aus: http://www.haendelhaus.de/gfhaendel/haendel_ausgabe.html

${ }^{9}$ Bei diesen Ausgaben handelt es sich um gemeinsame Edition: Bärenreiter-Verl. Kassel, Basel, Paris, London, New York sowie VEB Deutscher Verl. f. Musik Leipzig.
} 


\section{PPN: 31523623X}

Aci, Galatea e Polifemo : serenata a tre ; HWV 72 / hrsg. von Wolfram Windszus. [Partitur]. - Kassel [u.a.] : Bärenreiter ${ }^{10}$, 2000. - XXX, 124 S. : Faks., Notenbeisp. ; $4^{\circ}$ (Hallische Händel-Ausgabe : Ser. 1, Oratorien und große Kantaten ; Bd. 5) Einheitssacht.: Serenaten, HWV 72. - Text d. Serenata mit dt. und engl. Übers. S. XXI - XXX. - Kritischer Bericht S. [107] - 124. - Vorw. dt. und engl. - Gesangstext ital. ISMN M-006-49585-6

Best.-Nr.: BA 4068

Signatur: $\quad 4$ MUS 936:1,5

Notizen: $\quad$ NIEDERSÄCHS. STAATS. U. UNIV.-BIBLIOTHEK GÖTTINGEN

Vorh. in: $\quad$ GHG

\section{PPN: 030192846}

Ode for the birthday of Queen Anne = Ode für den Geburtstag der Königin Anna / Georg Friedrich Händel. Hrsg. von Walther Siegmund-Schultze. - [Partitur]. Kassel [u.a.] : Bärenreiter [u.a.], 1962. - X, [1] Bl., 80 S. : Faks. ; $4^{\circ}$

(Hallische Händel-Ausgabe : Ser. 1, Oratorien und große Kantaten ; Bd. 6)

Einheitssacht.: Oden, HWV 74. - Gesangstext engl. und dt.

Best.-Nr.: BA 4007

$\begin{array}{ll}\text { Signatur: } & 4 \text { MUS 936:1,6,HAUPTBD } \\ \text { Notizen: } & \text { 1962.56.2749 - NIEDERSÄCHS. STAATS. U. UNIV.-BIBLIOTHEK GÖTTINGEN } \\ \text { Vorh. } \text { in: } & \text { GHG, MuSe }\end{array}$

\section{PPN: 132939363}

Passion nach Barthold Heinrich Brockes / hrsg. von Felix Schroeder. - [Partitur]. Kassel [u.a.] : Bärenreiter [u.a.], 1965. - XV, [1] Bl., 169 S. : Faks. ; $4^{\circ}$

(Hallische Händel-Ausgabe : Ser. 1, Oratorien und große Kantaten ; Bd. 7) Einheitssacht.: Der für die Sünde der Welt gemarterte und sterbende Jesus, HWV 48. Gesangstext dt.

Best.-Nr.: BA 4021

$\begin{array}{ll}\text { Signatur: } & 4 \text { MUS 936:1,7,HAUPTBD } \\ \text { Notizen: } & \text { 1966.56/2749 - NIEDERSÄCHS. STAATS. U. UNIV.-BIBLIOTHEK GÖTTINGEN } \\ \text { Vorh. in: } & \text { GHG }\end{array}$

\footnotetext{
${ }^{10}$ Diese Ausgaben sind nur beim Bärenreiter-Verl. erschienen.
} 


\section{PPN: 191337307}

Esther : oratorio in six scenes ; (1. Fassung) ; HWV 50a / Georg Friedrich Händel. Hrsg. von Howard Serwer. - [Partitur]. - Kassel [u.a.] : Bärenreiter, 1995. - XXXI, 207 S. : Faks., Notenbeisp. ; $4^{\circ}$

(Hallische Händel-Ausgabe : Ser. 1, Oratorien und große Kantaten ; Bd. 8)

Einheitssacht.: Esther (Haman and Mordecai), HWV 50a. - Libretto-Dr., London 1732, mit dt. Übers., S. XXV - XXXI. - Critical report S. [181] - 207. - Vorw. dt. und engl. Gesangstext engl.

ISMN M-006-49566-5

Best.-Nr.: BA 4047

Signatur: $\quad 4$ MUS 936:1,8

Notizen: $\quad$ NIEDERSÄCHS. STAATS. U. UNIV.-BIBLIOTHEK GÖTTINGEN

Vorh. in: GHG

\section{PPN: 030192870}

Acis und Galatea : (1. Fassung) ; HWV 49a / Georg Friedrich Händel. Hrsg. von Wolfram Windszus. - [Partitur]. - Kassel [u.a.] : Bärenreiter [u.a.], 1991. - XXV, 217 S. : Faks., Notenbeisp. ; $4^{\circ}$

(Hallische Händel-Ausgabe : Ser. 1, Oratorien und große Kantaten ; Bd. 9,1)

Kritischer Bericht S. [191] - 217. - Vorw. und Gesangstext dt. und engl.

Best.-Nr.: BA/DVfM 4039

Signatur: $\quad 4$ MUS 936:1,9,1

Notizen: $\quad 1991$ F 56.2749 - NIEDERSÄCHS. STAATS. U. UNIV.-BIBLIOTHEK GÖTTINGEN

Vorh. in: $\quad$ GHG

\section{PPN: 148819184}

Saul : oratorio in three acts / Georg Friedrich Händel. Hrsg. von Percy M. Young. [Partitur]. - Kassel [u.a.] : Bärenreiter [u.a.], 1962. - XVII, 326 S. : Faks. ; $4^{\circ}$

(Hallische Händel-Ausgabe : Ser. 1, Oratorien und große Kantaten ; Bd. 13) Inh.-Verz. und Gesangstext engl. und dt.

Best.-Nr.: BA 4020

Signatur: $\quad 4$ MUS 936:1,13,HAUPTBD

Notizen: $\quad$ 1963.56/2749 - NIEDERSÄCHS. STAATS. U. UNIV.-BIBLIOTHEK GÖTTINGEN

Vorh. in: GHG 
PPN: 305977296

Israel in Egypt : oratorio in three parts ; HWV 54 ; Teilband 1: Part I-III / Georg Friedrich Händel. Hrsg. von Annette Landgraf. - [Partitur]. - Kassel [u.a.] : Bärenreiter, 1999. LII, 410 S. : Faks. ; $4^{\circ}$

(Hallische Händel-Ausgabe : Ser. 1, Oratorien und große Kantaten ; Bd. 14,1) Libretto-Dr., London 1739, mit dt. Übers., S. XLV - LII. - Vorw. dt. und engl. Gesangstext engl.

ISMN M-006-49581-8

Best.-Nr.: BA 4063

Signatur: $\quad 4$ MUS 936:1,14,1

Notizen: $\quad$ NIEDERSÄCHS. STAATS. U. UNIV.-BIBLIOTHEK GÖTTINGEN

Vorh. in: $\quad$ GHG

PPN: 305977652

Israel in Egypt : oratorio in three parts ; HWV 54 ; Teilband 2: Anhang I, II und Kritischer Bericht / Georg Friedrich Händel. Hrsg. von Annette Landgraf. - [Partitur]. - Kassel [u.a.] : Bärenreiter, 1999. - IX, S. [411] - 617 : Faks. ; $4^{\circ}$ (Hallische Händel-Ausgabe : Ser. 1, Oratorien und große Kantaten ; Bd. 14,2) Libretto-Dr., London 1757, S. VI - IX. - Kritischer Bericht S. [567] - 617. - Gesangstext engl. ISMN M-006-49581-8

Best.-Nr.: BA 4063

Signatur: $\quad 4$ MUS 936:1,14,2

Notizen: $\quad$ NIEDERSÄCHS. STAATS. U. UNIV.-BIBLIOTHEK GÖTTINGEN

Vorh. in: $\quad$ GHG

PPN: 030192897

L’ Allegro, il Penseroso ed il Moderato / Georg Friedrich Händel. Hrsg. von James S. Hall ... - [Partitur]. - Kassel [u.a.] : Bärenreiter [u.a.], 1965. - XIII, 205 S. : Faks. ; $4^{\circ}$ (Hallische Händel-Ausgabe : Ser. 1, Oratorien und große Kantaten ; Bd. 16) Inh.-Verz. und Gesangstext engl. und dt.

Best.-Nr.: BA 4023

Signatur: $\quad 4$ MUS 936:1,16,HAUPTBD

Notizen: $\quad$ 1966.56/2749 - NIEDERSÄCHS. STAATS. U. UNIV.-BIBLIOTHEK GÖTTINGEN

Vorh. in: $\quad$ GHG 


\section{PPN: 148819249}

The Messiah : oratorio in three parts = Der Messias / Georg Friedrich Händel. Hrsg. von John Tobin. - [Partitur]. - Kassel [u.a.] : Bärenreiter [u.a.], 1965. - XX, 306 S. : Faks., Notenbeisp. ; $4^{\circ}$

(Hallische Händel-Ausgabe : Ser. 1, Oratorien und große Kantaten ; Bd. 17) Inh.-Verz. und Gesangstext dt. und engl.

Best.-Nr.: BA 4012

Signatur: $\quad 4$ MUS 936:1,17,HAUPTBD

Notizen: $\quad$ 1966.56/2749 - NIEDERSÄCHS. STAATS. U. UNIV.-BIBLIOTHEK GÖTTINGEN

Vorh. in: $\quad$ MuSe

\section{PPN: 030192919}

Susanna : oratorio in three acts / Georg Friedrich Händel. Hrsg. von Bernard Rose. [Partitur]. - Kassel [u.a.] : Bärenreiter [u.a.], 1967. - XIV, 234 S. : Faks. ; $4^{\circ}$

(Hallische Händel-Ausgabe : Ser. 1, Oratorien und große Kantaten ; Bd. 28) Inh.-Verz. und Gesangstext dt. und engl.

Best.-Nr.: BA 4013

Signatur: $\quad 4$ MUS 936:1,28,HAUPTBD

Notizen: $\quad$ 1968.56/2749 - NIEDERSÄCHS. STAATS. U. UNIV.-BIBLIOTHEK GÖTTINGEN

Vorh. in: GHG, MuSe

\section{PPN: 030192927}

The choice of Hercules = Die Wahl des Herakles / Georg Friedrich Händel. Hrsg. von Walther Siegmund-Schultze. - [Partitur]. - Kassel [u.a.] : Bärenreiter [u.a.], 1963. XII, 148 S. : Faks. ; $4^{\circ}$

(Hallische Händel-Ausgabe : Ser. 1, Oratorien und große Kantaten ; Bd. 31)

Gesangstext engl. und dt.

Best.-Nr.: BA 4011

Signatur: $\quad 4$ MUS 936:1,31,HAUPTBD

Notizen: $\quad$ 1964.56/2749 - NIEDERSÄCHS. STAATS. U. UNIV.-BIBLIOTHEK GÖTTINGEN

Vorh. in: GHG, MuSe 


\section{PPN: 132170035}

Rinaldo : opera seria in tre atti ; HWV 7a / Georg Friedrich Händel. Hrsg. von David R. B. Kimbell. - [Partitur]. - Kassel [u.a.] : Bärenreiter, 1993. - L, 285 S. : Faks., Notenbeisp. ; $4^{\circ}$ (Hallische Händel-Ausgabe : Ser. 2, Opern ; Bd. 4,1)

Libretto-Dr., Thomas Howlatt, London 1711, mit dt. Übers., S. XX - L. - Kritischer Bericht S. [253] - 285. - (1. Fassung). - IL [i.e. XLIX]. - Vorw. dt. und engl. - Gesangstext ital. Best.-Nr.: BA 4033

Signatur: $\quad 4$ MUS 936:2,4,1

Notizen: $\quad$ NIEDERSÄCHS. STAATS. U. UNIV.-BIBLIOTHEK GÖTTINGEN

Vorh. in: GHG

PPN: 222542047

Rinaldo : opera seria in tre atti ; HWV 7b / Georg Friedrich Händel. Hrsg. von David R. B. Kimbell. - [Partitur]. - Kassel [u.a.] : Bärenreiter, 1996. - XL, 198 S. : Faks., Notenbeisp. ; $4^{\circ}+2$ Beil.

(Hallische Händel-Ausgabe : Ser. 2, Opern ; Bd. 4,2)

Libretto-Dr., Thomas Wood, London 1731, mit dt. Übers., S. XIX - XL. - Kritischer

Bericht S. [179] - 198. - (2./3. Fassung). - Vorw. dt. und engl. - Gesangstext ital.

ISMN M-006-49577-1

Best.-Nr.: BA 4059

Signatur: $\quad 4$ MUS 936:2,4,2

Notizen: $\quad$ NIEDERSÄCHS. STAATS. U. UNIV.-BIBLIOTHEK GÖTTINGEN

Vorh. in: GHG

PPN: 030192943

Amadigi : opera seria in tre atti / Georg Friedrich Händel. Hrsg. von J. Merrill Knapp. [Partitur]. - Kassel [u.a.] : Bärenreiter [u.a.], 1971. - XVII, 185 S. : Faks. ; ${ }^{\circ}$

(Hallische Händel-Ausgabe : Ser. 2, Opern ; Bd. 8)

Einheitssacht.: Amadigi di Gaula, HWV 11. - Gesangstext ital.

Best.-Nr.: BA 4031

Signatur: $\quad 4$ MUS 936:2,8,HAUPTBD

Notizen: $\quad$ 1972.56/2749 - NIEDERSÄCHS. STAATS. U. UNIV.-BIBLIOTHEK GÖTTINGEN

Vorh. in: GHG 
PPN: 237041197

Radamisto : opera seria in tre atti ; HWV 12a / Georg Friedrich Händel. Hrsg. von Terence Best. - [Partitur]. - Kassel [u.a.] : Bärenreiter, 1997. - LVIII, 274 S. : Faks., Notenbeisp. ; $4^{\circ}$ (Hallische Händel-Ausgabe : Ser. 2, Opern ; Bd. 9,1)

Libretto-Dr., Thomas Wood, London 1720, mit dt. Übers., S. XXVI - LVII. - Critical Report S. [231] - 274. - (1. Fassung). - Vorw. dt. und engl. - Gesangstext ital.

ISMN M-006-49580-1

Best.-Nr.: BA 4062

Signatur: $\quad 4$ MUS 936:2,9,1

Notizen: $\quad$ NIEDERSÄCHS. STAATS. U. UNIV.-BIBLIOTHEK GÖTTINGEN

Vorh. in: GHG

PPN: 315235993

Radamisto : opera seria in tre atti ; HWV 12b / Georg Friedrich Händel. Hrsg. von Terence Best. - [Partitur]. - Kassel [u.a.] : Bärenreiter, 2000. - LVII, 324 S. : Faks., Notenbeisp. ; $4^{\circ}$ (Hallische Händel-Ausgabe : Ser. 2, Opern ; Bd. 9,2)

Libretto-Dr., Thomas Wood, London 1720, mit dt. Übers., S. XXV - LVII. - Critical Report S. [281] - 324. - (2. Fassung). - Vorw. dt. und engl. - Gesangstext ital.

ISMN M-006-49583-2

Best.-Nr.: BA 4066

Signatur: $\quad 4$ MUS 936:2,9,2

Notizen: $\quad$ NIEDERSÄCHS. STAATS. U. UNIV.-BIBLIOTHEK GÖTTINGEN

Vorh. in: GHG

\section{PPN: 124021441}

Flavio, Re de’ Langobardi : dramma per musica in tre atti ; HWV 16 / Georg Friedrich Händel. Hrsg. von J. Merrill Knapp. - [Partitur]. - Kassel [u.a.] : Bärenreiter, 1993. [L], 229 S. : Faks., Notenbeisp. ; $4^{\circ}$

(Hallische Händel-Ausgabe : Ser. 2, Opern ; Bd. 13)

Libretto-Dr., Thomas Wood, London 1732, mit dt. Übers., S. XXI - [L]. - Critical report S. [207] - 229. - IL [i.e. XLIX]. - Vorw. dt. und engl. - Gesangstext ital.

Best.-Nr.: BA 4046

Signatur: $\quad 4$ MUS 936:2,13

Notizen: $\quad$ 1993.56.2749 - NIEDERSÄCHS. STAATS. U. UNIV.-BIBLIOTHEK GÖTTINGEN

Vorh. in: GHG 
PPN: 223092584

Tamerlano : dramma per musica in tre atti ; HWV 18 / Georg Friedrich Händel. Hrsg. von Terence Best. - [Partitur]. - Kassel [u.a.] : Bärenreiter, 1996. - LXXVII, 328 S. : Faks., Notenbeisp. ; $4^{\circ}$

(Hallische Händel-Ausgabe : Ser. 2, Opern ; Bd. 15)

Libretto-Dr., London 1724, mit dt. Übers., S. XXXIII - LXXVII. - Critical report S.

[277] - 328. - Vorw. dt. und engl. - Gesangstext ital.

ISMN M-006-49570-2

Best.-Nr.: BA 4052

Signatur: $\quad 4$ MUS 936:2,15

Notizen: $\quad$ NIEDERSÄCHS. STAATS. U. UNIV.-BIBLIOTHEK GÖTTINGEN

Vorh. in: GHG

PPN: 358802741

Rodelinda, Regina de’ Longobardi : dramma per musica in tre atti ; HWV 19 / Georg

Friedrich Händel. Hrsg. von Andrew V. Jones. - [Partitur]. - Kassel [u.a.] : Bärenreiter, 2002. - LXXI, 300 S. : Faks. ; $4^{\circ}$

(Hallische Händel-Ausgabe : kritische Gesamtausgabe : Ser. 2, Opern ; Bd. 16)

Libretto-Dr., London 1725, mit dt. Übers., S. XXXIV - LVII. - Critical report S. [233] - 300.

- Vorw. dt. und engl. - Gesangstext ital. und dt., Übers. S. LVIII - LXIX

ISMN M-006-49569-6

Best.-Nr.: BA 4064

Signatur: $\quad 4$ MUS 936:2,16

Notizen: $\quad$ NIEDERSÄCHS. STAATS. U. UNIV.-BIBLIOTHEK GÖTTINGEN

Vorh. in: $\quad$ GHG

\section{PPN: 323101569}

Tolomeo, Re d'Egitto : dramma per musica in tre atti ; HWV 25 / Georg Friedrich Händel. Hrsg. von Michael Pacholke. - [Partitur]. - Kassel [u.a.] : Bärenreiter, 2000. - [XLIX], 325 S. : Faks., Notenbeisp. ; $4^{\circ}$

(Hallische Händel-Ausgabe : Ser. 2, Opern ; Bd. 22)

Libretto-Dr., London 1728, mit dt. Übers., S. XXV - [XLIX]. - Kritischer Bericht S.

[269] - 325. - Vorw. dt. und engl. - Gesangstext ital.

ISMN M-006-49567-2

Best.-Nr.: BA 4058

Signatur: $\quad 4$ MUS 936:2,22

Notizen: $\quad$ NIEDERSÄCHS. STAATS. U. UNIV.-BIBLIOTHEK GÖTTINGEN

Vorh. in: GHG 
PPN: 382506073

Lotario : opera in tre atti ; HWV 26 / Georg Friedrich Händel. Hrsg. von Michael Pacholke.

- [Partitur]. - Kassel [u.a.] : Bärenreiter, 2003. - LIV, 246 S. : Faks. ; $4^{\circ}$

(Hallische Händel-Ausgabe : Ser. 2, Opern ; Bd. 23)

Libretto-Dr., Thomas Wood, London 1729 (S. XXI - XL). - Kritischer Bericht S. [195] - 239.

- Vorw. dt. und engl. - Gesangstext ital. - Text d. Hauptteils in dt. Übers.

ISMN M-006-49785-0

Best.-Nr.: BA 4074

Signatur: $\quad 4$ MUS 936:2,23

Notizen: $\quad$ NIEDERSÄCHS. STAATS. U. UNIV.-BIBLIOTHEK GÖTTINGEN

Vorh. in: GHG

PPN: 030192951

Orlando : opera seria in tre atti / Georg Friedrich Händel. Hrsg. von Siegfried Flesch.

- [Partitur]. - Kassel [u.a.] : Bärenreiter [u.a.], 1969. - XVII, 172 S. : Faks. ; $4^{\circ}$

(Hallische Händel-Ausgabe : Ser. 2, Opern ; Bd. 28)

Gesangstext ital.

Best.-Nr.: BA 4027

Signatur: $\quad 4$ MUS 936:2,28

Notizen: $\quad$ 1969.56/2749 - NIEDERSÄCHS. STAATS. U. UNIV.-BIBLIOTHEK GÖTTINGEN

Vorh. in: $\quad$ GHG (4 Ex.)

PPN: 03019296X

Serse : opera in tre atti = Xerxes / Georg Friedrich Händel. Hrsg. und dt. Fassung von Rudolf Steglich. - [Partitur]. - Kassel [u.a.] : Bärenreiter [u.a.], 1958. - XI, 179 S. : Faks. ; $4^{\circ}$

(Hallische Händel-Ausgabe : Ser. 2, Opern ; Bd. 39)

Inh.-Verz. und Gesangstext ital. und dt.

Best.-Nr.: BA 4010

Signatur: $\quad 4$ MUS 936:2,39

Notizen: $\quad$ 1959.56/2749 - NIEDERSÄCHS. STAATS. U. UNIV.-BIBLIOTHEK GÖTTINGEN

Vorh. in: GHG, MuSe 
PPN: 349239398

Imeneo : dramma per musica in tre atti ; HWV 41 / Georg Friedrich Händel. Hrsg. von Donald Burrows. - [Partitur]. - Kassel [u.a.] : Bärenreiter, 2002. - LXII, 338 S. : Faks. ; $4^{\circ}$ (Hallische Händel-Ausgabe : Ser. 2, Opern ; Bd. 40)

Libretto-Dr., London 1740, mit dt. Übers., S. XLIII - LX. - Critical report S. 273 - 338. Vorw. dt. und engl. - Gesangstext ital.

ISMN M-006-49787-4

Best.-Nr.: BA 4072

Signatur: $\quad 4$ MUS 936:2,40

Notizen: $\quad$ NIEDERSÄCHS. STAATS. U. UNIV.-BIBLIOTHEK GÖTTINGEN

Vorh. in: $\quad$ GHG

PPN: 335905382

Deidamia : opera in tre atti ; HWV 42 / Georg Friedrich Händel. Hrsg. von Terence Best. [Partitur]. - Kassel [u.a.] : Bärenreiter, 2001. - XLVIII, 286 S. : Faks. ; $4^{\circ}$

(Hallische Händel-Ausgabe : Ser. 2, Opern ; Bd. 41)

Nachdr. d. ital.-engl. Textbuches, London, Chrichley, 1741, mit dt. Übers., S. XX - XLVIII.

- Critical report S. [253] - 286. - Vorw. dt. und engl. - Gesangstext ital.

ISMN M-006-49587-0

Best.-Nr.: BA 4070

Signatur: $\quad 4$ MUS 936:2,41

Notizen: $\quad$ NIEDERSÄCHS. STAATS. U. UNIV.-BIBLIOTHEK GÖTTINGEN

Vorh. in: $\quad$ GHG

\section{PPN: 126141193}

Julius Caesar : Oper in drei Akten = Giulio Cesare $/$ Georg Friedrich Händel. Von Nicola Haym. Dt. Fassung von Emilie Dahnk-Baroffio. - Klavierausz. / von Walter Gieseler. Kassel [u.a.] : Bärenreiter [u.a.], 1972. - [X], 281 S. ; $4^{\circ}$

(Hallische Händel-Ausgabe : Ser. 2, Opern ; Klavierauszug)

Einheitssacht.: Giulio Cesare in Egitto, HWV 17. - Inh.-Verz. und Gesangstext dt. und ital. Best.-Nr.: BA 4019a

Signatur: $\quad 4$ MUS 936:2,KLAVIERAUSZ

Notizen: $\quad$ 1972.56/2749 - NIEDERSÄCHS. STAATS. U. UNIV.-BIBLIOTHEK GÖTTINGEN

Vorh. in: $\quad$ MuSe 


\section{PPN: 030192978}

Oreste : opera in tre atti ; HWV A11 / Georg Friedrich Händel. Hrsg. von Bernd Baselt. [Partitur]. - Kassel [u.a.] : Bärenreiter [u.a.], 1991. - XLVIII, 165 S. : Faks., Notenbeisp. ; $4^{\circ}$ (Hallische Händel-Ausgabe : Ser. 2, Opern ; Suppl., Bd. 1)

Libretto-Dr., T. Wood, London 1734, mit dt. Übers., S. XXX - XLVIII. - Kritischer Bericht S. [143] - 165. - Vorw. dt. und engl. - Gesangstext ital.

Best.-Nr.: BA/DVfM 4045

Signatur: $\quad 4$ MUS 936:2,SUP,1

Notizen: $\quad 1991$ F 56/2749 - NIEDERSÄCHS. STAATS. U. UNIV.-BIBLIOTHEK GÖTTINGEN

Vorh. in: GHG

\section{PPN: 126141274}

Dixit Dominus / Georg Friedrich Händel. Hrsg. von Eberhard Wenzel. - [Partitur]. -

Kassel [u.a.] : Bärenreiter [u.a.], 1960. - VIII, 87 S. : Faks. ; $4^{\circ}$

(Hallische Händel-Ausgabe : Ser. 3, Kirchenmusik ; Bd. 1)

Einheitssacht.: Dixit Dominus Domino meo, HWV 232. - Gesangstext lat.

Best.-Nr.: BA 4002

Signatur: $\quad 4$ MUS 936:3,1

Notizen: $\quad$ 1961.56/2749 - NIEDERSÄCHS. STAATS. U. UNIV.-BIBLIOTHEK GÖTTINGEN

\section{PPN: 248929038}

Te Deum zur Feier des Friedens von Utrecht : HWV 278 / Georg Friedrich Händel. Hrsg. von Gerald Hendrie. - [Partitur]. - Kassel [u.a.] : Bärenreiter, 1998. - XXIV, 180 S. : Faks. ; $4^{\circ}$ (Hallische Händel-Ausgabe : Ser. 3, Kirchenmusik ; Bd. 3)

Einheitssacht.: Te Deum, HWV 278. - Critical report S. [153] - 180. - Vorw. dt. und engl. Gesangstext engl., dt. Übers. S. XXII - XXIV. - Enth. außerdem: Jubilate zur Feier des Friedens von Utrecht, HWV 279

ISMN M-006-49572-6

Best.-Nr.: BA 4054

Signatur: $\quad 4$ MUS 936:3,3

Notizen: $\quad$ NIEDERSÄCHS. STAATS. U. UNIV.-BIBLIOTHEK GÖTTINGEN

Vorh. in: $\quad$ GHG 


\section{PPN: 030193001}

Anthems für Cannons I : HWV 246, 247, 248, 249b / Georg Friedrich Händel. Hrsg. von Gerald Hendrie. - [Partitur]. - Kassel [u.a.] : Bärenreiter [u.a.], 1985. - XVIII, 173 S. : Faks. ; $4^{\circ}$

(Hallische Händel-Ausgabe : Ser. 3, Kirchenmusik ; Bd. 4)

Einheitssacht.: Anthems / Ausw. - Vorw. und Gesangstext dt. und engl.

Best.-Nr.: BA/DVfM 4038

Signatur: $\quad 4$ MUS 936:3,4

Notizen: $\quad$ 1986.56/2749 - NIEDERSÄCHS. STAATS. U. UNIV.-BIBLIOTHEK GÖTTINGEN

Vorh. in: $\quad$ GHG, MuSe

\section{PPN: 03019301X}

Anthems für Cannons II : HWV 250a, 251b, 252, 253 / Georg Friedrich Händel. Hrsg. von Gerald Hendrie. - [Partitur]. - Kassel [u.a.] : Bärenreiter [u.a.], 1987. - XVII, 228 S. : Faks. ; $4^{\circ}$

(Hallische Händel-Ausgabe : Ser. 3, Kirchenmusik ; Bd. 5)

Einheitssacht.: Anthems / Ausw. - Vorw. und Gesangstext dt. und engl.

Best.-Nr.: BA/DVfM 4042

Signatur: $\quad 4$ MUS 936:3,5

Notizen: $\quad$ 1988.56/2749 - NIEDERSÄCHS. STAATS. U. UNIV.-BIBLIOTHEK GÖTTINGEN

Vorh. in: $\quad$ GHG, MuSe

\section{PPN: 030193028}

Anthems für Cannons III : HWV 254, 255, 256a / Georg Friedrich Händel. Hrsg. von Gerald Hendrie. - [Partitur]. - Kassel [u.a.] : Bärenreiter [u.a.], 1991. - XVII, 274 S. : Faks., Notenbeisp. ; $4^{\circ}$

(Hallische Händel-Ausgabe : Ser. 3, Kirchenmusik ; Bd. 6)

Einheitssacht.: Anthems / Ausw. - Critical report (Anthems für Cannons I-III), S. [235] - 274.

- Vorw. und Gesangstext dt. und engl.

Best.-Nr.: BA/DVfM 4044

Signatur: $\quad 4$ MUS 936:3,6

Notizen: $\quad 1991$ F 56.2749 - NIEDERSÄCHS. STAATS. U. UNIV.-BIBLIOTHEK GÖTTINGEN

Vorh. in: GHG 


\section{PPN: 122959876}

Anthems für die Chapel Royal : HWV 251a, 251d, 249a, 250b, 251c, 256b, 251e / Georg Friedrich Händel. Hrsg. von Gerald Hendrie. - [Partitur]. - Kassel [u.a.] : Bärenreiter, 1992. - XXII, 347 S. : Faks. ; $4^{\circ}$

(Hallische Händel-Ausgabe : Ser. 3, Kirchenmusik ; Bd. 9)

Einheitssacht.: Anthems / Ausw. - Critical report S. [315] - 347. - Inh.-Verz., Vorw. und Gesangstext dt. und engl.

Best.-Nr.: BA 4051

Signatur: $\quad 4$ MUS 936:3,9

Notizen: $\quad 1992$ F 56.2749 - NIEDERSÄCHS. STAATS. U. UNIV.-BIBLIOTHEK GÖTTINGEN

Vorh. in: GHG

\section{PPN: 393338037}

Anthem for the Funeral of Queen Caroline : HWV 264 / Georg Friedrich Händel. Hrsg. von Annette Landgraf. - [Partitur]. - Kassel [u.a.] : Bärenreiter, 2004. - XXXI, 179 S. : Faks. ; $4^{\circ}$ (Hallische Händel-Ausgabe : Ser. 3, Kirchenmusik ; Bd. 12)

Einheitssacht.: The ways of Zion do mourn, HWV 264. - Begräbnisprotokoll, London 1737 (S. XXVIII - XXX). - Kritischer Bericht S. [157] - 179. - Vorw. dt. und engl. - Gesangstext engl., dt. Übers. S. XXXI

ISMN M-006-49784-3

Best.-Nr.: BA 4075

Signatur: $\quad 4$ MUS 936:3,12

Notizen: $\quad$ NIEDERSÄCHS. STAATS. U. UNIV.-BIBLIOTHEK GÖTTINGEN

\section{PPN: 126141339}

Die acht grossen Suiten : [erste Sammlung von 1720] / Georg Friedrich Händel. Hrsg. von Rudolf Steglich. - [Musikdr.]. - Kassel [u.a.] : Bärenreiter [u.a.], 1955. - XXIII, 81 S. : Faks. ; $4^{\circ}$

(Hallische Händel-Ausgabe : Ser. 4, Instrumentalmusik ; Bd. 1: Klavierwerke ; Teilbd. 1) Einheitssacht.: Werke, Kl, 1720. - Notenbeisp. zur „Einführung in Händels Klaviersuiten“, S. XVII - XXIII

Best.-Nr.: BA 4005

Signatur: $\quad 4$ MUS 936:4,1

Notizen: $\quad 1955.3185$ - NIEDERSÄCHS. STAATS. U. UNIV.-BIBLIOTHEK GÖTTINGEN

Vorh. in: $\quad$ GHG, MuSe (2 Ex.) 


\section{PPN: 145829219}

Erste Sammlung von 1720 : die acht großen Suiten ; HWV 426-433 / Georg Friedrich Händel. Hrsg. von Rudolf Steglich. - [Musikdr.], Neuausg. / von Terence Best. - Kassel [u.a.] : Bärenreiter, 1993. - XXVII, 113 S. : Faks. ; $4^{\circ}$

(Hallische Händel-Ausgabe : Ser. 4, Instrumentalmusik ; Bd. 1, Klavierwerke : Teilbd. 1) Einheitssacht.: Werke, Kl, HWV 426 - 433. - Vorw. dt. und engl.

Best.-Nr.: BA 4049

Signatur: $\quad$ FB 18044:4,1

Notizen: $\quad$ NIEDERSÄCHS. STAATS. U. UNIV.-BIBLIOTHEK GÖTTINGEN

\section{PPN: 126141347}

Sechs Konzerte für Orgel oder Cembalo, Streicher, Holzbläser und Basso continuo : op. 4, Nr. 1-6 / Georg Friedrich Händel. Hrsg. von Karl Matthaei. - [Partitur]. - Kassel [u.a.] : Bärenreiter [u.a.], 1956. - VIII, 119 S. : Faks. ; $4^{\circ}$

(Hallische Händel-Ausgabe : Ser. 4, Instrumentalmusik ; Bd. 2: Orgelkonzerte ; Teilbd. 1) Einheitssacht.: Werke, Org Streicher Holzbläser Bc, op. 4. - Enth. im Anh. Rev.-Bericht Best.-Nr.: BA 4006

Signatur: $\quad 4$ MUS 936:4,2

Notizen: $\quad 1956.2749$ - NIEDERSÄCHS. STAATS. U. UNIV.-BIBLIOTHEK GÖTTINGEN

Vorh. in: GHG

\section{PPN: 332326349}

Sechs Konzerte für Orgel und Orchester, op. 4, HWV 289-294 / Georg Friedrich Händel. Hrsg. von Terence Best ... - [Partitur]. - Kassel [u.a.] : Bärenreiter, 2001. - XXVII, 168 S. : Faks. ; $4^{\circ}$

(Hallische Händel-Ausgabe : Ser. 4, Instrumentalmusik ; Bd. 2, Orgelkonzerte : Teilbd. 1) Einheitssacht.: Werke, Org Orch HWV 289 - 294. - Critical report S. [149] - 168. - Vorw. dt. und engl. - Enth außerdem: Konzert für Harfe und Orchester, HWV 294, Fassung Hf Orch ISMN M-006-49586-3

Best.-Nr.: BA 4069

Signatur: $\quad$ FB 18044:4,2

Notizen: $\quad$ NIEDERSÄCHS. STAATS. U. UNIV.-BIBLIOTHEK GÖTTINGEN

Vorh. in: GHG 


\section{PPN: 030193095}

Elf Sonaten für Flöte und bezifferten Bass / Georg Friedrich Händel. Hrsg. von HansPeter Schmitz. - [Partitur, Stimme]. - Kassel [u.a.] : Bärenreiter [u.a.], 1955. - XV, 73 S. ; $4^{\circ}+1$ St. (59 S.)

(Hallische Händel-Ausgabe : Ser. 4, Instrumentalmusik ; Bd. 3)

Einheitssacht.: Sonaten, Fl. - Stimme: Querfl/Blockfl

Best.-Nr.: BA 4003

Signatur: $\quad 4$ MUS 936:4,3,HAUPTBD 4 MUS 936:4,3,STIMME

Notizen: $\quad 1955.3185$ - NIEDERSÄCHS. STAATS. U. UNIV.-BIBLIOTHEK GÖTTINGEN

Vorh. in: $\quad$ GHG (nur Hauptbd.)

\section{PPN: 193461420}

Elf Sonaten für Flöte und Basso continuo : HWV 379, 359b, 360, 362, 363b, 365, 367b, 369, 374, 375, 376 / Georg Friedrich Händel. Hrsg. von Hans-Peter Schmitz. ContinuoAussetzung von Max Schneider. - [Klavierpartitur, Stimmen], Neuausg. / von Terence Best. - 1995. - XX, 88 S. : Faks. ; $4^{\circ}+4$ St. (59 S.)

(Hallische Händel-Ausgabe : Ser. 4, Instrumentalmusik ; Bd. 3)

Einheitssacht.: Sonaten, Fl Bc. - Critical report S. [75] - 88. - Stimmen: Querfl, Blfl, Vc, Vagb. - Vorw. dt. und engl.

ISMN M-006-49575-7 (Hauptbd.) - ISMN M-006-49576-4 (Stimmen)

Best.-Nr.: BA 4057

Signatur: $\quad$ FB 18044:4,3,HAUPTBD FB 18044:4,3,STIMME

Anmerkung: Stimmen zsgeb.

Notizen: $\quad$ NIEDERSÄCHS. STAATS. U. UNIV.-BIBLIOTHEK GÖTTINGEN

Vorh. in: $\quad$ GHG (nur Hauptbd.)

\section{PPN: 126141363}

Sechs Sonaten für Violine und bezifferten Bass / Georg Friedrich Händel. Hrsg. von Johann Philipp Hinnenthal. - [Partitur, Stimme]. - Kassel [u.a.] : Bärenreiter [u.a.], 1955. - VII, 55 S. : Faks. ; $4^{\circ}+1$ St. (43 S.)

(Hallische Händel-Ausgabe : Ser. 4, Instrumentalmusik ; Bd. 4)

Einheitssacht.: Sonaten, Vl. - Kritischer Bericht S. 55. - Stimme: Vl, Vc (Vagb)

Best.-Nr.: BA 4004

Signatur: $\quad 4$ MUS 936:4,4,HAUPTBD 4 MUS 936:4,4,STIMME

Notizen: $\quad 1955.4305$ - NIEDERSÄCHS. STAATS. U. UNIV.-BIBLIOTHEK GÖTTINGEN

Vorh. in: $\quad$ GHG (nur Hauptbd.) 


\section{PPN: 337909733}

Sechs Sonaten für Violine und Basso continuo : HWV 361, 371, 368, 370, 372, 373 / Georg Friedrich Händel. Hrsg. von Johann Philipp Hinnenthal. - [Klavierpartitur], Neuausg. / von Terence Best. - Kassel [u.a.] : Bärenreiter, 2001. - XX, 60 S. : Faks. ; $4^{\circ}+1$ Beih. (45 S.) (Hallische Händel-Ausgabe : Ser. 4, Instrumentalmusik ; Bd. 4)

Einheitssacht.: Sonaten, Vl Bc / Ausw. - Critical report S. [53] - 60. - Vorw. dt. und engl. ISMN M-006-49588-7 (Hauptbd., Stimme)

Best.-Nr.: BA 4071

Signatur: $\quad$ FB 18044:4,4,HAUPTBD FB 18044:4,4,STIMME

Anmerkung: Diese Ausg. besteht nicht aus einer Klavierpartitur + 1 Stimme, sondern aus 2 Partituren: Der Partitur-Teil ist als Klavierpartitur (mit ausgesetzter Bc, das Beih. als eine Partitur (ohne ausgesetzter Bc) ediert worden.

Notizen: $\quad$ NIEDERSÄCHS. STAATS. U. UNIV.-BIBLIOTHEK GÖTTINGEN

Vorh. in: GHG

\section{PPN: 126141371}

Zweite Sammlung von 1733 / Georg Friedrich Händel. Hrsg. von Peter Northway. [Klavierpartitur]. - Kassel [u.a.] : Bärenreiter [u.a.], 1970. - XII, 114 S. : Faks. ; $4^{\circ}$ (Hallische Händel-Ausgabe : Ser. 4, Instrumentalmusik ; Bd. 5: Klavierwerke ; Teilbd. 2) Einheitssacht.: Werke, Kl, 1733

Best.-Nr.: BA 4009

Signatur: $\quad 4$ MUS 936:4,5

Notizen: $\quad$ 1971.56/2749 - NIEDERSÄCHS. STAATS. U. UNIV.-BIBLIOTHEK GÖTTINGEN

Vorh. in: $\quad$ GHG, MuSe

\section{PPN: 309635675}

Suites de Pièces pour le Clavecin : zweite Sammlung von 1733 ; HWV 434 - 442 / Georg Friedrich Händel. Hrsg. von Peter Northway. - [Musikdr.], Neuausg. / von Terence Best.

- Kassel [u.a.] : Bärenreiter, 1999. - XXXVI, 133 S. : Faks. ; $4^{\circ}$

(Hallische Händel-Ausgabe : Ser. 4, Instrumentalmusik ; Bd. 5, Klavierwerke : Teilbd. 2)

Einheitssacht.: Werke, Kl, HWV 434 - 442. - Vorw. dt. und engl.

ISMN M-006-49582-5

Best.-Nr.: BA 4065

Signatur: $\quad$ FB 18044:4,5

Notizen: $\quad$ NIEDERSÄCHS. STAATS. U. UNIV.-BIBLIOTHEK GÖTTINGEN

Vorh. in: $\quad$ GHG 


\section{PPN: 12614138X}

Einzelne Suiten und Stücke / Georg Friedrich Händel. Hrsg. von Terence Best. - [Musikdr.].

- Kassel [u.a.] : Bärenreiter [u.a.], 1970. - XIV, 85 S. : Faks., Notenbeisp. ; $4^{\circ}$

(Hallische Händel-Ausgabe : Ser. 4, Instrumentalmusik ; Bd. 6: Klavierwerke ; Teilbd. 3)

Einheitssacht.: Werke, Kl / Ausw.

Best.-Nr.: BA 4028

Signatur: $\quad 4$ MUS 936:4,6

Notizen: $\quad$ 1971.56.2749 - NIEDERSÄCHS. STAATS. U. UNIV.-BIBLIOTHEK GÖTTINGEN

Vorh. in: $\quad$ MuSe

\section{PPN: 030193133}

Zwei Konzerte für Orgel und Orchester, HWV 295 und 296a / Georg Friedrich Händel. Hrsg. von Siegfried Flesch. - [Partitur]. - Kassel [u.a.] : Bärenreiter [u.a.], 1989. -

XXXII, 291 S. : Faks., Notenbeisp. ; $4^{\circ}+1$ Beil.

(Hallische Händel-Ausgabe : Ser. 4, Instrumentalmusik ; Bd. 8: Orgelkonzerte ; Teilbd. 2)

Einheitssacht.: Konzerte, Org Orch, HWV 295, 296a. - Kritischer Bericht S. [257] - 291. -

Vorw. dt. und engl. - Enth. außerdem: Sechs Konzerte für Orgel und Orchester, op. 7,

HWV 306-311 [Konzerte, Org, Orch, HWV 306 - 311]

Best.-Nr.: BA 4041

Signatur: $\quad 4$ MUS 936:4,8

Notizen: $\quad$ NIEDERSÄCHS. STAATS. U. UNIV.-BIBLIOTHEK GÖTTINGEN

Vorh. in: $\quad$ GHG

\section{PPN: 03019315X}

Sechs Sonaten für zwei Oboen und Basso continuo / Georg Friedrich Händel. Hrsg. von Siegfried Flesch. Continuo-Aussetzung: Walter Heinz Bernstein. - [Partitur, Stimmen]. Kassel [u.a.] : Bärenreiter [u.a.], 1976. - XIII, 69 S. : Faks. ; $4^{\circ}+3$ St. (je 27 S.)

(Hallische Händel-Ausgabe : Ser. 4, Instrumentalmusik ; Bd. 9)

Einheitssacht.: Sonaten, Ob Bc. - Stimmen: Ob 1 2, Bc

Best.-Nr.: BA/DVfM 4034

Signatur: $\quad 4$ MUS 936:4,9,HAUPTBD 4 MUS 936:4,9,STIMME

Notizen: $\quad$ 1977.56/2749 - NIEDERSÄCHS. STAATS. U. UNIV.-BIBLIOTHEK GÖTTINGEN

Vorh. in: $\quad$ GHG (nur Hauptbd.) 


\section{PPN: 179957163}

Neun Sonaten für zwei Violinen und Basso continuo : sechs Sonaten op. 2, Sonate F-Dur, Sonate g-Moll, Sonate E-Dur / Georg Friedrich Händel. Hrsg. von Siegfried Flesch. Continuo-Aussetzung: Ingeborg Schneider. - [Partitur, Stimmen]. - Kassel [u.a.] : Bärenreiter [u.a.], 1970. - XIX, 127 S. : Faks. ; $4^{\circ}+3$ St. (44, 44, 47 S.) (Hallische Händel-Ausgabe : Ser. 4, Instrumentalmusik ; Bd. 10,1)

Einheitssacht.: Sonaten, Vl Bc. - Stimmen: Vl 1 2, Bc

Best.-Nr.: BA 4029

Signatur: $\quad 4$ MUS 936:4,10,1,HAUPTBD 4 MUS 936:4,10,1,STIMME

Anmerkung: Stimmen nur komplett ausleihbar

Notizen: $\quad$ 1970.56/2749 - NIEDERSÄCHS. STAATS. U. UNIV.-BIBLIOTHEK GÖTTINGEN

Vorh. in: $\quad$ GHG (nur Hauptbd.)

\section{PPN: 179957376}

Sieben Sonaten für zwei Violinen und Basso continuo, opus 5 / Georg Friedrich Händel. Hrsg. von Siegfried Flesch unter Verwendung der Vorarbeiten von Walter Serauky. Continuo-Aussetzung: Max Schneider. - [Partitur, Stimmen]. - Kassel [u.a.] : Bärenreiter [u.a.], 1967. - XII, 94 S. : Faks. ; $4^{\circ}+4$ St. (31, 4 S.)

(Hallische Händel-Ausgabe : Ser. 4, Instrumentalmusik ; Bd. 10,2)

Einheitssacht.: Sonaten, Vl Bc, op. 5. - Stimmen: Vl 1 2, Va (ad lib.), Bc

Best.-Nr.: BA 4026

Signatur: $\quad 4$ MUS 936:4,10,2,HAUPTBD 4 MUS 936:4,10,2,STIMME

Notizen: $\quad$ 1968.56/2749 - NIEDERSÄCHS. STAATS. U. UNIV.-BIBLIOTHEK GÖTTINGEN

Vorh. in: $\quad$ GHG (nur Hauptbd.)

\section{PPN: 148819303}

Sechs concerti grossi, opus 3 / Georg Friedrich Händel. Hrsg. von Frederick Hudson. - [Partitur]. - Kassel [u.a.] : Bärenreiter [u.a.], 1959. - XVI, 127 S. : Faks. ; $4^{\circ}$ (Hallische Händel-Ausgabe : Ser. 4, Instrumentalmusik ; Bd. 11)

Einheitssacht.: Concerti grossi, op. 3

Best.-Nr.: BA 4017

Signatur: $\quad 4$ MUS 936:4,11,HAUPTBD

Notizen: $\quad$ 1959.56/2749 - NIEDERSÄCHS. STAATS. U. UNIV.-BIBLIOTHEK GÖTTINGEN

Vorh. in: GHG, MuSe 
PPN: 030193222

Acht concerti / Georg Friedrich Händel. Hrsg. von Frederick Hudson. - [Partitur].

- Kassel [u.a.] : Bärenreiter [u.a.], 1971. - XVI, 144 S. : Faks. ; $4^{\circ}$

(Hallische Händel-Ausgabe : Ser. 4, Instrumentalmusik ; Bd. 12)

Einheitssacht.: Konzerte / Ausw. - Copyright: 1970

Best.-Nr.: BA 4030

Signatur: $\quad 4$ MUS 936:4,12

Notizen: $\quad$ 1971.56/2749 - NIEDERSÄCHS. STAATS. U. UNIV.-BIBLIOTHEK GÖTTINGEN

Vorh. in: $\quad$ GHG

PPN: 126141509

Water music, music for the Royal Fireworks = Wassermusik, Feuerwerksmusik /

Georg Friedrich Händel. Hrsg. von Hans Ferdinand Redlich. - [Partitur]. - Kassel

[u.a.] : Bärenreiter [u.a.], 1962. - XIX, 123 S. : Faks., Notenbeisp. ; $4^{\circ}$

(Hallische Händel-Ausgabe : Ser. 4, Instrumentalmusik ; Bd. 13)

Best.-Nr.: BA 4018

Signatur: $\quad 4$ MUS 936:4,13

Notizen: $\quad$ 1963.56/2749 - NIEDERSÄCHS. STAATS. U. UNIV.-BIBLIOTHEK GÖTTINGEN

Vorh. in: $\quad$ GHG, MuSe

PPN: 148819311

Zwölf concerti grossi, opus 6 / Georg Friedrich Händel. Hrsg. von Adolf Hoffmann ... [Partitur]. - Kassel [u.a.] : Bärenreiter [u.a.], 1961. - XIV, 276 S. : Faks. ; $4^{\circ}$

(Hallische Händel-Ausgabe : Ser. 4, Instrumentalmusik ; Bd. 14)

Einheitssacht.: Concerti grossi, op. 6

Best.-Nr.: BA 4016

Signatur: $\quad 4$ MUS 936:4,14,HAUPTBD

Notizen: $\quad$ 1962.56/2749 - NIEDERSÄCHS. STAATS. U. UNIV.-BIBLIOTHEK GÖTTINGEN

Vorh. in: $\quad$ GHG (2 Ex.) 


\section{PPN: 030193249}

Sechs einzeln überlieferte Instrumentalwerke : Ouverture B-Dur HWV 336, Sinfonia B-Dur HWV 338, Sonata g-Moll HWV 404, Ouverture D-Dur HWV 337, Concerto grosso C-Dur (Alexanderfest-Konzert) HWV 318, Ouverture D-Dur HWV 424 / Georg Friedrich Händel. Hrsg. von Terence Best ... - [Partitur]. - Kassel [u.a.] : Bärenreiter [u.a.], 1979. - XVII, 102 S. : Faks., Notenbeisp. ; $4^{\circ}$

(Hallische Händel-Ausgabe : Ser. 4, Instrumentalmusik ; Bd. 15)

Einheitssacht.: Werke, Instr. / Ausw. - Enth. Quellen und Lesarten S. [93] - 102. - (HWV 336, 338, 404, 337, 424) hrsg. von Terence Best und (HWV 318) von Frederick Hudson

Best.-Nr.: BA/DVfM 4036

Signatur: $\quad 4$ MUS 936:4,15

Notizen: $\quad$ 1980.56/2749 - NIEDERSÄCHS. STAATS. U. UNIV.-BIBLIOTHEK GÖTTINGEN

Vorh. in: GHG

\section{PPN: 030193257}

Concerti a due cori : HWV 332, 335a, 335b, 333, 334 / Georg Friedrich Händel. Hrsg. von Frederick Hudson. - [Partitur]. - Kassel [u.a.] : Bärenreiter [u.a.], 1983. - XII, 287 S. : Faks., Notenbeisp. ; $4^{\circ}$

(Hallische Händel-Ausgabe : Ser. 4, Instrumentalmusik ; Bd. 16)

Einheitssacht.: Konzerte, Chor / Ausw. - Enth. Quellen und Lesarten S. 275 - 287. -

Copyright: 1971

Best.-Nr.: BA/DVfM 4037

Signatur: $\quad 4$ MUS 936:4,16

Notizen: $\quad$ 1984.56/2749 - NIEDERSÄCHS. STAATS. U. UNIV.-BIBLIOTHEK GÖTTINGEN

Vorh. in: GHG 


\section{PPN: 030193281}

Neun Sonaten für ein Soloinstrument und Basso continuo : HWV 358, 364, 359a, 377, 367a, 357, 366, 363a, 378 / Georg Friedrich Händel. Hrsg. von Terence Best. - [Partitur, Stimmen]. - Kassel [u.a.] : Bärenreiter [u.a.], 1982. - XV, 60 S. : Faks., Notenbeisp. ; $4^{\circ}+4$ St. (38 S.)

(Hallische Händel-Ausgabe : Ser. 4, Instrumentalmusik ; Bd. 18)

Einheitssacht.: Sonaten, Instr Bc. - Kritischer Bericht S. [47] - 60. -

Stimmen: Blfl/Bc, Querfl/Bc, Ob/Bc, Vl/Bc

Best.-Nr.: BA/DVfM 4040

Signatur: $\quad 4$ MUS 936:4,18,HAUPTBD 4 MUS 936:4,18,STIMME

Anmerkung: Stimmen in Beil.-Tasche im Hauptbd. - Nur komplett ausleihbar

Notizen: $\quad$ 1983.56/2749 - NIEDERSÄCHS. STAATS. U. UNIV.-BIBLIOTHEK GÖTTINGEN

Vorh. in: $\quad$ GHG (nur Hauptbd.)

\section{PPN: 030193311}

Einzeln überlieferte Instrumentalwerke II / Georg Friedrich Händel. Hrsg. von Terence Best. - [Musikdr.]. - Kassel [u.a.] : Bärenreiter [u.a.], 1988. - XXXI, 260 S. : Faks. ; $4^{\circ}+6$ St. (Hallische Händel-Ausgabe : Ser. 4, Instrumentalmusik ; Bd. 19)

Einheitssacht.: Werke, Instr. / Ausw. - Stimmen: Blfl/Querfl, Vl solo, Vl 1 2, Bc. Vorw. dt. und engl.

Best.-Nr.: BA/DVfM 4043

Signatur: $\quad 4$ MUS 936:4,19

Notizen: $\quad 1989$ F 56/2749 - NIEDERSÄCHS. STAATS. U. UNIV.-BIBLIOTHEK GÖTTINGEN

Vorh. in: GHG

\section{PPN: 164351531}

HWV 78, 79, 81, 82, 83, 89, 92, 96, 97, 98 / Georg Friedrich Händel. Hrsg. von Hans Joachim Marx. - [Partitur]. - Kassel [u.a.] : Bärenreiter, 1994. - XLVII, 287 S. : Faks. ; $4^{\circ}$ (Hallische Händel-Ausgabe : Ser. 5, Kleinere Gesangswerke ; Bd. 3: Kantaten mit Instrumenten ; Teilbd. 1)

Einheitssacht.: Kantaten / Ausw. - Vorw. dt. und engl. - Texte der Kantaten mit dt. und engl. Übers.

Best.-Nr.: BA 4048

Signatur: $\quad 4$ MUS 936:5,3

Notizen: $\quad 1994$ F 56/2749 - NIEDERSÄCHS. STAATS. U. UNIV.-BIBLIOTHEK GÖTTINGEN

Vorh. in: $\quad$ GHG 


\section{PPN: 186757700}

HWV 99, 105, 110, 119, 113, 122, 123, 132c, 134, 140, 142, 143 / Georg Friedrich Händel. Hrsg. von Hans Joachim Marx. - [Partitur]. - Kassel [u.a.] : Bärenreiter, 1995. - LIII, 283 S. : Faks. ; $4^{\circ}$

(Hallische Händel-Ausgabe : Ser. 5, Kleinere Gesangswerke ; Bd. 4: Kantaten mit Instrumenten ; Teilbd. 2)

Einheitssacht.: Kantaten / Ausw. - Texte der Kantaten mit dt. und engl. Übers., S. XXXI - LIII. - Vorw. dt. und engl.

ISMN M-006-49573-3

Best.-Nr.: BA 4055

Signatur: $\quad 4$ MUS 936:5,4

Notizen: $\quad$ 1995.56.2749 - NIEDERSÄCHS. STAATS. U. UNIV.-BIBLIOTHEK GÖTTINGEN

Vorh. in: $\quad$ GHG

PPN: 305976737

HWV 150, 165, 166, 170, 171, 173 / Georg Friedrich Händel. Hrsg. von Hans Joachim Marx. - [Partitur]. - Kassel [u.a.] : Bärenreiter, 1999. - XXVIII, 200 S. : Faks., Notenbeisp. ; $4^{\circ}$ (Hallische Händel-Ausgabe : Ser. 5, Kleinere Gesangswerke ; Bd. 5: Kantaten mit Instrumenten ; Teilbd. 3)

Einheitssacht.: Kantaten / Ausw. - Texte der Kantaten mit dt. und engl. Übers.,

S. XXIII - XXVIII. - Kritischer Bericht (Kantaten mit Instrumenten I-III),

S. [107] - 200. - Vorw. dt. und engl.

ISMN M-006-49568-9

Best.-Nr.: BA 4060

Signatur: $\quad 4$ MUS 936:5,5

Notizen: $\quad$ NIEDERSÄCHS. STAATS. U. UNIV.-BIBLIOTHEK GÖTTINGEN

Vorh. in: $\quad$ GHG

\section{PPN: 03019332X}

Aufzeichnungen zur Kompositionslehre : aus den Handschriften im Fitzwilliam Museum Cambridge = Composition lessons / Georg Friedrich Händel. Hrsg. von Alfred Mann. Kassel [u.a.] : Bärenreiter [u.a.], 1978. - [100] S. : zahlr. Faks., Notenbeisp. ; $4^{\circ}+1$ Beil. (Hallische Händel-Ausgabe : Suppl., Bd. 1)

Übertr. der Fugenbeispiele S. 91 - [100]. - Text dt. und engl.

Best.-Nr.: BA 4035

Signatur: $\quad 4$ MUS 936:SUP,1

Notizen: $\quad 1991$ F 56.2749 - NIEDERSÄCHS. STAATS. U. UNIV.-BIBLIOTHEK GÖTTINGEN 


\title{
4.2.2 Kritische Berichte
}

\section{PPN: 126140995}

Das Alexander-Fest oder Die Macht der Musik : Ode zu Ehren der heiligen Cäcilia von John Dryden ; kritischer Bericht / von Konrad Ameln. - Kassel [u.a.] : Bärenreiter [u.a.], 1958. - 51 S. : Ill., Faks., Notenbeisp. ; $8^{\circ}$

(Hallische Händel-Ausgabe : Ser. 1, Oratorien und große Kantaten ; Bd. 1, Kritischer Bericht) Literaturverz. S. 51. - Beitr. betr. der musikalischen Texte und Faks. in engl.

\author{
Signatur: $\quad 4$ MUS 936:1,1,KRIT.BERICHT \\ Notizen: $\quad$ 1965.56/2749 - NIEDERSÄCHS. STAATS. U. UNIV.-BIBLIOTHEK GÖTTINGEN \\ Vorh. in: GHG
}

\section{PPN: 126141029}

Ode für den Geburtstag der Königin Anna : (Friedens-Ode) ; kritischer Bericht / von Walther Siegmund-Schultze. - Kassel [u.a.] : Bärenreiter [u.a.], 1962. - 17, [2 ungez.] S. : Notenbeisp. ; $8^{\circ}$

(Hallische Händel-Ausgabe : Ser. 1, Oratorien und große Kantaten ; Bd. 6, Kritischer Bericht)

Signatur: $\quad 4$ MUS 936:1,6,KRIT.BERICHT

Notizen: $\quad$ 1965.56/2749 - NIEDERSÄCHS. STAATS. U. UNIV.-BIBLIOTHEK GÖTTINGEN

PPN: 302987657

Passion nach Barthold Heinrich Brockes : kritischer Bericht / von Felix Schröder. Kassel [u.a.] : Bärenreiter. [u.a.], 1973. - 71 S. : zahlr. Notenbeisp. ; $8^{\circ}$

(Hallische Händel-Ausgabe : Ser. 1, Oratorien und große Kantaten ; Bd. 7, Kritischer Bericht)

Signatur: $\quad 4$ MUS 936:1,7,KRIT.BERICHT

Notizen: $\quad$ 1973.56/2749 - NIEDERSÄCHS. STAATS. U. UNIV.-BIBLIOTHEK GÖTTINGEN

Vorh. in: GHG 


\section{PPN: 126141088}

Saul : kritischer Bericht / von Percy M. Young. [Aus dem Engl. übers. von Siegfried Flesch]. - Kassel [u.a.] : Bärenreiter [u.a.], 1964. - 184 S. : Notenbeisp. ; $8^{\circ}$ (Hallische Händel-Ausgabe : Ser. 1, Oratorien und große Kantaten ; Bd. 13, Kritischer Bericht)

Enth. Mehrfassungen, Vorformen und gestrichene Abschnitte, S. [105] - 184

Signatur: $\quad 4$ MUS 936:1,13,KRIT.BERICHT

Notizen: $\quad$ 1965.56/2749 - NIEDERSÄCHS. STAATS. U. UNIV.-BIBLIOTHEK GÖTTINGEN

Vorh. in: GHG

\section{PPN: 12614110X}

L' Allegro, il Penseroso ed il Moderato : kritischer Bericht / von James S. Hall ... [Aus dem Engl. übers. von Siegfried Flesch]. - Kassel [u.a.] : Bärenreiter [u.a.], 1969. 116 S. : Faks., Notenbeisp. ; $8^{\circ}$

(Hallische Händel-Ausgabe : Ser. 1, Oratorien und große Kantaten ; Bd. 16, Kritischer Bericht)

$\begin{array}{ll}\text { Signatur: } & 4 \text { MUS 936:1,16,KRIT.BERICHT } \\ \text { Notizen: } & \text { 1970.56/2749 - NIEDERSÄCHS. STAATS. U. UNIV.-BIBLIOTHEK GÖTTINGEN } \\ \text { Vorh. in: } & \text { GHG }\end{array}$

PPN: 126141126

Der Messias : kritischer Bericht / von John Tobin. [Aus dem Engl. übers. von Siegfried Flesch]. - Kassel [u.a.] : Bärenreiter [u.a.], 1965. - [108] S. : Notenbeisp. ; $8^{\circ}$ (Hallische Händel-Ausgabe : Ser. 1, Oratorien und große Kantaten ; Bd. 17, Kritischer Bericht)

Signatur: $\quad 4$ MUS 936:1,17,KRIT.BERICHT

Notizen: $\quad$ 1966.56/2749 - NIEDERSÄCHS. STAATS. U. UNIV.-BIBLIOTHEK GÖTTINGEN

Vorh. in: GHG 


\section{PPN: 126141150}

Susanna : HWV 66 ; kritischer Bericht / von Bernard Rose. [Übers. aus dem Engl.: Siegfried Flesch]. - Kassel [u.a.] : Bärenreiter [u.a.], 1985. - 82 S. : zahlr. Faks. ; $8^{\circ}$ (Hallische Händel-Ausgabe : Ser. 1, Oratorien und große Kantaten ; Bd. 28, Kritischer Bericht)

Signatur: $\quad 4$ MUS 936:1,28,KRIT.BERICHT

Notizen: $\quad$ 1986.56/2749 - NIEDERSÄCHS. STAATS. U. UNIV.-BIBLIOTHEK GÖTTINGEN

Vorh. in: $\quad$ GHG

PPN: 126141177

Die Wahl des Herakles : kritischer Bericht / von Walther Siegmund-Schultze. - Kassel [u.a.] : Bärenreiter [u.a.], 1962. - [20] S. : Notenbeisp. ; $8^{\circ}$

(Hallische Händel-Ausgabe : Ser. 1, Oratorien und große Kantaten ; Bd. 31, Kritischer Bericht)

Signatur: $\quad 4$ MUS 936:1,31,KRIT.BERICHT

Notizen: $\quad$ 1965.56/2749 - NIEDERSÄCHS. STAATS. U. UNIV.-BIBLIOTHEK GÖTTINGEN

Vorh. in: $\quad$ GHG

PPN: 126141223

Amadigi : HWV 11 ; kritischer Bericht / von Merrill Knapp. [Übers. aus dem Engl.: Siegfried Flesch]. - Kassel [u.a.] : Bärenreiter [u.a.], 1985. - 50 S. : Notenbeisp. ; $8^{\circ}$ (Hallische Händel-Ausgabe : Ser. 2, Opern ; Bd. 8, Kritischer Bericht)

Literaturangaben

Signatur: $\quad 4$ MUS 936:2,8,KRIT.BERICHT

Notizen: $\quad$ 1986.56/2749 - NIEDERSÄCHS. STAATS. U. UNIV.-BIBLIOTHEK GÖTTINGEN

Vorh. in: GHG 
PPN: 323102158

Georg Friedrich Händel: Klavierwerke I-IV : Die acht großen Suiten, erste Sammlung von 1720; Suites de Pièces pour le Clavecin, zweite Sammlung von 1733; Einzelne Suiten und Stücke, erste Folge; Einzelne Suiten und Stücke, zweite Folge ; kritischer Bericht / von Terence Best. - Kassel [u.a.] : Bärenreiter, 2000. - 146 S. : zahlr. Notenbeisp. ; $4^{\circ}$ (Hallische Händel-Ausgabe ; Ser. 4: Instrumentalmusik ; Bd. 7: Klavierwerke ; Teilbd. 1-4: Kritischer Bericht)

Text engl.

ISMN M-006-49584-9

Best.-Nr.: BA 4067

Signatur: $\quad 4$ MUS 936:4,7,KRIT.BERICHT

Notizen: $\quad$ NIEDERSÄCHS. STAATS. U. UNIV.-BIBLIOTHEK GÖTTINGEN

Vorh. in: $\quad$ GHG

PPN: 302988947

Sieben Sonaten für zwei Violinen und Basso continuo, opus 5 : kritischer Bericht / von Siegfried Flesch. - Kassel [u.a.] : Bärenreiter [u.a.], 1973. - 73 S. : Notenbeisp. ; $8^{\circ}$ (Hallische Händel-Ausgabe : Ser. 4, Instrumentalmusik ; Bd. 10,2, Kritischer Bericht) Literaturangaben

Signatur: $\quad 4$ MUS 936:4,10,2,KRIT.BERICHT

Notizen: $\quad$ NIEDERSÄCHS. STAATS. U. UNIV.-BIBLIOTHEK GÖTTINGEN

Vorh. in: $\quad$ GHG

PPN: 126141487

Sechs concerti grossi, opus 3 : kritischer Bericht / von Frederick Hudson. - Kassel [u.a.] : Bärenreiter [u.a.], 1963. - 122 S., [1] Bl. : Ill., Notenbeisp. ; $8^{\circ}$

(Hallische Händel-Ausgabe : Ser. 4, Instrumentalmusik ; Bd. 11, Kritischer Bericht)

Signatur: $\quad 4$ MUS 936:4,11,KRIT.BERICHT

Notizen: $\quad$ 1965.56/2749 - NIEDERSÄCHS. STAATS. U. UNIV.-BIBLIOTHEK GÖTTINGEN

Vorh. in: GHG 
PPN: 126141533

Zwölf concerti grossi opus 6 : kritischer Bericht / von Hans Ferdinand Redlich. Kassel [u.a.] : Bärenreiter [u.a.], 1964. - 92 S., [2] Bl. : Ill., Notenbeisp. ; $8^{\circ}$

(Hallische Händel-Ausgabe : Ser. 4, Instrumentalmusik ; Bd. 14, Kritischer Bericht)

Signatur: $\quad 4$ MUS 936:4,14,KRIT.BERICHT

Notizen: $\quad$ 1964.56/2749 - NIEDERSÄCHS. STAATS. U. UNIV.-BIBLIOTHEK GÖTTINGEN

Vorh. in: $\quad$ GHG, MuSe 


\section{Hä nd e l s W e r ke}

\section{$5.1 \quad$ O p e r n}

\section{PPN: 071017429}

Händel, Georg Friedrich:

Neun Sätze aus der Oper „Almira“, für Sopran-Blockflöte oder Violine und Cembalo (Klavier); Violoncello (Gambe) ad libitum / Georg Friedrich Händel. - Partitur, Stimmen. - Celle [u.a.] : Moeck [u.a.], 1957. - 12 S., [1] Bl. ; $4^{\circ}+2$ St.

(Moecks Kammermusik ; 34)

Einheitssacht.: Der in Kronen erlangte Glückswechsel, oder: Almira, Königin von Kastilien / Ausw. - Stimmen: Sopr-Blfl (Vl), Vc (Gambe). - Einf. dt., engl. und franz. Best.-Nr.: Edition Moeck 1034

\section{Signatur: $\quad 4$ Z MUS 122:34}

Notizen: $\quad 1958.1136$ - NIEDERSÄCHS. STAATS. U. UNIV.-BIBLIOTHEK GÖTTINGEN verknüpft zur Serie PPN 130218405

PPN: 135217709

[Flavius] The favourite songs in the opera call'd Flavius / [by Mr. Handel]. [Musikdr.]. - London : printed for \& sold by Walsh ... \& Ioseph Hare, [1723]. - 19 S., S. 22-23, 31-32, 38-39; $2^{\circ}$

Einheitssacht.: Flavio, re de’ Langobardi <Lied>. - Keine S.-Zählung, sondern Bl.-Zählung. Zählung ist unregelmäßig. - Gesangstext ital.

Signatur: $\quad 2$ MUS VII, 402

Notizen: $\quad$ EX BIBLIOTHECA ACAD. GEORGIAE AUGUSTAE

\section{PPN: 135217717}

[Rinaldo] Song's in the Opera of Rinaldo / compos'd by Mr. Hendel. - [Musikdr.]. London : Printed for J. Walsh Servant in Ordinary to her Britanick Majesty, at Harp \& Hoboy ... \& J. Hare at Viol \& Flute ..., [1711]. - 65 S. ; ${ }^{\circ}$ Einheitssacht.: Rinaldo $<$ Arie $>$

Signatur: $\quad 2$ MUS VII, 403

Notizen: $\quad$ EX BIBLIOTHECA ACAD. GEORGIAE AUGUSTAE 


\section{$5.2 \quad$ Oratoris che Werke}

\subsubsection{O r a t o rie n}

\section{PPN: 135213789}

Händel, Georg Friedrich:

Acis and Galatea : A Masque ; performed for the first time at Cannons in the year 1721 / Composed By George Frederic Handel. [Ed.: William Sterndale Bennett]. - [Partitur mit beigef. Klavierausz.]. - London, printed for The Handel Society : by Cramer, Beale, 1846-7. - IX, [1 ungez.], 232 S. ; $2^{\circ}$

(The works of Handel ; Vol. 10)

Einheitssacht.: Masques, HWV 49a

Signatur: $\quad 2$ MUS VII, 340:10

Notizen: $\quad 1896.1207$ - EX BIBLIOTHECA REGIA ACADEM. GEORGIAE AUG. Arnold Wehner [wahrscheinlich Vorbesitzer [d. Verf.]] verknüpft zum MBW PPN 135213681

PPN: 331361086

Acis und Galatea : Pastoral / von Georg Friedrich Händel. Dichtung von John Gay. Aus dem Engl. neu übertr. und für den praktischen Gebrauch hrsg. von Konrad Ameln. - Chorpartitur. - Wolfenbüttel ; Zürich : Möseler, 1951. - 48 S. ; $4^{\circ}$

Signatur: $\quad 80$ B 26185

Notizen: $\quad$ NIEDERSÄCHS. STAATS. U. UNIV.-BIBLIOTHEK GÖTTINGEN Geschenk des Verlags

\section{PPN: 126280460}

Acis und Galatea / vorgelegt von Andreas Holschneider. - [Partitur]. - Kassel [u.a.] : Bärenreiter, 1973. - XVIII, 175 S. : Faks. ; $4^{\circ}$ (Neue Ausgabe sämtlicher Werke : Serie 10, Supplement ; Werkgruppe 28: Bearbeitungen, Ergänzungen und Übertragungen fremder Werke ; Abt. 1: Bearbeitungen von Werken Georg Friedrich Händels ; Bd. 1) Best.-Nr.: BA 4564

Signatur: $\quad$ FB 574:10,28,1,1,HAUPTBD

Notizen: $\quad$ NIEDERSÄCHS. STAATS. U. UNIV.-BIBLIOTHEK GÖTTINGEN verknüpft zum MBW PPN 126278539 


\section{PPN: 135213711}

L’ Allegro, Il Pensieroso, ed Il Moderato : Composed in the Year 1740 ; with the Additional Songs, Composed in the Year 1741 / By George Frederic Handel. [Ed.: I. Moscheles]. [Partitur mit beigef. Klavierausz.]. - London : Cramer, Beale, 1843-4. - XVIII, 170 S. ; $2^{\circ}$ (The works of Handel ; Vol. 3)

Einheitssacht.: L' allegro, il penseroso ed il moderato, HWV 55

Signatur: $\quad 2$ MUS VII, 340:3

Notizen: $\quad$ EX BIBLIOTHECA REgia ACADEM. GEORGIAE AUG. - Arnold Wehner [auf der Titels., wahrscheinlich Vorbesitzer [d. Verf.]] verknüpft zum MBW PPN 135213681

PPN: 135217377

L' allegro il pensieroso ed il moderato : oratorische Composition / von Georg Friedrich Händel. Mit ausgeführtem Accompagnement bearb. von Robert Franz. - Partitur. Leipzig : Leuckart, 1871. - 230 S. : Ill. ; $4^{\circ}$

Mit dem Portr. Goerg Friedrich Händel’s, gest. von Adolf Neumann. - Gesangstext dt. und engl.

Best.-Nr.: F.E.C.L. 2317

Signatur: $\quad 4$ MUS VII, 370

Notizen: $\quad$ EX BIBLIOTHECA REgIA ACADEM. GEORGIAE AUG.

PPN: 135217563

[Jephtha] Das Autograph des Oratoriums „Jephtha“ : Fest-Ausgabe der Deutschen HändelGesellschaft zur zweiten Säcularfeier am 23. Februar 1885/ von G. F. Händel. - [Musikdr.]. - [Leipzig] : [s.n.], 1885. - IV, 268 S. ; quer-4

Einheitssacht.: Jephtha, HWV 70. - Vorw. dt. - Gesangstext engl. - In Fraktur

Signatur: $\quad 4$ MUS VII, 385

Notizen: $\quad$ EX BIBLIOTHECA REgIA ACADEM. GEORGIAE AUG.

Vorh. in: $\quad$ MuSe 


\title{
PPN: 135217369
}

[Messias] Das Autograph des Oratoriums „Messias“ / von G. F. Händel. Für die Dt. Händelges. hrsg. von Friedrich Chrysander. - [Musikdr.]. - Hamburg : Strumper, 1889-1892. - XV, 330 S. ; quer- $4^{\circ}$

Einheitssacht.: Messiah, HWV 56. - Das Werk ist in 3 Lfg. erschienen: 1.(1889) „Erster Theil des Oratoriums (S. 1-100)“; 2.(1890) „Zweiter Theil des Oratoriums (S. 101-208)“; 3.(1892) „Dritter Theil des Oratoriums, nebst Anhang (S. 209-330), Haupttitel, Vorwort und Index“. - Vorw. und Index dt. und engl.

\author{
Signatur: $\quad 4$ MUS VII, 368 \\ Notizen: $\quad$ 1889.2563 (1. Lfg.), 2890.3200 (2. Lfg.), 1892.3709 (3. Lfg.) - \\ EX BIBLIOTHECA REGIA ACADEM. GEORGIAE AUG. - \\ Geschenk des Königl. Oberpräsidiums der Prov. Hannover 1889
}

Vorh. in: $\quad$ MuSe (1. und 2. Lfg.)

\section{PPN: 135213819}

Belshazzar : An Oratorio ; Composed in the Year 1744 ; [Part I] / By George Frederic Handel. [Ed.: G. A. Macfarren]. - [Partitur mit beigef. Klavierausz.]. - London, printed for The Handel Society : by Cramer, Beale, 1847-8. - XVIII, 234 S. ; $2^{\circ}$ (The works of Handel ; Vol. 13)

Signatur: $\quad 2$ MUS VII, 340:13

Notizen: $\quad$ EX BIBLIOTHECA REgIA ACADEM. GEORGIAE AUG. Arnold Wehner [wahrscheinlich Vorbesitzer [d. Verf.]] verknüpft zum MBW PPN 135213681

PPN: 329230727

Belshazzar : An Oratorio ; Composed in the Year 1744 ; Part II / By George Frederic Handel. [Ed.: G. A. Macfarren]. - [Partitur mit beigef. Klavierausz.]. - London, printed for The Handel Society : by Cramer, Beale, 1848-9. - S. 235 - 555. ; $2^{\circ}$

(The works of Handel ; Vol. 14)

Signatur: $\quad 2$ MUS VII, 340:14

Notizen: $\quad$ EX BIBLIOTHECA REgIA ACADEM. GEORGIAE AUG. Arnold Wehner [wahrscheinlich Vorbesitzer [d. Verf.]] verknüpft zum MBW PPN 135213681 
PPN: 13521727X

Empfindungen am Grabe Jesu : Ein Oratorium / von G. F. Händel. - Partitur. Leipzig : Breitkopf und Härtel, [um 1800]. - 56 S. ; $4^{\circ}$

Einheitssacht.: The ways of Zion do mourn, HWV 264

Signatur: $\quad 4$ MUS VII, 359 RARA

Notizen: $\quad 1961.5895$ - Bibliothek d. Kgl. Conservatoriums f. Musik u. Theater z. Dresden ; Breitkopf \& Härtel ; Ausgeschieden Stabi

PPN: 13521372X

Esther : An Oratorio ; Composed in the Year 1720 ; with Additional Pieces, Composed at various Periods / By George Frederic Handel. [Ed.: Charles Lucas]. - [Partitur mit beigef. Klavierausz.]. - London, printed for the Members of The Handel Society : by Cramer, Beale, 1844-5. - XIV, 191 S. ; $2^{\circ}$

(The works of Handel ; Vol. 4)

Einheitssacht.: Esther (Haman and Mordecai), HWV 50a

Signatur: $\quad 2$ MUS VII, 340:4

Notizen: $\quad$ EX Bibliotheca Regia ACADEM. GeORgiae AUG. - Arnold Wehner [auf der Titels., wahrscheinlich Vorbesitzer [d. Verf.]] verknüpft zum MBW PPN 135213681

PPN: 333517849

Gloria : HWV deest / Händel. Hrsg. von Hans Joachim Marx. - Partitur, Urtext der Hallischen Händel-Ausg. - Kassel [u.a.] : Bärenreiter, 2001. - 31 S. ; $4^{\circ}+3$ St.

(Bärenreiter Urtext)

Einheitssacht.: Gloria, Vl 12 Bc, B-Dur. - Kritischer Bericht S. 28f. (dt.), S. 30f. (engl.). - Stimmen: Vl 1 2, Org, B. - Vorw. dt. und engl. - Gesangstext lat.

ISMN M-006-52011-4

Best.-Nr.: BA 4248

Signatur: $\quad$ K 2002 B 1825

Anmerkung: Nur komplett ausleihbar

Notizen: $\quad$ NIEDERSÄCHS. STAATS. U. UNIV.-BIBLIOTHEK GÖTTINGEN

Vorh. in: $\quad$ MuSe 
PPN: 135217288

[Der Messias] F. G. Händel’s Oratorium Der Messias / nach W. A. Mozart's Bearb. - Partitur. - Leipzig : Breitkopf und Härtel, [s.a.]. - 108, 95, 48 S. ; quer-4

Einheitssacht.: Messiah, HWV 56 / Arr. - Gesangstext dt.

Signatur: $\quad 4$ MUS VII, 360

Notizen: $\quad$ EX BIBLIOTHECA REgIA ACADEM. GEORGIAE AUG.

PPN: 042087775

Handel's conducting score of Messiah / introd. by Watkins Shaw. - [Musikdr.]. - Reprod. in facs. from the ms. in the Library of St Michael's College, Tenbury Wells. - London : Scolar Press, 1974. - [226] Bl. ; quer-4

Einheitssacht.: Messiah, HWV 56. - Publ. for the Royal Musical Assoc. on the occasion of its centenary

ISBN 0-85967-158-5

Signatur: $\quad 75$ B 5675

Notizen: $\quad$ NIEDERSÄCHS. STAATS. U. UNIV.-BIBLIOTHEK GÖTTINGEN

PPN: 135213703

Israel in Egypt: An Oratorio ; Composed in the Year 1738 / By George Frederic Handel. [Ed.: Felix Mendelssohn-Bartholdy]. - [Partitur mit beigef. Klavierausz.]. - London : printed for the Members of The Handel Society by Cramer, Beale, 1845-6. - [3] Bl., VIII, [1] Bl., 393 S. ; $2^{\circ}$

(The works of Handel ; Vol. 2)

Signatur: $\quad 2$ MUS VII, 340:2

Notizen: $\quad$ EX BIBLIOTHECA REgia ACADEM. GEORGIAE AUG. - Arnold Wehner [auf der Titels., wahrscheinlich Vorbesitzer [d. Verf.]] verknüpft zum MBW PPN 135213681 


\section{PPN: 135213800}

Jephtha : an oratorio ; composed in the year 1758 / by George Frederic Handel. [G. A. Macfarren [Ed.]]. - [Partitur mit beigef. Klavierausz.]. - London : Cramer, Beale, 1858.

- IX, [1 ungez.], 273 S. ; $2^{\circ}$

(The works of Handel ; Vol. 12)

Signatur: $\quad 2$ MUS VII, 340:12

Notizen: $\quad$ EX BIBLIOTHECA REGIA ACADEM. GEORGIAE AUG. verknüpft zum MBW PPN 135213681

PPN: 135217210

Judas Maccabäus / Händel. - Stimmen. - 21 St.

Einheitssacht.: Judas Maccabaeus, HWV 63. -

Stimmen: Fl 1 2, Ob 1 2, Fg, Hr 1 2, Trp 12 3, Pk, Vl 1 2, Va, Vc Bc 12 . $13 \mathrm{Bl}$. hs. Beil., 11 gedr. H.

Signatur: $\quad 2$ MUS VII, 354

Anmerkung: $\quad 2.4 .0 .1,2.5 .0 .0 .2 ; 7.7 .1 .2 .3$

Notizen: $\quad$ 1918.3467 - EX BIBLIOTHECA REGIA ACADEM. GEORGIAE AUG. Geschenk aus den Mitteln der Ludendorff-Spende 1918

PPN: 135213770

Judas Maccabaeus : an oratorio ; composed in the year 1746 / by George Frederic Handel, with the additional pieces subsequently introd. by the comp. [G. A. Macfarren [Ed.]]. - [Partitur mit beigef. Klavierausz.]. - London : Cramer, Beale, 1855. - XIII, [1 ungez.], $260 \mathrm{~S} . ; 2^{\circ}$

(The works of Handel ; Vol. 9)

App. S. 255 - 260.

Signatur: $\quad 2$ MUS VII, 340:9

Notizen: $\quad 1896.1207$ - EX BIBLIOTHECA REGIA ACADEM. GEORGIAE AUG. verknüpft zum MBW PPN 135213681 
PPN: 135217202

Judas Maccabaeus : Oratorium / von G. F. Händel. - [Partitur, Stimmen]. - 24 St. Stimmen: Gesang + Begl.-St., Fl 1 2, Klar 1 2, Fg, Vl 1 2, Va, Chor STB, Bc 12 , Org, Orch. - 24 Bl., 6 Bogen hs. Beil., 10 hs. H.

Signatur: $\quad 2$ MUS VII, 354/a

Anmerkung: $\quad$ Chor STB, 2.0.2.1, 0.3.0.0.1; 2.2.2.0.3

PPN: 135213827

The Messiah : An Oratorio ; Composed in the Year 1741 ; [Part I] / By George Frederic Handel. [Ed.: Edward F. Rimbault]. - [Partitur mit beigef. Klavierausz.]. - London, printed for The Handel Society : by Cramer, Beale, 1850. - XIV, 227 S. ; $2^{\circ}$

(The works of Handel ; Vol. 15)

Signatur: $\quad 2$ MUS VII, 340:15

Notizen: $\quad$ EX Bibliotheca Regia ACAdem. GeORgIAE AUG. - Arnold Wehner [auf der Titels., wahrscheinlich Vorbesitzer [d. Verf.]] verknüpft zum MBW PPN 135213681

PPN: 32923207X

Messiah : An Oratorio ; Composed in the Year 1741 ; [Part II] / By George Frederic Handel. [Ed.: Edward F. Rimbault]. - [Partitur mit beigef. Klavierausz.]. - London, printed for The Handel Society : by Cramer, Beale, 1850. - S. 229 - 593. ; $2^{\circ}$

(The works of Handel ; Vol. 16)

Signatur: $\quad 2$ MUS VII, 340:16

Notizen: $\quad$ EX BIBLIOTHECA REgIA ACADEM. GEORGIAE AUG. - Arnold Wehner [auf der Titels., wahrscheinlich Vorbesitzer [d. Verf.]] verknüpft zum MBW PPN 135213681 
PPN: 135217326

Der Messias / von Händel. - [Stimmen]. - 24 St. ; $2^{\circ}$, Org-St. quer-4 ${ }^{\circ}$

Einheitssacht.: Messiah, HWV 56. - Stimmen: Fl 1 2, Ob 1 2, Klar 1 2, Fg 12 , Hr 1 2, Trp ATB 12 3, Clarino 1 2, Pk, Vl 1 2, Va, Vc, Kb, Org. - Ms.

Signatur: $\quad 2$ MUS VII, 364 RARA

Anmerkung: $\quad$ 2.2.2.2, 2.3.2.0.0.1; 2.2.1.1.1; 1 - 1 Kapsel, 1 Mappe (Org)

Notizen: $\quad$ BIBL. R. ACAD. G. A.

PPN: 317545388

Der Messias : Oratorium / von G. F. Händel. Unter Zugrundelegung der Mozart'schen Partitur mit den nöthigen Erg. hrsg. von Robert Franz. - Partitur. - Leipzig : Kistner, [1884]. - V, S. 2 - $335 ; 4^{\circ}$

Einheitssacht.: Messiah, HWV 56. - Vorw. und Gesangstext dt. und engl.

Best.-Nr.: 6300

(M. 30.-)

Signatur: $\quad 4$ MUS VII, 362:PARTITUR

Notizen: $\quad$ EX BIBLIOTHECA REgIA ACADEM. GEORGIAE AUG.

PPN: 135334241

Der Messias : Oratorium ; Text deutsch und englisch / von Georg Friedrich Händel.

Übers. von Friedrich Chrysander. Hrsg. und mit einf. Worten vers. von Fritz Volbach.

- [Partitur]. - Leipzig : Eulenburg, [nach 1910]. - XVI, 354 S. ; $8^{\circ}$

(Eulenburg's kleine Orchester-Partitur-Ausgabe : Chorwerke ; 6)

Einheitssacht.: Messiah, HWV 56. - Gesangstext dt. und engl.

Best.-Nr.: Edition Eulenburg 956

(6 M.)

Signatur: $\quad 8$ MUS V, 520:956

Notizen: $\quad 1915.550$ - EX BIBLIOTHECA REGIA ACADEM. GEORGIAE AUG. -

Geschenk des Herrn Verlegers 1915 - Verknüpft zur Serie PPN 130781339 


\section{PPN: 126280479}

Der Messias / vorgelegt von Andreas Holschneider. - [Partitur]. - Kassel [u.a.] : Bärenreiter, 1961. - XVIII, 314 S. : Faks. ; $4^{\circ}$

(Neue Ausgabe sämtlicher Werke : Serie 10, Supplement ; Werkgruppe 28: Bearbeitungen, Ergänzungen und Übertragungen fremder Werke ; Abt. 1: Bearbeitungen von Werken Georg Friedrich Händels ; Bd. 2)

Einheitssacht.: Messiah, HWV 56 / Arr.

Best.-Nr.: BA 4529

Signatur: $\quad$ FB 574:10,28,1,2,HAUPTBD

Notizen: $\quad 1961.574$ - NIEDERSÄCHS. STAATS. U. UNIV.-BIBLIOTHEK GÖTTINGEN verknüpft zum MBW PPN 126278539

Vorh. in: $\quad$ MuSe

PPN: 135213762

Samson : an oratorio ; composed in the year 1741 / by Geroge Frederic Handel. [Ed.: Edward F. Rimbault]. - [Partitur mit beigef. Klavierausz.]. - London : Cramer, Beale, 1853. - XV, [1 ungez.], 290 S. ; $2^{\circ}$

(The works of Handel ; Vol. 8)

Signatur: $\quad 2$ MUS VII, 340:8

Notizen: $\quad 1896.1207$ - EX BIBLIOTHECA REGIA ACADEM. GEORGIAE AUG. Arnold Wehner [auf der Titels., wahrscheinlich Vorbesitzer [d. Verf.]] verknüpft zum MBW PPN 135213681

\section{PPN: 135213797}

Saul : an oratorio ; composed in the year 1738 / by George Frederic Handel. [Edward F. Rimbault [Ed.]]. - [Partitur mit beigef. Klavierausz.]. - London : Cramer, Beale, 1857. - XI, [1 ungez.], 269 S. ; $2^{\circ}$

(The works of Handel ; Vol. 11)

Signatur: $\quad 2$ MUS VII, 340:11

Notizen: $\quad 1896.1207$ - EX BIBLIOTHECA REGIA ACADEM. GEORGIAE AUG. verknüpft zum MBW PPN 135213681 


\subsubsection{S e r e n a d e n, O d e n}

\section{PPN: 135217407}

Händel, Georg Friedrich:

Alexanders Fest oder die Gewalt der Musik / von Händel und Mozart. - 28 St.

Einheitssacht.: Alexander's feast or The power of musick, HWV 75. -

Stimmen: Fl 1 2, Ob 1 2, Klar 1 2, Fg 1 2, Hr 1 2, Clarino 1 2, Pk, Vl A 12 ,

Vl B 1 2, Va 1 2, Kb/Vc AB. - Komp.: London, Jan. 1736. - Ms., gr.- und kl.-4

Signatur: $\quad 4$ MUS VII, 371

Anmerkung: $\quad 2.2 .4 .2,4.3 .0 .0 .2 ; 2.2 .1 .2 .2$

PPN: 126280495

Das Alexander-Fest / vorgelegt von Andreas Holschneider. - [Partitur]. - Kassel [u.a.] :

Bärenreiter, 1962. - XVI, 198 S. : Faks. ; $4^{\circ}$

(Neue Ausgabe sämtlicher Werke : Serie 10, Supplement ; Werkgruppe 28: Bearbeitungen,

Ergänzungen und Übertragungen fremder Werke ; Abt. 1: Bearbeitungen von Werken

Georg Friedrich Händels ; Bd. 3)

Best.-Nr.: BA 4527

Signatur: $\quad$ FB 574:10,28,1,3

Notizen: $\quad 1962.574$ - NIEDERSÄCHS. STAATS. U. UNIV.-BIBLIOTHEK GÖTTINGEN verknüpft zum MBW PPN 126278539

Vorh. in: $\quad$ MuSe

\section{PPN: 135213738}

Ode for St. Cecilia's Day : Composed in the Year 1739 / By George Frederic Handel. [Ed.: T. M. Mudie]. - [Partitur mit beigef. Klavierausz.]. - London : Cramer, Beale, 1844-5. - IV, [1] Bl., 95 S. ; $2^{\circ}$

(The works of Handel ; Vol. 5)

Einheitssacht.: Oden, HWV 76

Signatur: $\quad 2$ MUS VII, 340:5

Notizen: $\quad$ EX BIBLIOTHECA REgiA ACADEM. GEORgIAE AUG. - Arnold Wehner [auf der Titels., wahrscheinlich Vorbesitzer [d. Verf.]] verknüpft zum MBW PPN 135213681 
PPN: 126280517

Ode auf St. Caecilia / vorgelegt von Andreas Holschneider. - [Partitur]. - Kassel [u.a.] : Bärenreiter, 1969. - XVII, 119 S. : Faks. ; $4^{\circ}$

(Neue Ausgabe sämtlicher Werke : Serie 10, Supplement ; Werkgruppe 28: Bearbeitungen, Ergänzungen und Übertragungen fremder Werke ; Abt. 1: Bearbeitungen von Werken Georg Friedrich Händels ; Bd. 4)

Best.-Nr.: 4556

Signatur: $\quad$ FB 574:10,28,1,4

Notizen: $\quad$ NIEDERSÄCHS. STAATS. U. UNIV.-BIBLIOTHEK GÖTTINGEN verknüpft zum MBW PPN 126278539

Vorh. in: $\quad$ MuSe 


\subsection{Vokale und instrumentale Kammermusik}

\subsubsection{K a n t a t e n}

\section{PPN: 135217873}

Händel, Georg Friedrich:

O Amor, du Tyrann : Kantate für eine Sopranstimme, 2 Violinen, Viola und

Generalbaß = (Crudel tiranno Amor) $/$ Georg Friedrich Händel. Übers. von

Emilie Dahnk-Baroffio. Eingerichtet und hrsg. von Hermann Zenck. -

[Partitur, Stimmen], Neuausg. - Kassel : Bärenreiter, 1943. - 16 S. ; $4^{\circ}+4$ St.

(Italienische Kantaten ; [3])

Einheitssacht.: Kantaten, HWV 97. - Stimmen: Vl 1 2, Va, Vc. - Gesangstext dt. und ital.

Best.-Nr.: Bärenreiter-Ausgabe 1974

Signatur: $\quad 4$ MUS VII, 426/3

Notizen: $\quad 1943.800$ - Universitätsbibliothek Göttingen verknüpft zum MBW PPN 135217865

PPN: 026952858

Diana Cacciatrice : Cantata a voce sola con stromenti ; (HWV 79) / Georg Friedrich Händel. Mit einer Einf. von Bernd Baselt und einem Geleitw. von Otto Biba ... - [Musikdr.]. - Faks. nach dem Partiturautogr. Händels aus dem Bestand der Dt. Staatsbibliothek Berlin und der Ges. der Musikfreunde Wien. - Leipzig : Zentralantiquariat der Dt. Demokratischen Republik, 1985. - 8 S., [8] Bl. ; quer-4

Einheitssacht.: Kantaten, HWV 79

Signatur: $\quad 86$ A $10326 *$

Notizen: $\quad$ NIEDERSÄCHS. STAATS. U. UNIV.-BIBLIOTHEK GÖTTINGEN

\section{PPN: 135217938}

Du bist treu und beständig? : Kantate für eine Sopranstimme, 2 Violinen und Generalbaß = (Tu fedel, tu costante?) / Georg Friedrich Händel. Übers. von Emilie Dahnk-Baroffio. Eingerichtet und hrsg. von Hermann Zenck. -

[Partitur, Stimmen], Neuausg. - Kassel : Bärenreiter, 1943. - 23 S. ; $4^{\circ}+3$ St.

(Italienische Kantaten ; [2])

Einheitssacht.: Kantaten, HWV 171. - Stimmen: Vl 1 2, Vc. - Gesangstext dt. und ital.

Best.-Nr.: Bärenreiter-Ausgabe 1973

Signatur: $\quad 4$ MUS VII, 426/2

Notizen: $\quad 1943.2151$ - Universitätsbibliothek Göttingen verknüpft zum MBW PPN 135217865 


\section{PPN: 135217911}

Um die Flamme : Kantate für Sopran, Solo-Gambe, Flöten, Oboe, Fagott, Violinen I und II und Generalbaß = (Tra le fiamme) / Georg Friedrich Händel. Übers. von Emilie Dahnk-Baroffio. Eingerichtet und hrsg. von Hermann Zenck. - [Partitur, Stimmen], Neuausg. - Kassel : Bärenreiter, 1943. - 26 S. ; $4^{\circ}+8$ St.

(Italienische Kantaten ; [6])

Einheitssacht.: Kantaten, HWV 170. - Stimmen: Fl 1 2, Ob, Fg, Vl 1 2, Vagb, Vc/Kb. Gesangstext dt. und ital.

Best.-Nr.: Bärenreiter-Ausgabe 1977

Signatur: $\quad 4$ MUS VII, 426/6

Notizen: $\quad$ 1943.1456 - Universitätsbibliothek Göttingen verknüpft zum MBW PPN 135217865

Vorh. in: $\quad$ MuSe

PPN: 331925273

Ach Herr, mich armen Sünder : Kantate für 4 Soli, Chor, Orchester, Cembalo und Orgel / G. F. Händel. Bearb. von Max Seiffert. - [Partitur]. - Leipzig : Kistner \& Siegel, [ca. 1929]. - 41 S. ; $4^{\circ}$

(Organum : Reihe 1, Geistliche Gesangsmusik ; 12)

Einheitssacht.: Kantaten, Cemb Chor Orch

Best.-Nr.: 28167

Signatur: $\quad 4$ MUS V, 718:1,12

Notizen: $\quad$ 42.4889a - Universitätsbibliothek Göttingen verknüpft zur Serie PPN 130778184

PPN: 266530222

So wie der Hirsch nach Wasser schreit : [Psalm 42] ; für Sopran, Tenor und Baß, dreistimmigen Chor mit Instrumenten $/ 1$ Fassung = As pants the hart for cooling streams / Georg Friedrich Händel. - [Partitur]. - Berlin [u.a.] : Evang. Verl,-Anst. [u.a.], c 1948. - 40 S. ; $4^{\circ}$

(Psalm-Kantaten (Anthem) ; 2)

Einheitssacht.: As pants the hart, HWV 251a. - Gesangstext dt. und engl.

Best.-Nr.: Edition Merseburger 502

Signatur: $\quad 4$ MUS 57:2,PARTITUR

Notizen: $\quad 1948.2452$ - NIEDERSÄCHS. STAATS. U. UNIV.-BIBLIOTHEK GÖTTINGEN verknüpft zum MBW PPN 266529631

Vorh. in: $\quad$ MuSe 


\section{PPN: 13521789X}

Aus dem Kampf mit der Liebe : Kantate für eine Baßstimme mit Generalbaß = (Dalla guerra amorosa) / Georg Friedrich Händel. Übers. von Emilie DahnkBaroffio. Eingerichtet und hrsg. von Hermann Zenck. - [Partitur, Stimme], Neuausg. - Kassel : Bärenreiter, 1942. - 12 S. ; $4^{\circ}+1$ St.

(Italienische Kantaten ; [1])

Einheitssacht.: Kantaten, HWV 102. - Stimme: Vc. - Gesangstext dt. und ital.

Best.-Nr.: Bärenreiter-Ausgabe 1972

Signatur: $\quad 4$ MUS VII, 426/1

Notizen: $\quad 1943.799$ - Universitätsbibliothek Göttingen verknüpft zum MBW PPN 135217865

Vorh. in: $\quad$ GHG (18 Ex.)

PPN: 266535925

Mein Lied sing auf ewig : [Psalm 89] ; für Sopran, Tenor und Baß, vierstimmigen Chor mit Instrumenten $=$ My song shall be alway / Georg Friedrich Händel. Hrsg. von Kurt Fiebig ... - [Partitur]. - Berlin [u.a.] : Evang. Verl.-Anst. [u.a.], c 1947. - 47 S. ; $4^{\circ}$ (Psalm-Kantaten (Anthem) ; 1)

Einheitssacht.: My song shall be alway, HWV 252. - Gesangstext dt. und engl.

Best.-Nr.: Edition Merseburger 501

Signatur: $\quad 4$ MUS 57:1,PARTITUR

Notizen: $\quad 1948.388$ - NIEDERSÄCHS. STAATS. U. UNIV.-BIBLIOTHEK GÖTTINGEN verknüpft zum MBW PPN 266529631

Vorh. in: $\quad$ MuSe

\section{PPN: 135279054}

Pastorella, vagha bella : Kantate für Sopran (Tenor), obligates Cembalo und Violoncello = Hirtin meine, kleine, feine / Georg Friedrich Händel. Mit dt. und ital. Text. Dt. Text von Hans Joachim Moser. - [Partitur, Stimme], Erstausg. - Leipzig : Kistner \& Siegel, [ca. 1930]. - 16 S. ; $4^{\circ}+1$ St.

(Organum : Reihe 2, Weltliche Gesangsmusik ; 18)

Einheitssacht.: Kantaten, Vc Cemb. - Bearb. von Max Seiffert. - Stimme: Vc (kplt. M 2.-)

Best.-Nr.: 28800

Signatur: $\quad 4$ MUS V, 718:2,18

Notizen: $\quad 42.4889$ - Universitätsbibliothek Göttingen verknüpft zur Serie PPN 130778249 


\section{PPN: 132179105}

Tochter Zion, freue dich : Adventskantate für gemischten Chor und Streicher (Flöte ad lib.) ; nach dem Chorsatz aus dem Oratorium „Judas Maccabaeus“ / von Georg Friedrich Händel. Bearb. von Otto Kaufmann. - Partitur. - Wolfenbüttel : Möseler, c 1992. - 7 S. ; $4^{\circ}$ Einheitssacht.: Judas Maccabaeus, HWV $63<$ Kantate $>$ / Arr.

Signatur: $\quad 92$ B 26097

Notizen: $\quad$ NIEDERSÄCHS. STAATS. U. UNIV.-BIBLIOTHEK GÖTTINGEN

\section{PPN: 328671703}

Oft decken Wolken : Kantate für Baß, zwei Violinen Generalbaß = (Cuopre tal volta il cielo) / Georg Friedrich Händel. Übers. von Emilie Dahnk-Baroffio. Einger. und hrsg. von Hermann Zenck. - [Partitur, Stimmen], Neuausg. - Kassel : Bärenreiter, 1948. - 19 S. ; $4^{\circ}+3$ St. (Italienische Kantaten ; [5])

Einheitssacht.: Kantaten, HWV 98. - Stimmen: Vl 1 2, Vc. - Gesangstext dt. und ital. Best.-Nr.: Bärenreiter-Ausgabe 1976

Signatur: $\quad 4$ MUS 1036

Notizen: $\quad$ 1948.2926 - NIEDERSÄCHS. STAAT. U. UNIV.-BIBLIOTHEK GÖTTINGEN verknüpft zum MBW PPN 135217865

\section{PPN: 331392542}

Oft decken Wolken : für Baß, zwei Violinen und Basso continuo = (Cuopre tal volta il cielo) / Georg Friedrich Händel. Eingerichtet und hrsg. von Hermann Zenck. Übers. von Emilie Dahnk-Baroffio. - [Partitur, Stimmen]. - Kassel [u.a.] : Bärenreiter, 1968.

- 19 S. ; $4^{\circ}+3$ St., 1 Solost.

(Italienische Kantaten = Italian cantatas ; [5])

Einheitssacht.: Kantaten, HWV 98. - Stimmen: Vl 1 2, Bc, Solost. (Bass). - Text dt. und ital.

Best.-Nr.: Bärenreiter-Ausgabe 1976

Signatur: $\quad 71$ B 3207

Notizen: $\quad$ NIEDERSÄCHS. STAAT. U. UNIV.-BIBLIOTHEK GÖTTINGEN Beschafft aus Mitteln der Stiftung Volkswagen verknüpft zum MBW PPN 135217865 


\title{
5.3.2 Ka m merduet te und - trios
}

\section{PPN: 135217571}

Händel, Georg Friedrich:

Caro, più amabile beltà : aus „Giulio Cesare“, für Sopran und Alt = Der holden Schönheit Licht / von G. F. Händel. - [Klavierpartitur]. - Leipzig : Kistner, [s.a.]. - S. 3 - 11. ; $4^{\circ}$

(Duette mit Clavierbegleitung)

Einheitssacht.: Giulio Cesare in Egitto $<$ Caro, più amabile beltà>. - Gesangstext ital. und dt. Best.-Nr.: 3549

\author{
Signatur: $\quad 4$ MUS VII, 385/1 \\ Notizen: $\quad 1942.198$ - Universitätsbibliothek Göttingen \\ Geschenk von Frl. Antonie Dittrich, Göttingen
}

\section{PPN: 135213754}

Chamber duets and trios / comp. by George Frederic Handel. [Ed.: Henry Smart]. - [Partitur mit beigef. Klavierausz.]. - London : Cramer, Beale, 1852. - II, [1] Bl., 192 S. ; $2^{\circ}$

(The works of Handel ; Vol. 7)

Einheitssacht.: Duett und Terzett / Ausw.

\author{
Signatur: $\quad 2$ MUS VII, 340:7 \\ Notizen: $\quad 1896.1207$ - EX BIBLIOTHECA REGIA ACADEM. GEORGIAE AUG. - \\ Arnold Wehner [auf der Titels., wahrscheinlich Vorbesitzer [d. Verf.]] \\ verknüpft zum MBW PPN 135213681
}

Vorh. in: $\quad$ MuSe

\section{PPN: 239662466}

Vier Duette für zwei Blockflöten, for two recorders (A T) / Georg Friedrich Händel. [Bearb. und] hrsg. von Irmtraut Freiberg. - [Partitur]. - Celle : Moeck, 1997. - 7 S. ; $4^{\circ}$

(Zeitschrift für Spielmusik ; 701)

Einheitssacht.: Werke, Spieluhr / Ausw. Arr. - Text dt., engl. und franz.

ISMN M-2006-0701-7

\author{
Signatur: $\quad$ K 98 B 761 \\ Notizen: $\quad 1974.8189$ - NIEDERSÄCHS. STAATS. U. UNIV.-BIBLIOTHEK GÖTTINGEN - \\ verknüpft zur Serie PPN 130310433
}


PPN: 375254412

Neun Duette nach den „Pieces for Harpsichord“ : für Sopran- und Alt-Blockflöte oder Fideln / Georg Friedrich Händel. - Neue Ausg. - Celle : Moeck, 1957. - 8 S. ; quer-8 Einheitssacht.: Duette, Blfl. - Copyright-Jahr: 1956

(Zeitschrift für Spielmusik ; 76)

Best.-Nr.: Z.f.S. 76

Signatur: $\quad 8$ Z MUS 17:76

Notizen: $\quad$ NIEDERSÄCHS. STAATS. U. UNIV.-BIBLIOTHEK GÖTTINGEN Geschenk

PPN: 14024462X

Quel fior ch'all' alba ride / G. F. Händel. - [Musikdr.]. - Faks. d. Autogr. München : Drei-Masken-Verl., 1923. - [4] Bl. ; quer-4

Einheitssacht.: Quel fior che all’ alba ride, HWV 200

Signatur: $\quad 4$ MUS VII, 358

Notizen: $\quad$ 1984.14071 - NIEDERSÄCHS. STAATS. U. UNIV.-BIBLIOTHEK GÖTTINGEN 


\subsubsection{A rie n und Lieder}

\section{PPN: 13521758X}

Händel, Georg Friedrich:

[Samson] Aria aus Samson / von Haendel. - [Stimmen]. - 12 St. ; $2^{\circ}$

1 Singst., Fl 1 2, Fg 1 2, Vl 1 2, Va, Kb. - Komp.: London, Sept./Okt. 1741. - Ms. - [12] Bl

Signatur: $\quad 2$ MUS VII, 386

\section{PPN: 271289562}

Aria from Water Music Suite : original version for oboe and strings, transcription for oboe and piano / G. F. Handel. - [Klavierpartitur, Stimmen], 1. ed. - 1998. - [1 ungez.], 4 S. ; $4^{\circ}+7$ St. (The Robert Bloom collection : Solo works and chamber music for oboe ; Pt. 2, No. 7) Einheitssacht.: Water music <Aria>, Fassung Ob Kl. - Umschlags. ist die Haupttitels. Stimmen: Ob, Vl 1 2, Va, Vc/Doublebass

Signatur: $\quad$ FB 22480:2,7

Notizen: $\quad$ NIEDERSÄCHS. STAATS. U. UNIV.-BIBLIOTHEK GÖTTINGEN verknüpft zum MBW PPN 271289562

\section{PPN: 013549308}

Arien aus Opern $=$ Arias from operas $=$ Arias des operas $/$ Georg Friedrich Händel. Für Altblockflöte bearb. von Peter Prelleur (London 1735). Hrsg. von Gerhard Braun. [Musikdr.]. - [Celle] : Moeck, 1986. - 11 S. ; $4^{\circ}$ (Zeitschrift für Spielmusik : Doppelheft ; 566/567) Einheitssacht.: Arien / Ausw. Arr. - Umschlags. ist die Haupttitels. - Vorw. in dt., engl. und franz.

Best.-Nr.: Z.f.S. 566/567

\section{Signatur: $\quad 8$ Z MUS 17:566/567*}

Notizen: NIEDERSÄCHS. STAATS. U. UNIV.-BIBLIOTHEK GÖTTINGEN verknüpft zur Serie PPN 130310433 
PPN: 328675253

Herz, der Liebe süßer Born : Arie aus „Acis und Galathea“ für Sopran, 2 Alt-Blockflöten in -f'- und Basso continuo / Georg Friedrich Händel. Hrsg. von Willi Hillemann. - [Partitur, Stimmen]. - Celle : Moeck, c 1950. - 6 S. ; quer-8º 3 St.

(Moecks gelbe Musikhefte ; 2017)

Einheitssacht.: Acis and Galatea <Arie>. - Stimmen: Fl 2, Bass, Sopr/Bc

Signatur: $\quad 8$ MUS 349

Notizen: $\quad 1951.712$ - NIEDERSÄCHS. STAATS. U. UNIV.-BIBLIOTHEK GÖTTINGEN verknüpft zur Serie PPN 130775010

PPN: 135278910

Preis der Tonkunst : Konzert-Arie für Sopran (Tenor), Streichorchester und Cembalo = Praise of Harmony / Georg Friedrich Händel. [Bearb. von Max Seiffert]. - [Partitur, Stimmen]. - Leipzig : Kistner \& Siegel, 1929. - 14 S. ; $4^{\circ}+4$ St.

(Organum : Reihe 2, Weltliche Gesangsmusik ; 11)

Einheitssacht.: Look down, harmonious Saint, HWV 124. - Stimmen: Vl 1 2, Va, Vc/Kb.

- Gesangstext dt. und engl.

Best.-Nr.: 28318 (Partitur); 28319 (Stimmen)

Signatur: $\quad 4$ MUS V, 718:2,11

Notizen: $\quad 42.4889$ - Universitätsbibliothek Göttingen verknüpft zur Serie PPN 130778249

PPN: 135278791

Flammende Rose : Deutsche Arie für Sopran mit Begleitung von Violine, VioloncelloKontrabaß und Cembalo / G. Fr. Händel. [Bearb. von Max Seiffert]. - [Partitur, Stimmen]. - Leipzig : Kistner \& Siegel, [s.a.]. - 10 S. ; $4^{\circ}+2$ St.

(Organum : Reihe 2, Weltliche Gesangsmusik ; 4)

Einheitssacht.: Arien, HWV 210. - Teil aus dem Zyklus: Neun deutsche Arien, HWV

202 - 210. - Stimmen: Vl, Vc/Kb

Best.-Nr.: 27901 (Partitur); 27902 (Stimmen)

Signatur: $\quad 4$ MUS V, 718:2,4

Notizen: $\quad 42.4889$ - Universitätsbibliothek Göttingen verknüpft zur Serie PPN 130778249 


\section{PPN: 135279097}

Meine Seele hört : Deutsche Arie für Sopran mit Begleitung von Flöte oder Violine, Cembalo mit Violoncell und Baß / Georg Friedrich Händel. [Bearb. von Max Seiffert]. - [Partitur, Stimmen]. - Leipzig : Kistner \& Siegel, [ca. 1950]. - 8 S. ; $4^{\circ}+3$ St. (Organum : Reihe 2, Weltliche Gesangsmusik ; 20)

Einheitssacht.: Arien, HWV 207. - Stimmen: Fl/Vl, Vc

Best.-Nr.: 29467

Signatur: $\quad 4$ MUS V, 718:2,20

Notizen: $\quad$ 42.4889b - Universitätsbibliothek Göttingen verknüpft zur Serie PPN 130778249

\section{PPN: 135278813}

Süsse Stille : deutsche Arie für Sopran (Tenor) mit Begleitung von Flöte, Violoncello, Kontrabass und Cembalo / Georg Friedrich Händel. [Bearb. von Max Seiffert]. [Partitur, Stimmen]. - Lippstadt : Kistner \& Siegel, [s.a.]. - 6 S. ; $4^{\circ}+2$ St. (Organum : Reihe 2, Weltliche Gesangsmusik ; 5)

Einheitssacht.: Arien, HWV 205. - Teil aus dem Zyklus: Neun deutsche Arien, HWV 202 - 210. - Stimmen: Fl, Vc/Kb

Best.-Nr.: 27903

Signatur: $\quad 4$ MUS V, 718:2,5

Notizen: $\quad 1951.1931$ - NIEDERSÄCHS. STAATS. U. UNIV.-BIBLIOTHEK GÖTTINGEN verknüpft zur Serie PPN 130778249

PPN: 176678824

Alzo al volo di mia fama : Arie aus der Oper Radamisto / Georg Friedrich Händel. [Musikdr.], Faks. nach d. Autogr. - Leipzig : Dt. Verl. f. Musik, 1959. - [8] Bl. ; quer-4 Nachw. zur Faks.-Ausg. von Walther Siegmund-Schultze

Signatur: $\quad 84$ B 14072

Notizen: $\quad$ NIEDERSÄCHS. STAATS. U. UNIV.-BIBLIOTHEK GÖTTINGEN 
PPN: 135380847

Weihnachtsarie : »Und siehe! Der Nagel des Herrn kam über sie«; für eine Sopranstimme und Basso Continuo / G. F. Händel. Hrsg. von Rudolf Steglich. - [Partitur, Stimme]. Hannover : Nagel, 1933. - 6 S. ; $4^{\circ}+1$ St.

(Nagels Musik-Archiv ; 104)

Einheitssacht.: Messiah <But lo! The angel of the lord came upon them>. - Stimme: Vc. Gesangstext dt. und engl.

Signatur: $\quad 4$ MUS V, 760:104

4 MUS V, 760:104,STIMME

Notizen: $\quad 1933.15540$ - EX BIBLIOTHECA ACAD. GEORGIAE AUG. verknüpft zur Serie PPN 129658642 


\subsubsection{S o n a te n und Trios on a te n, F u gen}

\section{PPN: 13528371X}

Bach, Carl Philipp Emanuel:

[Sonaten und Fugen fürs Clavier] C. P. E. Bachs, Nichelmanns und Händels Sonaten und Fugen fürs Clavier. - [Musikdr.], 2. Aufl. - Berlin : bey Arnold Wever, 1774. - 28 S., [1] Bl. ; quer- $4^{\circ}$

Einheitssacht.: Werke, Kl / Ausw. - Signaturformel: A - G2.

Signatur: $\quad 8$ MUS V, $3330<2>$

Notizen: $\quad 1950.1176$ - EX BIBLIOTHECA REGIA ACADEM. GEORGIAE AUG.

PPN: 332105350

Händel, Georg Friedrich:

Sonata für drei Violinen ohne Baß / G. Fr. Händel. - [Partitur]. - Celle (Hann.)

[u.a.] : Nagel [u.a.], c 1949. - 7 S. ; quer-4 ${ }^{\circ}$

Einheitssacht.: Sonaten, Spieluhr, HWV 578

Best.-Nr.: 49,1

Signatur: 8 MUS 119*

Notizen: $\quad 1949.2159$ - NIEDERSÄCHS. STAATS. U. UNIV.-BIBLIOTHEK GÖTTINGEN

\section{PPN: 135381231}

4 Original-Sonaten für 1 Altblockflöte und Cembalo $<$ Klavier $>/$ Georg Friedrich Händel. Hrsg. von Albert Rodemann. - [Klavierpartitur, Stimmen]. - Hannover : Nagel, 1938. 24 S. ; $4^{\circ}+2$ St.

(Nagels Musik-Archiv ; 122)

Einheitssacht.: Sonaten, Blfl Cemb, op. 1 / Ausw. - Stimmen: Blfl, Vc

Signatur: $\quad 4$ MUS V, 760:122

Notizen: $\quad 1950.1176$ - Universitätsbibliothek Göttingen verknüpft zur Serie PPN 129658642 


\section{PPN: 328676284}

Drei neue Sonaten für Alt-Blockflöte (Querflöte, Violine) und Klavier (Cembalo) / G. Fr. Händel. Übertr. von Hans und Erna Dancker. - [Klavierpartitur]. - Celle (Hann.) [u.a.] : Nagel [u.a.], [um 1950]. - 26 S. ; $4^{\circ}+1$ St. (11 S.)

Einheitssacht.: Sonaten, Fl / Ausw. Arr. - Enth. Anh. - Stimme: Alt-Blfl

Best.-Nr.: 49/1

Signatur: $\quad 4$ MUS 215

Notizen: $\quad 1950.1176$ - NIEDERSÄCHS. STAATS. U. UNIV.-BIBLIOTHEK GÖTTINGEN

\section{PPN: 018934064}

Zwei Sonaten, für Altblockflöte und Basso continuo ... : HWV 367a und 377 / Georg Friedrich Händel. Hrsg. von Terence Best. - [Partitur, Stimmen], Urtext. - Kassel [u.a.] : Bärenreiter, 1991. - 15 [16] S. ; $4^{\circ}+2$ St.

Einheitssacht.: Sonaten, Blfl Bc, HWV 367a, 377. - Stimmen: Fl/Bc. - CopyrightJahr: 1982. - Vorw. dt., Nachw. engl.

Best. Nr.: HM 269

\section{Signatur: $\quad 4$ Z MUS 91:269}

Notizen: $\quad 1991.6622$ - NIEDERSÄCHS. STAATS. U. UNIV.-BIBLIOTHEK GÖTTINGEN verknüpft zur Serie PPN 036059021

\section{PPN: 018698182}

Vier Sonaten, für Altblockflöte und bezifferten Baß ... : op. 1/2, op. 1/4, op. 1/7, op. 1/11 / Georg Friedrich Händel. Hrsg. von Hans-Peter Schmitz. - [Partitur, Stimmen], Urtext, durchges. Aufl. - Kassel [u.a.] : Bärenreiter ; Leipzig : Dt. Verl. für Musik, 1988. $31 \mathrm{~S} . ; 4^{\circ}+2$ St.

Einheitssacht.: Sonaten, Blfl B / Ausw. - Stimmen: Fl, Bc (Vagb, Vc). - Copyright-Jahr: 1955. - Vorw. dt. und engl.

Best.-Nr.: HM 251

\section{Signatur: $\quad 4$ Z MUS 91:251}

Notizen: $\quad 1989.6622$ - NIEDERSÄCHS. STAATS. U. UNIV.-BIBLIOTHEK GÖTTINGEN verknüpft zur Serie PPN 036059021 


\section{PPN: 135288177}

Sonata C-dur für Alt-Blockflöte in -f'- und Basso continuo / G. F. Händel. [Hrsg. und ausgesetzt von Hermann Mönkemeyer]. - [Partitur, Stimmen]. - Celle : Moeck, 1935. Getr. Zählung. ; quer-8 ${ }^{\circ}$

(Moeck's gelbe Musikhefte ; 13)

Einheitssacht.: Sonaten, Blfl Bc, HWV 365. - S. 5 von „Fluato (solo)“ und S. 5 von „Basso“ vertauscht eingeb. - Umschlags. ist die Haupttitels.

Signatur: $\quad 8$ MUS I, 1035:13

Anmerkung: Partitur und Stimmen zsgeb.

Notizen: $\quad 1934.953$ - EX BIBLIOTHECA ACAD. GEORGIAE AUG. verknüpft zur Serie PPN 130775010

\section{PPN: 316470716}

Sonata C-Dur für Viola da Gamba (oder Viola) und Cembalo / Georg Friedrich Händel. Hrsg. von Folkmar Längin. - [Partitur, Stimmen]. - Kassel ; Basel : Bärenreiter, 1953. 13 S. ; $4^{\circ}+2$ St.

Einheitssacht.: Sonaten, Vagb Kl, C-Dur. - Stimmen: Vagb, Vc

Best.-Nr.: Hortus Musicus 112

Signatur: $\quad 4$ Z MUS 91:112

Notizen: $\quad 1953.6622$ - NIEDERSÄCHS. STAATS. U. UNIV.-BIBLIOTHEK GÖTTINGEN verknüpft zur Serie PPN 036059021

PPN: 329198343

Sonate D-Dur, für Flöte (Oboe, Violine) und Basso continuo / Georg Friedrich Händel. Hrsg. von W. Hinnenthal. - [Klavierpartitur, Stimmen]. - Kassel ; Basel : Bärenreiter, 1949. - 7 S. ; $4^{\circ}+2$ St.

Einheitssacht.: Sonaten, Fl Bc, D-Dur. - Stimmen: Fl, Bc

Best.-Nr.: Hortus Musicus 3; Bärenreiter-Ausgabe 928

Signatur: $\quad 4$ Z MUS 91:3

Notizen: $\quad 1952.6622$ - NIEDERSÄCHS. STAATS. U. UNIV.-BIBLIOTHEK GÖTTINGEN verknüpft zur Serie PPN 036059021 


\section{PPN: 135288150}

Sonata F-dur für Alt-Blockflöte in -f'- und Basso continuo / Georg Friedrich Händel. Hrsg. und ausgesetzt von Helmut Mönkemeyer. - [Partitur, Stimmen]. - Celle : Moeck, 1935. 8, 3, 4 S. ; quer-8 ${ }^{\circ}$ (Moeck's gelbe Musikhefte ; 12)

Einheitssacht.: Sonaten, Blfl Bc, HWV 369

Signatur: $\quad 8$ MUS I, 1035:12

Anmerkung: Partitur und Stimmen zsgeb.

Notizen: $\quad 1934.953$ - EX BIBLIOTHECA ACAD. GEORGIAE AUG. verknüpft zur Serie PPN 130775010

PPN: 135288193

Sonata a-moll für Alt-Blockflöte in -f'- und Basso continuo / G. F. Händel. [Hrsg. und ausgesetzt von Helmut Mönkemeyer]. - [Partitur, Stimmen]. - Celle : Moeck, 1935. 12, 4, 4 S. ; quer- $8^{\circ}$ (Moeck's gelbe Musikhefte ; 14)

Einheitssacht.: Sonaten, Blfl Bc, HWV 362. - Umschlags. ist die Haupttitels.

Signatur: $\quad 8$ MUS I, 1035:14

Anmerkung: Partitur und Stimmen zsgeb.

Notizen: $\quad 1935.953$ - EX BIBLIOTHECA REGIA ACADEM. GEORGIAE AUG. verknüpft zur Serie PPN 130775010

PPN: 135288134

Sonata g-moll für Alt-Blokflöte in -f'- und Basso continuo / Georg Friedrich Händel. Hrsg. und ausgesetzt von Helmut Mönkemeyer. - [Partitur]. - Celle : Moeck, 1934. - 9 S. ; quer-8 (Moeck’s gelbe Musikhefte ; 11)

Einheitssacht.: Sonaten, Blfl Bc, HWV 360

Signatur: $\quad 8$ MUS I, 1035:11

Notizen: $\quad 1934.953$ - EX BIBLIOTHECA ACAD. GEORGIAE AUG. verknüpft zur Serie PPN 130775010 
PPN: 331418118

Sonata g-moll für Alt-Blockflöte in -f'- : Sonata g-moll für Basso continuo / G. F. Händel. Ausgesetzt von Helmut Mönkemeyer. - [Stimmen]. - Celle : Moeck, 1934. - 2 St. (je 4 S.). ; quer-8 ${ }^{\circ}$

Einheitssacht.: Sonaten, Blfl Bc, HWV 360

Signatur: $\quad 8$ MUS I, 1035:FL/BC

Anmerkung: Beide St. zsgeb.

Notizen: $\quad$ EX BIBLIOTHECA ACAD. GEORGIAE AUG.

PPN: 026464810

Sonate C-Dur op. 1,7 für Flöte und bezifferten Baß = Sonata in C maj op. 1,7 for flute and figured bass / Georg Friedrich Händel. Bearb. für Flöte und Gitarre von Eberhard Heymann. - [Partitur, Stimme]. - Wolfenbüttel ; Zürich : Möseler, 1985. - 15, [1 ungez.] S. ; $4^{\circ}+1$ St. (Corda : Werkreihe für Gitarre)

Einheitssacht.: Sonaten, Blfl Bc, HWV 365 / Arr.

Best.-Nr.: M 24.656

Signatur: $\quad 85$ B 26949

Notizen: $\quad$ NIEDERSÄCHS. STAATS. U. UNIV.-BIBLIOTHEK GÖTTINGEN Geschenk des Verlags

PPN: 026464888

Sonate F-Dur op. 1,11 für Flöte und bezifferten Baß = Sonata in F maj op. 1,11 for flute and figured bass / Georg Friedrich Händel. Bearb. für Flöte und Gitarre von Eberhard Heymann. - [Partitur, Stimme]. - Wolfenbüttel ; Zürich : Möseler, 1985. - 8 S. ; $4^{\circ}+1$ St. (Corda : Werkreihe für Gitarre)

Einheitssacht.: Sonaten, Blfl Bc, HWV 369 / Arr.

Best.-Nr.: M 24.657

Signatur: $\quad 85$ B 26950

Notizen: $\quad$ NIEDERSÄCHS. STAATS. U. UNIV.-BIBLIOTHEK GÖTTINGEN Geschenk des Verlags 


\section{PPN: 026464896}

Sonate a-moll op. 1,4 für Flöte und bezifferten $\mathrm{Ba}=$ Sonata in A min op. 1,4 for flute and figured bass / Georg Friedrich Händel. Bearb. für Flöte und Gitarre von Eberhard Heymann. - [Partitur, Stimme]. - Wolfenbüttel ; Zürich : Möseler, 1985. - 19, [1 ungez.] S. ; $4^{\circ}+1$ St. (Corda : Werkreihe für Gitarre)

Einheitssacht.: Sonaten, Blfl Bc, HWV 362 / Arr.

Best.-Nr.: M 24.655

Signatur: $\quad 85$ B 26948

Notizen: $\quad$ NIEDERSÄCHS. STAATS. U. UNIV.-BIBLIOTHEK GÖTTINGEN Geschenk des Verlags

PPN: 029242916

Sonata 1 in B-dur ..., HWV 380 : Sonata 2 d-moll ..., HWV 381 / Georg Friedrich Händel. - [Partitur, Stimmen], Urtext der Hallischen Händel-Ausg. - Kassel [u.a.] : Bärenreiter ; Leipzig : Dt. Verl. für Musik, 1976. - 22 S., [1] Bl. ; $4^{\circ}+3$ St.

(Sechs Sonaten, für Oboe, Violine (Oboe) und Basso continuo ; H. 1)

Einheitssacht.: Sonaten, HWV 380 - 381, Nr. 1 - 2. - Stimmen: Ob, Vl, Bc. - Nachw. dt. und engl.

Best.-Nr.: HM 242; DVfM 8319

Signatur: $\quad 4$ Z MUS 91:242

Notizen: $\quad 1988.6622$ - NIEDERSÄCHS. STAATS. U. UNIV.-BIBLIOTHEK GÖTTINGEN verknüpft zur Serie PPN 036059021

\section{PPN: 029242924}

Sonata 3 in Es-dur ..., HWV 382 : Sonata 4 in F-dur ..., HWV 383. - [Partitur, Stimmen], Urtext der Hallischen Händel-Ausg. - Kassel [u.a.] : Bärenreiter ; Leipzig : Dt. Verl. für Musik, 1988. - 22 S., [1] Bl. ; $4^{\circ}+3$ St.

(Sechs Sonaten, für Oboe, Violine (Oboe) und Basso continuo ; H. 2)

Einheitssacht.: Sonaten, HWV 382 - 383, Nr. 3 - 4. - Stimmen: Ob, Vl, Bc. -

Copyright: 1976. - Nachw. dt. und engl.

Best.-Nr.: HM 243; DVfM 8320

Signatur: $\quad 4$ Z MUS 91:243

Notizen: $\quad 1988.6622$ - NIEDERSÄCHS. STAATS. U. UNIV.-BIBLIOTHEK GÖTTINGEN verknüpft zur Serie PPN 036059021 


\title{
PPN: 029242932
}

Sonata 5 in G-dur ..., HWV 384 : Sonata 6 in D-Dur ..., HWV 385. - [Partitur, Stimmen], Urtext der Hallischen Händel-Ausg. - Kassel [u.a.] : Bärenreiter ; Leipzig : Dt. Verl. für Musik, 1989. - 20 S., [1] Bl. ; $4^{\circ}+3$ St.

(Sechs Sonaten, für Oboe, Violine (Oboe) und Basso continuo ; H. 3)

Einheitssacht.: Sonaten, HWV 384 - 385, Nr. 5 - 6. - Stimmen: Ob, Vl, Bc. -

Copyright: 1976. - Nachw. dt. und engl.

Best.-Nr.: HM 244; DVfM 8323

Signatur: $\quad 4$ Z MUS 91:244

Notizen: $\quad 1989.6622$ - NIEDERSÄCHS. STAATS. U. UNIV.-BIBLIOTHEK GÖTTINGEN verknüpft zur Serie PPN 036059021

\section{PPN: 135381924}

Trio für Altblockflöte, Violine und Cembalo / G. Fr. Händel. Hrsg. von Albert Rodemann. - [Partitur, Stimmen]. - Celle (Hann.) [u.a.] : Nagel [u.a.], c 1940. - 15 S. ; $4^{\circ}+3$ St.

(Nagels Musik-Archiv ; 150)

Einheitssacht.: Sonaten, Vl 12 Bc, HWV 389. - Stimmen: Blfl, Vl, Vc

\author{
Signatur: $\quad 4$ MUS V, 760:150 \\ Notizen: $\quad 1952.8189$ - NIEDERSÄCHS. STAATS. U. UNIV.-BIBLIOTHEK GÖTTINGEN - \\ verknüpft zur Serie PPN 129658642
}

Vorh. in: $\quad$ MuSe

PPN: 24521450X

Trio »Sono liete, fortunate« : für Sopran- und Altblockflöte oder andere Melodieinstrumente und Klavier (Cembalo); Violoncello (Gambe) ad libitum / Georg Friedrich Händel. Hrsg. von Helmut Mönkemeyer. - Partitur, Stimmen. - Celle : Moeck, 1968. - 9 S. ; $4^{\circ}+4$ St.

Einheitssacht.: Duette, HWV 194, Nr. 3. - Stimmen: Blfl, ABlfl, ABlfl/Vl, Vc/Vagb. -

Text dt. und engl.

Best.-Nr.: Edition Moeck 2058

Signatur: $\quad$ K 2000 B 1558

Notizen: $\quad$ NIEDERSÄCHS. STAATS. U. UNIV.-BIBLIOTHEK GÖTTINGEN 


\section{PPN: 332446662}

Drei Triosonaten für zwei Violinen und Basso continuo : Sonata in $\mathrm{F}=$ Three trio sonatas for two violins and basso continuo / F major op. V/6, Sonata in e / E minor op. V/3, Sonata in D / D major op. V/2. - [Partitur, Stimmen]. - Kassel : Nagel ; London : Bärenreiter, 1981. - 32 S. ; $4^{\circ}+3$ St. (je 11 S.)

(Nagels Musik-Archiv ; 254)

Einheitssacht.: Sonaten, Vl 12 Bc, op. 5 / Ausw. - Continuo-Aussetzung: Max Schneider. -

Stimmen: Vl 1 2, Bc. - Copyright: 1967

Signatur: $\quad 4$ Z MUS 98:254

Anmerkung: Partitur und Stimmen zsgeb.

Notizen: $\quad 1981.8189$ - NIEDERSÄCHS. STAATS. U. UNIV.-BIBLIOTHEK GÖTTINGEN verknüpft zur Serie PPN 129658642

\section{PPN: 332446697}

Zwei Triosonaten für zwei Violinen und Basso continuo : Sonata in $G=$ Two trio sonatas for two violins and basso continuo / G major op. V/4, Sonata in g / G minor op. V/5. - [Partitur, Stimmen]. - Kassel : Nagel ; London : Bärenreiter, 1981. - 36. ; $4^{\circ}+4$ St. (11, 11, 4, 11 S.) (Nagels Musik-Archiv ; 255)

Einheitssacht.: Sonaten, Vl 12 Bc, op. 5 / Ausw. - Continuo-Aussetzung: Max Schneider. Stimmen: Vl 1 2, Va, Bc. - Copyright: 1967

Signatur: $\quad 4$ Z MUS 98:255

Anmerkung: Partitur und Stimmen zsgeb.

Notizen: $\quad 1981.8189$ - NIEDERSÄCHS. STAATS. U. UNIV.-BIBLIOTHEK GÖTTINGEN verknüpft zur Serie PPN 129658642

PPN: 316462500

Triosonate B-Dur, für Oboe, Violine (oder 2 Violinen) und Basso continuo / Georg Friedrich Händel. Hrsg. von W. Hinnenthal. - [Partitur, Stimmen]. - Kassel ; Basel : Bärenreiter, 1949. - 12 S. ; $4^{\circ}+3$ St.

Einheitssacht.: Sonaten, Ob Vl Bc, B-Dur. - Stimmen: Ob, Vl, Bc

Best.-Nr.: Hortus musicus 15; Bärenreiter-Ausgabe 929

\section{Signatur: $\quad 4$ Z MUS 91:15}

Notizen: $\quad 1952.6622$ - NIEDERSÄCHS. STAATS. U. UNIV.-BIBLIOTHEK GÖTTINGEN verknüpft zur Serie PPN 036059021 


\section{PPN: 018810209}

Triosonate F-dur, für 2 Altblockflöten und Basso continuo ... : HWV 405 / Georg Friedrich Händel. Hrsg. von Terence Best. - [Partitur, Stimmen], Urtext der Hallischen Händel-Ausg. - Kassel [u.a.] : Bärenreiter ; Leipzig : Dt. Verl. für Musik, 1988. - 6 S. ; $4^{\circ}+3$ St.

Einheitssacht.: Sonaten, Blfl Bc, HWV 405. - Stimmen: Fl 12 , Bc. - Vorw. dt. und engl. Best.-Nr.: HM 263; DVfM 8318

Signatur: $\quad 4$ Z MUS 91:263

Notizen: $\quad 1990.6622$ - NIEDERSÄCHS. STAATS. U. UNIV.-BIBLIOTHEK GÖTTINGEN verknüpft zur Serie PPN 036059021

PPN: 332463540

Triosonate in C-Moll für f'-Blockflöte, Violine (zwei Violinen) und Basso continuo = Trio sonata in $\mathrm{C}$ minor for treble recorder, violin (two violins) and basso continuo / Georg

Friedrich Händel. Hrsg. von Siegfried Flesch. - [Partitur, Stimmen]. - Kassel : Nagel [u.a.] ; London : Bärenreiter, 1971. - 15 S. ; $4^{\circ}+3$ St.

(Nagels Musik-Archiv ; 230)

Einheitssacht.: Sonaten, Fl Vl Bc, HWV 386a. - Continuo-Aussetzung: Ingeborg Schneider. Stimmen: Fl (Vl 1), Vl 2, Bc (Vc/Vagb). - Vorw. dt. und engl.

Signatur: $\quad 4$ Z MUS 98:230

Notizen: $\quad 1973.8189$ - NIEDERSÄCHS. STAATS. U. UNIV.-BIBLIOTHEK GÖTTINGEN verknüpft zur Serie PPN 129658642

PPN: 332462684

Triosonate in G-Moll für zwei Violinen und Basso continuo = Trio sonata in G minor for two violins and basso continuo / Georg Friedrich Händel. Hrsg. von Siegfried Flesch. - [Partitur, Stimmen]. - Kassel : Nagel ; London : Bärenreiter, c 1970. - 16 S. ; $4^{\circ}+3$ St.

(Nagels Musik-Archiv ; 235)

Einheitssacht.: Sonaten, Vl 12 Bc, HWV 393. - Continuo-Aussetzung: Ingeborg Schneider. Stimmen: Vl 1 2, Bc (Vc/Vagb). - Vorw. dt. und engl.

Signatur: $\quad 4$ Z MUS 98:235

Notizen: $\quad 1973.8189$ - NIEDERSÄCHS. STAATS. U. UNIV.-BIBLIOTHEK GÖTTINGEN verknüpft zur Serie PPN 129658642 


\section{PPN: 332446603}

Triosonate in G-Moll für zwei Violinen und Basso continuo = Trio sonata in G minor for two violins and basso continuo / Georg Friedrich Händel. Hrsg. von Siegfried Flesch. - [Partitur, Stimmen], Erstausg. - Kassel [u.a.] : Nagel [u.a.], 1976. - 15 S. ; $4^{\circ}+3$ St. (je 4 S.) (Nagels Musik-Archiv ; 252)

Einheitssacht.: Sonaten, g-Moll ${ }^{11}$. - Continuo-Aussetzung: Walter Heinz Bernstein. Stimmen: Vl 1 2, Bc. - Vorw. dt. und engl.

Best.-Nr.: DVfM 8324

Signatur: $\quad 4$ Z MUS 98:252

Anmerkung: Partitur und Stimmen zsgeb.

Notizen: $\quad$ NIEDERSÄCHS. STAATS. U. UNIV.-BIBLIOTHEK GÖTTINGEN verknüpft zur Serie PPN 129658642

\section{PPN: 332461475}

Triosonate in G-Moll für zwei Violinen und Basso continuo : Op. 2, No. 5 = Trio sonata in G minor for two violins and basso continuo / Georg Friedrich Händel. Hrsg. von Siegfried Flesch. - [Partitur, Stimmen]. - Kassel : Nagel ; London : Bärenreiter, 1974. - 19 S. ; $4^{\circ}+3$ St. (Nagels Musik-Archiv ; 240)

Einheitssacht.: Sonaten, Vl 12 Bc, HWV 390a. - Continuo-Aussetzung: Ingeborg Schneider. Stimmen: Vl 1 2, Bc (Vc, Vagb). - Vorw. dt. und engl.

Signatur: $\quad 4$ Z MUS 98:240

Notizen: $\quad 1974.8189$ - NIEDERSÄCHS. STAATS. U. UNIV.-BIBLIOTHEK GÖTTINGEN verknüpft zur Serie PPN 129658642

\section{PPN: 013585657}

Triosonate h-moll für Querflöte (Violine), Violine und Basso continuo / Georg Friedrich Händel. Hrsg. von Frank Nagel. - [Partitur, Stimmen]. - Wolfenbüttel ; Zürich : Möseler, 1986. - 19 S. ; $4^{\circ}+3$ St.

(Hausmusik ; 224)

Einheitssacht.: Sonaten, Fl Vl Bc, HWV 386b. - Stimmen: Querfl (Vl 1), Vl 2, Vc

Best.-Nr.: M 41.224

Signatur: $\quad$ ZB 58451:224

Notizen: $\quad$ NIEDERSÄCHS. STAATS. U. UNIV.-BIBLIOTHEK GÖTTINGEN Geschenk des Verlags - verknüpft zur Serie PPN 036059161

\footnotetext{
${ }^{11}$ Der Einheitssachtitel konnte nicht bibliographisch ermittelt werden, da diese Triosonate nicht zu den sechs Triosonaten op. 2 von Händel gehört, und erst 1965 aus dem Besitz von Sir Newman Flower an die Öffentlichkeit kam; sie ist in keinem der verfügbaren, einschlägigen Nachschlagewerke ausgewertet worden.
} 


\section{PPN: 032059485}

Sechs Fugen - I / Georg Friedrich Händel. Nach Klavierfugen für Blockflötenquartett eingerichtet von Grete Zahn. - [Partitur]. - Celle : Moeck, 1991. - 11 S. ; $4^{\circ}$ (Zeitschrift für Spielmusik : Doppelheft ; 629/630)

Einheitssacht.: Fugen, Cemb / Ausw. Arr. - Umschlags. ist die Haupttitels. Text dt., engl. und franz.

Signatur: $\quad 8$ Z MUS 17:629/630*

Notizen: $\quad$ NIEDERSÄCHS. STAATS. U. UNIV.-BIBLIOTHEK GÖTTINGEN Geschenk des Verlags - verknüpft zur Serie PPN 130310433

\section{PPN: 184211743}

Sechs Fugen - II / Georg Friedrich Händel. Nach Klavierfugen für Blockflötenquartett eingerichtet von Grete Zahn. - [Partitur]. - Celle : Moeck, 1993. - 10 S. ; $4^{\circ}$ (Zeitschrift für Spielmusik : Doppelheft ; 654/655)

Einheitssacht.: Fugen, Cemb / Ausw. Arr. - Umschlags. ist die Haupttitels.. Text dt., engl. und franz.

Best.-Nr.: Z.f.S. 654/655

\section{Signatur: $\quad 8$ Z MUS 17:654/655*}

Notizen: $\quad$ NIEDERSÄCHS. STAATS. U. UNIV.-BIBLIOTHEK GÖTTINGEN Geschenk des Verlags - verknüpft zur Serie PPN 130310433

\section{PPN: 182671380}

Sechs Fugen - III / Georg Friedrich Händel. Nach Klavierfugen für Blockflötenquartett (S A T B) eingerichtet von Grete Zahn. - [Partitur]. - Celle : Moeck, 1994. - 9, [1 ungez.] S. ; $4^{\circ}$

(Zeitschrift für Spielmusik : Doppelheft ; 666/667)

Einheitssacht.: Fugen, Kl, HWV 605 - 610 / Arr. - Umschlags. ist die Haupttitels. -

Text dt., engl. und franz.

Best.-Nr.: Z.f.S. 666/667

\section{Signatur: $\quad 8$ Z MUS 17:666/667*}

Notizen: $\quad 1994.922$ - NIEDERSÄCHS. STAATS. U. UNIV.-BIBLIOTHEK GÖTTINGEN Geschenk des Verlags - verknüpft zur Serie PPN 130310433 


\section{$5.4 \quad$ K i r c h e n m u s i k}

\subsubsection{A n the m s, Te D e u m, J u b i l a t e}

\section{PPN: 13521369X}

Anthems For The Coronation of King George II : Composed in the Year 1727 / By George Frederic Handel. [Ed.: William Crotch]. - [Partitur mit beigef. Klavierausz.]. - London : Cramer, Addison \& Beale, 1843-4. - V, [2 ungez.], 111 S. ; $2^{\circ}$ (The works of Handel ; Vol. 1)

Einheitssacht.: Coronation anthems, HWV 258 - 261

Signatur: $\quad 2$ MUS VII, 340:1

Notizen: $\quad 1896.1207$ - EX BIBLIOTHECA REGIA ACADEM. GEORGIAE AUG. Arnold Wehner [auf der Titels., wahrscheinlich Vorbesitzer [d. Verf.]] verknüpft zum MBW PPN 135213681

PPN: 135213746

The Dettingen Te Deum : Composed in the Year 1743 / By George Frederic Handel. [Ed.: George Smart]. - [Partitur mit beigef. Klavierausz.]. - London : Cramer, Beale, 1846-7. - VI, [1] Bl., 163 S., [1] Bl., 11 S. ; $2^{\circ}$

(The works of Handel ; Vol. 6)

Einheitssacht.: Te Deum for the victory of Dettingen, HWV 283. - App.: [1] Bl., 7, 4 S.

Signatur: $\quad 2$ MUS VII, 340:6

Notizen: $\quad 1896.1207$ - EX BIBLIOTHECA REGIA ACADEM. GEORGIAE AUG. Arnold Wehner [auf der Titels., wahrscheinlich Vorbesitzer [d. Verf.]] verknüpft zum MBW PPN 135213681 


\section{PPN: 135217644}

[Te Deum Laudamus] Georg Friedrich Händels Te Deum Laudamus, zur Utrechter Friedensfeyer / ehemals in Engländischer Sprache componirt und nun mit dem bekannten lateinischen Texte herausgegeben von Johann Adam Hiller. - [Partitur]. - Leipzig, im Schwickertschen Verlage, 1780. - [2] Bl., 72 S. ; quer-4 ${ }^{\circ}$

Einheitssacht.: Te Deum for the victory of Dettingen, HWV 283. - Autopsie nach Ex. der SUB Göttingen und der HAB Wolfenbüttel. - Bibliogr. Nachweis: Smith 159, 10; Schmieder 163; RISM H 1204. - Erscheinungsjahr nach der dat. Vorr. Signaturformel: *2, A - S2. - Vorw. dt.

\section{Signatur: $\quad 4$ MUS VII, 390}

Notizen: $\quad 1925.1094$ - EX BIBLIOTHECA REGIA ACADEM. GEORGIAE AUG.

\section{PPN: 135217482}

Jubilate / von Georg Friedrich Händel. Mit ausgeführtem Accompagnement hrsg. von Robert Franz. Text dt. und engl. - Partitur, mit unterlegtem Clavierauszuge. - Leipzig : Leuckart, 1868. - 89 S. ; $4^{\circ}$

Einheitssacht.: Jubilate (O be joyful), HWV 279

Signatur: $\quad 4$ MUS VII, 378

Notizen: $\quad 1888.5332$ - EX BIBLIOTHECA REGEIA ACADEM. GEORGIAE AUG. 


\subsubsection{Liturgis che Kompositionen}

PPN: 328687979

Händel, Georg Friedrich:

[Pieces for harpsichord] 6 Sätze aus den «Pieces for Harpsichord» für je 1 Sopran -c"und Alt -f'- Blockflöte / Georg Friedrich Händel. - [Partitur]. - Celle : Moeck, 1939. S. 601 - 608. ; quer-8 $8^{\circ}$

(Zeitschrift für Spielmusik auf allerlei Instrumenten ; 76)

Einheitssacht.: Werke, Cemb / Ausw. Arr. - Umschlags. ist die Haupttitels.

Signatur: $\quad 8$ MUS I, 2085:76

Anmerkung: H. $74-85$ zsgeb.

Notizen: $\quad 1939.922$ (in H. 74) - Universitätsbibliothek Göttingen verknüpft zur Serie PPN 130310433 


\section{$5.5 \quad$ Orch e s t e r we r ke}

\subsubsection{Ko n z e r t e}

\section{PPN: 135217857}

Händel, Georg Friedrich:

Concerti a 4 : Nr. 2 in D dur für zwei Violinen, obligates Violoncello und Basso continuo (Akkordinstrument mit Streichbaß ad lib.) / G. F. Händel. Hrsg. von Fritz Zobeley. Generalbaß-Partitur. - Schott [u.a.] : Mainz [u.a.], 1935. - 11 S. ; $4^{\circ}$

(Antiqva / Eine Sammlung alter Musik)

Vorw. dt., franz. und engl. - Einl. franz. und engl. - Die hier erstm. vorgelegte Triosonate in D-dur von Händel fand sich zs. mit der gleichzeitig veröff. in D-moll hs. in der Gräflich von Schönborn'schen Musikbibliothek ${ }^{12}$

Best.-Nr.: Edition Schott 2318; BSS 33912

Signatur: $\quad 4$ MUS VII, 425

Notizen: $\quad 42.9451$ - Universitätsbibliothek Göttingen

PPN: 332126773

Konzert für Flöte, Streichorchester und Klavier / Händel. - Partitur (zugl. Klavierstimme, Stimmen). - (Erstdr.). - Wolfenbüttel : Möseler, 1954. - 20 S. ; $4^{\circ}+6$ St.

(Deutsche Instrumentalmusik : Werkreihe für Kammerorchester ; 31)

Einheitssacht.: Konzerte, Fl Kl Orch. - Stimmen: Fl, Vl 12 3, Va Vc

\section{Signatur: $\quad 4$ Z MUS 94:31 \\ Notizen: $\quad 1955.10254$ - NIEDERSÄCHS. STAATS. U. UNIV.-BIBLIOTHEK GÖTTINGEN - verknüpft zur Serie PPN 131049070}

Vorh. in: $\quad$ MuSe

\footnotetext{
${ }^{12}$ Der Einheitssachtitel konnte nicht bibliographisch ermittelt werden, da diese nicht im »Händel-Handbuch« (Kassel, 1978-1985) verzeichnet ist. Über ihren Fund steht im »Händel-Jahrbuch« (Leipzig, 1931, S. 98-116) ein Bericht, woraus zu entnehmen ist, daß die Besetzung des 2. Konzerts für 2 Violinen, Cembalo und obligates Violoncello bestimmt ist - also eventuell folgender Einheitssacht.: Konzerte, Vl 12 Vc Cemb, D-Dur.
} 


\section{PPN: 135217954}

Orgel-Konzert No. 7 : B-Dur ... - opus $7^{\mathrm{I}}$ / Georg Friedrich Händel. Hrsg. von Helmuth Walcha. - Partitur. - Mainz [u. a.] : Schott [u.a.], 1943. - [2] Bl., 34 S. ; $4^{\circ}$

(Orgelkonzerte ; Nr. 7)

Einheitssacht.: Konzerte, Org, HWV 306. - Vorw. dt., franz. und engl.

Best.-Nr.: Edition Schott 3832

Signatur: $\quad 4$ MUS VII, 427:7

Notizen: $\quad 1971.5667$ - NIEDERSÄCHS. STAATS. U. UNIV.-BIBLIOTHEK GÖTTINGEN verknüpft zum MBW PPN 135217946

PPN: 135217962

Orgel-Konzert No. 8 : A dur (opus $7^{\mathrm{II}}$ ) / Georg Friedrich Händel. Hrsg. von Helmuth Walcha. - Partitur. - Mainz ; Leipzig : Schott, c 1942. - [2] Bl., 24 S. ; $4^{\circ}$

(Orgelkonzerte ; Nr. 8)

Einheitssacht.: Konzerte, Org, HWV 307

Best.-Nr.: Edition Schott 3833. - Pl.-Nr.: B.S.S 36503

Signatur: $\quad 4$ MUS VII, 427:8

Notizen: $\quad 1943.1366$ - Universitätsbibliothek Göttingen verknüpft zum MBW PPN 135217946

Vorh. in: $\quad$ GHG

\section{PPN: 135217970}

Orgel-Konzert No. 9 : B dur (opus $7^{\mathrm{III}}$ ) / Georg Friedrich Händel. Hrsg. von Helmuth Walcha. - Partitur. - Mainz ; Leipzig : Schott, c 1942. - [2] Bl., 32 S. ; $4^{\circ}$

(Orgelkonzerte ; Nr. 9)

Einheitssacht.: Konzerte, Org, HWV 308

Best.-Nr.: Edition Schott 3834. - Pl.-Nr.: B.S.S 36510

Signatur: $\quad 4$ MUS VII, 427:9

Notizen: $\quad 1943.1366$ - Universitätsbibliothek Göttingen verknüpft zum MBW PPN 135217946

Vorh. in: $\quad$ GHG (3 Ex.) 


\section{PPN: 135217989}

Orgel-Konzert No. 10 : d-Moll ... - opus $7^{\mathrm{IV}}$ / Georg Friedrich Händel. Hrsg. von Helmuth Walcha. - Partitur. - Mainz [u. a.] : Schott, 1940. - 30 S. ; $4^{\circ}$

(Orgelkonzerte ; Nr. 10)

Einheitssacht.: Konzerte, Org, HWV 309. - Vorw. dt., franz. und engl.

Best.-Nr.: Edition Schott 3835. - Pl.-Nr.: B.S.S.36101

Signatur: $\quad 4$ MUS VII, 427:10

Notizen: $\quad 1971.5667$ - NIEDERSÄCHS. STAATS. U. UNIV.-BIBLIOTHEK GÖTTINGEN verknüpft zum MBW PPN 135217946

PPN: 135217997

Orgel-Konzert Nr. 11 : g moll (opus $7^{\mathrm{V}}$ ) / Georg Friedrich Händel. Hrsg. von Helmuth Walcha. - Partitur. - Mainz [u.a.] : Schott, c 1942. - [2] Bl., 26 S. ; $4^{\circ}$

(Orgelkonzerte ; Nr. 11)

Einheitssacht.: Konzerte, Org, HWV 310

Best.-Nr.: Edition Schott 3836. - Pl.-Nr.: B.S.S 36478

Signatur: $\quad 4$ MUS VII, 427:11

Notizen: $\quad 1971.5667$ - NIEDERSÄCHS. STAATS. U. UNIV.-BIBLIOTHEK GÖTTINGEN verknüpft zum MBW PPN 135217946

Vorh. in: $\quad$ GHG (3 Ex.)

PPN: 135218004

Orgel-Konzert No. 12 : B dur (opus $7^{\mathrm{VI}}$ ) / Georg Friedrich Händel. Hrsg. von Helmuth Walcha. - Partitur. - Mainz ; Leipzig : Schott, c 1942. - [2] Bl., 18 S. ; $4^{\circ}$

(Orgelkonzerte ; Nr. 12)

Einheitssacht.: Konzerte, Org, HWV 311

Best.-Nr.: Edition Schott 3837. - Pl.-Nr.: B.S.S 36513

Signatur: $\quad 4$ MUS VII, 427:12

Notizen: $\quad 1943.1366$ - Universitätsbibliothek Göttingen verknüpft zum MBW PPN 135217946 
PPN: 266543790

Konzert B-dur für Oboe und Streichorchester : 2 Violinen, Viola, Violoncello (Kb.) und Basso continuo (Cembalo) / Händel. - Partitur (zugl. Cembalo, Stimmen). Wolfenbüttel : Möseler, 1961. - 12 S. ; $4^{\circ}+5$ St.

(Corona : Werkreihe für Kammerorchester ; 66)

Einheitssacht.: Konzerte, Ob Orch, HWV 301. - Stimmen: Ob, Vl 1 2, Va, Kb

Signatur: $\quad 4$ Z MUS 94:66

Notizen: $\quad 1962.10254$ - NIEDERSÄCHS. STAATS. U. UNIV.-BIBLIOTHEK GÖTTINGEN verknüpft zur Serie PPN 131049070

Vorh. in: $\quad$ MuSe

PPN: 245110100

Konzert B-dur für Violine und Streichorchester : 2 Violinen, Viola, Violoncello (Kb.) und Basso continuo (Cembalo) / Händel. - Partitur (zugl. Klavierstimme, Stimmen).

- Wolfenbüttel [u.a.] : Möseler, 1962. - 16 S. ; $4^{\circ}+5$ St.

(Corona : Werkreihe für Kammerorchester ; 74)

Einheitssacht.: Konzerte, Vl Orch, HWV 288. - Stimmen: Vl solo, Vl (Ob) 1 2, Va, Vc

Signatur: $\quad 4$ Z MUS 94:74

Notizen: $\quad 1962.10254$ - NIEDERSÄCHS. STAATS. U. UNIV.-BIBLIOTHEK GÖTTINGEN verknüpft zur Serie PPN 131049070

Vorh. in: $\quad$ GHG, MuSe

PPN: 135381584

Konzert B-Dur : op. 4 Nr. 6 ; für Klavier (Cembalo oder Orgel), zwei Violinen und Violoncello oder kleines Orchester / Georg Friedrich Händel. Hrsg. von Willi

Hillemann. - [Klavierpartitur, Stimmen]. - Hannover : Nagel, 1937. - 11 S. ; $4^{\circ}+3$ St.

(Nagels Musik-Archiv ; 136)

Einheitssacht.: Konzerte, Org, HWV 294. - Aus dem Zyklus: Konzerte, Org Orch, HWV 289 - 294, op. 4. - Stimmen: Vl/Fl 1 2, Vc/Kb

Signatur: $\quad 4$ MUS V, 760:136

Notizen: $\quad 1940.1183$ - Universitätsbibliothek Göttingen verknüpft zur Serie PPN 129658642 
PPN: 245110305

Konzert g-moll für Oboe und Streichorchester : 2 Violinen, Viola, Violoncello (Kb), Basso continuo (Cembalo) / Händel. - Partitur (zugl. Klavierstimme, Stimmen). - Wolfenbüttel [u.a.] : Möseler, 1962. - 20 S. ; $4^{\circ}+5$ St.

(Corona : Werkreihe für Kammerorchester ; 75)

Einheitssacht.: Konzerte, Ob Orch, HWV 287. - Stimmen: Ob, Vl 1 2, Va, Vc

Signatur: $\quad 4$ Z MUS 94:75

Notizen: $\quad 1963.10254$ - NIEDERSÄCHS. STAATS. U. UNIV.-BIBLIOTHEK GÖTTINGEN verknüpft zur Serie PPN 131049070

Vorh. in: $\quad$ MuSe

PPN: 246129913

[The musical entertainer] Spielstücke aus „The Musical Entertainer“, 1737, für Altblockflöte und Basso continuo ... / Georg Friedrich Händel. Hrsg. von Ilse Hechler. - [Partitur]. -

Celle : Moeck, 1997. - 7 S. ; $4^{\circ}$

(Zeitschrift für Spielmusik ; 692)

Text dt., engl. und franz. - Enth.: The judgment of Paris. - The melancholy nymph. -

The address to Sylvia. - The request to the nightingal

ISMN M-2006-692-8

Signatur: $\quad$ K 98 B 2868

Notizen: $\quad$ NIEDERSÄCHS. STAATS. U. UNIV.-BIBLIOTHEK GÖTTINGEN verknüpft zur Serie PPN 130310433

\section{PPN: 04217497X}

Landmann, Arno:

Variationen über ein Thema von Georg Friedrich Händel / Arno Landmann. - [Musikdr., Erstausg.]. - Wolfenbüttel und Zürich : Möseler, 1979. - 34 S. ; quer-4 ${ }^{\circ}$

(Orgelmusik der Klassik und Romantik ; 10)

Einheitssacht.: Variationen, Org, op. 29. - Vorw. dt.

Best.-Nr.: M 19.030

Signatur: $\quad$ ZA 51449:10

Notizen: $\quad$ NIEDERSÄCHS. STAATS. U. UNIV.-BIBLIOTHEK GÖTTINGEN Geschenk des Verlags - verknüpft zur Serie PPN 03606758X 


\subsubsection{Concerti gross i}

\section{PPN: 135217792}

Händel, Georg Friedrich:

Twelve grand concertos for violins \&c. : Op. 6 / G. F. Händel. - [Stimmen]. - [S.l.] : [s.n.], [s.a.]. - 11 St.

Einheitssacht.: Konzerte, Vl Va Vc, op. 6. - Stimmen: Vl 1 2, Va, Vc/Cemb 1, Kb/Cemb 2

Signatur: $\quad 2$ MUS VII, 410

Notizen: $\quad 1878.3055$

\section{PPN: 135331862}

Concerto grosso, No. 1, G dur / Händel. (G. Schumann). - [Partitur]. - Leipzig

[u.a.] : Eulenburg [u.a.], 1906. - IV, 30 S., [2] Bl. ; $8^{\circ}$

(Zwölf grosse Konzerte für Streichinstrumente ; No. 1)

(Payne's kleine Partitur-Ausgabe ; 264)

Einheitssacht.: Concerti grossi, Streicher, HWV 319. - Umschlags. ist die Haupttitels.

(70 Pf.)

Best.-Nr.: E.E.1348

Signatur: $\quad 8$ MUS V, 520:264

Anmerkung: $\quad$ Bd. 263 - 274 der Serie zsgeb.

Notizen: $\quad 1915.548$ - verknüpft zum MBW 32937740X und zur Serie PPN 130781339

Vorh. in: $\quad$ GHG, MuSe

\section{PPN: 135331889}

Concerto grosso, No. 2, F dur / Händel. (G. Schumann). - [Partitur]. - Leipzig : Eulenburg, 1906. - IV, 29 S., [2] Bl. ; $8^{\circ}$

(Zwölf grosse Konzerte für Streichinstrumente ; No. 2)

(Payne's kleine Partitur-Ausgabe ; 265)

Einheitssacht.: Concerti grossi, Streicher, HWV 320. - Umschlags. ist die Haupttitels.

(70 Pf.)

Best.-Nr.: E.E.1349

Signatur: $\quad 8$ MUS V, 520:265

Anmerkung: Bd. 263 - 274 der Serie zsgeb.

Notizen: $\quad 1915.548$ - verknüpft zum MBW 32937740X und zur Serie PPN 130781339

Vorh. in: MuSe 


\section{PPN: 135331900}

Concerto grosso, No. 3, E moll / Händel. (G. Schumann). - [Partitur]. - Leipzig

[u.a.] : Eulenburg [u.a.], 1906. - IV, 28 S., [2] Bl. ; $8^{\circ}$

(Zwölf grosse Konzerte für Streichinstrumente ; No. 3)

(Payne’s kleine Partitur-Ausgabe ; 266)

Einheitssacht.: Concerti grossi, Streicher, HWV 321. - Umschlags. ist die Haupttitels.

(70 Pf.)

Best.-Nr.: E.E.1350

Signatur: $\quad 8$ MUS V, 520:266

Anmerkung: Bd. 263 - 274 der Serie zsgeb.

Notizen: $\quad 1915.548$ - verknüpft zum MBW 32937740X und zur Serie PPN 130781339

Vorh. in: $\quad$ GHG, MuSe

PPN: 135331927

Concerto grosso, No. 4, A moll / Händel. (G. Schumann). - [Partitur]. - Leipzig

[u.a.] : Eulenburg [u.a.], 1906. - IV, 26 S., [2] Bl. ; $8^{\circ}$

(Zwölf grosse Konzerte für Streichinstrumente ; No. 4)

(Payne's kleine Partitur-Ausgabe ; 267)

Einheitssacht.: Concerti grossi, Streicher, HWV 322. - Umschlags. ist die Haupttitels.

(70 Pf.)

Best.-Nr.: E.E.3301

Signatur: $\quad 8$ MUS V, 520:267

Anmerkung: Bd. $263-274$ der Serie zsgeb.

Notizen: $\quad 1915.548$ - verknüpft zum MBW 32937740X und zur Serie PPN 130781339

Vorh. in: $\quad$ MuSe

\section{PPN: 135331943}

Concerto grosso, No. 5, D dur / Händel. (G. Schumann). - [Partitur]. - Leipzig

[u.a.] : Eulenburg [u.a.], 1906. - IV, 34 S., [2] Bl. ; $8^{\circ}$

(Zwölf grosse Konzerte für Streichinstrumente ; No. 5)

(Payne’s kleine Partitur-Ausgabe ; 268)

Einheitssacht.: Concerti grossi, Streicher, HWV 323. - Umschlags. ist die Haupttitels.

(70 Pf.)

Best.-Nr.: E.E.3302

Signatur: $\quad 8$ MUS V, 520:268

Anmerkung: Bd. 263 - 274 der Serie zsgeb.

Notizen: $\quad 1915.548$ - verknüpft zum MBW 32937740X und zur Serie PPN 130781339

Vorh. in: $\quad$ MuSe 


\section{PPN: 13533196X}

Concerto grosso, No. 6, G moll / Händel. (G. Schumann). - [Partitur]. - Leipzig

[u.a.] : Eulenburg [u.a.], 1906. - IV, 30 S., [2] Bl. ; $8^{\circ}$

(Zwölf grosse Konzerte für Streichinstrumente ; No. 6)

(Payne’s kleine Partitur-Ausgabe ; 269)

Einheitssacht.: Concerti grossi, Streicher, HWV 324. - Umschlags. ist die Haupttitels.

(70 Pf.)

Best.-Nr.: E.E.3303

Signatur: $\quad 8$ MUS V, 520:269

Anmerkung: Bd. 263 - 274 der Serie zsgeb.

Notizen: $\quad 1915.548$ - verknüpft zum MBW 32937740X und zur Serie PPN 130781339

Vorh. in: $\quad$ GHG, MuSe

PPN: 135331986

Concerto grosso, No. 7, B dur / Händel. (G. Schumann). - [Partitur]. - Leipzig

[u.a.] : Eulenburg [u.a.], 1906. - IV, 23 S., [2] Bl. ; $8^{\circ}$

(Zwölf grosse Konzerte für Streichinstrumente ; No. 7)

(Payne's kleine Partitur-Ausgabe ; 270)

Einheitssacht.: Concerti grossi, Streicher, HWV 325. - Umschlags. ist die Haupttitels.

(70 Pf.)

Best.-Nr.: E.E.3304

Signatur: $\quad 8$ MUS V, 520:270

Anmerkung: Bd. $263-274$ der Serie zsgeb.

Notizen: $\quad 1915.548$ - verknüpft zum MBW 32937740X und zur Serie PPN 130781339

Vorh. in: $\quad$ MuSe

\section{PPN: 135332001}

Concerto grosso, No. 8, C moll / Händel. (G. Schumann). - [Partitur]. - Leipzig

[u.a.] : Eulenburg [u.a.], 1906. - IV, 22 S., [2] Bl. ; $8^{\circ}$

(Zwölf grosse Konzerte für Streichinstrumente ; No. 8)

(Payne’s kleine Partitur-Ausgabe ; 271)

Einheitssacht.: Concerti grossi, Streicher, HWV 326. - Umschlags. ist die Haupttitels.

(70 Pf.)

Best.-Nr.: E.E.3305

Signatur: $\quad 8$ MUS V, 520:271

Anmerkung: Bd. 263 - 274 der Serie zsgeb.

Notizen: $\quad 1915.548$ - verknüpft zum MBW 32937740X und zur Serie PPN 130781339

Vorh. in: $\quad$ MuSe 


\section{PPN: 135332028}

Concerto grosso, No. 9, F dur / Händel. (G. Schumann). - [Partitur]. - Leipzig

[u.a.] : Eulenburg [u.a.], 1906. - IV, 27 S., [2] Bl. ; $8^{\circ}$

(Zwölf grosse Konzerte für Streichinstrumente ; No. 9)

(Payne's kleine Partitur-Ausgabe ; 272)

Einheitssacht.: Concerti grossi, Streicher, HWV 327. - Umschlags. ist die Haupttitels.

(70 Pf.)

Best.-Nr.: E.E.3306

Signatur: $\quad 8$ MUS V, 520:272

Anmerkung: Bd. 263 - 274 der Serie zsgeb.

Notizen: $\quad 1915.548$ - verknüpft zum MBW 32937740X und zur Serie PPN 130781339

Vorh. in: MuSe

PPN: 135332044

Concerto grosso, No. 10, D moll / Händel. (G. Schumann). - [Partitur]. - Leipzig

[u.a.] : Eulenburg [u.a.], [ca. 1906]. - IV, 27 S., [2] Bl. ; $8^{\circ}$

(Zwölf grosse Konzerte für Streichinstrumente ; No. 10)

(Payne's kleine Partitur-Ausgabe ; 273)

Einheitssacht.: Concerti grossi, Streicher, HWV 328. - Umschlags. ist die Haupttitels.

(70 Pf.)

Best.-Nr.: E.E.3307

Signatur: $\quad 8$ MUS V, 520:273

Anmerkung: $\quad$ Bd. $263-274$ der Serie zsgeb.

Notizen: $\quad 1915.548$ - verknüpft zum MBW 32937740X und zur Serie PPN 130781339

Vorh. in: $\quad$ MuSe

\section{PPN: 135332060}

Concerto grosso, No. 11, A dur / Händel. (G. Schumann). - [Partitur]. - Leipzig

[u.a.] : Eulenburg [u.a.], 1906. - IV, 44 S., [2] Bl. ; $8^{\circ}$

(Zwölf grosse Konzerte für Streichinstrumente ; No. 11)

(Payne’s kleine Partitur-Ausgabe ; 274)

Einheitssacht.: Concerti grossi, Streicher, HWV 329. - Umschlags. ist die Haupttitels.

(70 Pf.)

Best.-Nr.: E.E.3308

Signatur: $\quad 8$ MUS V, 520:274

Anmerkung: Bd. 263 - 274 der Serie zsgeb.

Notizen: $\quad 1915.548$ - verknüpft zum MBW 32937740X und zur Serie PPN 130781339

Vorh. in: $\quad$ MuSe 


\section{PPN: 135331846}

Concerto grosso, No. 12, H moll / Händel. (G. Schumann). - [Partitur]. - Leipzig : Eulenburg, [1906]. - IV, S. 3 - 28, [2] Bl. ; $8^{\circ}$

(Zwölf grosse Konzerte für Streichinstrumente ; No. 12)

(Payne's kleine Partitur-Ausgabe ; 263)

Einheitssacht.: Concerti grossi, Streicher, HWV 330. - Umschlags. ist die Haupttitels.

(1 Mk.)

Best.-Nr.: E.E.1347

Signatur: $\quad 8$ MUS V, 520:263

Anmerkung: Bd. 263 - 274 der Serie zsgeb.

Notizen: $\quad 1915.548$ - EX BIBLIOTHECA REGIA ACADEM. GEORGIAE AUG. verknüpft zum MBW 32937740X und zur Serie PPN 130781339

Vorh. in: $\quad$ MuSe

PPN: 245087745

Concerto grosso B-dur für Oboe, 2 Violinen und Streichorchester : 2 Violinen, Violoncello (Kontrabaß), Basso continuo (Cembalo) / Händel. - Partitur (zugl. Klavierstimme). -

Wolfenbüttel [u.a.] : Möseler, 1962. - 19 S. ; $4^{\circ}+4$ St.

(Corona : Werkreihe für Kammerorchester ; 72)

Einheitssacht.: Concerti grossi, Ob Orch, HWV 302a. - Stimmen: Ob, Vl 1 2, Vc

Signatur: $\quad 4$ Z MUS 94:72

Notizen: $\quad 1963.10254$ - NIEDERSÄCHS. STAATS. U. UNIV.-BIBLIOTHEK GÖTTINGEN verknüpft zur Serie PPN 131049070

Vorh. in: $\quad$ MuSe

\section{PPN: 245086021}

Concerto grosse en do majeur extrait de la Fête d'Alexandre (1736), pour 2 violons solo, violoncelle, cordes et basse continue : 2 violons, (2 hautbois ad lib.), alto (ou violon III), violoncelle/contrebasse ... = Concerto grosso C-dur aus dem Alexanderfest (1736), für 2 Solo-Violinen, Violoncello, Streicher und Generalbaß / Händel. - Partitur (zugl.

Klavierstimme), Stimmen. - Wolfenbüttel [u.a.] : Möseler, 1968. - 30 S. ; $4^{\circ}+9$ St. (Corona : Werkreihe für Kammerorchester ; 99)

Einheitssacht.: Alexander's feast or the power of musick, Vl Vc Bc, HWV $318<$ Concerto grosso>. - Stimmen: Ob 1 2, Vl 12 3, Va, Vc/Kb. - Vorw. dt., franz. und engl.

\section{Signatur: $\quad 4$ Z MUS 94:99 \\ Notizen: $\quad 1969.10254$ - NIEDERSÄCHS. STAATS. U. UNIV.-BIBLIOTHEK GÖTTINGEN - Geschenk des Verlages - verknüpft zur Serie PPN 131049070}

Vorh. in: $\quad$ MuSe 


\section{PPN: 135334020}

Concerto grosso, D major for 2 oboes and strings : Op. 3 No.6 / by Georg Friedrich Handel. Ed. and with forew. by Stanley Sadie. - [Partitur]. - London [u.a.] : Eulenburg, 1959. [2] Bl., 24 S., [2] Bl. ; $8^{\circ}$

Einheitssacht.: Concerti grossi, HWV 317. - Aus dem Zyklus: Concerti grossi, HWV 312 - 317, op. 3. - [Kammermusik]. - Vorw. engl. und dt.

Best.-Nr.: Edition Eulenburg 382; E.E.61

Signatur: $\quad 8$ MUS V, 520:382

Notizen: $\quad 1962.4556$ - NIEDERSÄCHS. STAATS. U. UNIV.-BIBLIOTHEK GÖTTINGEN verknüpft zur Serie PPN 130781339

\section{PPN: 135333989}

Concerto grosso, F major for 2 oboes and string orchestra : Op. 3 No. 4a / by Georg Friedrich Handel. Ed. and with forew. by Stanley Sadie. - [Partitur]. - London [u.a.] : Eulenburg, [1959]. - [2] Bl., 24 S. ; $8^{\circ}$

Einheitssacht.: Concerti grossi, HWV 315. - Aus dem Zyklus: Concerti grossi, HWV 312 - 317, op. 3. - [Kammermusik]. - Vorw. engl. und dt.

Best.-Nr.: Edition Eulenburg 380; E.E.6196

Signatur: $\quad 8$ MUS V, 520:380

Notizen: $\quad 1962.4556$ - NIEDERSÄCHS. STAATS. U. UNIV.-BIBLIOTHEK GÖTTINGEN verknüpft zur Serie PPN 130781339

\section{PPN: 135334004}

Concerto grosso, D minor for 2 oboes and strings : Op. 3 No. 5 / by Georg Friedrich Handel. Rev. and with forew. by Stanley Sadie. - [Partitur]. - London [u.a.] : Eulenburg, 1959. [2] Bl., 24 S., [2] Bl. ; $8^{\circ}$

Einheitssacht.: Concerti grossi, HWV 316. - Aus dem Zyklus: Concerti grossi, HWV 312 - 317, op. 3. - [Kammermusik]. - Vorw. engl. und dt.

Best.-Nr.: Edition Eulenburg 381; E.E.6197

Signatur: $\quad 8$ MUS V, 520:381

Notizen: $\quad 1962.4556$ - NIEDERSÄCHS. STAATS. U. UNIV.-BIBLIOTHEK GÖTTINGEN - verknüpft zur Serie PPN 130781339 


\subsubsection{O uvertüren, S i n fonien, Su it e n, M är s che}

\section{PPN: 031884490}

Händel, Georg Friedrich:

Händel, Chaconne / mit kritisch-instruktiven Anm., Vortragszeichen und sorgfältigem Fingersatz hrsg. von Eugen d’ Albert. - [Musikdr.]. - Leipzig : Forberg, c 1907. $10 \mathrm{~S} . ; 4^{\circ}$

(89 ausgewählte Werke aus dem Konzertprogramm von Eugen d' Albert's Klavierabenden ; Nr. 8)

Best.-Nr.: 5986

\section{Signatur: $\quad 4$ MUS VIII, 2600:8 \\ Notizen: $\quad$ 1987.25995 - NIEDERSÄCHS. STAATS. U. UNIV.-BIBLIOTHEK GÖTTINGEN - verknüpft zum MBW PPN 031884482}

Vorh. in: $\quad$ MuSe

\section{PPN: 245211756}

Drei Ouvertüren für Oboe (Flöte), 2 Violinen, Violoncello und Generalbaß : Sinfonia pastorale für 2 Violinen (Blockflöten), Violoncello (Blockflöte) und Generalbaß ... = Trois ouvertures pour hautbois (flûte), 2 violons, violoncelle et basse continue / Händel. - Partitur (zugl. Klavierstimme), Stimmen. - Wolfenbüttel [u.a.] : Möseler, 1971. - 32 S. $; 4^{\circ}+4$ St.

(Corona : Werkreihe für Kammerorchester ; 108)

Einheitssacht.: Chandos anthems < Ouvertüre $>$ und Messiah $<$ Pastorale $>$ / Ausw. Stimmen: Ob, Vl 1 2, Vc/Kb. - Vorw. dt., franz. und engl.

\section{Signatur: $\quad 4$ Z MUS 94:108}

Notizen: $\quad 1972.10254$ - NIEDERSÄCHS. STAATS. U. UNIV.-BIBLIOTHEK GÖTTINGEN Geschenk des Verlags - verknüpft zur Serie PPN 131049070 


\section{PPN: 266515193}

Festmusik in B-Dur : Ouvertüre und Tänze aus der Oper Alcina (1735) ; für 2 Violinen, Viola, Violoncello, Klavier (Generalbaß) / Händel. - Partitur (zugl. Klavierstimme), Stimmen. [Neudr.]. - Wolfenbüttel : Möseler, 1951. - 14 S. ;4 + 4 St.

(Deutsche Instrumentalmusik : Werkreihe für Kammerorchester ; 1)

Einheitssacht.: Alcina, $1735<$ Ouvertüre $>$

\section{Signatur: $\quad 4$ Z MUS 94:1}

Anmerkung: Stimmen nicht vorh.

Notizen: $\quad 1951.2677$ - NIEDERSÄCHS. STAATS. U. UNIV.-BIBLIOTHEK GÖTTINGEN verknüpft zur Serie PPN 131049070

Vorh. in: $\quad$ MuSe

\section{PPN: 332466353}

Ouvertüren und Tänze : aus den Opern Alexander, Berenice und dem Oratorium Theodora ; für 2 Violinen (2 Oboen), Viola, Violoncello, Kontrabaß (Fagott) und Generalbaß (Cembalo, Klavier) / Händel. Hrsg. von Adolf Hoffmann. - Partitur zugl. Klavierstimme, Stimmen. Wolfenbüttel : Möseler, 1959. - 32 S. ; $4^{\circ}+5$ St.

(Corona : Werkreihe für Kammerorchester ; 55)

Einheitssacht.: Ouvertüren und Tänze, Fg Vl 12 Va Vc Cemb / Ausw. - Stimmen: Ob 1/Vl 1, Ob 2/Vl 2, Vl 3, Va, B (Fg, Vc, Cemb)

\section{Signatur: $\quad 4$ Z MUS 94:55}

Notizen: $\quad$ 1959.10254 - NIEDERSÄCHS. STAATS. U. UNIV.-BIBLIOTHEK GÖTTINGEN verknüpft zur Serie PPN 131049070

PPN: 024684686

Stay shepherd stay : Ouverturen und Arien aus Opern ; für Altblockflöte solo / von G. F. Händel. Hrsg. von Annette Struck. - [Musikdr.]. - Celle : Moeck, 1984. - 24 S. ; $4^{\circ}$

(Das Blockflöten-Repertoire)

Vorw. dt., engl. und franz.

Best.-Nr.: Edition Moeck 2530

Signatur: $\quad 91$ B 26123

Notizen: $\quad$ NIEDERSÄCHS. STAATS. U. UNIV.-BIBLIOTHEK GÖTTINGEN 


\section{PPN: 26710183X}

Xerxes : Ouvertüre, Sinfonie, Arien und Gigue aus der gleichnamigen Oper ; für 2 Violonen, Viola, Violoncello und Klavier (Generalbaß) / Händel. - Partitur (zugl. Klavierstimme). Wolfenbüttel : Möseler, 1955. - 23 S. ; $4^{\circ}+4$ St.

(Deutsche Instrumentalmusik : Werkreihe für Kammerorchester ; 35)

Einheitssacht.: Serse, Vl 12 Va Vc / Ausw. - Stimmen: Vl 1 2, Va, Vc. - Gesangstext ital.

\section{Signatur: $\quad 4$ Z MUS 94:35}

Notizen: $\quad$ 1956.10254 - NIEDERSÄCHS. STAATS. U. UNIV.-BIBLIOTHEK GÖTTINGEN verknüpft zur Serie PPN 13103071X

Vorh. in: $\quad$ MuSe

\section{PPN: 33245858X}

The water music $=$ Wassermusik $/$ George Frideric Handel. Ed. by Roger Fiske. -

Dirigierpartitur. - London [u.a.] : Eulenburg, 1973. - XVI, 88 S. ; $8^{\circ}$

Einheitssacht.: Water music <Ouvertüre>. - Dt. Übers. d. Vorw.: Stefan de Haan. -

Vorw. engl. und dt.

Best.-Nr.: Edition Eulenburg 1308; E. E. 6493

Signatur: $\quad$ ZA 25934:1308

Notizen: $\quad$ NIEDERSÄCHS. STAATS. U. UNIV.-BIBLIOTHEK GÖTTINGEN

\section{PPN: 266551440}

12 Sinfonien für Streichorchester und Klavier (Generalba $\beta$ ) : Nr. 1-9 für Violinen, Viola (Violine III), Cello (Kontrabaß), Klavier; Nr. 10-11 für 2 Violinen, Cello (Kontrabaß), Klavier; Nr. 12 für 3 Violinen, Viola, Cello (Kontrabaß), Klavier / Händel. - Partitur, Stimmen. - Wolfenbüttel : Möseler, 1954. - 28 S. ; $4^{\circ}+4$ (5) St.

(Deutsche Instrumentalmusik : Werkreihe für Kammerorchester ; 29)

Einheitssacht.: Sinfonien, Kl Orch / Ausw. Arr. - Stimmen: Vl 12, Va, Vc

Signatur: $\quad 4$ Z MUS 94:29

Notizen: $\quad 1954.10254$ - NIEDERSÄCHS. STAATS. U. UNIV.-BIBLIOTHEK GÖTTINGEN verknüpft zur Serie PPN 13103071X

Vorh. in: $\quad$ MuSe 
PPN: 332473155

Rinaldo-Suite : Ouverture, Tänze, Sinfonie, Marsch und Arien aus der Oper Rinaldo ; für 2 Violinen, Viola (oder Violine III), Violoncello (Kontrabaß) und Klavier (Generalbaß) / Händel. - Partitur, Stimmen. - Wolfenbüttel : Möseler, 1953. - 24 S. ; $4^{\circ}+4$ St.

(Deutsche Instrumentalmusik : Werkreihe für Kammerorchester ; 26)

Einheitssacht.: Rinaldo $<$ Suite $>$

Signatur: $\quad 4$ Z MUS 94:26

Anmerkung: Stimmen nicht vorh.

Notizen: $\quad 1954.10254$ - NIEDERSÄCHS. STAATS. U. UNIV.-BIBLIOTHEK GÖTTINGEN verknüpft zur Serie PPN PPN 13103071X

Vorh. in: $\quad$ MuSe

PPN: 266600360

Suite mit dem Marsch, für 2 Violinen, Violoncello (Kontraba $\beta$ ) und Klavier (Generalba $\beta$ ) / Händel. - Partitur, Stimmen. - Wolfenbüttel : Möseler, 1949. - 16 S. ; $4^{\circ}+3$ St.

(Deutsche Instrumentalmusik : Werkreihe für Kammerorchester ; 10)

Einheitssacht.: Suiten, Vl 12 Vc Kl / Arr.

Signatur: $\quad 4$ Z MUS 94:10

Anmerkung: Stimmen nicht vorh.

Notizen: $\quad 1950.129$ - NIEDERSÄCHS. STAATS. U. UNIV.-BIBLIOTHEK GÖTTINGEN verknüpft zur Serie PPN 13103071X

Vorh. in: $\quad$ MuSe

PPN: 144330415

Suite in D moll / von G. F. Händel. Rev. von Otto Singer. - [Musikdr.]. - Berlin : Bote \& Bock, [um 1915]. - 20 S. ; $4^{\circ}$

(Ausgewählte Klavierwerke von Joh. Seb. Bach, G. F. Händel ; [Abt. 2,2])

Einheitssacht.: Suiten, d-Moll / Arr.

Best.-Nr.: 11019.11020

Signatur: $\quad 4$ MUS VII, 2855:2,2

Notizen: $\quad$ 1987.25991 - NIEDERSÄCHS. STAATS. U. UNIV.-BIBLIOTHEK GÖTTINGEN Verknüpft zum MBW PPN 144330377 
PPN: 135380928

Zwölf Märsche für Streichorchester mit Bläsern nach Belieben / G. F. Händel. Hrsg. von Rudolf Steglich. - Klavierpartitur. - Hannover : Nagel, 1938. - 15 S. ; $4^{\circ}$

(Nagels Musik-Archiv ; 108)

Einheitssacht.: Märsche, Orch / Ausw. - Die Vorlage erweist sich eigentlich als Partitur. Enth. außerdem: Kreuzrittermarsch aus der Oper "Rinaldo"; Marsch der Perser aus der Oper "Floridante”; Siegesmarsch aus dem Oratorium "Judas Maccabäus”; Sarazenenmarsch aus der Oper "Rinaldo"; Trauermarsch aus dem Oratorium "Saul”

Signatur: $\quad 4$ MUS V, 760:108

Notizen: $\quad 1940.1183$ - Universitätsbibliothek Göttingen verknüpft zur Serie PPN 129658642

Vorh. in: $\quad$ MuSe 


\title{
6. K l a vi e r a u s üge
}

\section{PPN: 135217687}

Händel, Georg Friedrich:

Acis und Galatea : Pastoral / von Georg Friedrich Händel. - Clavierauszug, übereinstimmend mit der Ausg. der Dt. Händelges. - Leipzig ; Winterthur : Rieter-Biedermann, [1868]. 111 S. ; $4^{\circ}$

Gesangstext engl. und dt.

(2 Mk. 40 Pf.)

Best.-Nr.: 546.H.W.3

Signatur: $\quad 4$ MUS VII, 400

Notizen: $\quad 1876.1911$ - EX BIBLIOTHECA REGIA ACADEM. GEORGIAE AUG.

Vorh. in: $\quad$ GHG (4 Ex.)

\section{PPN: 266513433}

Acis und Galatea : Pastoral / von Georg Friedrich Händel. Dichtung von John Gay. Aus dem Engl. neu übertr. und für den prakt. Gebrauch hrsg. von Konrad Ameln. - Klavierausz. Wolfenbüttel : Möseler, 1951. - 129, [2 ungez.] S. ; $4^{\circ}$

Signatur: $\quad 4$ MUS 457

Notizen: $\quad 1951.5171$ - NIEDERSÄCHS. STAATS. U. UNIV.-BIBLIOTHEK GÖTTINGEN

\section{PPN: 135217385}

Alexander’s Fest oder Die Gewalt der Musik / [von G. F. Händel]. - Im Clavierauszug, mit dt. und engl. Texte. - Bonn : Simrock, [s.a.]. - 88 S. ; $4^{\circ}$

(Händel's Oratorien)

Einheitssacht.: Alexander's feast or The power of musick, HWV 75. - Gesangstext dt. und engl.

$\left(6 \mathrm{Fr}^{\mathrm{s}}\right)$

Best.-Nr.: 5790

\author{
Signatur: $\quad 4$ MUS VII, 371:KLAVIERAUSZ \\ Notizen: $\quad$ EX BIBLIOTHECA REGIA ACADEM. GEORGIAE AUG. ; \\ BIBL. R. ACAD. G. A.
}




\section{PPN: 135217415}

Alexander's Fest oder Die Macht der Tonkunst : eine Ode zu Ehren der heil. Cäcilia von John Dryden / in Musik gesetzt von Georg Friedrich Händel. - Clavierauszug, übereinstimmend mit der Ausg. der Dt. Händelges. - Leipzig ; Winterthur : RieterBiedermann, [ca. 1920]. - 107 S. ; $4^{\circ}$

Einheitssacht.: Alexander's feast or The power of musick, HWV 75. - Gesangstext engl. und dt.

(2 Mk. 40 Pf.)

Best.-Nr.: 761.H.W.12

Signatur: $\quad 4$ MUS VII, 372

Notizen: $\quad$ 1876.1917 - EX BIBLIOTHECA REGIA ACADEM. GEORGIAE AUG.

\section{PPN: 135217849}

Ariadne : Oper in drei Akten / von G. F. Händel. Text von Francis Colman. Übers. von Emilie Dahnk-Baroffio. - Klavierausz. / von Paul Greven. - Kassel : Bärenreiter, 1940. - [2] Bl., 176 S. ; $4^{\circ}$

(Veröffentlichungen der Göttinger Händel-Gesellschaft)

Einheitssacht.: Arianna in Creta, HWV 32

Best.-Nr.: Bärenreiter-Ausgabe 1632

Signatur: $\quad 4$ MUS VII, 419

Notizen: $\quad 1942.4921$ - Universitätsbibliothek Göttingen

Vorh. in: $\quad$ GHG (10 Ex.), MuSe, StAr

PPN: 135217105

Athalia : Oratorium / von Georg Friedrich Händel. - Clavierauszug, übereinstimmend mit der Ausg. der Dt. Händelges. - Leipzig ; Winterthur : Rieter-Biedermann, [s.a.]. - 186 S. ; $4^{\circ}$ Gesangstext engl. und dt.

(3 Mark)

Best.-Nr.: 560.H.W.5

Signatur: $\quad 4$ MUS VII, 350

Notizen: $\quad 1876.1914$ - EX BIBLIOTHECA REGIA ACADEM. GEORGIAE AUG. 


\section{PPN: 135217113}

Belsazar : Oratorium / von Georg Friedrich Händel. - Clavierauszug, übereinstimmend mit der Ausg. der Dt. Händelges. - Leipzig ; Winterthur : Rieter-Biedermann, [19. Jh.]. - 253 S. ; $4^{\circ}$ Einheitssacht.: Belshazzar, HWV 61. - Gesngstext engl. und dt.

(4 Mark)

Best.-Nr.: 610.H.W.19

Signatur: $\quad 4$ MUS VII, 351

Notizen: $\quad 1876.1915$ - EX BIBLIOTHECA REGIA ACADEM. GEORGIAE AUG.

Vorh. in: $\quad$ MuSe

\section{PPN: 135217695}

Cäcilien-Ode / von G. F. Händel. - Clavierauszug, Ausg. der Händelges. -

Leipzig : Engelmann, [ca. 1890]. - 80 S. ; $4^{\circ}$

Einheitssacht.: Ode for St. Cecilia's Day, HWV 76

Signatur: $\quad 4$ MUS VII, 401

Notizen: $\quad 1876.1912$ - EX BIBLIOTHECA REGIA ACADEM. GEORGIAE AUG.

PPN: 135217490

Debora : Oratorium / von G. F. Händel. - Klavier-Auszug / in der Neugestaltung von Friedrich Chrysander. - Leipzig : Breitkopf \& Härtel, 1909. - [1] Bl., 157 S. : Ill. ; $4^{\circ}$ Einheitssacht.: Deborah, HWV 51

Best.-Nr.: H.W.29

Signatur: $\quad 4$ MUS VII, 379

Notizen: $\quad 1937.564$ - EX BIBLIOTHECA ACAD. GEORGIAE AUG. Geschenk von Fräulein Bibl. Inspekt. G. Dittrich Göttingen

Vorh. in: $\quad$ GHG (2 Ex.) 
PPN: 352025832

Deidamia : opera in tre atti ; HWV 42 / Händel. Dt. Übers. von Michael Pacholke. Klavierauszug nach dem Urtext der Hallischen Händel-Ausg. / von Michael Pacholke.

- Kassel [u.a.] : Bärenreiter, 2002. - XI, 273 S. ; $4^{\circ}$

(Bärenreiter-Urtext)

Dirigierpartitur und Aufführ.-Material leihweise erhältlich. - Vorw. dt. und engl. -

Gesangstext ital. und dt.

ISMN M-006-50743-6 : EUR 32.00

Best.-Nr.: BA 4070a

Signatur: $\quad 2003$ B 396

Notizen: $\quad$ Niedersächsische Staats- u. Univ.-Bibliothek Göttingen

Vorh. in: $\quad$ GHG

\section{PPN: 135217261}

Der Feldherr : Freiheitsoratorium / Georg Friedrich Händel. In der Einrichtung von Hermann Stephani. - Klavierausz., [engl. Urtext / von Thomas Morell]. - Leipzig : Siegel, 1939. - VIII, S. 3 - 134, [1] Bl. ; $4^{\circ}$

Einheitssacht.: Judas Maccabaeus / Ausw. - Vorw. in Fraktur (RM. 5.-)

Signatur: $\quad 4$ MUS VII, 357

Notizen: $\quad 1940.1325$ - Universitätsbibliothek Göttingen

PPN: 349212104

Gloria : HWV deest / Händel. - Klavierauszug nach dem Urtext der Hallischen HändelAusg. / von Andreas Köhs. - Kassel [u.a.] : Bärenreiter, 2001. - 22 S. ; $4^{\circ}$

(Bärenreiter-Urtext)

Einheitssacht.: Gloria, Vl 12 Bc, B-Dur. - Besetzung: Sopr, Vl 12, Org, B. - Gesangstext lat. ISMN M-006-52012-1

Best.-Nr.: BA 4248a

Signatur: $\quad$ K 2002 B 1826

Notizen: $\quad$ NIEDERSÄCHS. STAATS. U. UNIV.-BIBLIOTHEK GÖTTINGEN

Vorh. in: $\quad$ MuSe 
PPN: 135217180

[Judas Maccabaeus] Händel's Oratorium Judas Maccabaeus / nach Mozarts Bearbeitung. - Im Clavier-Auszuge / von Ludwig Hellwig. - Bonn ; Köln : bey N. Simrock, 1820. 62, 65, 41 S. ; quer- $4^{\circ}$

Aus dem Engl. übers. - Erscheinungsjahr nach der dat. Vorr.

Signatur: $\quad 4$ MUS VII, 354

Notizen: $\quad$ EX BIBLIOTHECA REgIA ACADEM. GEORGIAE AUG.

PPN: 135217334

[Der Messias] Händel's Oratorium Der Messias / Mit deutschem Texte von Klopstock und Ebeling. - Im Clavierauszuge / von C. F. G. Schwencke. - Hamburg : bey Iohann August Böhme, 1809. - 166 S. ; quer- $4^{\circ}$

Einheitssacht.: Messiah, HWV 56. - Erscheinungsjahr nach der dat. Vorr.

Signatur: $\quad 4$ MUS VII, 365

Notizen: $\quad 1896.956$ - EX BIBLIOTHECA REGIA ACADEM. GEORGIAE AUG. Geschenk d. lonr. Glücksberg (och. D. Kgl. Bibl. Berl.) 1896

Vorh. in: $\quad$ GHG (4 Ex.)

PPN: 135217296

[Der Messias] Händel's Oratorium der Messias / mit deutschem und neu hinzugefügtem lateinischem Texte nach der Mozartschen Bearbeitung eingerichtet von Xaver Gleichauf und dem Caecilien Verein in Frankfurt a/m gewidmet vom Verleger. - Im Clavierauszuge. - Bonn : bei N. Simrock, [ca. 1828]. - II, S. 2 - 139. ; quer-4

Einheitssacht.: Messiah, HWV 56 / Arr.

(18 Francs)

Best.-Nr.: 2679

Signatur: $\quad 4$ MUS VII, 361

Notizen: $\quad$ EX BIBLIOTHECA REgIA ACADEM. GEORGIAE AUG. 


\section{PPN: 135217466}

Herakles : Oratorium / von Georg Friedrich Händel. - Clavierauszug, übereinstimmend mit der Ausg. der Deutschen Händelges.. - Leipzig ; Winterthur : Rieter-Biedermann, [1873-1875]. - 208 S. ; $4^{\circ}$

Einheitssacht.: Hercules, HWV 60. - Gesangstext engl. und dt.

(4 Mk.)

Best.-Nr.: 826.H.W.4

Signatur: $\quad 4$ MUS VII, 377 (1. Ex.)

4 MUS VII, 377/a (2. Ex.)

Notizen: $\quad 1877.1356$ - EX BIBLIOTHECA REGIA ACADEM. GEORGIAE AUG. (1. Ex.) ; 1940.1295 - Universitätsbibliothek Göttingen (2. Ex.)

Vorh. in: $\quad$ MuSe

\section{PPN: 31929269X}

So wie der Hirsch nach Wasser schreit : Psalm $42 ; 1$. Fassung = As pants the hart for cooling streams / Georg Friedrich Händel. Hrsg. von Kurt Fiebig ... - Klavierausz. Berlin [u.a.] : Evang. Verl.-Anst. [u.a.], c 1948. - 32 S. ; $4^{\circ}$

(Psalm-Kantate ; 2, Klavierauszug)

Einheitssacht.: As pants the hart, HWV 251a. - Gesangstext dt. und engl.

Best.-Nr.: Edition Merseburger 502

Signatur: $\quad 4$ MUS 57:2,KLAVIERAUSZ

Notizen: $\quad 1948.2453$ - EX BIBLIOTHECA REGIA ACADEM. GEORGIAE AUG. verknüpft zum MBW PPN 266529631

\section{PPN: 135217512}

Israel in Egypten : Oratorium ; Mit englischem und deutschem Texte / von G. F. Haendel. Übersetzung und Clavierauszug / von K. Breidenstein. - Bonn u. Köln : bei N. Simrock, 1826. - [2] Bl., 168 S., [1] Bl. ; quer- $4^{\circ}$

Einheitssacht.: Israel in Egypt (Exodus), HWV 54. - Erscheinungsjahr nach dem dat. Vorw. - Vorw. dt. - Gesangstext engl. und dt. $\left(22 \mathrm{Fr}^{\mathrm{s}}\right.$.)

Best.-Nr.: 2388

\section{Signatur: $\quad 4$ MUS VII, 381:KLAVIERAUSZ \\ Notizen: $\quad$ EX BIBLIOTHECA REGIA ACADEM. GEORGIAE AUG. ; BIBL. R. ACAD. G. A. - Leuschner [vermutlich Vorbesitzer [d. Verf.]]}

Vorh. in: $\quad$ GHG (106 Ex.) 
PPN: 135217121

Josua : grosses Oratorium ; mit deutschem Texte von $* * *$ / Musik von G. F. Händel. Im vollständigen Clavierauszug / von I. H. Clasing. - Hamburg : bei A. Cranz, [ca. 1810]. - [2] Bl., 144 S., [1] Bl. ; quer-4 ${ }^{\circ}$

Einheitssacht.: Joshua, HWV 64. - Gesangstext dt.

Signatur: $\quad 4$ MUS VII, 352

Notizen: $\quad$ EX BIBLIOTHECA REgIA ACADEM. GEORGIAE AUG.

PPN: 135217148

Josua : Oratorium / von Georg Friedrich Händel. - Clavierauszug, übereinstimmend mit der Ausg. der Dt. Händelges. - Leipzig ; Winterthur : Rieter-Biedermann, [s.a.]. - 162 S. ; $4^{\circ}$ Einheitssacht.: Joshua, HWV 64. - Gesangstext engl. und dt. (3 Mk.)

Best.-Nr.: 759.H.W.17

Signatur: $\quad 4$ MUS VII, 353:KLAVIERAUSZ

Notizen: $\quad 1878.1075$ - EX BIBLIOTHECA REGIA ACADEM. GEORGIAE AUG.

PPN: 135217237

Judas Maccabäus : Oratorium / von Georg Friedrich Händel. - Clavierauszug, übereinstimmend mit der Ausg. der Dt. Händelges.. - Leipzig ; Winterthur :

Rieter-Biedermann, [um 1870]. - 195 S. ; $4^{\circ}$

Einheitssacht.: Judas Maccabaeus, HWV 63. - Gesangstext engl. und dt. (22 1/2 Ngr.)

Best.-Nr.: 505.H.W.22

Signatur: $\quad 4$ MUS VII, 355

Notizen: $\quad$ EX BIBLIOTHECA REgIA ACADEM. GEORGIAE AUG.

Vorh. in: $\quad$ GHG (120 Ex.) 


\section{PPN: 135217245}

Judas Maccabäus : Oratorium / von Georg Friedrich Händel. - Clavierauszug, übereinstimmend mit der Ausg. der Dt. Händelges. - Leipzig : Rieter-Biedermann, [um 1910]. - 195 S. ; $4^{\circ}$

Einheitssacht.: Judas Maccabaeus, HWV 63. - Gesangstext engl. und dt. (3 Mk.)

Best.-Nr.: 505.H.W.22

Signatur: $\quad 4$ MUS VII, 355/a

Notizen: $\quad 1918.3467$ - EX BIBLIOTHECA REGIA ACADEM. GEORGIAE AUG. Aus den Mitteln der Ludendorff-Spende 1918

\section{PPN: 266535054}

Mein Lied sing auf ewig : [Psalm 89] = My song shall be alway / Georg Friedrich Händel. Hrsg. von Kurt Fiebig ... - Klavierausz. - Berlin [u.a.] : Evang. Verl.-Anst. [u.a.], c 1947. - 44 S. ; $4^{\circ}$

(Psalmkantate (Anthem) ; 1, Klavierauszug)

Einheitssacht.: My song shall be alway, HWV 252. - Gesangstext dt. und engl.

Best.-Nr.: Edition Merseburger 501

Signatur: $\quad 4$ MUS 57:1,KLAVIERAUSZ

Notizen: $\quad 1948.388$ - EX BIBLIOTHECA REGIA ACADEM. GEORGIAE AUG. verknüpft zum MBW PPN 266529631

PPN: 135217822

Ptolomäus : Oper in drei Akten / von G. Fr. Händel. Text von Nicola Haym. Übers von Emilie Dahnk-Baroffio. - Klavierausz. / von Anton Heilmann. - Hannover : Verl. für musikalische Kultur und Wiss. Küster, 1939. - [2] Bl., 97 S. ; $4^{\circ}$

(Veröffentlichungen der Göttinger Händel-Gesellschaft)

Einheitssacht.: Tolomeo, re d' Egitto, HWV 25

Best.-Nr.: Bärenreiter-Ausgabe 1633

Signatur: $\quad 4$ MUS VII, 416

Notizen: $\quad 1942.4922$ - Universitätsbibliothek Göttingen

Vorh. in: $\quad$ GHG (8 Ex.), MuSe, StAr 
PPN: 135217350

[Der Messias] Einzelne Recitative und Arien aus dem Oratorium „der Messias“ / von G. F. Händel. - Clavierauszug. - [6, 9] Bl., [4] doppels. Bl., [4] Bl.

Einheitssacht.: Messiah, HWV $56<$ Rezitativ und Air>. - Komp.: London, Aug./Sept. 1741. - Ms., verschiedene Formate

Signatur: $\quad 2$ MUS VII, 367

PPN: 135217423

Salomo : Oratorium / von Georg Friedrich Händel. - Clavierauszug, übereinstimmend mit der Ausg. der Dt. Händelges. - Leipzig ; Winterthur : Rieter-Biedermann, [1874]. - 231 S. ; $4^{\circ}$ Einheitssacht.: Solomon, HWV 67. - Gesangstext engl. und dt.

(4 Mrk. netto)

Best.-Nr.: 757.H.W.26

Signatur: $\quad 4$ MUS VII, 373

Notizen: $\quad 1876.1918$ - EX BIBLIOTHECA REGIA ACADEM. GEORGIAE AUG.

Vorh. in: $\quad$ GHG, MuSe

PPN: 135217628

Samson : Oratorium / von Georg Friedrich Händel. - Clavierauszug, übereinstimmend mit der Ausg. der Dt. Händelges. - Leipzig ; Winterthur : Rieter-Biedermann, [ca. 1890]. - 277 S. ; $4^{\circ}$ Gesangstext engl. und dt.

(3 Mk.)

Best.-Nr.: 548.H.W.10

Signatur: $\quad 4$ MUS VII, 388

Notizen: $\quad$ 1877.2042 - EX BIBLIOTHECA REGIA ACADEM. GEORGIAE AUG.

Vorh. in: $\quad$ GHG, MuSe 
PPN: 13521744X

Saul : Oratorium / von Georg Friedrich Händel. - Clavierauszug, übereinstimmend mit der Ausg. der Dt. Händelges. - Leipzig ; Winterthur : Rieter-Biedermann, [ca. 1885]. - [2] Bl., 212 S. ; $4^{\circ}$

Gesngstext engl. und dt.

(3 Mk.)

Best.-Nr.: 514.H.W.13

Signatur: $\quad 4$ MUS VII, 375

Notizen: $\quad 1876.1919$ - EX BIBLIOTHECA REGIA ACADEM. GEORGIAE AUG.

Vorh. in: $\quad$ MuSe

PPN: 135217784

Semele : Oratorium / von Georg Friedrich Händel. In der Neugestaltung von Alfred Rahlwes. - Klavierausz. - Leipzig : Leuckart, c 1917. - [3] Bl., 165 S. ; $4^{\circ}$

Best.-Nr.: F.E.C.L. 7689

Signatur: $\quad 4$ MUS VII, 409/1

Notizen: $\quad 1942.5177$ - Universitätsbibliothek Göttingen

Vorh. in: $\quad$ GHG (9 Ex.)

PPN: 135217636

Dettinger Te Deum / von Georg Friedrich Händel. - Clavierauszug, übereinstimmend mit der Ausg. der Dt. Händelges. - Leipzig ; Winterthur : Rieter-Biedermann, [1868]. - 80 S. ; $4^{\circ}$ Einheitssacht.: Te Deum for the victory of Dettingen, HWV 283. - Gesangstext engl. und dt. (2 Mk.)

Best.-Nr.: 590.H.W.25

Signatur: $\quad 4$ MUS VII, 389

Notizen: $\quad 1876.1916$ - EX BIBLIOTHECA REGIA ACADEM. GEORGIAE AUG.

Vorh. in: GHG, MuSe 
PPN: 135217652

Theodora : Oratorium / von Georg Friedrich Händel. - Clavierauszug, übereinstimmend mit der Ausg. der Dt. Händelges. - Leipzig ; Winterthur : Rieter-Biedermann, [um 1870]. -176 S. ; $4^{\circ}$

Gesangstext engl. und dt.

(1 Thlr.)

Best.-Nr.: 651.H.W.8

Signatur: $\quad 4$ MUS VII, 391

Notizen: $\quad 1876.1913$ - EX BIBLIOTHECA REGIA ACADEM. GEORGIAE AUG.

Vorh. in: $\quad$ MuSe

PPN: 135217539

Trauerhymne auf den Tod der Königin Karoline / von G. F. Händel. - Clavierauszug, Ausg. der Händelges. - Leipzig : Engelmann, [s.a.]. - 80 S. ; $4^{\circ}$

Einheitssacht.: The ways of Zion do mourn, HWV 264. - Gesangstext dt.

Signatur: $\quad 8$ MUS VII, 382:KLAVIERAUSZ*

Notizen: $\quad$ EX BIBLIOTHECA REGIA ACADEM. GEORGIAE AUG.

\section{PPN: 135217660}

Triumph von Zeit und Wahrheit : weltliches Oratorium = The triumph of time and truth / von Georg Friedrich Händel. Bearb. und hrsg. von Alfred Rahlwes. - Klavierauszug mit Text. - Leipzig : Leuckart, c 1937. - [3] Bl., 129 S. ; $4^{\circ}$

Einheitssacht.: Il trionfo del tempo e della verità, HWV 46b. - Nach Morell's engl. Übers. des ital. Urtextes von Kardinal Panfili und der dt. Übers. von Gervinus. - Anm. d. Hrsg. Gesangstext dt. und engl.

Signatur: $\quad 4$ MUS VII, 392

Notizen: $\quad 1942.5178$ - Universitätsbibliothek Göttingen 


\section{C h orsti m m e n}

\section{PPN: 135217393}

Händel, Georg Friedrich:

Alexanders Fest : Cantate / von G. F. Haendel. - [Chorstimme]. - [S.l.] : [Peters], [s.a.]. - 1 St. (9 S.). ; $4^{\circ}$

Einheitssacht.: Alexander's feast or The power of musick, HWV 75. - Chor B

Best.-Nr.: Edition Peters 6267

Signatur: $\quad 4$ MUS VII, 371:BASS

Notizen: $\quad$ Bachverein Heidelberg

PPN: 331734478

Das Alexanders-Fest : Cantate / von Haendel. - [Chorstimmen]. - Berlin : Trautwein, [s.a.]. - 57 St. (Aufführ.-Material, je 16 S.). ; quer-8 ${ }^{\circ}$

(Klassische Werke älterer und neuerer Kirchenmusik in ausgesetzten Chorstimmen ; 8)

Einheitssacht.: Alexander's feast or The power of musick, HWV 75. - Chor SATB

Signatur: $\quad 8$ MUS VII, 371:SOPR.ALT

8 MUS VII, 371:TEN.BASS

Anmerkung: 23 St. Sopr, 12 St. Alt, 6 St. Ten, 16 St. Bass. - Stimmen nur komplett, Kapseln aber einzeln ausleihbar. - 2 Kapseln

Notizen: $\quad$ BIBL. R. ACAD. G. A. - verknüpft zur Serie PPN 331766043

PPN: 332132463

8 Chorstimmen zum Oratorium Die Israeliten in Egipten / von G. F. Händel. - Bonn ;

Cöln : Simrock, [19. Jh.]. - 8 St. ; quer-8 ${ }^{\circ}$

Einheitssacht.: Israel in Egypt, HWV 54. - Chor SATB. - Text engl. und dt. $\left(15 \mathrm{Fr}^{\mathrm{s}} .50 \mathrm{C}^{\mathrm{s}}\right.$.)

Best.-Nr.: 2388

Signatur: $\quad 2$ MUS VII, 381

Anmerkung: Jeweils 2 Stimmen Sopr, Alt, Ten, Bass. - Nur komplett ausleihbar

Notizen: $\quad$ BIBL. R. ACAD. G. A. 
PPN: 135217458

Herakles / von G. F. Händel. - Chorstimmen, übereinstimmend mit der Ausg. der Dt. Händelges. - Leipzig ; Winterthur : Rieter-Biedermann, [s.a.]. - 59 St.

(Aufführ.-Material) ; $4^{\circ}$

Einheitssacht.: Hercules, HWV 60. - Umschlags. ist die Haupttitels. - Chor SATB Best.-Nr.: 827.HW.4

(1 Mk.)

Signatur: $\quad 8$ MUS VII, 376:SOPR.ALT* 8 MUS VII, 376:TEN.BASS*

Anmerkung: $\quad$ Mappe 1: 26 St. Sopr, 12 St. Alt; Mappe 2: 9 St. Ten, 12 St. Bass. Stimmen nur komplett, Mappen aber einzeln ausleihbar. - 2 Mappen

PPN: 135217520

Israel in Aegypten / von G. F. Händel. - Chorstimmen, übereinstimmend mit der Ausg. der Dt. Händelges. - Leipzig ; Winterthur : Rieter-Biedermann, [s.a.]. 83 St. (Aufführ.-Material) ; $4^{\circ}$

Einheitssacht.: Israel in Egypt (Exodus), HWV 54. - Umschlags. ist die Haupttitels.

- Chor SSAATTBB

Best.-Nr.: 498.HW.16

(15 Ngr.)

Signatur: $\quad 4$ MUS VII, 381:SOPR/I

4 MUS VII, 381:SOPR/II

4 MUS VII, 381:ALT

4 MUS VII, 381:TEN

4 MUS VII, 381:BASS

Anmerkung: 38 St. Sopr, 18 St. Alt, 10 St. Ten, 19 St. Bass. - Stimmen nur komplett, Mappen aber einzeln ausleihbar. - 5 Mappen

PPN: 135217555

Jephta : grosses Oratorium in 3 Abtheilungen / Musik von G. F. Händel. Übers. und bearb. von I. F. v. Mosel. - [Chorstimmen]. - Wien : Haslinger, [s.a.]. - 4 St. ; quer- $8^{\circ}$ (Dr.), $2^{\circ}$ (Ms.)

Einheitssacht.: Jephtha, HWV 70 / Arr. - Chor SSB. - 2 gedr. Stimmh. (Sopr; je 19 S.), 2 hs. Stimmh. (Sopr, 12 Bl.; Bass, 10 Bl.)

Signatur: $\quad 2$ MUS VII, 384 
PPN: 329612247

Josua / von G. F. Händel. - Chorstimmen, übereinstimmend mit der Ausg. der Dt. Händelges. - Leipzig ; Winterthur : Rieter-Biedermann, [s.a.]. - 103 St. (Aufführ.-Material) ; $4^{\circ}$

Einheitssacht.: Joshua, HWV 64. - Umschlags. ist die Haupttitels. - Chor SATB Best.-Nr.: 760.HW.17

(10 Ngr.)

Signatur: $\quad 4$ MUS VII, 353:SOPR

4 MUS VII, 353:ALT

4 MUS VII, 353:TEN

4 MUS VII, 353:BASS

4 MUS VII, 353:SINGSTIMME

Anmerkung: 22 St. Sopr, 18 St. Alt, 12 St. Ten, 20 St. Bass; Mappe Singst. Enth.: 12 St. Sopr, 4 St. Alt, 6 St. Ten, 9 St. Bass - Stimmen nur komplett, Mappen aber einzeln ausleihbar. - 5 Mappen

Notizen: $\quad 1880.4577,1880.2115$

PPN: 13521713X

Josua : grosses Oratorium / Georg Friedrich Haendel. - [Chorstimmen]. - 20 St. (je 4 Bl.)

Ms. - Chor SATB. - Komp.: London, Juli/Aug. 1747

Signatur: $\quad 2$ MUS VII, 352/a

Anmerkung: 8 St. Sopr, 4 St. Alt, 3 St. Ten, 5 St. Bass

Notizen: $\quad$ BIBL. R. ACAD. G. A.

PPN: 135217202

Judas Maccabaeus : Oratorium / von G. F. Händel. - [Partitur, Stimmen]. - 24 St. -

Stimmen: Gesang + Begl.-St., Fl 1 2, Klar 1 2, Fg, Vl 1 2, Va, Chor STB, Bc 1 2,

Org, Orch. - 24 Bl., 6 Bogen hs. Beil., 10 hs. H.

Signatur: $\quad 2$ MUS VII, 354/a

Anmerkung: $\quad$ Chor STB, 2.0.2.1, 0.3.0.0.1; 2.2.2.0.3 
PPN: 331724111

Judas Maccabaeus : Oratorium / von Haendel. - [Chorstimmen]. - Berlin : Trautwein, [s.a.]. - 34 St. (je 20 S.). ; quer-8 ${ }^{\circ}$

Chor SATB. - Eine (Sopr)-Stimme (24 S.) ist hs., alle anderen Stimmen sind gedr.

Signatur: $\quad 8$ MUS VII, 355:SOPR.ALT

8 MUS VII, 355:TEN.BASS

Anmerkung: $\quad$ Kapsel 1: 10 St. Sopr, 8 St. Alt; Kapsel 2: 7 St. Ten, 9 St. Bass Stimmen nur komplett, Kapseln aber einzeln ausleihbar. - 2 Kapseln

Notizen: $\quad$ BIBL. R. ACAD. G. A.

PPN: 135217199

Judas Maccabäus / von G. F. Händel. - Chorstimmen, übereinstimmend mit der Ausg. der Dt. Händelges. - Leipzig ; Winterthur : Rieter-Biedermann, [s.a.]. - 69 St.

(Aufführ.-Material) ; $4^{\circ}$

Einheitssacht.: Judas Maccabaeus, HWV 63. - Umschlags. ist die Haupttitels. - Chor SATB

Best.-Nr.: 506.HW.22

(71/2 Ngr.) $\begin{array}{lll}\text { Signatur: } & 8 \text { MUS VII, 354:SOPR* } & 8 \text { MUS VII, 354:ALT* } \\ & 8 \text { MUS VII, 354:TEN* } & 8 \text { MUS VII, 354:BASS* }\end{array}$

Anmerkung: 27 St. Sopr, 17 St. Alt, 13 St. Ten, 12 St. Bass. - Stimmen nur komplett, Mappen aber einzeln ausleihbar. - 4 Mappen

\section{PPN: 135217318}

Messias : Oratorium / von G. F. Haendel. - [Stimmen]. - [S.l.] : [s.n.], [s.a.]. - 91 St.

(Aufführ.-Material) ; $4^{\circ}$

Einheitssacht.: Messiah, HWV 56. - Chor SATB

Best.-Nr.: 2679

Signatur: $\quad 4$ MUS VII, 362:SOPR

4 MUS VII, 362:ALT

4 MUS VII, 362:TEN

4 MUS VII, 362:BASS

4 MUS VII, 362:BEIL

Anmerkung: 18 St. Sopr, 13 St. Alt, 9 St. Ten, 8 St. Bass.; Mappe „Beilagen“ enth. Chorst.: 21 St. Sopr, 7 St. Alt, 7 St. Ten, 8 St. Bass. - Stimmen nur komplett, Mappen aber einzeln ausleihbar. - 5 Mappen

Notizen: $\quad$ Universitätsbibliothek Göttingen (Tenor) ; BIBL. R. ACAD. G. A. ; NIEDERSÄCHS. STAATS. U. UNIV.-BIBLIOTHEK GÖTTINGEN (Sopran, Alt, Bass) 


\section{PPN: 135217598}

Samson / von G. F. Händel. - Chorstimmen, übereinstimmend mit der Ausg. der Dt. Händelges. - Leipzig : Rieter-Biedermann, [s.a.]. - 150 St. (Aufführ.-Material). ; $4^{\circ}$ Umschlags. der gedr. St. ist die Haupttitels. - Chor SATB, SSTTB. - Mappe „Stimme“ enth. Ms. in Folio-Format Best.-Nr.: 549.HW.10 (90 Pf.)

$\begin{array}{lll}\text { Signatur: } & \begin{array}{l}\text { 8 MUS VII, 387:SOPR.TEN* } \\ \text { 8 MUS VII, 387:SOPR* }\end{array} & \text { 8 MUS VII, 387:Alt.BASS* } \\ & \text { 8 MUS VII, 387:TEN* } & \text { 8 MUS VII, 387:AlT* } \\ & \text { 8 MUS VII, 387:STIMME* } & \text { 8 MUS VII, 387:BASs* } \\ \text { Anmerkung: } & \text { 10 St. Sopr, 10 St. Alt, 5 St. Ten, 10 St. Bass; 38 St. Sopr, 23 St. Alt, 13 St. } \\ & \begin{array}{l}\text { Ten, 23 St. Bass; Mappe „Stimme“ enth.: 9 St. Sopr, 4 St. Ten, 5 St. Bass. - } \\ \text { Stimmen nur komplett, Mappen aber einzeln ausleihbar. - 7 Mappen }\end{array} \\ \text { Notizen: } & \text { 1884.4421 (Sopr.Ten und Alt.BAss) }\end{array}$

\section{PPN: 135217431}

Saul : Oratorium / von G. F. Händel. - Chorstimmen, Ausg. der Händelgesellschaft. Leipzig : Engelmann, [nach 1848]. - 90 St. (Aufführ.-Material, je 16 S.). ; $4^{\circ}$ Umschlags. ist die Hauptitels. - Chor SATB (Ladenpreis à 71/2 Ngr., complet 1 Thlr.)

$\begin{array}{lll}\text { Signatur: } & 8 \text { MUS VII, 374:SOPR* } & 8 \text { MUS VII, 374:ALT* } \\ & 8 \text { MUS VII, 374:TEN* } & 8 \text { MUS VII, 374:BASS* }\end{array}$

Anmerkung: 38 St. Sopr, 20 St. Alt, 14 St. Ten, 22 St. Bass. - Stimmen nur komplett, Mappen aber einzeln ausleihbar. - 4 Mappen

Notizen: $\quad$ BIBL. R. ACAD. G. A.

\section{PPN: 135217547}

Trauerhymne auf den Tod der Königin Karoline / von G. F. Händel. - Chorstimmen, Ausg. der Händelges. - Leipzig : Engelmann, [s.a.]. - 90 St. (je 12 S.). ; $4^{\circ}$ Einheitssacht.: The ways of Zion do mourn, HWV 264. - Umschlags. ist die Haupttitels. - Chor SATB

Best.-Nr.: H.W.11

(Ladenpreis à 71⁄2 Ngr., complet 1 Thlr.)

Signatur: 8 MUS VII, 382:SOPR* 8 MUS VII, 382:ALT* 8 MUS VII, 382:TEN* 8 MUS VII, 382:BASS*

Anmerkung: 33 St. Sopr, 21 St. Alt, 12 St. Ten, 24 St. Bass. - Stimmen nur komplett, Mappen aber einzeln ausleihbar. - 4 Mappen 


\section{Q u e l l e n z u H änd e ls W e rken}

\section{PPN: 135216753}

Clari, Giovanni Carlo Maria

Fünf italienische Duette / von Giovanni Carlo Maria Clari. Für die Dt. Händelges. hrsg. von Friedrich Chrysander. - [Musikdr.]. - Leipzig : St. und Dr. der Ges., 1892. - [1] Bl., 84 S. ; $4^{\circ}$ (Supplemente, enthaltend Quellen zu Händel's Werken ; Suppl. 4)

Einheitssacht.: Duette. - Vorw. dt. - In Fraktur. - Gesangstext lat.

Best.-Nr.: HW: S.4

Signatur: $\quad 4$ MUS VII, 342:4

Notizen: $\quad 1892.131$ - EX BIBLIOTHECA REGEIA ACADEM. GEORGIAE AUG. verknüpft zum MBW PPN 135216710

PPN: 135216729

Erba, Dionigi:

Magnificat / von D. Erba. Für die Dt. Händelges. hrsg. von Friedrich Chrysander. -

[Partitur]. - Leipzig : St. und Dr. der Ges., 1888. - [2] Bl., 64 S. : Faks. ; $4^{\circ}$

(Supplemente, enthaltend Quellen zu Händel’s Werken ; Suppl. 1)

Vorw. dt. - In Fraktur. - Gesangstext lat.

Best.-Nr.: HW: S.1

Signatur: $\quad 4$ MUS VII, 342:1

Notizen: $\quad$ 1888.2886 - EX BIBLIOTHECA REGEIA ACADEM. GEORGIAE AUG. verknüpft zum MBW PPN 135216710

Vorh. in: $\quad$ MuSe

\section{PPN: 13521677X}

Keiser, Reinhard:

Octavia / von Reinhard Keiser. Für die Dt. Händelges. hrsg. von Friedrich Chrysander. -

[Partitur]. - Leipzig : St. und Dr. der Ges., 1902. - [2] Bl., 216 S. ; $4^{\circ}$

(Supplemente, enthaltend Quellen zu Händel's Werken ; Suppl. 6)

Vorw. und Gesangstext dt. - In Fraktur

Best.-Nr.: HW: S.6

Signatur: $\quad 4$ MUS VII, 342:6

Notizen: $\quad 1903.1863$ - EX BIBLIOTHECA REgEIA ACADEM. GEORGIAE AUG. verknüpft zum MBW PPN 135216710 


\section{PPN: 135216761}

Muffat, Gottlieb:

Componimenti musicali per il cembalo / von Gottlieb Muffat. Für die Dt. Händelges. hrsg. von Friedrich Chrysander. - [Klavierpartitur]. - Leipzig : St. und Dr. der Ges., 1896. - [7] Bl., 165 S. ; $4^{\circ}$

(Supplemente, enthaltend Quellen zu Händel's Werken ; Suppl. 5)

Enth. Widmung an den Leser in Ital. und Dt. - In der Vorlage (S. 2) folgender Verl. erwähnt: Musikaliendruckerei, M. Dreissig, Hamburg. - Vorw. dt. - In Fraktur

Best.-Nr.: HW: S.5

Signatur: $\quad 4$ MUS VII, 342:5

Notizen: $\quad 1896.1207$ - EX BIBLIOTHECA REGEIA ACADEM. GEORGIAE AUG. verknüpft zum MBW PPN 135216710

\section{PPN: 135216745}

Stradella, Alessandro

Serenata / von Alessandro Stradella. Für die Dt. Händelges. hrsg. von Friedrich Chrysander. [Partitur]. - Leipzig : St. und Dr. der Ges., 1888. - [1] Bl., 56 S. ; $4^{\circ}$

(Supplemente, enthaltend Quellen zu Händel's Werken ; Suppl. 3)

Einheitssacht.: Serenaten / Ausw. - Vorw. dt. - Gesangstext lat. - In Fraktur

Best.-Nr.: HW: S.3

Signatur: $\quad 4$ MUS VII, 342:3

Notizen: $\quad$ 1888.2886 - EX BIBLIOTHECA REGEIA ACADEM. GEORGIAE AUG. verknüpft zum MBW PPN 135216710

Vorh. in: $\quad$ MuSe 
PPN: 135216737

Urio, Francesco Antonio:

Te Deum / von Francesco Antonio Urio. Für die Dt. Händelges. hrsg. von Friedrich Chrysander. - [Partitur]. - Leipzig : St. und Dr. der Ges., 1902. - [1] Bl., 160 S. ; $4^{\circ}$ (Supplemente, enthaltend Quellen zu Händel's Werken ; Suppl. 2)

Einheitssacht.: Te Deum. - Vorw. dt. - In Fraktur. - Gesangstext lat.

Best.-Nr.: HW: S.2

Signatur: $\quad 4$ MUS VII, 342:2

Notizen: $\quad$ 1903. 1863 - EX BIBLIOTHECA REGEIA ACADEM. GEORGIAE AUG. verknüpft zum MBW PPN 135216710

PPN: 136146104

Te Deum von F. A. Urio als Quelle zu Händels Saul, Allegro, Dettinger Te Deum \&c. / hrsg. von Friedrich Chrysander. - [Partitur]. - Bergedorf bei Hamburg : Weissenborn, 1871. - 152 S. ; $4^{\circ}$

(Denkmæler der Tonkunst ; 5). - (Expedition der Denkmæler)

Signatur: $\quad 4$ MUS V, 480:5

Notizen: $\quad$ EX BIBLIOTHECA REGEIA ACADEM. GEORGIAE AUG. verknüpft zum MBW PPN 136145817 


\section{Händel, z w i s che n d e n Z e i l e n “}

\section{PPN: 224947834}

Händel, Georg Friedrich:

Arie aus dem Oratorium: Josua ... [Doch wer ist dies?]

In: Cantiones XVII, XVIII saeculorum praestantissimas altae voci accommodatas = Sammlung der besten Meisterwerke des 17t und 18t Jahrhunderts für die Alt-Stimme nach den Original Partituren mit Begleitung des Piano-Forte. - Berlin ; Posen : Bote \& Bock, 4 (са. 1844), S. 24-26

\section{Signatur: $\quad 4$ MUS V, 450:4 \\ Notizen: $\quad 1887.5988$}

\section{PPN: 224947834}

Arie aus dem Oratorium: Josua ... [Nun gieb dem Herrn] In: Cantiones XVII, XVIII saeculorum praestantissimas altae voci accommodatas $=$ Sammlung der besten Meisterwerke des 17t und 18t Jahrhunderts für die Alt-Stimme nach den Original Partituren mit Begleitung des Piano-Forte. - Berlin ; Posen : Bote \& Bock, 4 (ca. 1844), S. 27-30

$\begin{array}{ll}\text { Signatur: } & 4 \text { MUS V, 450:4 } \\ \text { Notizen: } & 1887.5988\end{array}$

PPN: 224947834

Arie aus dem Oratorium: Josua ... [O welch ein Preis] In: Cantiones XVII, XVIII saeculorum praestantissimas altae voci accommodatas = Sammlung der besten Meisterwerke des 17t und 18t Jahrhunderts für die Alt-Stimme nach den Original Partituren mit Begleitung des Piano-Forte. - Berlin ; Posen : Bote \& Bock, 4 (ca. 1844), S. 31-33

$\begin{array}{ll}\text { Signatur: } & 4 \text { MUS V, 450:4 } \\ \text { Notizen: } & 1887.5988\end{array}$


PPN: 224947834

Arie aus dem Oratorium „Salomon“ [Preis sei dem Herrn gnädig auf uns sah] In: Cantiones XVII, XVIII saeculorum praestantissimas altae voci accommodatas = Sammlung der besten Meisterwerke des 17t und 18t Jahrhunderts für die Alt-Stimme nach den Original Partituren mit Begleitung des Piano-Forte. - Berlin ; Posen : Bote \& Bock, 4 (ca. 1844), S. 46-48

Signatur: $\quad 4$ MUS V, 450:4

Notizen: $\quad 1887.5988$

PPN: 224947834

Arie aus dem Oratorium „Salomon“ [Preis sei dem Herrn von ihm kommt meine Weisheit] In: Cantiones XVII, XVIII saeculorum praestantissimas altae voci accommodatas = Sammlung der besten Meisterwerke des 17t und 18t Jahrhunderts für die Alt-Stimme nach den Original Partituren mit Begleitung des Piano-Forte. - Berlin ; Posen : Bote \& Bock, 4 (ca. 1844), S. 49-52

Signatur: $\quad 4$ MUS V, 450:4

Notizen: $\quad 1887.5988$

PPN: 224947834

Arie aus dem Oratorium „Samson“ [o hör mein Flehn]

In: Cantiones XVII, XVIII saeculorum praestantissimas altae voci accommodatas = Sammlung der besten Meisterwerke des 17t und 18t Jahrhunderts für die Alt-Stimme nach den Original Partituren mit Begleitung des Piano-Forte. - Berlin ; Posen : Bote \& Bock, 4 (са. 1844), S. 53-55

Signatur: $\quad 4$ MUS V, 450:4

Notizen: $\quad 1887.5988$

PPN: 135282004

Their bodies are buried in peace : ecclesiasticus xliv. 15

In: The church anthem book : one hundred anthems. - London : Oxford Univ. Press, (1934), S. 454-462

Signatur: $\quad 8$ MUS V, 2750

Notizen: $\quad$ 1934.1371 - EX BIBLIOTHECA ACAD. GEORGIAE AUG. -

Überwiesen von der Notgemeinschaft der deutschen Wissenschaft Berlin 


\section{PPN: 13536471X}

Halleluja! : (a. d. Oratorium: „Der Messias“)

In: Soli Deo Gloria! : eine Auswahl religiöser Gesänge für gemischten Chor ; zum Gebrauch für höhere Schulen und Kirchenchöre. - Hannover-Linden : Verl.-Anst. Manz, (1890), S. 36-47

Signatur: $\quad 8$ MUS V, 2450

Notizen: $\quad$ EX BIBLIOTHECA REGIA ACADEM. GEORGIAE AUG.

\section{PPN: 13536471X}

Des Herrn Einzug : (Chor a. d. Oratorium: „Makkabäus“)

In: Soli Deo Gloria! : eine Auswahl religiöser Gesänge für gemischten Chor ; zum Gebrauch für höhere Schulen und Kirchenchöre. - Hannover-Linden : Verl.-Anst. Manz, (1890), S. 51-53

Signatur: $\quad 8$ MUS V, 2450

Notizen: $\quad$ EX BIBLIOTHECA REGIA ACADEM. GEORGIAE AUG.

PPN: 135324130

Hymnus auf den Erlöser : aus dem Oratorium: Der Messias

In: 40 vierstimmige Gesänge für gemischten Chor. - Essen : Bädeker, (1877), 3. H., S. $35-36$

Signatur: $\quad 8$ MUS V, 3610

Notizen: $\quad$ EX BIBLIOTHECA REgIA ACADEM. GEORGIAE AUG.

\section{PPN: 13536471X}

Würdig ist das Lamm : (Chor a. d. Oratorium: „Der Messias“)

In: Soli Deo Gloria! : eine Auswahl religiöser Gesänge für gemischten Chor ; zum Gebrauch für höhere Schulen und Kirchenchöre. - Hannover-Linden : Verl.-Anst. Manz, (1890), S. 96-98

Signatur: $\quad 8$ MUS V, 2450

Notizen: $\quad$ EX BIBLIOTHECA REGIA ACADEM. GEORGIAE AUG. 
PPN: 224947834

Lied [Wenn Christus der Herr]

In: Cantiones XVII, XVIII saeculorum praestantissimas altae voci accommodatas = Sammlung der besten Meisterwerke des 17t und 18t Jahrhunderts für die Alt-Stimme nach den Original Partituren mit Begleitung des Piano-Forte. - Berlin ; Posen : Bote \& Bock, 4 (са. 1844), S. 94-95

Signatur: $\quad 4$ MUS V, 450:4

Notizen: $\quad 1887.5988$

PPN: 224950207

Lied [Wenn Christus der Herr]

In: Sammlung religiöser Gesänge älterer und neuester Zeit zum bestimmten Gebrauch für den Königl. Berliner Domchor. - Berlin ; Posen : Bote \& Bock, 12 (1846), S. 64

Signatur: $\quad 4$ MUS V, 450:12

Notizen: $\quad 1887.5988$

PPN: 135280745

Ouvertüre des „Messias“ (1724)

In: Musikgeschichte in Beispielen : eine Auswahl von 150 Tonsätzen ; geistliche und weltliche Gesänge und Instrumentalkompositionen ; zur Veranschaulichung der Entwicklung der Musik im 13.-18. Jahrhundert. - Leipzig : Seemann, (1912),

S. 294-296

Signatur: $\quad 4$ MUS V, 710

Notizen: $\quad 1920.2260$ - EX BIBLIOTHECA REGIA ACADEM. GEORGIAE AUG.

PPN: 224948164

Tu Rex Gloriae

In: Sammlung religiöser Gesänge älterer und neuester Zeit zum bestimmten Gebrauch für den Königl. Berliner Domchor. - Berlin ; Posen : Bote \& Bock, 6 (1841), S. 78-79

Signatur: $\quad 4$ MUS V, 450:6

Notizen: $\quad 1887.5988$ 
PPN: 135378737

Erster Satz einer Sonatina in d-moll

In: Deutsche Klaviermusik aus dem Beginne des 18. Jahrhunderts : Suiten- und Sonatensätze von Gottfried Kirchhoff und anderen Meistern. - Hannover : Nagel, (1927), S. 15

Signatur: $\quad 4$ MUS V, 760:3

Notizen: $\quad 1927.10361$

PPN: 135378737

Erster Satz einer Suite in g-moll

In: Deutsche Klaviermusik aus dem Beginne des 18. Jahrhunderts : Suiten- und

Sonatensätze von Gottfried Kirchhoff und anderen Meistern. - Hannover : Nagel, 3 (1927), S. 16-17

Signatur: $\quad 4$ MUS V, 760:3

Notizen: $\quad 1927.10361$

PPN: 135324130

Tod und Auferstehung : 1. Cor. 15, 21 u. 22

In: 40 vierstimmige Gesänge für gemischten Chor. - Essen : Bädeker, (1877), 3. H., S. $33-35$

Signatur: $\quad 8$ MUS V, 3610

Notizen: $\quad$ EX BIBLIOTHECA REGIA ACADEM. GEORGIAE AUG. 


\section{Text b ü c h e r}

\section{PPN: 135917492}

Lalin, Lars:

Acis och Galatea : heroisk ballet, i tre acter, upförd på den Kongl. Svenska Theatren första gången, Den 10 Maji, 1773. / Poesien af Lars Lalin. Musiken dels ny, dels af Handels Acis och Galatéa, samt andra berömda Mästares arbeten utsökt och i ordning satt, äfven af Lars Lalin. - 1778. - S. [69] - 104

Enth. Werk im Bd. 1 (PPN 136628818): Kongl. Svenska Theatren ; Bd. 1. -

Stockholm : Trykt i Kongl. Tryckeriet, 1778. - 266 S. ; kl.-8

Signatur: $\quad 8$ P DRAM IV, 300:1

Notizen: $\quad$ verknüpft zum MBW PPN 13662880X

\section{PPN: 176678794}

Händel, Georg Friedrich:

Acis und Galatea : Pastoral von Georg Friedrich Händel ; Textbuch / Dichtung von John Gay. Aus dem Engl. neu übertr. und hrsg. von Konrad Ameln. - Wolfenbüttel : Möseler, 1951. - 12 S. ; kl.-8

*geh. : -.40

Signatur: $\quad 8$ MUS 418

Notizen: $\quad 1951.3649$ - NIEDERSÄCHS. STAATS. U. UNIV.-BIBLIOTHEK GÖTTINGEN

Vorh. in: MuSe

\section{PPN: 013428152}

Alessandro (1726) : Oper in drei Akten / Georg Friedrich Händel. Text von Paolo Antonio Rolli. Konzertante Aufführ. in der orig. ital. Version. [Red.: Alte Musik / Klaus L. Neumann]. - Repr. der Ausg. Hamburg, Stromer, 1726. - Köln : Westdt. Rundfunk (WDR), 1984. 71 S. ; $8^{\circ}$

Sacht. d. Hamburgischen Ausg. d. Librettos: Der Hochmüthige Alexander ... Vorgestellet Im Jahr 1726. - Aufführ.: 05.02.1984, Frankfurt Alte Oper, 06.02.1984, Düsseldorf, Tonhalle. Sendung 12.02.1984, WDR 3. - Libretto in ital. und dt. Sprache. - In Fraktur

\section{Signatur: $\quad 84$ A 26137}

Notizen: $\quad$ NIEDERS. STAATS. U. UNIV.-BIBLIOTHEK GÖTTINGEN

Vorh. in: StAr 


\title{
PPN: 33142794X
}

Das Alexander-Fest oder Die Macht der Musik : Ode zu Ehren der heiligen Cäcilia von John Dryden ; Textbuch / Georg Friedrich Händel. Aus dem Engl. übertr. von Konrad Ameln. - Kassel ; Basel : Bärenreiter, 1955. - 8 S. ; kl.-8

*geh. : - .30

Signatur: $\quad 59$ A 5912

Notizen: $\quad 1959.5912$ - NIEDERSÄCHS. STAATS. U. UNIV.-BIBLIOTHEK GÖTTINGEN

\section{PPN: 135217830}

Ariadne : Oper in drei Akten ; Textbuch / G. F. Händel. Text von Francis Colman. Übers. von Emilie Dahnk-Baroffio. Mit einer Einf. von Emilie Dahnk-Baroffio. Kassel : Bärenreiter, 1940. - 31 S. ; $8^{\circ}$

(Veröffentlichungen der Göttinger Händelgesellschaft)

In Fraktur

Signatur: $\quad 8$ MUS VII, 418

Notizen: $\quad 1941.1839$ - Universitätsbibliothek Göttingen Geschenk der Händel-Gesellschaft Göttingen

Vorh. in: $\quad$ GHG (6 Ex.), StAr

PPN: 331428423

Belsazar : Oratorium ; Textbuch / Georg Friedrich Händel. Neue Fassung in zwei Akten für Bühne und Konzert von Wilhelm Brückner-Rüggeberg.- Kassel [u.a.] : Bärenreiter, 1958. - 24 S. ; kl.-8

Einheitssacht.: Belshazzar <dt.>

*geh. : 1.-

Signatur: $\quad 59$ A 5913

Notizen: $\quad 1959.5913$ - NIEDERSÄCHS. STAATS. U. UNIV.-BIBLIOTHEK GÖTTINGEN

Vorh. in: $\quad$ GHG

\section{PPN: 271009837}

Deidamia : Oper in drei Akten ; Textbuch / Georg Friedrich Händel. Text von Paolo Rolli. Ins Dt. übers. und eingerichtet von Rudolf Steglich. - Kassel [u.a.] : Bärenreiter, [1951]. - 32 S. ; kl.-8

\author{
Signatur: $\quad 59$ A 5914 \\ Notizen: $\quad 1959.5914$ - NIEDERSÄCHS. STAATS. U. UNIV.-BIBLIOTHEK GÖTTINGEN
}




\section{PPN: 056091206}

Esther : Oratorium ; 1. Fassung (um 1720) ; Textbuch / von Georg Friedrich Händel. Text wahrscheinlich von John Arbuthnot unter Mithilfe von Alexander Pope auf der Grundlage von Racines „Esther“, Übers. (an einigen Stellen rev.) von Georg Gottfried Gervinus. [Göttingen] : Göttinger Händel-Ges., 1963. - 12 S. ; kl.-8

*geh. : DM 1.00

Signatur: $\quad$ K 2001 A 735

Notizen: [Neuentdeckung]

Vorh. in: $\quad$ GHG (83 Ex.)

\section{PPN: 135893755}

Der Beglückte Florindo : In einem Singe-Spiel Auf dem Hamburgischen Theatro vorgestellet / [Komp.: Georg Friedrich Händel. Textverf.: Hinrich Hintsch]. [Hamburg], 1708. - [25] Bl. ; $8^{\circ}$

([Hamburgische Opern ; 5,126])

Bibliogr. Nachweis: Hamburger Gänsemarkt-Oper, 39. - Komp. und Textverf. ermittelt. - Vorlageform d. Erscheinungsvermerks: Gedruckt im Jahr 1708. Signaturformel: x2, A4-F4. - In Fraktur. - Text d. Arien teilw. ital. und dt. Inh.: Persohnen, Vorrede, 3 Handlungen

Signatur: $\quad 8$ P DRAM III, 1292

Notizen: $\quad$ EX BIBLIOTHECA REGIA ACADEM. GEORGIAE AUG. ; Ex Bibliotheca Hoffmanni Fallerslebens

PPN: 270934286

Judas Maccabäus : Oratorium für Solo, Chor und Orchester / von G. F. Händel. Text von Thomas Morell. Uebers. von G. G. Gervinus. - Leipzig : Rieter-Biedermann, 1904. - 16 S. ; kl.-8

Einheitssacht.: Judas Maccabaeus < dt.>. - Aus dem Engl. übers.

\section{Signatur: $\quad$ ALT 2001 A 1554}

Notizen: [Neuentdeckung]

Vorh. in: $\quad$ GHG (40 Ex.) 


\section{PPN: 13521775X}

Julius Cäsar : [Oper in drei Akten] / G. Fr. Händel. [Textbuch von Nicola Haym. Für die dt. Bühne übers. und auf Grund der Partitur der Dt. Händelges. eingerichtet von Oskar Hagen]. Göttingen : Turm-Verl. Lange, 1922. - 30 S. ; kl.-8

Einheitssacht.: Giulio Cesare in Egitto <dt.>. - Die eckig eingeklammerten Angaben im Titel- und Verf.-Teil sind der ersten Texts. entnommen. - Als Ms. gedr. - In Fraktur

Signatur: $\quad 8$ MUS VII, 407

Notizen: $\quad 1922.864$ - EX BIBLIOTHECA REGIA ACADEM. GEORGIAE AUG.

Vorh. in: $\quad$ StAr

PPN: 135217741

Otto und Theophano : [Oper in drei Aufzügen von Nicola Haym] / [Musik von] von G. Fr. Händel. [Auf Grund der Partitur der Dt. Händelges. übers. und f. die moderne Bühne eingerichtet von Oskar Hagen]. - Göttingen : Komm.-Verl. Kuhnhardt, 1921. - 28 S. ; kl.-8 Die eckig eingeklammerten Angaben im Titel- und Verf.-Teil sind der ersten Texts. entnommen. - Als Ms. gedr. - In Fraktur

Signatur: $\quad 8$ MUS VII, 406

Notizen: $\quad 1920.6727$ - EX BIBLIOTHECA REGIA ACADEM. GEORGIAE AUG.

Vorh. in: $\quad$ StAr

PPN: 135217814

Ptolomäus : Oper in drei Akten / von G. F. Händel. Text von Nicola Haym. Übers. von Emilie Dahnk-Baroffio. - Hannover : Verl. für Musikalische Kultur und Wiss., 1938. - 31 S. ; kl.-8 (Veröffentlichungen der Göttinger Händel-Gesellschaft)

Einheitssacht.: Tolomeo $<\mathrm{dt}$. $>$

Signatur: $\quad 8$ MUS VII, 415

Notizen: $\quad 1938.1823$ - Universitätsbibliothek Göttingen

Vorh. in: $\quad$ GHG (2 Ex.), StAr 
PPN: 135217725

Rodelinde : [Musikdrama in drei Aufzügen von Nicola Haym] / [Musik] von G. Fr. Händel. [Auf Grund der Partitur der Dt. Händelges. übers. und f. die moderne Bühne eingerichtet von Oskar Hagen]. - Göttingen : Komm.-Verl. Kuhnhardt, 1920. - 32 S. ; kl.- $8^{\circ}+1$ Beil. (Mitteilungsbl.)

Einheitssacht.: Rodelinda, Regina de' Langobardi <dt.>. - Die eckig eingeklammerten Angaben im Titel- und Verf.-Teil sind der ersten Texts. entnommen. - Als Ms. gedr. In Fraktur

Signatur: $\quad 8$ MUS VII, 404

Notizen: $\quad 1920.6726$ - EX BIBLIOTHECA REGIA ACADEM. GEORGIAE AUG.

Vorh. in: $\quad$ StAr

\section{PPN: 176679030}

Rodelinde : Oper in drei Akten ; Textbuch / G. F. Händel. Text von Nicola Haym. Übers. von Emilie Dahnk-Baroffio. - Kassel ; Basel : Bärenreiter, 1950. - 39 S. ; 8 ○

(Veröffentlichungen der Göttinger Händelgesellschaft)

Einheitssacht.: Rodelinda, Regina de’ Langobardi <dt.>. - Aus dem Engl. übers. - Mit einer Einf. von Rudolf Gerber

*geh. : 1.80

Signatur: $\quad 8$ MUS 277

Notizen: $\quad 1950.4632$ - EX BIBLIOTHECA ACAD. GEORGIAE AUG.

Vorh. in: $\quad$ GHG (15 Ex.)

PPN: 135217806

Scipio : Oper in 3 Akten / von G. F. Händel. Text von Paolo Rolli. Übers. von Emilie Dahnk. - Wolfenbüttel : Verl. f. musikalische Kultur und Wiss., 1937. - 32 S. ; kl.-8 (Veröffentlichungen der Göttinger Händelgesellschaft)

Einheitssacht.: Publio Cornelio Scipione <dt.>

Signatur: $\quad 8$ MUS VII, 413

Notizen: $\quad 1937.2316$ - EX BIBLIOTHECA ACAD. GEORGIAE AUG.

Vorh. in: $\quad$ GHG (5 Ex.), StAr 
PPN: 135217776

Congreve, William:

Semele : an opera ; as performed at the New Theatre, Cambridge 10-14 February 1925 / by William Congreve. With the alterations adopted by Handel. - Cambridge [u.a.] : Univ.-Press, 1925. - 47 S. ; kl.-8

Signatur: $\quad 8$ MUS VII, 409

Notizen: $\quad 1925.5$ - EX BIBLIOTHECA REGIA ACADEM. GEORGIAE AUG.

PPN: 176679065

Theseus : Oper in fünf Akten ; Textbuch / G. F. Händel. Text von Nicola Haym. Übers. von Emilie Dahnk-Baroffio. - Kassel : Bärenreiter, 1947. - 47 S. ; $8^{\circ}$

(Veröffentlichungen der Göttinger Händelgesellschaft)

Mit einer Einf. von Rudolf Gerber

(2.-)

Signatur: $\quad 8$ MUS 29

Notizen: $\quad 1947.2089$ - EX BIBLIOTHECA ACAD. GEORGIAE AUG.

Vorh. in: $\quad$ GHG (5 Ex.), StAr

PPN: 135217768

Xerxes oder der verliebte König (Serse) : heitere Oper in 3 Akten / Musik von G. Fr. Händel (1738). Musikalische Einrichtung auf Grund der Partitur der Dt. Händelges., freie Neugestaltung des Textbuches und der Secco-Rezitative von Oskar Hagen. Göttingen : Turmverl. Lange, [1924]. - 47 S. ; kl.-quer-8º

Signatur: $\quad 8$ MUS VII, 408

Notizen: $\quad 24.19813$ - EX BIBLIOTHECA REgIA ACADEM. GEORGIAE AUG.

Vorh. in: $\quad$ GHG, StAr 


\section{A b h andlungen über Händels Werke}

\section{PPN: 135314542}

Chorley, Henry Fothergill:

The Dettingen Te Deum. - London : Augener, 1859. - 32 S. : Notenbeisp. ; $8^{\circ}$

(Handel studies ; No. 2/3)

In der Vorlage als No. 2 bezeichnet. - Die Vorlage enth. insges. 2 Werke

\section{[Enthaltenes Werk, PPN 356043045]}

Israel in Egypt. - 1859. - S. 13 - 32.

In der Vorlage als No. 3 bezeichnet

Signatur: $\quad 8$ MUS III, 1053/g:2/3

Notizen: $\quad 1951.2897$ - NIDERSÄCHS. STAATS. U. UNIV.-BIBLIOTHEK GÖTTINGEN verknüpft zum MBW PPN 135314526

\section{PPN: 058830618}

Clausen, Hans Dieter:

Händels Direktionspartituren ("Handexemplare") / von Hans Dieter Clausen. - Hamburg : Verl. der Musikalienh. Wagner, 1972. - VIII, 282 S. : Ill., Notenbeisp. ; 8 + 16 Beil. (Hamburger Beiträge zur Musikwissenschaft ; 7)

Zugl.: Hamburg, Univ., Diss., 1972

ISBN 3-921029-09-0

Signatur: $\quad$ ZA 30787:7

Notizen: $\quad$ NIDERSÄCHS. STAATS. U. UNIV.-BIBLIOTHEK GÖTTINGEN verknüpft zur Serie PPN 130108928

PPN: 150141637

Dietz, Hanns-Bertold:

Die Chorfuge bei G. F. Händel : ein Beitrag zur Kompositionstechnik des Barock / Hanns-Bertold Dietz. - Tutzing : Schneider, 1961. - 150 S. : zahlr. Notenbeisp. ; $8^{\circ}$ Teilw. zugl.: Innsbruck, Univ., Diss., 1956

Signatur: $\quad 62$ A 3618

Notizen: $\quad 1962.3618$ - NIDERSÄCHS. STAATS. U. UNIV.-BIBLIOTHEK GÖTTINGEN 
PPN: 355604957

Ehrlinger, Friedrich:

Georg Friedrich Händels Orgelkonzerte / von Friedrich Ehrlinger. - 1940. - XI, 79 S. : Tab., Notenbeisp. ; $8^{\circ}$

Erlangen, Univ., Diss., 1940. - Zugl.: Literarhistorisch-musikwissenschaftliche Abhandlungen ; 8

HS-Nr.: U 41.1616

Signatur: $\quad 8 \mathrm{U} 41.1616$

PPN: 238759199

Etscheit, Ulrich:

Händels »Rodelinda« : Libretto - Komposition - Rezeption / von Ulrich Etscheit. - Kassel

[u.a.] : Bärenreiter, 1998. - 350 S. : Notenbeisp. ; $8^{\circ}$

(Bärenreiter-Hochschulschriften)

Literaturverz. S. 335 - 350. - Zugl.: Heidelberg, Univ., Diss., 1997

ISBN 3-7618-1404-6*kart. : DM 78.00

Signatur: $\quad 98$ A 9123

Notizen: $\quad$ NIDERSÄCHS. STAATS. U. UNIV.-BIBLIOTHEK GÖTTINGEN

PPN: 335885993

Goerges, Horst:

Das Klangsymbol des Todes im dramatischen Werk Mozarts : Studien über ein

klangsymbolisches Problem und seine musikalische Gestaltung durch Bach, Händel,

Gluck und Mozart / von Horst Goerges. - 1937. - IV, 228 S., [1] Bl. : Notenbeisp. ; $8^{\circ}$

Kiel, Univ., Diss., 1937

HS-Nr.: U 37.5923

Signatur: $\quad 8$ U 37.5923 
PPN: 135217733

Hagen, Oskar:

[Rodelinde] Händels Musikdrama „Rodelinde“ und seine Bearbeitung / von Oskar Hagen. - Göttingen : Kuhnhardt, [1920]. - [4] Bl. ; kl.-8

In Fraktur

Signatur: $\quad 8$ MUS VII, 405

Notizen: $\quad 1920.6726$ - EX BIBLIOTHECA REGIA ACADEM. GEORGIAE AUG.

Vorh. in: $\quad$ MuSe, StAr

PPN: 224853538

Holschneider, Andreas:

Kritische Berichte : Band 1: Acis und Galatea (1995) ; Band 3: Das Alexander-Fest (1963) ; Band 4: Ode auf St. Caecilia (1970) / (Andreas Holschneider). - Kassel [u.a.] : Bärenreiter, 1995. - a/43, b/42, c/25 S. : Notenbeisp. ; $8^{\circ}$

(Neue Ausgabe sämtlicher Werke : Serie 10, Supplement ; Werkgruppe 28: Bearbeitungen, Ergänzungen und Übertragungen fremder Werke ; Abt. 1: Bearbeitungen von Werken Georg Friedrich Händels ; Bd. 1-4: Kritischer Bericht)

Erscheinungsbeginn: 1963

Signatur: $\quad$ FB 574:10,28,1,1,KRIT.BERICHT

Notizen: $\quad$ NIDERSÄCHS. STAATS. U. UNIV.-BIBLIOTHEK GÖTTINGEN verknüpft zum MBW PPN 126278539

PPN: 246181036

Kahle, Felix:

Georg Friedrich Händels Cembalosuiten / von Felix Kahle. - 1928. - 217 S., [35] Bl. : zahlr. Notenbeisp. ; $8^{\circ}$

Berlin, Univ., Diss., 1928

HS-Nr.: U 29.485

Signatur: $\quad 8$ DISS PHIL BERLIN 1929,Hoh-Kiq,83

Anmerkung: Diss. 71 - 87 als Konvolut zsgeb. 


\section{PPN: 014291339}

Kubik, Reinhold:

Händels Rinaldo : Geschichte, Werk, Wirkung / Reinhold Kubik. - NeuhausenStuttgart : Hänssler, 1982. - 264 S. : Ill., graph. Darst., Notenbeisp. ; 8 ○

Zugl.: Erlangen, Univ., Diss., 1982

ISBN 3-7751-0594-8

Signatur: $\quad$ DISS 83 A 8037

Notizen: $\quad$ NIEDERSÄCHS. STAATS. U. UNIV.-BIBLIOTHEK GÖTTINGEN

PPN: 045585490

Pauly, Paul Gerhard:

G. Fr. Händels Klavierfugen : ein Beitrag zur Geschichte der Fuge in der ersten Hälfte des 18. Jahrhunderts / von Paul Gerhard Pauly. - 1961. - 169 S. : Notenbeisp. ; $8^{\circ}$

Saarbrücken, Univ., Diss. 1961

HS-Nr.: U 61.8458

Signatur: $\quad 8 \mathrm{U} 61.8458$

Notizen: $\quad$ NIEDERSÄCHS. STAATS. U. UNIV.-BIBLIOTHEK GÖTTINGEN

PPN: 305828428

Roters, Katja:

Bearbeitungen von Händel-Oratorien im Dritten Reich / Katja Roters. - Halle an der Saale : Händel-Haus, 1999. - 101, [2 ungez.] S. ; $8^{\circ}$

(Schriften des Händel-Hauses in Halle ; 16)

Literaturverz. S. 98 - 101

ISBN 3-910019-15-3*Pp. : DM 7.00

Signatur: $\quad 2000$ A 25184

Notizen: $\quad$ NIEDERSÄCHS. STAATS. U. UNIV.-BIBLIOTHEK GÖTTINGEN verknüpft zur Serie PPN 036115452 


\section{PPN: 014655780}

Sauerzapf, Dörte:

Untersuchungen zur Dramaturgie und Wirkungsweise der Opern Georg Friedrich Händels zwischen 1733 und 1735, dargestellt an "Ariodante" und "Alcina" / von Dörte Sauerzapf. 1991. - 251 S., 8 S. : Ill. ; $4^{\circ}$

Nicht f. den Austausch. - Halle-Wittenberg, Univ., Diss., 1990

Signatur: $\quad$ DISS 92 B 5241

Notizen: $\quad$ NIDERSÄCHS. STAATS. U. UNIV.-BIBLIOTHEK GÖTTINGEN

\section{PPN: 025688278}

Scheibler, Albert:

Georg Friedrich Händel : Philosophie und Beredsamkeit seiner Musik / Albert Scheibler ; Julia Evdokimova. - Graz : Akad. Dr.- und Verl.-Anst., 1991. - 335 S. : Frontisp., Ill., graph. Darst., Notenbeisp. ; $8^{\circ}$

Literaturverz. S. 328 - 332

ISBN 3-201-01532-6

\section{Signatur: $\quad 92$ A 11536}

Notizen: $\quad$ NIEDERSÄCHS. STAATS. U. UNIV.-BIBLIOTHEK GÖTTINGEN

PPN: 24117287X

Schröder, Alfred:

Die englischen Texte G. F. Händels / von Alfred Schröder. - 1924. - 122 Bl. ; $4^{\circ}$

Göttingen, Univ., Diss., 1924

[Auch Sekundärausg.]

HS-Nr.: U 25.3664

Signatur: $\quad 4$ DISS PHIL GÖTTINGEN 1924,Schröder,Alfred,1 (Maschinenschriftl.) 4 DISS PHIL GÖTTINGEN 1924,Schröder,Alfred,2 (Xerokopie)

Notizen: $\quad$ EX BIBLIOTHECA REGIA ACADEM. GEORGIAE AUG. 
PPN: 183314298

Smith, Ruth:

Handel's oratorios and eighteenth-century thought / Ruth Smith. - Cambridge

[u.a.] : Cambridge Univ. Press, 1995. - XIV, 484 S. ; $8^{\circ}$

Literaturverz. (S. 438 - 466) und Index (S. 467 - 484)

ISBN 0-521-40265-4*hbk.

Signatur: $\quad 97$ A 4789

Notizen: $\quad$ NIEDERSÄCHS. STAATS. U. UNIV.-BIBLIOTHEK GÖTTINGEN

PPN: 310932181

Völsing, Erwin:

G. F. Händels englische Kirchenmusik / von Erwin Völsing. - 1940. - VII, 69 S. : Notenbeisp. ; $8^{\circ}$

Umschlags. ist die Haupttitels. - Gießen, Univ., Diss., 1940

HS-Nr.: U 40.2781

Signatur: $\quad 8$ U 40.2781

Notizen: $\quad$ Universitätsbibliothek Göttingen

PPN: 04629564X

Wieber, Georg-Friedrich:

Die Chorfuge in Händels Werken / von Georg-Friedrich Wieber. - 1958. - 235 S.,

[1] Bl. : graph. Darst., Notenbeisp. ; $8^{\circ}$

Frankfurt (Main), Univ., Diss., 1958

HS-Nr.: U 58.2095

Signatur: $\quad 8$ U 58.2095

Notizen: $\quad$ NIEDERSÄCHS. STAATS. U. UNIV.-BIBLIOTHEK GÖTTINGEN 
PPN: 022468137

Wolff, Hellmuth Christian:

Die Händel-Oper auf der modernen Bühne : ein Beitrag zur Geschichte und Praxis der OpernBearbeitung und -Inszenierung in der Zeit von 1920 bis 1956 / Hellmuth Christian Wolff. [1. Aufl.]. - Leipzig : Dt. Verl. f. Musik, 1957. - 54 S., [50] Bl. : zahlr. Ill. ; $4^{\circ}$

Signatur: $\quad 57$ B 4311

Notizen: $\quad 1957.4311$ - NIEDERSÄCHS. STAATS. U. UNIV.-BIBLIOTHEK GÖTTINGEN

Vorh. in: $\quad$ MuSe 


\section{PPN: 337780927}

Händel, Georg Friedrich:

Arianna in Creta / Georg Friedrich Händel. - Göttingen : Göttinger Händel-Ges. ; Norddt. Rundfunk, 1999. - 3 CD in Box mit Schuber (64, 79 und 56 Min.). : ADD, stereo. ; $12 \mathrm{~cm}+$ Booklet (106 S.)

Göttinger Händel-Festspiele ; 79 (Göttingen) : 1999.05.27-06.01. - Ital. gesungen. - Text des Booklets dt., engl. und ital. - Interpr.: Sophie Daneman [Arianna]. Christine Brandes [Alceste]. Wilke te Brummelstroete [Teseo]. Cécile van de Sant [Tauride]. Jennifer Lane [Carilda]. Philip Cutlip [Minos]. Tilmann Prautzsch [Il Sono]. New York Baroque Dance Co. Philharmonia Baroque Orchestra <San Francisco>. Nicholas McGegan [Ltg.]

Signatur: $\quad$ DISKO G 2001-55:1-3

Anmerkung: Rundfunkmitschnitt: NDR, 28.05./01.06.1999 ${ }^{13}$

Notizen: [Geschenk von der Göttinger Händel-Gesellschaft, 2001]

Vorh. in: GHG

PPN: 377365378

Jephtha : Oratorium in drei Akten, HWV 70 (1752) / Georg Friedrich Händel. Libretto von Thomas Morell. - Göttingen : Göttinger Händel-Ges., 2003. - 2 CD in Box mit Schuber (74, 79 Min.). : ADD, stereo. ; $12 \mathrm{~cm}+$ Booklet [56 S.] Internationale Händel-Festspiele ; 83 (Göttingen) : 2003.05.27-06.03. - Engl. gesungen. Text d. Booklets dt. und engl. - Interpr.: John Mark Ainsley [Jephtha]. Dominique Labelle [Iphis]. Wilke te Brummelstroete [Storgé]. Franz Vitzthum [Hamor]. William Berger [Zebul]. Netta Or [Engel]. The English Concert < London>. Winchester Cathedral Choir. Nicholas McGegan [Ltg.]

Signatur: $\quad$ DISKO G 2004-1

Anmerkung: Rundfunkmitschnitt: NDR, 01.06.2003

Notizen: [Geschenk von der Göttinger Händel-Gesellschaft, 2003]

Vorh. in: GHG

\footnotetext{
${ }^{13}$ Hiervon wie auch von den CD Partenope und Rodelinda konnte das Aufnahmedatum nicht mehr mitgeteilt werden. Alle drei Stücke wurden in den jeweiligen Festspieljahren mehrmals aufgeführt, deshalb sind für die Katalogisierung lediglich der erste und der letzte Aufführungstag genannt.
} 


\section{PPN: 387259570}

Julius Caesar / Georg Friedrich Händel. - Luxembourg : Compact music, [ca. 1990]. - 3 CD in Box (219 Min.). : AAD, stereo, digitally remastered. ; $12 \mathrm{~cm}+$ Booklet (52 S.) Einheitssacht.: Giulio Cesare in Egitto, HWV 17. - Dt. gesungen. - Text d. Booklets dt. und engl. - Interpr.: Walter Berry [Julius Caesar]. Hans Bruno Ernst [Curio]. Christa Ludwig [Cornelia]. Fritz Wunderlich [Sextus]. Lucia Popp [Cleopatra]. Karl Christian Kohn [Ptolemäus]. Hans Günther Nöcker [Achillas]. Max Pröbstl [Nirenus]. Chor des Bayerischen Rundfunks $<$ München $>$. Münchner Philharmoniker. Ferdinand Leitner [Ltg.] Best.-Nr.: 27035/37 (Verona)

Signatur: $\quad$ DISKO G 2004-30

Anmerkung: Rundfunkmitschnitt: 01.07. - 05.07.1965

\section{PPN: 338019782}

Partenope : dramma per musica in drei Akten, HWV 27 (1730) / Georg Friedrich Händel. Text nach Silvio Stampiglia. - Göttingen : Göttinger Händel-Ges. ; Norddt. Rundfunk, 2001. - 3 CD in Box mit Schuber (79, 58 und 55 Min.). : ADD, stereo. ; $12 \mathrm{~cm}+$ Booklet (124 S.) Internationale Händel-Festspiele ; 81 (Göttingen) : 2001.05.30-06.05. - Ital. gesungen. Text d. Booklets dt., engl. und ital. - Interpr.: Meredith Hall [Partenope]. Annette Markert [Rosmira]. Kai Wessel [Arsace]. Christopher Josey [Armindo]. John McVeigh [Emilio]. William Berger [Ormonte]. Philharmonia Baroque Orchestra $<$ San Francisco $>$. Nicholas McGegan [Ltg.]

\section{Signatur: $\quad$ DISKO G 2001-56:1-3}

Anmerkung: Rundfunkmitschnitt: NDR, 31.05./05.06.2001

Notizen: [Geschenk von der Göttinger Händel-Gesellschaft, 2001]

Vorh. in: GHG 


\section{PPN: 475549449}

Rinaldo : dramma per musica drei Akten, HWV $7^{\mathrm{a}}$ (1711) / Georg Friedrich Händel. Libretto von Giacomo Rossi nach einem Szenarium von Aaron Hill. - Göttingen : Göttinger HändelGes. ; Norddt. Rundfunk, 2004. - 3 CD in Box mit Schuber (75, 51,41 Min.). : ADD, stereo ; $12 \mathrm{~cm}+$ Booklet [109 S.]

Internationale Händel-Festspiele ; 84 (Göttingen) : 2004.05.23-06.02. - Ital. gesungen. Text d. Booklets dt., engl. und ital. - Interpr.: Diana Moore [Rinaldo]. Dominique Labelle [Armida]. Cyndia Sieden [Almirena]. Cécile van de Sant [Goffredo]. Christophe Dumaux [Eustazio]. Andrew Foster-Williams [Argante]. Jean-Sébastien Stengel [Mago, Herald]. Irmela Brünger, Theresa Nelles [Sirenen]. Concerto Köln. Nicholas McGegan [Ltg.]

\section{Signatur: $\quad$ DISKO G 2004-178}

Anmerkung: Rundfunkmitschnitt: NDR, 27.05./01.06.2004

Notizen: [Geschenk von der Göttinger Händel-Gesellschaft, 2004]

Vorh. in: $\quad$ GHG

\section{PPN: 338017755}

Rodelinda : dramma per musica in drei Akten, HWV 19 (1725) / Georg Friedrich Händel. Text von Nicola Francesco Haym nach Antonio Salvi. - Göttingen : Göttinger HändelGes. ; Norddt. Rundfunk, 2000. - 3 CD in Box mit Schuber (59, 52 und 54 Min.). : ADD, stereo. ; $12 \mathrm{~cm}+$ Booklet [112 S.]

Internationale Händel-Festspiele ; 80 (Göttingen) : 2000.06.07-13. - Ital. gesungen. Text d. Booklets dt., engl. und ital. - Interpr.: Dominique Labelle [Rodelinda]. Robin Blaze [Bertarido]. Iain Paton [Grimoaldo]. Ewa Wolak [Eduige]. Cécile van de Sant [Unulfo]. Andrew Foster [Garibaldo]. Arne Kolb, Fabian Lindhorst [Flavio]. Concerto $<$ Köln>. Nicholas McGegan [Ltg.]

Signatur: $\quad$ DISKO G 2001-57:1-3

Anmerkung: Rundfunkmitschnitt: NDR, 08./13.06.2000

Notizen: [Geschenk von der Göttinger Händel-Gesellschaft, 2001]

Vorh. in: GHG 


\section{PPN: 381904830}

Festspiel-Edition 2000 : Arien und Duette von Georg Friedrich Händel und Henry Purcell ; Konzert in der Aula der Universität Göttingen vom 10. Juni 2000. - Göttingen : Göttinger Händel-Ges. ; Norddt. Rundfunk, 2000. - 1 CD in Box (79 Min.). : ADD, stereo. ; 12 cm + Booklet (31 S.)

Kongr.: Internationale Händel-Festspiele ; 80 (Göttingen) : 2001.06.07-13

Ital. und engl. gesungen. - Text d. Booklets dt., engl. und ital. - Interpr.: Dominique Labelle [Sopran], Robin Blaze [Altus], Phoebe Carrai [Violoncello], Nicholas McGegan [Cembalo]. Nicholas McGegan [Ltg.]

\section{Signatur: $\quad$ DISKO G 2004-27}

Anmerkung: Rundfunkmitschnitt: NDR, 10.06.2001

Notizen: [Geschenk von der Göttinger Händel-Gesellschaft, 2004]

Vorh. in: GHG

\section{PPN: 381903931}

Festspiel-Edition 2001 : Gloria von Georg Friedrich Händel ; Ausschnitte aus dem Galakonzert vom 3. Juni 2001 und der Caecilien-Vesper von Alessandro Scarlatti. Göttingen : Göttinger Händel-Ges. ; Norddt. Rundfunk, 2001. - 1 CD in Box (67 Min.) : ADD, stereo. ; $12 \mathrm{~cm}+$ Booklet (36 S.)

Kongr.: Internationale Händel-Festspiele ; 81 (Göttingen) : 2001.05.30-06.05 Lat. gesungen. - Text d. Booklets dt., engl. und lat. - Interpr.: Dominique Labelle, Susanne Rydén [Sopran], Ralf Popken [Altus], James Oxley [Tenor], Andrew FosterWilliams [Bass], Elizabeth Blumenstock [Violine]. Arcadian Academy $<$ Rom $>$. Choir of the Age of Enlightenment $<$ London $>$. Philharmonia Baroque Orchestra $<$ San Francisco $>$. Nicholas McGegan [Ltg.]

\section{Signatur: $\quad$ DISKO G 2004-28}

Anmerkung: Rundfunkmitschnitt: NDR, 03.06.2001

Notizen: [Geschenk von der Göttinger Händel-Gesellschaft, 2004]

Vorh. in: GHG 


\section{PPN: 38190251X}

Festspiel-Edition 2002 : Alcina ; Oper von Georg Friedrich Händel ; dramma per musica in drei Akten, HWV 34 (1735) ; Ausschnitte aus der Festspiel-Aufführung im Deutschen Theater Göttingen / Text nach Antonio Fanzaglia. Göttingen : Göttinger Händel-Ges. ; Norddt. Rundfunk, 2002. - 1 CD in Box (79 Min.). : ADD, stereo. ; $12 \mathrm{~cm}+$ Booklet (35 S.) Kongr.: Internationale Händel-Festspiele ; 82 (Göttingen) : 2002.05.15-21 ${ }^{14}$ Ital. gesungen. - Text d. Booklets dt. ital. und engl. - Interpr.: Yvonne Kenny [Alcina], Wilke te Brummelstroete [Ruggiero], Cyndia Sieden [Morgana], Ewa Wolak [Bradamante], Iain Paton [Oronte], Andrew Foster-Williams [Melisso], Susanne Rydén [Oberto]. Baroque Dance Company $<$ New York $>$. Opernkammerchor der Hochschule für Musik und Theater $<$ Hannover $>$. Philharmonia Baroque Orchestra $<$ San Francisco $>$. Nicholas McGegan [Ltg.]

Signatur: $\quad$ DISKO G 2004-29

Anmerkung: Rundfunkmitschnitt: NDR, 16.05.2002

Notizen: [Geschenk von der Göttinger Händel-Gesellschaft, 2004]

Vorh. in: $\quad$ GHG

PPN: 377367796

Festspiel-Edition 2003 : Ausschnitte aus dem Galakonzert ; 2. Juni 2003, Aula der Universität ; Arcangelo Corelli, Georg Friedrich Händel, John Clerk of Penicuik. Göttingen : Göttinger Händel-Ges. ; Norddt. Rundfunk, 2003. - 1 CD in Box (64 Min.) : ADD, stereo. ; $12 \mathrm{~cm}+$ Booklet [19 S.] Kongr.: Internationale Händel-Festspiele ; 83 (Göttingen) : 2003.05.27-06.03 Ital. gesungen. - Text d. Booklets dt. ital. und engl. - Interpr.: Dominique Labelle, Susanne Rydén [Solisten]. The Arcadian Academy $<$ Rom $>$. Nicholas McGegan [Ltg.]

Signatur: $\quad$ DISKO G 2004-2

Anmerkung: Rundfunkmitschnitt: NDR, 02.06.2003

Notizen: [Geschenk von der Göttinger Händel-Gesellschaft, 2003]

Vorh. in: GHG

\footnotetext{
${ }^{14}$ Nach Arbeitskreis RAK-Musik wird auch diese Veröffentlichung als Kongreß-Veröffentlichung gewertet.
} 
PPN: 475539184

Festspiel-Edition 2004 : Ausschnitte aus dem Galakonzert ; 31. Mai 2004, Stadthalle Göttingen ; Georg Philipp Telemann, Georg Friedrich Händel. - Göttingen : Göttinger Händel-Ges. ; Norddt. Rundfunk, 2004. - 1 CD in Box (76 Min.) : ADD, stereo. ; $12 \mathrm{~cm}+$ Booklet [24 S.]

Kongr.: Internationale Händel-Festspiele ; 84 (Göttingen) : 2004.05.23-06.02

Ital. gesungen. - Text d. Booklets dt. und ital. - Interpr.: Andreas Scholl [Altus].

Concerto $<$ Köln $>$. Nicholas McGegan [Ltg.]

Signatur: $\quad$ DISKO G 2004-177

Anmerkung: Rundfunkmitschnitt: NDR, 31.05.2004

Notizen: [Geschenk von der Göttinger Händel-Gesellschaft, 2004]

Vorh. in: $\quad$ GHG 


\section{A n on y m a}

\section{PPN: 151341788}

Alceste : [in drei Akten]. - S. 1-29.

In: Textbuch zu beliebten Opern ; Theil 1. - Stereotyp-Ausg. - Berlin : Guß, Druck und Verlag von Julius Sittenfeld, 1845. - [2] Bl., 478 S., [1] Bl. ; $8^{\circ}$

In Fraktur

Signatur: $\quad 8$ MUS V, 233:1

Notizen: $\quad 39386$ - Universitätsbibliothek Göttingen -

Meyer’s Buchhandl. - verknüpft zum MBW PPN 15134177X

PPN: 157151778

Armida : Dramma Per Musica $=$ Die Armida : ein musikalisches Schauspiel. Schwerin : [s.n.], 1755. - 95 S. ; $8^{\circ}$

Signaturformel: A8-F8. - Bl. D5 fälschl. als Bl. D4 gezeichnet. - Dt.-ital. Paralleltext Fingerprints: n.r- e.t. --r. AmAr 3 1755A

\section{Signatur: $\quad$ DD91 A 33571 (4)}

Anmerkung: Stück 1 - Stück 8 zsgeb.

Notizen: $\quad$ Sammlung deutscher Drucke 1450 bis 1912 | Erworben mit Mitteln der Volkswagen-Stiftung 


\section{PPN: 184396662}

Ezio : Dramma Per Musica Da Rappresentarsi = Ezius : in einem Musicalischen Schau-Spiel vorgestellet. - [Hamburg] : Gedruckt bey Johann Heinrich Spieringk, [ca. 1750]. - 143 S. ; $8^{\circ}$

Impr. nur als Kolophon angegeben. - Text ital. und dt.

Fingerprints: r-in .)ch e.ie CoEa 3 1750Q

Signatur: $\quad$ DD94 A 275 (5)

Anmerkung: Stück 1 - Stück 7 zsgeb.

Notizen: $\quad$ Sammlung deutscher Drucke 1450 bis 1912 | Erworben mit Mitteln der Volkswagen-Stiftung

PPN: 15715176X

Tamerlano : Dramma Per Musica. - Lubecca : [s.n.], 1755. - 79 S. ; $8^{\circ}$

Signaturformel: A8-E8. - Bl. A2 fälschl. als Bl. [invert. Kl.] 2 gezeichnet, Bl.E4 als Bl.D4. - Dt.-ital. Paralleltext

Fingerprints: ery- a?Du t.re RiMa 3 1755A

Signatur: $\quad$ DD91 A 33571 (3)

Anmerkung: Stück 1 - Stück 8 zsgeb.

Notizen: $\quad$ Sammlung deutscher Drucke 1450 bis 1912 | Erworben mit Mitteln der Volkswagen-Stiftung 


\section{Ge s a m t t it e l a u f a h m en}

\subsection{M e h r bändige W e r ke}

\section{PPN: 031884482}

Albert, Eugen d':

89 ausgewählte Werke aus dem Konzertprogramm von Eugen d’ Albert's Klavierabenden. - Leipzig : Forberg, [s.a.]

Betr. Sign.: $\quad 4$ MUS VIII, 2600:8

\section{PPN: 30968045X}

Musikalisch-historisches-lustiges Anekdoten-Büchlein aus der Zeit von Bach und Händel bis Richard Wagner, Dr. Richard Strauß und Caruso : drei Bändchen / ges. und hrsg. von Josef Seiling. - Diessen vor München : Huber, 1913

Mit Beitr. von Dr. Ernst von Possart, Karl Ettlinger, Moritz Rosenthal, Leo Slezak, Emmy Destin, Sophie Menter, Dr. Wilhelm Kienzl etc. und Original-Beitr. von Felix Mottl, mitgeteilt von Dr. W. Krienitz, Felix von Weingartner, Kammersängerin Berta Morena, den Kammersängern Paul Bender, Gg. Sieglitz, Prof. Dr. von Bary u. einem größeren Aufsatz „Dramatische Autoren und Theaterdirektoren“, von dem Componisten Hermann W. von Waltershausen

(Bd. I. II. III. Preis à Mk. 1.20)

Betr. Sign.: $\quad$ ALT 2001 A 921:2

\section{PPN: 21665551X}

Autenrieth, Ronald Joachim:

Quartettsätze nach Stücken von Georg Friedrich Händel (1685-1795) / für Blockflöten bearb. von Ronald Joachim Autenrieth. - Partitur, Stimmen. - Celle : Moeck, 1995

(Edition Moeck ; ...)

Betr. Sign.: $\quad$ FB 20421:1

FB 20421:2

FB 20421:3 
PPN: 271288620

Bloom, Robert:

[Collection] The Robert Bloom collection. - Cranberry Isles, Me. : [s.n.], 1998

Betr. Sign.: $\quad$ FB 22480:2,7

\section{PPN: 144330377}

Bülow, Hans von:

Ausgewählte Klavierwerke von Joh. Seb. Bach, G. F. Händel / Bearb. durch Hans von Bülow. - [Musikdr.]. - Berlin : Bote \& Bock, [ca. 1915-]

(Ausgabe Hans von Bülow)

Einheitssacht.: Werke, Kl

Betr. Sign.: $\quad 4$ MUS VII, 2855:2,2

\section{PPN: 135314526}

Chorley, Henry Fothergill:

Handel studies / by Henry F. Chorley. - London : Augener, 1859

Betr. Sign.: $\quad 8$ MUS III, 1053/g:2/3

\section{PPN: 135314445}

Chrysander, Friedrich:

G. F. Händel / von Friedrich Chrysander. - Leipzig : Breitkopf und Härtel ; Dt. Verl. für Musik ; Hildesheim : Olms, 1858-

Betr. Sign.: $\quad 8$ MUS III, 1053:1

8 MUS III, 1053:2

8 MUS III, 1053:3,1

PPN: 136145817

Denkmæler der Tonkunst. - Bergedorf bei Hamburg : Weissenborn, 1871-1888

Betr. Sign.: 4 MUS V, 480:5 


\section{PPN: 135306248}

Eisenschmidt, Joachim:

Die szenische Darstellung der Opern Georg Friedrich Händels auf der Londoner Bühne seiner Zeit / Joachim Eisenschmidt. - Wolfenbüttel ; Berlin : Kallmeyer, 1940-1941 (Schriftenreihe des Händelhauses in Halle ; ...)

HS-Nr.: U 40.3234

Betr. Sign.: $\quad 8$ MUS I, 2105:5

8 MUS I, 2105:6

PPN: 135217865

Händel, Georg Friedrich:

Italienische Kantaten / Georg Friedrich Händel. Übers. von Emilie Dahnk-Baroffio.

Eingerichtet und hrsg. von Hermann Zenck. - Kassel : Bärenreiter, 1942-

Betr. Sign.: $\quad 4$ MUS VII, 426/1

4 MUS VII, 426/2

4 MUS VII, 426/3

4 MUS VII, $426 / 6$

4 MUS 1036

71 B 3207

PPN: 32937740X

Händel, Georg Friedrich:

Zwölf grosse Konzerte für Streichinstrumente / von G. F. Händel. Hrsg. und mit einem Vorw. vers. von Georg Schumann. - [Partitur]. - Leipzig [u.a.] : Eulenburg [u.a.], 1906 (Payne’s kleine Partitur-Ausgabe ; ...)

Betr. Zyklus: Concerti grossi, HWV 319 - 330, op. 6

Betr. Sign.: $\quad 8$ MUS V, 520:263

8 MUS V, 520:264

8 MUS V, 520:265

8 MUS V, 520:266

8 MUS V, 520:267

8 MUS V, 520:268

8 MUS V, 520:269

8 MUS V, 520:270

8 MUS V, 520:271

8 MUS V, 520:272

8 MUS V, 520:273

8 MUS V, 520:274 
PPN: 135217946

Händel, Georg Friedrich:

Orgelkonzerte / Georg Friedrich Händel. Hrsg. von Helmuth Walcha. - [Musikdr.]. Mainz [u.a.] : Schott [u.a.], 1940-

Einheitssacht.: Werke. - Betr. Zyklus: Konzerte, Org Orch, HWV 306 - 311, op. 7

Betr. Sign.: $\quad 4$ MUS VII, $427: 7$

4 MUS VII, 427:8

4 MUS VII, 427:9

4 MUS VII, 427:10

4 MUS VII, 427:11

4 MUS VII, 427:12

\section{PPN: 135310490}

Parke, William Thomas:

Musical memoirs : comprising an account of the general state of music in England, from the first commemoration of Handel, in 1784, to the year 1830 ; in two volumes / by W. T. Parke. - London : Henry Colburn and Richard Bentley, 1830

Betr. Sign.: $\quad 8$ MUS II, 2700:1

8 MUS II, 2700:2

PPN: 266529631

Händel, Georg Friedrich:

Psalm-Kantate (Anthem) / Georg Friedrich Händel. - Berlin : Evang. Verl.-Anst. ;

Leipzig : Merseburger, 1947 -

Betr. Sign.: 4 MUS 57:1,KLAVIERAUSZ

4 MUS 57:1,PARTITUR

4 MUS 57:2,KLAVIERAUSZ

4 MUS 57:2,PARTITUR 


\section{PPN: 135213681}

Händel, Georg Friedrich:

The works of Handel. - [Partitur mit beigef. Klavierausz.]. - London : Cramer, Beale, 1844-1858

Einheitssacht.: Werke. - Print. for the members of The Handel Society

Betr. Sign.: $\quad 2$ MUS VII, 340:1

2 MUS VII, 340:2

2 MUS VII, 340:3

2 MUS VII, 340:4

2 MUS VII, 340:5

2 MUS VII, 340:6

2 MUS VII, 340:7

2 MUS VII, 340:8

2 MUS VII, 340:9

2 MUS VII, 340:10

2 MUS VII, 340:11

2 MUS VII, 340:12

2 MUS VII, 340:13

2 MUS VII, 340:14

2 MUS VII, 340:15

2 MUS VII, 340:16

PPN: 031203345

Händel-Handbuch : in vier Bänden / hrsg. vom Kuratorium der Georg-Friedrich-

Händel-Stiftung von Walter Eisen ... - Kassel [u.a.] : Bärenreiter, 1978-

Gemeinsame Ed. mit: Dt. Verl. für Musik, Leipzig. - Gleichzeitig Suppl. zu: Hallische

Händel-Ausgabe (kritische Gesamtausgabe)

Betr. Sign.: $\quad 4$ MUS 936:HANDBUCH,1

4 MUS 936:HANDBUCH,2

4 MUS 936:HANDBUCH,3

4 MUS 936:HANDBUCH,4

PPN: 135310776

Hiller, Johann Adam:

Lebensbeschreibungen berühmter Musikgelehrter und Tonkünstler, neuerer Zeit / von Johann Adam Hiller. - Leipzig : im Verlage der Dykischen Buchhandlung, 1784

Betr. Sign.: $\quad 8$ MUS III, 57 
PPN: 125277504

Katalog der Sammlung Anthony van Hoboken in der Musiksammlung der Österreichischen Nationalbibliothek : musikalische Erst- und Frühdrucke / hrsg. vom Inst. für Österreichische Musikdokumentation unter der Ltg. von Günter Brosche. - Tutzing : Schneider, 1982-2000

Betr. Sign.: $\quad$ FB 12165:5

PPN: 032912676

Katalog zu den Sammlungen des Händel-Hauses in Halle. - Halle an der Saale : Kreuz-Verl., 1961-

Betr. Sign.: $\quad$ FA 3135:1

FA 3135:2

FA 3135:3

FA 3135:4

PPN: 125882319

I libretti italiani di Georg Friedrich Händel e le loro fonti / a cur. di Lorenzo

Bianconi. - Firenze : Olschki, 1992

(Quaderni della rivista italiana di musicologia ; ...)

Betr. Sign.: $\quad$ ZA 36398:26,1/1

ZA 36398:26,1/2

PPN: 135269202

Mohr, Ernst:

Die Allemande : eine Untersuchung ihrer Entwicklung von den Anfängen bis zu Bach und Händel / Ernst Mohr. - Zürich und Leipzig : Hug, 1932

Der Titel besteht aus zwei Teilen

Betr. Sign.: $\quad 8$ MUS II, 746:1,TEXT

8 MUS II, 746:2,NOTEN 
PPN: 135278139

Musica sacra. - [Musikdr.]. - Berlin ; Posen : Bote \& Bock, 1841-

Betr. Sign.: $\quad 4$ MUS V, 450:4

4 MUS V, 450:6

4 MUS V, 450:12

PPN: 125453515

Alte Musik als ästhetische Gegenwart : Bach, Händel, Schütz ; Bericht über den internationalen musikwissenschaftlichen Kongreß, Stuttgart 1985 / Ges. für Musikforschung. Hrsg. von Dietrich Berke ... - Kassel [u.a.] : Bärenreiter, 1987 Kongr.: Internationaler musikwissenschaftlicher Kongreß ; (Stuttgart) : 1985.09.15-20

Betr. Sign.: $\quad 96$ A 22541:1

96 A 22541:2

PPN: 125306091

Musikgeschichte in Bildern / hrsg. von Heinrich Besseler ... (1973 ff.: Begr. von Heinrich Besseler [u.a.]. Hrsg. von Werner Bachmann). - Leipzig : Dt. Verl. für Musik, 1961-

Betr. Sign.: $\quad$ FB 2624:4,2

PPN: 135307961

The Oxford history of music / William Henry Hadow [Hrsg.]. - London : Oxford Univ. Press, 1901-

Betr. Sign.: $\quad 8$ MUS II, 225:4

PPN: 135308178

The Oxford history of music. - 2. ed. - London : Oxford Univ. Press, 1929-

Betr. Sign.: $\quad 8$ MUS II, 225:4 <2> 


\section{PPN: 031764487}

Rackwitz, Werner:

Geschichte und Gegenwart der hallischen Händel-Renaissance / Werner Rackwitz. Halle an der Saale : Händel-Haus, 1977-1979

(Schriften des Händelhauses in Halle ; ...)

Teilw. zugl.: Halle, Univ., Diss., 1963 u.d.T.: Die hallische Händel-Renaissance von 1859-1952

HS-Nr.: U 63.4207

Betr. Sign.: $\quad$ ZA 74426:1

ZA 74426:2

PPN: 22183432X

Rudolph, Johanna:

Händelrenaissance : eine Studie / Johanna Rudolph. - Berlin ; Weimar : Aufbau-Verl., 1960-1969

Zugl.: Berlin, Humboldt-Univ., Diss., 1966

Betr. Sign.: $\quad$ FA 1874:1

FA 1874:2

PPN: 031830714

Sasse, Konrad:

Händel-Bibliographie : unter Verwendung des im Händel-Jahrbuch 1933 von Kurt Taut veröffentlichten Verzeichnisses des Schrifttums über Georg Friedrich Händel / zsgest. von Konrad Sasse. - Leipzig : Dt. Verl. für Musik, 1963-1967

Erschienen: Hauptbd. (1963), Nachtr. 1 (1967)

Betr. Sign.: $\quad 64$ B 4378:HAUPTW

64 B 4378:NACHTR

PPN: 135372240

Serauky, Walter:

Musikgeschichte der Stadt Halle / von Walter Serauky. - Halle/Saale ; Berlin : Buchh. des Waisenhauses, 1935-

(Beiträge zur Musikforschung ; ...)

Betr. Sign.: $\quad 8$ MUS II, 2379:2,1 
PPN: 029175178

Smither, Howard E.:

A history of the oratorio / by Howard E. Smither. - Chapel Hill : Univ. of North Carolina Press, 1977-

Bd. 3 erschienen im Verl. Clarendon Press, Oxford

Betr. Sign.: $\quad$ FA 9250:2

PPN: 136714528

Squire, William Barclay:

Catalogue of the King's Music Library / by William Barclay Squire. -

London : Clowes, 1927-1929

Vermerk auf der Titels.: Printed by order of the trustees sold at the British Museum and by Bernard Quaritch ...; Oxford University Press ...; and Kegan Paul ...

Betr. Sign.: $\quad 4$ HLL IX, 2546:1

PPN: 135216710

Supplemente, enthaltend Quellen zu Händel's Werken / für die Dt. Händelges. hrsg. von Friedrich Chrysander. - [Musikdr.]. - Leipzig : St. und Dr. der Ges., 1888-1902

Betr. Sign.: $\quad 4$ MUS VII, 342:1

4 MUS VII, 342:2

4 MUS VII, 342:3

4 MUS VII, 342:4

4 MUS VII, 342:5

4 MUS VII, 342:6 
PPN: 15134177X

Textbuch zu beliebten Opern. - Berlin : Guß, Druck und Verlag von Julius Sittenfeld, 1845

Betr. Sign.: $\quad 8$ MUS V, 233:1

PPN: 13662880X

Kongl. Svenska Theatren. - Stockholm : Trykt i Kongl. Tryckeriet, 1778-1796

Betr. Sign.: $\quad 8$ P DRAM IV, 300:1 


\subsection{S e ri e n}

PPN: 169455076

Kleines Bärenreiter-Buch. - Kassel : Bärenreiter, 1.1941; 2.1940 -

Betr. Sign.: $\quad 8$ MUS III, 1098

PPN: 167050397

Beiträge zur Musikforschung / hrsg. von Max Schneider. - Halle/Saale ; Berlin : Buchh. des Waisenhauses, 1.1935 -

Betr. Sign.: $\quad 8$ MUS II, 2379:2,1

PPN: 130108928

Hamburger Beiträge zur Musikwissenschaft. - Hamburg : Wagner, 1969-

Betr. Sign.: $\quad$ ZA 30787:7

\section{PPN: 167351621}

[Wissenschaftliche Beiträge / G] Wissenschaftliche Beiträge / Martin-Luther-Universität Halle-Wittenberg. Reihe G: Musikwissenschaftliche Beiträge. - Halle (Saale) : Univ. Halle-Wittenberg, 1.1968 -

Nebent.: Hallische Universitätsreden. - Hauptsacht. anfangs: Wissenschaftliche Beiträge der Martin-Luther-Universität, Halle-Wittenberg. - Alle Bd. zugl. Bd. von: Universität $<$ Halle, Saale $>$ : Wissenschaftliche Beiträge

ISSN 0440-1298

Betr. Sign.: $\quad$ ZA 27855:1977,39

ZA 27855:1979,8

ZA 27855:1980,7

ZA 27855:1981,14

ZA 27855:1982,21

ZA 27855:1983,24

ZA 27855:1984,38

ZA 27855:1988,26 
PPN: 182181545

Bericht über die Symposien der Internationalen Händel-Akademie. - Laaber : Laaber-Verl., 1986/87(1988) - 1990/91(1992); 1992/93(1994) -

$1986 / 1987=2 ; 1988 / 1989=3 ; 1990 / 1991=4 ; 1992 / 1993=5 ; 1994 / 1997=6$ von: Internationale Händel-Akademie < Karlsruhe> : Veröffentlichungen der Internationalen Händel-Akademie Karlsruhe

Betr. Sign.: $\quad$ ZA 67246:2

ZA 67246:3

ZA $67246: 4$

96 A 13978

PPN: 131074113

The Ernest Bloch lectures. - London, 1.1965/66(1970) -

Nebent.: The Bloch lectures

Betr. Sign.: ～ZB 31856:1,1965/66

\section{PPN: 131049070}

Corona : Werkreihe für Kammerorchester. - Wolfenbüttel [u.a.] : Möseler, 1.1951 Nebent.: Werkreihe Corona. -

Vorg.: Deutsche Instrumentalmusik

Betr. Sign.: $\quad 4$ Z MUS 94:1

4 Z MUS 94:31

4 Z MUS 94:55

4 Z MUS 94:66

4 Z MUS 94:72

4 Z MUS 94:74

4 Z MUS 94:75

4 Z MUS 94:99

4 Z MUS 94:108 


\section{PPN: 130781339}

Edition Eulenburg. - Leipzig : Eulenburg, 1.1874 -

Ersch. abwechselnd mit den Zusätzen: Paynes kleine Partiturausgabe; Paynes kleine Kammermusikpartiturausgabe; Eulenburgs kleine Orchesterpartiturausgabe (bzw. mit einem 2. Zus.: Symphonien; Ouverturen; Konzerte; Verschiedene Werke); Eulenburgs kleine Partiturausgabe (bzw. mit einem 2. zs.: Symphonien; Ouverturen; Konzerte; Verschiedene Werke; Bühnenwerke; Chorwerke). - Darin: Thematisches Verzeichnis

Betr. Sign.: $\quad 8$ MUS V, 520:263 8 MUS V, 520:264 8 MUS V, 520:265 8 MUS V, 520:266 8 MUS V, 520:267 8 MUS V, 520:268 8 MUS V, 520:269 8 MUS V, 520:270 8 MUS V, 520:271 8 MUS V, 520:272 8 MUS V, 520:273 8 MUS V, 520:274 8 MUS V, 520:380 8 MUS V, 520:381 8 MUS V, 520:382 8 MUS V, 520:956

PPN: 035942029

Edition Merseburger. - Kassel : Merseburger, nachgewiesen 343-344.1953; 371.1964 Nebent.: EM. - Anfangs erschienen bei Merseburger in Berlin

Betr. Sign.: $\quad 59$ A 6568

\section{PPN: 03607571X}

Garland composer resource manuals. - New York [u.a.] : Garland, 1.1981 -

Teilw. u.d.T.: Composer resource manuals. $1.1981=272.1981 ; 2.1983=330.1983 ; 12.1988=757.1988 ; 14.1988=796.1988$; $16.1989=910.1989 ; 18.1989=885.1989 ; 19.1988=717.1988 ; 20.1989=895.1989$; $27.1990=771.1990 ; 31.1990=740.1990 ; 35.1991=897.1991 ; 37=1017 ; 50=1961$ von: Garland reference library of the humanities

Betr. Sign.: $\quad$ ZA 40336:717 
PPN: 035825324

Garland reference library of the humanities. - New York, NY [u.a.] : Garland, 1.1975 Bd. 910 und 1444 doppelt gez. - Ab 2001 im Verl. Routledge, New York [u.a.] erschienen ISSN 1059-3454

Betr. Sign.: $\quad$ ZA 40336:717

\section{PPN: 315683457}

Göttinger Händel-Festspiele : Programme, Texte und Werkeinführungen / hrsg. vom Vorstand der Göttinger Händel-Ges. e.V. - Göttingen, nachgewiesen 1990 Nebent. teilw.: Händel-Festspiele

$\begin{array}{ll}\text { Betr. Sign.: } & \text { K 99 A } 316 \\ & \text { K 99 A } 317 \\ & \text { K 99 A } 2766 \\ & \text { K 99 A } 2768 \\ & \text { K 99 A } 2770 \\ \text { K } 99 \text { A } 2774 \\ \text { 99 A } 18217 \\ \text { 99 A 18218 } \\ \text { K 2000 A } 1855 \\ \text { 2000 A 21489 } \\ \text { 2001 A 27220 } \\ \text { 2002 A 28035 }\end{array}$

\section{PPN: 036162779}

Kleine Handbücher der Musikgeschichte nach Gattungen. - Leipzig : Breitkopf \& Härtel, 1.1905 - 12.1930; 13.1922 - 14.1921

Reprod.: Hildesheim : Olms; zeitw. Trennung Wiesbaden und Leipzig : Breitkopf \& Härtel

Betr. Sign.: $\quad 67$ A 6510

\section{PPN: 036059161}

Hausmusik : Werkreihe für Kammermusik. - Wolfenbüttel ; Zürich : Möseler, 1.1970 Nebent. teils: Werkreihe Hausmusik

Betr. Sign.: $\quad$ ZB 58451:224 


\section{PPN: 035934859}

Europäische Hochschulschriften = Publications universitaires européennes = European university studies. Reihe 36: Musikwissenschaft. - Frankfurt am Main [u.a.] : Lang, 1.1978 Teilw. Nebent.: European university papers: Series 36, Musicology. - Unterreihe teilw. u.d.T.: Musikwissenschaft ISSN 0721-3611

Betr. Sign.: $\quad$ ZA 46593:38

\section{PPN: 036059021}

Hortus musicus. - Kassel [u.a.] : Bärenreiter ; Leipzig : Dt. Verl. für Musik, 1.1949 Nebent.: HM

$\begin{array}{ll}\text { Betr. Sign.: } & 4 \text { Z MUS 91:3 } \\ & 4 \text { Z MUS 91:15 } \\ & 4 \text { Z MUS 91:112 } \\ & 4 \text { Z MUS 91:242 } \\ & 4 \text { Z MUS 91:243 } \\ & 4 \text { Z MUS 91:244 } \\ & 4 \text { Z MUS 91:251 } \\ & 4 \text { Z MUS 91:263 } \\ & 4 \text { Z MUS 91:269 }\end{array}$

\section{PPN: 13103071X}

Deutsche Instrumentalmusik : Werkreihe für Kammerorchester. - Wolfenbüttel : Möseler, 1.1937 - 35.1955

Neudr. einzelner Bde. unter dem späteren Titel (Corona) erschienen. - Forts.: Corona

Betr. Sign.: $\quad 4$ Z MUS 94:10

4 Z MUS 94:26

4 Z MUS 94:29

4 Z MUS 94:35

\section{PPN: 130888591}

Meyers Bildbändchen. - Mannheim : Bibliogr. Inst., nachgewiesen 10.1935 - 47.1941; N.F., 1.1956 - 16/17.1959

Betr. Sign.: $\quad$ ZA 17555:13 
PPN: 130218405

Moecks Kammermusik. - Celle : Moeck, 1.1939 -

Betr. Sign.: $\quad 4$ Z MUS 122:34

PPN: 130775010

Moecks gelbe Musikhefte. - Celle : Moeck, 1.1933 - 38.1940

Nebent.: Gelbe Musikhefte

Betr. Sign.: $\quad 8$ MUS 349

PPN: 131030965

Kleine Musikbücherei. - Hamburg : Sikorski, 1.1953 -

Betr. Sign.: $\quad 8$ Z MUS 128:2

PPN: 182197425

Musikerreihe in auserlesenen Einzeldarstellungen. - Olten : Walter, 1.1947 -

Betr. Sign.: $\quad 8$ MUS 153

${ }^{15}$ Der Verlag hat auf die Frage nach dem Erscheinungsverlauf wie folgt geantwortet: „Das Heft Nr. 1 der Reihe „Moeck's gelbe Musikhefte“ ist 1933 erschienen, das letzte Heft, Nr. 38, 1940. Später wurden „Moeck’s gelbe Musikhefte" in der 2000er Editionsreihe des Moeck-Verlages herausgegeben, dann aber nicht mehr unter diesem Namen.“ (2002) 
PPN: 129658642

Nagels Musik-Archiv : NMA. - Kassel : Nagel ; London : Bärenreiter, 1.1927 Springende Erscheinungsjahre

$\begin{array}{ll}\text { Betr. Sign.: } & \text { 4 MUS V, 760:3 } \\ & \text { 4 MUS V, 760:108 } \\ & \text { 4 MUS V, 760:104 \& 4 MUS V, 760:104,STIMME } \\ & \text { 4 MUS V, 760:122 } \\ & \text { 4 MUS V, 760:136 } \\ & \text { 4 MUS V, 760:150 } \\ & \text { 4 Z MUS 98:230 } \\ & \text { 4 Z MUS 98:235 } \\ & \text { 4 Z MUS 98:240 } \\ & \text { 4 Z MUS 98:252 } \\ & \text { 4 Z MUS 98:254 } \\ & 4 \text { Z MUS 98:255 }\end{array}$

\section{PPN: 130778184}

[Organum / 1] Organum : ausgewählte ältere vokale und instrumentale Meisterwerke / kritisch durchges. und zum praktischen Gebrauch hrsg. unter Leitung von Max Seiffert. Reihe 1: Geistliche Gesangsmusik. - Lippstadt [u.a.] : Kistner \& Siegel, 1.1923 Erscheint unregelmäßig

Betr. Sign.: $\quad 4$ MUS V, 718:1,12

PPN: 130778249

[Organum / 2] Organum : ausgewählte ältere vokale und instrumentale Meisterwerke / kritisch durchges. und zum praktischen Gebrauch hrsg. unter Leitung von Max Seiffert. Reihe 2: Weltliche Gesangsmusik für Solo- oder Chorstimmen mit oder ohne Begleitung. - Lippstadt [u.a.] : Kistner \& Siegel, 1.[1943] -

Erscheint unregelmäßig

Betr. Sign.: $\quad 4$ MUS V, 718:2,4 4 MUS V, 718:2,5

4 MUS V, 718:2,11

4 MUS V, 718:2,18

4 MUS V, 718:2,20 
PPN: 03606758X

Orgelmusik der Klassik und Romantik. - Wolfenbüttel [u.a.] : Möseler, 1.1975 -

Betr. Sign.: $\quad$ ZA 51449:10

PPN: 036252840

[Rivista italiana di musicologia / Quaderni] Quaderni della rivista italiana di musicologia : RIDM / Soc. italiana di musicologia. - Firenze : Olschki, 1966 -

Betr. Sign.: $\quad$ ZA 36398:26,1/1

ZA 36398:26,1/2

PPN: 035855584

Rowohlts Monographien. - Reinbek bei Hamburg : Rowohlt, 1.1958 -

Nebent.: Rororo-Bildmonographien. - rm. - rororo-monographie

ISSN 0485-5256

Betr. Sign.: $\quad$ ZA 16436:36

PPN: 036115452

Schriften des Händel-Hauses in Halle. - Halle an der Saale : Händel-Haus, 1.1977 ISSN 0232-3214

Betr. Sign.: $\quad$ ZA 74426:1

ZA 74426:2

ZA 74426:3

96 A 26283

2000 A 25184

2001 A 25815

PPN: 036121495

Schriftenreihe der Internationalen Bachakademie Stuttgart. - Kassel [u.a.] : Bärenreiter, 1.1988 -

Teilw. u.d.T.: Internationale Bachakademie < Stuttgart $>$ : Schriftenreihe. -

Teilw. im Verl. Internat. Bachakad., Stuttgart, erschienen

ISSN 1012-8034

Betr. Sign.: $\quad$ ZA 74577:4 


\section{PPN: 036112534}

Schriftenreihe des Händelhauses in Halle : Veröffentlichungen aus dem Musikleben Mitteldeutschlands. - Wolfenbüttel ; Berlin : Kallmeyer, 1.1937 - 6.1941; 7.1940

Betr. Sign.: $\quad 8$ MUS I, 2105:5

8 MUS I, 2105:6

\section{PPN: 035920246}

Skrifter från Musikvetenskapliga Institutionen, Göteborg = Studies from Gothenburg University, Department of Musicology. - Göteborg [u.a.] : Symposion Bokförl. \& Tryckeri AB, 1978 -

Bd. 22 im Verl. Gehrmans Musikförl., Stockholm, erschienen

Teilw. mit Parallelt.: Studies from the Department of Musicology, Göteborg University Teilw. mit Parallelt.: Studies from the Department of Musicology, University of Göteborg Teilw. u.d.T.: Musikhögskolan <Göteborg> / Avdelningen för Musikvetenskap: Skrifter från Musikvetenskapliga Avdelningen. Teilw. u.d.T.: Skrifter från musikvetenskap. Teilw. u.d.T.: Skrifter från Institutionen för Musikvetenskap, Göteborgs Universitet. Teilw. u.d.T.: Skrifter från Musikvetenskapliga Institutionen, Göteborgs Universitet. Nr. 72 u.d.T.: Skrifter från Istitutionen för Musik- och Filmvetenskap, Göteborgs Universitet

ISSN 0348-0879 - ISSN 1103-2251 - ISSN 1650-9285

Betr. Sign.: $\quad$ DISS 96 A 4184

\section{PPN: 167350005}

Taschenbücher zur Musikwissenschaft. - Wilhelmshaven : Heinrichshofen, 1.1969 ISSN 0082-1969

Betr. Sign.: $\quad$ ZA 39691:66

\section{PPN: 130148296}

Hallische Universitätsreden / Martin Luther Univ., Halle-Wittenberg. - Halle (Saale) : Univ., 1.1915 - 78.1941; N.F. 1.1960 -

Früher erschienen bei Verl. Niemeyer

Betr. Sign.: $\quad 8$ SVA I, 7449/5:68 


\title{
PPN: 036066869
}

Veröffentlichungen der Internationalen Händel-Akademie Karlsruhe. - Laaber : Laaber-Verl., nachgewiesen 2.1988 -

5=4 von: Internationale Händel-Akademie: Bericht über die Symposien der Internationalen Händel-Akademie. - Laaber : Laaber-Verl.

Betr. Sign.: $\quad$ ZA 67246:1

\section{PPN: 040724379}

Bibliographische Veröffentlichungen der Musikbibliothek d. Stadt Leipzig. Leipzig : Musikbibliothek d. Stadt Leipzig, 1964 -

\section{Betr. Sign.: $\quad$ ZA 42204:4}

\section{PPN: 331766043}

Klassische Werke älterer und neuerer Kirchenmusik in ausgesetzten Chorstimmen. - Berlin : Trautwein, [19. Jh.]

\section{Betr. Sign.: 8 MUS VII, 371:SOPR.ALT 8 MUS VII, 371:TEN.BASS}

\section{PPN: 130310433}

Zeitschrift für Spielmusik. - Celle : Moeck, Nr.1.1932 - 124.1944; 125.1947/48 -

Nebent.: ZfS. - Hauptsacht. anfangs: Zeitschrift für Spielmusik auf allerlei Instrumenten. -

Beil.: Der Blockflöten-Spiegel

Beil.: Archiv für Spielmusik

Beil.: Der Celler Spielmann

Beil.: Blockflöten-Spiel

\author{
Betr. Sign.: 4 Z MUS 17:566/567 \\ 4 Z MUS 17:629/630 \\ 4 Z MUS 17:654/655 \\ 4 Z MUS 17:666/667 \\ K 98 B 761 \\ K 98 B 2868
}




\section{Händel a f $M$ i kroformen}

$1 \quad$ Acis and Galatea

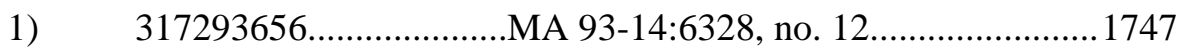

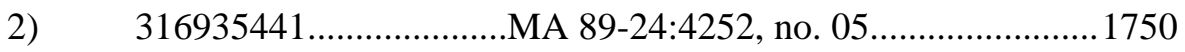

3) $317161261 \ldots \ldots \ldots \ldots \ldots \ldots \ldots . . . . . . . . . . . .93-14: 7571$, no. 10.......................1756

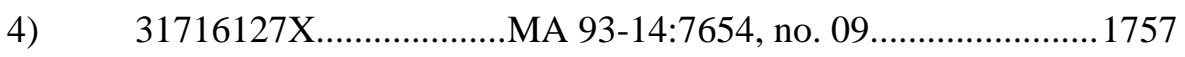

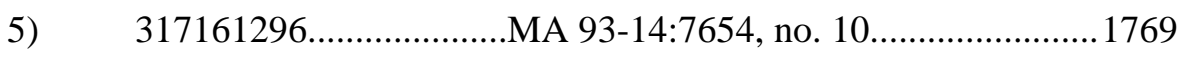

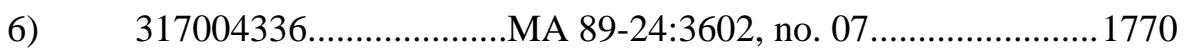

7) 31656799X......................A 83-57:3059, no. 15......................... 1775

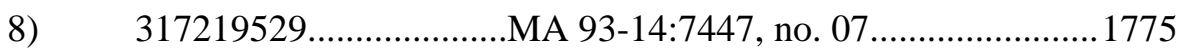

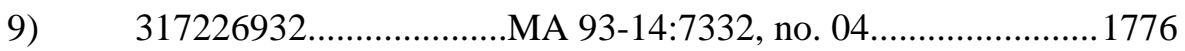

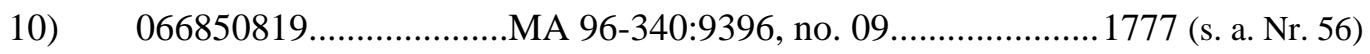

11) $\quad 317026208 \ldots \ldots \ldots \ldots \ldots \ldots \ldots . . . . . M A ~ 89-24: 5230$, no. $17 \ldots \ldots \ldots \ldots \ldots \ldots \ldots \ldots . . . .1777$

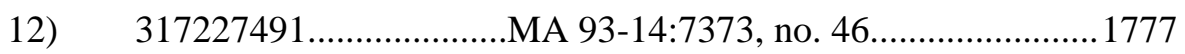

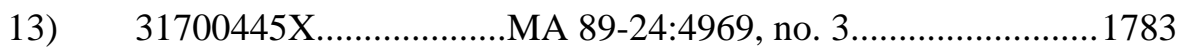

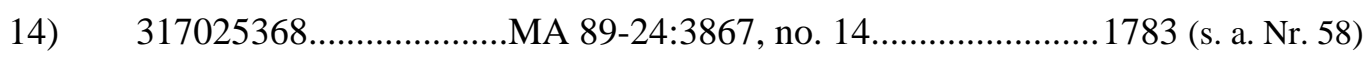

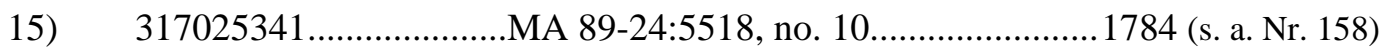

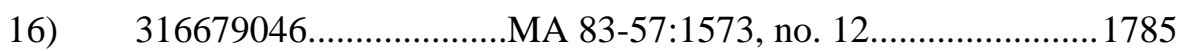

17) 31702762X....................MA 89-24:3867, no. 04......................1785 (s. a. Nr. 159)

18) 317161318.......................A 93-14:7654, no. 11........................1787

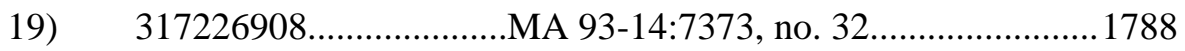

20) 317228072......................A 93-14:7373, no. 13........................1789

21) $\quad 066791456 \ldots \ldots \ldots \ldots \ldots \ldots \ldots . . . . M A ~ 96-340: 8608$, no. $12 \ldots \ldots \ldots \ldots \ldots \ldots \ldots \ldots . . .1790$ (s. a. Nr. 145)

22) 317226746.......................A 93-14:7373, no. 02........................1790

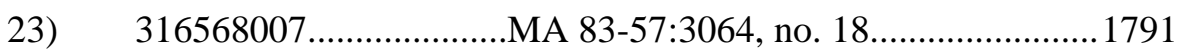

24) 317188631.......................A 93-14:7759, no. 13........................1792

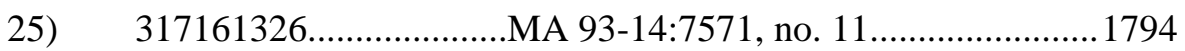

2 Admeto

26) 316938785......................A 89-24:4058, no. 11.......................1727

27) 317094998......................A 89-24:3280, no. 16.....................1731 
$5 \quad$ Alexander's feast or The power of musick

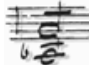

30) 317114751

MA 89-24:5439, no. 6 1750

31) 316598151.

MA 83-57:1573, no. 29 1751

32) 316567981. MA 83-57:3062, no. 9 1753

33) 066859034 MA 96-340:9508, no. 11 1760

34) 066808189. MA 96-340:8829, no. 04 1765

35) 316701424 MA 83-57:2966, no. 4 1780

36) 317035541 MA 89-24:3602, no. 08 1780

37) 317027646 .MA 89-24:3866, no. 07 1782 (s. a. Nr. 57)

38) 317025325 .MA 89-24:3867, no. 16 1783 (s. a. Nr. 157)

39) 317027654 . .MA 89-24:3867, no. 05 1785

40) 066807913. .MA 96-340:8821, no. 03 1788

41) $31722686 \mathrm{X}$ .MA 93-14:7373, no. 30 1788

42) 317227637. .MA 93-14:7438, no. 02 1790

\section{$6 \quad$ L' allegro, il penseroso ed il moderato}

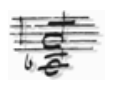

\begin{tabular}{|c|c|}
\hline ) & 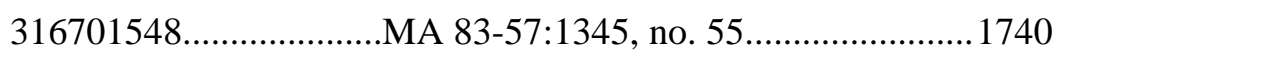 \\
\hline 44) & ......MA 93-14:6426, no. $04 \ldots$ \\
\hline 45) & ....MA 93-14:6669, no. 17.... \\
\hline 6) & 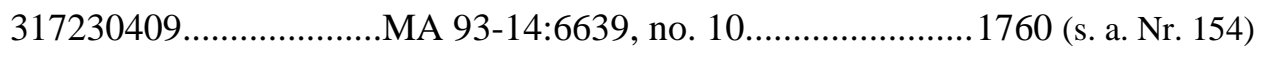 \\
\hline & .......MA 89-24:4969, no. 5.... \\
\hline
\end{tabular}




\begin{tabular}{|c|c|}
\hline 48) & 317024531......................MA 89-24:5518, no. 26........................1783 (s. a. Nr. 155) \\
\hline 49) & 317025317....................MA 89-24:3867, no. 15......................1783 (s. a. Nr. 156) \\
\hline 50) & 317035673.......................A 89-24:4969, no. 2.........................1783 \\
\hline 51) & 317227122......................MA 93-14:7342, no. 11......................1794 \\
\hline 52) & 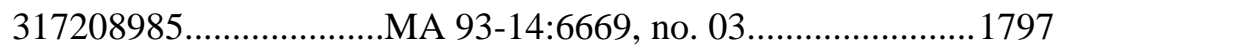 \\
\hline 53) & 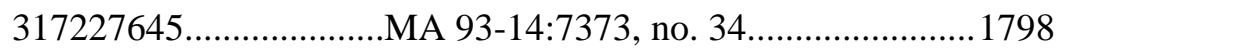 \\
\hline
\end{tabular}

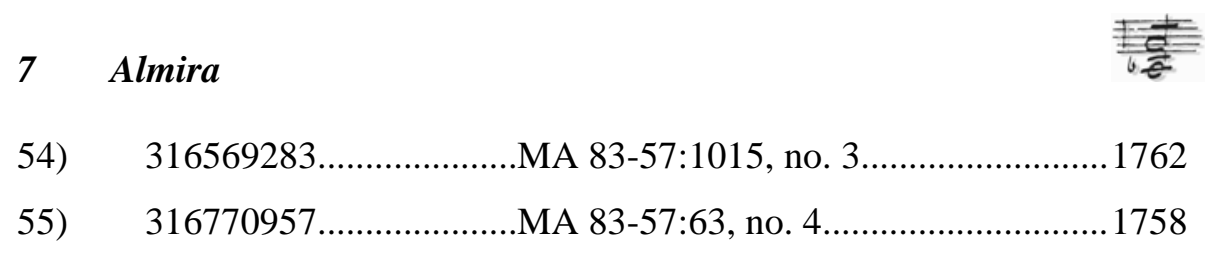

\section{Coronation anthems}

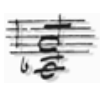

\begin{tabular}{|c|c|}
\hline 56) & 066850819....................MA 96-340:9396, no. 09..................1777 (s. a. Nr. 10) \\
\hline 57) & .............MA 89-24:3866, no. 07.... \\
\hline 8) & 317025368......................AA 89-24:3867, no. 14......................1783 (s. a. Nr. 14) \\
\hline &.. MA 93-14:7373, no. $14 \ldots .$. \\
\hline
\end{tabular}

\section{$9 \quad$ Arianna in Creta}

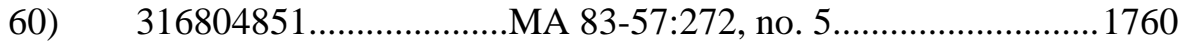

61) 317120476......................A 89-24:3708, no. 03.......................1784

\section{$10 \quad$ Athalia}

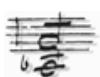

62) 316704431.

MA 83-57:1226, no. 13

1733

63) 317133985.

MA 89-24:4393, no. 03 1756

64) 066803977. MA 96-340:8775, no. 05 1763 


\section{Belshazzar}

65) 317036009......................A 89-24:5314, no. 12......................1745

66) 316702285........................A 83-57:1573, no. 21........................1751

\section{The choice of Hercules}

67) 316549479......................A 83-57:1494, no. 12 1758 (s. a. Nr. 153)

68) 317044133 .MA 89-24:4969, no. 6 1864

13 Deborah

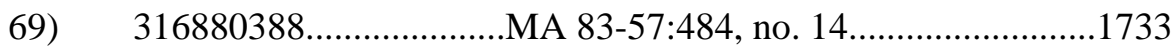

70) 317133977 ......................AA 89-24:4583, no. 14......................1749

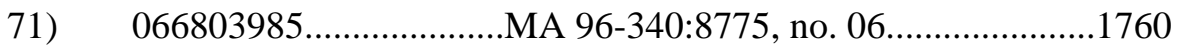

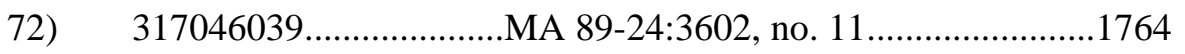

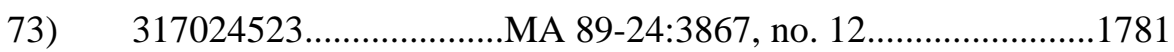

14 Esther

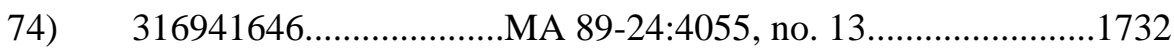

75) 31672176X.......................A 83-57:1226, no. 15.......................1733

76) 316994715......................AA 89-24:5524, no. 10......................1743

77) 066823307......................AA 96-340:9093, no. 05.....................1765

\section{Ezio}

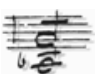

78) $\quad 317048201$ .MA 89-24:4333, no. 07 .1764

79) $31467473 \mathrm{X}$ .MC 2002-2024:1-3. .1999 


\section{Giulio Cesare in Egitto}

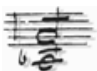

81) 317255134...................... MA 93-14:6817, no. 04........................ 1724

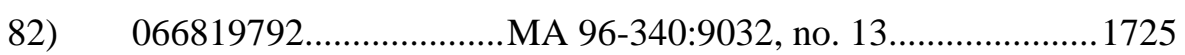

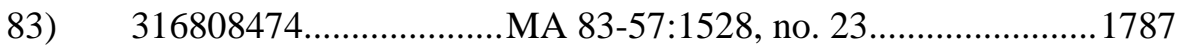

\section{Hercules}

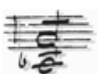

83) 066778093

MA 96-340:8363, no. 02

1745

19 Israel in Egypt

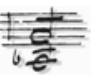

84) 316728934.....................MA 83-57:1226, no. 14......................1740

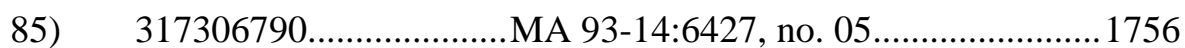

86) 316728926.......................

87) 31705175X.....................MA 89-24:3602, no. 04.......................1765

88) 31720114X.....................MA 93-14:6711, no. 04.......................1766

89) 316728918.......................AA 83-57:1573, no. 19.......................1768 (Israel in Babylon)

20 Jephtha

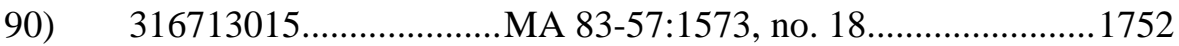

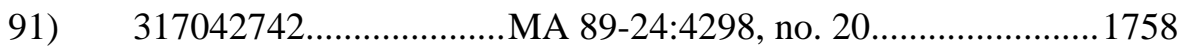

92) $\quad 317019430 \ldots \ldots \ldots \ldots \ldots \ldots \ldots . . . . . M A ~ 89-24: 4961$, no. $12 \ldots \ldots \ldots \ldots \ldots \ldots \ldots \ldots . . . .1762$

93) 317215183......................MA 93-14:7413, no. 09.......................1773

94) 317226916.....................MA 93-14:7376, no. 03......................1776

95) 317227173........................A 93-14:7373, no. 48.........................1784 


\section{Joseph and his brethren}

96) 317042815.....................MA 89-24:5314, no. 11......................1744

97) 317042823....................... $\quad$ MA 89-24:3602, no. 03......................... 1768

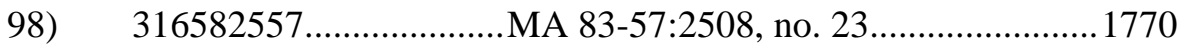

\section{Joshua}

99) 31704284X..................... MA 89-24:4297, no. 08.........................1752

100) 317042858....................... MA 89-24:3602, no. 05......................... 1754

101) 316713236......................MA 83-57:1314, no. 34......................1756

\section{Judas Maccabaeus}

102) 317174274......................A 93-14:7689, no. 03......................1747

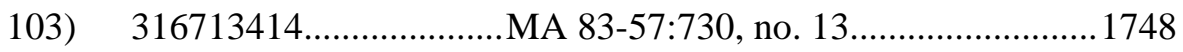

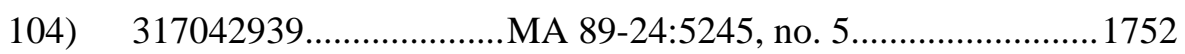

105) 317072013.......................

106) 317042947........................A 89-24:4541, no. 07........................1762

107) 317105000......................A 89-24:4298, no. 07......................1763

108) 317042955......................MA 89-24:4297, no. 06......................... 1765

109) 316713422......................A 83-57:1343, no. 47......................1768

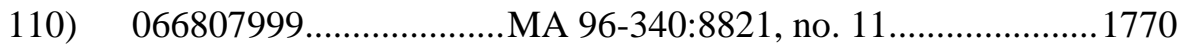

111) 317042963.......................A 89-24:3602, no. 09........................ 1770

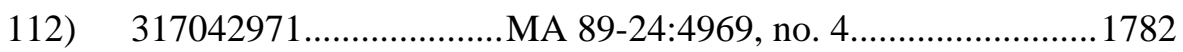

113) 31722719X......................A 93-14:7473, no. 08......................1783

114) 317025376.........................A 89-24:5518, no. 30..........................1784

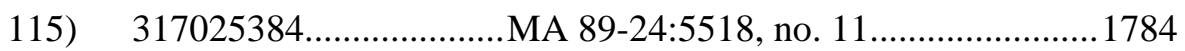

116) 317027638.....................MA 89-24:3867, no. 09......................1785

117) 317228277......................MA 93-14:7023, no. 07........................1785

118) $\quad 066767644 \ldots \ldots \ldots \ldots \ldots \ldots \ldots . . . . . M A ~ 96-340: 8178$, no. $14 \ldots \ldots \ldots \ldots \ldots \ldots \ldots . . . . .1786$

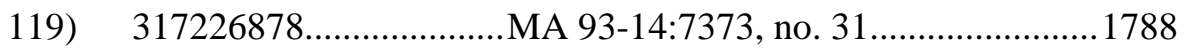

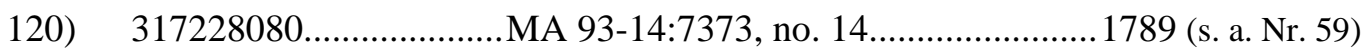




\section{Messiah}

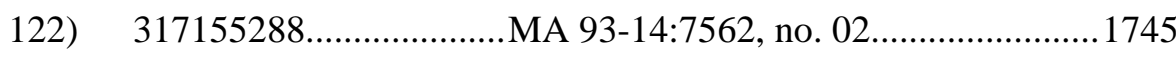

123) 316733016......................

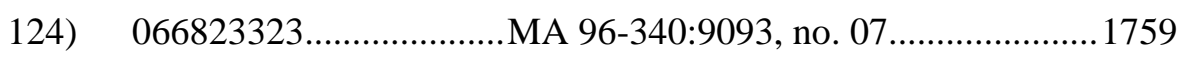

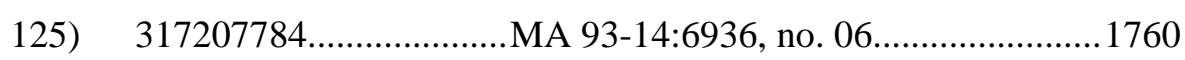

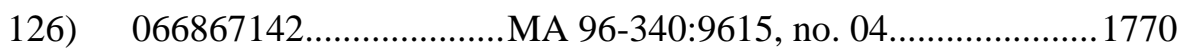

127) 31704074X..................... MA 89-24:3573, no. 13........................1770

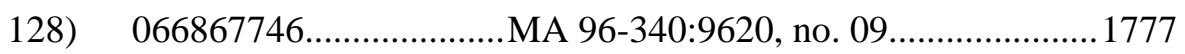

129) 317227181......................MA 93-14:7373, no. 45.......................1777

130) 31716547X..................... MA 93-14:7718, no 09..........................1782

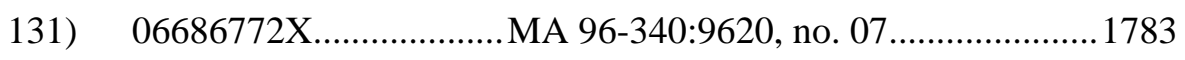

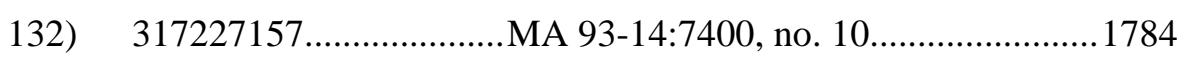

133) 317227165......................

134) 06686769X...................... 9A 96-340:9620, no. 04......................1785

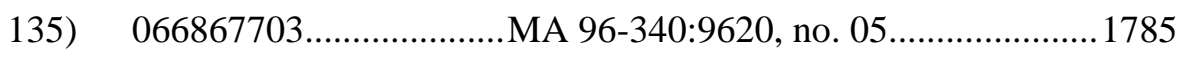

136) 317027611....................... 89-24:3867, no. 10........................1785

137) 317228056......................A 93-14:7473, no. 06......................1785

138) 317228064......................A 93-14:7400, no. 11.......................1785

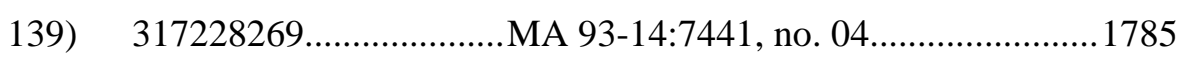

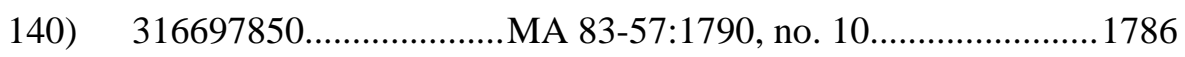

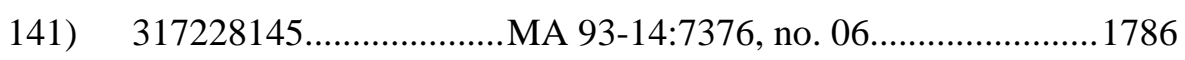

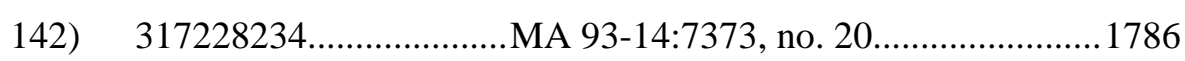

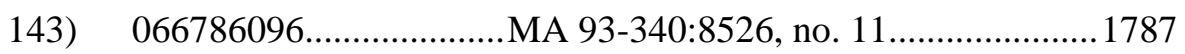

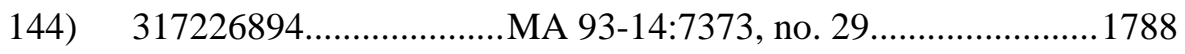

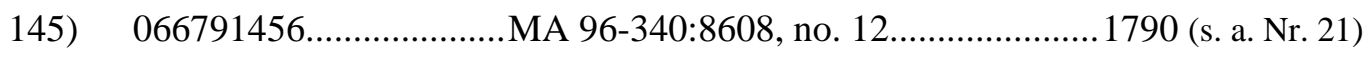

146) 317226711......................

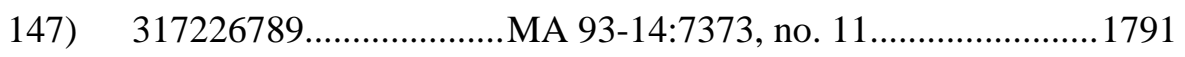

148) 317227653...................... MA 93-14:7373, no. 35........................ 1798

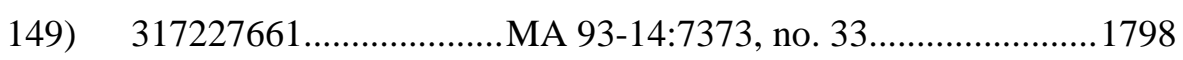


26 Ode for St. Cecilia's Day

\begin{tabular}{|c|c|}
\hline 50) & 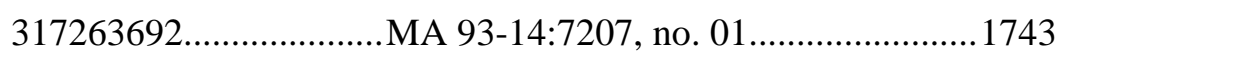 \\
\hline 51) & ...MA 93-14:6426, no. 04..... \\
\hline 152) & MA 93-14:6669, no. $17 \ldots$ \\
\hline 3$)$ &. MA 83-57:1494, no. $12 \ldots$. \\
\hline 154) & .. MA 93-14:6639, no. $10 \ldots$ \\
\hline 5) & ..MA 89-24:5518, no. $26 \ldots$ \\
\hline 6) & ..MA 89-24:3867, no. $15 .$. \\
\hline 157) & ..MA 89-24:3867, no. $16 . . .$. \\
\hline 8) & .. MA 89-24:5518, no. $10 .$. \\
\hline 59) & ... MA 89-24:3867, no. 04... \\
\hline
\end{tabular}

\section{Occasional oratorio}

\begin{tabular}{|c|c|}
\hline 60) &.. MA 89-24:5320, no. $10 \ldots \ldots \ldots \ldots . . . .$. \\
\hline 61$)$ & ... MA 96-340:8353, no. 07...... \\
\hline 2) & ... MA 93-14:6051, no. 01.. \\
\hline & ... MA 93-14:5623, no. 28. \\
\hline
\end{tabular}

28 Omnipotence

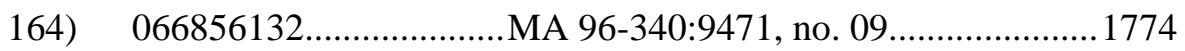

\section{Ottone, re di Germania}

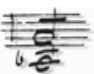

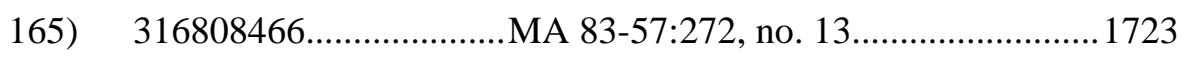

166) 317255142.....................MA 93-14:6644, no. 05......................1726 


\section{Redemption}

\begin{tabular}{|c|c|}
\hline 59) & 14.7373 33 \\
\hline 70) & .. MA 93-14:7376, no. $08 \ldots$. \\
\hline & ... MA 93-14:7376, no. $10 \ldots$. \\
\hline & .... MA 93-14:7376, no. $11 \ldots$. \\
\hline & ... MA 93-14:7373, no. 24.. \\
\hline & ...MA 93-14:7376, no. 09... \\
\hline & ......MA 93-14:7373, no. $22 \ldots$ \\
\hline & ....MA 93-14:7511, no. 03. \\
\hline & .......MA 93-14:7511, no. $02 \ldots$ \\
\hline & .......MA 93-14:7373, no. 21.. \\
\hline & .....MA 93-14:7373, no. 26.. \\
\hline & $317226819 \ldots \ldots \ldots \ldots \ldots \ldots . . . . M A ~ 93-14: 7373$, no. $25 \ldots$ \\
\hline & ......MA 93-14:7373, no. $27 \ldots$ \\
\hline & .......MA 93-14:7473, no. $07 \ldots$. \\
\hline & ... MA 93-14:7373, no. 28.. \\
\hline
\end{tabular}

\section{Riccardo I., re d' Inghilterra}

184) 316802824.

MA 83-57:272, no. 1

\section{Samson}

\begin{tabular}{|c|c|}
\hline 85) & 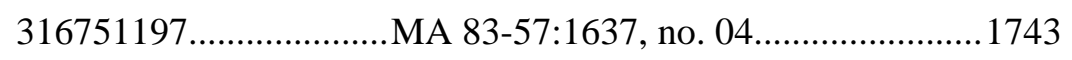 \\
\hline 6) & 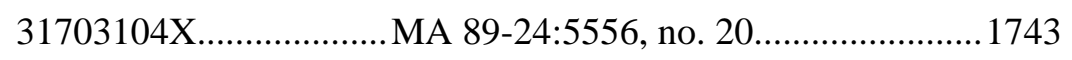 \\
\hline & ..............MA 89-24: \\
\hline
\end{tabular}




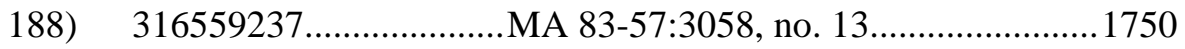

189) 317291823...................... MA 93-14:6425, no. 05........................1754

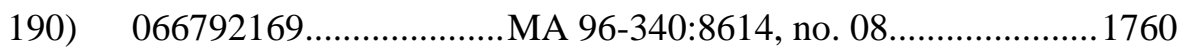

191) 316559245..................... MA 83-57:3058, no. 12......................1760

192) 317241702....................... 93-14:6710, no. 06.......................1760

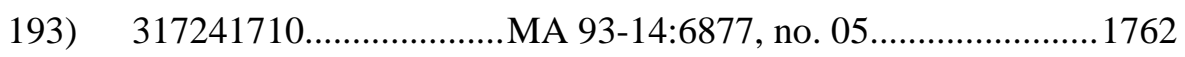

194) 317241729...................... 93 93-14:6709, no. 15.......................1768

195) 317165488...................... 9A 93-14:7718, no. 08.......................1782

196) 317227203...................... MA 93-14:7473, no. 09........................1783

197) 317228323...................... MA 93-14:7441, no. 02........................ 1785

198) 317228331..................... MA 93-14:6697, no. 06........................ 1785

199) 31722834X.....................

200) 316929115........................A 89-24:3520, no. 19........................1790

\section{Saul}

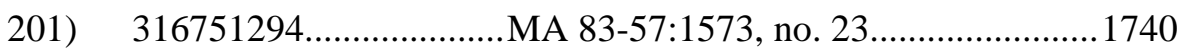

202) 317309110........................A 93-14:6082, no. 06.........................1750

\section{Semele}

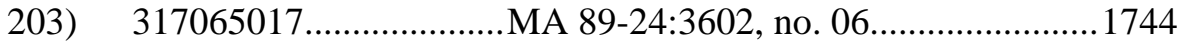

204) 066769647.......................A 96-340:8226, no. 09.....................1762

\section{Siroe, re di Persia}

205) $\quad 317095064 \ldots \ldots \ldots \ldots \ldots \ldots \ldots . . . . . M A ~ 89-24: 5527$, no. $12 \ldots \ldots \ldots \ldots \ldots \ldots \ldots \ldots . . . .1728$

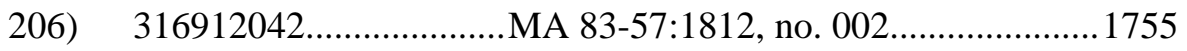

\section{Solomon}

207) 316754412. MA 83-57:1573, no. 26 1749 
208) 317309544.....................MA 93-14:5620, no. 3........................1759

209) 066771161......................MA 96-340:8265, no. 15......................1760

210) 317309536....................... 9A 93-14:6184, no. 05.......................1760

$39 \quad$ The spring

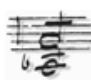

211) 316756822. MA 83-57:475, no. 42 1762

40 Susanna

212) 317065556.

MA 89-24:3602, no. 10 1759

41 The tears of music

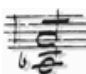

213) 316757195

MA 83-57:1540, no. 32 1760

$42 \quad$ Theodora

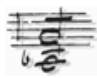

214) 31696056X

MA 89-24:5239, no. 3 1750

43 Tolomeo, re d' Egitto

215) 317243861. MA 93-14:6817, no. 05 1728

44 The triumph of time and truth

216) 316544124.....................MA 83-57:2136, no. 13....................... 1757

217) 316760765 .....................MA 83-57:1573, no. 25_.....................1758

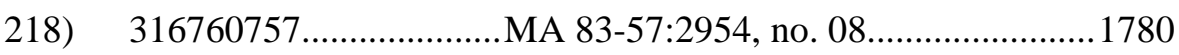


45 Selection from the works of Handel

219) 31683548X....................MA 83-57:1645, no. 16......................1763

220) 317023357.....................MA 89-24:5458, no. 12.....................1792

221) 317025058......................

222) 317025066.....................MA 89-24:5458, no. 14.......................1792

223) 317026356.....................MA 89-24:3628, no. 04......................1794

$46 \quad$ Andere musikalische Werke

Händel als sonst. beteiligte Person

224) 316579939.....................MA 83-57:990, no. 47.........................1724

225) 316551821......................MA 83-57:1013, no. 5..........................1739

226) 316739561.....................MA 83-57:1226, no. 30......................1745

227) 317319094....................... 9A 93-14:6050, no. 15........................1764

228) 317241435...................... 93 93-14:6993, no. 07.......................1786

229) 31665650X.......................A 83-57:579, no. 14..........................1791

\section{Textausgaben}

230) Memoirs of the life of the late George Frederic Handel 066780810 MA 96-340:8421, no. 01 1760

231) An account of the musical performances in Westminster-Abbey ... 317226401 MA 93-14:7307, no. 02 1784 316547298. MA 83-57:1501, no. 46 1785

232) Anecdotes of George Frederick Handel and John Christopher Smith 317007947 MA 89-24:5454, no. 5 1799 317220748. MA 93-14:6715, no. 06 1799 
233) The miscellaneous pieces, as set to music, by Geo. Fred. Handel 317215353. . MA 93-14:6712, no. 03 .1799

234) Die englischen Texte G. F. Händels 254780512 .MM 99-063(1). 1924

254780547 1924 MCC 4 DISS PHIL GÖTTINGEN 1924,Schröder,Alfred,1 


\section{Regis te $r$}

\subsection{A b k ür $\mathbf{z}$ ung s verze ich $n$ is}

\begin{tabular}{|c|c|}
\hline Abb. & Abbildung \\
\hline Abt. & Abteilung \\
\hline ad lib. & ad libitum (lat.) = nach Belieben \\
\hline Akad. & Akademie \\
\hline amerikan. & amerikanisch \\
\hline Anh. & Anhang \\
\hline Anm. & Anmerkung \\
\hline Anst. & Anstalt \\
\hline app. & appendix \\
\hline Arr. & Arrangement \\
\hline assoc. & association \\
\hline Aufführ. & Aufführung \\
\hline Aufl. & Auflage \\
\hline Auftr. & Auftrag \\
\hline Ausg. & Ausgabe \\
\hline Ausschn. & Ausschnitt \\
\hline Ausst. & Ausstellung \\
\hline Ausw. & Auswahl \\
\hline autogr. & autographiert \\
\hline Bd. & Band \\
\hline bearb. & bearbeitet \\
\hline beigef. & beigefügt \\
\hline Beih. & Beiheft \\
\hline Beil. & Beilage \\
\hline Beitr. & Beitrag \\
\hline Best.-Nr. & Bestell-Nummer \\
\hline betr. & betreffend \\
\hline Bibliogr. & Bibliographie \\
\hline $\mathrm{Bl}$. & Blatt \\
\hline brosch. & broschiert \\
\hline Buchh. & Buchhandlung \\
\hline $\mathrm{C}$ & copyright \\
\hline
\end{tabular}




\begin{tabular}{|c|c|}
\hline ca. & circa \\
\hline cloth. & clothed \\
\hline d. & der / des \\
\hline dargest. & dargestellt \\
\hline Darst. & Darstellung \\
\hline dat. & datiert \\
\hline demokrat. & demokratisch \\
\hline dergl. & dergleichen \\
\hline Diskogr. & Diskographie \\
\hline Diss. & Dissertation \\
\hline Dok. & Dokument \\
\hline Dr. & Druck \\
\hline dt. & deutsch \\
\hline durchges. & durchgesehen \\
\hline ed. & edition \\
\hline Einf. & Einführung \\
\hline eingeb. & eingebunden \\
\hline Einheitssacht. & Einheitssachtitel \\
\hline Einl. & Einleitung \\
\hline engl. & englisch \\
\hline enth. & enthält \\
\hline erstm. & erstmals \\
\hline erw. & erweitert \\
\hline europ. & europäisch \\
\hline Ex. & Exemplar \\
\hline f. & für \\
\hline fälschl. & fälschlich \\
\hline Faks. / facs. & Faksimile \\
\hline Forts. & Fortsetzung \\
\hline franz. & französisch \\
\hline Frontisp. & Frontispiz \\
\hline geb. & gebunden \\
\hline geh. & geheftet \\
\hline gem. & gemäß \\
\hline ges. & gesammelt \\
\hline Ges. & Gesellschaft \\
\hline
\end{tabular}




\begin{tabular}{|c|c|}
\hline Gesch. & Geschenk \\
\hline gest. & gestochen \\
\hline getr. & getrennt \\
\hline gr. & groß \\
\hline graph. & graphisch \\
\hline $\mathrm{H}$. & Heft \\
\hline Hauptw & Hauptwerk \\
\hline hbk. & hardback \\
\hline hrsg. & herausgegeben \\
\hline hs. & handschriftlich \\
\hline HS-Nr. & Hochschulschriftennummer \\
\hline i.e. & id est (lat.) = das ist (in Wirklichkeit) \\
\hline Ikonogr. & Ikonographie \\
\hline Ill. & Illustration \\
\hline Impr. & Impressum \\
\hline Inh.-Verz. & Inhaltsverzeichnis \\
\hline insges. & insgesamt \\
\hline Inst. & Institut \\
\hline internat. & international \\
\hline Interpr. & Interpret \\
\hline introd. & introduction \\
\hline ital. & italienisch \\
\hline Jg. & Jahrgang \\
\hline Jh. & Jahrhundert \\
\hline Kal. & Kalender \\
\hline kart. & kartoniert \\
\hline Kat. & Katalog \\
\hline $\mathrm{kl}$. & klein \\
\hline Klavierausz. & Klavierauszug \\
\hline Komm. & Kommission \\
\hline komp. & komponiert \\
\hline Kongr. & Kongreß \\
\hline krit. & kritisch \\
\hline Kt. & Karte \\
\hline Kupferst. & Kupferstich \\
\hline lat. & lateinisch \\
\hline
\end{tabular}




\begin{tabular}{|c|c|}
\hline Lfg. & Lieferung \\
\hline Literaturverz. & Literaturverzeichnis \\
\hline Ltg. & Leitung \\
\hline Lw. & Leinwand \\
\hline maschinenschriftl. & maschinenschriftlich \\
\hline MBW & mehrbändiges Werk \\
\hline Min. & Minute \\
\hline Ms. & Manuskript \\
\hline Musikalienh. & Musikalienhandlung \\
\hline Musikdr. & Musikdruck \\
\hline Nebent. & Nebentitel \\
\hline N.F. & Neue Folge \\
\hline Nachdr. & Nachdruck \\
\hline Neudr. & Neudruck \\
\hline Nachtr. & Nachtrag \\
\hline Nachw. & Nachwort \\
\hline Notenbeisp. & Notenbeispiel \\
\hline not. & notiert \\
\hline Nr. & Nummer \\
\hline Op. & Opus \\
\hline orig. & original \\
\hline Parallelsacht. & Parallelsachtitel \\
\hline pbk. & paperback \\
\hline Pl.-Nr. & Platten-Nummer \\
\hline Portr. & Porträt \\
\hline Pp. & Pappband \\
\hline PPN & PICA-Produktionsnummer \\
\hline pr. & printed \\
\hline pref. & preface \\
\hline pt. & part \\
\hline publ. & published \\
\hline Red. & Redaktion \\
\hline Reg. & Register \\
\hline Reprod. & Reproduktion \\
\hline Reprogr. & Reprographie \\
\hline rev. & revidiert \\
\hline
\end{tabular}




\begin{tabular}{|c|c|}
\hline ...s. & ...seite \\
\hline s.a. & sine anno (lat.) = ohne Jahr \\
\hline Ser. & Serie \\
\hline Sign. & Signatur \\
\hline s.l. & sine loco (lat.) = ohne Ort \\
\hline s.n. & sine nomine (lat.) = ohne Verlag \\
\hline soc. & society \\
\hline St. & Stimme \\
\hline Sup. / Suppl. & Supplement \\
\hline Tab. & Tabelle \\
\hline Taf. & Tafel \\
\hline teilw. & teilweise \\
\hline Titelaufn. & Titelaufnahme \\
\hline tschech. & tschechisch \\
\hline Tsd. & Tausend \\
\hline u.a. & und andere \\
\hline u.d.T. & unter dem Titel \\
\hline übers. & übersetzt \\
\hline übertr. & übertragen \\
\hline überw. & überwiegend \\
\hline ungar. & ungarisch \\
\hline ungez. & ungezählt \\
\hline Univ. & Universität \\
\hline $\mathrm{V}$. & von \\
\hline veränd. & verändert \\
\hline Veranst. & Veranstalter \\
\hline Verf. & Verfasser \\
\hline Verl. & Verlag \\
\hline verm. & vermehrt \\
\hline veröff. & veröffentlicht \\
\hline vol. & volume \\
\hline Vorg. & Vorgänger \\
\hline vorh. & vorhanden \\
\hline Vorr. & Vorrede \\
\hline Vorw. & Vorwort \\
\hline Werkverz. & Werkverzeichnis \\
\hline
\end{tabular}




\begin{tabular}{ll}
\hline Widmungsr. & Widmungsrede \\
\hline Wiss. & Wissenschaft \\
\hline zahlr. & zahlreich \\
\hline Zsfassung & Zusammenfassung \\
\hline zsgeb. & zusammengebunden \\
\hline zsgest. & zusammengestellt \\
\hline Zsstellung & Zusammenstellung \\
\hline zugl. & zugleich \\
\hline
\end{tabular}




\subsection{A b kürzungen von Instrumentenund Stimmen}

\begin{tabular}{ll}
\hline Bc & Basso continuo \\
\hline Blfl & Blockflöte \\
\hline Cemb & Cembalo \\
\hline Fg & Fagott \\
\hline Fl & Flöte \\
\hline Hf & Harfe \\
\hline Hr & Horn \\
\hline Kb & Kontrabaß \\
\hline Klar & Klarinette \\
\hline Kl & Klavier \\
\hline Ob & Oboe \\
\hline Orch & Orchester \\
\hline Org & Orgel \\
\hline Pk & Pauke \\
\hline Sopr & Sopran \\
\hline$\ldots$. st. & $\cdots$..stimme \\
\hline Ten & Tenor \\
\hline Trp & Trompete \\
\hline Va & Viola \\
\hline Vagb & Viola da gamba \\
\hline Vc & Violoncello \\
\hline Vl & Violine \\
\hline &
\end{tabular}


17. S i g n a t u r - Verzeich n is

\section{MUS I - MUS VIII}

$2^{\circ}$ MUS I - VIII

1) 2 MUS III, 1047

2) 2 MUS VII, 340:1 165

3) 2 MUS VII, 340:2 137

4) 2 MUS VII, 340:3 134

5) 2 MUS VII, 340:4 136

6) 2 MUS VII, 340:5 142

7) 2 MUS VII, 340:6 165

8) 2 MUS VII, 340:7 148

9) 2 MUS VII, 340:8 141

10) 2 MUS VII, 340:9 138

11) 2 MUS VII, 340:10 133

12) 2 MUS VII, 340:11 141

13) 2 MUS VII, 340:12 138

14) 2 MUS VII, 340:13 135

15) 2 MUS VII, 340:14 135

16) 2 MUS VII, 340:15 139

17) 2 MUS VII, 340:16 139

18) 2 MUS VII, 341:1 71

19) 2 MUS VII, 341:2 71

20) 2 MUS VII, 341:3 72

21) 2 MUS VII, 341:4 72

22) 2 MUS VII, 341:5 72

23) 2 MUS VII, 341:6 73

24) 2 MUS VII, 341:7 73

25) 2 MUS VII, 341:8 73

26) 2 MUS VII, 341:9 74

27) 2 MUS VII, 341:10 74

28) 2 MUS VII, 341:11 74

29) 2 MUS VII, 341:12 75

30) 2 MUS VII, 341:13 75

31) 2 MUS VII, 341:14 75

32) 2 MUS VII, 341:15 76 
33) 2 MUS VII, 341:16 76

34) 2 MUS VII, 341:17 76

35) 2 MUS VII, 341:18 77

36) 2 MUS VII, 341:19 77

37) 2 MUS VII, 341:20 77

38) 2 MUS VII, 341:21 78

39) 2 MUS VII, 341:22 78

40) 2 MUS VII, 341:23 78

41) 2 MUS VII, 341:24 79

42) 2 MUS VII, 341:25

43) 2 MUS VII, 341:26 79

44) 2 MUS VII, 341:27 80

45) 2 MUS VII, 341:28 80

46) 2 MUS VII, 341:29 80

47) 2 MUS VII, 341:30 81

48) 2 MUS VII, 341:30,3 81

49) 2 MUS VII, 341:31 81

50) 2 MUS VII, 341:32 82

51) 2 MUS VII, 341:32<2> 82

52) 2 MUS VII, 341:33 82

53) 2 MUS VII, 341:34 83

54) 2 MUS VII, 341:35 83

55) 2 MUS VII, 341:36 83

56) 2 MUS VII, 341:37 84

57) 2 MUS VII, 341:38 84

58) 2 MUS VII, 341:39 84

59) 2 MUS VII, 341:40 85

60) 2 MUS VII, 341:41 85

61) 2 MUS VII, 341:42 85

62) 2 MUS VII, 341:43 86

63) 2 MUS VII, 341:44 86

64) 2 MUS VII, 341:45 86

65) 2 MUS VII, 341:46A 87

66) 2 MUS VII, 341:46B 87

67) 2 MUS VII, 341:47 87

68) 2 MUS VII, 341:47,SUP 88

69) 2 MUS VII, 341:48 88 
70) 2 MUS VII, 341:50 88

71) 2 MUS VII, 341:51 89

72) 2 MUS VII, 341:52A $\quad 89$

73) 2 MUS VII, 341:52B $\quad 89$

74) 2 MUS VII, 341:53 90

75) 2 MUS VII, 341:54 90

76) 2 MUS VII, 341:55 90

77) 2 MUS VII, 341:56 91

78) 2 MUS VII, 341:57 91

79) 2 MUS VII, 341:58 91

80) 2 MUS VII, 341:58<2> 92

81) 2 MUS VII, 341:59 92

82) 2 MUS VII, 341:60 92

83) 2 MUS VII, 341:61 93

84) 2 MUS VII, 341:62 93

85) 2 MUS VII, 341:63 93

86) 2 MUS VII, 341:64 94

87) 2 MUS VII, 341:65 94

88) 2 MUS VII, 341:66 94

89) 2 MUS VII, 341:67 95

90) 2 MUS VII, 341:68 95

91) 2 MUS VII, 341:69 95

92) 2 MUS VII, 341:70 96

93) 2 MUS VII, 341:71 96

94) 2 MUS VII, 341:72 96

95) 2 MUS VII, 341:73 97

96) 2 MUS VII, 341:74 97

97) 2 MUS VII, 341:75 97

98) 2 MUS VII, 341:76 98

99) 2 MUS VII, 341:77 98

100) 2 MUS VII, 341:78 98

101) 2 MUS VII, 341:79 99

102) 2 MUS VII, 341:80 99

103) 2 MUS VII, 341:81 99

104) 2 MUS VII, 341:82 100

105) 2 MUS VII, 341:83 100

106) 2 MUS VII, 341:84 100 
$\begin{array}{lll}107) & 2 \text { MUS VII, 341:85 } & 101 \\ 108) & 2 \text { MUS VII, 341:86 } & 101 \\ 109) & 2 \text { MUS VII, 341:87 } & 101 \\ 110) & 2 \text { MUS VII, 341:88 } & 102 \\ 111) & 2 \text { MUS VII, 341:89 } & 102 \\ 112) & 2 \text { MUS VII, 341:90 } & 102 \\ 113) & 2 \text { MUS VII, 341:91 } & 103 \\ 114) & 2 \text { MUS VII, 341:92 } & 103 \\ 115) & 2 \text { MUS VII, 341:93 } & 104 \\ 116) & 2 \text { MUS VII, 341:94 } & 104 \\ 117) & 2 \text { MUS VII, 352/a } & 197 \\ 118) & 2 \text { MUS VII, 354 } & 138 \\ 119) & 2 \text { MUS VII, 354/a } & 139,197 \\ 120) & 2 \text { MUS VII, 364 RARA } & 140 \\ 121) & 2 \text { MUS VII, 367 } & 192 \\ 122) & 2 \text { MUS VII, 381 } & 195 \\ 123) & 2 \text { MUS VII, 384 } & 196 \\ 124) & 2 \text { MUS VII, 386 } & 150 \\ 125) & 2 \text { MUS VII, 402 } & 132 \\ 126) & 2 \text { MUS VII, 403 } & 132 \\ 127) & 2 \text { MUS VII, 410 } & 173\end{array}$

$4^{\circ}$ MUS I - VIII

128) 4 MUS III, 1060

129) 4 MUS III, 1085

130) 4 MUS III, 1092

131) 4 MUS III, 1094

132) 4 MUS III, 9200

133) 4 MUS III, 9205

134) 4 MUS III, 9220 (1) 41

135) 4 MUS III, $9220(5) \quad 41$

136) 4 MUS V, 450:4 203, 204, 206

137) 4 MUS V, 450:6 206 


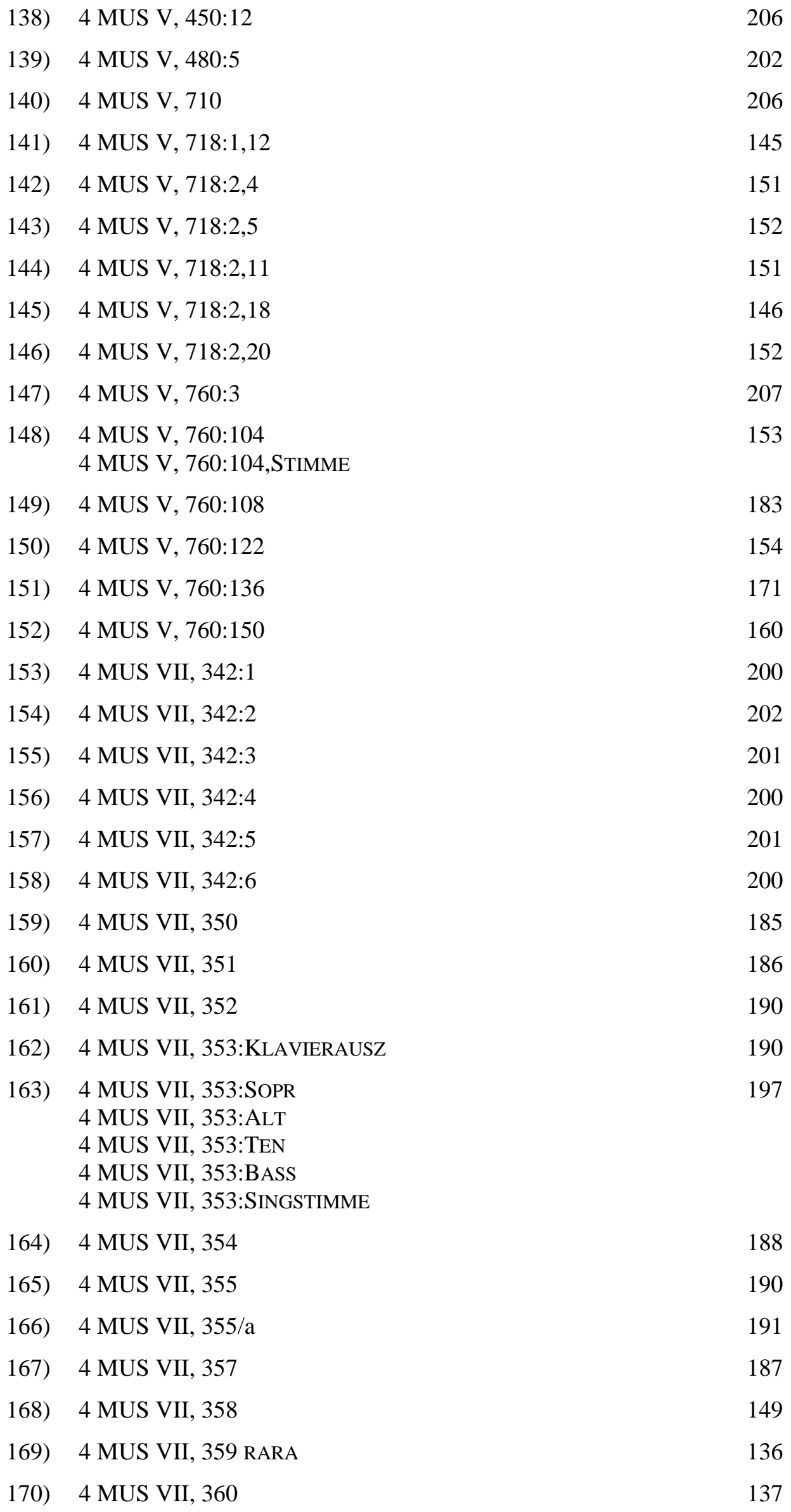


171) 4 MUS VII, $361 \quad 188$

172) 4 MUS VII, 362:PARTITUR 140

173) 4 MUS VII, 362:SOPR 198

4 MUS VII, 362:ALT

4 MUS VII, 362:TEN

4 MUS VII, 362:BASS

4 MUS VII, 362:BEIL

174) 4 MUS VII, 365

175) 4 MUS VII, 368

176) 4 MUS VII, 370

177) 4 MUS VII, 371

178) 4 MUS VII, 371:BASS 195

179) 4 MUS VII, 371:KLAVIERAUSZ 184

180) 4 MUS VII, 372

181) 4 MUS VII, 373

182) 4 MUS VII, 375

183) 4 MUS VII, $377 \quad 189$

184) 4 MUS VII, 377/a 189

185) 4 MUS VII, 378

186) 4 MUS VII, 379

187) 4 MUS VII, 381:KLAVIERAUSZ 189

188) 4 MUS VII, 381:SOPR/I 196

4 MUS VII, 381:SOPR/II

4 MUS VII, 381:ALT

4 MUS VII, 381:TEN

4 MUS VII, 381:BASS

189) 4 MUS VII, 385

190) 4 MUS VII, 385/1 148

191) 4 MUS VII, 388

192) 4 MUS VII, 389

193) 4 MUS VII, 390

194) 4 MUS VII, 391

195) 4 MUS VII, 392

196) 4 MUS VII, $400 \quad 184$

197) 4 MUS VII, 401

198) 4 MUS VII, 409/1 193

199) 4 MUS VII, 416

200) 4 MUS VII, 419

201) 4 MUS VII, 425 
$\begin{array}{lll}202) & 4 \text { MUS VII, 426/1 } & 146 \\ 203) & 4 \text { MUS VII, 426/2 } & 144 \\ 204) & 4 \text { MUS VII, 426/3 } & 144 \\ 205) & 4 \text { MUS VII, 426/6 } & 145 \\ 206) & 4 \text { MUS VII, 427:7 } & 169 \\ 207) & 4 \text { MUS VII, 427:8 } & 169 \\ 208) & 4 \text { MUS VII, 427:9 } & 169 \\ 209) & 4 \text { MUS VII, 427:10 } & 170 \\ 210) & 4 \text { MUS VII, 427:11 } & 170 \\ 211) & 4 \text { MUS VII, 427:12 } & 170 \\ 212) & 4 \text { MUS VII, 2855:2,2 } & 182 \\ 213) & 4 \text { MUS VIII, 2600:8 } & 179\end{array}$

$8^{\circ}$ MUS I - VIII

214) 8 MUS I, $83 \quad 20$

215) 8 MUS I, $86 \quad 19$

216) 8 MUS I, $100<7>21$

217) 8 MUS I, 1035:11 157

218) 8 MUS I, 1035:12 157

219) 8 MUS I, 1035:13 156

220) 8 MUS I, 1035:14 157

221) 8 MUS I, 1035:FL/BC 158

222) 8 MUS I, 2085:76 167

223) 8 MUS I, 2105:5 13

224) 8 MUS I, 2105:6 14

225) 8 MUS I, 2744

226) 8 MUS I, 2826

227) 8 MUS II, 225:4 20

228) 8 MUS II, 225:4 <2> 20

229) 8 MUS II, 746:1,NOTEN 22

230) 8 MUS II, 746:1,TEXT 21

231) 8 MUS II, 2379:2,1 24

232) 8 MUS II, 2700:1 70 
233) 8 MUS II, 2700:2 70

234) 8 MUS III, $84: 3$

235) 8 MUS III, 248

236) 8 MUS III, $248<3>\quad 23$

237) 8 MUS III, 249

238) 8 MUS III, 251

239) 8 MUS III, 374

240) 8 MUS III, 1040

241) 8 MUS III, $1043 \quad 8$

242) 8 MUS III, 1050

243) 8 MUS III, 1053:1 3

244) 8 MUS III, 1053:2 3

245) 8 MUS III, 1053:3,1 3

246) 8 MUS III, 1053/g:2/3 214

247) 8 MUS III, 1056

248) 8 MUS III, 1064

249) 8 MUS III, 1065/i 11

250) 8 MUS III, 1066 (1921) 42

251) 8 MUS III, 1067 (1922) 42

252) 8 MUS III, 1067 (1923) 42

253) 8 MUS III, 1067 (1924) 42

254) 8 MUS III, 1067 (1927) - (Forts. mit ZA 87468) 42

255) 8 MUS III, 1068

256) 8 MUS III, 1070

257) 8 MUS III, 1072

258) 8 MUS III, 1075

259) 8 MUS III, 1089:1 35

260) 8 MUS III, 1089:2 35

261) 8 MUS III, 1089:3 35

262) 8 MUS III, 1089:4 35

263) 8 MUS III, 1089:5 35

264) 8 MUS III, 1089:6 - (Forts. mit 8 Z MUS 119) 35

265) 8 MUS III, 1093

266) 8 MUS III, 1096

267) 8 MUS III, 1098

268) 8 MUS III, 1099

269) 8 MUS III, $1140 \quad 21$ 
270) 8 MUS III, 9210

271) 8 MUS III, 9213

272) 8 MUS III, 9216

273) 8 MUS IV, $880 \quad 20$

274) 8 MUS V, 233:1 227

275) 8 MUS V, 520:IND 31

276) 8 MUS V, 520:263 177

277) 8 MUS V, 520:264 173

278) 8 MUS V, 520:265 173

279) 8 MUS V, 520:266 174

280) 8 MUS V, 520:267 174

281) 8 MUS V, 520:268 174

282) 8 MUS V, 520:269 175

283) 8 MUS V, 520:270 175

284) 8 MUS V, 520:271 175

285) 8 MUS V, 520:272 176

286) 8 MUS V, 520:273 176

287) 8 MUS V, 520:274 176

288) 8 MUS V, 520:380 178

289) 8 MUS V, 520:381 178

290) 8 MUS V, 520:382 178

291) 8 MUS V, 520:956 140

292) 8 MUS V, 2450

293) 8 MUS V, $2750 \quad 204$

294) 8 MUS V, $3330<2>\quad 154$

$\begin{array}{ll}\text { 295) } 8 \text { MUS V, } 3610 & 205,207\end{array}$

296) 8 MUS VII, 354:SOPR 198

8 MUS VII, 354:ALT

8 MUS VII, 354:TEN

8 MUS VII, 354:BASS

297) 8 MUS VII, 355:SOPR.ALT 198

8 MUS VII, 355:TEN.BASS

298) 8 MUS VII, 356

299) 8 MUS VII, 371:SOPR.ALT 195

4 MUS VII, 371:TEN.BASS

300) 8 MUS VII, 374:SOPR 199

8 MUS VII, 374:ALT

8 MUS VII, 374:TEN

8 MUS VII, 374:BASS 
301) 8 MUS VII, 376:SOPR.ALT 196

8 MUS VII, 376:TEN.BASS

302) 8 MUS VII, 382:KLAVIERAUSZ 194

303) 8 MUS VII, 382:SOPR 199

8 MUS VII, 382:ALT

8 MUS VII, 382:TEN

8 MUS VII, 382:BASS

304) 8 MUS VII, 387:SOPR.TEN

8 MUS VII, 387:ALT.BASS

199

8 MUS VII, 387:SOPR

8 MUS VII, 387:ALT

8 MUS VII, 387:TEN

8 MUS VII, 387:BASS

8 MUS VII, 387:STIMME

305) 8 MUS VII, 404

306) 8 MUS VII, $405 \quad 216$

307) 8 MUS VII, $406 \quad 211$

308) 8 MUS VII, $407 \quad 211$

309) 8 MUS VII, 408

310) 8 MUS VII, 409

311) 8 MUS VII, 413

312) 8 MUS VII, 415

313) 8 MUS VII, 418

\section{$4^{\circ} / 8^{\circ}$ MUS}

\section{$4^{\circ}$ MUS}

314) 4 MUS 57:1,PARTITUR 146

315) 4 MUS 57:1,KLAVIERAUSZ 191

316) 4 MUS 57:2,PARTITUR 145

317) 4 MUS 57:2,KLAVIERAUSZ 189

318) 4 MUS $69 \quad 10$

319) 4 MUS 215

320) 4 MUS $457 \quad 184$

321) 4 MUS $708 \quad 69$

322) 4 MUS 936:1,1,HAUPTBD 105

323) 4 MUS 936:1,1,KRIT.BERICHT 127 
324) 4 MUS 936:1,2 105

325) 4 MUS 936:1,5 106

326) 4 MUS 936:1,6,HAUPTBD 106

327) 4 MUS 936:1,6,KRIT.BERICHT 127

328) 4 MUS 936:1,7,HAUPTBD 106

329) 4 MUS 936:1,7,KRIT.BERICHT 127

330) 4 MUS 936:1,8 107

331) 4 MUS 936:1,9,1 107

332) 4 MUS 936:1,13,HAUPTBD 107

333) 4 MUS 936:1,13,KRIT.BERICHT 128

334) 4 MUS 936:1,14,1 108

335) 4 MUS 936:1,14,2 108

336) 4 MUS 936:1,16,HAUPTBD 108

337) 4 MUS 936:1,16,KRIT.BERICHT 128

338) 4 MUS 936:1,17,HAUPTBD 109

339) 4 MUS 936:1,17,KRIT.BERICHT 128

340) 4 MUS 936:1,28,HAUPTBD 109

341) 4 MUS 936:1,28,KRIT.BERICHT 129

342) 4 MUS 936:1,31,HAUPTBD 109

343) 4 MUS 936:1,31,KRIT.BERICHT 129

344) 4 MUS 936:2,4,1 110

345) 4 MUS 936:2,4,2 110

346) 4 MUS 936:2,8,HAUPTBD 110

347) 4 MUS 936:2,8,KRIT.BERICHT 129

348) 4 MUS 936:2,9,1 111

349) 4 MUS 936:2,9,2 111

350) 4 MUS 936:2,13 111

351) 4 MUS 936:2,15 112

352) 4 MUS 936:2,16 112

353) 4 MUS 936:2,22 112

354) 4 MUS 936:2,23 113

355) 4 MUS 936:2,28 113

356) 4 MUS 936:2,39 113

357) 4 MUS 936:2,40 114

358) 4 MUS 936:2,41 114

359) 4 MUS 936:2,KLAVIERAUSZ 114

360) 4 MUS 936:2,SUP,1 115 


\begin{tabular}{|c|c|c|}
\hline 361) & 4 MUS 936:3,1 & 115 \\
\hline 362) & 4 MUS 936:3,3 & 115 \\
\hline 363) & 4 MUS 936:3,4 & 116 \\
\hline 364) & 4 MUS 936:3,5 & 116 \\
\hline 365) & 4 MUS 936:3,6 & 116 \\
\hline 366) & 4 MUS 936:3,9 & 117 \\
\hline 367) & 4 MUS 936:3,12 & 117 \\
\hline 368) & 4 MUS 936:4,1 & 117 \\
\hline 369) & 4 MUS 936:4,2 & 118 \\
\hline 370) & $\begin{array}{l}4 \text { MUS 936:4,3,HAUPTBD } \\
4 \text { MUS 936:4,3,STIMME }\end{array}$ & 119 \\
\hline 371) & $\begin{array}{l}4 \text { MUS 936:4,4,HAUPTBD } \\
4 \text { MUS 936:4,4,STIMME }\end{array}$ & 119 \\
\hline 372) & 4 MUS 936:4,5 & 120 \\
\hline 373) & 4 MUS 936:4,6 & 121 \\
\hline 374) & 4 MUS 936:4,7,KRIT.BERICHT & 130 \\
\hline 375) & 4 MUS 936:4,8 & 121 \\
\hline 376) & $\begin{array}{l}4 \text { MUS 936:4,9,HAUPTBD } \\
4 \text { MUS 936:4,9,STIMME }\end{array}$ & 121 \\
\hline 377) & $\begin{array}{l}4 \text { MUS 936:4,10,1,HAUPTBD } \\
4 \text { MUS 936:4,10,1,STIMME }\end{array}$ & 122 \\
\hline 378) & $\begin{array}{l}4 \text { MUS 936:4,10,2,HAUPTBD } \\
4 \text { MUS 936:4,10,2,STIMME }\end{array}$ & 122 \\
\hline 379) & 4 MUS 936:4,10,2,KRIT.BERICHT & 130 \\
\hline 380) & 4 MUS 936:4,11,HAUPTBD & 122 \\
\hline 381) & 4 MUS 936:4,11,KRIT.BERICHT & 130 \\
\hline 382) & 4 MUS 936:4,12 & 123 \\
\hline 383) & 4 MUS 936:4,13 & 123 \\
\hline 384) & 4 MUS 936:4,14,HAUPTBD & 123 \\
\hline 385) & 4 MUS 936:4,14,KRIT.BERICHT & 131 \\
\hline 386) & 4 MUS 936:4,15 & 124 \\
\hline 387) & 4 MUS 936:4,16 & 124 \\
\hline 388) & $\begin{array}{l}4 \text { MUS 936:4,18,HAUPTBD } \\
4 \text { MUS 936:4,18,STIMME }\end{array}$ & 125 \\
\hline 389) & 4 MUS 936:4,19 & 125 \\
\hline 390) & 4 MUS 936:5,3 & 125 \\
\hline 391) & 4 MUS 936:5,4 & 126 \\
\hline 392) & 4 MUS 936:5,5 & 126 \\
\hline 393) & 4 MUS 936:SUP,1 & 26 \\
\hline
\end{tabular}


394) 4 MUS 936:HANDBUCH,1

395) 4 MUS 936:HANDBUCH, 2

396) 4 MUS 936:HANDBUCH,3

397) 4 MUS 936:HANDBUCH,4

398) 4 MUS 1036

147

$\begin{array}{rll}\mathbf{8}^{\circ} \text { MUS } & & \\ 399) & 8 \text { MUS 29 } & 213 \\ 400) & 8 \text { MUS 119 } & 154 \\ 401) & 8 \text { MUS 129 } & 8 \\ 402) & 8 \text { MUS 153 } & 2 \\ 403) & 8 \text { MUS 277 } & 212 \\ 404) & 8 \text { MUS 349 } & 151 \\ 405) & 8 \text { MUS 418 } & 208 \\ 406) & 8 \text { MUS 448 } & 12 \\ 407) & 8 \text { MUS 759 } & 58\end{array}$

\section{$4^{\circ} / 8^{\circ} \mathrm{Z}$ MUS}

$4^{\circ} \mathrm{Z}$ MUS

$\begin{array}{lll}\text { 408) } & \text { 4 Z MUS 91:3 } & 156 \\ 409) & 4 \text { Z MUS 91:15 } & 161 \\ 410) & 4 \text { Z MUS 91:112 } & 156 \\ 411) & 4 \text { Z MUS 91:242 } & 159 \\ 412) & 4 \text { Z MUS 91:243 } & 160 \\ 413) & 4 \text { Z MUS 91:244 } & 160 \\ 414) & 4 \text { Z MUS 91:251 } & 155 \\ 415) & 4 \text { Z MUS 91:263 } & 165 \\ 416) & 4 \text { Z MUS 91:269 } & 180 \\ 417) & 4 \text { Z MUS 94:1 } & 182 \\ 418) & 4 \text { Z MUS 94:10 }\end{array}$ 


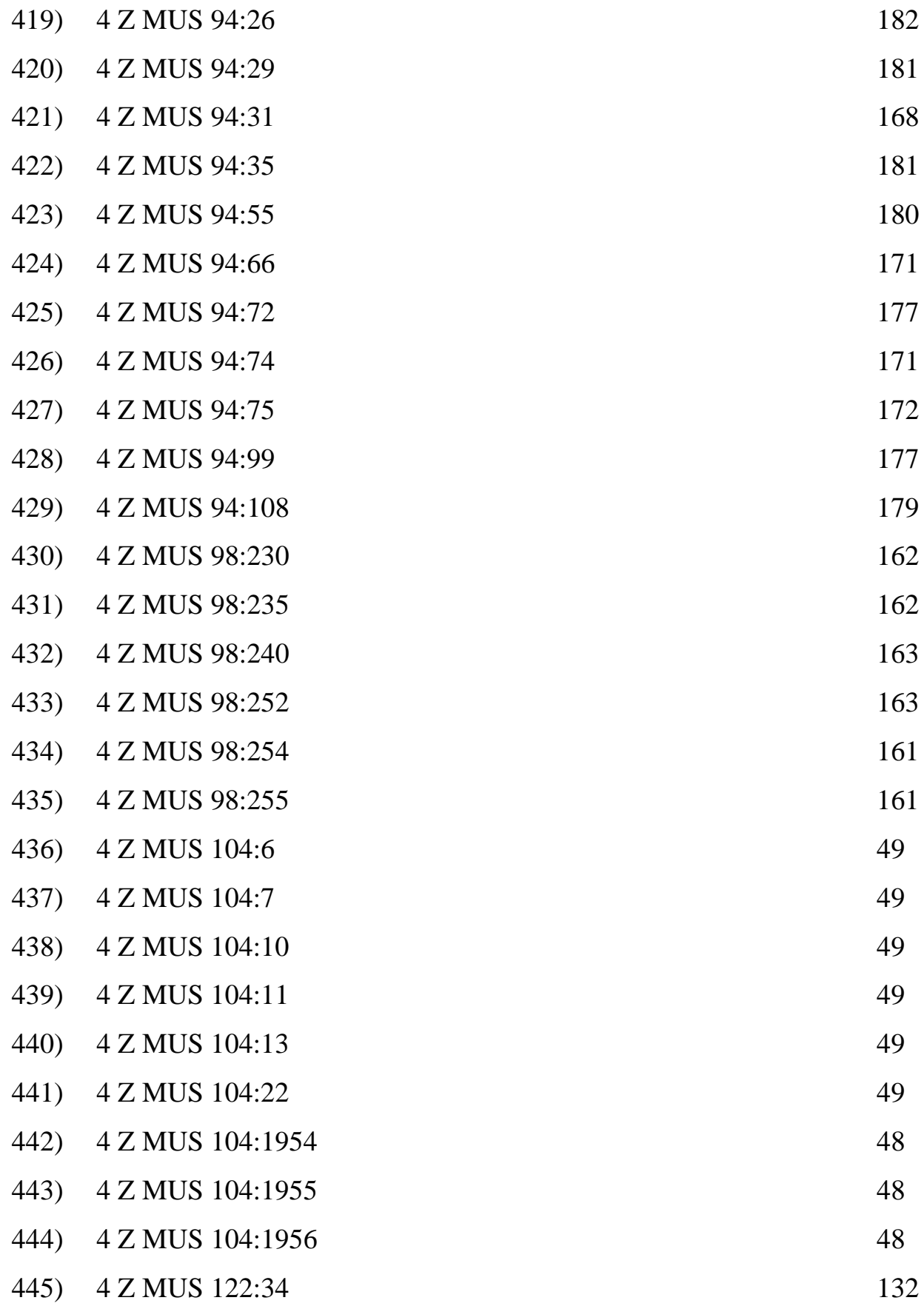

\section{$8^{\circ} \mathrm{Z}$ MUS}

446) 8 Z MUS 17:76 149

447) 8 Z MUS 17:566/567 150

448) 8 Z MUS 17:629/630 164

449) 8 Z MUS 17:654/655 164 
450) 8 Z MUS 17:666/667

451) 8 Z MUS 119:1-46

452) 8 Z MUS $128: 2$

FA / FB und ZA / ZB

\section{$F A / F B$}

453) FA 1874:1 16

454) FA 1874:2 17

455) FA 3135:1 37

456) FA 3135:2 36

457) FA 3135:3 36

458) FA 3135:4 36

459) FA 9250:2 24

460) FB 574:10,28,1,1,HAUPTBD 133

461) FB 574:10,28,1,1,KRIT.BERICHT 216

462) FB 574:10,28,1,2,HAUPTBD 141

463) FB 574:10,28,1,3 142

464) FB 574:10,28,1,4 143

465) FB 18044:4,1 118

466) FB 18044:4,2 118

467) FB 18044:4,3,HAUPTBD 119 FB 18044:4,3,STIMME

468) FB 18044:4,4,HAUPTBD 120

469) FB 18044:4,5 120

470) FB 22480:2,7 150

471) FB 2624:4,2 24

472) FB 12165:5 25 


\section{$\mathbf{Z A} / \mathbf{Z B}$}

473) ZA 16436:36 5

474) ZA 17555:13 11

475) ZA 25934:1308 181

476) ZA 27855:1977,39 59

477) ZA 27855:1979,8 60

478) ZA 27855:1980,7 60

479) ZA 27855:1981,14 61

480) ZA 27855:1982,21 61

481) ZA 27855:1983,24 62

482) ZA 27855:1984,38 62

483) ZA 27855:1988,26 64

484) ZA 30787:7 214

485) ZA 39691:66 19

486) ZA 40336:717 32

487) ZA 42204:4 26

488) ZA 46593:38 15

489) ZA 49162:24 59

490) ZA 49162:34 63

491) ZA 51449:10 172

492) ZA 56715:60 54

493) ZA 60330

494) ZA 67246:1 14

495) ZA 67246:2 64

496) ZA 67246:3 65

497) ZA 67246:4 65

498) ZA 74426:1 16

499) ZA 74426:2 16

500) ZA 74577:4 65

501) ZA $87468 \quad 42$

502) ZB 31856:1,1965/66 13

503) ZB 58451:224 163 


\section{U / DISS}

504) 4 DISS PHIL GÖTTINGEN 1924,Schröder,Alfred,1 218 4 DISS PHIL GÖTTINGEN 1924,Schröder,Alfred,2

505) 8 DISS PHIL BERLIN 1929,Hoh-Kiq,83 216

506) 8 U 37.5923

507) 8 U 40.2781 219

508) 8 U $41.1616 \quad 215$

509) 8 U 58.2095

510) 8 U 61.8458

511) DISS 83 A $8037 \quad 217$

512) DISS 92 B 5241

513) DISS 96 A 4184

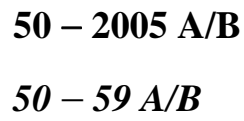


527) 62 А 3622

528) 63 А $2828 \quad 15$

529) 63 А $7211 \quad 12$

530) 64 В 4378:HAUPTW 26

531) 64 B 4378:NACHTR 26

532) 66 А $2938 \quad 2$

533) 67 А $6510 \quad 22$

$\begin{array}{rrrr}70-79 \boldsymbol{A} / \boldsymbol{B} & & \\ & & \\ 534) & 71 \text { А } 3781 & 69 \\ 535) & 71 \text { В } 3207 & 147 \\ 536) & 75 \text { В } 5675 & 137\end{array}$

$80-89 A / B$

537) 80 A 10785

538) 80 В 26185

539) 81 A $11612 \quad 6$

540) 84 А $26137 \quad 208$

541) 84 В $14072 \quad 152$

542) 85 А 14268

543) 85 A $26920 \quad 56$

544) 85 В $14160 \quad 67$

545) 85 В $26948 \quad 159$

546) 85 В $26949 \quad 158$

547) 85 В $26950 \quad 158$

548) 86 А $10326 \quad 144$

549) 86 А $13535 \quad 70$

550) 87 A 11044

551) 87 A $12000 \quad 67$

552) 87 A $12682 \quad 30$

553) 87 A $12846 \quad 30$

554) 87 А 13662 
555) 87 А 25649

556) 88 А $13588 \quad 69$

557) 88 А 26118

558) 88 В 14142

559) 89 А 11198

560) 89 А 18104

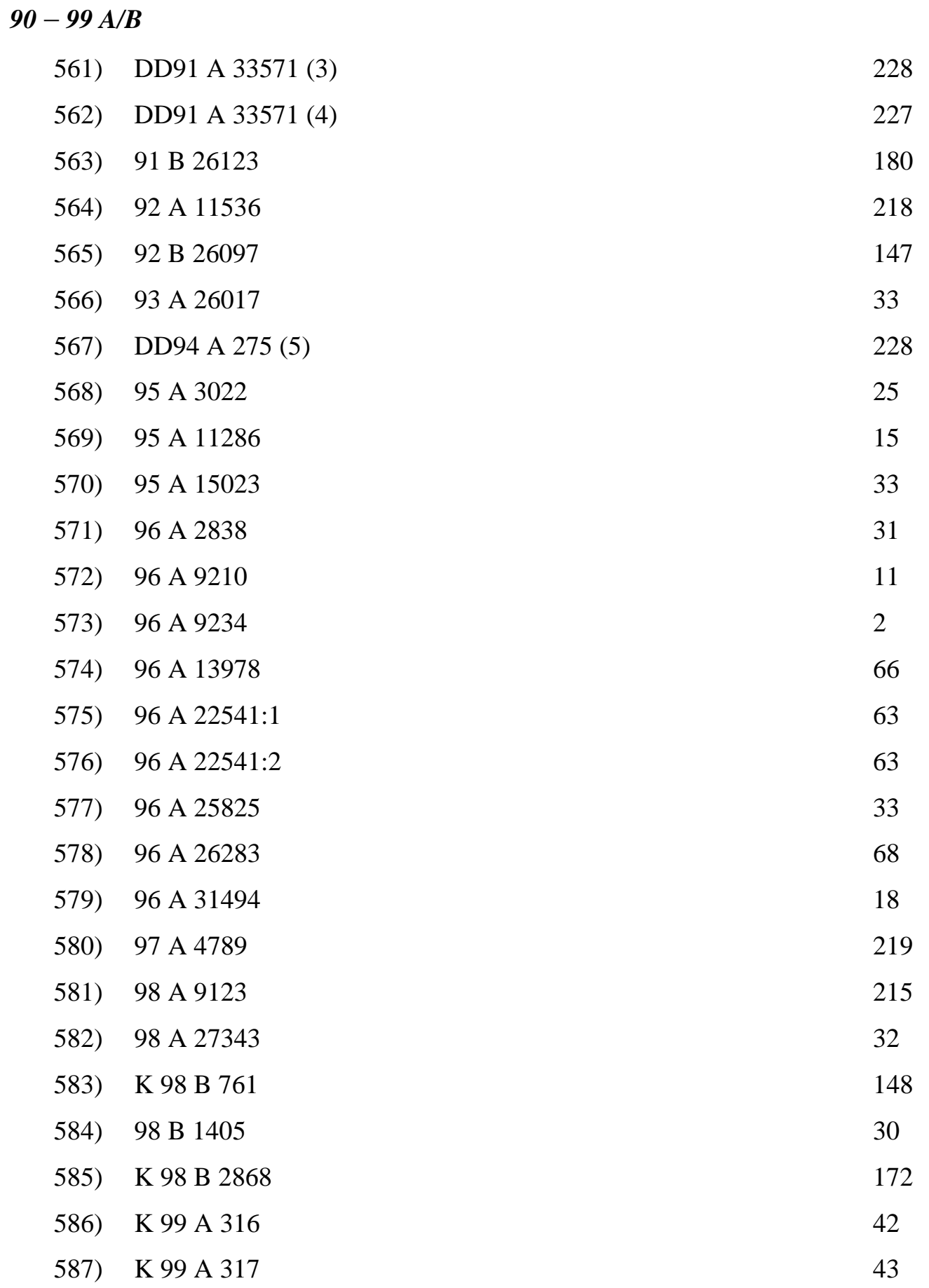




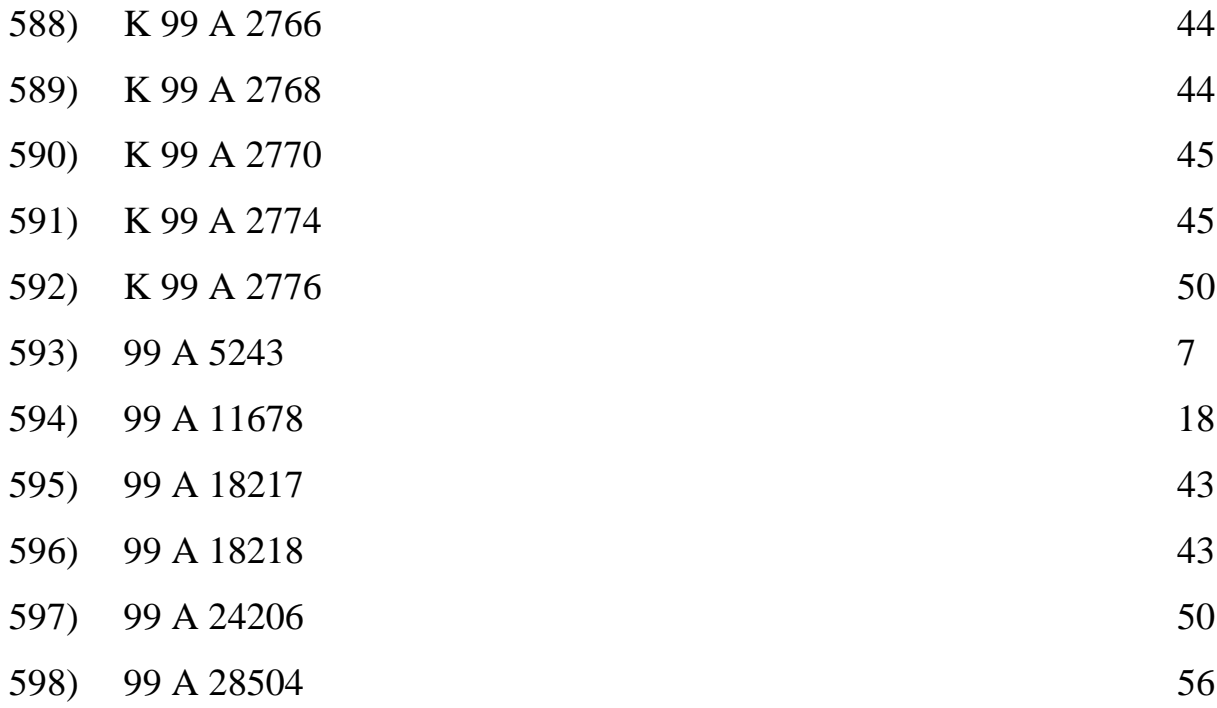

$2000-2005 \mathrm{~A} / \mathrm{B}$

599) K 2000 A 1855

600) 2000 A 19162

601) 2000 А 21489

602) 2000 А $25184 \quad 217$

603) 2000 А 29299

604) 2000 А $29300 \quad 49$

605) 2000 А $29301 \quad 50$

606) К 2000 B 1558

607) K 2001 A 735

608) ALT 2001 A 1554

609) ALT 2001 A 921:2 18

610) 2001 А 25815

611) 2001 А $27220 \quad 46$

612) 2001 А 27221

613) 2002 A $1723 \quad 10$

614) 2002 А 1892

615) 2002 А 1893

616) 2002 А $22676 \quad 66$

617) 2002 А $28035 \quad 46$

618) К 2002 B 1825

619) К 2002 B 1826 
620) 2003 А 26658

621) 2003 А $26806 \quad 46$

622) 2003 В $396 \quad 187$

623) 2004 A 8815

624) 2005 А $26147 \quad 47$

andere Systematik \& Signaturform

$\begin{array}{lll}625) & \text { 4 HLL IX, 2546:1 } & 25 \\ 626) & \text { 8 P DRAM III, 1292 } & 210 \\ 627) & \text { 8 P DRAM IV, 300:1 } & 208 \\ 628) & \text { 8 SVA I, 7449/5:68 } & 67 \\ 629) & \text { Cod. Ms. K. Brandi } 21 & 38-40 \\ 630) & \text { Za } 1 / 2 & 45\end{array}$

\section{Neue Medien (CD)}

631) DISKO G 2001-55:1-3 221

632) DISKO G 2001-56:1-3 222

633) DISKO G 2001-57:1-3 223

634) DISKO G 2004-1 221

635) DISKO G 2004-2 225

636) DISKO G 2004-27 224

637) DISKO G 2004-28 224

638) DISKO G 2004-29 225

639) DISKO G 2004-30 222

640) DISKO G 2004-177 226

641) DISKO G 2004-178 223 